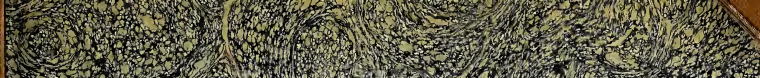

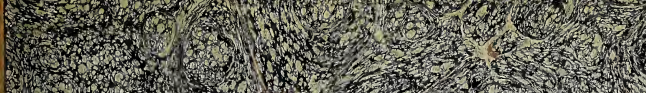

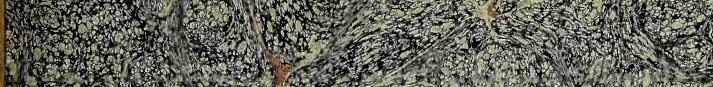

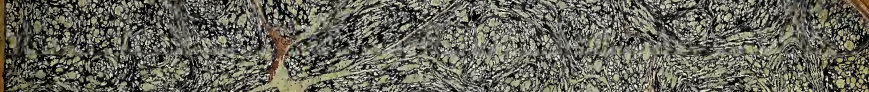

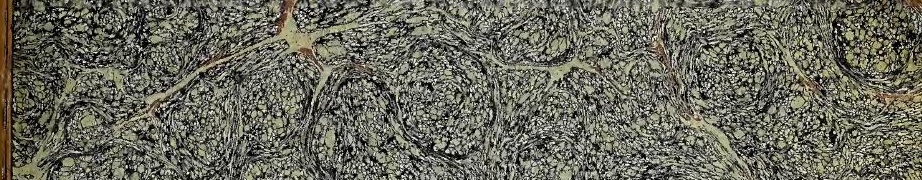

(6)

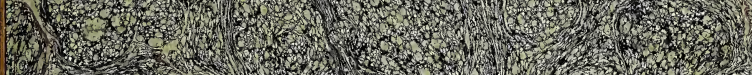

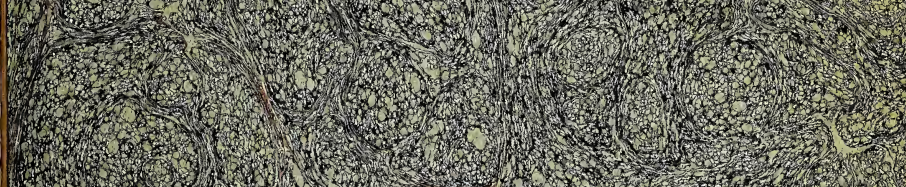
1.7.

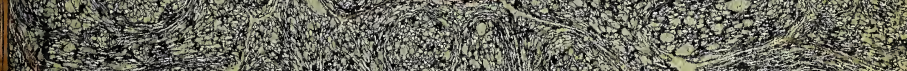

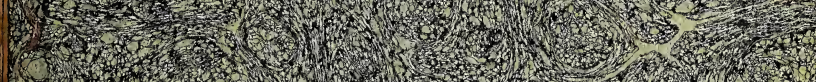

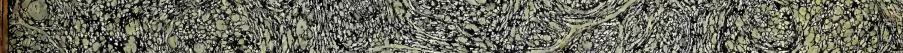

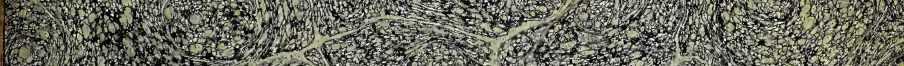

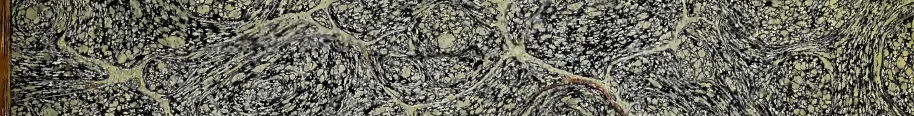

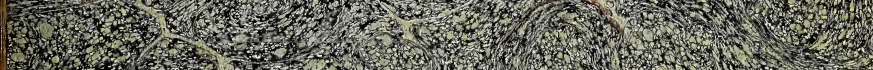

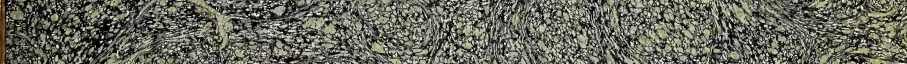

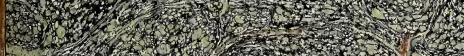

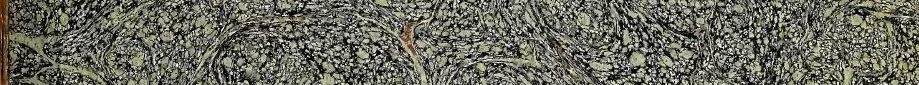

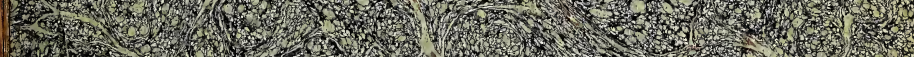

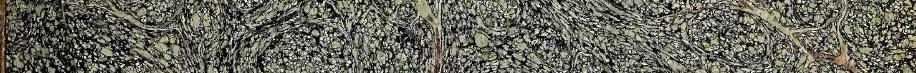

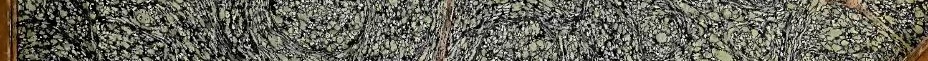
3
3

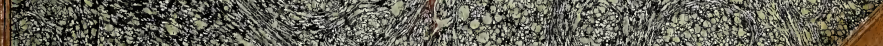

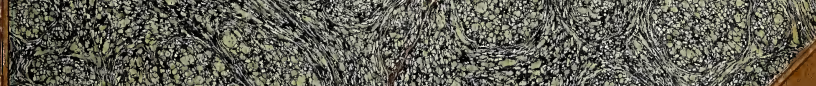
Fb 


\section{Smithsonian Institution \\ Libraries}

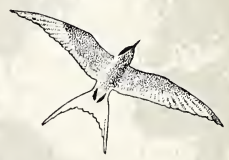

GIFT OF

Marcia Brady Tucker 




\title{
INDEX ORNITHOLOGICUS,
}

\author{
SIVE
}

SYSTEMA ORNITHOLOGIE;

COM L E C TEN S

A VI U M DIVISIO N E M

IN CLASSES, ORDINES; GENERA, SPECIES, I P ARUMQUE VARIETATES:

A D $J$ I C T I S

SYNONYMIS, LOCIS, DESCRIPTIONIBUS, \&C.

STUDIO ET OPERA

JOANNIS LATHAM, S. R.S.

V O L U M E N II.

\section{O N D I N I,}

S U M P T I B US A U T HORIS :

PROSTANT VENALES APUD LEIGH ET SOTHEBY, YORK-STREET, COVENT-GARDEN.

M.DCC.XC. 



\section{GEN US XL. MUSCICA PA.}

Roftrum fubtrigonum, utrinque emarginatum, apice in. curvo: vibriffa patentes verfus fauces. Digiti ad imum fiffi.

I.

Grifola M. fubfufca fubtus albicans, collo longitudinaliter maculato, criflo rufefcente.

Mufcicapa Grifola, Lin. Syft. i. p. 328. 20.-Gmel. Syft. i. p. 949.Brif, ii. p. 357 . 1. t. 35. f. 3.-Id. 8 vo. i. p. $257 .-$ Raii Syn. p. 81. 7.-Will. p. 153. 17 1. 7.-Id. (Angl.) p. $211 .-$ Bororefk. Nat. iii. p. 176.3 .

Stoparola Aldr? Raii Syn. p. 77. A. 1.-Will. p. 159.-Id. (Angl.) p. 217.-Zinnan. Uov. p. 45. t. 6. f. 30.

Sylvia fufca, Klein. Stem. p. 14. t. 16. f. 9. a-c.

Curruca fubfufca, Frifch. t. 22 ?

Sylvia peftilentialis, Klein. $A v$. p. 79. r 2.-Ld. Ov. p. 25. t. ro. f. 7.8. Le Gobemouche, Buf. iv. p. 517. t. 25 . f. 2. - Pl. Enl. 565 . f. 1. Cobweb, Mort. North. p. 426.

Spotted Flycatcher, Br. Zool. N $\mathrm{N}^{\circ}$ 134.-Id. fol. 99. t. P. 2. f. 4.Lewin Br. Birds, iii. t. 87.-Lath. Syn. iii. p. 323. x.

Habitat in Europa. $-5 \frac{3}{4}$ pollices longa.-Hortos et pomaria aftate frequentat; victitans infectis. Ovum pallidum, maculis parvis rubris, majoribus fparfim interjectis.

atricapilla, M. nigra, fubtus frontifque macula alarumque fpeculo albis, reetricibus lateralibus extus albis.

Mufcicapa atricapilla, Lin. Syft. i. p. 326. 9.-Gmel. Syft. i. p. 935.Kram. El. p. 377.-Facq. Vog. p. 41.32. t. I9.-Borowjk. Nat. iii. p. 176.2 .

I.ufcinia alis variegatis, Klein. Av. p. $75 . \mathrm{I} 2$.

Rubetra anglicana, Brif. iii. p. $436.27 .-I d .8$ vo. i. p. 27 r.

Traquet d'Angleterre, Buf. v. p. 222 .

Curruca tergo nigro, Frifch. t. 24.

Enanthe noftra quarta, Raii Syn. p. 77. A. 5.-Will.p. 170. 
Cold Finch, Edw. t. 30.-Will. (Angl.) p. $23^{6}$.

Pied Flycatcher, Br. Zool. No $135 .-I d$. fol. 103. t. S. f. I. (mas.)Arct. Zool. ii. p. 391. B.-Id. Sup. p. 64.-Lewin. Br. Birds, iii. t. 88.-Latb. Syn. iii. p. 324. 2.

Habitat in Europa; in montofis et locis frigidioribus Anglice. $-4 \frac{3}{4}$ pollices longa.

Femina fufca ubi mas niger, fubtus albida, macula frontali obfoleta.

6. Mufcicapa nigra, Brif. ii. p. 381 1 3 .

Major, fupra grifeo varia : femoribus fufco alboque variis : rectricibus tribus extimis margine albis.

$\boldsymbol{\gamma}$. Le Gobe-mouche noir à collier, Buf. iv. p. 520. t. 25. f. r.Pl. Enl. 565. f. 2. 3.-Kram. El. p. 377. 16.

A priore differt collari albo : rectrice extima margine albo.

§. M. fufca, fubtus fronte lateribus capitis lineaque longitudinali $a b$ humero ad dorfum albis.

Mufcicapa variegata, Lin. Syft. i. p. 328. 21.-Gmel. Syft. i. p. 949.

Haвıт Aт India.-Rectrix extima vix apice alba.

torquata. M. nigra fubtus alba, pectore rufo, remigibus intimis apice albis.

Mufcicapa torquata, Lin. Syft. i. p. 328. 17. (mas.)-Gmel. Syft. i. p. 945.-Brif. iii. p. 379. 1 2. t. 36. f. 4.-Id. 8 vo. i. p. 263. Le Gobe-mouche à collier du Cap de B. E. Pl. Enl. 572. f. 2. Cape Flycatcher, Latb. Syn. iii. p. 326. 3.

Habitat ad Caput Bone Spei; magnitudine precedentis. Collum a tergo album.

ß. M. fufca fubtus alba, pectore nigro, fafcia alarum rufa, rectricibus apice albis.

Mufcicapa capenfis, Lin. Syft. i. p. 327. 16.-Gmel. Syft. i. p. 945.Brif. ii. p. 372 . 9. t. 36. f. 3.-Id. 8 vo. i. p. 262.

Gobe-mouche du Cap de B. Efp. Pl. Enl. 572. f. 1.-Latb. Syn. iii. p. $327 \cdot 3 \cdot \mathrm{A}$.

Hав тат cum priore, cujus forte femina.-Latera abdominis rufa: tectrices alcrum majores apice rufi. 
4.

A V E S P A S S E E S. Mufcicapa. 469

bicolor. M. nigra, corpore fubtus fronte orbitis uropygio fafcia alarum rectricibufque apice albis.

Mufcicapa bicolor, Ginel. Syft. i. p. 946.

Le Gobe-mouche à ventre blanc de Cayenne, Buf.iv. p. 542.-Pl. Enl. 566. f. 3 .

Black and white Flycatcher, Edw. t. 348. fo r.-Latb. Syn. iii. p. 327. 4.

HaBit AT in Cayana. $-4 \frac{x}{2}$ pollices longa.

ß. M. alba, occipite cervice alis uropygio caudaque nigris.

Le Gillit de Cayenne, Buf. iv. p. 542.-Pl. Enl.675. f. 1.-Latb. Syn. iii. 328. 4. A.

Habitat in Cayana.-Femina tota grifea.

5.

albifrons. M. fupra nigro-fufca, jugulo et pectore fordide albis, abdomine dilute ferrugineo, fronte albida, pedibus nigris.

Mufcicapa albifrons, Muf. Carlf. fafc. i. t. 24.-Gmel. Syft. i. p. 948.

White-fronted Flycatcher, Latb. Syn. Sup. p. 175.

Habitat ad Caput Bone Spei.-Ab atricapilla differt alis abfque fafcia alba, et cauda corpore concolore.

6.

melano- M. nigra, dorfo albo, femoribus albo nigroque annulatis, rectricibus

leuca. albis apice nigris.

Mufcicapa melanoleuca, N. C. Petr. xix. p. 468. 3. t. 15.-Gmel. Syft. i. p. 948 .

Black and white Warbler, Lath. Syn. iv. p. 457.59.

Habitat aftate in Georgia campeftri, prefertim circa T'efifun ad ripas Cyri; ultra 6 pollices longa.

Femina partes, que mari albæ funt, fordide cinereæ; quæ mari nigræ, tufcæ.

7.

leucomela. M. nigra, pileo nucha uropygio abdomine rectricibufque maxima parte albis.

Motacilla leucomela, N. C. Petr. xiv. p. 584. 6. t. 22. f. 3.-Falk. It iii. t. 30.-Gmel. Syft. i. p. 974 .

Motacilla Plefchanka, N. C. Petr. xiv. p. 503. 5. t. I 4 . f. 2.

Leucomele Warbler, Lath. Syn. iv. p. $456.5^{8 .}$

Hавгтат ad fluvium Volgam; nidificans in præruptis ; victitans vermibus et coleopteris; motitat caudan. -6 pollices et ultra longa.

Orbite 
470 A VES P A S E R E S. Mufcicapa.

Orbita albefcentes: remiges tectricefque alarum exteriore margine ob. folet:, interiore verfus marginem albicantes.

Femina fufco-cinerea, fubtus cinerafcens, gula jugulumque cinereo-

8. grifea : Jupercilia alba,

fenegalen- M. varia, fuperciliis albis, rectricibus extimis dimidiato-albis.

fis. $\quad$ Mufcicapa fenegalenfis, Lin. Syft. i. p. 327. 15.-Gmel. Syft. i. p. 938.

Id. 8 vo. i. p. 262 . pectore rufo, Brif. ii. p. 374. 10. t. 37. f. 2.-

Gobe-mouche à bandeau blanc du Senegal, Buff. iv. p. 528.-Pl. Enl. 567. f. 1 .

Senegal Flycatcher, Lath. Syn. iii. p. 328. 5 .

Habitat in Senegala. $-4 \frac{\mathrm{T}}{4}$ pollices longa.

Corpus nigro, fufco, alboque varium: gene nigræ: pectus pallide rufum: reitrices 4 mediæ nigræ, reliquæ apice albæ, extima exteriore la. tere alba.

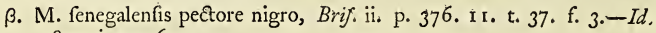
8 vo. i. p. 263 .

Gobe-mouche à poitrine noire, Pl. Enl. 567. f. 2.-Lath. Syn. iii. p. 329. var. A.

Habitat cum priore, cujus fexus alter.

Corpus fupra nigro alboque nebulofum : pectore nigro: reErrices octo mediæ nigræ, reliquæ apice albæ, extima exteriore latere alba.

9.

criftata. M. criftata caftanea, fubtus cinerea, capite colloque inferiore nigro-virefcentibus, rectricibus caftaneo-purpureis, cauda elongata.

Mufcicapa criftata, Gmel. Syft. i. p. $93^{8}$.

Mufcicapa fenegalenfis criftata, Brif. ii. p. 422.33 . t. 39. f. 2.-Id. 8 vo. i. p. 274 .

Gobe-mouche huppé du Seriegal, Buf. iv. p. 530.-Pl. Enl. 573. f. 2. Crefted Senegal Flycatcher, Lath. Syn. iii. p. 329. 6.

HaBitat in Senegala $-8 \frac{1}{2}$ pollices longa.-Cauda cuneiformis, elonI0. gata.

borbonici。 M. criftata fpadicea, fubtus cinerea, capite nigro-virefcente, rectricibus pallide fpadiceis.

Mufcicapa borbonica, Gmel. Syt. i. p. 939.

Mufcicapa 
Mufcicapa borbonica criftata, Brif. ii. p. 420.32 . t. 39. f. $5 .-I d$. 8 vo. i. p. 274 .

Gobe-mouche huppé de l'ine de Bourbon, Pl. Enl. 573. I. mas.

Bourbon Flycatcher, Lath. Syn. iii. p. 330. 7.-Id. Sup. p. 17 I.

$\mathrm{H}_{\text {aвıт }}$ it in infula Borbonica et Madagafcaria. $-5 \frac{x}{2}$ pollices longa.

Ir. Femina capite cinereo.

collaris. M. plumbeo-cinerea, fubtus fafciaque alarum alba, collo inferiore fubcaftaneo, rectricibus nigris, lateralibus apice albis.

Mufcicapa melanoptera, Gmel. Syjt. i. p. 939.

Mufcicapa fenegalenfis torquata, Brif. ii. p. 370.8 . t. 36. f. I. $-I d$. 8vo. i. p. $26 \mathrm{r}$.

Gobe-mouche à gorge brune du Senegal, Buf. iv. p. 533 .

Collared Flycatcher, Lath. Syn. iii. p. 330.8.

Habitat in Senegala.-4 pollices longa.-Supra peEtus fafcia an-

I 2. gufta, nigra: rectrix extima exterius alba.

nigrifrons. M. fufca fubtus fufco-olivacea, fronte lateribufque capitis nigris, gurture flavo.

Mufcicapa nigrifrons, Gmel. Syft. i. p. 939.

Black-fronted Flycatcher, Lath. Syn. iii p. 331. 9.

I3.

Magnitudo atricapilla. $-4 \frac{x}{2}$ pollices longa.

leucura. M. cinereo-grifea fubtus alba, rectricibus lateralibus nigro alboque oblique dimidiatis.

Mufcicapa leucura, Gmel. Syft. i. p. 939 .

White-tailed Flycatcher, Latb Syn. iii. p. 331. 10.

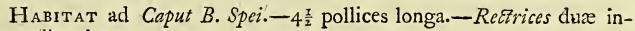
termediæe nigræ.

14.

ponticeria- M. cinereo-grifea fubtus alba, fuperciliis albis, tectricibus alarum albo

na. maculatis, rectricibus lateralibus grifeo alboque dimidiatis.

Mufcicapa pondiceriana, Gmel. Syjt. i. p. 939.

Le Gobe-mouches de Pondichery, Son. Voy. Ind. ii. p. I99.

Coromandel Flycatcher, Latb. Syn. iii. p. 33I. II.

Habrtat in Coromandela; Fr. domeftica paulo major; fuaviter cantat uti Pbilomela.-Caput faturate cinereo-grifeum. 
15.
472
A V E S
P A S S E E S.
Mufcicapa.

afra. M. fordide flava maculis obfcuris, vertice rufo nigro ftriato, alis caudaque rufis.

Mufcicapa afra, Gmel. Syft. i. p. 940.

Spotted yellow Flycatcher, Lath. Syn. iii. p. 332. I2.

Habitat ad Caput Bone Spei.-8 pollices longa.

Striga faucium maculaque colli obfcura.

I6.

cana. M. cinerea, capite faturatiore, reetricibus nigris, duabus extimis apice cinerafcentibus, remigibus intus albis.

Mufcicapa cana, Gmel. Syft. i. p. 940.

Mufcicapa madagafcarienfis cinerea major, Brif. ii. p. 389.17. t. 37. f. 1. $-I d .8$ vo. i. p. 366 .

Le Kinki-manou, Buf. iv. p. $5^{8} 4$.

Grand Gobe-mouche cendré de Madagafcar, Pl. Enl. 54r.

Afh-coloured Flycatcher, Latb. Syn. iii. p. 332. I 3 .

Habitat in Madagafcaria. $-8 \frac{x}{2}$ pollices longa.

I7.

ochracea. M. collo et pectore cinereo-ferrugineis, alis caudaque nigro-cinereis.

Mufcicapa ochracea, Muf. Carlf. fafc. i. t. 22.-Gmel. Syft. i. p. 947. African Flycatcher, Latb. Syn. Sup. p. 175.

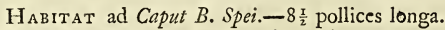

Roftrum pallidum : caput et dorfum brunneum : collum pectufque plumis crebris ciliatis acute lanceolatis : aurium regiones plumarum longiorum ciliatarum fafciculo notatæ: abdomen ochreo-ferrugineum: cauda longitudine corporis. Præcedenti multum affinis.

18.

madagaf- M. viridi-olivacea, gutture flavo, collo inferiore pectoreque flavefcarienfis. centibus.

Mufcicapa madagafcarienfis, Gmel. Syft. i. p. 940.

Ficedula madagafcarienfis major, Brif. iii. p. 482.46. t. 24. f. 5. $-1 d$. 8 vo. i. p. 442.

Le Vira-ombé de Madagafcar, Son. Voy. Ind. ii. p. 198.

Madagafcar Flycatcher, Latb. Syn. iii. p. 333. I4.

Haвiт Aт in Madagafcaria; magnitudine Alaude.

19.

undulata. M. albido fufcoque undulatim varia, capite fufco-nigricante, alis rufofufcis.

Mufcicapa undulata, Gmel. Syft. i. p. 940. 


\section{A VES PASSERES. Mufcicapa.}

Le Gobe-mouche de l'ine de France, Buf. iv. p. 527.

Undulated Flycatcher. Latb. Syn. iii. p. 333. 15.

Habitat in infula Francia; atricapilla minor.

Fenine mare pallidior, pectore pallide rufo admixto.

20.

Tectec. M. fufca, pennis rufefcente marginatis, fubtus rufefcens, collo inferiore fordide albo.

Mufcicapa Tectec, Gmel. Syft. i. p. 94 r.

Mufcicapa borbonica, Brif. ii. p. 360. 2. t. 39. f. I. $-I d .8$ vo. i. p. 259. Indian Flycatcher, Lath. Syn. iii. p. 334. 16.

Habitat in infula Borbonica; magnitudine Grijola. Femina fubtus toto fordide alba.

$2 \mathrm{I}$.

rufiventris. M. nigra, abdomine criffo macula alarum bafique caudæ fulvo-rufis.

Mufcicapa rufiventris, Gmel. Syft. i. p. 94 I.

Gobe-mouche de l'ine de Bourbon, Pl. Enl. 572 . f. 3 .

Rufous-vented Flycatcher, Lath. Syn. iii. p. 334. 17.

HaBITAT in infula Borbonica. $-4 \frac{3}{4}$ pollices longa.

Caput, collum, peEzus, corpus fupra, ale, rectrices intermedia tote, apicelque lateralium, nigra : corpus fubtus a pectore, macula remigum, reEtricefque laterales a bafi ultra medium rufo-fulvæ.

22.

ruticilla. M. nigra fubtus alba, pectore macula alarum bafique remigum rectricumque flavis.

Mufcicapa ruticilla, Lin. Syft. i. p. 236. 10.-Gmel. Syft. i. p. 935.

Mufcicapa americana, Brif. ii. p. 383 . 14. -Id. 8 vo. i. p. 264.

Motacilla flavicauda, Gmel. Syft. i. p. 997. (fem.)

Le Gobe-mouche d'Amerique, Pl. Enl. 566. f. I. 2.

Le petit Noir-aurore, Buf. iv. P. 546 .

Serino affiris e croceo et nigro varia, Raii. Syn. p. 188. 5 1.-Sloan. Fam.

p. 312. 50.-Klein. Av. p. 89. 13.

Small american Redftart, Edw. t. 80.-Cat. Car. i. t. 67. mas.

Yellow-tailed Flycatcher, Edw. t. 257. femina.

- Warbler, ArEz. Zool. ii. No 301.

Black-headed Warbler, Arct. Zool. ii. No 282. mas.-30r. femina?Latb. Syn. iv. p. 427 . 18.

IAsitat in America, famaica. $-4 \frac{3}{3}$ pollices longa. 
474 A V E S P A S S E R E S. Mufcicapa.

Mas a precedente vix differt, nifi abdomine albo: pectus, macula alarum, bafes remigum et rearicum lateralium rufo-flava.

Femina cinereo-fufcefcens, fubtus alba, rectrices laterales, excepto

23. apice, macula alorum, et pectus ad latera flava.

flammea. M. nigra, corpore fubtus dorfo poftico fafcia alarum caudaque apice fulvis.

Mufcicapa flammea, Zool. Ind. p. 25. t. 15.-Gmel. Syft. i. p. 942. Flammeous Flycatcher, Lath. Syn. iii. p. 338.-Id. Sup. p. I 7 I.

Haвiтат in India.-6 pollices longa.

Roftrum, pedes, coput, collum, tectrices antepenultimæ alarum, primores remigum, et femora nigra: dorfum, tectrices ultimæ alarum, pectus, criffum aurantia : reniges fecundariæ nigræ aurantio maculatæ : cauda nigra: rectrices ad apicem aurantiæ.

Femina cinerea, fubtus albo-flavefcens; uropygio, pectore, fafciaque alarum pallide fulvis; gula, alis, coudaque nigris.

ß. M. cana, fubtus coccinea, gula nigra, remigibus quatuor primis bafi rubris.

Motacilla cinnamomea, Lin. Syf. i. p. 335. 32.-Gmel. Syft. i. p. $9^{8} 5$. Cinnamon Warbler, Latb. Syn. iv. p. $4 \mathrm{I}$.

HABITAT in Zeylona.-Uropygium coccineum: remiges nigra, exceptis quatuor primis, bafi rubris; unde macula alarum rubra, in altero fexu : rectrices nigræ, fed quatuor intermediæ latere oblique rufæ.

nigra. M. nigra, corpore toto nigro, roftro capite interfcapulio pedibufque atris.

Mufcicapa nigra, Muf. Carlf. fafc. i. t. 23.-Gmel. Syft. i. p. 947.

Society Flycatcher, Lath. Syn. Sup. p. I74.

Habitat in infulis Societatis, Otabeite-Rofrum plumbeum.

3. M. nigro-fufca, forte femina.

25 .

comata. M. nigra, capite criftato, corpore fubtus uropygio reetricibufque duabus intermediis apice albis, crifio flavo.

Mufcicapa comata, Gmel. Syft. i. p. 941.

Tufted Flycatcher, Lath. Syn. iii. p. 334. 18.

Hавіт Aт in Zeylona.-Roftrum nigrum: pedes cærulefcentes.

M. fufco- 
26.

A V E S P S S E R E S. Mufcicapa.

hæmor- M. fufco-undulata, capite fubcriftato caudaque nigris, pectore abdomirhoufa. neque albis, criffo rubro.

Mufcicapa hæmorrhoufa, Gmel. Syft. i. p. 94 I.

Red-vented Flycatcher, Lath. Syn. iii. p. 335. I 9.-Brown. Ill. p. 78 .t. 3 I.

Hавттат in Zeylona.-4 $\frac{x}{2}$ pollices longa.-Pedes atri.

$\beta$. M. fronte verticeque criftato nigris, lateribus colli pectore abdomineque albis, crifío flavo.

Yellow-vented Flycatcher, Lath. Syn. iii. p. 335. 19.-Brown. Ill. p. 76. t. $3 \mathrm{I}$.

Habitat in infula Fava.

27. M. fufca, fubtus fuperciliifque albis, criffo flavefcente, fafcia fuboculari nigra.

Mufcicapa Pfidii, Gmel. Syft. i. p. 94I.

Petit Goiavier de Manille, Son. Voy. p. 59. t. 28.

Guava Flycatcher, Lath. Syn. iii. p. 335. 20.

Навітат in Pbilippinis infulis, circa habitationes; Fr. domeftica paulo minor.-Roftrum et pedes nigri : irides flavefcentes.

28.

melanic- M. cinereo-fufca luteo mixta, pectore luteo, capite nigro, remigibus

tera.

Mufcicapa melanictera, Gmel. Syft. i. p. 941.

Yellow-breafted Flycatcher, Latb. Syn. iii. p. 336. 2 1.-Brown. Ill. p. 8o. t. 82 .

Haвiт at in Zeylona; magnitudine Carduelis; fuave cantat.

29.

nitens. M. viridis nitens, gutture pectoreque rufis, uropygio abdomineque $\mathrm{fla}$ vis, cauda longiore.

Mufcicapa nitens, Gmel. Syft. i. p. 942.

Green Flycatcher, Latb. Syn. iii. p. 336. 22:

Habitat in India.

30.

finenfis. M. virefcenti-grifea fubtus flavefcens, capite nigro, fuperciliis gulaque albis, collo inferiore pectoreque grifeis.

Mufcicapa finenfis, Gmel. Syft. i. p. 942. 
476 A VES P A S S ERES. Mufcicapa.

Le Gobe-mouches verdâtre de la Chine, Son. Voy. Ind. ii. p. 107.

Wreathed Flycatcher, Latb. Syn. iii. 336. 23 .

Habitat in Cbina; Fr. domefica minor.-Irides rubre.

$3 \mathrm{I}$.

grifea. M. nigra fubtus rubefcens, collo inferiore faturate grifeo, fafcia alarum alba.

Mufcicapa grifea, Gmel. syft. i. p. 942.

Grey-necked Flycatcher, Lath. Syn. iii. p. 337. 24.

HaBrTat in Cbina.-Cauda fubcuneiformis.

flavicollis. M. viridis, fronte myftacibufque nigris, vertice orbitis collo inferiore maculifque tribus abdominis flavis, rectricibus 2 intermediis apice albis.

Mufcicapa flavicollis, Gmel. Syft. i. p. 942.

Yellow-necked Flycatcher, Latb. Syn. iii. p. 337. 25.

Habrtat in Cbina.-Couda forficata: Rofirum pedeqque rubri.

33.

fufcefcens. M. fubcriftata fufcefcens fubtus albida, uropygio criffoque fulvis, cauda fubforficata.

Motacilla fufcefcens, Gmel. Syft. i. p. 942.

Orange-vented Flycatcher, Latb. Syn. iii, p. 338. 27.

Habitat in Cbina. -6 pollices longa.-Rofrum rubrum.

34.

lucionen- M. violaceo-atra, fubtus obfcure grifea, macula alarum alba.

fis. Mufcicapa lucionenfis, Gmel. Syft. i. p. 942.

Gobe-mouche noir de Luçon, Son. Voy. p. 58. t. 27. f. 2.

Black Flycatcher, Latb. Syn. iii. p. 338.28.-Id. Sup. p. 172.

Habitat in Pbilippinis, Madagafcaria.-Magnitudo $P$. caudatio.

philippen- M. grifeo-fufca fubtus albida, fuperciliis albis.

fis. Mufcicapa philippenfis, Gmel. Syft. i. p. 943 .

Le Moucherolle des Philippines, Buf. iv. p. 565.

Philippine Flycatcher, Latb. Syn. iii. p. 339. 29.

Habitat in Pbilippinis; Luscinie magnitudine.

36. M. cærulea nitens fubtus cærulefcenti-alba, macula occipitis pectorifque nigra.

Mufcicaps 


\section{A V E S P A S S E ES. Mufcicapa.}

Mufcicapa cærulea, Gmel. Syft. i. p. 943.

Le petit Azur, Buf. iv. p. 534 .

Le Gobe-mouche bleu des Philippines, Pl. Enl. 666. f. r. Azure Flycatcher, Lath. Syn. iii. p. 339.-Id. Sup. p. 172.

HabtтAт in Pbilippinis. -5 pollices longa.-Remiges rectricefque cæruleo-atræ.

37.

cyanocephala.

38. manillen- M. grifea fubtus flava, dorfo alifque caftaneis, fafcia genarum duplici: fis. $\quad$ alarum folitaria rectricibufque lateralibus albis.

Mufcicapa manillenfis, Gmel. Syjt. i. p. 943 .

Gobe-mouche à gorge jaune de Luçon, Son. V(y. p. 57. t. 26.

Yellow-throated Flycatcher, Lath. Syn. iii. p. 340. 32 .

39 .

Habitat in Manilla; priore major.-Rectrices 2 intermediæ nigræ.

Habellifera. M. fufco-olivacea, capite torqueque colli nigris, corpore fubtus fuperciliis macula alarum rectricibufque lateralibus albis.

Mufcicapa flabellifera, Gmel. Syft. i. p. 943.

Fan-tailed Flycatcher, Latb. Syn. iii. p. 340. 33.t. 49.

Habitat in infulis nova Zealandia et Tanna. $-6 \frac{1}{2}$ pollices longa.

Cauda cuneiformis : pectus rufum: cauda flabelli inftar volitans; facile cicuranda.

40.

fupercilio- M. cinerea fubtus incarnata, fuperciliis rectricibufque duabus interfa. mediis nigris, lateralibus albis.

Mufcicapa fuperciliofa, Gmel. Syjt. i. p. 944.

Supercilious Flycatcher, Lath. Syn. iii. p. 341. 34.

Longitudo $4 \frac{x}{2}$ pollicum. - Rectrices laterales 5,5 , apice nigræ.

41.

ferruginea. M. fufco-murina fubtus flavo-alba, gutture candido, alis nigris, pennarum margine ferrugineo.

Mufcicapa ferruginea, Merrem. Is. Av. p. 19. t. 6.-Gmel. Syft. i. p. 947. 
478 A V E S P A S S E R E S. Mufcicapa.

Habitat in Carolina; magnitudine Carduelis. $-5 \frac{x}{2}$ pollices longa.

Rofrum bafi depreffum, nigrum, margine caftaneum: ale ad uropygium porriguntur: cauda brevis: reetrices nigra, fubtus cinereæ, 'margine fufcefcentes; $1, I$, vero albæ fcapo nigro.

42.

Acdon. M. fufco-ferruginea fubtus flavefcenti-albida, cauda elongata, rectricibus intermediis fulbequalibus, extima utrinque longe breviore. Mufcicapa Aëdon, Pall. reije. iii. p. 695. I I. *-Gmel. Syjt. i. p. 947.

Habitat in rupeftribus et apricis Dauurice crebra; canora etiam noetu; carmine fuavifimo, Lufcinix majoris, qua in Sibiria orientali deeft, æmulo.

Cauda cinereo-fufcefcens.-Magn. T. arundinacei, a quo tamen diverfifima.

43.

novæHol- M. fufca fubtus albida, fub oculis utrinque ad aures ftriga flava.

landix.

Habitat in nova Hollandia; magnitudine H. urbica. -7 poll. longa. Roftrum bafi dilatatum, flavicans: caput, corpus fupra cum alis et cauda fufcum: gula, jugulum, pectus albefcens : abdomen album : ftriga aurium poftice dilatata fava : cauda fubbifida elongata.

44 .

Deferti. M. corpore ex ferrugineo nigricante-fuliginofo, alis caudaque nigricantibus, roftro flavicante.

Mufcicapa Deferti, Gmel. Syft. i. p. 949.

Mufcicapa fuliginofa, Muf. Carlf. fafc. ii. t. 47.

Habitat in deferto Africano, inter rivulum Heuj et fontem 2uammedacka; magnitudine $P$. caudati.

Roftrum pallide flavicans: pedes nigri : cauda nigra corporis menfura et dimidii.

$45^{\circ}$. ferrugineis. Mufcicapa caledonica, Gmel. Syft. i. p. 944.

Olive Flycatcher, Latb. Syn. iii. p. 342. 35 .

46.

Навітат in nova Caledonia ; magnitudine Calibis. -6 poll. longa.

lutea. M. obfcure flava, tectricibus alarum remigibufque nigricante-nebulofis, cauda ad apicem nigricante.

Mufcicapa 
Mufcicapa lutea, Gmel. Syft. i. p. 944 .

Luteous Flycatcher, Latb. Syn. iii. p. 342. 36.

Mавгтат in Otabeite. -6 pollices longa. - Roftrum plumbeum.

47.

ochroce- M. flavefcente-viridis fubtus alba, capite collo pectoreque aureo-flavis..

phala. Mufcicapa ochrocephala, Gmel. Syft. i. p. 944 .

Yellow-headed Flycatcher, Lath. Syn. iii. p. 342. 37.

48 .

Habitat in nova Zealandia. $-5 \frac{\mathrm{T}}{2}$ pollices longa.

flavifrons. M. flavo-olivacea, fubtus fronteque flava, pone oculos lunula alba, alis caudaque fufcis.

Mufcicapa flavifrons, Gmel. Syft. i. p. 944.

Yellow-fronted Flycatcher, Lath. Syn. iii. p. 342. 38 .

49.

Habitat in infula Tanna. $-5 \frac{\mathrm{x}}{2}$ pollices longa.

nævia. M. nigricans fubtus pallidior, dorfo medio humerifque albo nebulofis.

Mufcicapa nævia, Gmel. Syft. i. p. 944.

Nævous Flycatcher, Lath. Syn. iii. p. 343. 39.

Haвiтат in nova Caledonia. $-8 \frac{3}{4}$ pollices longa.

50.

Roftrum, pedes, palpebra nigræ: irides pallide cinerex.

erythro- M. nigra, fronte fafciaque alarum albis, pectore abdomineque cocgaftra. cineis.

Mufcicapa multicolor, Gmel. Syft. i. p. 94\%.

Red-bellied Flycatcher, Latb. Syn. iii. p. 343. 4.0. t. 50.

Habitat in infula Norfolcienfl Maris pacifici, præfertim locis inculris. $-4 \frac{x}{2}$ pollices longa.

Femina fufca ubi mas niger, fubtus flavo-aurantia.

$5 \mathrm{r}$.

fanduicen- M. fufca, fubtus fuperciliifque albidis, pectore ferrugineo, tectricibus

fis. alarum remigibus rectricibufque lateralibus apice albis.

Mufcicapa fandwichenís, Gmel. Syft. i. p. 945 .

Sandwich Flycatcher, Latb. Syn. iii. p. 344. 41.

Haвiт at in infulis Sanduicenfibus. $-5 \frac{x}{2}$ pollices longa.

52.

obfcura. M. fufca fubtus cinerafcens, abdomine rufo imbuto, cauda longiore integra, rectricibus apice acutiufculis,

Mufcicapa: 
480

A V ES P A S E R E S. Mufcicapa.

Mufcicapa obfcura, Gmel. Syft. i. p. 945.

Dufky Flycatcher, Latb. Syñ. iii. p. 34.4. 42.

53.

HАвітат cum pracedente. $-7 \frac{1}{2}$ pollices longa.

maculata. M. ferrugineo-fufca, fubtus fufco-rufefcens, tectricibus alarum apice ferrugineo-albis, rectrice extima apice intus alba.

Mufcicapa maculata, Gmel. Sy/t. i. p. 945 . Spotted-winged Flycatcher, Lath. Syn. iii. p. 345.43.

Habitat cum pracedentibus.-Uropygium ferrugineum : criffum albidum.

54.

Paradifi. M. capite criftato nigro, corpore albo, cauda cuneata, rectricibus intermediis longiffimis.

Mufcicapa Paradifi, Lin. Syjt. i. p. 324. 1.-Ger. Orn. ii. p. 42. t. 159. -Borowfk. Nat. iii. p. 175. t. 70.-Gmel. Syft. i. p. 929 .

Pica papoenfis, Brif. ii. p. 45. 6.-Id. 8vo. i. . . I67.

Todus paradifæus, Gmel. Syft. i. p. 445 .

Icterus maderafpatanus criftatus, Brif. ii. p. $92.7 .-I d .8$ vo. i. p. I 8 r. Mufcicapa criftata alba Capitis B. Spei, Brif. ii. p. 414. 29. t. 41. f. 2. $-I d .8$ vo. i. p. 272.

Avis paradifiaca or. Seb. i. p. 85. t. 52 . f. 3.-Klein. Av. p. 63. 9. Manucodiata criftata, \&c. Raii Syn. p. 195. 13. t. 2. f. 13. Le Moucherolle huppé à tête couleur d'acier poli, Buf. iv. p. $55^{8}$. La Vardiole, Buf. iii. p. 105.

Pied Bird of Paradife, Edw. t. 113 .

Paradife Flycatcher, Lath. Syn. iii. p. 345. 44.-Id. Sup. p. I72.

Habitat in Africa, Afia; magnitudine Sturni.-8 poll. longa.

Roftri bafis plumis teeta: caput azureum, crifta declinata: corpus album, rachibus pennarum nigris: remiges nigre, utroque margine alba: rectrices nivex, rachi et margine exteriore nigra.

ß. M. caftanea fubtus alba, collo inferiore pectoreque grifeis, capite nigro-virefcente.

Mufcicapa crittata Capitis B. Spei, Brif. ii. p. 4 I 8. t. 4 r. f. I. $-I d$. 8 vo. i. p. 273.--Lath. Syn. iii. p. 346. 44 . A.

$\gamma$. M. caftanea fubtus alba, corpore fubtus albo, pectore carulefcente.

Gobe mouche huppé du Cap de B. E. Pl. Enl. 234. f. I ?

Crefted long-tailed Pye, Edw. t. 325.-Lath. Syn。 iii. p. 347. B. 
A VES PASSERES. Mufcicapa. 48 I

s. Mufcicapa brafilienfis criftata, Brif. ii. p. 416.-Latb. Syn. iii. p. 347. C.

Cuiriri akamaki, Seb. ii. p. 93. t. 87. f. 2.-Klein. Av. p. 70. 31.

Præcedentibus fimilis, corpore pallidiore, tedtricibus alarum aureis.

55.

mutata. M. capite criftato, cauda cuneata, rectricibus intermediis longiflimis, palpebris cæruleis.

Mufcicapa mutata, Lin. Syft. i.p. 347: 2.-Gmel. Syft. i. p. 930.

Mufcicapa madagafcarfenfis varia longicauda, Brif. ii. p. 430.36 . t. 40. f. 3. $-I d .8$ vo. i. p. 276.

Gobe-mouche à longue queue et ventre blanc, Buf. iv. p. 568.- $P \%$ Enl. 248. f. 2.

Mutable Flycatcher, Latb. Syn. iii. p. 347. 45 .

Habitat in Madagafcaria. $-1 \mathrm{I} \frac{\mathrm{T}}{2}$ pollices longa.

Corpus fupra nigro-virefcens : irides flavæ: palpebre cærulex: rec* trices duæ intermediæ longiffimæ albæ, oris et rachi nigris, prope apicem macula nigra, laterales vero nigræ, latere exteriore albo, oris nigris.

ß. Mufcicapa madagafcarienfis longicauda, Brif. ii. p. $424 \cdot 34$. t. 40. f. I. $-I d .8$ vo. i. p. 275 .

Gobe-mouche à longue queue de Madagafcar, Pl. Enl. 248. f. I. Schet-all, Buf. iv. p. 568.-Lath. Syn. iii. p. 348. 45. var. A.

A præcedente differt corpore caudaque cinnamomea.

$\gamma$. Mufcicapa madagafcarienfis albicilla longicauda, Brif. ii. p. p. 427 . 35. t. 40 . f. $2 .-I d .8 \mathrm{vo}$. i. p. 276.

Schet vouloulou, Buf. iv. p. 569.-Latb. Syn. iii. p. 348. B.

In omnibus prioribus confert: corpore caudaque caftaneis : reatrices duæ intermediæ nigro alboque variæ.

ftriata. M. cinereo-virens, dorfo nigro ftriato, fubtus fiavefcens, gula lateribufque pectoris fufco maculatis, rectricibus extimis tribus apice albis. Mufcicapa ftriata, Pbil. Tranf. lxii. pp. 406. 428.-Miller Ill. $\mathrm{N}^{\circ} 15$ 。 A. B. -Gmel. Syjt. i. p. 930.

Striped Flycatcher, Arct. Zool, ii. NN 277.-Lath. Syn. iii. p. 349. 46 . 3 Q HABITAT 
482 A V E S P A S S E R E S. Mufcicapa.

HABITAT in America Septentrionali.-5 pollices longa.-Gene albæ: nucha nigra albo varia: gula lateraque nigro maculata.

Femina a mare difcrepat capite viridi-flavefcente nigro ftriato: Juper-

57. ciliis palpelrifque flavis.

virens. M. fufco-virens fubtus lutea, fuperciliis albis.

Mufcicapa virens, Lin. Syjt. i. p. 327. 11.-Ginel. Syjt. i. p. 936.

- carolinenfis cinerea, Brif. ii. p. 368. 7.-Id. 8vo. i. p. 26r.Klein. Av. p. 74. 7.

Le Gobe-m ouche brun de la Caroline, Buf. iv. p. 543.

Little Brown Flycatcher, Catef. Car. i. p. 54 .

Cinereous Flycatcher, Arct. Zool. ii. N²70.-Lath. Syn. iii. p. 350.47 .

$5^{8}$.

Habitat in Carolina $-5 \frac{3}{4}$ pollices longa.

viridis. M. obfcure viridis fubtus lutea, fuperciliis maculaque fub oculis candidis, imo ventre fordide albo, rectricibus fufcis.

Mufcicapa viridis, Gmel. Syft. i. p. $93^{6}$.

Merula viridis Carolinenfis, Brif. ii. p. 31 5. 55.-Id. 87o. i. p. 245.

Le Merle vert de la Caroline, Buf. iii. p. 396.

Turdus pectore luteo, Klein. Av. p. 6 i. 26.

Yellow-breafted Chat, Catef. Car. i. p. 50.

Chattering Flycatcher, Arct. Zool. ii. $\mathrm{N}^{\circ}$ 266. - Lath.Syn. iii. p. 350. 47。

HaBITAT in Caroline interioribus, circa ripas fluviorum; timida avis

59. et canora. $-7 \frac{1}{4}$ pollices longa.

fibirica. M. fufca fubtus cinerea, gula criffoque albo maculatis.

Mufcicapa fibirica, Gmel. syft. i. p. 936 .

Dun Flycatcher, ArE7. Zool. ii. p. 390 . A.-Lath. Syn. iii. p. 35 1. 49 .

60.

HaBitat circa lacum Baikal, Kamtichatka.

erythropis. M. fupra varia fubtus alba, fronte rubra, fub alis rufa.

Mufcicapa erythropis, Gmel. Syft. i. p. 937.

Red-faced Flycatcher, Lath. Syn. iii. p. 35 I. 50.

$6 \mathrm{I}$.

Habitat circa fluvium Fenifei.

olivacea. M. olivacea fubtus albidior, fuperciliis albis, oculis rubris.

Mufcicapa olivacea, Lin. Syft. i. p. 327. 14.-Gmel. Syft. i. p. 938.

oculis rubris, Klein. Av. p. 74. 6.

Mufcicapa 


\section{A V E S P A S SERES. Mufcicapa. 483}

Mufcicapa jamaicenfis, Brif. ii. p. 410. 27.-Id. 8 vo. i. p. 27 r.

Gobe-mouche de la Caroline et de la Jamaique, Buf. iv. p. 539.

Olive-coloured Flycatcher, Edwo. t. 253 .

Red-eyed Flycatcher, Catef. Car. t. 54.-Brown. Fam. p. 476.-ArEt. Zool. ii. $\mathrm{N}^{\circ} 27$ 1. - Latb. Syn. iii. p. 35 1. 52.

Habitat xeftate in Carolina, hyeme in famaica. $-5 \frac{\frac{x}{2}}{2}$ pollices longa.

B. Mufcicapa canadenfis olivacea, Brif. ii. p.408.26.-1d. 8vo. i. p. 27 I.

Habitat in Canada, et variat corpore fubtus pallidiore, Jupercilits corpore concoloribus : fafcia alarum duplici pallida.

62.

martinica. M. capite criftato, corpore fufco fubtus cinereo, remigum margine exteriore albido.

Mufcicapa martinica, Lin. Syft. i. p. 325. 3.-Gmel. Syft. i. p. 930.

—_ martinicana criftata, Brif. ii. p. 362.3 . t. 36. f. 2. -Id. $8 \mathrm{vo}$. i. p. 259 .

Gobe-mouche huppé de la Martinique, Buf.iv.p. 540.-Pl.Enl.568. f. I. Martinico Flycatcher, Lath. Syn, iii. p. 352.52.

Habitat in Martinica. -6 pollices longa.

63.

fufca. M. fufca fubtus albo-flavicans, pileo nigro, cauda fubforficata

Mufcicapa fufca, Gmel. Syft. i. p. 931.

Mufcicapa carolinenfis fufca, Brif. ii. p. 367. 6. $-I d$. 8vo. i. p. 260.Klein. Av. p. 74. 5.

Le Gobe-mouche noirâtre de la Caroline, Buf. iv. p. 54I.

Black-6ap Flycatcher, ArEt. Zool. ii. No 269.-Cat. Car. i. to 53.Latb. Syn. iii. p. 353. 53 .

Habiтat in Carolina; Lufcinia magnitudine.-6 $6 \frac{\mathrm{T}}{4}$ pollices longa.

64. Femina vertice nigricante.

carolinen- M. fufca fubtus cinerea, capite nigro, criffo rubro.

fis. Mufcicapa carolinenfis, Lin. Syft. i. p. 328. 18.-Gmel. Syft. i. p. 946.

virginiana fufca, Brif. ii. p. 365. 5.-Id. 8 vo. i. p. 260.

Le Moucherolle de Virginie, Buf. iv. p. 562.

Cat Flycatcher, Ariz. Zool. ii. No 272.-Cat. Car. i. t. 66.-Lath. Syn. iii. p. $353 \cdot 54$.

Habitat in Virginia -8 pollices longa - Migratoria $_{\text {. Cati more }}$ $3 \mathrm{Q}_{2}$ miaulizat, 


\section{A V E S P A S S E R E S. Mufcicapa.}

miaulizat, unde nomen Anglicum. Habitat quoque in Kamtfcbotka, at criffum non rubrum.

65.

canadenfis, M. cinerea fubtus lutea, loris luteis, vertice nigro maculato.

Mufcicapa canadenfis, Lin. Syft. i. p. 327. 1 3.-Gmel. Syft. i. p. 937.

i. p. 270 .

Canada Flycatcher, ArE7. Zool. ii. No 273.-Latb. Syn. iii. p. 354. 5.

HaBitat in Canada: $-4 \frac{\mathrm{T}}{2}$ pollices longa.

Roftrum fufcum : pedes flavefcentes : jugulum nigro maculatum : macula infra-ocularis nigra: tętrices alarum intus, remiges rectricefque grifeo-fufcæ, margine cinereæ.

66.

cinnamo- M. flavo-cinnamomea nebulofa, fubtus uropygio fafciaque tectricum

mea.

Mufcicapa cinnamomea, Gmel. Syft. i. p. 937.

Cinnamon Flycatcher, Latb. Syn. iii. p. $354 \cdot 56$.

Haвiт Aт in Cayana.-8 pollices longa.

67.

fpadicea. M. rubro-fufca fubtus obfcure flavefcens, uropygio flavo, remigibus rectricibufque fufcis.

Mufcicapa fpadicea, Gmel. Syft.i. p. 937.

Yellow-rumped Flycatcher, Latb. Syn. iii. p. 354. 57.

68.

Habrtat in Cayana. -7 pollices longa.

cayanenfis. M. fufca fubtus lutea, fuperciliis albis, vertice fubaurantio.

Mufcicapa cayanenfis, Lin. Syft. i. p. 327. 12.-Gmel. Syft. i. p. 937.-

Brif. ii. p. 404. 24. t. 38. f. 4.-Id. 8 vo. i. p. 270.

Gobe-mouche à ventre jaune, Buf. iv. p. 550.-Pl. Enl. 569. f. 2.

Cayenne Flycatcher, Latb. Syn. iii. p. 355. 58.-Id. Sup. p. 173.

Yellow-bellied Flycatcher, Latb. Syn. iii. p. 359. 65 .

Haвiтat in Cayana et infula Dominicenfi. $-7 \frac{x}{2}$ pollices longa.

Verticis pennæ mediæ bafi aurantiæ: gula alba: remiges rectricefque margine rufæ.

69.

Tyrannus. M. cauda longiffima forficata, corpore nigro, fubtus albo.

Mufcicapa Tyrannus, Lin. Syft. i. p. 325. 4.-Gmel. Syft. i. p. 931.

Tyrannus cauda bifurca, Brif. ii. p. 395.20. t. 39. f. 3.-Id. 8vo. i. p. 268 .

Savana, 


\section{A V E S P A S S E R E S. Mufcicapa. 485}

Savana, Tyran à queue fourchue, Buf. iv. p. 557.t. 26.-Pl. Enl. 57 1. 2.

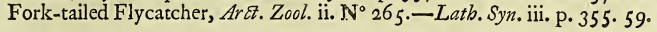

Haвitat in Surinamo, Canada.- 44 pollices longa.

Rectrix extima utrinque $9 \frac{x}{4}$, intermediæ 2 vix 2 pollices longæ. $S u$ rinamenfi rectrix extina margine exteriore verfus bafin alba: corpus nigrum.

Canadenfi rectrices fimiles: corpus fupra cinereum: pennæ verticis 70. bafi luteæ: tempora nigra.

forficata. M. cauda longiffima forficata, corpore pallide grifeo fubtus albo, tectricibus alarum cinereis albido undulatis, inferioribus rubris.

Mufcicapa forficata, Gmel. Syft. i. p. 93r.

Le Moucherolle à queue fourchue du Mexique, Buf. iv. p. 564.-Pl. Enl. 677.

Swallow-tailed Flycatcher, Lath. Syn. iii. p. 356.60.

Habitat in Mexico.-ro pollices longa.

Irides rubræ: remiges caudaque nigræ: cauda 5 pollices longitudine aquat.

71.

crinita. M. capite criftato colloque cærulefcentibus, abdomine flavefcente, dorfo virefcente, remigibus rectricibufque rufis.

Mufcicapa crinita, Lin. Syft. i. p. 325. 6.-Gmel. Syft. i. p. 934.

virginiana criftata, Brif. ii. p. 412. 28.-Id. 8vo. i. p. 272.

Gobe-mouche huppé de Virginie, Pl. Enl. 569. f. I.

Le Moucherolle de Virginie à huppe verte, Buf. iv. p. 565 .

Crefted Flycatcher, Arit. Zool. ii. N $\mathrm{N}^{\circ}$ 67,-Cat. Car. i. t. 52,-Gent.

Mag. xxii. t. p. 556.-Latb. Syn. iii. p. 357.61.

Habitat in Carolina, Virginia; migratoria. -8 pollices longa.

72.

ferox. M. fufca fubtus flavefcens, collo inferiore pectoreque cinereis.

Mufcicapa ferox, Gmel. Syft. i. p. 934.

Tyrannus cayanenfis, Brif. ii. p. 398. 21,-Id. 8 vo. i. p. 268.

Tyran de Cayenne, Buf. iv. p. $5^{8} \mathrm{I}$.

Tyrant Flycatcher, Latb. Syn. iii. p. 357. 62.

HaBitat in Cayana. $\rightarrow 7$ pollices longa.

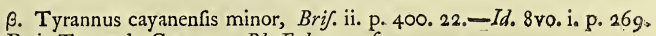
Petit Tyran de Cayenne, Pl. Enl. 571 . f. 1 . Tyrant Flycatcher, Latb. Syn. iii. p. 358. A. 
Hавітат cum præcedente.

73.

Minor; color fufcus ad rufum vergens.

ludovicia- M. grifeo-fufca fubtus flavefcens, gula cinerea, tectricibus alarum ma-

na. Mufcicapa ludoviciana, Gmel. Syft. i. p. 934.

I.e Tyran de la Louifiane, Buf. iv. p. $5^{8} 3$.

Louifiane Flycatcher, ArCZ. Zool. ii. N²64.-Lath. Syn. iii. p. 358.63.

Habitat in Louifiana; magnitudine præcedentis.

74 .

audax. M. nigricans rufo undulata, fubtus flavicans, vertice flavo, capiftro albo, uropygio caudaque rufis.

Mufcicapa audax, Gmel. Syft. i. p. 934 .

Le Gobe-mouche tacheié de Cayenne, $P l$. Enl. 453. f. 2.

Le Caudec, Buf. iv. p. $5^{82}$.

Yellow-crowned Flycatcher, Lath. Syn. iii. p. 358. 64 .

HАвІтат in Cayana. -8 pollices longa.-Victitat infectis.

Fafcia per oculos nigricans. Femina abfque vertice flavo.

75 .

petechia. M. fufca fubtus cinerea rufo maculata, gutture criffoque rufis.

Mufcicapa petechia, Lin. Syft. i. p. 328. I y.-Gmel. Syft. i. p. 948.

Mufcicapa martinicana fufca, Brif. ii. p. 36 r. 4. t. $3^{8}$. f. 1. $-I d .8 \mathrm{vo}$.

i. p. 259 .

Gobe-mouche brun de la Martinique, Pl. Enl. 568. f. 2.

Le Moucherolle brun de la Martinique, Buf. iv. p. $5^{6} 3$.

Petechial Flycatcher, Lath. Syn. iii. p. 360. 66.

HАвлтат in Martinica. $-6 \frac{\pi}{2}$ pollices longa.

76.

virgata. M. fubcriftata fufca, fubtus fordide alba fufco ftriata, fafcia alarum du= plici rufa.

Mufcicapa virgata, Gmel. Syft. i. p. 948.

Le Gobe-mouche tacheté de Cayenne, Buf.iv.p. 545- - Pl. Enl. 574. f. 3 . Streaked Flycatcher, Lath. Syn. iii. p. 360.67.

HАBIтAT in Cayana. $-\frac{4}{2} \frac{1}{2}$ pollices longa.-Vertex cinereus, flavo variegatus.

77. agilis.

M. fufco-olivacea fubtus albida, gutture fubrufo, remigibus caudaque nigricantibus.

Mufcicapa 


\section{A VES P A S S E R E S. Mufcicapa.}

Mufcicapa agilis, Gmel. Syft. i. p. 948.

Le Gobe-mouche olive de Cayenne, Buf. iv. p. 544.-Pl. Enl. 574. f. 2. Active Flycatcher, Lath. Syn. iii. p. 360.68.

Habitat in Cayane; magnitudine præcedentis; agilis et inquieta.78. Victitat infectis.-Cauda longiufcula.

furinama. M. cauda rotundata apice albo, corpore nigro fubtus albo.

Mufcicapa furinama, Lin. Syjt. i. p. 325. 5.-Gmel. Syjt. i. p. 932.

Surinum Flycatcher, Lath. Syn. iii. p. 36 I. 69.

Habitas in Surinamo.

79.

fuliginofa. M. fufea $\hat{\mathrm{A}}$ vefcente marginata, fubtus albida, pectore fubrufo.

Murcicapa fuliginof, Gmel. Syjt. i. p. 932.

Le Gobe-mouche brun de C yenne, Buf. iv. p. 536. -Pl. Enl. 574. f. r.

Brown Flyc stcher, Latb. Syn.iii. p. 36 r. 70 .

Haзттат in Cayana; parva fpecies; vix 4 pollices longa.

Femina fufco-viridis, fubtus flavefcens; pectore fufco-olivaceo.

80.

aurantia. M. rufo-virefcens fubtus alba, pectore pallide aurantio, capite cerviceque ulivareo-fufcis.

Mufcicapa curantia, Gmel. Syff.i. p. 932.

Le Gobe-mouche roux à poirrine orangée de Cayenne, Buf. iv. p. 537. - Pl. Enl. 8 3r.f. .

Orange-breafted Flycatcher, Lath. Syn. iii. p. 361. $7 x$.

HaBITAT in Guiene uliginofis. $-44^{\frac{3}{4}}$ pollices longa.

8.

coronata. M. crifta erecta rotundata, corpore fupra fufco, fubtus crifta lateribufque capitis coccineis.

Mufcicapa coronata, Gmel. Syft. i. p. 932.

Le Rubin, ou Gobe-mouche rouge huppé, Buif. iv. p. 547.-Pl. Enl. $675 \%$ f. $\mathrm{x}$.

Round-crefted Flycatcher, Latb. Syn: iii..p. 362. 72.

Habitat in America meridionali.- $5 \frac{x}{2}$ pollices longa.

Femina abfque crifta : color pennarum ut in mare, fed dilutior.

82.

rufefcens. M. rufefcente-nitens fubtus rufo-alba, remigibus nigris, vertice macula rufa.

Mufcicapa 
488 A V E S P A S S E R S. Mufcicapa.

Muícicapa rufefcens, Gmel. Syft. i. p. 932.

Le Gobe-mouche roux de Cayenne, Buf. iv. p. 549.-Pl. Enl. 453. f. I. Rufous Flycatcher, Latb. Syn. iii. p. 362. 73 .

83.

Habitat in Cayana ; magnitudine Pafferis. $-5 \frac{1}{2}$ pollices longa.

cinerta. M. rufo-fufca, abdomine ruffefente, capite colloque cinereis, uropygio pectore caudaque rufis.

Mufcicapa cinerea, Gmel. Syft. i. p. 933.

Mufcicapa cayanenfis rufa, Brif. Orn. Sup. p. 5 r. t. 3. f. 3. $-I d$. 8 vo. i. p. $277.3^{8}$.

Rufous-bellied Flycatcher, Lath. Syn. iii. p. 363. 74 .

HaBitat in Cayana. $-8 \frac{\frac{1}{4}}{4}$ pollices longa.-Fugulum albo undulatum. Variat abdomine flavefcente-albo.

84.

pygmæa. M. fufco-cinerea, fubtus flavefcens, capite cerviceque rufis nigro maculatis, fub oculis fafcia pallida.

Mufcicapa pygmia, Gmel. Syft. i. p. 933.

Gobe-moucheron, Buf. iv. p. 554 .

Le petit Gobe-mouche tacheté de Cayenne, Pl. Enl. 83r.f. 2.

Dwarf Flycatcher, Latb. Syn. iii. p. 363.75.

Habitat in Cayana; vix 3 poll. longa.-Ala caudaque rufa.

85. minuta.

86.

M. olivaceo-grifea, dorfo fupremo corporeque fubtus viridi adumbratis, ftriis alarum flavefcentibus fparfis.

Mufcicapa minuta, Gmel. Syft. i. p. 933.

Gobe-moucheron, Buf. iv. p. 553 .

Petty Flycatcher, Latb. Syn. iii. p. 364. 76.

HaBitat cum præcedente, qua paulo major.

barbata. M. olivaceo-fufca, fubtus uropygioque virefcente-flava, vertice aurantio.

Mufcicapa barbata, Gmel. Syft. i. p. 933 .

Le Barbichon de Cayenne, Buf. iv. p. 534.-Pl. Enl. 830. fo т. 2. Whifkered Flycatcher, Latb. Syn. iii. p. 364. 77.

Haвiтat in Cayana. -5 pollices longa; fuaviter fiftulat.-Roftrum depreffum, latum : myftaces ultra apicem elongatæ.

Femina viridi-nigricans, fubtus flavefcens : pectore fufcefcente; vertice macula oblonga flava: myftaces breviores.

M. nigra, 
87.

A VES PAS S E R S. Mufcicapa.

rubricollis. M. nigra, jugulo macula fpeciofa purpureo-coccinea.

Mufcicapa rubricollis, Gmel. Syft. i. p. 933.

Mufcicapa cayanenfis nigra major, Brif. ii. p. 386 . t. 3 3. f. 3 .

Grand Gobe-mouche noir de Cayenne, Pl. Enl. $38 \mathrm{r}$.

Le Piauhau, Buf.iv. p. $5^{88}$.

Purple-throated Flycatcher, Latb. Syn. iii. p. $365 \cdot 77$.

Habitat in Cayana; magnitudine Merule.-I2 poll. longa.

88. Funior avis (forte femina) abfque macula jugulari.

Phœbe. M. cinereo-olivacea fubtus flavefcens, pectore cinerafcente, rectrice extima latere exteriore alba.

Mufcicapa atra, Gmel. Syft. i. p. 946.

DuRky Flycatcher, Arct. Zool. ii. N N $^{\circ} 75$.

Phobe Hlycatcher, Lath. Syn. Sup. p. 173.

Habitat aftate in America Septentrionali, Noveboraco; apibus vistitans.-Ovum album.

89.

ochroleu- M. olivacea fubtus albida, gula margineque alarum fulvis, remigibus

ca. rectricibufque olivaceo-viridibus.

Mufcicapa ochroleuca, Gmel. Syft. i. p. 946.

Golden-throat Flycatcher, ArEt. Zool. ii. N 276,-Latb. Syn. Sup. p. 173. 80 .

Habitat in America Septentrionali.

90.

nitida. M. pallide viridis, te£tricibus alarum margine albo, remigibus rectrici* bufque nigricantibus margine flavo.

Nitid Flycatcher, Latb. Syn. Sup. p. 173. 8 I。

Habitat in Cbina; parva fpecies.

91.

acadica. M. fubcriftata cinereo-viridis, fubtus flavefcente-alba, faicia alarum duplici alba.

Mufcicapa acadica, Gmel. Syft. i. p. 947.

Leffer crefted Flycatcher, ArEz. Zool. ii. No 268.-Lath. Syn. Sup. p. I74. 82 .

Habitat in nova Scotia.

92.

novebora- M. pallide viridis, capite cinerafcente, abdomine medio albo, fafcia cenfis. alarum duplici alba, macula narium lateribufque corporis flavis. 
Mufcicapa noveboracenfis, Gmel. Syft. i. p. 947.

Green Flycatcher, Arct. Zool. ii. $\mathrm{N}^{\circ} 274$.

Hanging Flycatcher, Latb. Syn. Sup. p. 174.

93.

Habitat rarior a Maio ad Auguftum in Noveboraco.

pafferina. M. nigricans fubtus alba, cauda nigra,

Pafferine Flycatcher, Latb. Syn. Sup. p. 175.

Habitat in infula Tanna Maris Pacifici.

94.

dichroa. M. corpore fupra cinereo fubtus ochraceo, cauda ex rectricibus ochraceis cinereifque.

Mufcicapa bicolor, Muf. Carlf. fafc. ii. t. 46. dichroa, Gmel. Sy/t. i. p. 949.

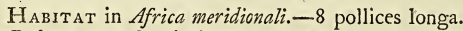

Roftrum et pedes nigricantes: tectrices alarum margine canefcentes:cauda longitudine circiter corporis, et rectricibus ochraceis cinereifque conftans.

95: javanica. M. cauda longiffima rotundata, corpore nigro ferrugineoque vario fubtus albo, jugulo nigro, fuperciliis albis.

Mufcicapa javanica, Mus. Carlf. fafc. iii. t. 75.

Haвiтat in Fava; magnitudine Grifole.

Roftrum et pedes nigri : corpus fupra plumis nigricantibus apice ferrugineis : jugulum nigrum: gula, linea fuperciliaris, abdomen, criffum, et octo rectricum apices alba.

$9^{6 .}$

alba.

M. tota alba, capite fulphureo-flavicante.-

Mufcicapa alba, Muf. Carlf. fafc. iii. t. 74.

Haвiтat ad Holmiam.-Roftrum depreffiufculum, album : caput, gu$l a_{3}$ juguli pars læte flavicantia: cauda longiufcula. Forte inter Motacillas numeranda.

97.

cambaien- M. nigra nitens, dorfo viridi-flavefcente, corpore fubtus fulvo-flavo,

fis. tectricibus alarum fafcia duplici alba.

HaBitat in Cambaia; magnitudine atricapille.

Roftrum depreffum, latum, nigricans, bafi fetulis raris: tectrices alarum apice alba, unde fafcia duplex: corpus totum fubtus flavum ad fulyum inclinans: pedes cærulefcentes. . Muf. Brit.

GENus 


\section{A VES PASSERES. Alatida? \\ GENUS XLI. ALAUDA.}

Roftrum cylindrico-fubulatum, rectum, recta protenfum; mandibulis requalibus, bafi deorfum dehifcentibus.

Lingua bifida.

Unguis pofticus rectior, digito longior.

I.

arvenfis. A, nigricante grifeo-rufefcente et albido varia, fubtus rufo-alba, rectricibus extimis duabus extrorfum longitudinaliter albis, intermediis interiori latere ferrugineis.

Alauda arvenfis, Lin. Syft. i. p. 287. 1.-Faun. Suec. $\mathrm{N}^{\circ} 209 .-S c o p$. Ann. i. $\mathrm{N}^{\circ}$ I 84.-Brun. $\mathrm{N}^{\circ} 221 .-$ Muller, $\mathrm{N}^{\circ} 229 .-$ Frifch. t. I 5 . f. 1.-Kram. El. p. 362. 2.-Faun. Arag. p. 88. -Sepp. Vog. t. p. 27.-Borowfk. Nat. iii. p. 196. 2.-Gmel. Syft. i. p. 791.-Kolb. Cap. ii. p. I 5 I ?

Alauda vulgaris, Raii. Syn. p. 69. A. 1.-Will. p. 149. t. 40.-Brif: iii. p. 335. 1. - Id. 8 vo. i. p. $404 .-S c h$. El. Av. t. 18.

Alauda colipeta, Klein. Av. p. 7 I. I.-1d. Stem. p. I 3. t. I 5. f. I. a. b. c. d. $-I d$. Ov. p. 23 . t. 9. f. r.

L'Alouette, Buf. v. p. I. t. 1. $-P l$. Enl. $3^{6} 3$. f. 1.

Lodola, Olin. uc. t. p. I 2.-Zinnan. Uov. p. 55. t. 8. f. 43 .

Lerche, Wirfing. Vog. t. 22.

Sky-lark, or Field Lark, Br. Zool. i. No 13 6.-Id. fol. 93. t. S. 2. f. 7 . -Arct. Zool. ii. p. 394. A.-Kolb. Cap. iii. p. 164.-Albin. i. t. 4 I. -Id. Song. Birds, p. 38.-Will. (Angl.) p. 203:-Lath. Syn. iv. p. $3^{68 .} \mathrm{I}$.

HaвiтAт in Europo, Afia, Africa.-7 pollices et ultra longa.-In Anglia frequens; victitans frugibus, infectis.-Humi nidificat.-Suave cantillando fpiraliter æthera fcandit juncta conjugio.-Ovum albido-virefcens, maculis obfcurioribus confluentibus.

ß. Alauda candida, Brif. iii. p. 339. t. 19. f. 1. $-I d$. 8 vo. i. p. 405. Frifcb. t. 16.-Klein. Av. p. 72.4 .

Alouette blanche, Buf. v. p. 20.

White Lark, Latb. Syn. iv. p. 369. A.

Per univerfum corpus albicat. 
$\gamma$. Alauda nigra, Brif. iii. p. 340 . B.-Id. 8 vo. i. p. 405 .

Alouette noire, Buf. v. p. 22. - Pl. Enl. 650. f. I.

Black Lark, Alb. iii. t. $5 \mathrm{I}$.

Dufky Lark, Latb. Syn. iv. p. 370.

Fufco-nigra, vel penitus fuf́ca evadit.

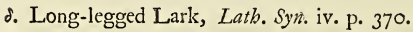

Hавітат in Ruffa, finibus Mongolicis.

Variac pedilus longioribus; in terra fedens cantillar.

2.

fulva. A. fufco-nigricans, cervice dorfo fcapularibufque rufo-aurantiis, alis caudaque obfcuris.

Alauda rufa, Gmel. Syft. i. p. 792.

L'Alouette noire à dos fauve, Buf. v. p. 23.

Rufous-backed Lark, Lath. Syn. iv. p. 371. 2.

HaBItat in Bonaria; vix 5 pollices longa.

3.

arborea. A. varia, capite vitta annulari alba cineto.

Alauda arborea, Lin. Syft. i. p. 287. 3.-Faun. Suec. $\mathrm{N}^{\circ} 211 .-$ Gmel.

Syft. i. p. 793.-Scop. Ann. i. $\mathrm{N}^{\circ}$ 186.-Brun. $\mathrm{N}^{\circ}$ 224. 225.-

Muller, $\mathrm{N}^{\circ} 231 .-K r a m$. El. p. 362. 3.-Raii Syn. p. 69. A. 2.-

Will.p. 149.t. 40. - Brif. iii. p. 340.t. 20. f. 1. $-I d .8$ vo. i. p. 405.

-Klein. Av. p. 7 1. 2.-Id. Stem. p. 13. t. 15. f. 4. a-c.-Id. Ov.

p. 24. t. 9. f. 5.-Borowe. Nat. iii. p. $19^{8.4} 4$.

L'Alouette de bois, ou le Cujelier, Buf. v. p. 25.--Pl. Enl. 66o. f. 2.

Tottovilla, Olin. uc. t. p. 27.

Wood-Lark, Br. Zool. No 137.-Id. fol. 94. t. Q. f. 3.-ArEt. Zool.

ii. p. 395. B.-Alb. i. t. 42.-Id. Song Birds t. p. 46.-Will. (Angl.) p. 204.-Lath. Syn. iv. p. 37 I. 3.

HaBitat in Europa, Afia.-Ab arvenfi differt quod arboribus infideat, cum illa terræ plerumque.-Humi nidificat. Ovuin grifeo-album, snaculis numerofis confluentibus.

italica. A. fufco-caftanea fubtus alba, capite vitta annulari albicante, rectrice. extima alba, proxima apice alba.

Alauda italica, Brif. iii. p. 355. 7.-Id. 8vo. i. p. 409.-Gmel. Syft. i。. p. 793 .

Giarolas. 
Giarola, Raii Syn. p. 70. 10.-Will. p. 152.-Id. (Angl.) p. 209. 9.Buf. v. p. 47 .

Italian Lark, Latb. Syn. iv. p. 373. 4.

5.

Habitat in Italia. -8 pollices longa. - An varietas arborea?

pratenfis. A. viridi-fufca, rectricibus duabus extrorfum albis, linea fuperciliari alba.

Alauda pratenfis, Lin. Syff. i. p. 287. 2.-Faun. Suec. No 210.-Gmel. Syft. i. p. $792 .-$ Brun. $\mathrm{N}^{\circ} 223 .-$ Muller $\mathrm{N}^{\circ} 230 .-$ Frifcb. t. 16.

- Faun. Arag. p. 84.-Raii Syn. p. 69. A. 3.-Will. p. $150 .-$ Brif. iii. p. 343. 3.-Id. 8vo. i. p. 406.-Borowejk. Nat. iii. p. 198. 3.

Alauda ftratorum, Klein. Stem. p. 13. t. 15. f. 2. a-c.-Id. Ov. p. 24. t. 9. f. 4 .

Spipola altera Aldr. Raii Syn. p. 80. 4.-Will. p. 153.-17 I.

L'Alouette de prés, Buf. v. p. 31. t. 3.-Pl. Enl. 660. f. 1.-Hijt. Prov. i. p. 504 .

Mattolina, Zinnan. Uov. p. 55. t. 8. f. 44.

Spippola minore, Zinnan. Uov. p. 50 o. t. 7 . f. 37 ?

Lodola di prato, Olin. uc. t. p. 27.-Cett. uc. Sard. p. 158.

Titlark, Br. Zool. No 138.-Id. fol. 94. pl. Q. f. 6.-P. r. f. 3. var.ArEz. Zool. ii. p. 395. C. -Will. (Angl.) p. 110 ? 206.-Alb. i. t. 43.-Id. Song Birds, t. p. 53.-Latb. Syn. iv. p. 374. 5.

Habitat in Europa pratis, ubi fedens fuave cantillat. $-5 \frac{1}{2}$ pollices longa.-In Anglia frequens.

Corpus fubtus albidum: pectus ochroleucum maculis oblongis nigris, ad latera magis maculofum: pedes flavicantes. Ovum fufco-rubrum, maculis minutis obfcurioribus.

6.

trivialis. A. nigricante et olivaceo varia, fubtus albo-flavicans maculis nigricantibus, rectrice extima dimidiato, fecunda apice alba.

Alauda trivialis, Lin. Syft. i. p. 288. 5.-Gmel. Syft. i. p. 796.

fepiaria, Brif. iii. p. 349. 5.-Id. 8vo. i. p. 407.

Alouette pipi, Buf. v. p. 39. t. 4.-Pl. Enl. 66 I. f. 2 ?

Piep Lerche, Frifcb. t. 26.

Pipit Lark, Alb. i. t. 44 .

Grafshopper Warbler, Lath. Syn. iv. p. 429. 20. (quoad Jynon.)

Habitat in Europa; circa medium Septembris in Anglia copiofe invenitur.

A. olivaceo- 
7. 494 A VES P.AS S E R E S. Alauda:

obfcura. A. olivaceo-fufca nigricante varia fubtus flavicans, lateribus colli pectoreque maculis fufcefcentibus, rectrice extima dimidiato, fecunda apice albo-cinerafcente.

Habrtat in Anglia paludofis; habitus pratenfis, at major; folitaria ; vix cantat, potius Grylli inftar ftridens. $-7 \frac{\pi}{4}$ pollices longa.

Rofrum tenue, elongatum, fufcum, apice faturatiore: color totius corporis obicurus, fupra olivaceo-fufcus, pennis medis faturatioribus: gula, collum medium, et abdomen flavicans: latera colli cum peztore coloris ejufdem, maculis longitudinalibụs obfcure fufcis: cauda 3 pollices longa, apice integra, rectrice extima fufco et albo-cinerafcente oblique dimidiata, fecunda apice tantum albo-cinerafcente: pedes fufco-rubri, ungue poftico adunco, vix digito longior. Lervin.

8.

minor. A. rubro-fufca fubtus maculata, gula abdomineque albis, jugulo pectoreque obfcure flavefcentibus.

Alauda minor, Gmel. Syft. i. p. 793.

Leffer field Lark, Will. (Angl.) p. 207.

Field Lark, Br. Zool. N' 139. -Arct. Zool. ii. p. 395. D.-Lath. Syn. iv. p. $375 \cdot 6$.

Habiтat in Europa; in Anglia aftate frequens; forte migratoria; pratenfi magnitudine circiter æqualis, at cantu præftantior. Unguis pofticus nonnihil aduncus.

9.

ludovicıa- A. fufco-nigricans fubtus fulva, jugulo pectoreque flavefcente-grifeis,

na. pectore fufco maculato.

Alauda ludoviciana, Gmel. Syft. i. p. 793.

La Farlouzanne, Buf. v. p. $3^{8}$.

Louifiane Lark, Latb. Syn. iv. p. 376.7 .

HАВітAт in Louifiana. -7 pollices longa.

Rectrix extima fufco alboque dimidiata, proxima apice albo. An varietas præcedentis?

ro.

rubra. A. obfcure fufca, fubtus fulvo-rufefcens maculis fufcis varia, genis nigricantibus, fuperciliis pallide rufis.

Alauda rubra, Gmel. Syf. i. p. 794.

Alauda penfylvanica, Brif. Sup. p. 94.-Id. 8vo. i. p. 419. I 3.

Alouette à joues brunes de Penfylvanie, Buf. v. p. 58 .

Lark from Penfylvania, Edw. t. 297.

Red 
Red Lark, Br. Zool. No 140.-Arit. Zool. ii. N²79.-Lath. Syn. iv. p. 376.8 .

Habiтat in America Septentrionali; in Anglia quoque, prope Londinum, interdum invenitur:-Magnitudo arvenfis.

Rectrix extima alba, proxima apice albo : unguis pofticus valde elon-

II. gatus, vix incurvatus.

motellana. A. rufa fufco varia fubtus rufefcens, pectore fufco maculato, fafciis tribus fubocularibus fufcis.

Alauda mofellana, Gmel. Syft. i. p. 794.

La Rouffeline, ou l'Alouette de marais, Buf.v. p. 60.-PL. Enl.66r.f. r. Marfh Lark, Latb. Syn. iv. p. 377. 9.

Habitat in Germania, ad Aluvium Mofellam.-6 6 pollices longa.A pracedente non multum diverfa? egregie cantat.

Cauda nigricans margine rufo : pedes flavicantes.

12.

campeftris. A. rectricibus fufcis, inferiore medietate, exceptis intermediis duabus, albis, gula pectoreque flavefcente.

Alauda campeftris, Lin. Syf. i. p. 288. 4.-Faun. Suec. $\mathrm{N}^{\circ} 2$ 12.-

Gmel. Syjt. i. p. 794.-Brun. No 226.-Muller, No 232.-Georgi,

p. 173.-Raii Syn. p. 7o. A. 6.-Brif. iii. p. 349.5.-Id. 8 vo. i.

p. 408.-Frifcb. t. 1 5.-Borowes. Nat. iii. p. 199. 5.

Alauda dumetorum, Klein. Stem. p. 13. t. I5. f. 3. a-c.

La Spipolette, Buf. v. p. 43 .

Kraut Vogel, Gunth. Neft. u. Ey. t. 19. fig. inf.

Meadow Lark, Lath. Syn. iv. p. 378. 10.

Habitat in Europe novalibus, et locis erica confitis. $\rightarrow 7$ poll. long.

$\beta$. A rectricibus fufcis, extimis duabus oblique dimidiato albis.

Alauda fpinoletta, Lin. Syft. i. p. 288. 7.-Scop. Ann. i. N $187 .-D e c$. Ruff. i. p. 249.-Gmel Syyt. i. p. 794. 4. $\beta$.

Spipoletta, Raii Syn. p. 70. 9.-Will. p. 1 52.-Id. (Angl.) p. 209. \$. 10. -Cet. uc. Sard. p. 158.- Latb. Syn. iv. p. 378. 10. A.

13.

malabari- A. fufca pennis rufo marginatis, apice albo maculatis, collo rufefcente

ca. maculis fagittatis nigris.

Alauda malabarica, Gmel. Syjt. i. p. 795.

L'Alouette huppée de la côtede Malabar, Son. Voy, Ind.ii.p. 203 .t. I I 3. f. I. Malabar Lark, Latb. Syn, iv. p. 37.9. I I. 
496 A V E S P A S E R E S. Alauda.

Habitat in Malabaria. $-5 \frac{3}{3}$ pollices longa. - Pulcherrima fpecies. Vertex fubcriftatus.

14.

gingica. A. cinereo-fufca, capite cinerco, fubtus vittaque per oculos nigra.

La petite Alouette grife de Gingi, Son. Voy. Ind. ii. p. 203. t. I I3. 2.

Gingi Lark, Lath. Syn. iv. p. $3^{80}$. 12.

I 5 .

Habitat in Coromandela. $-4 \frac{x}{2}$ pollices longa.

tatarica. A. fufco-nigricans, pennis albido marginaris, remigibus rectricibufque nigris.

Alauda tatarica, Pall. It. ii. p. 707. 15. t. C.-Gmel. Syft. i. p. 795.

- nigra, Falck. It. iii. p. 393. t. 27.

Tanagra fibirica, Muf. Carlf. fafc. I. t. 19.-Gmel. Syft. i. p. 899.

Black Lark, Latb. Syn. iv. p. 380. 13.-Id. Sup. p. 177.

Habitat in Europa, Tartaria; Sturni magnitudine.-Cauda fubforcipata. Funiores aves et fomine maxima parte fufcefcentes.

$\beta$. A. nigra pennis margine canis fubtus toto nigra, remigibus rectricibufque fufcis.

Alauda mutabilis, Act. Petrop. xr. p. 459. t. 23. f. 2,-Gmel. Syft. i. p. 796.

Mutable Lark, Lath. Syn. iv. p. 38 I. 14.

Habitat ad Aftracbanum. $\rightarrow 7$ pollices longa.-Cauda fubforficata.

Femina fronte car.a; junior avis cinerea, vel fubrubra, grifeo variegata;

16. vix canora.

yeltonien- A. nigta fupra rufefcente varia, fexta remigum margine exteriore alba, fis. $\quad$ rectricibus duabus intermediis rufis.

Alauda yeltonienfis, Pbil. Tranf. lvii. p. 350. (Forfter.)

Habitat trans Volgam, ad lacum Yelton; faporis exquifiti, et admodum pinguis menfe Augufto; gregaria.-Magnitudo Sturni.

Roftrum cylindricum, fubulatum, rectum, ad bafin nigrum, craffufculum, apice albefcens; lingua bifida : unguis pofticus rectior, digito multo longior: caput, dorfum, et fumma ala pennis paucis rufefcentibus.

Calandra. A. rectrice extima exterius tota alba, fecunda tertiaque apice albis, fafcia pectorali fufca.

Alauda 
Alauda Calandra, Lin. Syft. i. p. 288. 9.-Gmel. Syft. i. p. 800.-Brif. iii. p. 352 . 6. t. 20 . f. r. -Id. 8 vo. i. p. $408 .-$ Klein. Av. p. 72.7. -Will. p. 151.-Olin. uc. t. p. 30.-Cet. uc. Sard. t. p. 147.Faun. Arag. p. 84.

Calandre Lark, ArEt. Zool. ii. No 280.-Edw. t. 268.-Will. (Angl.) p. 2c8. -Lath. Syn. iv. p. 382. I8.-Id. Sup. p. 177.

HaBITAT in Italia. $-7 \frac{\mathrm{r}}{4}$ pollices longa.

Rafrum reliquis craffior : remiges fecundariæ apice albæ.

ß. A. flavo-ferruginea fubtus albida, jugulo ferrugineo vario, remigibus fecundariis maxima parte albis.

Alauda fibirica, Gmel. Syft. i. p. 799.-Pall. It. ii. p. 708. 15. *.-Id iii. p. 697 .

White-winged Lark, Latb. Syn. iv. p. $3^{8} 3$.

Habiтat in Sibiria; abundat in campis apricis ad Irtin; hum1 n1dificans; volatu haud excelfo, cantuque arvenfi inferior; Calandre valde affinis, fi non eadem avis.

18.

mongoli- A. capite colloque ferrugineis, vitta annulari verticis marginali macula-

ca. que medio albis, gula macula bifida.

Alauda mongolica, Pall. It. iii. p. 697. 19.-AEt. Stock. I778. 3. 6.Gmel. Syft. i. p. 799.

Mongolian Lark, Latb. Syn. iv. p. $3^{84}$. 16.

Habitat in Mongolia; Calandra major, cui affinis. In campis falfis, inter Ononem et Argunum abundat; humi cantillans fuaviter.

Roftrum craflum, ut in tatarica.

I 9.

novæ Zea- A. obfcura pennis cinerafcente marginatis, abdomine albo, fuperciliis landiæ. albis, fafcia oculari nigra. Alauda novæ Seelandiæ, Gmel. Syf. i. p. 799.

New Zealand Lark, Latb. Syn. iv. p. 384. I7. t. 5 1.

Haвітат in nova Zealandia, ad littora. $-7 \frac{x}{2}$ pollices longa.

ß. A. cinerea fubtus cinereo-alba, remigibus rectricibufque nigris niargine exteriore albis.

Cinereous Lark, Portl. Voy. t. p. 37.

Habitat cum priore, at paulo minor. 
20.

$49^{8}$ A.V

capenfis. A. rectricibus tribus lateralibus apice albis, gula lutea nigro marginata, fuperciliis flavis.

Alauda capenfis, Lin. Syjt. i. p. 288. 8.-Brif. iii. p. 364 . 1 1. t. 19. f. 3. -Id. 8 vo. i. p. $4 \mathrm{II}$.

Cravate jaune, ou Calandre du Cap de B. E. Buf. v. t. 54.-Pl. Enl. 504. f. 2.

Cape Lark, Lath. Syn. iv. p. 384 . I 8.

Habitat ad Caput Bone Spei.-8 pollices longa.

Femina gula nigro non marginata.

21.

alpeftris. A. rectricibus dimidio interiore albis, gula flava, fafcia fuboculari pectoralique nigra.

Alauda alpeftris, Lin. Syft.i. p. 289. 10.-Gmel. Syft. i. p. 800.-Georgi, p. 173.-Frifch. t. 16.-Borow/k. Nat. iii. p. 201.8.-S. G. Gmel. reife. i. p. 52. t. 12.

Alauda virginiana, Brif. iii. p. $367.12 .-I d$. 8 vo. i. p. 4 I 2.-Klein. $A v$ 。 p. 72. 5.-Id. Stem. p. 13. t. 1 5. f. 5. c. d.

Le Hauffecol noir, Buf. v. p. 55 .

Shore Lark, Arct. Zool. ii. N 278.-Catef. Car. i. t. 32.-Pbil. Tranf. Ixii. p. 398.-Lath. Syn. iv. p. $3^{8} 5019$.

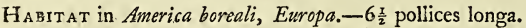

Corpus fupra fufcum: guttur ad pectus ufque flavum : abdomen album.

ß. A. rufa grifeo varia fubtus alba, vertice nigro maculato, fafcia pectorali fuboculari lorifque nigris.

Alauda flava, Gmel. Sy/t. i. p. 800.

La Ceinture de Prêtre, Buf. v. p. 61.-Pl. Enl. 650. f. 2.-Latb. Syn. iv. p. 387 .

Habitat in Sibiria. $-5^{\frac{3}{4}}$ pollices longa.

22.

rufa,

A. nigricans rufo nebulofa, corpore fubtus gulaque albis, rectricibus duabus extimis albo marginatis.

Alauda rufa, Gmel. Syft. i. p. $79^{8}$.

Variole, Buf. v. p. 63.

Petite Alouette de Buenos Ayres, $P l$. Enl. 738. f. I.

Rufous Lark, Latb. Syn. iv. p. 388. 20.

Habitat in America meridionali, ad fluvium Plata, $-5 \frac{1}{4}$ poll. long.

A. cinerea, 
23.

A VES P A S E R E S. Alauda.

cinerea. A. cinerea, abdomine albo, remigibus rectricibufque fufcis, reetrice extima extus apice alba.

Alauda cinerea, Gmel. Syft. i. p. 798.

La Cendrille, Buf. v. p. 64 .

Cinereous Lark, Lath. Syn. iv. p. 388. 2x.

Habrtat ad Caput B. Spei? -6 pollices longa.

24.

africana. A. fufca rufo alboque varia, fubtus alba maculis fufcis, alis caudaque fufcis.

Alauda africana, Gmel. Syft. i. p. $79^{8}$.

Le Sirli du Cap de B. Efperance, Buf. v. p. 65.-Pl. Enl. 712.

African Lark, Latb. Syn. iv. p. 389. 22.

Habitat ad Caput Bone Spei-8 pollices longa.

25.

criftata. A. rectricibus nigris, extimis duabus margine exteriore albis, capite criftato.

Alauda criftata, Lin. Syyt. i. p. 288.6.-Gmel. Syft. i. p. 796.-Scop. Ann. i. $\mathrm{N}^{\circ} 185 .-$ Brun. $\mathrm{N}^{\circ}$ 228.-Muller, $\mathrm{N}^{\circ}$ 234.-Kram. El. p. 362.-Georgi. p. 173.-Faun. Arag. p. 84.-Raii Syn. p. 69. 4. -Will. p. I5 1. t. 40.-Brif. iii. p. 357. 8.-Id. 8 vo. i. p. 410.Klein. Av. p. 7 1. 3.-Id. Stem. ii. p. 13. t. 1 5. fo 6. a-co-Id. Ov. t. 9. f. 4 ? -Borowes. Nat. iii. p. 200. 7.

Le Cochevis, ou la groffe Alouette huppée, Buf. v. p. 66.-Pl. Enl. 503. f. 1. - Hift. Prov. i. p. 503 .

Lodola capelluta, Olinv uc. t. p. 13-Zinnan. Uov. p. 64. t. g. f. 56. Korn-lerche, Guntb. Neft.u. Ey, t. 28. fig. fup. ?

Crefted Lark, Will. (Angl.) p. 208.-Albin。 iii. to 52.-Latb. Syn. iv. p. 38 . 23 .

Habitat in Europa. $-6 \frac{3}{4}$ pollices longa.

Crifta capitis ex 7-12 pennulis compofita: cauda brevior. Ovum cinerafcens, maculis numerofis fufco-nigricantibus.

26.

crittatella. A. criftata, corpore fupra fufco fubtus albicante, remigibus rectricibufo que fufcis, pedibus fubrubris.

Alauda nemorofa, Gmel. Syft. i. p. 797 .

Alauda criftata minor, Raii Syn. p. 69. A. 5.-Will. p. 152,-Brif. iii。 p. $3^{6} \mathrm{r} .9 .-I d .8 \mathrm{vo}$. i. p. $4 \mathrm{Ir}$.

Le Lulu, Buf. v. p. 74.-Pl. Enl. 503. f. 2。 
500 A V E S P A S S E R S. Alauda.

Leffer crefted Lark, Br. Zool. i. No 141.-Id. fol. 95.-Will. (Angl.)

p. 207.-Lath. Syn. iv. p. 391. 24.

Habitat in Europa; frequens in Italia; in Anglia, comitatu Eboracenf $f$, rarius; præcedente minor.

Color pennarum pallide fufcus, crifta magis elongata.

$=7$.

undata. A. criftata nigricans rufo varia, fubtus alba, pectore nigro maculato, tectricibus alarum majoribus apice albis.

Alauda undata, Gmel. Syft. i. p. 797 .

La Coquillade, Buf. v. p. 77.-Pl. Enl. 662.

Undated Lark, Lath. Syn. iv. p. 391. 25.

Haвiтat in Europa, Africa.-Ale caudaque fufca, crifta e pennis

28. nigris albo marginațis.

fenegalen- A. fufco grifeoque varia fubtus albida, collo inferiore fufco maculato, fis. rectricibus duabus extimis extus rufo-albis.

Alauda fenegalenfis, Gmel. Syft. i. p. 797.

Alauda fenegalenfis criftata, Brif. iii. p. 362 . Io. t. I9. f. $2 .-1 d .8$ vo. i. p. 411 .

Grifette, ou Cochevis du Senegal, Buf. v. p. 79.-Pl. Enl. 504. f. I. Senegal Lark, Latb. Syn. iv. p. 392. 26.

Habitat in Senegala. $-6 \frac{\pi}{2}$ pollices longa.

29.

teftacea. A. teftacea fubtus albida, vertice tectricibufque alarum nigro maculatis, - rectricibus quatuor exterioribus teftaceo-albis.

Alauda teftacea, Gmel. Syft. i. p. 798.

Teftaceous Lark, Lath. Syn. iv. p. 393. 27.

Haвitat in Europa, ad Calpen.

30.

lufitana. A, fufco-flavefcens, pennis medio fufcis, fubtus rectricibufque exterioribus flavefcente-albis.

Alauda Lufitana, Gmel. Syft. i. p. 798.

Portugal Lark, Lath. Syn. iv. p. 393. 28 .

Habitat in Lufitania. 
A V ES PAS S R E S. Motacilla.

\section{G E N S XLII. MOT A I L L A.}

Roftrum fubulatum, gracile, apice nonnihil emarginatum. Lingua lacera.

Cauda elongata.

1.

alba. M. pectore nigro, rectricibus duabus lateralibus dimidiato oblique albis.

Motacilla alba, Lin. Syft. i. p. 331. xx.-Faun. Suec. No 252.-Gmel. Syf. i. p. 960.-Scop. Ann. i. N ${ }^{\circ} 224 .-B r u n . N^{\circ} 271 .-$ Muller, $\mathrm{N}^{\circ}$ 272.-Kram. El. p. 373. 1.-Fricch. t. 23. f. 4.-Georgi, p. 174.-Faun. Arag. p. 88.-Sepp. Vog. t. p. I 1 9.-Raii Syn. p. 75. A. 1. -Will. p. 17 1. t. $42 .-$ Brif. iii. p. 46 1. $3^{8 .-}-I d$. 8 vo. i. p. 437.-Borowejk. Nat. iii. p. 188. 6 .

Sylvia pectore nigro, Klein. Av. p. 78.6.-Id. Stem. p. 14. t. I6. f. 6. a. b. -Id. Ov. p. 26. t. Io. f. I9.

La Lavandiere, Buf. v. p. 25 1. t. 14. f. 1.-Pl. Enl. 652. f. 1.-Hift. Prov. i. p. 496.

Hoche-queue noire et blanche, Ferm. Surin. ii. p. 183 ?

Coda tremola, Zininan. Uov. p. 5 1. t. 7. f. $3^{8}$.

Ballarina, Olin. uc. t. p. 43 .

Bachftelzen, Gunth. Neft. u. Ey. p. 25. t. I. fig. fup.-Wirf. Vog. t. 2 I. White Wagtail, Br. Zool. i. No 142. t. 55.-Id. fol. 104.-ArEt. Zool. ii. p. 396. B.-Will. (Angl.) p. 237.-Alb. i. t. 49.-Latb. Syn. iv. p. 395. 1.-Id. Sup. p. 178 .

Habitat in Europa, Afia, forte in America ad aquas; ad pagos frequens; curfitans; irrequieta cauda. In feptentrionali Anglice parte hyeme raro apparet, meridionalem petens.

Corpus fupra cinerco-nigrum, fronte, lateribus capitis, abdomineque albis; gula, collo inferiore, pectoreque nigris. Femina vertice fufco.

Variat collo inferiore albo, lunula pectoris nigra; forte pullus primi anni, feu adulta avis veftitu autumnali. Qvum albo-rubefcens maculis fufco-rubris diftantibus.

$\beta$. M. albida, dorfo tectricibus alarum caudaque cinerafcentibus, roffro pedibufque purpurafcentibus.

Motacilla albida, Gmel. Syft. i. p. 961,-Facq. Vog. p. 23. 17. t. 8. $\gamma$. M. cinerea, 
502 A VES PAS S E R S. Motacilla.

\%. M. cinerea, peitore nigro, capinto gula genis fafcia alarum rectricibufque duabus extimis albis.

La Bergeronette à collier de l'ine de Luçon, Sora. Voy. p. 6r. t. 29.

Collared Wagtail, I.atb. Syn. iv. p. 396.

Habitat in Pbilippinis, Kamtchatka.-Nucha cum cervice, collum inferius, peitufque nigra: fafcia alarum obliqua alba.

2.

maderaf- M. nigra, ventre albo, fafcia alarum longitudinali alba, rectricibus patenfis. duabus intermediis nigris, lateralibus albis.

Motacilla maderafpatenfis, Gmel. Syft. i. p. $96 \mathrm{r}$.

Motacilla maderafpatana, Brif. iii. p. 478 . $44 .-$ Id. 8 vo. i. p. $440 .-$ Raii Syn. p. 194. 3. t. ז.f. I. (mas.)-Id. N 4. t. I. f. 6. (fem.) Pied Wagtail, Lath. Syn. iv. p. 397. 2.

Habitat circa Maderajpatum. - Femina cinerea ubi mas niger.

cinerea. M. cinerea fubtus alba, fafcia pectorali fufca, rectrice prima alba, fecunda bafi apiceque alba,

Motacilla cinerea, Brif. iii. p. 465 . 39. t. 25 . f. r. $-I d .8$ vo. i. p. 437. -Gmel. Syjt. i. p. $96 \mathrm{r}$.

Bergeronette grife, Buf. v. p. 26r.-Pl. Enl. 674. 1.-Hijt. Prov. i。 p. 457 .

Cinereous Wagtail, Latb. Syn. iv. p. 397.3.

HaBitat in Europa; alba paulo minor. $-6 \frac{5}{4}$ pollices longa.

Femina abfque fafcia pectorali.

Boarula. M. cinerea fubtus flava, rectrice prima tota, fecunda latere interiore, alba.

Motacilla boarula, Lin. Mant. I77 I. p. 527.-Gmel. Syft. i. p. 997. cinerea, an flava altera Aldr. Raii Syn. p. 75. 3.-Will. p. 172. 3.-Scbaf. El. Orn. t. 33. f. I.-Faun. Arag. p. 85. II.

Motacilla flava, Brif. iii. p. 47 I. 4I. t. 23. f. 3. (mas.)-Id. 8vo. i.p. 439. - Scop. Ann. i. p. 225.

Bergeronette jaune, Buf. v. p. 268.-Pl. Enl. 28. 1. (mas.)

Coda tremola gialla, Zinnan. Uov. p. 5 I. t. 7. f. 39 .

Yellow Wagtail, Alb. ii. t. 58. (fem.)

Grey Wagtail, Edwo t. 259.-Br. Zool. j. No 144-Id. fol. 105.Will. (Angl.) p. 238.-Latb. Syn. iv. p. 398. 4.-Id. Sup. p. 178.

Habitat 


\section{A VES PASSERES. Motacilla.}

Haвiтat in Europa. $\rightarrow \frac{x}{2}$ pollices longa.-In Angiia fluvios lapidofos frequentat, nidificans in borealibus; tempore hyberno auftraliores petens. Linea alba fupra infraque oculum: restrix extima tota alba, fecunda latere interiore et apice, tertia difco albo: gula mari nigra. Ovum albo-rufefcens maculis rubris, lineis anomalis fparfim interjectis.

ß. M. fufco-olivacea fubtus flava, collo inferiore et pectore grifeis, rectrice prima tota, fecunda et tertia latere interiore apiceque albis.

Motacilla javenfis, Brif. iii. p. 474. 42. t. 25. f. 2.-Id. 8 vo. i. p. 440 . Bergeronette de Java, Buf. v، p. 272.

Javan Wagtail, Lath. Syn. iv. p. 399. 4. A.

5 .

Habitat in Gava infula. $\rightarrow 7$ pollices longa.

melanopa. M. cærulefcenti-cinerea fubtus flava, loris et gutture nigris, fuperciliis et rectricibus utrinque 3 lateralibus albis, extima margine exteriore nigra.

Motacilla melanopa, Pall. It. iii. p. 6g6. 16.-Gmel. Syf. i. p. 997.

Habitat rarior circa ripas glaciofas orientales Dauuric; habitu fla-

6. va, fed minor, pedibus minoribus, cauda æquali longiore : linea alba a rictu per collum utrinque longitudinalis.

hudfonica. M. ferrugineo-fufca fubtus albida, collo fubtus ftriis obfcuris, rectrice extima alba, fecunda alba margine intus nigro, tertia difco albo.

HABITAT ad finum Hudfonis. -6 pollices longa.

Roftrum breviufculum et pedes fufco-flavicantes: corpus fupra fufcum pennis margine ferrugineis: gula et jugulum fubferrugineum: pętus, abdomen, et crifum albida : cauda 3 pollices longa, nigricans, reitricibus $\mathbf{I}, \mathrm{I}$, toto albis; 2,2 , albis, margine tenuiore medio fufcis; 3,3 , medio longitudinaliter albis.

7.

incica. M. grifeo-virefcens fubtus flavefcens, pectore lunulis duabus nigris confluentibus, rectricibus duabus extimis femoribus criffoque albis. Motacilla indica, Gmel. Syft. i. p. 962 .

La Bergeronette grife des Indes, Son. Voy. Ind. ii. p. 207.

Indian Warbler, Lath. Syn. iv. p. 399. 5.

Habitat in India.-Irides flavæ. 
8. 504 A V E S P A S S E R E S. Motacilla.

flava. M. pectore abdomineque flavis, rectricibus duabus lateralibus dimidiato oblique albis.

Motacilla flava, Lin. Syft. i. p. 331. 12.-Faun. Suec. N॰253.-Gmel. Syft. i. p. 963.--Brun. $\mathrm{N}^{\circ} 273.274 .-$ Muller, $\mathrm{N}^{\circ} 273 .-$ Kram. El. p. 374. 2.-Frifch. t. 23.-Georgi, p. 174.-Faun. Arag. p. 88. -Bororofk. Nat. iii. p. 189.7.-Sepp. Vog. t. p. 103.-Raii Syn. p. 75. A. 2.-Will. p. 172. t. 68 .

Sylvia flava, Klein. Av. p. 78. 7.-Id. Stem. t. 16. 7. f. 7. a-c.-Id. Ov. p. 26. t. 10. f. 18 .

Motacilla boarula, Scop. Ann. i. $\mathrm{N}^{\circ} 226$.

Motacilla verna, Brif. iii. p. $468.40 n-1 d$. 8 vo. i. p. 438 .

Bergeronette de Printems, Buf. v. p. 265 . t. I 4. f. 1.--Pl. Enl. 674. 2. - Tiift. Prov. i. p. 497.

Gelbe Weyer-Backitelze, Gunth. Neft.u. Ey. t. 72.

Yellow Wagtail, Br. Zool. i. N $143 .-I d$. fol. r 05.-ArEt. Zool. ii. p. 396. F.-Will. (Angl.) p. 238 . t. 68.-Edw. t. 258.-Lath. Syn. iv. p. $400.6 .-I d$. Sup. p. 179.

Habitat in Europe, Afie pratis; gregaria, nec aquatica; tempore aetivo adit greges armentorum in pafcuis, curfitat, et infecta venatur circa eorum ora pedefque.-Minor Boarula, a qua diftinctiffima avis.

Corpus fupra olivaceum: fupercilia flava vel albida: rectrices nigræ, extimæ 2 albo nigroque oblique dimidiatæ. Veftitu vernali gula maculis aliquot albis, in femina vix diftinctis. Ovum plumbefcens maculis flavicantibus varium.

ß. M. cinereo-grifea fubtus flava, fuperciliis flavis, remigibus rectricibufque nigris, fafcia alarum alba.

Bergeronette de l'inle de Timor, Buf. v. p. 275.

Timor Wagtail, Lath. Syn. iv. p. 401. 6. A.

Haв тат in infula Timor Indie orientalis.

$\gamma$. Parus luteus, S. G. Gmel. It. iii. p. Ior. t. 20. f. I.

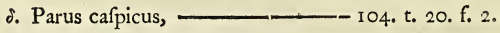

£. - variegatus, — I05. t. 20. f. 3 .

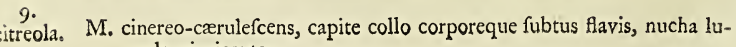
nula nigricante.

Motacilla 
A VES P A S E R E S. Motacilla. 505

Motacilla citreola, Pall. It. iii. p. 696. 14.-Falck. It. iii. t. 29.-Gmel. Syyt. i. p. 962.

Motacilla Sheltobriufchka, Lepecb. It. ii. p. 187. t. 8. f. r.

Yellow-headed Wagtail, Arct. Zool. ii. p. 297. G.-Lath. Syn. iv. p. 401. 7 .

HaBITAT in Sibiria; orientaliore frequens; rarior, minorque in Rufia; flave affinis, a qua cervice media lunula cucullari precipue differt.

I0.

capenfis, M. fufca fubtus albida, fafcia peorali fufca, fuperciliis albis, cauda nigra, rectricibus lateralibus oblique albis.

Motacilla capenfis, Lin. Syfl: i. p. 333. 24.-Gmel. Syft. i. p. 979.-Brif. iii. p. 476 . 45 . t. 25 . f. $3 .-1$ Id. 8 vo. i. p. 440 .

La Bergeronette du Cap de B. Efperance, Buf. v. p. 273.-Pl. Enl. 28. f. 2.

Cape Wagtail, Latb. Syn. iv. p. 402. 8.

Habitat ad Caput B. Spei; magnitudine alba.

II.

afra. M. flavefcente-fufca fubtus flava, criffo albo, fupercilis alis caudaque nigris.

Motacilla afra, Gmel. Syft. i. p. 962 .

La petite Bergeronette du Cap de B. Efperance, Buf. v. p. 274.

African Wagtail, Latb. Syn. iv. p. 402. 9.

Habitat cum precedente, qua paulo minor.

\section{2.}

tfchurf- M. olivaceo-fufca, fubtus loris fafciaque duplici alarum alba, reetrice chenfis. $\quad$ prima tota, fecunda latere interiore alba.

Motacilla tfchutfchenfis, Gmel. Syft. i. p. 962.

Tfchuthi Wagtail, Arct. Zool. ii. p. 397. H.-Latb. Syn. iv. p. 403. 10.

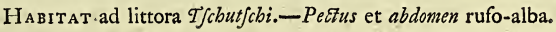

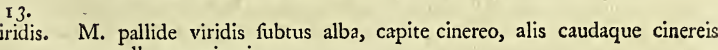
albo marginatis.

Motacilla viridis, Gmel. Syft. i. p. 962 .

Green Wagtail, Brozon. Illuftr. p. 86. t. 33.-Lath. Syn. iv. p. 403. x r.

Habitat in Zeylona. 


\section{G E N U XLIII. S Y L V I A.}

Rofrum fubulatum, rectum, tenue; mandibulis fub. æqualibus.

Nares obovatx, deprefliuficulx.

Digitus exterior medio bafi fubtus connexus.

Cauda modica.

r.

Lufcinia. S. rufo-cinerea fubtus cinereo-alba, rectricibus fufco-rufis, armillis cinereis.

Motacilla Lufcinia, Lin. Syft. i. p. 328.-Faun. Suec. $\mathrm{N}^{\circ}$ 244.-Gmel. Syft. i. p. 950.-Scop. Ann. i. $\mathrm{N}^{\circ} 227:-$ Brun. $\mathrm{N}^{\circ}$ 270.-Muller, $\mathrm{N}^{\circ} 265 .-$ Kram. El. p. 376. 10.-Frifch. t. 21.-Faun. Arag. p. 87. *-Sepp. Vog. t. p. 123.-Raii. Syn. p. 78. A. 2.-Will. p. I61. t. 41.-Brif. iii. p. 397. 13.-Id. 8 vo. i. p. 420-Borow/. Nat. iii. p. $185.2 .-K l e i n . A v$. p. 73. 1.-Id. Stem. p. 13. t. 16. f. 1. a. b. $-I d$. Ov. p. 24. t. I0. 5 .

Le Roffignol, Buf. v. p. 81 . t. 6. f. 1.-Pl. Enl. 6i 5. 2.-Hift. Prov. i. p. 498.-Voy. en Barb. i. p. 273.

Rufignuolo, Zinnan. Uov. p. 54. t. 8. f. 42.-Olin. ac. t. p. I. L'Ufignuolo, Cet. uc. Sard. p. 214.

Nachtigall, Guntb. Neft. u. Ey. t. 65.-Wirf. Vog. t. 55.

Nightingale, Br. Zool. i. $\mathrm{N}^{\circ}$ 154--Id. fol. 100. t. 8. I. f. 2.-ArEz. Zool. ii. p. 416. A.-Alb. iii. t. 53.-Id. Song Birds, t. p. 67.RufJ. Alep. p. 7.-Kampf. Fap. p. I 30 ?-Will. (Angl.) p. 220. t. 4 1. -Gent. Mag. xxii. t. p. 265.-Lath. Syn. iv. p. 408. x.Id. Sup. p. I 80.

Habitat in Europa, Afia, Africa; in frondofis Anglice auftralioris fatis frequens ; noctu vefpereque vernali cantans.-Formicarum aliorumque infectorum larvis victitat, at tenebrionis molitoris potiffimum delectatur.-Ovum olivaceo-fufcum.

A. Lufcinia major, Brif. iii. p. 400 . A.-Id. 8vo. i. p. 421.-Frifch. to 21. - Buf. v. p. I 3 .

Greater Nightingale, Lath. Syn. iv. p. $4 \mathrm{II}$.

Habitat in Silefia.-Pracedentem magnitudine paululum antecellit. 


\section{A VES PASSERES. Sylvia.}

B. I.ufcinia candida, Brif. iii. p. 40 I. B. $-I d .8$ vo. i. p. $421 .-B u f$. v. P. II 14 .

White Nightingale, Latb. Syn. iv. p. 4I 2.

2.

A Lufcinia difcrepat colore in toto corpore candido.

madagaf- S. fufco-olivacea fubtus rufo-fufca, capite rufo, gutture albo, macula carienfis. pone oculos fufca.

Motacilla madagafcarienfis, Gmel. Syft. i. p. 952.

Lufcinia madagafcarienfis, Brif. iii. p. 40 r. 14. t. 22. f. r. $-I d .8$ vo. i. p. 422 .

I.e Foudi-jala, Buf. v. p. I 16.

Madagafcar Warbler, Lath. Syn. iv. p. 4I2. 2.

Hавітат in Madagafcaria; magnitudine Lufcinice.

3.

hortenfis. S. grifeo-fufca fubtus rufefcente-alba, fuperciliis albidis, rectricibus fufcis extus grifeo marginatis, extima oblique dimidiato alba.

Motacilla hortenfis, Gmel. Syjt. i. p. 955 .

Curruca, Brif. iii. p. $372.2 .-I d$. 8 vo. i. p. 414.

La Fauvette, Buf. v. p. 117. t. 7.-Pl. Enl. 579. f. r.-Hift. Prov. i. p. 506.

Pettychaps, Lath. Syn. iv. p. 413.3.

HaBitat in Europe campis et hortis; fatis numerofa; magnitudine modularis. -6 pollices longa.

$\beta$. S. viridi-fufca fubtus fuperciliifque albida, remigibus rectricibufque fufco-obfcuris.

Haritat in Anglice hortis; magnitudine prioris.

Roftrum et pedes fufci: pectus et femora fufcefcentia : cauda unicolor, reftrice extima abfque albedine. Ovum albidum, maculis anomalis ob. fcuris, lineifque fparfis nigricantibus.

4.

Hippolais. S. virefcente-cinerea fubtus flavefcens, abdomine argenteo, artubus fufcis, fuperciliis albidis.

Motacilla Hippolais, Lin. Syft. i. p. 3jo. 7.-Faun. Suec. No 248.Gmel. Syft. i. p. 954 .

Ficedula feptima Aldrovandi (Pettychaps) Raii Syn, p. 79. A. 7.Will. p. 158.-Id. (Angl.) p. $216 .-Z i n n a n$. Uov. p. 44. t. 6.f. 29 ? 
Leffer Pettychaps, Br. Zool. i. $N^{\circ}$ 149. (defcr.)-ArZz. Zool. ii. p. 418. G.-Id. Sup. p. 64.-Lath. Syn. iv. p. $413 \cdot 3$. *.

Habrtat in Europa, Anglia ; Linaria minor. $-4 \frac{x}{2}$ pollices longa.Nidificat ad fepes prope terram.-Ovum album, maculis minutis numerofis rubris adfperfum. - Supra et infra oculum linea flavicans : pectus ad flavum inclinat: tectrices alarum inferiores flavæ.

pafterina. S. grifea fubtus cinereo-alba rufefcente varia, abdomine albo, fuperciliis albidis.

Motacilla pafferina, Gmel. Syjt. i. p. 954.

Curruca minor, Brif. iii. p. 374. 3.-Id. 8 vo. i. p. 414.

Mufcicapa fecunda Aldrov. (Borin,) Raii Syn. p. 8 r. 10.-Will. p. 158. -Id. (Angl.) p. 216.-Aldrov. Av. ii. p. 733. t. p. 734.-Zinnan. Uov. p. 46 . t. 6. f. 3 I.

Pafferinette, Buf. v. p. 123.-Pl. Enl. 579. f. 2.-Hift. Prov. i. p. 507. Pafferine Warbler, Latb. Syn. iv. p. 414. 4.

Н Нв гтат in Europa.- $5 \frac{1}{4}$ pollices longa.-Uropygium albidum.

Ovum albidum viridi maculatum.

6. atricapilla. S. teftacea fubtus cinerea, pileo obfcuro.

Motacilla atricapilla, Lin. Syft. i. p. 332. 18.-Faun. Suec. No 256.Gmel, Syft. i. p. 970.-Scop. Ann. i. N $\mathrm{N}^{\circ} 229 .-$ Brun. $\mathrm{N}^{\circ}$ 278. 279. -Muller, $\mathrm{N}^{\circ}$ 277.-Kram. El. p. 377. 15.-Frifch. t. 23.Borowfk. Nat. iii. p. 193. I3.

Curruca atricapilla, Brif. iii. p. 380. 6.-Id. 8 vo. i. p. 4 16.-Klein. Av. p. 79. 14.-Id. Ov. p. 26 . t. 10. f. 17.

Atricapilla, feu Ficedula Aldrov. Raii Syn. p. 79. A. 8.-Will. p. 162. t. 41 .

Meiffen Moenche, Guntb. Neft. u. Ey. t. 68.

La Fauvette à tête noire, $B u f$. v. p. 125. t. 8. f. 1. -Pl. Enl. t. 580 . f. 1. 2. Capinera, Olin. uc. t. p. 9.-Zinnan. Uov. p. 56. t. 8. f. 45.-Cet. uc. Sard. p. 216.

Blackcap, Br. Zool. i.p. 148.-Id. fol. 101. t. 8. f 5.-Arct. Zool. ii. p. 418. F. -Will. (Angl.) p. 226.-Latb. Syn. iv. p. 41 5 . 5 .

HaBıт $\mathrm{T}$ in Anglia, paffinque in Europa. $-5 \frac{1}{2}$ pollices longa. Mas pileo nigro, femina caftaneo; voce Lufcinice dulciffime cantat; migratoria. Ovum fufco-rubefcens, nebulis obfcurioribus, maculifque fparfis nigricantibus.

ß. Curruca 
B. Curruca albo et nigro varia, Brif. iii. p. $3^{8} 3 .-I d .8$ vo. i. p. $4 \mathbf{I} 7$.

Ficedula varia, Zimnan. Uov. p. 44. t. I2. f. 29 . I.

A pracedente differt : in univerfo corpore ex albo et nigro variat.

భ. S. fupra nigricans, lateribus grifeis, gula alba.

La petite Columbaude, Buf. v. p. 131,-Lath. Syn. iv. p. 416.

ঠ. S. fufco-virefcens, pileo nigricante, cervice cinereo, fuperciliis albis, alis caudaque nigricantibus.

Fauvette verdâtre de la Louifiane, Buf.v. p. 162.-Latb. Syn.iv. p. 417\%

HABITAT in Louifiana.

7.

melanoce- S. ex virefcente cinerea fubtus grifea, vertice nigro, oculorum fafcia phala. rubra.

Motacilla melanocephala, Gmel. Syf. i. p. 970.-Cett.uc. Sard. p. 215.

Habitat in Sardinia; atricapille multum affinis, nonne varietas? minor tamen, et vix canora.

8.

mofchita. S. plumbea, pileo rufefcente.

Motacilla mofchita, Gmel. Syft. i. p. 970.-Cett. uc. Sard. p. 215.

Habitat in Sardinia; Cuculi ovis, nido fuo ingeftis, fæpius incubans.

Curruca. S. fupra fufca fubtus albida, reetricibus fufcis, extima margine tenuiore alba.

Motacilla Curruca, Lin. Syft. i. p. 329. 6.-Faun. Suec. No 247.Gmel. Syft. i. p. 954.-Scop. Ann. i. No 228.-Brun. p. 72. -Muller, $\mathrm{N}^{\circ}{ }_{267}$.-Faun. Arag. p. 88.-Frifcb. t. 21.-Borowes. Nat. iii. p. 187.4 .

Curruca garrula, Brif. iii. p. 384. 7.-Id. 8vo. i. p. 417.-Klein. Av. p. 73. 2. 3.-Id. Stem. p. 13. t. I6. f. 3. a. b. -Id. Ov. p. 24. to Io. f. 6.-Will. p. 99 ? iv. t. 23 .

Graas-Mucken, Guntb. Neft. u. Ey. p. 6r. t. 15.

La Fauvette babillarde, Buf. v. p. r 35.-Pl. Enl. 580 . f. 3 .

Beccafico canapino, Olin. uc. t. p. II. f. 2.

Cannevarola, Zinnan. Uov. p. 57. t. 8. f. 46.

Babbling Warbler, Arct. Zool. ii. p. 422. U.-Latb. Syn. iv. p. 417.6. 
510

A V E S P A S E R E S. Sylvia.

Habitar in Europa.-5 pollices longa.-Avicula inquieta, garrula, fimia aliarum; wefte in hortis pifa frequentans.

Vertex et ftria infra-ocularis cinerea. Ovun virefcens, fufco maculatum.

10.

Schæno- S. teftaceo-fufca fubtus pallide teftacea, capite maculato, remigibus banus.

Motacilla Schœnobanus, Lin. Sy/t. i. p. 329. 4.-Faun. Suec. $\mathrm{N}^{\circ} 246$. -Gmel. Syft. i. p. 953.-Faun. Arab. p.6. 17.-Faun. Arag. p. 88. Curruca fylveftris, f. Lufciniola, Birf. iii. p. 393. i1.-Id. 8vo. i. p. 4 I 9. -Raii Syn. p. 80. 1.-Will. p. 87 1.-Id. ( ingl.) p. 237.

Motacilla yvica, Haffelq. It. p. 286. 50.-Id. Vcy. p. 205.

La Fauvette de bois, ou la Rouffette, Buf. v. p. i39.

Ufignuolo di fiume, Cet. uc. Sord. p, 216 ?

Bog-rufh Warbler, ArE7. Zool. ii. p. 419 . I.

Reed Warbler, Lath. Syn. iv. p. 418.7 .

HaBItat in Furope fylvis; magnitudine Curruce.

Roftruin nigricans: couda fufca: pedes albidi. Ovun coloris cæleftis.

I I.

aquatica. S. rufefcens fufco maculata, abdomine uropygio maculaque pone oculos albidis, fafcia alarum alba.

Motacilla aquatica, Gmel. Syjt. i. p. 953.

Sylvia fchoenobanus, Sccp. Linn. i. $\mathrm{N}^{\circ} 235$.

Aquatic Warbler, Lath. Syn. iv. p. 419. 8.

HАвiтат in Italia; migratoria.-Gula cum peftore rufefcens: abda. men et uropygium albidum: fafcia alba ad bafin alarum: rectrices acuminatæ.

12. arundinacea.

S. fupra olivaceo-fufca fubtus albida, loris et orbitis fufco-albefcentibus, angulo carpi fubius luteo-fulvo, cauda fubcuneata fufca.

Motacilla arundinacea, Pbil. Tranf.lxxv. p. 8. t. I.-Gnel. Syft i. p. 992. Turdus arundinaceus minimus, $\operatorname{Sepp}$. Vog. t. p. 101. (Avis?) $-I d$. p. 97. (Nidus.)

Paffer arundinactus minor, Raii Syn. p. 47. A. 3 ?-Will.p. 99 ?

Schilffmachen, Rohrfperling, Guntb. Neft. u. Ey. t. I 2 ?

Boufcarle de Provence, Buf. v. p. I 34?-Pl. Enl. 655. f. 2 ?

Leffer Reed-Sparrow, Will. ( Angl.) p. 144 ?

Reed Wren, Latb. Syn. Sup. p. I84.-Gent. Mag. Iv. 462. t. p. 640.

Ha BIт Aт in In $_{\text {, lia }}$ arundinetis. $-7 \frac{1}{2}$ pollices longa. - Nidum inter $3-4$ arundines 
arundines ftruit, et ova plerumque quatuor pariens albida, lineis anomalis obfcuris fparfis maculifque olivaceis numerofioribus, ad extremitatem obturam.

Roftrum corneum, bafi potius dilatatum : palatum aurantium : pedes pallide olivacei, plantis luteo-virefcentibus : lora et palpebre albidæ: 1.3. irides fufcre. Mas feminam magnitudine paulo excedit.

modularis. S. fupra grifeo-fufca, tectricibus alarum apice albis, pectore cærulefcente-cinereo.

Motacilla modularis, Lin. Syft. i. p. 329. 3.-Faun. Suec. $\mathrm{N}^{\circ} 245 .-$ Gmel. Syft. i. p. $952 .--$ Brun. $\mathrm{N}^{\circ}$ 269.-Muller, $\mathrm{N}^{\circ}$ 266.-Frifch. t. 2 1. - Borowek. Nat. iii. p. I 86.3 .

Curruca fepiaria, Brif. iii. p. 394. I 2.-Id. 8 vo. i. p. 420.

Sylvia gula plumbea, Klein. Av. p. 77. III. 4 .

Curruca Eliotæ, Raii syn. p. 79.A. 6.-Will. p. 157 .

Magnanima Aldr. Will. p. $157 .-$ Zinnan. Uov. p. 45. t. 6. f. 30 . х.

Traine-buifon, Mouchet, ou Fauvette d'hyver, Buf. v. p. 151.-Pl. Enl. 615.f. 1.

Paffera falvatica, Cet. uc. Sard. p. 205.

Braunelle, Gunth. Neft. u. Ey. t. I. f. inf.

Hedge Sparrow, Br. Zool. i. No 1 50.-1d. fol. t. S. I. f. 3. 4.-ArEz. Zool. ii. p. 418. H.-Alb. iii.t. 59.-Id. Song Birds, t. p. 81.Will. (Angl.) p. 2 15.-Lath. Syn. iv. p. 419.9.

Ha вiтat in Europa; in Anglia paffim frequens; hyeme canens; non migratoria. $-5 \frac{1}{4}$ pollices longa.-Ovum cærulefcens.

I4.

juncorum. S. fufca tota fubtus dilutior, cauda fubforcipata.

Motacilla juncorum, Gmel. Syft. i. p. 952.

Paffer virginianus, Brif.iii. p. 101. 14.-Id.8vo. i. p. 335.-Klein. Av。 p. 89. 10.

Little brown Sparrow, Cat. Car. i. p. 35 .

Rußh Warbler, Arct. Zool. ii. N³23.-Latb. Syn. iv. p. 420. 10.

Habitat in Virginia et Carolina; modulari minor. $-4 \frac{3}{4}$ poll. longa.

F5.

Phœnicu- S. gula nigra, abdomine caudaque rufis, capite dorfoque canis, fronte rus. alba.

Motacilla phœnicurus, Lin. Syft. i. p. 335. 34.-Faun. Suec. $\mathrm{N}^{\circ} 257 .-$ Gmel. Syft. i. p. 987.-Scop. Ann. i. No 232.-Brun. $\mathrm{N}^{\circ} 280.281$. - Muller, $\mathrm{N}^{\circ} 278 .-$ Frifch. t. 19.-Kram. El. p. 376. I 1.-Georgi, 
p. 174,-Faun. Arag. p. 89.-Berowfk, Nat. iii. p. 193. 14,-Sipp. Vog. t. 45.-Wirf. Vog. to 17.

Ruticilla, Rais Syn. p. 78. A. 5.-Will. p. 159. t. 39.-Brif. iii. p. 403. I 5. -Id. 8vo, i. p. 422.-Klein. Av. p. 77. 2.-Id. Stem. p. 14. I6. f. 8. a. b.

Motacilla cchruros, Georg. It. iii. p. Ior. t. ig. Rofiignol de muraille, Buf. v. p. 170. t. 6. f. $2,-$ Pl. Enl. 35 I. f. 1. 2. -Hijit. Prov. i. p. 501 .

Culo ranzo, Culo roffo, Zinnan. Uov. p. 53. t. 8. f. 4 1.-Olin. uc. t. p. 47. Redftart, Br. Zool. i. N $\mathrm{N}^{\circ}$ i6. - Id. fol. 99. t. S. f. 6. 7.-ArE7. Zool. ii. p. 4I6. B.-Will. (Angl.) p. 218.-Allin. i. t. 50.-1d. Song Birds, t. p. 62.-Hayes Br. Birds, t. 40.-Lath. Syn. iv. p. 42 I. I I, MABIтAт in Europa; in Anglia frequens; in foraminibus muriun. nidificat; egregie cantillat; migratoria. -5 pollices longa.

Femina pileo dorfoque cinereo-grifeis: gula alba. Ovun caruleum.

B. Ruticilla peçtore maculato, Brif. iii. p. 407. B. -Id. 8 vo, i. p. 4.23 . Sylvia thorace argentata, Klein. Av. p. 78. 1o. Roth-fchwcentzlein, lirifch. t. 20.

Forte Pbenicuri femine varietas, ab illa enim non difcrepat nifi pectore maculis rufis infignito.

\%. Ruticilla cinerea, Brif. iii. p. 4c6, A.-Id. 8 vo. i. p. 12.3.

Ruticilla tertia Aldr. Kaii.Syn. p. 78, A. 5. var,-Will. p. 160,-Id. (Angl.) p. 218 .

Waldroth Schwanz, Gunth. neft. u, Ey, to Ig. fo fup.

Mari per omnia fimillima, nifi quod in hac alba illa fincipitis macula in longam lineam fit immutata; dorf $m$ quogue magis videtur cinereum, imus autem venter non albet.

16.

Tithys. S. remigibus nigricantibus, rectricibus rufis, intermedio pari nigro extrorfum rufefcente.

Motacilla Tithys, Lin. Sy/t. i. p. 335: 34. B.-Gmel. Syft. i. p. 987. Sylvia Tithys, Ecop. Ann. i. Na $233,-$ Lath. Syn. iv. p. $423.11 . \mathrm{C}$. Notacilla corpore nigro, cauda rufa, Kram. El. p. 376. 12 ?

Garten Rothichwanz, Gunib. Nefl. H. Ey. t. 30. f. inf.

Habitat in Italia. - ReElrices cum ani regione rubre.

Mes fupra cinerafcens, gula peqtoreque nigris; abdomine inter femora albido, alibi albo nigroque varius. 


\section{A VES PASSERES. Sylvì.}

Fenine tota fufco-cinerea.

Utrique fexui rectrices dure intermedix fufcx, alix verfo ad apicem 17.

gibralta- S. cinerea, fronte abdomineque albis, genis colloque fubtus nigris, urorienfis. pygio rectricibufque lateralibus rufis.

Rusicilla gibraltarienfis, Erif, iii. p. 40, , 16.-Id. 8vo.i. p. 424,-Gmcl. Syft. i. p. 987.

Sylvia corpore grifeo, gutture nigro, Klein. Av. p. So. 25 .

Roffignol de muraille de Gibraltar, Buf.v: p. 177.

Grey Redftart, Arct. Zool. ii. p. 4I7. C.-Edwo. t. 29.-Latb. Syn. iv. P. 42.3 .12$.

Habitat circa Gibraltariom; magnitudine Pbonicuri.-ReEtrices 2 intermediæ fufcæ, laterales rufæ fufco terminatæ, extimæ toto rufæ.

18.

erythro- S. nigra, fubtus abdomine uropygio caudaque caftanea, pileo cinerafgaftra.

Motacilla erythrogaftra, N. C. Petr. xix. p. 469. t. 16. 17,-Gmel. Syg. i. p. 975 .

Chefnut-bellied Warbler, Latb. Syn. iv. p. 424. I 3 .

Habitat eftate ad alveos glareofos torrentiam Caucaficorum. -7 pollices longa.-Femina cinerea, abdomine medio rufo : reelricibus duabus intermediis totis, lateralibus apice fufcis. Vietitat feminibus Hippopbe rbemnoidis.

19.

Erithacus. S. derfo remigibufque cinereis, abdomine reetricibufque rufis, extinis duabus cinereis.

Motacilla Erithacus, Lin. Syft. i. p. 335.35.-Faun. Suec. No 258.Gmel. Syft. i. p. 988.

Phœnicurus torquatus. Brif. iii. p. 4 II. I 8. (mas.) -Id. 8vo. i. p. 425 . Phonicurus, Brif. iii. p. 409. 17. (femina.)

Sylvia gula grifea, Klein. Av. p. 78. 4. 5 .

Rouge-queue à collier, Buf. v. p. 180.

Roth-Schwantzlein, Frijch. t. 2o. f. b.

Rothfchwentzel, Raii Syn. p. 78. A. 5. var. 20-Will. p. 160.-Id. (Angl.) p. 218.

Red-tail, Latb. Syn. iv. p. 425. I4.

: Habitat in Europa; Pbenicuro paulo minor; migratoria, $3 \mathrm{U}$ 


\section{A V E S P A S E R E S. Sylvia.}

Mas collo inferiore lunula et macula inter roftum et oculum fufca, reciricibus duabus intermediis fufcis : caro fapida. Ovum album grifeo varium.

20.

guianerís. S. grifea fubtus alba, alis caudaque rufis. Motacilla guianenfis, Gmel. Syft. i. p. 988. Le Rouge-queue de la Guiane, Buf. v. p. 186.-Pl. Enl. 686. f. 2. Guiana Redtail, Latb. Syn. iv. p. 426 . I 5 .

Habitat in Guiana. $-6 \frac{x}{2}$ pollices longa. - Roftrum pallidum: pedes incarnati.

21.

atrata. S. nigra fufco marginata, pileo cinereo, remigibus rectricibufque 2 intermediis fufcis, lateralibus rufis.

Motacilla atrata, Gmel. Syft. i. p. 988.

Black Redtail, Lath. Syn. iv. p. 426. I6.

Longitudo 6 pollicụm.

22.

caffra. S. olivacea, gula caudaque ferrugineis, fuperciliis albis.

Motacilla caffra, Lin. Mantif. 177 I. p. 527.-Gmel. Syjt. i. p. 997.

Caffrarian Warbler, Latb. Syn. iv. p. 426 . 17.

Haвitat ad Caput Bone Spei; Mot. albe magnitudine.

Pectus abdomenque albicantia : couda xqualis ferruginea, rectricibus apice fufcis, intermediis duabus toto fufcis.

23. cinerea.

S. fupra cinerea fubtus alba, reetrice prima longitudinaliter dimidiato alba, fecunda apice alba.

Motacilla fylvia, Lin. Syft. i. p. 330. 9?-Foun. Suec. No 250 ?Gmel. Syft. i. p. 956.-Brun. N $^{\circ}$ 275.-Muller, 269.-Faun. Arag. p. 83. 5.-Borow/k. Nat. iii. p. 188. 5 .

Turdus Calamoxenus, Sepp. Vog. c. p. 97. (avis.)

Parus cinereus, Brif. iii. p. 549. 4.-Id. 8 vo. i. p. $463 .-B u f$. v. p. 409. iii.

Ficedulæ affinis, an Spipola prima Aldr. Raii Syn. p. 77. A. 6.-Will. p. 171.

Firft Spipola of Aldrovandus, Will. (Angl.) p. 210.

HaвıтAт in Europa, forte in Anglia; longitudine 6 pollicum.

Rojtrum nigricans, fubtus album: irides avellaneæ: corpus fupra cinereo-rufefcens, fubtus albo-rufefcens: caput cinereum: gula alba: 
pars colli inferior ex albo rufefcit: pedes fufco-flavefeentes, vel plum. bei. Femina a mare difcrepat pelzore penitus candido.

$\beta$. S. fupra rufo-cinerea fubtus rufo-alba, gula alba, reqrice extima extus toto intus dimidiato alba.

Curruca cinerea five cineraria, Brif. iii. p. 376. t. 2 I. f. I. $-I d$. 8 vo. i. p. 415.

Spipola Aldr. Raii Syn. p. 77. A. I ?-Will. p. 1 53.-ld. (Angl.) p. 210. - pectore et ventre candido, Will.p. 17 1.5. - Id. (Angl.) p. 237.5. Fauvette grife, ou la Grifette, Buf. v. p. 132.-Pl. Enl. 579. f. 3 .

La Vitréc à menton blanc, Salern. Orn. p. 226. 6.

White Throat, Br. Zool. i. $\mathrm{N}^{\circ}$ 160.-Id. fol. ro4. t. S. f. 4.-ArEt. Zool. ii. p. 422. S. - Alb. iii. t. 58.-Hift. Selb. p. 103.-Lath. Sym. iv. p. 428 . 19.

Haвiтat in Europa, Angliz; migratoria; hortos frequentans; victitans infectis. $-5 \frac{1}{2}$ pollices longa.-Nidificat in rubis, non procul ab humo.-Nidus ex mufcis et culmis aridioribus, intus gramine tenuicre, conftruitur. Ova circiter 5 grifeo-virefcentia, maculis rufo-fufcis vel faturate avellaneis.

24.

Sylviella. S. cinereo-fufca fubtus fordide alba, rectricibus duabus intermedíis brevioribus fubulatis.

Leffer White-throat, Latb. Syn. Sup. p. 185. t. I I3.

HaB:Tat in Europa; in Anglia ad fepes fatis frequens, at minus obfervata.-Magnitudo Trocbili; vix 5 pollices longa.-Nidificat in fruticetis haud procul a terra. - Nidus ex ftipitibus et lana intertextis, crinibus albis intus duplicatus.-Ovum album maculis fufcis mediocribus, majoribus interjectis ad extremitatem obtufiorem, apice acuto iminaculato.

Roftrum femipollicare obfcurum, fubtus bafi flavefcens : irides obfcuræ: corpus fupra pallide cinereo-fufcum, vertice faturatiore, fubtus toto album : redirix extima margine extus pallida, intermedix 2 reliquis paulo breviores, unde cauda fubforficata: pedes fufci.

Locuftella. S. fufco-viridis maculis nigricantibus fubtus flavefcens, pectore faturatiore, cauda cuneata rectricibus apice mucronatis.

Locuftella avicula, Will. p. I 5 1.-Raii Syn. p. 70. A. 7.-Id. Letters, p. 108.

La Locuftelle, Buf. v. p. 42.-Hift. Prov. i. p. 359 . 
gIG AVES PASSERES. Sylvia.

Titlark that fings like a Grafshopper, Will. (Angl.) p. 207.

Grafshopper Warbler, Br. Zool. i. No 1 56.-Id. fol. 95. t. Q. f. 5.ArEt. Zool. ii. p. 419. L.-Wbite Hift. Selb. p. 4.5.-Lath. Syn. iv. p. $4.29 \cdot 20$.

Habitat in Suecia, Sibiria, alibique forte in Europa; in Anglia, inter rariores. $-5-6$ pollices longa.-Stridet more Locufte fed fonantius; dum cantat fummo plerumque fpinofi alicujus fruticis ramulo infidet corpore erecto, aperto ore, alis paululum expanfis.

Rofrlim obfcurum: pedes albidi : lora alba : corpus fupra fufco-vire cens, pennis medio obfcuris, fubtus albo-flavefcens, pectore fordide albo: cauda longiufcula, fubcuneiformis, rectricibus margine exteriore pal-: lidis.

26.

falicaria. S. cinerea fubtus alba, fuperciliis albis.

Motacilla falicaria, Lin. Syft. i. p. 330. 8.-Faun. Suec. $\mathrm{N}^{\circ} 249 .-$ Gmel. Syyt. i. p. 955.-Klein. Av. p. 74. 4.-Id. Stem. p. I 3. t. 16 :

f. 2. a. b.-Id. Ov. p. 25. t. 10. f. 10.-Borowefk. Nat. iii. p. 184. Curruca arundinacea, Brif. iii. p. 378. 5-Id. 8vo. i. p. 4 I 5 .

Junco minor, Sepp. Vog. t. p. 99 ?

Avis confimilis Stoparole et Magnanine, Raii Syn. p. 8 1. 6.-Will. p. 153.-Id. (Angl.) p. 217 .

Salicaria, Raii Syn. p. 8 I. 11.-Will. p. 158.

La Fauvette de rofeaux, Buf. v. p. 142.-Pl. Enl. 58-1. f. 2.

Rohr-fperling, Guntb. Neft. u. Ey. t. 12 ?

Willow Lark, Br. Zool. ii. 24r.

Sedge Warbler, Br. Zool. i. No ${ }^{\circ}$ 5 5.-Br. Zool. iv, t. x.-Arz. Zool.

ii. p. 4 I 9. M.-Hift. Selb. pp. 67. 7 I. 74.-Alb. iii. t. 60.-Latb. Syn. iv. p. 430. 21.-Id. Sup. p. 180.

Habitat in Europe paludofis locis, in arundinetis Anglie. $-5 \frac{x}{3}$ poll. longa.-Egregie cantillat per totam noctem, et aliarum avium voces imitatur.-Pennæ corporis medio obfcuræ : fupra fupercilia fafcia nigra:cauda rotundata. Ovum fufco-virefcens, maculis obfcurioribus ob. foletis.

27.

rufa.

S. grifeo-fufca, fubtus fuperciliifque rufefcentibus.

Curruca rufa, Brij. iii. p. 387.8.-Id. 8vo. i. p. 418.-Gmel. Syft. i. p. 955 .

Mufcipeta minima, Friscb. t. 24.

La Fauvette roufe, Buf. v. p. 146.-Pl. Enl. 58 I. 1.

Rufous Warbler, Latb. Syn. iv. P. 431. 22.

Habitat 
HaB1TAT in Europe hortis ; falicaria minor.-4 $4 \frac{3}{2}$ pollices longa.28. Nidificat inter fruticeta. Ovum albo-virefcens, obfcure maculatum.

Ficedula. S. fubfufca fubtus alba, pectore cinereo maculato.

Motacilla Ficedula, Lin. Syft. i. p. 330. 10.-Faun. Suec. N'251.Gmel. Syft. i. p. 956.-Muller. No 27 I.-Klein. Av. p. 79. 13.Frifch. t. 22. (Mas.)-Zinnon. Uov. p. 43. t. 6. f. 28 ?

Ficedula, Brif. iii. p. 369. 1.-Id. 8vo. i. p. 41 3.-Raii. Syn. p. 8 1. 12. -Will.p. 163. -Id. (Angl.) p. 227.

Le Becfigue, Buf.v. p. 187.-Pl. Enl. 668. г.

Beccafico, Olin. uc. t. p. 8 I. $-R u f$. Alep. p. 64.-Cet. uc. Sard. p. 22 1. Wuftling, Guntb. Neft. u. Ey. t. 59 .

Epicurean Warbler, Arct. Zool.ii. p. 41 9. K.-Latb. Syn. iv. p. 432. 26.

Habitat in Europa. -5 pollices longa.-Caro fapidifima.

Orbit. rufefcentes: restrix 1,1 , latere exteriore toto; 2,2 , ad duas tertias ejufdem lateris albæ; remiges fecundariæ latese exteriore albr.

29.

nævia. S. fufco-rufefcens flavicante varia fubtus alba, pectore flavicante maculis albis, rectricibus nigricantibus albo extus marginatis.

Motacilla nævia, Gmel. Syft. i. p. 957.

Curruca nævia, Brif. iii. p. $3^{8}$ 9. 9.-Id. 8 vo. i. p. 41 8. - Brun. $\mathrm{N}^{\circ} 282$. Boarina, Mufcicapa prima Aldrov. Raii Syn. p. 77. 7.-Will. p. 158 . $-I d$. p. 17 I. 6 .

La Fàuvette tachetée, Buf. v. p. 149.-Pl. Enl.581.3.

Bouvier, Salern. Orn. p. 226.7.

Fig-eater, Alb. iii. t. 26.-Latb. Syn. iv. p. 433.24.

Habitat in. Ilalia, circa Bononiam. $-5 \frac{\frac{T}{2}}{2}$ pollices longa.

30.

patagoni- S. cinerea fubtus albo maculata, fuperciliis albis; alarum maculis fafciaca. que fufca, rectricibus extimis albis.

Motacilla patagonica, Gmel. Syft. i. p. 957.

Patagonian Warbler, Latb. Syn. iv. p. 434. 25.-Dixon's Voy. t. p. 359.

Habitat in Patagonia et. Terra del Fuego, ad maris littora; vietitans teftaceis et vermibus marinis. - 9 pollices longa.

$3 \mathrm{I}$.

dartfordi-. S. faturate rufo-fufca fubtus ferruginea, abdomine medio albo, palpeenfis. bris iridibufque coccineis, pedibus flavis.

Motacilla 
Motacilla provincialis, Gmel. Syfh. i. p. 958.

Le Pitchou de Provence, Buf: v. p. 158.-Pl. Enl. 655. x.

Dartford Warbler, Br. Zool. i. N ${ }^{2} 6$ 1. t. 56.-Latb. Syn. iv. p. 435. 27.-Id. Sup. p. 181 .

Mabrtat in Europa; in Anglie ericetis rarior; victitans infectis, mufcis. -5 pollices et ultra longa. - Specimina varia a nobis vifa, hyberno tempore, aut vere primo deprehenfa.-Ubi nidificet nobis nondum conftat.

Rofrum nigrum, bafi fubtus album : alula alba : cauda longitudine corporis, fubcuneiformis, rectrice extima extus alba.

32.

africana.

33.

novebora- S. cinerea furco varia fubtus flavefcens nigro ftriata, fuperciliis albis.

cenfis. Motacilla noveboracenfis, Gmel. Syft. i. p. $95^{8}$.

La Fauvette tachetée de la Louifiane, Buf. v. p. 56 r. - Pl. Enl.752.f. x.

New York Warbler, Arct. Zool. ii. N 308.-Lath. Syn. iv. p. 436. 29.

Habitat in Louifiana, Noveboraco. $-5 \frac{3}{4}$ pollices longa.

Color peEioris ut in Alauda pratenfi.

34.

umbria. S. grifeo fufca obfcuro maculata fubtus alba maculis fparfis nigris, alis caudaque nigricantibus albo marginatis.

Motacilla umbria, Gmel. Syft. i. p. 959 .

La Fauvette ombrée de la Louifiane, Buf. v. p. 162.-Pl. Enl.70g. f. 1. Dufky Warbler, ArEt. Zool. ii. No 309 .

Umbrofe Warbler, Latb. Syn. iv. p. 437. 30.

Hавітат cum præcedente, at paulo minor.-Uropygium flavefcens.

350 ${ }^{35}$. S. grifea fubtus alba, gutture luteo, fronte fuperciliis lateribufque colli nigris, fafcia alarum duplici alba.

Motacilla 


\section{A VES PAS S R E S. Sylvia.}

Motacilla flavicollis, Gmel. Syft. i. p. 959 :

Parus carolinenfis grifeus, Brif. iii. p. $563 \cdot 10 .-1 d$. 8 vo. i. p. 467 .

americanus gutture luteo, Klein. Av. p. $87 \cdot 14$.

1.a Mefange grife à gorge jaune, Buf. v. p. 454 .

Yellow-throated Creeper, Catef. Car. i. t. 62 .

Yellow-throated Warbler, Arct. Zool. ii. $\mathrm{N}^{\circ} 286 .-$ Lath. Syn. iv. p. 437. 31.

Habitat in Carolina. $-5^{\frac{\pi}{4}}$ pollices longa. - Redrices nigræ, laterales intus albæ.

Femina a mare difcrepat in eo quod neque luteo neque nigro in36. figniatur.

Trichas. S. olivacea, corpore fubtus flavo, fafcia oculari nigra.

Turdus Trichas, Lin. Syft. i. p. 293. 7.-Gmel. Syft. i. p. 8 I I.

Ficedula marylandica, Brif. iii. p. 506. 58.-Id. 8 vo. i. p. 4482

Le Figuier aux joues noires, Buf. v. p. 292.

Maryland Yellow-throat, Edw. t. 237.-Petiv. Gaz. t. 6. f. I.

Yellow-breafted Warbler, Arct. Zool. ii. $\mathrm{N}^{\circ} 283 .-$ Lath. Syn. iv. p. 438. 32 .

Habitat in America Septentrionali.-5 pollices longa.-Area oculorum nigricans convergit ad roltri bafin fuperiorem: pedes incarnati.

ß. La Fauvette à poitrine jaune de la Louifiane, Buf. v. p. 162.-Pl. Enl. 709. f. 2.

Orange-thighed Warbler, Arct. Zool. ii. $\mathrm{N}^{\circ} 284 .-$ Latb. Syn. iv. p. 439. 32. var. A.

Habitat in Louifiana.-Fafcia tranfverfa capitis alba: femora criffumque aurantia: couda rotundata. An fpecies diftincta?

37.

ruficauda. S, rufo-fufca fubtus alba, gula rufo circumdata fufco maculata, tectricibus alarum caudaque rufis.

Motacilla ruficauda, Gmel. Syft. i. p. 959.

La Fauvette de Cayenne à queue rouffe, Buf. v. p. 163.

Rufous-tailed Warbler, Lath. Syn. iv. p. 439. 33.

Habitat in Cayana. $-5 \frac{\pi}{4}$ poll. longa. - Pechus fufcefcens.

S. fufco- 
38. 520 A VES P A S ERES. Sylvia.

fufcicollis. S. fufco-virefcens, pectore alidomincque fulvo-favis, alis fufcis rubefcente marginatis.

Motacilla fufcicollis, Gmel. Syft. i. p. 959.

Fauvette à gorge brune et ventre jaune, Buf. v. p. 163 .

Yellow-bellied Warbler, Latb. Syn. iv.p. 440. 34 .

39.

cærulef- S.cinereo-cærulefcens fubtus alba, gula nigra, alis fufcis, teetricibus

cens.

Habizat in Caycna; magnitudine Trochili.

ericana. S. cinereo-cærulefcens, interfcapularibus olivaceo-Havis, jugulo peetoreque flavis, abdomine fafciaque alarum albis.

Motacilla americana, Gmel. Syft. i. p. 960.

Figuier cendré de la Caroline, Buf. 5. p. 301.-Pl. Enl. 73 r. f. т.

Yellow-backed Warbler, Latb Syn. iv. p. 440. 36 .

Haditat in America.-Fafcia alarum ex apicibus teetricum albis.

$4 \mathrm{I}$.

penfilis. S. grifea, abdomine fuperciliifque albis, collo fubtus flavo, alis albo nigroque fafciatis, reetricibus lateralibus quatuor albo maculatis.

Motacilla penfilis, Gmel. Syft. i. p. 960.

Le Cou-jaune, Buf. 5. p. 165.-Pl. Enl.686. f. т.

Penfile Warbler, Latb. Syn. iv. p. 441. 37.

Habitat in infula Dominicenfi. $-4^{\frac{3}{3}}$ pollices longa.-Nidum penfilem conftruit ex fibrillis plantarum ficcis, foliis deciduis intertextis, fubtus apertum, et fupra aquam $a b$ apicibus falicum dependentem.

Inter roftrum et oculum maculæ aliquot flava: latera colli et byposhondria nigfo maculata.

42.

Rubecula. S. grifea, gula pectoreque ferrugineis.

Motacilla rubecula, Lin. Syft. i. p. 337. 45.-Faun. Suec. $\mathrm{N}^{\circ} 260$. Gmel. Syf. i. p. 993.-Scop. Ann. i. $\mathrm{N}^{\circ} 231 .-B r u n . \mathrm{N}^{\circ} 283 .-$ Muller, $\mathrm{N}^{\circ} 276 .-K r a n$. El. p. 376. I 3.-Frifch. t. 19.-Sepp. Vog. t. p. 85.-Raii Syn. p. 78. A. 3.-Will. p. 160. t. 39.-Brif. iii. p. 418. 21.-Id. 8vo. i. p. 427.-Klein. Av. p. 77. r.-Id. 
Stem. p. 14. t. 16. f. 13. a-c.-Id. Ov. p. 26. t. 10. f. 16.-Borore/k. Nat. iii. p. 194. 16.

Rouge-gorge, Buf. v. p. 196. t. I 1.-Pl. Enl. 361. f. 1.-Hif. Prov. i. p. 508 .

Pettirofio, Olin. uc. t. p. 16.-Zinnan. Uor. p. 46. t. 6. f. 32.-Cet. uc. Sard. p. 220.

Rothkehlein, Gunth. Neft. u. Ey. p. 32. t. 3. f. inf.-Wirf. Vog. t. 25 . Redbreaft, Br. Zool. N $\mathrm{N}^{\circ}$ 47.-Id. fol. 100. t. S. 2.-Arct. Zool. ii. p.

4 17. D. - Alb. i. t. 5 1.-Id. Song Birds, t. p. 55.-Will. (Angl.) p. 2 19. t. 39.-Hayes Br. Birds, t. 40.-Lath. Syn. iv. p. $442.3^{8}$.

Haвiтat in Europa; in Anglia omnibus fatis nota.

Roftrum cingit color ferrugineus: rectrices angulo acuto terminate : abdomen album. Ovum albidum, maculis rubefcentibus confertis.

ß. S. cinerea, gula alba, collo inferiore pectoreque rufis, teetricibus alarum albo nigro rufoque variis, remigibus rectricibufque nigris rufo marginatis.

Rubecula bononienfis, Brif. iii. p. 422. 22.-Id. 8 vo. i. p. 427.

Spipola prima Aldr. Raii Syn. p. 80. 3.-Will. p. 153.-Id. (Angl.) p. 210.

Spippola maggiore, Zinnan. Uov. p. 50. t. 7. f. 36. - Lath. Syn. iv. p. 444. 38 . A.

Habitat in Italia, circa Bononiam.

43.

S. cinereo-fufca, pectore ferrugineo, fafcia cærulea, rectricibus fufcis verfus bafin ferrugineis.

Motacilla fuecica, Lik. Syft. i. p. 336. 37.-Faun. Suec. $\mathrm{N}^{\circ} 259 .-$ Gmel. Syft. i. p. 989.-Frifch. t. 19.-Georgi, p. 174.-Bororejk. Nat. iii. p. 194. 15.

Cyanecula, Brif. iii. p. 413. I9. (mas.)-Id. 8 vo. i. p. 425.-Klein. Av. p. 80.24 . p. 486 .

gibraltarienfis, Brif. iii. p. 416. 20. (femina.)-Id. 8vo. i.

icilla Wegheckin, Raii Syn. p. 78. A. 5. 3.-Will. p. 160.-Id. (Angl.) p. 219.

La Gorge-bleue, Buf. v. p. 206. t. 1 2.-Pl. Enl. 610. I. (mas.)-f. 2. (femina.)-f. 3. (junior.)

Blaukehlein, Gunth. Neft. u. Ey. t. 74.-Wiring. Vog. t. 9. 
Blue-throated Warbler, ArEt. Zool. ii. p. 417. E. -Edw. t. 28. (femina.)-Lath. Syn. iv. p. 444. 30.

Iaвıтат in Europa; magnitudine Rubecule.-Supercilia rufo-alba. Femina fubtus albida: gula alba ; collo inferiore lunula cærulea.

ß. S. macula pectoris argentea,

L.a Gorge-bleue, Pl. Enl. 36r. f. 2.

Variat macula medio pectoris alba, cæterum priori convenit.

44.

Sialis. S. fupra cærulea fubtus rufo-rubra, abdomine albo.

Motacilla fralis, Lin. Syft: i. p. 336. 38.-Gmel. Syf. i. p. 989.-Kalm. It. iii. p. 30.

Rubecula carolinenfis cærulea, Brif: iii. p. $423 \cdot 23 \cdot-I d$. 8 vo. i. p. 428 . -Klein. Av. p. 77. III. 3.-Buf. v. p. 21 2.-Pl. Enl. 396. f. 1. 2. Blue Redbreaf, Edrv. t. 24.-Catef. Car. i. t. 47.

Blue Warbler, Arct. Zool. ii. N²8 r.-Latb. Syn. iv. p. 446. 40.

Haвıтат in Carolina, Virginia; migratoria. $-5^{\frac{3}{4}}$ pollices longa.

Remiges primores apice nigra, fed fummo apice lutefcentes. Femina obfcurior.

45.

Dumeto- S. cinereo-fufca, capite crerulefcente, gula pectoreque albis.

rum. Motacilla dumetorum, Lin. Syft. i. p. 334. 31.-Kram. El. p. 377. I9. -Georgi, p. 174.-Gmel. Syft. i. p. $9^{8} 5$.

White-breafted Warbler, Latb. Syn. iv. p. 447. 4I.

HaBitat in Germanio et Ruffed dumetis.

46.

nigrirof- S. fufco-olivacea fubtus alba, pectore rufo nigro ftriato, loris gulaque:

tris. rufo-flavis, ftriga maxillari nigricante, rectrice extima toto, fe-. quente apice alba.

Motacilla nigriroftris, Gmel. Syf. i. p. 986.

Black-jawed Warbler, Latb. Syn. iv. p. $447 \cdot 43$.

Longitudo 7 pollicum.

47. S. viridi-olivacea fubtus flava, fronte genis gulaque ferrugineis, rectricibus lateralibus apice albis.

Motacilla borealis, Gmel. Syft: i. p. 986.

Rufty-headed Warbler, Lath. Syn. iv. p. 448. 44.

Haßıтат in Kamtfchatka. -5 pollices longa,

S. ferrugineo 
43.

lutefcens. S. ferrugineo-fufca fubtus rufo-alba, fronte gulaque flavefcentibus, macula aurium obfcure rubra.

Motacilla lutefcens, Gmel. Syf. i. p. 986.

Buff-faced Warbler, Lath. Syn. iv. p. 448,45 .

49.

Longitudo 6 pollicum,-Pectus obfcure nebulofum.

Rubicola. S. grifea fubtus rufefcens, jugulo fafcia alba, loris nigris, uropygio maculaque alarum alba.

Motacilla rubicola, Lin. Syft. i. p. 332. 17.-Gmel. Syft. i. p. 969.Scop. Ann. i. N $\mathrm{N}^{\circ}$ 236.-Kram. El. 375. 6.-Georgi, p. I74.

Rubetra, Brif. iii. p. 428.25 .t. 23. f. r. (mas.)-Id. 8 vo. i. p. 429.

Enanthe noftra tertia, Raii Syn. p. 76. A. 4.-Will. p. 169. t. 4.r.

Sylvia lutea, capite nigro, Klein.Av. p. $78.8 .-I d$. Ov. p. 25 . t. Io. f. I4. Traquet, Buf. v. p. 2 1 5. t. 13.-Pl. Enl. 678. f. 1.-Hifl. Prov. i. p. 508. Occhio di Bue, Zinnan. Uov. p. 52. t. 7. f. 40.

Tfchecantfchiki, N. C. Petr. xv. p. 488. t. 25. f. 3 .

Steinfchmazer, Gunth. Neft. u. Ey. t. 26. f. fup.

Stone Smich, Stone-chatter, Moor-titling, Br. Zool. i. No 1 59.-Id. fol. 103. t. S. 2. f. 5. 6.-Will. (Angl.) p. 235. t. 41.-Albin. i. t. 52.-Hayes Br. Birds, t. 39.-Lath. Syn. iv. p. 448. 46.

Habitat in Europe fepibus. $-4 \frac{3}{4}$ pollices longa.-Mas capite colloque nigris.-Ovum viridi-cærulefcens, maculis obfcurioribus rufis.

so.

Sybilla. S. nigricans fubtus alba, pectore rufo, rectricibus nigris, macula alarum alba.

Motacilla fybilla, Lin. Syft. i. p. 337. 44.-Gmel. Syft. i. p. 992.

Rubetra madagafcarienfis, Brif. iii. p. 439. 28. t. 24 . f. $4 .-I d$. 8 vo. i. p. $43 \mathrm{I}$.

Traquet de Madagafcar, Buf. v. p. 23I.

Sybil Warbler, Latb. Syn. iv. p. 450.47.

Haвiтat in Madagafcaria; Rubicole affinis; egregie fibilat.

$5 \mathrm{I}$.

Sperata. S. fufco-viridis fubtus uropygioque rufo-grifea, rectricibus duabus intermediis nigricantibus, lateralibus fufco-fulvo oblique dimidiatis. Le Traquet du Cap de B. Efp. Buf. v. p. 233.

Sybil Warbler, Lath. Syn. iv. p. 450.47 . A.

Habitat ad Caput Bone Spei.-6 pollices longa.

Cauda fubforcipata. Variat gula alba, pectore rufo. An femine?

$$
3 \mathrm{X}_{2} \quad \text { S. nigra, }
$$



524
A V E S
P A S S
E R E S.
Sylvia

caprata. S. nigra, uropygio criffo maculaque tectricum albis.

Motacilla caprata, Lin. Syft. i. p. 335.33.-Gmel. Syft. i. p. 986.

Rubetra lucionenfis, Brif. iii. p. 442. 30.t. 24. f. 2. (mas.)-f. 3. (femina.) - Id. 8 vo. i. p. 432 .

Le Traquet de l'ine de Luçon, Buf. v. p. 229.-Pl. Entl. 235. f. ז. 2.

Luzonian Warbler, Latb. Syn. iv. p. 45 1. 48.

Habitat in Lucionenfi infula. $-4 \frac{3}{4}$ pollices longa.-In quibufdam uropygium album.

Femina caret macula alarum alba, e tectricibus in altero fexu facta : Corpus ei fupra fufcum, fubtus rufo-fufcum: gula albida : uropygium rufefcens : cauda fufca.

$\beta$. S. capite collo corporeque fupra nigro fubtus rufo-albido, fafcia alarum alba.

Habitat in Cbina.-Roftrum pedefque rubri.

53.

fulicata. S. nigro violacea, criffo caftaneo, macula tectricum alba.

Motacilla fulicata, Lin. Syft. i. p. 336. 39.-Gmel. Syft. i. p. 990.

Rubetra philippenfis, Brif. iii. p. 444 . 31. t. 23. f. 2.-Id. 8 vo. i. p. 433.

Traquet noir des Philippines, Buf. v. p. 230.-Pl. Enl. 185. f. 1.

Sooty Warbler, Latb. Syn. iv. p. 45 I. 49.

Habitat in Pbilippenfibus infulis. -6 pollices longa.

54.

perfpicil-

lata.

S. nigra, macula alarum alba, orbitis nudis carunculatis flavis.

Motacilla perfpicillata, Gmel. Syft. i. p. 969.

Le Clignot, ou Traquet à lunette, Buf. v. p. 234.

Spectacle Warbler, Latb. Syn. iv. p. 452.50.

Habitat in America, ad fluvium Plata; magnitudine Carduelis.

Irides flavæ, pupilla cærulea: criffum nonnullis album.

55. coromandelica.

S. nigra flavefcente maculata fubtus nigro fafciata, uropygio et abdomine rufefcentibus, remigibus caudaque nigris.

Motacilla coromandelica, Gmel. Syft. i. p. 968.

Le petit Traquet des Indes, Son. Voy. Ind. ii. p. 207.

Coromandel Warbler, Latb. Syn. iv. p. 452.51 .

Habitat in Coromandela; magnitudine Pari.-Irides rufo-flava: tectrices alarum (minoribus exceptis) albo maculatx. 
philippen-S. nigro-violacea, fubtus capiteque rufo-albo, pectore cærulefcente, fis. rectrice extima extus rufefcente-alba.

Motacilla philippenfis, Gmel. Syft. i. p. 968 .

Rubetra philippenfis major, Brif.iii.p.446.32.t.22.f.3.-Id. 8 vo. i. p. 433 .

Le grand Traquet des Philippines, Buf. v. p. $230 .-P l$. Enl. 185. f. 2.

Philippine Warbler, Latb. Syn. iv. p. 453. 52.

Haвiтat in Pbilippenfibus infulis. -6 pollices longa.

57.

Roftrum flavicans: pedes fufci : fafcia alarum fefquialtera alba.

magna. S. fufca fubtus rufefcens, gula albefcente, remigibus rectricibufque rufo fufcoque dimidiatis, exterioribus duabus extus albis.

Motacilla magna, Gmel. Syft. i. p. 968 .

Le grand Traquet, Buf. v. p. 232.

Dark Warbler, Latb. Syn. iv. p. 453. 53 .

58.

Longitudo $7 \frac{x}{2}$ pollicum.

Rubetra. S. nigricans, fuperciliis albis, macula alarum alba, gula pectoreque flavefcente.

Motacilla Rubetra, Lin. Syft. i. p. 332. 16.-Faun. Suec. $\mathrm{N}^{\circ} 255 .-$ Gmel. Syft. i. p. $967 .-$ Scop. Ann. i. $\mathrm{N}^{\circ} 237 .-$ Brun. $\mathrm{N}^{\circ} 277 .-$ Muller, $\mathrm{N}^{\circ} 275 .-$ Kram. El. p. 375. 5.-Friccb. t. 22.-Borowfk. Nat. iii. p. I 92.12.

Rubetra major, five Rubicola, Brif. iii. p. 432. 26. t. 24. f. I.-Id. 8 vo. i. p. 430.

Sylvia petrarum, Klein. Av. p. 78. I I ?-Id. Ov. p. 25. t. 10. f. 9 ?

Grand Traquet, ou Tarier, Buf. v. p. 224.-Pl. Enl. 678. f. 2 .

Enanthe fecunda, Raii Syn. p. 76. A. 3.-Will. p. 234.

Whin Chat, Br. Zool. i. No 158.-Id. fol. 103. t. S. 2. f. 3. 4.-Will. (Angl.) p. 234.-Hayes Br. Birds, t. 39.-Latb.Syn. iv. p. 454. 54.

HAвгтAT in Europa ufque in Spitfbergam; in Anglia in pratis et ericetis frequens.-Duæ maculæ albæ utramque alam infigniunt.

Mas genis nigris. Ovum cæruleun, immaculatum.

59.

fervida. S. fufca rufo marginata fubtus flavefcente-alba, pectore rufefcente, maculis alarum duabus albis.

Motacilla fervida, Gmel. Syft. i. p. 968.

Le Traquet du Senegal, Buf. v. p. $228 . .-P l$. Enl. $5^{8} 3$. f. 1.

Sultry Warbler, Latb. Syn. iv. p. $455 \cdot 55$.

Haвітат in Senegala; magnitudine Rubetra. 

60. 526
A V E S
P A S S I
R E S. Sylvia.

montanel- S. teftacea fufco maculata, fubtus fuperciliifque flavefcentibus, macula

la. aurium nigra.

Motacilla montanella, Pall. It. iii. p. 695. 12.-Gmel. Syft. i. p. 968.

Sibirian Warbler, Lath. Syn. iv. p. 456. 57.

Habitat in Sibiria.-Magnitudo paulo fupra Rubetran.-Adventat in Daturian Februario, turmis Coccobrauftarum immixta.

Fuguli pennæ fucce: aures nigræ, areola canefcente: tectrices fecundariæ apice albæ: rectrix utrinque extima intermediæque 2 reliquis

$6 \mathrm{I}$. breviores.

fenegalen- S. fufca, remigibus intus rufis, rectricibus nigris apice albis.

fis. Motacilla fenegalenfis, Lin. Syft. i. p. 333. 22.-Gmel. Syft. i. p. 974. Rubetra fenegalenfis, Brif. iii. p. 44I. 29.t. 20. f. 3.-Id. 8 vo. i. p. 432 . Senegal Warbler, Lath. Syn. iv. p. 456. 57 .

62.

Habitat in Senegala et ad Caput B. Spei. $-5^{-6}$ pollices longa.

maura. S. nigra grifeo marginata fubtus alba, gula ferruginea, macula alarum uropygio bafique caudæ albis.

Motacilla maura, Pall. It. ii. p. 708. 17.-Gmel. Syf. i. p. 975. .

Moor Warbler, Latb. Syn. iv. p. 458.60. .

Habitat in Ruffic betuletis; magnitudine et habitu Rubetra.

Femina et junior avis capite grifeo fufcoque undulato, corpore fcolopaceo.

ß. S. rufo-fufca fubtus albida, fuperciliis rufis, gula abdomine uropygio bafique cauda albis.

Hæc avis inter Afram et Americam capta fuit.

Rectrices 2 intermediæ nigræ.

63.

fupercilio- S. virefcens fubtus pallida, fuperciliis flavis, lineola verticis pallida.

fa. Motacilla fuperciliofa, Gmel. Syft. i. p: 975 .

Yellow-browed Warbler, Latb. Syn. iv. p. 459. 6r.

Habitat in Rufia.

64.

ferruginea. S. cinerea fubtus albida, gula colloque ferrugineis.

Motacilla ferruginea, Gmel. Syft. i. p. 976.

Gilt-throat Warbler, Latb. Syn. iv. p. 459.63.

HABIтAт in Rußia, præfertim circa fluvium Tungu/ka.

S. cinereo 
65.

A V E S P A S S E R E. Sylvia.

cyanura. S. cinereo-flavefcens, fubtus fuperciliifque flavo-aibis, alis caudaque fufcis, uropygio rectricumque marginibus cæruleis.

Motacilla cyanura, Pall. It. ii. p. 709. I8.-Gmel. Syjt. i. p. 976.

Blue-tailed Warbler, Latb. Syn. iv. p. 459.63.

Haвiтat in Sibiria; magnitudine Rubecula.-Occurrit in arbuftis rivulos fuviofque alpeftres obumbrantibus auftralioris regionis circa $\mathrm{Fe}$ nifeam; in hyemis ufque initium præens.

66.

aurorea. M. nigra, vertice grifeo-albo, fronte maculaque alarum albis, corpore fubtus rectricibufque lateralibus fulvis, 2 intermediis nigris.

Motacilla aurorea, Pall. It. iii..p. 695. 1 3.-Gmel. Syft. i, p. 976.

Daurian Warbler, Latb. Syn, iv. p. 460. 64.

Habitat in Sibiria; magnitudine Pbanicuri, fed procerior.-In falicetis circa Selengam, et collaterales fuvios ufque ad Sinarum fines, ab Aprili; vulgaris avicula, pagos familiariter frequentans.

67.

ftriata. S. nigro ftriata fupra cinerea fubtus alba, fafcia alarum duplici alba, rectricibus duabus extimis apice macula alba.

Motacilla ftriata, Gmel. Syfl. i. p. 976.

Black-poll Warbler, Aret. Zool. ii. No 290.-Latb. Syn. iv. p. 460. 65.

Habitat in Noueboraco; migratoria.-Vertex niger: gene albæ.

68.

incana. S. late grifea, fubtus fafciaque alarum duplici alba, jugulo aurantio, gula pectoreque flavis.

Motacilla incana, Gmel. Syft. i. p. 976.

Grey-poll Warbler, Arct. Zool. ii. N²91.-Latb. Syn. iv. p. 461.66.

Habitat in Noveboraco.

69.

flavifrons. S. grifeo-cærulefcens fubtus alba, pileo maculaque alarum flavis, jugulo fafciaque oculorum nigris, reetricibus extimis albo maculatis.

Motacilla flavifrons, Gmel. Syft. i. p. $\$ 76$.

Yellow-fronted Warbler, Arct.Zool. ii. N²96.-Lath.Syn.iv.p.46r.67.

Habitat in Penfylvania.-Macula e tectricibus alarum ampla.

70.

Blackbur- S. pileo atro, linea verticali et fuboculari loris pectoreque medio flavis, nia. fafcia alarum criffo rectricibufque extimis tribus albis, per oculos vitta nigra.

Motacilla 


\section{A VES PASSERES. Sylvia,}

Notacilla Blackburniæ, Gmel. Sy/. i. p. 977.

Blackburnian Warbler, Ari7.Zool. ii. No 317.-Lath.Syn.iv.p. 461.67.*.

Habitat in Noveboraio.

71.

mitrata. S. olivacea fubtus capite antice gulaque luteis, torque nigro.

Motacilla mitrata, Gmel. syft. i. p. 977.

Parus carolinenfis torquatus, Brif. iii. p. 578. 16. $I d$. 8 vo. i. p. 47 I. -Klein. Av. p. 85. 5 .

Hooded Titmoufe, Cat. Car. i. t. 60.

Hooded Warbler, Arct. Zool. ii. N²87.-Latb. Syn. iv. p. 462. 68.

Habitat in Carolina; magnitudine Carduelis. -5 pollices longa.

Ex Cucullo facies angulata apparet.

ß. S. grifeo-virefcens fubrus flava, capite colloque inferiore nigro-fericeis, fronte lateribus capitis corporeque fubtus flavis.

Le Gobe-mouche citrin de la Louifiane, Buf. iv. p. 538.-Pl. Enl. 666. f. 2.

72.

\section{Habitat in Louifiano.}

cucullata. S. virens fubtus fava, fronte genifque nigris, cauda cuneiformi.

Magnitudo mitrate, cujus forte varietas. Muf. D. Parkinfon.

73.

murina. S. murina fubtus fafciaque per oculos alba, capite collo abdomineque medio nigris.

Motacilla murina, Gmel. Syft. i. p. 978.

Murine Warbler, Latb. Syn. iv. P. 463. 70.

Magnitudo Fr. domeftica.

74 . fpinicau-

da.

S. fufca fubtus humerifque alba, pileo flavo nebulofo, cauda cuneiformi, rectricibus apice nudis fubulatis.

Motacilla fpinicauda, Gmel. Sy/f. i. p. $97^{8}$.

Thorn-tailed Warbler, Latb. Syn. iv. p. 463. 7 I. t. 52.

Habitat in Terra del Fuego. - 6 pollices longa. - Linea fupra oculos flavo-rufefcens verfus occiput ducta : reltrices 4 media ferruginex, reliquæ apice albicantes.

75 . magella- S. fufco-flavefcens nigro undulata fubtus cinereo-flava nigricante tranfnica. verfim ftriata, cauda breviore nigra lineis tranfverfis.

Motacilla 


$$
\text { A V E S P A S ER ES. Sylvia. }
$$

Motacilla magellanica, Gmel. Syf. i. p. 979.

Magellanic Warbler, Latb. Syn. iv. p. 464. 72.

76.

Habitat cum precedente. $-4 \frac{1}{2}$ pollices longa. $-P e d e s$ flavi.

citrina. S. flava ftriis nigricantibus, fubtus uropygioque flavo, genis collo inferiore pectoreque albis, cauda breviore nigra apice flavefcente.

Motacilla citrina, Gmel. Syjt. i. p. 979.

Citrine Warbler, Lath. Syn. iv. p. 464.73.

Habitat in nova Zealandia; Reguli magnitudine. $-3 \frac{x}{2}$ poll. longa.

77.

longipes. S. pallide viridis fubtus cinerafcens, fronte genis colloque lateribus cinereis, fupra oculos lunula alba, cauda breviffima.

Motacilla longipes, Gmel. Syft. i. p. 979 .

Long-legged Warbler, Latb. Syn. iv. p. 465. 74.-Id. Sup. p. 18 .

HABITAT in nova Zealandia. $-4 \frac{1}{2}$ pollices longa.

Roftrum fufcum: pedes longiores incarnati. Variat corpore fufco.

78.

minima. S. pallide fufca fubtus albida, roftro caudaque breviffima flavefcentibus. Long legged Warbler, Latb. Syn. Sup. p. $18 \mathrm{I}$.

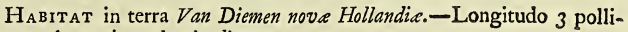
cum.-An varietas longipedis.

79.

OEnanthe. S. dorfo cano, fronte linea fupra oculos uropygio bafique caudæalbis, per oculos fafcia nigra.

Motacilla OEnanthe, Lin. Syft. i. p. 332. I 5.-Faun. Suec. N 254.Gmel. Syft. i. p. 966.-Scop. Ann. i. N N $^{\circ} 30 .-B r u n . \mathrm{N}^{\circ} 276 .-$ Muller, $\mathrm{N}^{\circ}$ 274.-Kram. El. p. 374. 4.-Faun. Groenl. p. 122.84. -Sepp. Vog. t. p. 163.-Raii Syn. p. 75. A. 1.-Will. p. 168. t. 41.-Borowek. Nat. iii. p. 192 . I I.

Vitifora, Brif. iii. p. 449. 33.-Id. 8vo. i. p. 434-Klein. Av. p. 78. 9. Culo bianco, Zinnan. Uov. p. 41. t. 6. f. 24.-Cett. uc. Sard. p. 223.

Le Cul-blanc, Vitrec, ou Motteux, Buf. v. p. 237.-Pl. Enl. 554. f. r. 2. -Hift. Prov. i. p. 498.-Voy. en Barb. i. p. 273.

Wheat-ear, Fallow Smich, White-tail, Br. Zool. i. N ${ }^{\circ}$ 157.-Id. fol. 102. t. S. ז. f. 5. 6.-Arct. Zool. ii. p. 420. P.-Will. (Angl.) p. 133. t. 4 I. $-A l b$. i. t. 55. (mas.)-3. t. 54. (fem.) $-E d w . A v$. pref. p. 12.-Latb. Syn. iv. p. 465.75.-Id. Sup. p. I 82. 
530 A VES P A S E R E S. Sylvia.

Habitat in Afia, Africa, frequentius in Europa. $-5 \frac{1}{2}$ pollices longa. -In Angliam venit Martii medio, migrat Septembri; nidificat humi inter faxa.

Femina obfcurior, linea fupra oculos minus confpicua, fafcia fuboculari fufca. Ovum dilute cæruleum, zona faturatiore ad extremitatem obtufam.

$\beta$. S. corpore fupra fulvo albidoque vario, collo infimo grifeo maculato, rectricibus duabus intermediis toto nigris.

Motacilla Enanthe, Lin. Syft. i. p. 332. 15. $\beta$.

Vitiflora grifea, Brif. iii. p. 452 . 34. t. 21. f. 2.-Id. 8 vo. i. p. 434 .

Cul-blanc gris, Buf. v. p. 244 .

Grey Wheat-ear, Br. Zool. App..-Lath. Syn. iv. p. 467 .

$\gamma$. S. fupra cinerea, grifeo-fufco varia.

Vitiflora cinerea, Brif. iii. p. 454. 35. t. 21. f. 3.-1d. 8 vo. i. p. 435 .

Cul-blanc cendré, Buf. v. p. 245.-Lath. Syn. iv. p. 468.

Uropygium grifeo-fufcum.

ঠ. S. fupra alba, gula alis rectricibus intermediis fere totis aliarumque maculis binis atris.

Habitat circa Duinum. Scopoli.

so.

Stapazina. S. ferruginea, area oculorum alis caudaque fufcis, rectricibus extimis latere albis.

Motacilla Stapazina, Lin. Syft. i. p. 331. 14.-Gmel. Syft. i. p. 966.

Vitiflora rufa, Brif. iii. p. 459 . 37. - Id. 8 vo. i. p. $436 .-K l e i n . A v$. p. 8०. 26 .

Cul-blanc roux, Buf. v. p. 246.

OEnanthe altera Aldr. Raii Syn. p. 76. 2.-Will. p. 168.-Id. (Angl.) p. 233 .

Stapazina, ArEt. Zool. ii. p. 241. Q.

Ruffet Wheat-ear, Edw. t. 31.-Lath. Syn. iv. p. 468. 76.

Habitat in Europa. Mas gula nigra, femina alba.

ק. S. ruffefcens fubtus albida, tænia per oculos nigra, rectricibus 2 intermediis nigris, lateralibus albis utrinque verfus apicem nigro fimbriatis.

Vitiflora 
Vitiflora rufefcens, Brif. iii. p. 457 . 36. t. 25. f. 4. $-I d$. 8 vo. i. p. 435 . Le Cul-blanc rouffatre, Buf. v. p. 245 .

Stapazina, Raii Syn. p. 81. 1 3.-Will. p. 168.-Id. (Angl.) p. 233. -Latb. Syn. iv. p. 469.

$8 \mathrm{r}$.

Habitat circa Nemaufum et Bononiam.

leucorhoa. S. rufo-fufca fubtus albo-flavefcens, pectore rubefcente, uropygio bafique caudx albis.

Motacilla leucorhoa, Gmel. Syft. i. p. 966.

Le Motteux du Senegal, Buf. v. p. 249.

Cul-blanc du Senegal, Pl. Enl. $5^{8} 3.2$.

Rufous Wheat-ear, Lath. Syn. iv. p. 469.77.

82.

Habitat in Senegala. $\rightarrow 7$ pollices longa.

hottentot- S. fulvo-fufca fubtus gulaque albida, vertice pectoreque nebulofis, ab-

ta. domine fuperiore uropygioque fulvis, rectricibus lateralibus bafi albis.

Motacilla hottentotta, Gmel. Syft. i. p. 963.

Grand Motteux, ou Cul-blanc du Cap de B. E. Buf. v. p. 248.

Cape Wheat-ear, Lath. Syn. iv. p. 470.78.

83.

Habitat ad Caput Bona Spei. -8 pollices longa.

aurantia. S. nigricans viridi nebulofa fubtus fulvefcens, gula macula tectricum tectricibus caudæ rectricibufque lateralibus apice albis.

Motacilla aurantia, Gmel. Syft. i. p. 965 .

Motteux, ou Cul-blanc brun verdatre, Buf. v. p. 248.

Orange-breafted Wheat-ear, Latb. Syn. iv. p. 470.79. rium.

HАвітат cum præcedente. -6 pollices longa.- Fugulum nigro va-

84.

pileata. S. rufo-fufca, capite pectoreque nigris, fronte gula fuperciliis uropygio rectricibufque lateralibus a bafi ad medium albis.

Motacilla pileata, Gmel. Syft. i. p. 965 .

Black-hooded Wheat-ear, Latb. Syn. iv. p. 47 1. 80.

Habitat ad Caput B. Spei et in Cbina.-6 pollices longa.

85.

maffilien- S. fufco rufoque varia fubtus rufo-alba, pectore nigro maculato, fub fis. oculis macula flavefcente, rectricibus duabus extimis albis. 


\section{A V E S P A S E R E S. Sylvia.}

Motacilla mafilienfis, Gmel. Syft. i. p. $9^{65}$.

Le Fift de Provence, Buf. v. p. 194.-Pl. Enl. 654. 1.

Provence Wheat-ear, Lath. Syn. iv. p. 47 I. 81 .

86.

HАвiтат in Galloprovincia. -7 pollices longa.

maculata. S. nigro maculata fupra fufca fubtus cinereo-alba, alis caudaque nigris, rectricibus duabus extimis margine exteriore apiceque toto albis.

Motacilla maculata, Gmel. Syft. i. p. 965 .

La Pivote ortolane, Buf. v. p. 195.-Pl. Enl. 654. 2.

Spotted Wheat-ear, Lath. Syn. iv. p. 472.82.

Habitat in Galloprovincia; antecedenti æqualis et affinis.

87.

albicapilla. S. viridis fubtus albida, gula macula verticis fubocularique albis.

Motacilla albicapilla, Gmel. Syft. i. p. 964 .

White-crowned Warbler, Lath. Syn. iv. p. 472.83.

88.

Habitat in Cbina. -7 pollices longa.

grifea. S. cinereo-grifea fubtus fafciaque per oculos alba, vertice collo inferiore pectoreque nigris.

Motacilla grifea, Gmel. Syft. i. p. 964 .

Le Grifin de Cayenne, Buf. iii. p. 408.-Pl. Enl. 643. f. I. 2.

Grilly Warbler, Lath. Syn. iv. p. 473.84.

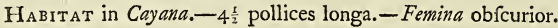

89.

caryophyl- S. dilute caryophyllea, alis caudaque obfcuris, roftro pedibufque rubris.

lacea. Motacilla caryophillacea, Gmel. Syft. i. p. 964.

Pink Warbler, Brown. Ill. p. 84. t. 33.-Latb. Syn. iv. p. 473.85.

HaBıтат in Zeylona; magnitudine Trocbili.

90.

olivacea. S. olivacea, corpore fubtus albo, capiftro flavefcente.

Motacilla olivacea, Gmel. Syft. i. p. 964.

Olive Warbler, Brown. Ill. p. 33.t. 14.-Lath. Syn. iv. p. 473. 86.

HaBitat in Zeylona; magnitudine modularis.

Caudam frequenter elevat. $9 \mathbf{I}$.
zeylonica. S. viridis fubtus flavefcens, vertice nucha alifque nigris, fafcia alarum bifida alba.

Motacilla 
Motacilla tiphia, Lin. Syft. i. p. 331. 1 3.-Gmel. Syft. i. p. 963.

Ficedula bengalenfis, Brif. iii. p. $484.47 .-I d .8$ vo. i. p. $442 .-$ Klein. Av. p. 75.17 .

Le Figuier vert et jaune, Buf. v. p. $27^{8}$.

Ceylon Warbler, Brown. Ill. p. 36.-Lath. Syn. iv. p. 474. 87.-Id. Sup. p. 474.

Green Indian Flycatcher, Edw. t. 79. (fem.)-t. 1 5. (mas.)

Green Indian Warbler, Lath. Syn. iv. p. 474. 90.

Haвiтat in Zeylona, Bengala. $-4 \frac{1}{2}$ pollices longa.

Femina abfque vertice nucbaque nigra.

92.

cingalen- S. viridis variegata fubtus flava, collo inferiore fulvo.

fis. Motacilla lingalenfis, Gmel. Syft. i. p. 964 .

Green Warbler, Brown. Ill. p. 82. t. 32.

Cingalefe Warbler, Lath. Syn. iv. p. 474.88.

HАвітат in Zeylona.- $-4 \frac{\mathrm{T}}{2}$ pollices longa.

93.

finenfis. S. viridis fubtus incarnata, macula aurium poneque oculos pallida, rectricibus mucronatis.

Motacilla finenfis, Gmel. Syft. i. p. 963 .

China Warbler, Latb. Syn. iv. p. 474.89 .

Habitat in Cbina. -6 pollices longa.

94.

madagaf- S. virefcens fubtus albida, gula anoque flavis, palpebris albis.

carienfis. Motacilla maderafpatana, Lin. Syft. i. p. 334. 28.

madagafcarienfis, Gmel. Syft. i. p. 981 .

Ficedula madagafcarienfis minor, Brif. iii. p. 498. 54. t. 28. f. 2.-Id. 8 vo. i. p. 446.

Le Cheric, Buf. v. p. 279.

White-eyed Warbler, Latb. Syn. iv. p. 475. 91 .

Hавітат in Madagafcaria; vix $3 \frac{1}{2}$ pollices longa; gregaria.

95.

borbonica. S. grifeo-fufca fubtus grifeo-flavefcens, remigibus rectricibufque grifeo marginatis.

Ficedula borbonica, Brif. iii. p. 5 10. 6o. t. 28. f. 3.-Id. 8 vo. i. p. 449 . Figuier de l'ille de Bourbon, Pl. Enl. 705. f. 2.

Le petit Simon, Buf. v. p. 280.

Bourbon Warbler, Latb. Syn. iv. p. 475. 92 . 


\section{4 \\ A VES PASSERES. Sylvia.}

$9^{6 .}$

HaBITAT in Madagajcaria et Borbonica infula; magnitudine precedentis; vietitat fructibus. Ovum cæruleum.

mauritia- S. grifeo-cærulefcens fubtus alba, remigibus rectricibufque nigris marna.

$9^{8}$. gine albis.

Motacilla mauritiana, Gmel. Syyt. i. p. $98 \mathrm{r}$.

Le Figuier bleu, Buf. v. p. 282.-Pl. Enl. 705. f. I.

Maurice Warbler, Latb. Syn. iv. p. 476. 93.

Habiт at in infula Mauritio. - $3 \frac{x}{2}$ pollices longa.

Pedes cærulefcentes.

97.

livida. S. grifeo-crrulefcens, criffo albido, remigibus caudaque nigris, rectricibus duabus exterioribus albis.

Motacilla livida, Gmel. Syft. i. p. 981 .

Le Figuier bleu de Madagafcar, Pl. Enl. 705. f. 3.

Madagafcar Warbler, Latb. Syn. iv. p. 476. 94.

Habitat in Madagafcaria; precedenti fimillima, fed cauda multo longior.-Roftrum et pedes plumbei.

flavefcens. S. fufca fubtus citrina, genis albidis, remigibus rectricibufque fufcis.

Motacilla flavefcens, Gmel. Syft. i. p. 982 .

Figuier à ventre jaune du Senegal, Pl. Enl. 582. f. 3.-Buf. v. p. 282. Citron-bellied Warbler, Latb.Syn. iv. p. 477. 95 .

HaвiтAт in Senegala. $-4 \frac{\frac{x}{4}}{4}$ pollices longa.-Rofrum et pedes obfcuri.

99.

rufigattra. S. olivaceo-fufca fubtus rufo-flavefcens, remigibus rectricibufque fufcis. Figuier du Senegal, Pl. Enl. 582. 1.-Buf. v. p. 282.-Latb. Syn. iv. p. 477.95 .

Habitat cum flavefcente, a qua differt cauda breviore, corpore fubtus ad rufum inclinante. - Avis tota $3^{\frac{3}{4}}$ pollices longa.

100.

wndata. S. nigra, marginibus pennarum uropygioque rufis, fubtus alba, remigibus caudaque cuneata fufcis.

Motacilla undata, Gmel. Syft. i. p. 982.

Figuier tacheté du Senegal, Pl. Enl. 582. f. 2.-Buf. v. p. 282.

Undated Warbler, Latb. Syn. iv. p. 477. 96.

Habitat cum precedentibus. -4 pollices longa.

Cauda maxime cuneiformis. 


\section{A VES PASSERES. Sylvia.}

ror.

£ufcata. S. fufca fubtus grifea, lateribus rufefcentibus, remigibus rectricibufque obfcurioribus, cauda elongata.

Motacilla fufcata, Gmel. Syft. i. p. 982 .

Figuier brun du Senegal, Pl. Enl. 584. f. т.

Duky Warbler, Latb. Syn. iv. p. 477.

Haвiтat in Senegala. -6 pollices longa.

Cauda elongata, integra: pedes flavi.

102.

fubflava. S. rufo-fufca fubtus grifea, uropygio pallido, lateribus corporis rufercentibus, cauda cuneiformi.

Motacilla fubllava, Gmel. Syft. i. p. $9^{82}$.

Figuier blond du Senegal, Pl. Enl. 584. f. 2.-Buf. v. p. 284.

à ventre gris du Senegal, Pl. Enl. 584. f. 3 .

Flaxen Warbler, Latb. Syn. iv. p. 478.98.

Habitat in Senegala. $-4 \frac{x}{4}$ pollices longa.-Pedes flavi.

In altero fexu corpus fupra fufcum, fubtus toto grifeum, uropygio flavefcente.

I03.

petechia. S. olivacea fubtus flava rubro guttata, pileo rubro.

Motacilla petechia, Lin. Syft. i. p. 334. 30.-Gmel. Syft. i. p. 983.

Ficedula erythrocephalos, Brif. iii. p. 488 . 49.-Id. 8 vo. i. p. 443.

Figuier à tête rouge de Penfylvanie, Buf. v. p. 286.

Yellow Redpole, Edw. t. 256.

Red-headed Warbler, Arcz. Zool. ii. N ${ }^{\circ}$ 289. - Lath. Syn. iv. p. 479. 39.

Habitat in Penfylvania; magnitudine atricapille; folitaria; migratoria.-Remiges rectricefque margine flava. - Femina pallidior.

104.

albicollis. S. viridi-olivacea fubtus albo-flavicans ftrigis rufefcentibus, rectricibus. lateralibus intus dimidiato fulphureis.

Motacilla albicollis, Gmel. Syft. i. p. $9^{8} 3$.

Ficedula dominicenfis, Brif. iii. p. 494.52.t. 26. f. 5. - Id. 8vo. i. p. 445 o

Figuier à gorge blanche, Buf. v. p. 287.

St. Domingo Warbler, Lath. Syn. iv. p. 479. 100.

HaBITat in Dominicenfi infula. -5 fere pollices longa.-Latera capitis flavefcentia. Femina cervice viridi-cinerea.

105.

ludovicia- S. viridi-olivacea fubtus alba luteo varia, collo fubtus flavo, fafcia ala-

na. rum duplici alba, rectricibus duabus exterioribus apice intus albis. Motacilla ludoviciana, Gmel. Syft. i. p. 983.

Ficedula 


\section{$53^{6}$ AVES PASSERES. Sylvia.}

Ficedula ludoviciana, Brif. iii. p. 500 . 55. t. 26. f. 4. $-I d$. 8 vo. i. p. 44.6 . Figuier à gorge jaune, Buf. v. p. 288.

Louifiane Warbler, Arct. Zool. ii. $\mathrm{N}^{\circ}$ 303.-Lath. Syn. iv. p. 480. $10 \mathrm{r}$.

Hавттат in Louifiana et infula $S$. Dominici. $-4 \frac{1}{2}$ pollices longa.

106. Mas peitore rubefcente maculato.

chloroleu- S. viridi-olivacea fubtus flavicans, capite colloque fuperius cinereis, ca. rectricibus lateralibus intus dimidiato-luteis.

Motacilla chloroleuca, Gmel. Syft.i. p. 984.

Ficedula dominicenfis minor, Brif. iii. p. 496.53. t. 26. f. 2. $-I d .8 \mathrm{vo}$. i. p. 445 .

Le Figuier vert et blanc, Buf. v. p. 289 .

Green and white Warbler, Lath. Syn. iv. p. 480. 102.

Habitat in Dominicenfi infula. $-4 \frac{T}{2}$ poll. longa.-Cauda fubfurcata.

107.

auricollis. S. olivacea fubtus flava, collo fubtus pectoreque flavo-aurantiis, crifo rectricibufque lateralibus intus albis.

Motacilla auricollis, Gmel. Syft. i. p. 984.

Ficedula canadenfis major, Brif. iii. p. 508. 59. t. 26. f. 1. $-I d .8$ vo. i. p. 449.

Le Figuier à gorge orangée, Buf. v. p. 290.

Orange-throated Warbler, Arct. Zool. ii. No 304.-Lath. Syn. iv. p. 481 . 103 .

Habitat in Canada; ultra 5 pollices longa.

108.

maculofa. S. nigro maculata, fupra viridi-olivacea fubtus uropygioque lutea, capite cinereo, fafcia alarum duplici rectricibufque lateralibus medio intus albis.

Motacilla maculofa, Gmel. Syft. i. p. 984.

Ficedula penfylvanica nævia, Brif. iii. p. 502. 56.-Id. 8 vo. i. p. 447 .

Le Figuier à tête cendrée, Buf. v. p. 291.

Yellow-rumped Flycatcher, Edwo. t. 255.

Yellow-rumped Warbler, ArEt. Zool. ii. No 288. - Latb. Syn. iv. p. 48 I. 104.-Id. Sup. p. 182.

Habitat in Penfylvania; magnitudine Hippolaidis. -5 poll. longa. Abdomen album: corpus fupra pec7ufque nigro maculatum. 
109.

A V E S P A S E R E S, Sylvia.

fufcefcens. S. fufcefcens fubtus rufo grifeoque varia, fafcia per oculos juguloque faturate fufcis.

Motacilla fufcefcens, Gmel. Syft. i. p. 984.

Ficedula jamaicenfis, Brif. iii. p. 5 I 2. 61.-Id. 8 vo. i. p. 450.

Le Figuier brun, Buf. v. p. 292.

Mufcicapa pallide fufca, (Worm-eater) Raii Syn. p. 186. 38.-Sloan. fam. p. 310.45 . t. 265 . f. 2.-Klein. Av. p. 75 . 14.

Brown-throated Warbler, Latb. Syn. iv. p. 482. I05.

Навітат in famaica. -5 pollices longa.

110.

tigrina. S. fufco et olivaceo-viridi varia fubtus flava, collo fubtus pectoreque nigro maculato, pone oculos macula rufa, fafcia alarum alba.

Motacilla tigrina, Gmel. Syft. i. p. 985 .

Ficedula canadenfis fufca, Brif. iii. p. $515 \cdot 6 \hat{\jmath}$. t. 27 . f. $4 .-I d$. 8 vo. i. p. $45 \mathrm{I}$.

Le Figuier tacheté de jaune, Buf. v. p. 293.

Spotted yellow Flycatcher, ArSt. Zool. ii. $\mathrm{N}^{\circ} 302 .-E d w$. t. 257.Latb. Syn. iv. p. 482 . 106.

Habitat in Canada. $-4 \frac{1}{2}$ pollices longa.

ReZtrices 2 extimæ apice intus albæ.

ß. Ficedula dominicenfis fufca, Brif. iii. p. 5 I3.62, t. 28 . f. 5.-Id. 8 vo. i. p. 450.

Variat corpore pallidiore, fubtus albido; pectore fufco maculato; alis abfque fafcia alba.

II.

Pinus. S. olivacea fubtus flava, loris nigris, alis cæruleis fafciis duabus albis.

Certhia Pinus, Lin. Syft. i. p. 187. 16.-Gmel. Syft. i. p. 478.

Parus americanus, Brif. iii. p. 576. 1 5. $-I d .8$ vo. i. p. 47 I.

Le Figuier des fapins, Buf. v. p. 296.

Pine Creeper, Cat. Car. i. t. 46.-Edw. t. 277.

Pine Warbler, Arct. Zool. ii. No 318.-Latb. Syn. iv. p. 483. 107.

Hавітат æitate in Carolina. $-4 \frac{x}{2}$ pollices longa.-Cauda fubfurcata.

Femina tota fufca.

II 2.

virens. S. viridi-olivacea fubtus alba, genis lateribus colli pettoreque flavis, collo fubtus nigro, fafcia alarum duplici alba.

Motacilla virens, Gmel. Syft. i. p. 985 .

Ficedula 
$53^{8}$ A VES P A S E R E S. Sylvia.

Ficedula penfilvanica gutture nigro, Brif. Sup. p. I04.-Id. 8vo. i. p. 548 .

Le Figuier à cravate noire, Buf. v. p. 298.

Black-throated green Flycatcher, Edw. t. 300.

Green Warbler, Arct. Zool. ii. N 297.-Latb. Syn. iv. p. 484. 108.

Habitat in Penjylvania; Hippolaidis magnitudine.

Reetrices 3 exteriores intus albo maculatæ: bypocbondria albo nigro-

II 3 . que varia.

icteroce- S. grifea fubtus albida, pileo luteo, fafcia oculari nigra duabufque alaphala.

Motacilla ifterocephala, Lin. Syft. i. p. 334. 25.-Gmel. Syft. i. p. 980 . Ficedula canadenfis icterocephalos, Brif. iii. p. $517 \cdot 64$. t. 27. f. 2.Id. 8 vo. i. p. $45 \mathrm{I}$.

Figuier à tête jaune, Buf. v. p. 299.

Le Figuier de Miffiffipi, Pl. Enl. 731. f. 2.

Quebec Warbler, ArEt. Zool. ii. N 305 -Lath. Syn. iv. p. 484. Iog.

HaвiтAт in Canada. $-4 \frac{T}{2}$ pollices longa.-Inter roftrum et oculum: macula triquetra nigra.

Nonnullæ, fexu vel ætate variantes, macula oculari carent.

114. dominic

S. cinerea fubtus alba, macula ante oculos lutea, pone alba, infra nigra. Motacilla dominica, Lin. Syft. i. p. 334. 26.-Gmel. Syft. i. p. 980.

Ficedula dominicenfis cinerea, Brif. iii. p. $520.65 \cdot t_{2} 27$. f. 3.-Id. 8 vo.

i. p: 452 .

Le Figuier cendré à gorge jaune, Buf. v. p. 300.

Mufcicapa è cæruleo, cinereo, fufco, et luteo varia, Raii Syn. p. 186.

37.-Sloan. Jam. ii. p. 310. 44.-Klein. Av. p. 75. 16.

Jamaica Warbler, Lath. Syn. iv. p. 485 . 1 ro.

Habitat in Famaica. $-4 \frac{1}{2}$ pollices longa.-Fafcia alarum duplex alba : rectrices 2 exteriores prope apicem intus macula alba.

115.

coronata. S. nigro maculata, pileo hypochondriis uropygioque flavis, fafcia per: oculos gulaque nigra.

Motacilla coronata, Lin. Syft. i. p. 332. 31.-Gmeh. Syft. i. p. 974.

Ficedula penfilvanica cinerea nævia, Brif. Sup. p. 1 10,-Id. 8vo. i. p. $460.8 \mathrm{I}$.

Le Figuier couronné d'or, Buf. v. p. $3 \mathbf{1} 2$.

Golden-crowned Flycatcher, Edw. t. 298. 
Golden-crowned Warbler, Ariz. Zool. ii. No 294,-Latb. Syn. iv. p. 486. III.

I16.

Haвгтat in Penfylvania vere; magnitudine Hippolaidis; migratoria. Femina caret fafcia oculari et maculis pectoralibus nigris.

cincta. S. cinerafcens fubtus alba, vertice fafciaque abdominali lutea, pectore fufco maculato.

Motacilla canadenfis, Lin. Syft. i. p. 334. 27 . cincta, Gmel. Syft. i. p. 980 .

Ficedula canadenfis cinerea, Brif. iii. p. 524. 67. t. 27. f. I. -Id. $8 \mathrm{vo}$. i. P. 453 .

Le Figuier à ceinture, Buf. v. p. 303 .

Belted Warbler, ArEt. Zool. ii. No 306.-Latb. Syn. iv. p. 487. 112.

Habitat in Canada. -5 pollices longa.-Fafcia alarum duplex alba. Mas tectricibus caudre luteis.

117.

canadenfis. S. fupra cærulea fubtus alba, jugulo remigibus rectricibufque nigris. Motacilla canadenfis, Lin. Syft. i. p. 336. 42.-Gmel. Syft. i. p. 991.

Ficedula canadenfis cinerea major, Brif. iii. p. 527. 68. t. 27 . f. 6.-Id. 8 vo. i. p. 453 .

Le Figuier cendré du Canada, Pl. Enl. 685. f. 2.

Le Figuier bleu, Buf. v. p. 304 .

Blue Flycatcher, Edw. t. 252 .

Black-throated Warbler, ArEt. Zool. ii. N $\mathrm{N}^{\circ}$ 285.-Latb. Syn. iv. p. 487. II 3 .

Habitat in Penfylvania. $-4 \frac{x}{2}$ pollices longa. - Remiges primores bafi albæ, unde macula alarum: restrices $1,2,3$, bafi apiceque albx, 4,5 , apice albæ.

$x 18$.

yaria. S. albo nigroque maculata, fafciis alarum duabus albis, cauda bifida.

Motacilla varia, Lin. Syft. i. p. 333.: 23.-Gmel. Syft. i. p. 979.

Ficedula dominicenfis varia, Brif. iii. p. 529. 60. t. 27. f. 5.-Id. 8 vo. i. p. 454 .

Figuier varié de St. Domingue, Buf. v. p. 305.

Mufcicapa è fufco et albo varia, Raii Syn. p. x 86. 36. -Sloan. Fam. p. 309. 42. t. 265 . f. 1. $-K l e i n$. Av. p. 75 . I1.

Black and white Creeper, Edrw. t. 300 .

White-poll Warbler, Arit. Zool, ii. $\mathrm{N}^{\circ}$ 293.-Lath. Syno iv.p. 488. 1 I4. 
HABITAт in Penfylvania, Famoica; migratoria. $-4 \frac{3}{4}$ pollices longa.

Vertex albus : tempora nigra ftrigis 2 albis : pectus et latera nigro maculata.

119.

ruficapilla. S. viridi-olivacea fubtus flava, collo fubtus pectoreque ftrigis fufcis, vertice rufo, reetricibus duabus exterioribus intus lutefcentibus. Motacilla ruficapilla, Gmel. Syft. i. p. 97 I.

Ficedula martinicana, Brif. iii. p. 490 . 50. t. 22. f. 4. $-I d .8$ vo. i, p. 444. Le Figuier à tête rouffe, Buf. v. p. 306.

Bloody-fide Warbler, Lath. Syn. iv. p. 489. 115.

× 20.

Hавгтат in infula Martinica. $-4 \frac{1}{4}$ pollices longa.

penfylva- S. pileo flavefcente, hypochondrïs fanguineis.

nica. Motacilla penfylvanica, Lin. Syft. i. p. 333. 19.-Gmel. Syft. i. p. 97 I. Ficedula penfilvanica icterocephalos, Brif. $A p p$. p. $105 .-I d .8$ vo. i. p. $45^{8} .78$.

Le Figuier à poitrine rouge, $B u f$. v. p. 308.

Red-throated Flycatcher, Edw. t. joI.

Bloody-fide Warbler, ArEt. Zool. ii. N $29^{8}$.

Haвitat in Penfylvania; præcedentis magnitudine.

Corpus virefcens nigro varium, fubtus albicans: lateribus fub alis peltoreque fupra fanguineis : caput fupra albicans: fub oculis macula

121. nigra oblonga.

cxerulea. S. fupra cærulea fubtus alba, alis caudaque nigris.

Motacilla cærulea, Lin. Syft. i. p. 337.43.-Gmel. Syft. i. p. 992.

Ficedula penfilvanica cinerea, Brif. Sup. p. 107.-Id. 8vo. i. p. 459. 79.

Le Figuier gris de fer, Buf. v. p. 309 .

Little blue-grey Flycatcher, Edw. t. 302.

Cærulean Warbler, ArEz. Zool. ii. N² 29. -Latb. Syn iv. p. 490. 127.

Haвiтat in Penfylvania; conftruens nidum artificiofifrmum, cylindricum, fupra apertum.

Mas a bafi roftri ad occiput fafcia nigra: palpebre recticefque latesales extimæ albæ, proximæ apice albæ.

ß. Le Figuier à tête noire de Cayenne, $P l$. Enl. 704. f. x.

Variat capite fupra oculos nigro; remigibus rectricibufque 6 intermediis nigris, reliquis albis.

S. faturate 
122 .

Cyane. S. faturate cyanea fubtus nivea, a roftro ad alas ftriga atra.

Motacilla Cyane, Pall. Reife. iii. p. 697. 18.-Gmel. Syft. i. p. 992.

Habitat in Daunrie extremis campis inter Ononem et Argunum; rarius obfervata vere; proportiones Curruce, at proxime affinis præcedenti, quæ ftriga fuperciliari atra rectricibufque lateralibus albis præcipue differt.

I23.

chryfopte- S. fufca fubtus alba, pileo maculaque alarum luteis, gula fafciaque per ra. oculos nigris.

Motacilla chryfoptera, Lin. Syft. i. p. 333. 20.-Gmel. Syft. i. p. 97 I.

Ficedula penfilvanica cinerea gutture nigro, Brif. Sup. p. 109.-Id. 8 vo. i. p. 458.77 .

Le Figuier aux ailes dorées, Buf. v. p. 3 I 1 .

Gold-winged Flycatcher, Edw. t. 299.

II 8 .

Warbler, ArEt. Zool. ii. $\mathrm{N}^{\circ} 295$ - -Lath. Syn. iv. p. 492.

Habitat autumno et vere in Penfylvania.-Magnitudo carulea.

Fileus fulvus: macula pone oculos gulaque nigra: linea alba fupra infraque oculos: teitrices alarum lutex, maculam magnam conftituentes.

I 24.

chryfoce- S. rufo-fufca fubtus alba, capite anterius colloque fubtus fulvis, tectriphala.

Motacilia chryfocephala, Gmel. Syft. i. p 971 .

Le Figuier orangé, Buf. v. p. 313.

- étranger, Pl. Enl. 58. f. 3 .

Orange-headed Warbler, Latb. Syn. iv. p. 492. I Ig:

Habitat in Guiona.-Rofrum nigrum: pedes Gavi: fafcia fupr. infraque oculos fufca.

125.

criftata. S. virefcens fupra fufca fubtus grifea, capite crifta plicatili fufca albo marginata.

Motacilla crittata, Gmel. Syft. i. p. 972.

Le Figuier huppé de Cayenne, Pl. Enl. 39r. f. 1.-Buf. v. p. 314.

Crefted Warbler, Latb. Syn.iv. p. 493. I 20.

126.

HaвıтAт in Guiane apricis.-4 pollices longa.

multico- S, nigra fubtus alba, colli pectorifque lateribus cauda a bafi ad medium lor. fafciaque alarum rufis. 
Motacilla multicolor, Gmel. Syft. i. p. 972.

Le Figuier noir, Buf. v. p. 3I4.

et jaune de Cayenne, Pl. Enl. 39r. f. 2.

Rufous and black Warbler, Latb. Syn. iv. p. 493. I 2 r.

Habitat in Cayane, inter rariores. -5 poilices longa.-Multum 127.

æquinocti- S. fufco-viridis fubtus flaveícente-alba, gutture pectoreque pallide fla-

alis. affinis Mufc. ruticilla.

Protono- S. Alava, dorfo olivaceo, uropygio cinereo, remigibus rectricibufque
tarius.

Protono- S. Alava, dorfo olivaceo, uropygio cinereo, remigibus rectricibufque
tarius.
cinereo et nigricante variis. Motacilla æquinoctialis, Gmel. Syf. i. p. 972.

Le Figuier olive de Cayenne, Pl. Enl 685. f. 1.-Buf. v. p. 315. Æquatorial Warbler, Latb. Syn. iv. p. 493. 122.

Habitat in Cayana; præcedente paulo minor.

128. Motacilla Protonotarius, Gmel. Syft. i. p. 972.

Le Figuier protonotaire, Buf. v. p. 316.

L à ventre et tête jaunes, Pl. Enl. 704. f. 2.

Prothonotary Warbler, Arct. Zool. ii. $\mathrm{N}^{\circ} 3$ ro.-Latb. Syn. iv. p. 494. 123.

HABITAT in Louifiana; magnitudine præcedentis.-Criffum album.

I29. femitorquata.

S. fufca fubtus flavo-cinerafcens, cervice infima lunula flava, rectricibus quatuor extimis intus albis.

Motacilla femitorquata, Gmel. Syft. i. p. 972.

Le Figuier à demi collier, Buf. v. p. 316 .

Half-collared Warbler, ArEt. Zool. ii. No 31 I.-Lath. Syn. iv. p. 494. $124 \circ$

HАВ1тAт in Louifiana. $-4 \frac{1}{2}$ poll. longa. $\rightarrow$ Regtrites apice acutæ.

130.

fulva.

S. fulvo-olivacea fubtus rufa, collo inferiore criffoque flavis.

Motacilla fulva, Gmel. Syft. i. p. 973 .

Le Figuier à gorge jaune, $B u f$. v. p. 317 .

Orange-bellied Warbler, ArEt. Zool. ii. $\mathrm{N}^{\circ}$ 312.-Latb. Syn。 iv. 1. 495. 125.

Habitat cum femitorquata,

S. fufco. 
I3I.

fufca. S. fufco-olivacea fubtus albo-flavefcens, collo fuhtus grifeo alboque nebulofo, rectricibus duabus extimis intus ad apicem albo maculacis.

Motacilla fufca, Gmel. Syft. i. 973.

Le Figuier brun-olive, Buf. v. p. 318.

Olive-brown Wąrbler, Arct. Zool. ii. No 313.-Lath. Syn. iv. p. 495. 126.

HaвiтAт in Louifrana.

32.

pinguis. S. grifeo-olivacea fubtus albida, macula verticis uropygioque flavis, rectricibus quatuor extimis intus albo maculatis.

Motacilla pinguis, Gmel. Syft. i. p. 973 .

Le Figuier graftet, Buf. v. p. 3 r 9 .

Graffet Warbler, Arbt. Zool. ii. N`314.-Lath. Syn. iv. p. 496.127.

Habitat in Louifiana.

133.

cana.

134.

calidris. S. fufco-virefcens fubtus fulva, linea oculari fubocularique nigra, rectricibus apice luteis.

Motacilla calidris, Lin. Syft. i. p. 329. 2.-Gmel. Syft. i. p. 950.

Ficedula jamaicenfis major, Brif. Sup. p. Ior.-Id. 8vo. i. p. 457. 75.

Icterus minor nidum fufpendens, Raii Syn. p. 184. 27 ?-Sloan. Fam. ii. p. 299 ?

American Nightingale, Edro. t. I21. f. 2.

Hang neft Warbler, Lath. Syn. iv. p. 497. 129.

Habitat in Famaica; magnitudine Rubicilla.-Nidum penfilem ex. Tillondfia ftruit.

Tempora obfcure aurantia; tectrices alarum margine flavicantes.

135.

bonarien- S. nigra fubtus ferruginea, gula loris abdomine medio rectricibufque

fis. extimis apice albis.

Motacilla 
544 AVES PASSERES, Sylvia.

Motacilla bonarienfis, Gmel. Syft. i. p. 95 r.

Le Demi-fin noir et roux, Buf.v. p. 328.

White-chinned Warbler, Latb. Syn. iv. p. 497. 130.

r 36.

Habitat in Bonaria. $-5 \frac{2}{3}$ pollices longa.

Palma- S. fufca fubtus albo-flavefcens, uropygio olivaceo, remigibus rectrici-

rum.

137.

bananivo- S. grifeo-nigricans fubtus uropygioque flavefcente, fafcia per oculos

ra. bufque fufcis.

Motacilla Palmarum, Gmel. Syft. i. p. $95 \mathrm{r}$.

Le Bimbelé, ou faufe Linotte, Buf. v. p. 330.

Palm Warbler, Lath. Syn. iv. p. 498. 13 r.

Habitat in infula Dominicenfi. -5 pollices longa.-Vietitat feminibus et fructibus; inter palmas nidificans.

138. nigra, fuperciliis macula alarum reEtricibufque apice albis.

Motacilla bananivora, Gmel. Syft. i. p. 95 1.

Le Bananifte, Buf. v. p. 332 .

Banana Warbler, Latb. Syn. iv. p. 498. 132.

HaBitat in infule Dominicenfis incultis. $-3 \frac{3}{7}$ pollices longa. $-\mathrm{Nidi-}$ ficat in falicibus. - Fructibus Mufa potifimum victitat.

vermivora. S. viridi-olivacea fubtus albida, capite collo fubtus pectoreque aurantiis, fafcia per oculos arcuque fupra nigris, fuperciliis albis.

Motacilla vermivora, Gmel. Syft. i. p. 95 I.

Ficedula penfilvanica, Brif. Sup. p. 102.-Id. 8vo. i. p. 457. 76.

Le Demifin mangeur de vers, Buf. v. p 325.

Worm-eater, Arסt. Z00l, ii. $\mathrm{N}^{\circ} 300,-E d w$. t. 305,-Lath. Syn. iv. p. 499. 133.

Habitat in Penfylvania.-Magnitudo modularis; migratoria.

I39. campeftris. S. grifea, capite virefcente-cinereo, rectricibus concoloribus, abdomine albido.

Motacilla campeftris, Lin. Syft. i. p. 329. 5.-Gmel. Syft. i. p. 953.

Curruca fepiaria jamaicenfis, Brif. App. p. 100.-Id. 8vo. i. p. 456.74 .

L'Habit-uni, Buf. v. p. 336 .

American Hedge-Sparrow, Edw. t. 122. f. I.

Simple Warbler, Latb. Syn. iv. p. 500.134.

Habitat in Famaica; magnitudine pracedentis. 
140.

A V E S P A S S R E S. Sylvia.

macroura. S. fufca fubtus albo-flavefcens maculis nigricantibus, fuperciliis albis, cauda cuneiformi elongata.

Motacilla macroura, Gmel. Syft. i. p. 953.

La petite Fauvette tachetée du Cap de B. Efp. Buf. v. p. ז6r.-Pl. Enl. 752 . f. 2.

Great-tailed Warbler, Lath. Syn. iv. p. 500. 135 .

Habitat ad Caput Bone Spei.-6 pollices longa.

I4I.

longicau- S. olivaceo-virefcens, vertice rufefcente, remigibus fufcis, cauda cuda. neiformi elongata.

Motacilla longicauda, Gmel. Syft. i. p. 954.

Le petit Figuier à longue queue de la Chine, Son. Voy. Ind. ii. p. 206.

Long-tailed Warbler, Latb. Syn. iv. p. 501. 136.

Habitat in Cbina; domeftica et familiaris avis.

I42.

cyanea. S. nigro-cyanea fubtus alba, capite nigro-fericeo tumido, fincipite genis lunulaque cervicis cæruleo-nitidis, fafcia per oculos nigra.

Motacilla cyanea, Ellis's Norr. p. 22.-Cook's laft Voy. i. p. 109.Gmel. Syft. i. p. 99 r.

Superb Warbler, Pbil. Bot. Bay. t. p. 157. (Mas.)-Id. t. p. I59. (Fem.)-Latb. Syn. iv. p. 501 . 137. t. 53 .

Habitat in nove Hollandie variis partibus. $-5 \frac{3}{4}$ pollices longa.

Cauda cuneiformis elongata, quam frequenter gerit erectam. Variat macula cervicis abfque lunula.

Femina fupra fimpliciter fufca, fubtus alba; circa oculos cærulea.

ß. S. grifeo-nigricans, capite gula cerviceque cyaneis, tectricibus alarum fufcis, remigibus rectricibufque nigris.

Gobe-mouche à tête bleue de Luçon, Son. Voy. p. 58. t. 27. f. x.

Habitat in Manilla infula.

143. cayana.

S. cærulea, capiftro humeris alis caudaque nigris.

Motacilla cayana, Lin. Syft. i. p. 336. 40.-Gmel. Syft. i. p. 990.

Sylvia cayanenfis carulea, Brif. iii. p. 534.72 . t. 28 . f. 1.-Id. 8 vo. i. p. 455 .

Elotototl quarta, Reii Syn. p. 170? 
546 A V E S P A S S E R E S. Sylvia.

Le Pitpit bleu de Cayenne, Buf. v. p. 339.-Pl. Enl. 66g. f. 2.

Cayenne Warbler, Latb. Syn. iv. p. 502.138.

Habitat in Cayana. $-4^{\frac{3}{4}}$ pollices longa.-Frons et tempora nigra.

ß. Blue Manakin, Edw. t. 263.-Latb. Syn. iv. p. 503. A.

Variat capite cæruleo, gula rigra.

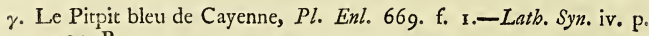
403. B.

Differt a præcedentibus capite toto cæruleo.

144. cyanocephala.

145. lineata.

S. viridis, capite tectricibufque alarum cæruleis, gula grifeo-cærulefcente, remigibus fufcis.

Motacilla cyanocephala, Gmel. Syfl. i. p. 990.

Sylvia viridis, Brif. iii. p. 531. 70. t. 28. f. 4. - Id. 8vo. i. p. 455.

Pitpit vert, Buf. v. p. 338 .

Blue-headed Warbler, Latb. Syn. iv. p. 503. 139.

Habitat in Cayana. -4 ? pollices longa.

S. corpore fubtus maculaque verticis cæruleis, fronte vitta fuperciliari lateribufque colli cæruleo-nitidis, fafcia pectoris abdominifque alba.

Motacilla lineata, Gmel. Syft. i. p. 990.

Le Pitpit à coiffe bleue, Buf. v. p. 342.

Blue-ftriped Warbler, Latb. Syn. iv. p. 504. 140.

Habitat cum precedente.

146.

Yelia. S. nigra viridi-cæruleo varia fubtus rufa, collo fubtus violaceo, uropy-
Yel gio viridi-aureo.

Motacilla velia, Lin. Syft. i. p. 336. 41.-Gmel. Syf. i. p. 99 I.

Lufcinia ex ceruleo et rubro varia, Klein. Av. p. 75 . I 5 .

Le Pitpit varié, Buf. v. p. 34I.

Pitpit bleu de Surinam, Pl. Enl. 66g. f. 3.

Red-bellied Warbler, Latb. Syn. iv. p. 504. 141.

Habitat in Surinamo, Guiona, Cayana; magnitudine Hippolaidis.

B. S. fronte 
$\beta$. S. fronte uropygioque aureis, corpore fubtus cærulefcente, ventre imo caftaneo.

Sylvia furinamenfis cærulea, Brij. iii. p. 536. 73. $-I d .8$ vo. i. p. 456.

$\gamma$. S. cærulea, dorfo imo abdomineque rufis.

Red-bellied Blue-bird, Edw. t. 22.-Bancr. Guian. p. $x 82$ ?

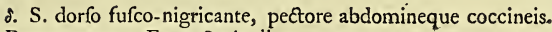

Rouge-gorge, Ferm. Surin. ii. p. 194.

147.

Guira. S. viridis fubtus uropygioque lutea, genis gulaque nigris linea lutea cinctis.

Motacilla Guira, Lin. Syft. i. p. 335. 36.-Gmel. Syft. i. p. 988.

Tanagra nigricollis, Gmel. Syjt. i. p. 894 .

Sylvia brafilienfis viridis, Brif. iii. p. 533.7 I. $-I d$. 8 vo. i. p. 455 .

Guira guacu beraba, Raii Syn. p. 83. ro.-Will. p. 173. t. 41.-Id. (Angl.) p. 239. t. 41.-Buf. v. p. 342.-Edre. t. 351. f. r.

Tangara à gorge noire, Buf. iv. p. 283 . - Pl. Enl. 720 . f. x.

Guira Warbler, Arct. Zool. ii. No 316.-Latb. Syn. iv. p. 505. 142.

Black-throated Tanager, Lath. Syn. iii. p. 237. 33.

Haвiтat in Brafilia; magnitudine Carduelis.

Femina vertice olivaceo maculis nigris; gula juguloque nigris : pettus 148. et abdomen flava maculis rubris. Ovum album maculis nigris.

Troglody- S. grifea, fuperciliis albidis, alis nigro cinereoque undulatis.

tes. Motacilla Troglodytes, Lin. Syft. i. p. 337. 46. - Faun. Suec. $\mathrm{N}^{\circ}$ 26r. Scop. Ann. i. No 239.-Brun. No 284-Muller, No 279.-Gmel. Syft. i. p. 993-Kram. El. p. 378. 20.-Georgi, p. 175.-Frifcb. t. $24 .-$ Klein. Av. p. 76.1 . - Id. Stem. p. 14. t. I 6. f. 4. a. b.-Id. Ov. p. 25 . t. 10. f. 1 3.-Foun. Arag. p. 89.-Sepp. Vog. t. p. r 10. -Borowes. Nat. iii. p. 190. 9.-Raii Syn. p: 80. A. 11-Will. p. 164. t. 42.

Regulus, Brif. iii. p. $425.24 .-I d$. 8 vo. i. p. 428 .

Troglodyte, Roitelet, Buf. v. p. 352. t. 16. f. 1. $-P l$. Enl. 651 . f. 2. - Hijt. Prov. i. p. 5 io.

Reattino, Olin. uc. t. p. 6.

Ii Lui, Cett. uc. Sard. p. 225 .

Zaun Kœnig, Gunth. Neft. u. Ey. p. 28. t. 2.

Wren, Br. Zool. i. $\mathrm{N}^{\circ}{ }_{1}$ 54.-Id. fol. IO2. t. $42 .-A r E$. Zool. ii. $\mathrm{N}^{\circ} 322$. $4 \mathrm{~A}_{2}$

$-A l b$. 
-Alb. i. t. 53. B.-Id. Song Birds, t. p. 64.-Will. (Angl.) p. 229. t. 42.-RuJ. Alep. p. 7 1.-Hayes Br. Birds, t. 38.-Lath. Syn. iv. p. so6. 143 .

Ha Bitat in Europa, Afia, forte in America.

Pufilla volucris; penetrabile frigus nivefque tolerat, et cantu lato pranuntiat. Caudam erectam plerumque gerit hæc avis. Omnibus fatis nota.-Nidum ovalem ex lichene et mufcis conftruit artificiofum. -Ova 10-18 albida maculis rubefcentibus.

149.

platenfis. S. fupra rufo nigroque varia fubtus alba, remigibus rectricibufque fafciatis.

Roitelet de Buenos-Ayres, Buf. v. p. 36r.-Pl. Enl. 730. 2.

Haвiт at in Bonaria; præcedentis magnitudine, at cauda longiore.

Corpus fupra rufo albo nigroque maculato-varium: caput et collum fuperius pennis longitudinaliter ftriatis: corpus fubtus a gula album: bypocbondria fubferruginea.

150.

ludovicia- S. rufo-fufca, fuperciliis genis fubtufque flavefcens, remigibus caudaque

na. fafciatis.

Roitelet de la Louifiane, Pl. Enl. 730. f. 1.-Buf. v. p. 36 r.

HABITAT in Louifiana; præcedentibus tertia parte major.

Fafcia fupra-ocularis lateribus colli defcendit: genæ fufco nebulofæ: remiges et cauda nigro rufoque fafciata. Tres ultimæ aves multum affines; an diftinctæ fpecies ?

$15 \mathrm{x}$.

furva. S. fufca fubtus pallidior, dorfo alis caudaque nigricante fafciatis.

Motacilla furva, Gmel. Syft. i. p. 994.

Le Roitelet de Surinam, Ferm. Surin. ii. p. 201.

Brown Warbler, Brown. Ill. p. 68. t. 1 8.--Latb. Syn. iv. p. 508. 144.

HaBitat in Surinaino; egregie cantans. $-4 \frac{1}{2}$ pollices longa.

152.

Regulus. S. virefcens, remigibus fecundariis exteriori margine flavis, medio albis vertice luteo.

Motacilla Regulus, Lin. Syft. i. p. 338. 48.-Faun. Suec. $\mathrm{N}^{\circ} 262 .-$

Gmel. Syft. i. p. 995.-Scop. Ann. i. N $\mathrm{N}^{\circ} 240 .-B r u n . \mathrm{N}^{\circ} 285 .-$ Muller $\mathrm{N}^{\circ}$ 280.-Kram. El. p. 378.21.-Georgi, p. 175.-Frifch. t. 24.-Faun. Arag. p. 89.-Borows. Nat. iii. p. 189. 8. t. 72 . B. Regulus criftatus, Raii Syn. p. 79. A. 9.-Will. p. 163. t. 42.-Brif. 
iii. p. 579. 17.-Id. 8 vo. i. p. 47 2.-Klein. Av. p. 76. 3.-Id. Stem. p. 14. t. I6. f. 5. a-c. -Id. t. 28. f. 2.-Pbil. Tranf. xxviii. p. 170. Roitelet, Poul, Souci, Buf. v. p. 363. t. 16. f. 2.-Pl. Enl. 651. 3.Hijt. Prov. i. p. 509.

Fior Rancio, Olin. uc. t. 6.

Scricciolo, Cet. uc. Sard. p. 225.

Gold-Vögelein, Wirfing. Vog. t. 14. $M$. et $F$ :

Gold-crefted Wren, Br. Zool. No $153 .-I d$. fol. Io1. t. S. f. 3.-ArEt.

Zool. ii. No 321. -Id. Sup. p. 64.-Will. (Angl.) p. 227.-Edw.

t. 254. 1.-Alb. i. t. 53.-Cat.Car. App. 36. 37.-Hayes Br. Birds,

t. 38.-Latb. Syn. iv. p. 508. 445 .

Habitat per omnem orbem cognitum.- $3 \frac{1}{2}$ pollices longa.-In Anglia frequenter occurrit; in fummitatibus maximarum arborum, præcipue quercuum, plerumque verfatur. In crifta aliquid nigri cum aurantio colore mixtum.

Feminæ vertex capitis flavus. Ovum album, maculis minutis obfcuris rubris.

153.

elata. S. criftata virefcens fubtús cinereo-albida, occipite criffoque pallide flavo, tectricibus alarum margine rectricibufque lateralibus apice albis.

Le Roitelet mefange, Buf. v. p. 375 .

Mefange huppée de Cayenne, Pl. Enl. 708 2.-Lath. Syn. iv. p. 510.

Habitat in Cayane uliginofis, inter fruticeta; Regulo minor.

Roftrum brevius: verticis pennæ elongatæ poftice flavæ, alias cum capite fufcæ: fafcix tedtricum 2 pallidæ: remiges et redtrices nigræ; 2 intermediæ totæ, reliquæ apice albæ.

154.

Calendula. S. cinereo-virens, linea verticali rubini colore, abdomine alifque fubtus flavefcentibus.

Motacilla Calendula, Lin. Syft. i. p. 337. 47.-Gmel. Syff. i. p. 994.

Calendula penfylvanica, Brif. iii. p. $5^{84}$. 18.-Id. $8 \mathrm{vo}$. i. p. 473 .

Le Roitelet rubis, Buf. v. p. 373 .

Ruby-crowned Wren, ArEt. Zool. ii. No 320.-Edw. t. 254. f. 2.Latb. Syn. iv. p. 5 I I. 146.

HaBITAT in America Septentrionali.- $4 \frac{x}{4}$ fere pollices longa.

Remiges et redtrices fufcefcentes margine exteriore pallefcente. Variat nucba lunula coccinea.

Femina a mare difcrepat capitis vertice nullo modo rubro tincto.

S. cinereo- 
Trochilus. S. cinereo-virens, alis fubtus tectricibufque flavefcentibus, fuperciliis luteis.

Motacilla Trochilus, Lin. Syft. i. p. 338. 49.-Faun. Suec. No 264.Gmel. Syft. i. p. 995.-Scop. Ann. i. $\mathrm{N}^{\circ} 238 .-$ Brun. $\mathrm{N}^{\circ} 286 .-$ Muller, No $281 .-K$ ram. El. p. 378. 22.-Klein. Av. p. 76. 2.Frifcb. t. 24. f. 2.-Faun. Arag. p. 89.-Borow/k. Nat. iii. p. IgI. 10.

Motacilla hifpanica, Hafjelq. It. 287. 52.-Id. Voy. p. 206.5 I. Afilus, Brif. iii. p. $479.45 .-I d .8$ vo. i. p. 441.-Raii. Syn. p. 80. A. 10.-Will. p. 164.-Id. (Angl.) p. 228.

Le Pouillot, Buf. v. p. 344.-Pl. Enl. p. 65 1. f. 1.-Hift. Prov. i. p. 5 10.

Green Wren, Alb. ii. t. 86.6.

Yellow Wren, Br. Zool. i. N॰ 15 1.-Id. fol. 1or. t. S. f. 2. S. 2. f. 1. -Arct. Zool. ii. N $\mathrm{N}^{\circ}$ 1 9.-Hift. Selb. pp. 28. 55.-Hayes Br. Birds, t. 38. - Latk. Syn. iv. p. 512.147.

Habitat in Europa, America; frequens in Anglia. $-4 \frac{x}{2}$ poll. long. Ovum albido-purpurafcens maculis obfcuris purpureo-rubris.

ß. Motacilla acredula, Lin. Syft. i. p. 338. 49. $\beta$.

Ficedula carolinenfis, Brif. iii. p. $486.48 .-I d$. 8 vo. i. p. $443 .-K l e i n$. Av. p. 86. I I.

Enanthe fufco-lutea minor, Raii Syn. p. 186. 39.-Sloan. Fam. ii. p. 310.46.

Le Figuier brun et jaune, Buf. v. p. 295.

Yellow Titmoufe, Cat. Car. i. t. 63 .

Wren, Edw. t. 278 . f. 2.

Scotch Wren, Br. Zool. i. N ${ }^{\circ}$ 152.-ArEz. Zool. ii. p. 420. N.-Id. Sup. p. 64.-Latb. Syn. iv. p. 513.

Habitat cum priore, cujus mera varietas; forte junior avis.

Corpus fupra fufco-virens, fubtus flavum; gula peetoreque ex albo flavefcentibus : ala fubtus fulphureæ, tectricibus non remigibus.

$\gamma$. S. minor fupra nigricante varia fubtus rufo-alba, gula fuperciliifque albis.

ઈ. Afilus major, Brif. iii. p. 482 . A. $-I d$. 8 vo. i. p. 442 .

Regulus non criftatus major, Will. p. 164.-Id. (Angl.) p. 228.

Afilo per omnia exacte fimilis eft, fed duplo major. 
156.

A V E S P A S S E R E S. Sylvia.

mediterra- S. fufco-virefcens fubtus ferruginea, collo fubtus pectoreque fulvis.

nea. Motacilla afilus, Gmel. Syjt. i. p. 996. 168. $\delta$.

Motacilla corpore ex fufco viridefcente, pectore ferrugineo, Haffelq. Voy. 286. 51 .

HaBITAт in Hifpania.-Roftri mandibula fuperior apice parum incurvata.

157.

reftiva.

S. viridi-olivacea fubtus flava, collo fubtus pectoreque maculis rubefcentibus, rectricibus lateralibus intus luteis.

Motacilla æeftiva, Gmel. Syft. i. p. $99^{6}$.

Ficedula canadenfis, Brif. iii. p. 492.5 1. t. 26 . f. 3. $-I d .8$ vo. i. p. 444 . Le Figuier tacheté, Buf. v. p. 28 5.-Pl. Enl. 58. f. 2.

Yellow-poll Warbler, Arct. Zool. ii. N 292.-Latb. Syn. iv. p. 515. -Id. Sup. p. 183 .

HaвIтAт in Guiana; æeftate in Canada fylvis inter faliceta; inquieta. $-4 \frac{\pi}{2}$ pollices longa. - Nidus ex mufcis, gramine, crinibus, et plumis intertextis. Ova 3-5 alba maculis ferrugineis.

Irides cæruleæ: collum et pectus maculis longitudinalibus rubefcen tibus varia. Vox Linarice, debilis.

$15^{8}$.

caroliner. S. viridi-olivacea fubtus flavefcens, remigibus caudaque fufcis, rectrici-

fis. bus flavo marginatis.

Le Figuier de la Caroline, Buf. v. p. 285.-Pl. Enl. 58. f. x.

Olive Warbler, Arct. Zool. ii. N $\mathrm{N}^{\circ} 307$.

Yellow Poll, Lath. Syn. iv. p. 51 5. 148 . fpec. 2.-Id. Sup. p. 183.

Habitat ad fretum Hudfonis; magnitudine aftive.

159.

futoria. S. tota flava.

Motacilla futoria, Gmel. Syft. i. p. 997.

Tati, ou Oifeau-mouche, $W$. Scbout. Voy. Ind. ii。 p. 5 I 3 . to f. xv.

Motacilla futoria, Zool. Ind. p. I7: t. 8.

Tailor Warbler, Latb. Syn. iv. p. 515. I49.-Ind. Zool. t. 8.

Habstat in India. Tres uncias longa eft hæc avicula; nec ultra nonaginta granorum habet pondus. Nidulum pennis, plumulis, et pappis plantarum inter folia duo fimul affuta, fternit. Ova funt candida, nec formicarum ova excedunt magnitudine. 

160.
552
A V.E S
PAS SERES.
Sylvia.

gularis. S. fupra ferruginea fubtus alba, gula alis caudaque nigris.

Motacilla gularis, 7. F. Miller. t. 30. C.-Gmel. Syft. i. p. 997.

161.

HaвiтAт in America aufrali.

tfchecan- S. fupra nigricans fubtus ferruginea, capite atro, nucha albicante, tortfchia.

162.

Kamtf- S. fufco-olivacea, abdomine medio albo, fronte genis gulaque pallide chatkenfis. ferrugineis, roitro elongato.

Motacilla caintfchatkenfis, Gmel. Syft. i. p. 986.

Long-billed Warbler, ArEt. Zool. ii. p. 420. O.

163.

littorea. S. fupra obfcure viridis fubtus ochroleuca, remigibus rectricibufque nigricantibus.

Moracilla littorea, Gmel. Syft. i. p. 977.-S. G. Gmel. It. iii. p. 98. t. r. f. 1 .

164.

longirof- S. cinerea fubtus atra, roftro longo.

Habitat ad littus Maris Cajpii, vermibus victitans; canora.

tris.

165.

Motacilla longiroftris, Gmel. Syft. i. p. 977.-S. G. Gmel. It. iii. 100. t. 19. f. 2 ,

Habitat in montibus finitimis Maris Cajpii.

ochrura. S. capite cinereo, cervice et dorfo antice atro, jugulo et pectore fplendide nigris, abdomine flavo.

Motacilla ochrura, Gmel. Syft. i. p. 978.-S. G. Gmel. It. iv. p. 178.Pall. N. Nord. Beytr. iv. p. 56 .

HABITAT in alpibus Perfie funamificis; Lufcinia magnitudine.

Roftrum fufcum: palpebre fubnudx: vertex et cervix ex cinereo fufcefcens: uropygium et criffum ex cinereo alboque varium: pedes nigricantes.

$x 66$.

funamifi- S. ex cinereo rufefcens, mento gulaque nigris, pectore et abdomine $c a$. rufefcentibus, pennarum apice albo, criffo niveo, rectricibus intermediis fufcis, lateralibus fulvis.

Motacilla 
Motacilla funamifica, Gmel. Syft. i. p. 978.-S. G. Gmel. It. iv. p. 18 r. 182.-Pall. N. Nord. Beytr. iv. p. 60.

HABITAT in alpium Perfice funamificarum rupeftribus; fuecica magnitudine.

Linea alba a bafi roftri fupra oculos ad nucham ducta : remiges tec167. tricefque alarum margine exteriore et apice albæ.

Awatcha. S. fufca fubtus alba, pectore nigro maculato, rectricibus lateralibus bafi fulvis.

Motacilla Awatcha, Gmel. Syft. i. p. 986.

Awatcha Warbler, ArEZ. Zool. ii. p. 422. T.-Lath. Syn. Sup. p. 184.

Habitat in Kamtfchatka. - Inter roftrum et oculum linea obliqua

168. alba.

canefcens. S. fufco-canefcens fubtus alba, capite nigro, fronte albo ftriata, pectore criffoque ftriis nigris, macula alarum rectricum bafi marginibufque fulvis.

Van Diemen's Warbler, Lath. Syn. Sup.p. I87.

HaвtтAт in terra Van Diemen $N$. Hollandice- $6 \frac{x}{2}$ pollices longa.

Cauda corpore brevior, fubcuneata, reEtricibus margine exteriore bafi

169. ad medium fubfulvis, exterioribus 2 apice intus macula alba.

æquinoctialis.

170.

nigricollis. S. fubcriftata fupra pallide grifea fubtus incarnata, pileo cervice remigibus reetricibufque nigris.

Black-necked Warbler, Latb. Syn. Sup. p. 187.

foletis.

Equinoctial Warbler, Latb. Syn. Sup. p. 187.

Habiтat in infula Cbrifi Natalis; magnitudine fere Fr. domefice ; debili fed haud ingrata voce cantans.

HaBITAT in India.-Roftrum pede/que flavi.

171.

plumbea. S. plumbea fubtus cinerea, remigibus rectricibufque obfcuris.

Plumbeous Warbler, Lath. Syn. Sup. p. 188.

Magnitudo parva. 
I72. 554 A V E S P A S E R E S. Pipra.

cambaien- S. fufco-nigricans fubtus nigra nitida, abdomine imo crifoque rufo-

fis. ferrugineis, tectricibus alarum albis.

HaBıтAт in India regno Guzurat; magnitudine Lufcinie.-6 poll. longa. - Roftrum nig!um: cauda 3 pollices longa apice integra: pedes fufci. Muf. Brit.

173.

guzurata. S. virefcens fubtus alba, vertice fpadiceo, remigibus caudaque fufcis.

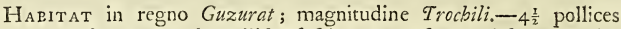
longa.-Rofirum et pedes pallide fufci: corpus fupra obfcure viridis: remiges et rectrices fufca margine viridi : couda rotundata. Muf. Brit.

174 .

afiatica. S. fufca fubtus flavicans, capite colloque nigris, loris gulaque albis, cauda elongata.

HABIтAт in regno Guzurat; magnitudine Lufcinic.

Roftrum nigricans bafis fetulis raris: caput et collum nigrum: lora et gula alba: corpus fupra fufcum, fubtus flavefcens, pectore maculis aliquot albis : cauda $3^{\frac{3}{4}}$ pollices longa, cuneiformis, rectricibus exterioribus a medio ad apicem pallidis. Mufcicape affinis. Muf. Brit.

ß. S. fufca, fronte fuperciliis corporeque fubtus albis, rectricibus lateralibus dimidiato-albis.

Habitat cum priore.

\section{G ENUS XLIV. PI P R A.}

Roftrum breve, validum, bafi fubtrigonum, apice incurvum.

Cauda brevis.

Pedes grefforii.

I. P. crifta erecta margine purpurea, corpore croceo, tectricibus rectricum truncatis.

Pipra Rupicola, Lin. Syft. i. p. 338. 1.-Gmel. Syft. i. p. 998.-Brif. iv. p. 437 . I. t. 34 . f, I. $-I d$. 8 vo. ii, p. I66.-Bororofk. Nat. iii. p. $163 . t_{0} 66$.

Upupa 
Upupa americana lutea, Ger. Orn. ii. p. 64. t. 206.

Coq-de-roche, Buf. iv. p. 432. t. 20.-Pl. Enl. 39. (mas.) -747. (fem.) - Vofmaer monagr. t. 6.

Felfenhahn, Walch. Naturf. xi. p. I. t. 1,-xiii. p. I1,-xvii. p. 12.

Hoopoe Hen, Edw. t. 264.

Crefted Manakin, Gen. Birds, p. 64. t. ro.

Rock Manakin, Latb. Syn. iv. p. 518. 1.

HABIT at in Surinamo, Guiana; magnitudine Turluris. -1 I-1 2 pollices longa.

Roftrum et pedes flavi : crifta rotundata: tectrices caude elongatæ, truncata : caude breviffima. Funiores aves primo anno grifex.

Femina adultior fufca. Nidum in abditiffimis rupium receffibus conftruit, et ova 2 rotunda alba columbinis æqualia parit.

2.

peruviana. P. corpore croceo-rubro, tectricibus alarum majoribus cinereis, remigibus caudaque nigris, tectricibus rectricum non truncatis.

Le Coq-de-roche de Perou, Buf. iv. p. 437.-Pl.Enl. 745.

Peruvian Manakin, Latb. Syn.iv. p. 5 I g. 1. A.

Habitat in Peru; magnitudine rupicole, at cauda multo longiore, nec apice truncata.

Roftrum et pedes flavi : crifta minus fpeciofa, pennis laxis retro fpectantibus : color criffe et corporis fulvo-ruber: ale et cauda nigra, remigibus fecundariis cum uropygio rubris.

3.

pareola. P. crifta fanguinea, corpore nigro, dorfo cæruleo.

Pipra pareola, Lin. Syjt. i. p. 339. 2.-Gmel. Syft. i. p. 999.-Borowfk. Nat. iii. p. 162 .

Manacus criftatus niger, Brif. iv. p. 459 . 10. t. 35 . f. I. $-I d$. 8 vo. ii, p. 172.

Tije-guacu Marcgr. Will. p. 159.-Id. (Angl.) p. 218.

Le Tije, ou grand Manakin, Buf. iv. p. 4I I, t. 19. f. 2.

Le Manakin noir huppé, Pl. Enl. 687. f. 2.

verd huppé de Cayenne, Pl. Enl. 303. 2. (junior.)
Blue-backed Manakin, Edw. t. 26r. f. 1. -Latb. Syn. iv. p. 520. 2.

H Aвітат in Brafilia, Coyona, Cuba. $-4 \frac{\pi}{2}$ pollices longa.

Roftrum nigricans: irides cæruleæ: pedes rubri: crifta plicatilis poftice concava.

Femina olivacea, crifta fanguinea, ut in mare. funior avis viridis.

$$
{ }_{4} \mathrm{~B}_{2} \quad \mathrm{P} \text {. aterrima, }
$$


4.

fuperba. P. aterrima, verticis mediis plumis longiufculis ex flammeo-rubris, dorfi inter alas area lunata dilute cærulea, remigibus primoribus fufcefcentibus.

Manacus fuperbus, Pall. Spic. i. p. 8. t. 3. f. I.

Pipra fuperba, Gmel. Syft. i. p. 999.

Aureola major; pareola multum affinis.

Roftrum nigrum: pedes lutei : plumæ frontis nares obtegentes : pili ad nares et oris angulos inque gula crebri : remiges primores acutæ: cauda brevis, reftricibus io conftans.

5.

ferena. P. nigra, fronte alba, uropygio cyaneo, ventre fulvo.

Pipra ferena, Lin. Syjt. i. p. 340. I r.-Gmel. Syft. i. p. 1002.-AEt. Petr. xi. p. 433 . t. 15. f. 5 .

Manacus alba fronte, Brif. iv. p. 457.936 . f. 2. $-I d .8$ vo. ii. p. 172.

Le Manakin varié, Buf. iv. p. 423.t. I gr.f. r.

Manakin à front blanc de Cayenne, Pl. Enl. 324. f. I.

White-fronted Manakin, Latb. Syn. iv. p. 52 I. 3.

Haвiтат in Cayana et Guiana, inter rariores. $-3 \frac{x}{2}$ pollices longa.

6.

Manacus. P. nigra fubtus alba, macula cervicis alarumque alba.

Pipra Manacus, Lin. Syft. i. p. 340. 12.-Gmel. Syft. i. p. 1002.-Brif. iv. p. 442. 1.-Id. 8 vo, ii.p. I68.

Le Caffe-noifette, Buf. iv. p. 4i3.

Manakin du Brefil, Pl. Enl. 302. f. I.

Black-capped Manakin, Edw. t. 260. f. 1.-Latb. Syn. iv. p. 52 1. 4.

Habitat in Guiane fylvis.-Pedes fulvi.

P. Manakin à tête noire de Cayenne, $P l$. Enl. 303. f. I.

Cum præcedente omnibus convenit, at macula alarum nulla.

7.

crythroce- P. nigra, vertice armillifque fulvis.

phala. Pipra erythrocephala, Lin. Syft. i. p. 339. 6.-Gmel. Syft. i. p. roor. Parus erythrocephalus, Scop. Ann. i. N $\mathrm{N}^{\circ} 248$.

Manacus aurocapillus, Brif. iv. p. 448 . 4. t. 34. f. 2.-Id. 8vo. ii. p. 169.-Klein. Av. p. 86. I3.

Avicula nigra, capite e luteo croceo, Pet. Gaz. t. 46. f. I3. Le Manakin à tête d'or, Buf. iv. p. 418.-Pl. Enl. 34. f. I I. Gold-headed black Titmoufe, Edw. t. 2 I 
Gold-headed Manakin, Gen. of Birds, p. 64. t. Iо. f. 2.-Lath. Syn. iv. p. 522.5 .

Habitat in Brafilia. $-3^{\frac{T}{4}}$ pollices longa.-Pedes incarnati.

ß. P. nigra, vertice armillifque rubris.

Pipra erythrocephala, Lin. Syft. i. p. 339. 6. $\beta$.

Manacus rubro-capillus, Brif. iv. p. $450.5 .-I d .8$ vo. ii. p. 170.

Avicula mexicana altera, $S e b$. i. p. 96. t. 60. f. 7. 8.-Klein. Av. p. 94. 7.

Tangaræ altera fpecies, Raii Syn. p. 84. 14.-Will. p. 177.

Second kind of Tangara, Will. (Angl.) p. 244.-Lath. Syn. iv. p. 523. 5. A.

8.

Habitat cum pracedente. $-P$ edes flavefcentes.

Ieucocilla. P. atra, pileo albo.

Pipra leucocilla, Lin. Syf. i. p. 340. 9.-Muf. Adolph. Fr. ii. p. 33.*. - Borowfs. Nat. iii. p. 162.3.

Parus Pipra, Sy $f$. Nat. x. p. 1 90.

Pipra leucocapilla, Gmel. Syjt. i. p. ICO2.

Manacus albo-capillus, Brif. iv. p. 446 . 3. t. 35 . f. 2. -1 d. 8 vo. ii. p. 169.-Klein. Av. p. 90. 17.-Seba, ii. p. 102. t. 96. f. 5 .

Le Manakin à tête blanche, Buf. iv. p. 418.-Pl. Enl. 34. f. 2 .

White-capped Manakin, Edw. t. 260.-Latb. Syn. iv. p. 523.6.

Habitat in Brafilia, Surinamo; in arundinetis egregie cantillans.

Variat armillis rubris.

9.

leucoce- P. nigra, capite albo.

phala, Pipra leucocephala, Lin. Syft. i. p. 340. 8.-Muf. Adolph. ii. p. 33.*. Gmel. Syft. i. p. 1001.

White-headed Manakin, Lath. Syn. iv. p. 524. 7.

HABITAT in Surinamo; magnitudine Motacille, fed roftro validiore, bafi fetis obfito.

Io.

gutturalis. P. nigra, gutture albo.

Pipra gutturalis, Lin. Syft. i. p. 340. s0.-Gmel. Syft. i. p. 1002.

Manacus gutture albo, Brif. iv. p. 444. 2. t. $3^{6}$. f. r. $-I d .8$ vo. ii. p. 168.

Le Manakin à gorge blanche, Buf. iv. p. 42 I. $-P l$. Enl. 324. f. I.

White-throated Manakin, Latb. Syn. iv. P. 524. 8.

HaBITAT 
$55^{8}$ AVES PASSERES. Pipra.

Habitat in Ainerice calidioribus. $-3 \frac{x}{2}$ pollices longa. Remigum intermediarum nonnullæ intus albæ: pedes rubri.

I I. aureola. P. nigra, capite peftoreque coccineis, remigibus antrorfum macula alba.

Pipra aureola, Lin. Syft. i. p. 339. 7.-Muf. Ad. Fr, ii. p. 32. *-Gmel. Syft. i. p. $100 \mathrm{r}$.

Parus aureola, Syjt. Nat. x. p. г 1 r.

Manacus ruber, Brif. iv. p. 452 2. 6. t. 34. f. 3. $-I d$. 8 vo. ii. p. 170.

Avicula, forte furinamenfis, nigro rubroque mixta, Pet. Gaz.t. 46. f. I 2.

Le Manakin rouge, Buf. iv. p. 415.

Manakin rouge, Pl. Enl. 34. f. 3.

Red and black Manakin, Edro. t. 261. f. 2.-Lath. Syn. iv. p. 525. 9.

Habitat in Guiana, communis.- $3 \frac{3}{4}$ pollices longa.

Capif Irum fulvum : abdomen medio fubrubrum: pedes rubri.

Femina olivacea, capite rubro circumdato, cateris mari fimilis.

funior avis olivacea, capite gutture pectore abdomineque rubro maculatis.

ß. P. nigra, capite collo inferiore pectore abdomine marginibufque alarum aurantiis, remigibus intus macula alba.

Pipra aureola, Lin. Syf. i. p. 339. 7. $\beta$.

Manacus aurantius, Brif. iv. p. $454 \cdot 7 \cdot-I d .8$ vo. ii. p. I7I.

Le Manakin orangé, Buf. iv. p. 417.-Pl. Enl. 302. f. 2.

Black and yellow Manakin, Edw. t. 83. f. 2.-Lath. Syn. iv. p. 525. 9. A.

12.

minuta. P. grifea, capite nigro albo punctato, pectore flavefcente lineis tranfverfis nigris.

Pipra minuta, Lin. Syft. i. p. 340. 13.-Muf. Ad. Fr. ii. p. 34. *Gmel. Syft. i. p. 1003 .

Motacilla minuta, Syft. Nat. x. p. 189.

Little Manakin, Lath. Syn. iv. p. 526. 10.

Habitat in India; Reguli magnitudine.

Caput nigrum, adfperfum punctis albis rotundis, in fingula penna fingulis. Mas antice capite lineis carneis, poftice punctis albis.

I3.

ftriata. P. cinereo fufca fubtus flavefcens, vertice nigro ftriis albis, loris remigibufque fecundariis apice flavis, alula rectriceque extima apice albis.

Pipra 


\section{A VES P A S ERES. Pipra.}

Pipra ftriata, Gmel. Syft. i. p. 1003 .

Striped-headed Manakin, Lath. Syn. iv. p. 526. t. 54.-Id. Sup. p. I 88.

Habrтat in Terra Van Diemen; longitudine $4 \frac{5}{2}$ pollicum.

Cauda breviulcula nigra, rectrice extima apice alba: remix tertia brevifima.

3. P. fufca fubtus alba, loris fafciifque alarum duabus flavefcentibus.

Lanius fufcus, Gmel. Syft. i. p. 308.

Brown Shrike, Lath. Syn. i. p. I91. 47.

Навітат cum priore; forte varietas, aut fexus alter.

I4.

nævia. P. fufca fubtus fulva, gula juguloque nigris, pectore fafcia alarum bifida rectricibufque apice albis.

Pipra nævia, Gmel. Syft. i. p. 1003.

Fourmilier tacheté de Cayenne, Pl. Enl. 823. f. 2.

Spotted Manakin, Latb. Syn. iv. p. 527 . I2.

Haвiтат in Cayana.-4 pollices longa.

I5.

criftata. P. crifta lutea, corpore purpureo, cauda rubra.

Pipra criftata, Lin. Syft. i. p. 339. 3.-Gmel. Syft. i. p. 999.

Manacus criftatus ruber, Brif. iv. p. 462. 12.-Id. 8 vo. ii. p. I73.

Picictli, Klein. Av. p. 90. 14. -Seba, i. p. 95. t. 59. f. 4.-Buf. iv. p. 426.

Serin de Surinam, Ferm. Surin. ii. p. 194.

Purple Manakin, Lath. Syn. iv. p. 528.14.

16.

Habitat in Mexico. $-3 \frac{x}{2}$ pollices longa; cantu modico.

Picicitli. P. cinerea, capite colloque atris, macula candente oculos ambiente, acumine in pectus ufque procedente.

Avis Picicitli Tetzcoquenfis, Fern. N. Hijp. p. 53. cap. CC.

Habitat in Mexico; parva fpecies; oculi magni.-Poft imbres apparent, educatæque domi brevi moriuntur; carent cantu ; bonum preftant alimentum, fed nefciunt Indi referre ubi producant fobolem. Fern. An vere Pipra?

17.

Rubetra. P. crifta lutea, corpore teftaceo, remigibus rectricibufque teftaceis.

Pipra Rubetra, Lin. Syft. i. p. 339. 4.-Gmel. Syst. i. p. I000. 
Manacus criftatus rufus, Brif.iv. p. $46 \mathrm{r}, 11 .-1 d$. 8 vo. ii. p. 173. A.vis americana criftata, Rubetra dicta, Seb. i. p. 160. t. 102. f. 4:Klein. Av. p. 108. 10.-Buf. iv. p. 425.

Yellow Manakin, Lath. Syn. iv. p. 529.15 .

Habitat in Brafilia, Cayana.- $4^{\frac{1}{2}}$ pollices longa.

18.

Roftrum flavum: gula fufca : rectrices et cauda cærulea.

torquata. P. nigra, capite rubro, collo torque aureo cincto, alis cæruleis, cauda nigra.

Pipra torquata, Gmel. Sy.t. i. p. 1000.

Manacus torquatus, Brif. iv. p. $456.8 .-I d .8$ vo. ii. p. 172.

Maizi de Miacototl, Seba, i. p. $9^{2}$. t. 57. f. 3.-Buf. iv. p. 424.

Collared Manakin, Latb. Syn. iv. p. 529.16.

\section{Habitat in Brafilia.}

19.

Miacato- P. nigra plumis candentibus interfertis, ventre pallente, alis caudaque totl.

20. inferne cinereis.

Miacatototl, feu avis germinis Maizi, Fernand. Hift. N. Hifp. p. 30.

Habitat in nova Hifpania, fatis parva; germinibus Maizi infidere -folet, frigidis locis degit, at bono conftat alimento. Fern. An Pipra?

grifea. P. criftata grifea fubtus flavefcens, fincipite luteo, tectricibus alarum minoribus flavefcentibus, majoribus rubris.

Pipra grifea, Gmel. Syft. i. p. 1000.

Manacus criftatus grifeus, Brif. iv. p. 463 . I 3.-Id. 8 vo. ii. p. 174.

Coquantototl, avicula criftata, formâ pafferis, $S e b a$, ii. p. 74 . t. 30 . f. 7.-Klein. Av. p. 90. 16. -Buf. iv. p. 427 .

Grey Manakin, Lath. Syn. iv. p. 530. 17.

Habitat in America. $-3 \frac{\frac{1}{4}}{4}$ pollices longa.-Roftrum flavum.

21.

albifrons. P. crifta alba, corpore rubro teltaceo, dorfo nigro, gutture albo nigro marginato, femoribus cærulefcentibus.

Pipra albifrons, Lin. Syft. i. p. 339. 5.-Gmel. Syft. i. p. 1000.

Le Demi-fin à huppe et gorge blanches, Buf. v. p. 335 .

White-faced Manakin, Edw. r. 344.-Lath. Syn. iv. p. 530.18.

Habitat in America auftrali.- $5 \frac{1}{4}$ pollices longa.

Crifta plicatilis e pennis acutis decumbentibus: pedes rubro-flavi, 


\section{A VES P A S E RES. Pipra. 561}

3. Le Plumet blanc, Buf. iv. p. 4.29 .

Le Manicup de Cayenne, Pl. Enl. 707. f. r.-Lath. Syn. iv. p.531. A.

HABrtat in Cayana.-6 pollices longa.--Simillima præcedenti, fed corpus teftaceo-ferrugineum, et crifta longior pennis inequalibus retro fpectantibus.

22.

atricapilla. P. cinerea fubtus grifeo-alba, teetricibus alarum majoribus remigibufque nigricantibus, vertice nigro.

Pipra atricapilla, Gmel. Syft. i. p. 1003.

L'Oifeau cendré de la Guiane, Buf. iv. p. 430.

Manakin cendré de Cayenne, $\mathrm{Pl}$. Enl. 687. f. I.

Black-crowned Manakin, Latb. Syn. iv. p. 532. Ig.

HАвітAт in Guiana.-6 pollices longa.-Cauda quam in congeneribus longior, fubcuneata : pedes pallide grifei.

23.

papuenfis. P. nigro-virefcens fubtus albida, pectore macula ovata fulva, reetricibus 2 intermediis brevioribus.

Pipra papuenfis, Gmel. Syjt. i. p. 1004.

Le Manikor, Buf. iv. p. 431.-Pl. Enl. 707. f. 2.

Papuan Manakin, Lath. Syn. iv. p. 532. 20.

HaвiтAт in nova Guinea. $-3^{\frac{1}{4}}$ pollices longa.

24.

hæmor- P. nigricans fubtus alba, criffo macula coccinea.

rhoa. Pipra hæmorrhoa, Gmel. Syjt. i. p. 1004.

Crimfon-vented Manakin, Lath. Syn. iv. p. 533. 21.

Longitudo $3^{\frac{3}{4}}$ pollicum.-Roftrum pallidum: pedes fufci : tectrices caude inferiores albæ rectricibus fere æquales.

25.

nigricollis، P. nigro-cærulefcens fubtus alba, gula criftoque nigris.

Pipra nigricollis, Gmel. Syft. i. p. 1004.

Black-throated Manakin, Latb. Syn. iv. p. 533. 22.

Longitudo 4 pollicum.

26.

capenfis. P. obfcura, fubtus fulvo-flavefcens.

Pipra capenfis, Gmel. Syft. i. p. 1004:

Orange-bellied Manakin, Lath. Syin. iv. p. 533. 23.

Habitat ad Caput Bone Spei; magnitudine precedentis. $4 \mathrm{C} P$. cinerea, 


\section{7.}

cinerea. P. cinerea, abdomine cinereo-albido.

Pipra cinerea, Ginel. Syft. i. p. 1004.

Cinereous Manakin, Latb. Syn. iv.p. 533. 24.

28.

Longitudo $3^{\frac{x}{4}}$ pollicum.

mufica, P. nigricans, corpore fubtus uropygioque fulvis, gutture genifque nigris, vertice nuchaque cæruleis, fronte flaya.

Pipra mufica, Gmel. Syjt. i. p. 1004.

L'Organifte, Buf. iv. p. 290.-Pl. Enl. 80g. f. 1.

L'Evếque, Hitt. de la Louifiane, ii. p. 140 .

Tuneful Manakin, Lath. Syn. iv. p. 534. 25.

Habitat in infula $S$. Dominisi. -4 pollices longa; cantus fuavis et: harmonicus vix Lufcinie cedens.

\section{GENUS XLV. PAR US.}

Roftrum validiufculum, integerrimum, fubcomprefum, bafi fetis tectum.

Lingua truncata, fetis terminata.

Pedes ambulatorii, digitis ad imum fiffis, poftico valido.

I. major.

P. viridi-olivaceus fubtus flavefcens, capite nigro, temporibus albis, nucha lutea.

Parus major, Lin. Syft. i. p. 341. 3.-Faun. Suec. No 265.-Gmel. Syft. i. p. 1006.-Scop. Ann. i. $\mathrm{N}^{\circ} 242 .-B r u n . \mathrm{N}^{\circ} 287 .-$ Muller, $\mathrm{N}^{\circ}$ 283.-Kram. El. p. 378. r.-Georgi, p. 175.-Scbaf. El. t. 52.Klein. Av. p. 84. r.-Id. Stem. p. r6. t. 17. f. 8. a-b.-Frifch. to. 13.-Faun Arag. p. 90. 1.-Sepp. Vog. t. p. I 13.-Raii Syn. p. 73. A. r.-Will. p. 174. t. 43.-Brif. iii. p. 539. r. -Id. 8vo. i。 p. $46 \mathrm{r}$.-Borowes. Nat. iii. p. 180. 3 .

La groffe Mefange, ou Charbonniere, Buf. v. p. 392. t. 17.-Pl. Enlo 3. f. 1 .

Spernuzzola, Olin. uc. t. p. 28.

Kohlmeife, Wirf. Vog.t. 10.

Great Titmoufe, or Ox-eye, $B r$. Zool. i. Nor62.-Id. fol. II 3. t. W. f. 4.-ArEt. Zool. ii. p. 425. A.-Will. (Angl.) p. 240. t. 43.Albin。 i. to 46. - Hayes Br. Birds, t. 38.-Lath. Syn. iv. p. $53^{6 .}$. 
Habitat in Europa, Africa, Afa ; in Anglia circa arbores frequens, in quarum cavitatibus nidificat; victitat infectis, feminibus, etiam parvis aviculis. Ovum album maculis numerofis rufis.

Stria longitudinalis nigra a pectore ad crifun : fafcia tectricum alba: cauda nigricans, rectricibus 2 exterioribus extus albis, reliquis extus cæruleo-grifeis.

ß. P. fufco-olivaceus fubtus fordide flavicans, capite nigro, temporibus cinereis, roitro forficato.

Crofs-billed Titmoufe, Lewin. Br. Birds, i. t. tit. praf.

Hrc avis in Anglia, prope Faver/מan, Cantii oppidum, occifa fuit.

Color pennarum ut in majore, at maxime obfcurus : roftrum valde 2. elongatum, mandibulis apice incurvatis, ut in Loxia curvirofira.

Strömei. P. viridi-flavefcens, pectore rufo maculato, abdomine cæruleo, cauda forficata, rectricibus duabus exterioribus extus albis.

Parus ignotus, Brun. p. 73.-Gmel. Sy/t. i. p. 1006.

Strömian Titmoufe, Arct. Zool. ii. p. 426. B.

Norway Titmoufe, Latb. Syn. iv. 537. 2.

Habitat in Norvegia; majori fimillimus, excepto capite nequaquam nigro.-Collum et corporis pars fupina flavo-viridis: guttur flavum: peøus flavum fpadiceo maculatum: abdomen cæruleum, prope anum flavefcens: cauda bifurca: relzrices intermedia virefcentes, extimæe extus albæ.

$3 \cdot$

cyanus. P. dilute cæruleus fubtus albus, uropygio et vertice cano-albidis, cervicis albæ fafcia lata, humeris tectricibufque caudæ caruleis.

Parus cyanus, N. C. Petr. xiv. p. 588. 8. t. 23. f. 3.-Falck. It. iii. p. 407. t. 31. -Gmel. Syft. i. p. 1007.

Parus indicus Aldr. Raii Syn. p. 74. 7.-Will. p. 177.-Aldrov. Av. ii. p. 714 . t. p. 715 .

Parus dorfo ceruleo, \&cc. N.C. Petr. xiv. p. 498 . t. I 3 . f. I.

— cæruleus major, Brif. iii. p. 548. 3.-Id. 8 vo. i. p. 463 .

- frabyenfis, Muf. Carls. fafc. i. t. 25.-Gmel. Syft. i. p. 1008.

La groffe Mefange bleue, Buf. v. p. 455 .

Azure Titmoufe, Arct. Zool. ii. p. 426. C. -Id. Sup. p. 64.-Lath. Syn. iv. p. 538. 3.-Id. Sup. p. 189.

$\mathrm{H}_{\text {ABIt AT }}$ in Rufra, Sibirie, Suecie falicetis. $-5 \frac{r}{2}$ poll. longus. Roftrun et pedes nigricantes: per oculos a roftro vitta nigra : ale ${ }_{4} \mathrm{C}_{2}$ albo 
564 A V E S PAS S E E S. Parus.

albo creruleoque variæ: fafcia te£tricum alba: cauda fubcuneiformis, elongata, fupra cærulea fubtus alba, reatricibus 4 fuperioribus cyaneis, apice albis, rachibus nigris.

4 .

peregri- P. uropygio coccineo, corpore cinereo fubtus albo.

nus. Parus peregrinus, Iin. Syjt. i. p. 342, I0.-Muf. Carlf. fafc. ii. t. 48 . 49.-Gmel. Sy/. i. p. Iо Iо.

Parus coccineus, Ginel. Syft. i. p. I0I7.

Crimfon-rumped Titmoufe, Lath. Syn. iv. p. 539. 4.

Corpus magnitudine $P$. majoris, cinereum, fubtus totum album: uropygium coccineum : remiges fufcæ: reftrices omnes nigræ, exceptis quatuor intermediis poftice oblique luteis; ita tantum ut luteus color prævaleat in 5,5 ; non vero in 6, 6. Confer Mufc. flammeam.

5. malabari- P. grifeus, gula alis rectricibufque duabus intermediis nigris, corpore cus. fubtus uropygio macula alarum bafique tectricum lateralium fulvis.

Parus malabaricus, Gmel. Syft. i. p, IOI2.

La Mefange de la côte de Malabas, Son. Voy. Ind. ii. p. 204. t. I I4. f. r。 Malabar Titmoufe, Lath. Syn. iv. p. 555.22.

HaBitat in Malabaria. $-5 \div$ pollices longus.

Irides rubræ: tectrices alarum nigræ, inferiores nonnullæ macula ru $\mathrm{s}$.

6. befcente notatæ. Femina fubtus ex rufo-flava; peregrino valde affinis.

grifeus. P. grifeus, vertice coccineo.

Parus grifeus, Muller, p. 34. 284.-Gmel. Syft. i. p. roro.

Crimfon-crowned Titmoufe, Latb. Syn. iv. p. 539. 5.

HABIтAт in Groenlandia. Confer Fr. flammeam.

afer. P. nigricans, genis nucha abdomineque albis, collo fubtus pectoreque nigris.

Parus afer, Gmel. Syft. i. p. Iого.

Black-breafted Titmoufe, Lath. Syn. iv. p. 539.6.

Haвitat ad Caput Bone Spei, India.-Ad latera colli ftriga alba: re\&trix extima extus, fecunda apice alba.

8.

2ter. $\quad \mathrm{P}$. dorfo cinereo, capite nigro, occipite pectoreque albo.

Parus ater, Lin. Syf. i. p. 34I. 7.-Faun. Sues. $\mathrm{N}^{\circ}$ 268.-Gmel. Syft. 
i. p. Ioog. -Scop. Ann. i. $\mathrm{N}^{\circ} 245 .-K r a m$. El. p. 379. 4.-Georgi, p. 175.-Frifcb. t. 13.--Raii Syn. p. 73. A. 2.-Will. p. 175. t. 43.-Borowes. Nat. iii. p. I81. 5 .

Parus atricapllius, Brif. iii. p. 55 I. 5.-Id. 8 vo. i. p. 464 .

— fylvaticus, Klein. Av. p. 852 .

- carbonarius, Klein. Stem. p. i6. t. 17. f. 9. a. b.

La petite Charbonniere, Buf. v. p. 400 . - Hift. Prov. i. p. 5 I6.

Cingallegra, Zinnan. Uov. p. 75. t. 1 1. f. 67.-Cet. uc. Sard. p. 226.

Tannenmeife, Wirfing. Vog. t. 59.

Colemoufe, Br. Zool. i. N ${ }^{\circ}$ 164. t. 57. f. 3.-Id. fol. I i 4.-Arct. Zool. ii. $\mathrm{N}^{\circ}$ 327.-Will. (Angl.) p. 24.1. t. 43.-Latb. Syn. iv. p. 540. 7.

Habitat in Europa, America; in Anglia pafim in hortis.-4 poll. longus.-Corpus fubtus rufo-album: fafciæ tectricum alarum duæ albæ. Ovum albidum maculis parvis rubentibus.

9.

paluftris. P. capite nigro, dorfo cinereo, temporibus albis.

Parus paluftris, Lin. Syft. i. p. 341. 8.-Foun. Suec. No 269.-Gmel. Syjt. i. p. 1009.-Scop. Ann. i. $\mathrm{N}^{\circ} 246 .-$ Brun. $\mathrm{N}^{\circ}$ 288.-Muller; No 286.-Kram. El. p. 379. 5.-Georgi, p. 175.-Sepp. Vog. t. p. 47.-Raii Syn. p. 73. A. 3.-Will. p. 175. t. 43.-Brif. iii. p. 555. 7.-Id. 8vo. i. p. 465.-Klein. Av: p. 85. 4.-Id. Stem. p. I6. t. 17. f. I1. a-c.-Bororefk. Nat: iii. p. 18 1. 6.

La Mefange de marais, Buf. v. p. 403.-Pl. Enl. 3. f. 3 .

Bymeife, Gunth. Neft. u. Ey. p. 55. t. 1 3. fig. fup.

Parolozino paluftre, Zinnan. Uov. p. 77. t. 12. f. 68. 1 .

Marfh Titmoufe, or Black-cap, Br. Zool. i. N 165. t. 57. f. 4.-Id. fol. I I 4. t. W. f. 3.-Arcz. Zool. ii. p. 427. E.-Will. (Angl.) p. 24 . t. $43 .-A l b$. iii. t. 58 . f. 1.-Lath. Syn. iv. p. 541.8.-Id。 Sup. p. 189 .

Habitat cum præcedente, et a nonnullis pro altero fexu habetur. Delectatur apibus.-Fafciæ tectricum alarum duæ albæ: gula macula. nigra.

ß. Mefange à gorge noire, Pl. Enl. 502. f. r.-Latb. Syn. iv. p. 54r.

HABITAT in Louiffana; cum præcedente convenit, at abfque macula accipitis et fafciis alarum albis. 
$\gamma$. Parus corpore fubtus albo, Lath. Syn. iv. p. 542. 8. B.

Hæc varietas fubtus et fafcia occipitali alba, cæteris ut in primo. In altero fpecimine vertex niger, nucba flavefcens.

Io. atricapil- P. pileo gulaque nigris, corpore cinereo fubtus albo.

lus. Parus atricapillus, Lin. Syft. i. p. 341. 6.-Gmel. Syft. i. p. roo8.Brif. iii. p. 553.6. t. 29 . f. 1.-Id. 8 vo. i. p. 464.-Pbil. Tranf. lxii. p. 407.

La Mefange à tête noire de Canada, Buf. v. p. 408.

Canada Titmoure, Arct. Zool. ii. No 328.-Latb. Syn. iv. p. 548. 9.

Habitat in America Septentrionali; magnitudine præcedentis.-Latera capitis et corpus fubtus a gula album.

I I.

hudfoni- P. fufco-rubefcens, dorfo cinereo, jugulo atro, fafcia fuboculari pecto-

cus.

Parus hudfonicus, Pbil. Tranj. Ixii. p. 430.-F. Fr. Miller, t. 21. A.Gmel. Syft. i. p. 1013.

Hudfon's Bay Titmoufe, Pbil. Tranf. Ixii. p. 408.-Arct. Zool. ii. No 329.-Lath. Syn. iv. p. 557. 24.-Id. Sup. p. 190.

Habitat ad finum Iludfonis, in juniperitis. $-5 \%$ pollices longus.

Ale et cauda fubrotundata fufca, pennis margine cineress.

12.

cæruleus. P. olivaceo virefcens fubtus luteus, remigibus cærulefcentibus, primoribus margine exteriore albis, fronte alba, vertice cærulco.

Parus cæruleus, Lin. Syft. i. p. 341. 5.- Faun. Snec. N'267-Gmel. Syft. i. p. 1008.-Scop. Ann. i. $\mathrm{N}^{\circ}$ 244.-Muller, $\mathrm{N}^{\circ} 285 .-$ Kram. El. p. 379. 3.-Frifch. t. 14.-Raii Syn. p. 74. A. 4.-Will. p. I75. t. 43.-Brif. iii. p. 544. 2.-Id. 8 vo. i. p. $462 .-$ Klein. Av. p. 85. 3.-Id. Stem. p. 16. t. 17. f. I o. a. b.-Id. Ov. p. 29. t. 4. f. 10.-Faun. Arag. p. 90.-Sepp. Vog. t. p. 45-Borowfk. Nat. iii. p. 180.4 .

La Mefange bleue, Buf. v. p. 4I 3.-Pl. Enil. iii. f. 2.-Hift. Prov. i. p. 5 I5.

Blaumeife, Guntb. Neft.u. Ey. t. 66.-Wirfing. Vog. t. 32.

Spernuzzolo, Olin. uc. p. 28.

Parozolino, o Fratino, Zinnan. Uov. p. 76. t. r1. f. 68.

Blue Titmoufe, $B r$. Zool. i. $\mathrm{N}^{\circ}$ 163. t. 57. f. 2.-Id. fol. I14. t. W. f. 5.-Arct. Zool. ii. p. 427. D.-Alb. i. t. 47.-Will. (Angl.) p. 242. t. 43.-Hayes Br. Birds, t. 38.-Latb. Syn. iv. p. 543. 10. 
HaBiт a t Europa paffim; in Anglia fatis numerofus. $-4 \frac{x}{2}$ pollices longus. - Victitat infectis eorumque larvis; nidificans in caveis arborum, et ponens ova $14-22$ alba maculis obfcuris rubris notata.

r.3.

bicolor. P. capite criftato antice nigro, corpore cinereo, fubtus ex albido rufefcente.

Parus bicolor, Lin. Syft. i. p. 544. 1.-Gmel. Syft. i. p. 1005.-Faun. Groenl. p. 123.85 .

Parus carolinenfis criftatus, Brif. iii. p. 56 1. 9.-Id. 8 vo. i. p. $466 .-$ Klein. Av. p. 86. 12.

La M fange huppée de la Caroline, Buf. v. p. 45 I.

Crefted Titmoufe, Cat. Car. i. t. 57 .

Toupet Titmoufe, ArEt. Zool. i. N 324.-Latb. Syn. iv. p. 544. II.

Hавіт ат in Europa et America boreali, Groenlandia.-6 poll. longus.

Tempora circum oculos, gula, collum, pectus, abdomen rufefcentia funt: cauda fubfurcata. Femina abdomine albo.

i4.

criftatus. P. grifeo-rufefcens criftatus, collari nigro, ventre albo.

Parus criftatus, Lin. Syft. i. p. 340. 2.-Faun. Suec. No 266.-Gmel. Syft. i. p. $1005 .-S c o p$. Ann. i. $\mathrm{N}^{\circ}$ 243.-Muller, $\mathrm{N}^{\circ} 282 .-$ Kram. El. p. 379. 2.-Georgi, p. 175.-Frifch. t. 14.-Raii Syn. p. 74. 6.-Will. p. 175. t. 43.-Borowf: Nat. iii. p. 179. 2.-Brif. iii. p. $55^{8} .8 .-I d$. 8 vo. i. p. 466 .

La Mefange huppée, Buf. v. p. 447.-Pl. Enl. 502. f. 2.

Hop-Meife, Gunth. Neft. u. Ey. t. 5. f. fup.

Crefted Titmoufe, ArEZ. Zool. ii. p. 427. F.-Will. (Angl.) p. 242. to 43.-Alb. ii. t. 57.-Latb Syn. iv. p. 545. 12.

Навітат in Europe denfis fylvis, potifimum pinetis. $-4 \frac{3}{7}$ pollices longus.-Solitaria avis.-Frons et gene albæ: crifta plicatilis, apice acuta nigra albo marginata : gula et macula auriuın nigra. Ovum rufoalbidum maculis parvis rubefcentibus.

15. virginianus.

P. fufco-olivaceus fubtus grifeus, uropygio luteo.

Parus virginianus, Lin. Syft. i. p. 342. 9.-Gmel.Syft. i. p. 10 10.-Brifa iii. p. 575 . 14. $-I d$. 8 vo. i. p. 470 .

Lufcinia uropygio luteo, Klein. Av. p. 74. 8.

La Mefange à croupion jaune, Buf. v. p. 453 .

Yellow-Rump, Cat. Car. i. t. 58.

Virginian Titmoufe, Arct. Zool. ii, $\mathrm{N}^{\circ} 325$-Lath. Syn. iv. p. 546. 13. 
Habitat in Americe feptentrionalis arboribus; victitans infectis.5 pollices longus.

I6.

Cela. P. niger, roftro albo, macula alarum bafique cauda flavis.

Parus Cela, Lin. Sjfh. i. p. 343. 14.-Gmel. Syjt. i. p. 1015.-Kaln. Voy. ii. p. I5I.

La Mefange noire, Buf. v. p. $45^{8}$.

Guiana Titmoufe, Latb. Syn. iv. p. 546. 14.

HÄвтат in Guione.-Rofrum album.

amorofus. P. cæruleo-nigricans, macula alarum longitudinali rufo flavoque dimidiata.

Parus amatorius, Gmel. Syft.i. p. IOI5.

La Mefange amoureufe, Buf. v. p. 456.

Amorous Titmoufe, Lath. Syn. iv. p. 546. 15.

HaвIтAт in $A f a a_{0}-5 \frac{1}{+}$ pollices longus. - Rofruin apice aurantium.

I 8 .

penduli- P. capite fubferrugineo, fafcia oculari nigra, remigibus rectricibufque

nus.

Parus pendulinus, Lin, Syft. i. p. 342. I3.-Gmel. Syft. i. p. Ior4.Georgi, p. 175.-Borows. Nat. iii. p. 178. t. 71.

— polonicus, five pendulinus, Brif. iii. p. 565 . I1. t. 29. f. 2.Id. 8 vo. i. p. $467 .-A C t$. Bonon. ii. p. 57 . t. 7 .

Parus lithuanicus, Klein. Av. p. 86.. ro.-Id.Stem. p. 17. t. 17. f. I3. a.b. Mefange de Pologne, Reiniz, Buf. v. p. 423.-Pl. Enl. 618. f. 3.Titius LipS. 1755 . differt.-Rzaczynk. Polon. i. p. 294.

Cotton-vogel, Gunth. Neft. u. Ey. t. 4 .

Mountain Titmoufe, Alb. iii. t. 57 .

Penduline Titmoufe, Coxe's. Trav. i. t. in p. 218. (fivis cum Nido.) Latb. Syn. iv. p. 547 . I6.

Habitat in Polonia, Hungaria, Italia. $-4 \frac{x}{2}$ pollices longus. - Fdificat nidum pendulum ex pappo populi typhaque, cum introitu laterali. Ovum album, fubdiaphanum. Bononiis rufticis facer.

Femina abfque fafcia oculari nigra.

narbonien- P. rufo-grifeus, vertice cano, alis caudaque nigricantibus rufo margi-

fis. natis, remigibus primoribus margine albis.

Parus narbonienfis, Gmel. Syft. i. p. IOI4. 


\section{A VES P A S E RES. Parus.}

La Penduline, Buf. v. p. 433 .

La Pendulino, ou Canari fauvage, Hift. Prov. i. p. 5 17.

Mefange de Languedoc, Pl. Enl. 708. f. I.

Languedoc Titmoufe, Lath. Syn. iv. p. 549. 17.

Habitat in Gallia narbonienfi. - Nidum conftruit pappofum, uti precedens, cui moribus et ftatura accedit, at paulo minor.

20.

caudatus. P. albo rofeo nigroque longitudinaliter varius, vertice albo, cauda longiore.

Parus caudatus, Lin.Syf. i. p. 342. I r.-Faun. Suec. No 8.3. t. r. f. 83 . -Gmel. Syft. i. p. 1010.-Scop. Ann. i. No 247.-Kram. El. p. 379. 6.-Frisch. to 14.-Raii Syn. p. 74. A. 5.-Will. p. 176. t. 43.-Sepp. Vog. t. p. 49.-Klein. Av. p. 85. 7.-Id. Stem. p. 16. t. I7. f. I 2. a. b.-Id. Ov. p. 28. t. 4. f. 7.-Borovefk. Nat. iii. p. 182. 7 .

Parus longicaudus, Brif. iii. p. 570. I3.-Id. 8vo. i. p. 469.

La Mefange à longue queue, Buf. v. p. 437. t. 19.-Pl. Enl. 502. f. 3. Schwanzmeife, Pfannenftiel, Guntb. Neft. u. Ey. t. 21.-Wirfing. Vog. t. 20.

Pendolino, o Paronzino, Zinnan. Uov. p. 77. t. r1. f. 69 .

Long-tailed Titmoufe, Br. Zool. i. $\mathrm{N}^{\circ}$ 166.-ArEt. Zool. ii. p. 428. G.Will. (Angl.) p. 242. t. 43.-Alb. ii. t. 57. f. r.-Hayes Br. Birds, t. 33.-Lath. Syn. iv. p. 550.-Id. Sup. p. 190.

Habitat in Europa pafim, et Sibiria hortis. -5 fere poll. longus.

Cauda fingularis formæ, reetricibus quafi per gradus inæequalibus. Nidum artificiofifimum ex mufcis, lichenibus cum lana intertextis, conftruit hæc avis, foramine laterali. Ova numerofa ponit, ufque ad 20 , fubrotundata, alba, maculis crebris rubris.

2 I.

alpinus. P. niger fubtus rufefcens nigro maculatus, linea alba a bafi roftri ad cervicem decurrente, ungue poftico longiffimo.

Parus alpinus, Gmel. Sylt. i. p. IOI2.-S. G. Gmel. It. iv. p. 17 I.Pall. n. Nord. Beytr. iv. p. 49.

Habitat in alpibus Perfice funamificis; caudato affinis et requalis; infectis victitans.

Pennæ corporis fuperiores margine cinereæ: remiges 18 earumque tedirices fupra nigræ, fubtus cinereæ; hæ apice albæ: cauda bifurcata; restrices extimæ macula ad apicem alba cuneata.
P. cinereo- 
22. 570 A V E S P A S E R S. Parus.

capenfis. P. cinereo-grifeus, remigibus nigris albo marginatis, cauda nigra fubtus : alba.

Parus capenfis, Gmel. Syft. i. p. Iогі.

La Mefange du Cap de B. Efp. Son. Voy. Ind. ii. p. 206. t. I I5.

Le petit Deuil, Buf.v. p. 445 .

Cape Titmoufe, Lath. Syn. iv. p. 552 . I9.

Habitat ad Caput B. Spei; in fruticibus nidum ampullaceum, ez: goflipio vel pappo diverfarum plantarum ftruens collo breviufculo, $\mathrm{e}$ ramulis pendulum.

23.

biarmicus. P. rufus, vertice cano, cauda corpore longiore, capite barbato, criffo nigro.

Parus biarmicus, Lin. Syft. i. p. 342. 12.-Faun. Suec. N 84.-Gmel. Syft. i. p. 101 1. -Scop. Ann. i. No 24 1. -Frifch. t. 8.-Sepp. Vog. t. p. 83.-Borow/k. Nat. iii. p. 183.8 .

tanius biarmicus, Brun. p. 8.

Parus barbatus, Brif. iii. p. $567.12 .-1 d .8$ vo. i. p. 468.-Klein. Av. p. 86. 8.

— rufficus, Gmel. reife. ii. p..164. t. I0.

Pendulus, Kram. El. p. 373 .

La Mefange barbue, ou la Mouftache, Buf.v. p. 5 18.t, 18.-Pl. Enl. 618. f. 1. 2 .

Leaft Butcher-Bird, Edw. t. 55 .

Bearded Titmoufe, Br. Zool. i. No 167.-Id. fol. 74. t. C. 2.-ArEz.

Zool. ii. p. 428. H.-Alb. i. t. 48.-Lath. Syn. iv. p. 552 20.Id. Sup. p. I 90 .

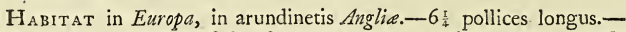
Nidum inter 3 arundines fufpenfum, ex typhæ populique pappis, conficiens.-Ovum albo-rubefcens maculis minutis rubris.

Roftrum fulvum: irides flavæ: pedes nigri : cauda cuneiformis : my-taces e loris pennis nigris elongatis : criffum nigrum: rectrices 3 exteriores bafi nigræ, apice albidæ.

Femina caret barba et criffo nigro.

24.

knenfis. P. ferrugineo-fufcus, capite colloque dilutioribus, remigibus caudaque elongata fufcis nigro marginatis.

Parus finenfis, Gmel. Syjt.i. p. 2 r.

Chinefe Titmoufe, Lath. Syn. iv. p. 555. 21 .

HaBIT AT in Cbina, $-3 \frac{x}{2}$ poll. long,- - Roftrum nigrum : pedes rubri.

P. grifeo- 
25.

fibiricus. P. grifeo-fufcus fubtus albidus, abdomine rufo-grifeo, collo inferiore medio nigro, hypochondriis rufefcentibus.

Parus fibiricus, Gmel. Syft. i. p. 1013.

La Mefange à ceinture blanche, Buf. v. p. 4.46 .

de Siberie, Pl. Enl. 708. f. 3 .

Sibirian Titmoufe, Latb. Syn. iv. p. 556. 23.

Hавгтат in Sibiria. -5 pollices longus.

Roftrum et pedes nigricantes: gula, jugulum, et peltus albida, medio per totam longitudinem nigra, pectore imo cinerafcente; remiges et cauda fubcuneiformis cinereo-fufca.

$\beta$. P. cinereo-fufcus fubtus fronteque albus, collo fubtus pectoreque medio nigris, cauda longiore obfcura, Lath. Syn. iv. p. 556.23. A.

26.

macroce- P. niger, abdomine albido, pectore fubfulvo, fronte maculaque alarum phalus.

Parus macrocephalus, Gmel. Syft. i. p. Ior 3.

Great-headed Titmoufe, Latb. Syn. iv. p. 557. 24. t. 55 .

HaBıтAт in nova Zealandia. $-4 \frac{x}{2}$ pollices longus.

Plumæ totius capitis elongatæ, confertæ, laxæ; unde caput amplum, tumidum : cauda elongata, rectricibus 2 exterioribus albis apice nigris, reliquis nigris, 3,3 , intus verfus apicem albis.

Femina fufca ubi mas niger.

6. P. niger, macula alarum fronteque albis, pectore coccineo.

Great-headed Titmoufe, Latb. Syn. Sup. p. IgI.

Habitat in infula Norfolk.

27.

novæ Zea- P. cinereo-ruber fubtus rufo-grifeus, fuperciliis albis, rectricibus duabus landix. intermediis nigris, lateralibus medio macula quadrata alba.

Parus novæ Zealandiæ, Gmel. Syjf. i. p. ror 3 .

New Zealand Titmoufe, Latb. Syn. iv. p. 558. 26.

Habitat in nova Zealandia, -5 pollices longus, -Frons rufa,

28.

america- P. cærulefcens, temporibus pectore dorfoque flavefcentibus, hypochon-

nus. driis purpurafcentibus.

Parus americanus, Lin. Syft. i. p. 341. 4.-Gmel. Syft. i. p. 1007.

Ficedula carolinenfis cinerea, Brif. iii. p. 522. 66.-Id. 8 vo. i. p. 452 . 
Finch Creeper, Cat. Car. i. t. 64.

Creeping Titmoufe, Arct. Zool ii.. N $\mathrm{N}^{\circ}$ 326.-Lath. Syn. iv. p. 558. 27.

Habitat in Carolina et Conada. $-4 \frac{3}{4}$ pollices longus.-Mandibula inferior pedefque flavicantes: macula fupra infraque oculum alba.

Femina nigro fufcoque varia. An Parus verus? Confer Sylv. americanom.

29.

indicus. P. cinereus fubtus albidus, pectore abdomine criffoque ferrugineis, roftro pedibus alis caudaque nigro-fufcis.

Parus indicus, Muf. Carlf. fafc. ii. t. 50.-Gmel. Syf. i. p. 1015.

30.

Habitat in India; magnitudine $P$. majoris.

Knjaefcik. P. albus, fubtus macula continua, linea oculari et collari lividis. Parus Knjaefcik, Gmel. Syft. i. p. IOI3.-Lepech. It. i. p. 18 I.

Habitat in Sibirie quercetis.

\section{GEN U S XLVI. HIRUNDO.}

Roftrum minimum, incurvum, fubulatum, bafi depreffum. Lingua brevis.

RiEtus capite amplior.

Cauda plerifque forficata.

- Digitis tribus anticis, uno poftico.

1. H. nigrc-carulefcens fubtus albida, fronte gulaque caftaneis, rectricibus lateralibus macula alba notatis.

Hirundo ruftica, Lin. Syft. i. p. 343. 1. -Faun. Suec. $\mathrm{N}^{\circ} 270 .-G m e l$. Syft. i. p. ror 5.-Scop. Ann. i. N 249.-Brun. No 289.-Muller, $\mathrm{N}^{\circ}$ 287.-Kram.El. p. 380. 1.-Georgi, p. 175.-Frijcb. t. 18.Faun. Arag. p. 90.-Sepp. Vog. t. p. 31.-Klein. Av. p. 82. 2.-1d.

Stem. p. 15. t. 17. f. 2. a.-c. -Id. Ov. p. 27. t. io. f. 2.-Borovek. Nat. iii. p. 155. 2. -Schaf. El. Orn. t. 40.

Hirundo domeftica, Raii Syn. p. 7 1. A. r.-Will. p. 155. t. 39.-Brif. ii. p. 486. 1. $-I d$. 8 vo. i. p. 294.

Hirondelle de cheminée, Buf. vi. p. 591 . t. 25. f. s. $-P$ l. Enl. 543. f. x. 


\section{A V E S P A S E R E S. Hirundo.}

Schwalbe, Gunth. Neft.u. Ey. p. 62. t. i 5. f. inf.

Rondine minore, Zinnan. Uov. p. 48. t. 7. f. 35.-Cet. uc. Sard. p. 227. Chimney or common Swallow, Br. Zool. i. N N $^{\circ}$ 68. t. 58. -Id. fol. $9^{6}$. -Arzt. Zool. ii. $\mathrm{N}^{\circ} 330 .-P b i l$. Tranf. li. p. 459-II. liii. p. Ior. -Id. lxv. pp. 528. 343.-Alb. i. t. 45.-Will. (Angl.) p. 212. t. 39.-Lath. Syn. iv. p. 561.-Id. Sup. p. 192.

HABITAT in Europe domibus intra tectum, frpius in caminis, alibi que per omnem orbem; migratoria. -6 pollices et ultra longa.-Ovum album maculis rubefcentibus.

B. Hirundo alba, Brif. ii. p. 48 g. A.

Hirundo prorfus candida, Will. p. 155.

White Swallow, Latb. Syn. iv. p. 563.-Will. (Angl.) p. 213.

2.

A præcedente differt colore in univerfo corpore candido.

tahitica. H. fufco-nigricans, corpore fupra cæruleo-nitente, fronte colloque fubtus purpureo-fulvis, cauda fubforficata nigra.

Hirundo tahitica, Gmel. Syft. i. p. 1016.

Otaheite Swallow, Latb. Syn. iv. p. $5^{6} 3$. t. in tit. pref.

Habitat in montibus infula Otabeite maris pacifici. -5 poll. longa. PeCtus in quibufdam fulvum.

3.

urbica. H. nigro-carulefcens fubtus alba, rectricibus immaculatis.

Hirundo urbica, Lin. Syft. i. p. 344. 3.-Faun. Suec. N॰271. r.-Gmet. Syft. i. p. 1017. -Scop. Ann. i. $\mathrm{N}^{\circ}$ 250.-Brun. $\mathrm{N}^{\circ} 290 .-$ Muller, $\mathrm{N}^{\circ}$ 288.-Frijcb. t. 17.-Kram. El. p. 380. 2.-Georgi, p. 175. -Faun. Arag. p. 90.-Sepp.Vog. t. p. 33.-Klein. Av. p. 82 . I. Id. Stem. p. 15. t. 17. f. 3. a.-c.-Borowe/k. Nat. iii. p. 154. t. 65. Hirundo ruftica, five agreftis, Roii Syn. p. 7 I. A. 2.-Will. p. 155.to 39.-Brif. ii. p. 490 . 2.-Id. 8 vo. i. p. 295.

Hirondelle à cul blairc, Buf. vi. p. 614. t. 25 . f. 2.

Le petit Martinet, Pl. Enl. 542. f. 2.

Rondone minore, Zinnan. Uov. p. 48. t. 7. f. 34.-Cet.uc. Sard. p. 231. Haus-fchwalbe von anderer art, Gunth. Neft. u. Ey. t. 28.

Martin, Martlet, or Martinet, Br. Z ol. i. N' 169.-Id. fol. 96. t. Q. f. 2. - Arcz. Zool. ii. No 331. -Will. (Angl.) p. 21 3. t. 39.-Alb. ii. t. 56. a.-Latb. Syn. iv. p. 564. 3.-Id. Sup. p. 192 .

Habitat in Europa, Afa $a_{0}-5 \frac{\mathrm{I}}{2}$ pollices longa.-Sub tectorum fug. grundiis 
577 AVES P A S E RES. Hirundo.

grundiis inque feneftris Anglia, non in camini, nidum ex luto et Atramine conftruit. - Uropygium candidum: pedes ad ungues ufque lanugi. nofi. Ovum album.

ß. H. nigricans fubtus aiba, remigibus rectricibufque apice albis, Lath. Syn. iv. p. 565 .

4.

Habitat in America Septentrionali.

panayana. H. nigro-fericea fubtus alba, fronte gulaque ferrugineo-flavis, gula lunula nigro marginata.

Hirundo panayana, Gmel. Syft. i. p. ror 8.

L'Hirondelle d'Antigue, Son. Voy. p. I 18. t. 76.

- à gorge couleur de rouille, Buf. vi. p. 607 .

Panayan Swallow, Lath. Syn. iv. p. $565 \cdot 4$.

HaBIтAт in infulis Pbilippinis; magnitudine riparia. - Tectrices ala. rum minores violaceæ.

5

rufa. H. nigro-fplendens fubtus rufa, fronte albida.

Hirundo rufa, Gmel. Syft. i. p. I0I8.

L'Hirondelle à ventre roux de Cayenne, Buf. vi. p. 607.-Pl. Enl. 724 . f. s.-Mem. Jur Cay. ii. p. 275.

Rufous-bellied Swallow, Latb. Syn. iv. p. 566. 5.

HАВıтА 1 in Cayana. $-5 \frac{\pi}{2}$ pollices longa.-In domibus nidum artificiofum, loculiformem, $I \frac{\pi}{2}$ pedem longum, ex fibrillis mufco et virgultis fabricatum, et e tegminibus dependentem, ædificat; $4-5$ ova

6. pariens.

capenfis. H. nigro-cærulefcens fubtus flavefcens nigricante ftriata, pileo rufo, rectricibus lateralibus macula alba.

Hirundo capenfis, Gmel. Syft. i. p. rorg.

L'Hirondelle à capuchon roux, Buf. vi. p. 608.

L'Hirondelle à tête rouffe, Pl. Enl. 723 . f. 2.

Cape Swallow, Latb. Syn. iv. p. 566.6.

Habitat ad Caput B. Spei.-7 pollices longa.-In domibus nidum ex luto, intus plumis ftratum, conitruit.-Ovun maculatum.

7.

fenzgalen- H. nigra cæruleo-nitens, fubtus uropygioque rufa, remigibus rectricifis. bufque nigris. 
Hirundo fenegalenfis, Lin. Syft. i. p. 345. 8.-Brif. ii. p. 496.5 . t. 45 . f. 1. $-I d .8$ vo. i. p. 296.-Gmel. Syft. i. p. 1021.

La grande Hirondelle à ventre roux du Senegal, Buf. vi. p. 6ro.-Pl. Enl. 310.

Senegal Swallow, Latb. Syn. iv. p. 567.7.

8.

Habitat in Senegala. $-8 \frac{1}{2}$ pollices longa.

fafciata. H. nigra, fafcia abdominis maculaque femorum albis.

Hirundo fafciata, Gmel. Syft. i. p. IO22.

L'Hirondelle à ceinture blanche, Buf. vi. p. 6 I 1 .

Hirondelle de Cayenne à bande blanche, Pl. Enl. 724. f. 2.

White-bellied Swallow, Lath. Syn. iv. p. 567.8.

Hавітат in Cayana, Guiana, ad ripas fluviorum. -6 poll. longa.

9.

ambrofia- H. grifeo-fufca fubtus dilutior, cauda maxime forficata.

ca. Hirundo ambrofiaca, Gmel. Syft. i. p. 1021 .

Hirundo riparia fenegalenfis, Brif. ii. p. 508. I 3. t. 45 . f. $4 .-I d$. $8 \mathrm{vo}$. i. p. 300 .

82. 4 .

L'Hirondelle ambrée, Buf. vi. p. 6 I 2.

Ambergris Swallow, Latb. Syn. iv. p. 568. 9.

Habitat in Senegala. $-5 \frac{t}{2}$ pollices longa.-Ambram grifeam maxime redolere fertur.

ß. H. cinerafcens fubtus cinereo-alba, cauda elongata maxime forfcata.

Ambergris Swallow, Latb. Syn. Sup. p. 193.

Habitat in Cbina?

10.

riparia. H. cinerea, gula abdomineque albis. .

Hirundo riparia, Lin. Syft. i. p. 344. 4.-Faun. Suec: $\mathrm{N}^{\circ}$ 273.-Gmel. Syft. i. p. 1019.-Brun. $\mathrm{N}^{\circ} 29$ 1.-Muller, p. $289 .-$ Frifch. t. i 8. -Georgi, N ${ }^{\circ} 75 .-K r a m . ~ E l$ : p. 38 1. 4.-Sepp. Vog. p. 35. -Raii Syn. p. 7 1. A. 3.-Will. p. I56. t. 39-Brif. ii. p. 506. 12.-Id. 8 vo. i. p. 299.-Klein. Av. p. 83.3.-Id. Stem. p. I6. t. 17. f. 5. a,-c,-Id. Ov. p. 27 . t. 10. f. 4,-Borowfk. Nat. iii. p. 156. 4 . .

L'Hirondelle 
L'Hirondelle de rivage, Buf. vi.p. 632.-Pl. Enl. 543. f. 2. Rondine riparia, Zinnan. Uov. p. 49. t. 1 2. f. 35.-Cett. uc. Sard. p. 235. Sand-Martin, or Shore-bird, Br. Zool. i. N' $170 .-I d$. fol. 97.t. Q. f. 1.-Arct. Zool. ii. $\mathrm{N}^{\circ}$ 332.-Alb. ii. t. 56. b.-Cat. Car. App. 37. -Lath. Syn. iv. p. $5^{68}$. 10.

Habitat in Europe et Americe collibus arenofis abruptis, foramine ferpentino. $-4 \frac{3}{4}$ pollices longa. $-N i d u s$ ex ftraminibus et plumis.Ovum albidiffimum, femipellucidum, immaculatum. $-P$ edes nudi, poftice plumofi.-Inter hirundines forte fpecies minima.

I.

rupeftris. H. murina fubtus albida, remigibus caudaque nigricantibus, rectricibus latere interiore macula ovali alba.

Hirundo rupeftris, Scop. Ann. i. N०253--Gmel. Syft. i. p. 1019. Rock Swallow, Lath. Syn. iv. p. 569. I 1 .

HaBitat in Carniola; magnitudine urbica.-Pectus pallidum : $a b$ domen cinereum: cauda emarginata nec forcipata: pedes nudi,-Nidum argillofum ædificat in fcaphis rupium præruptarum.

12.

montana. H. cinerea fubtus rufefcens, rectricibus, duabus intermediis extimifque exceptis, latere interiore macula ovata alba.

Hirundo montana, Gmel. Syft. i. p. 1020.

L'Hirondelle grife des rochers, Buf. vi. p. 641.-Faun. Arag. p. 91.

Crag Swallow, Lath. Syn. iv. p. 570. 12.

Habitat in Europa auftraliore; vix a præcedente diftincta.

13.

dauurica. H. cærulea fubtus alba, temporibus uropygioque ferrugineis, rectrice extima longiffima macula alba intus notata.

Hirundo daurica, Lin. Mant. I77 1. p. 528.-AEt. Holm. 1769.-Gmel. Syjt. i. p. 1024.

alpeftris, Pall. It. ii. p. 709. I9.

Daurian Swallow, Lath. Syn. iv. p. 570. I3.

HaBItat in Sibirice rupibus elatis, et fpeluncis montanis.-Nidus maximus, hæmifphericus, tuberculis limofis eleganter purifimeque exftructus, fine ullo gramine admifto; canalis ad aliquot pollices a nido extenfus pro aditu.

Corpus magnitudine domeftice, fupra caruleo-chalybeum, nitens, fubtus canum : tempora ferrugineo-rufa, colore pofterius coadunato ad nucham : remiges primores nigricantes apicibus obtufis ftria fufca, prima longiore: criffum cinerafcens, pennarum apicibus nigris.

H. nigricans, 
I4.

A V E S P A S E R E S. Hirundo.

erythroce- H. nigricans fupra albo marginata fubtus alba, capite rubro, alis cau. phala.

15. daque fufcis.

Hirundo erythrocephala, Gmel. Syft. i. p. 1024.

Red-headed Swallow, Lath. Syn. iv. p. 57 I. 14.

Habitat in India; parva fpecies.

aoona- H. nigricans fubtus cinerafcens, uropygio albido.

lafchken- Hirundo Unalafchkenfis, Gmel. Syft. i. p. 1025.

fis. Aoonalafchkan Swallow, Lath. Syn. iv. p. 571 . 15.

I6.

Habitat in Aoonalajcbka. $-4 \frac{1}{2}$ pollices longa.

indica. H. fufca, pileo rufo, corpore fubtus albido.

Hirundo indica, Gmel. Syft. i. p. 1025.

Rufous-headed Swallow, Lath. Syn. iv. p. 571 . 16. t. 56.

HABItat in India. -4 pollices longa.

17.

nigra. H. tota nigra, alis longiffimis, cauda forficata.

Hirundo apos dominicenfis, Brif. ii. p. 5 I 4. I6. t. 46. f. 3.-Id. 8 vo. i. p. 301 .

- nigra, Gmel. Syft.i. p. 1025.

Le petit Martinet noir, Buf. vi. p. 668.-Mem. Sur Cay. ii. p. 276.

Black Swallow, Lath. Syn. iv. p. 572.17.

Haвiтat in Dominicenfi infula, Cayana. -6 fere pollices longa.-Nidificat in terra.-Variat fafcia frontali alba.

18.

domini- H. nigro-chalybea, abdomine albo, rectricibus nigricantibus.

cenfis. Hirundo dominicenfis, Brif. ii. p. 493. 3.-Id. 8 vo. i. p. 295.-Gmel. Syfti. i. p. 1025 .

- cantu Alaudam referens, Klein. Av. p. 83. 5.

Le grand Martinet à ventre blanc, Buf. vi. p. 669 .

Hirondelle d'Amerique, $P l$. Enl. 545. f. r.

St. Domingo Swallow, Lath. Syn. iv. p. 573. 18.

Навітат in Dominicenfi infula. -7 pollices longa.

19.

peruviana. H. nigra fubtus alba, fafcia abdominali cinerafcente, alis caudaque pallide grifeis.

Hirundo peruviana major, Brif. ii. p. $498.7 .-I d .8$ vo. i. p. 297. Gmel. Syft. i. p. 1025 . 


\section{8 \\ A V E S P A S S E R S. Hirundo.}

Le Martinet noir et blanc à ceinture grife, Buf. vi. p. 670.

Peruvian Swallow, Lath. Syn. iv. p. 573. 19.

20.

cinerea. H. nigra nitens fubtus cinerea, rectricibus margine grifeo-flavicantibus.

Hirundo cinerea, Gmel. Syft. i. p. 1026.

Hirundo peruviana, Brif. ii. p. 498. 6.-Id. 8 vo. i. p. 297.

La petite Hirondelle noire à ventre cendré, Buf. vi. p. 673.

Afh-bellied Swallow, Latb. Syn. iv. p. 573. 20.

Habitat in Peru et Otabeite; domeftica minor.

ß. H. tota grifeo-nigricans.

Martinet de la Louifiane, Pl. Enl. 725. f. 2.-Buf. vi. p. 669.-Lath. Syn. iv. p. 572.17 . fect. 3 .

HabITAT in Louifiana.-Ale cauda longiores.

$2 \mathrm{I}$.

chalybea. H. nigro-chalybea fubtus fufco-grifea, rectricibus nigris.

Hirundo chalybea, Gmel. Syft: i. p. 1026.

Hirundo cayanenfis, Brif. ii. p. 495 . 4. t. 46. f. r. -Id. 8 vo. i. p. 296.

Hirondelle de Cayenne, Buf. vi. p. 675. - Pl. Enl. 545. f. 2.

Chalybeate Swallow, Lath. Syn. iv. p. 574. 22.

Habitat in Cayana; ova ponens in cavis arborum emortuarum abfque nido.

22.

purpurea. H. violacea cæruleo-nitens, cauda forficata. (Mas.)

Hirundo purpurea, Lin. Syft. i. p. 344. 5.-Kalm. It. iii. p. 88.-Gmel. Syf. i. p. 1020 .

- apos carolinenfis, Brif. ii. p. 515. 17.-Id. 8 vo. i. p. 30 I.

- violacea, Gmel. Syft. i. p. 1026.

Le Martinet couleur de pourpre, Buf. vi. p. 676.

Hirondelle bleue de la Caroline, Buf. vi. p. 674.-Pl. Enl. 722.

Purple Martin, Cat. Car. i. t. 5 I.

Violet Swallow, Latb. Syn. iv. p. 574. 2 I.

Purple Swallow, Arct. Zool. ii. No 333. -Lath. Syn.iv. p. 575.23.

H. nigro-cærulefcens, ore fubtufque cinereo-exalbida. (Femina.)

Hirundo fubis, Lin. Syft. i. p. 344. 7.-Gmel. Syft. i. p. IO21.

Hirundo freti Hudfonis, Brif. $s p p$. p. 56. 18.-Id. 8vo. i. p. 302.

Hirondelle 


\section{A V E S P A S E R E S. Hirundo.}

Hirondelle de la baie d'Hudfon, Buf. vi. p. 677.

Great American Martin, Edw. t. I 20.

Canada Swallow, Lath. Syn. iv. p. 575. 24.

Habitat in America Septentrionali, ad domos. $-7^{-8}$ pollices longa.

-Indicat Gallinis appropinquantes Accipitres.

23.

Tapera. H. rectricibus fubæqualibus, corpore fufco fubtus grifeo-fufco, abdomine albo.

Hirundo Tapera, Lin. Syft. i. p. 345. 9.-Gmel. Syft. i. p. 1022.-Raii Syn. p. 72.5.-p. $185.32 .-$ Will. p. 1 57.-Sloan. Fam. p. 312. 5 1.

Hirundo americana, Brif. ii. p. 502 . I0. t. 45 . f. 3. $-I d .8$ vo. i. p. 298. -Klein. Av. p. 83. IV. I.

La Tapere, Buf. vi. p. 678.

Brafilian Swallow, Latb. Syn. iv. p. 576.25.

Habitat in Brafilia, Cayane, Jamaica. $-5 \frac{3}{4}$ pollices longa.

Cauda vix forficata.

24.

torquata. H. fufca fubtus alba, fafcia pectorali femoribufque fufcis.

Hirundo torquata, Gmel. Syjt. i. p. 1022.

Hirondelle brune et blanche à ceinture brune, Buf. vi. p. 680.

Hirondelle brune à collier du Cap de B. Efp.-Pl. Enl. 723. f. I.

Brown-collared Swallow, Lath. Syn. iv. p. 577. 26.

Habitat ad Caput Bone Spei.-6 pollices longa.

Roftrum inter et oculum macula alba: cauda apice integra.

25.
leucoptera. H. cirerea cæruleo-nitens, fubtus uropygio alifque nebulofo-albis.

Hirundo leucoptera, Gmel. Syft. i. p. ro22.

Hirondelle à ventre blanc de Cayenne, Buf. vi.p. 68 I.-Pl. Enl. 546.2.

White-winged Swallow, Latb. Syn. iv. p. 577.27.

Habitat in Cayana.-4-5 pollices longa.

ß. H. fupra fufca fubtus alba fufco maculata.

Hirondelle à ventre tacheté de Cayenne, Buf. vi. p. 682.-Pl. Enl. 546. 1.-Lath. Syn. iv. p. 577. A.

HaBItat in Guiane paludolis. 

26.
580
A V E S
P A S S E R E S.
Hirundo.

efculenta. H. nigricans fubtus albida, rectricibus omnibus apice albis.

Hirundo efculenta, Lin. Syft. i. p. 343. 2.-Gmel. Syft. i. p. 1016.Borowelk. Nat. iii. p. 156. 3.- Oß. Voy. ii. p. 330.

Apus marina, Rumph. Herb. vi. p. 183. t. 75. f. 4.-Olear. Muf. xxv. t. I4. f. 5.6 .

Hirundo riparia cochinfinenfis, Brif. ii. p. 5 10. 14. t. 46. f. 2. A. (avis cum nido.)-Id. 8 vo. i. p. 30o.-Kampf. Aman. 833 .

Hirundo finenfis nido eduli, Raii Syn. p. 72. 6.-Will. p. 157.-Id. (Angl.) p. 21 5.-Klein. Av. p. 84. 7 .

Hirundo maritima, Pbil. Tranf. xxiii. p. I 396.36.

La Salangane, Buf. vi. p. 682.-Voy. de Siam, i. pp. 278, 279.

Layong-Layong, Marfd. Sumatr. p. $14 \mathrm{I}$.

Efculent Swallow, Lath. Syn. iv. p. 578. 28.-Forrefi. Voy. p. 28.

HABITAт in $A f_{i \in}$ variis partibus; magnitudinis incerte.-In fcopulis ad littora maris nidificant hæ aves; ex fpuma maris bafin fcopulorum alluentis, quamdam colligentes materiam, forte ex mollufcis aliifve gelatinofis marinis, fubftantia Icthyocollam referentem, ex qua nidos conftruunt, et quos sinenfes in fummas habent delicias.

27.

borbonica. $\mathrm{H}$. fufco-nigricans fubtus grifea fufco maculata, cauda integra.

Hirundo borbonica, Gmel. Syyt. i. p. 1017.

L'Hirondelle des blés, Buf. vi. p. 694 .

Wheat Swallow, Latb. Syn. iv. p. 581.29.

Habitat in infule Francie campis tritico confitis; magnitudine apodis. Ovum grifeum fufco maculatum.

$\beta$. H. fufco-nigricans fubtus grifea maculis longitudinalibus fufcis, rectricibus 3 exterioribus apice albidis.

Hirondelle de Bourbon, Pl. EnI. 544. 2.-Lath. Syn. iv. p. $58 \mathrm{I}$.

28:

francica. H. nigricans, fubtus uropygioque albido.

Hirundo francica, Gmel. Syft. i. p. 1017.

La petite Hirondelle noire à croupion gris, Buf. vi. p. 696.

Grey-rumped Swallow, Latb. Syn. iv. p. 582. 30.

Habitat in India, infula Francia, ad aquas dulces, $-4 \frac{1}{2}$ pollices longa.

H. fufco- 
29.

A V E S P A S E R E S. Hirundo.

americana. $H$. fufco-nigricans viridi nitens fubtus albida, uropygio criffoque rufis. Hirundo americana, Gmel. Syst. i. p. 1017.

L'Hirondelle à croupion rouge et queue quarrée, Buf. vi. p. 698. Rufous-rumped Swallow, Latb. Syn. iv. p. 582. 31 .

Habitat in America meridionali. $-6 \frac{1}{2}$ pollices longa.

Cauda apice integra.

$\beta$. H. fufco-nigricans fubtus albida, gula uropygio criffoque rufis.

A priore variat gula rufa, uropygio criffoque albo magis vario, remigibus abfque albedine, cauda fubforcipata. An diftincta fpecies?

30.

Pelafgia. H. fufca, gula albida, rectricibus æqualibus apice nudo fubulatis. Hirundo pelafgia, Lin. Syft. i. p. 345. 10.-Gmel. Syft. i. p. I023. _ cauda vel fexies divifa, Klein. Av. p. 84. 6.

Hirundo carolinenfis, Brif. ii. p. 501. 9. -Id. 8 vo. i. p. 1023.

Hirondelle de la Caroline, Buf. vi. p. 700.

American Swallow, Cat. Car. App. t. 8.

Aculeated Swallow, Arct. Zool.ii. N'335.t. 1 8.-Lath.Syn. iv. p. $5^{8} 3.32$. longa.

Habitat in America; in caminis nidum conftruens. $-4 \frac{x}{4}$ pollices

$\beta$. L'Hirondelle brune acutipenne de la Louliane, Buf. vi. p. 699.Pl. Enl. 726. 2 .

Variat gula juguloque albidis, fufco maculatis.

$\gamma$. Hirondelle acutipenne de Cayenne, Buf. vi. p. 701.-Pl. Enl. 726 . f. I.

HaвIтAт in Cayana.-Corpus fupra fufco-cærulefcens; uropygio grifeo; collo fubtus grifeo-rufo.

31.

acuta. H. nigra fubtus fufca, gula grifea, rectricibus apice nudo fubulatis.

Hirundo acuta, Gmel. Syft. i. p. 1023.

-martinicana, Brif. ii. p. 499. 8. t. 45 . f. 2. -Id. 8 vo. i. p. 297. L'Hirondelle noire acutipenne de la Martinique, Buf. vi. p. 702.-Pl. Enl. 544. f. 1 . Sharp-tailed Swallow, Lath. Syn. iv. p. 584. 33.

Habit at in Martinica; præcedentibus multo minor.--In quibufdam corpus fubtus rubro-fufcum. An a Pelafgia fatis diftincta? 
Apus, H. nigricans, gula alba, digitis omnibus quatuor anticis. Hirundo Apus, Lin. Syjt. i. p. 344. 6. - Faun. Suec. $\mathrm{N}^{\circ}$ 272.-Gmel. Syft. i. p. 1020.-Scop. Ann. i. $\mathrm{N}^{\circ} 25$ I. - Brun. $\mathrm{N}^{\circ}$ 292.--Muller, No $290 .-$ Kram. El. p. 380 . 3.-Frifch. t. 17. f. 1.-Georgi, p. 175.-Faun. Arag. p. 90.-Sepp. Vog. t. p. 37.-Raii Syn. p. 72. A. 4.-Will. p. I56. t. 39--Brif. if. p. 512 . 15.-Id. 8 vo. i. p. 301.-Klein. Av. p. 83. 4.-Borowfk. Nat. iii. p. $157 \cdot 5$.

Le grand Martinet, Pl. Enl. 542. f. r.-Buf. vi. p. 643 . Rondone, Ziman. Uov. p. 47. t. 7. f. 33.-Cett. uc. Sard. p. 23 I. Swift, Br. Zool. i. No 171. t. 57.-Id. fol. 97.-Arct. Zool. ii. No 334. -Will. (Angl.) p. 2 14. t. 39.-Alb. ii, t. 55.-Latb. Syn. iv. p. $584 \cdot 34$.

HaвiтAт per omnem terrarum orbem; nidificans in templorum foraminibus et turribus; migratoria; fub initio Niaii veniens, et medio Augupi rediens.

Color totus, excepta gula, nigricans; femina ad fufcum vergens.$\mathrm{Ob}$ alarum longitudinem et brevitatem pedum humo ægre fe tollere poteft: cauda rectricibus decem. Ovum album.

Ex digitis omnibus anticis, naribus ellipticis cum duplicatura in latere interno, mondibula quoque inferiore deflexa, poffet hæc avis cum fequentibus proprium genus conftituere?

33 .

Melba. H. grifeo-fufca, gula abdomineque albis.

Hirundo Melba, Lin. Syft. i. p. 345. I I.-Gmel. Syft. i. p. 1023.Faun. Arag. p. 90.

- major hifpanica, Brif. ii. p. 504. I1.-Id. 8vo. i. p. 299.Klein. Av. p. 83. IV. 2.

- - alpina, Scop. Ann. i. $\mathrm{N}^{\circ} 252$.

Le grand Martinet à ventre blanc, Buf. vi. p. 660.

Greateft Martin or Swift, Edw. t. 27.-RuJJ. Alep. p. 70.

White-bellied Swift, Latb. Syn. iv. p. 586. 36 .

Habitat in Europa aufraliore, Afia; pracedente paulo major; nidificat in excelfis alpium rupibus.

Corpus fupra obfcure fufcum fubtus album, lateribus fufcis maculis variegatis : lorquis fufcus maculis nigris : pedes incarnati anterius et intus plumofi, digitis omnibus antrorfum verfis.

H. violaceo: 
A VES PAS SERES. Caprimulgus. 583

$34 \cdot$

cayanenfis. H. violaceo-nigricans, capite nigro, gutture fafcia oculari bifida femoribufque albis.

Hirundo cayanenfis, Gmel. Syft. i. p. 1024.

Le Martinet à collier blanc, Buf. vi. p. 671.-Pl. Enl. 725. f. 2.

White-collared Swift, Latb. Syn. iv. p. 587. 37 .

Habitat in Cayana; magnitudine urbica.-Nidum conicum intus longitudinaliter bipartitum ex pappo apocyni ftruit, 9 pollices longum.

Pedes plumofi, digitis omnibus anticis.

35 .

finenfis. H. fufca fubtus grifeo-ruffefcens, pileo rufo, gula orbitifque albis.

Hirundo finenfis, Gmel. Syft. i. p. 1021.

Le grand Martinet de la Chine, Son. Voy. Ind. ij. p. 199.

Chinefe Swift, Latb. Syn. iv. p. 586. 35 .

HABITAT in Cbina. $-\mathrm{I} I \frac{\mathrm{T}}{2}$ pollices longa.

\section{G EN S XLVII. CA PRIMULGUS.}

Roftrum modice incurvum, minimum, fubulatum, bafi depreffum.

Vibriffe ad os ferie ciliari.

Rictus amplifimus.

Lingua acuta, integerrima.

Cauda integra, rectricibus decem.

Pedes breves, ungue medio latiufculo, plerifque ferræ inftar intus dentato.

I.

grandis. C. nigricante albo flavefcenteque variegatus fubtus albo nigroque varius, area oculorum flavefcente, pedibus albis.

Caprimulgus grandis, Gmel. Sy/t. i. p. 1029 .

Ibijau, Caprimulgus americanus (magn. Noctua) Raii Syn. p. 27.20Will. p. 70.-Id. (Angl.) p. 108. t. I4. f. mala.

Caprimulgus brafilienfis major nævius, Brif. ii. p. 485.70. 7.-Id. $8 \mathrm{vo}$. i. p. 293 .

Le grand Ibijau, Buf. vi. p. 54I.

Grand Goatfucker, Lath. Syn. iv, p. 590. I.

Habitat 
${ }_{584}$ A V E S P A S S E R E. Caprimulgus.

HaBitat in Cayana; longitudine fere 2 pedum.-Inter congeneres gigas. - Os quando aperit pugnum humanum facile admittit.

Pedes fufci, ad digitos fere plumofi : unguis intermedius planus.

2.

jamaicen- C. ferrugineus nigro ftriatus, alis albo variegatis, remigibus fufcis ma-

fis. culis albis, rectricibus fafciis nigris.

Caprimulgus jamaicenfis, Gmel. Syft. i. p. I029. .

Guira querea, Raii Syn. p. I80. 3.-Buf. vi. p. 536.-Sloan. Fam. ii. p. 295 .

Mountain Owl, Brozon. Fam. p. 473.

Jamaica Goatfucker, Lath. Syn. iv. p. 591. 2. t. 57.

Hавгтат in famaica fylvis. - 16 pollices longus.

Irides rubro-flavefcentes : pedes flavi, ungue medio plano.

grifeus. C. grifeus, alis nigricantibus grifeo fafciatis, rectricibus fafciis fufcis.

Caprimulgus grifeus, Gmel. Syft.i. p. 1029 .

L'Éngoulevent gris, Buf. vi. p. 548.

Grey Goatfucker, Lath. Syn. iv. p. 592.3.

HaвiтAт in Cayana.-I 3 pollices longus.

4.

carolinen- C. grifeo nigricanteque undulatus, fubtus grifeo-rufefcens lineolis ni-

fis. $\quad$ gricantibus, rectricibus tribus exterioribus latere interiore albis.

Caprimulgus carolinenfis, Brif. ii. p. $475.2 .-I d$. 8 vo. i. p. $290 .-$ Gmel. Syft. i. p. 1028.

Engoulevent de la Caroline, Buf. vi. p. 532.

Carolina Goatfucker, Cat. Car. i. t. 8.

Rain Bird, Brown. Fam. p. 467.

Short-winged Goatfucker, ArEt. Zool. ii. N 336. t. I 8.

Carolina Goatfucker, Latb. Syn. iv. p. 592. 4.

HABITAT in Caroline montibus. - I I $\frac{1}{4}$ pollices longus.

Rerizges primores tres majufcula macula alba: pedes fufci, unguibus nigris, medio ferrato. Ovum olivaceum, maculis nigricantibus.

5 .

europæus. C. niger cinereo fufco ferrugineo et albo varius, fubtus albo-rufefcens fafciis fufcis.

Caprimulgus europæus, Lin. Syft. i. p. 346. x.-Faun. Suec. $\mathrm{N}^{\circ} 274 .-$ Gmel. Syf. i. p. 1027... Ger. Orn. i. p. 91. t. 99.-Faun. Arag. p. 91.-Scop. Am. i. $\mathrm{N}^{\circ} 254 .-$ Brun. $\mathrm{N}^{\circ} 293 .-$ Muller, $\mathrm{N}^{\circ} 29 \mathrm{I} .-\frac{\mathrm{P}}{\text { Georgi, }}$ 
A V E S P A S S E R E S. Caprimulgus. $\quad 585$

Georgi, p. 175.-Frifch. t. 101.-Kram. El. p. 28 1. 5. (Hirundo.) Sepp. Vog. t. p. 39.-Raii Syn. p. 26. A. 1.-Will. p. 70. t. 14.Brif. ii. p. 470 . 1. t. $44 .-I d$. 8 vo. i. p. $289 .-S c b a f$. El. t. 23.Klein. Av. p. 8 r. 1. t. 1. f. 1.-Id. Stem. p. 15. t. 17. f. 1. $\alpha . \beta . \gamma$. Borowfe. Nat. iii. p. 152. t. 64 .

L'Engoulevent, Buf. vi. p. 512.

Le Crapaud-volant, $P l$. Enl. 193.

Chathuant, Hift. Prov. i. p. 338.

Covaterra, Zinnan. Uov. p. 94. t. 15. f. 84.-Cett. uc. Sard. p. 236. (Caprimulgo.)

Nocturnal Goatfucker, Br. Zool. ii. $\mathrm{N}^{\circ}$ 173. t. 59. $-I d$. fol. 97. t. R. R. I.

European Goatfucker, Arct. Zool. ii. p. 437. A.-Will. (Angl.) p. 107. -Alb. i. t. 10.-Borlaf. Cornw. t. 24. f. 13.-Hift. Selb. pp. 62. 94.-Latb. Syn. iv. p. 593. 5.-Id. Sup. p. 194.

Навітат in Europa, Afia, Africa; nemoribus Anglia fumma æeftate frequens. - $10 \frac{1}{2}$ pollices longus.-Nocturna avis, victitans fcarabais, pbalanis.-Unguis medius intus ferratus.

Mas remigibus tribus primoribus intus macula alba: rectricibus duabus exterioribus albo terminatis. Ova 2 in nuda terra parit caruleoalbida maculis majufculis difformibus cæruleo-fufcis.

6.

virginia- C. fufco-nigricante rufefcente cinereoque varius, fubtus albidus fafciis nus. nigricantibus, gula lunula alba.

Caprimulgus minor americanus, Lin. Syft. i. p. 346. I. $3 .-G e r$. Orn. i, p. 92. t. 100.-Kalm. It. iii. p. 93 .

Gmel. Syft. i. p. 1028.

Whip-poor-will, Buf. vi. p. 534.-Cat. Car. iii. t. 16.-Edw. t. 63.

Long-winged Goatfucker, ArEt. Zool. ii. $\mathrm{N}^{\circ} 337$.

Virginia Goatfucker, Lath. Syn. iv. p. 595. 6.-Id. Sup. p. 194.

Habitat in America; Europao minor.-8-9 pollices longus.

Unguis medius intus denticulatus. Mas remigibus quinque primoribus fafcia alba : rectricibus duabus extimis macula alba.

$7 \cdot$

albicollis. C. rufo-fufcus albo nigricanteque varius, fubtus fufco nigricanteque tranfverfim lineatus, gula macula triangulari alba.

Caprimulgus albicollis, Gmel. Syft. i. p. 1030.

White-throated Goatfucker, Lath. Syn. iv. P. 596. 7. 
586 A V E S P A S S E R E S. Caprimulgus.

Habitat in Cayana.-10 10 pollices longus.-Unguis medius elongatus, intus dentatus: fafcia remigum alba: ređtrices 3,3 , albæ, 2, 2, latere interiore albæ, macula prope bafin alba; extima nigræ, macula 8. pariter prope bafin alba notatæ. Præcedenti multum affinis.

guianenfis. C. fulvus maculis difformibus ftriifque rufis notatus, fub gula lunula alba.

Caprimulgus guianenfis, Gmel. Syft. i. p. I030.

Le Montroyau de la Guiane, Buf. vi. p. 549.

Tette-chevre roux de la Guiane, Pl. Enl. 733 .

Guiana Goatfucker, Latb. Syn. iv. p. 598. 9.

Habitat in Guiana. -9 pollices longus.-Remiges 5 vel 6 medio macula alba notate. Variat fafcia rectricum alba.-Remiges et rectrices: 2 exteriores laterales nigricantes.

9.

rufus. C. rufus nigro varius, tectricibus alarum corporeque fubtus fafciis nigricantibus, remigibus rufo nigroque, rectricibus nigro fafciatis.

Caprimulgus rufus, Gmel. Syft. i. p. 1030.

L'Engoulevent roux de Cayenne, Buf. vi. p 550.

Crapaud-volant, ou Tette-chevre de Cayenne, $P l$ Enl. 735.

Rufous Goat-fucker, Lath. Syn. iv. 597. 8.

HABITAT in Cayana.-10 $\frac{x}{2}$ pollices longus.-Irides flavæ.

ro.

brafilia- C. nigricans flavefcente varius punctulis albis, fubtus albo nigroque vanus. rius, area oculorum flavefcente-alba.

Caprimulgus brafilianus, Gmel. Syf. i. p. I031.

Caprimulgus brafilienfis nævius, Brif. ii. p. $4^{8} 3$. 6. -Id. 8 vo. i. p. 292 . Caprimulgus americanus (minor) Raii Syn. p. 27. 2.-Will. p. 70. t. 14. Ibijau, Buf. vi. p. 539--Will. (Angl.) p. 108.-Pet. Gaz. t. 59. f. I. Brafilian Goatfucker, Lath. Syn. iv. p. 598. Io.

Habitat in Brafilia; magnitudine Hirundinis.

Pedes albi, ungue medio dentato: caudam flabelli inftar expandit.

11.

femitor- C. nigricans rufo grifeoque maculatus, collo inferiore lunula alba.

quatus. Caprimulgus femitorquatus, Gmel. Syft. i. p. 103I.

Le petit Engoulevent de Cayenne, Buf: vi. p. 540.-Pl. Enl. 734.

White-collared Goatfucker, Lath. Syn. iv. p. 599. 11 .

Habitat in Cayana. -8 pollices longus. 
12.

A V E S P A S S E R E S. Caprimulgus. $\quad 587$

cayanus. C. rufo grifeoque varius nigro undulato-lineatus, gula fafciaque alarum alba, temporibus rufis ftriis 5 nigris.

Caprimulgus cayennenfis, Gmel. Syjt. i. p. $10 \jmath_{\mathrm{I}}$.

L'Engoulevent de Cayenne, Buf. vi. p. 545.-Pl. Enl. 760.

White-necked Goatfucker, Lath. Syn. iv. p. 599. 12.

Habitat in Cayana. $-7 \frac{x}{2}$ pollices longus.

Rectrices laterales renigefque nigræ; harum 5 primæ macula alba notatæ, unde fafcia : rectrices 2 intermediæ grifex, fafciis 5 nigricantibus, laterales margine albæ.

I3.

acutus. C. nigricante fafciatus fupra grifeus fubtus rufus, capite colloque rufofufcis, rectricibus apice fubulatis.

Caprimulgus acutus, Gmel. Syft. i. p. I०31.

L'Engoulevent acutipenne de la Guiane, Buf. vi. p. 547.-Pl. Enl. 732. Sharp-tailed Goatfucker, Lath. Syn. iv. p. 600. 13.-Id. Sup. p. 195.

HaBıт Aт in Guiana. $-7 \frac{x}{2}$ pollices longus.

Remiges 4-5 primores macula alba: ređtrices rufæ maculis nigris, fafciaque apicis nigra fuperius albo marginata.

I4.

america- C. toto corpore grifeo nigro et xerampelino variegatus, naribus cylinnus. draceis.

Caprimulgus americanus, Lin. Syft. i. p. 346. 2.-Gmel. Syft. i. p. 1032. -Borowfk. Nat. iii. p. I 52.2.

_- jamaicenfis, Brif. ii. p. 480.4.-Id. 8 vo. i. p. $291 .-R a i i$ Syn. p. 180. 4.-Sloan. Fam. p. 296. 4. t. 255 . f. 1. $-K l e i n . A v$. p. 81.2.

Strix capite lavi, \&c. Brown. Fam. p. 473.

L'Engoulevent à lumettes, Buf. vi. p. 543.

American Goatfucker, Lath. Syn. iv. p. 600. 14.

Hавітат in famaica, Guiana. -7 pollices longus.--Unguis medius intus dentatus. - Nares velut tubuli quidam ad $\div$ digiti altitudinem fupra roftri fuperficiem extent.

I5.

corquatus. C. cinereo-fufcus maculis obfcure flavis et albicantibus varius, torque aureo, reetricibus binis intermediis longioribus.

Caprimulgus torquatus, Gmel. Syft. i. p. 1032.

Caprimulgus brafilienfis, Brif. ii. p. 48 I. 5-Id. 8vo. i. p. 292. 
588 A V E S P A S S E R E S. Caprimulgus.

Guira-querea, Raii Syn. p. 27.3.-Will. p. 71. t. 14.-Klein. Av. p. 82.3 .

Gold-collared Goatfucker, Lath. Syn. iv. p. 601. 15.

Haвiт at in Brafilia; magnitudine Alauda.

16.

Cauda rotundata: pedes obfcuri, ungue medio ferrato.

afiaticus. C. cinerafcens nigro ferrugineoque nebulofus, pectore fafciis cinereis, ftriga verticali nigricante, maxillari maculaque gulæ pallidis.

Bombay Goatfucker, Lath. Syn. Sup. p. 195. 16.

$\mathrm{H}_{\text {ABIT AT }}$ in India. $-8 \frac{1}{2}$ pollices longus.

Unguis medius dentatus: remiges primores 4 intus macula alba: 17. rectrices rufo fafciatæ, extimæ 2 apice albæ.

indicus. C. cinerafcens, nigro tranfverfim lineatus, genis pectore alifque ferrugineo maculatis, rectricibus cærulefcentibus nigro fafciatis, extima ferrugineo nigroque varia.

Indian Goatfucker, Lath. Syn. Sup. p. 196. 17.

Habitat in India.-Vertex et dorfun cinerafcens lineis minutis ni-

18.

novæHol- C. fufco nigro albidoque nebulofus fubtus albidus, collo pectoreque landix. fafciis obfcuris, crifta frontali ereste fetacea.

Crefted Goatfucker, Pbill. Bot. Bay, t. p. 270.

Habitat in nova Hollandia; Europao paulo minor. $-9 \frac{x}{2}$ poll. long.

Roftrum, ut in congeneribus, rictu amplo intus flavefcente, ad latera fetis duriufculis obfito: pone bafin roftri fuperius quafi crifta ereeta e fetulis 12 lateribus fparfim barbatis: corpus fupra fufcum nebulis fafciifque albidis, fubtus album, collo peztoreque fafciolis nigricantibus minus confpicuis: remiges fufcæe, 5-6 exteriores latere exteriore maculis albidis : cauda rotundata fufca, fafciis $\mathbf{2} 2$ albidis nigricante nebulofis : roftrum nigrum: pedes longiores flavi. 
A V E S C O L U M B Æ. Columba.

\section{O R D O IV. C O L U M B Æ.}

\section{GENUS XLVIII. C O L U M B A.}

Roftrum rectum, verfus apicem defcendens.

Nares oblongæ, membrana molli tumida femitectæ.

Lingua integra.

Pedes breves, ambulatorii.

I.

* Cauda æquali.

Enas. C. cærulefcens, cervice viridi-nitente, dorfo poftico cinerafcente, fafcia alarum duplici apiceque caudæ nigricante.

Columba CEnas, Lin. Syst. i. p. 279. 1. $\beta .-F a n$. Suec. $\mathrm{N}^{\circ} 207 .-$ Gmel. Syft. i. p. 769.-Frifch. t. 139.-Georgi, p. 173.-Faun. Arag. p. 83.-Faun. Arab. p. 7. 1 1.-Sepp. Vog. t. p. 13.-Kram. El. p. 358. 1. a.-Scbaef. El. Orn. t. 28.-Raii Syn. p. 62. A. 10. -Will. p. 136 t. 35-Brif. i. p. 86. 5.-Id. 8 vo. i. p. 20.-Brun. $\mathrm{N}^{\circ}$ 203.-Borowfk. Nat. iii. p. 207. 2.

Columba, lignorum proprie, Klein. Av. p. I I g. 8.-Id. Ov. p. 33. Palumbus minor, Klein. Stem. p. 27. t. 29. f. 2. a-c ?

Stock Pigeon, or Stock Dove, Br. Zool. ii. App.-Arct. Zool. ii. p. 329. A.-Will. (Angl.) p. 185.-Alb. ii. t. 46.-Latb. Syn. iv. p. 604. 1.-Id. Sup. p. 197 .

HaвiтAт in Europa.-14 poll. longa.-Fugulum et pectus vinaceum. Omnes Columbe regulariter ova pariunt alba.

2.

domeftica. Columba minor verficolor, dorfo inferiore albo.

Columba CEnas, Lin. Syft. i. p. 279. 1.-Faun. Suec. N॰207.-Gmel. Syft. i. p. $769 .-S c o p$. Ann. i. N 177.-Kram. El. p. 358. 1. $\beta$.

Columba vulgaris, feu domeftica, Raii Syn. p. 59. A. 1.-Will. p. 130. -Brif. i. p. 68. r. -Id. 8vo. i. p. 13.-Brun. $\mathrm{N}^{\circ} 203 .-$ Klein. Av. p. I18. 1.-Rom. Orn. i. p. 76. t. I1. 
2. $\beta$.

Le Pigeon commun, Buf. ii. p. 501.-Pl. Enl. 466.

Colombo domeftico, Cet. uc. Sard. p. I 35.

Common Pigeon, Br. Zool. $\mathrm{N}^{\circ}$ 101. t. 45.-Id. fol. 88. t. 88.-Sloan. fam. p. 302.-Brown. Fam. p. 468.-Alb. iii. t. 42. 44.-Will. (Aigl.) p. $180 .-$ Borow/k. Nat. iii. p. 207.

Livia. C. cinereo-cærulefcens, fafcia alarum duplici nigra, dorfo inferiore albo. Columba Livia, Brif. i. p. 82. 3.-Id. 8vo. i. p. 18.-Gmel. Syft. i. p. 769.-Raii Syn. p. 62. 8.-Will. p. 136.-Id. (Angl.) 186.Klein. Av. p. 119 . 10.-Rom. Orn. i. p. 8.3.

Le Bifet, Buf. ii. p. $498 .--$ Pl. Enl. 5 10.-Hift. Prov. i. p. 490.

Le Ramier, Hift. Surin. ii. p, 164. (m.)

Stock Dove, Alb. iii. t. 44 .

2. $\gamma$. Bifet Pigeon, Lath. Syn. iv. p. 605. 2. A.

rupicola. C. cinerea, pectore dilute vinaceo, fafcia alarum duplici fufco-nigricante, remigibus majoribus fufcis.

Columba rupicola, Raii Syn. p. 63. A. I 1.-Will. p. 136.-Klein. Av. p. II 9.9 .

Columba faxatilis, Brif. i. p. 84. 4.-Id. 8vo. i. p. I 9.-Will. p. I 36. -Gmel. Syft. i. p. 769 .

Rock Pigeon, Lath. Syn. iv. p. 608.-Will. (Angl.) 186. 9.

2. $\delta$.

hifpanica. C. verficolor, cera albido-furfuracea.

Columba hifpanica, Lin. Syft. i. p. 279.- Borowfk. Nat. iii. p. 210.4. Columba romana, Brif. i. p. 7 I. 2.-Id. 8vo. i. p. i 3.-Gmel. Syft. i. p. 770.-1t. Wgotb. 8 .

Pigeon Romain, Buf. ii. p. 5 10.-Pl. Enl. s 10.

Columba domeftica major, Raii Syn. p. 6o. 1.-Will. p. 131. t. 33.34. Roman Pigeon, Latb. Syn. iv. p. 608.-Will. (Angl.) p. I8I.

$\mathrm{Hæc}$ varietas duplo major $C$. domeftica.

2. E.

dafypus. C. pedibus hirfuto-pennaceis.

Columba dafypus, Lin. Syft. i. p. 279. A.-Gmel. Syft. i. p. 770.Frifcb. t. 145.-Brif. i. p. 73. A.-Id. 8 vo. i. p. 14.-Rom. Orn.

i. p. 78.-Borow/k. Nat. iii. p. 2 10. 3.-Zinnan. Uov. p. 32. t. 4. f. 12 .

Rough-footed Pigeon, Lath. Syn. iv. p. 6og.-Will. (Angl.) t. 33. 34 . C. pedibus 
2. $\zeta$.

A V E S C O L U M B Æ. Columba.

criftata. C. pedibus hirfuto-pennaceis, capite criftato.

Columba criftata, Brif. i. p. 73. B.-Id. 8vo. i. p. 14.-Gmel. Syft. i. p. 770.-Frifch. t. 144.

Pigeon huppé, Buf. ii. p. 510.

Crefted Pigeon, Latb. Syn. iv. p. 609.

2. $\eta$.

norvegica. C. capite criftato, corpore niveo, pedibus plumofis.

Columba norvegica, Brif. i. p. 74. C.-Id. 8vo. i. p. 14.-Gmel. Syf. i. p. 770 .

mercurialis, Brun. $\mathrm{N}^{\circ} 2150$

Norway Pigeon, Latb. Syn. iv. p. 609.

2. $\theta$.

Habitat in Norvegia.

barbarica. C. area oculorum nuda tuberculata furfuracea, macula alarum duplici nigricante.

Columba barbarica, Brif. i. p. 74. D.-Id. 8vo. i. p. 14.-Gmel. Syft. i. p. 770.-Raii Syn. p. 60. 8.-Will. p. 132.8. 16. t. 34.-Id. (Angl.) 182. 8. 16.-Buf. ii. p. 519.2 .

Columba turca, Brun. $\mathrm{N}^{\circ} 217$.

Barbary Pigeon, Latb. Syn. iv. p. 609.

Habitat in Barbaria. - Variant hæ capite criftato et fimplici.

2. $t$.

cucullata. C. pennis occipitis reflexo-erectis.

Columba cucullata, Lin. Syft. i. p. 280.-Gmel. Syft. i. 770,-Faun. Suec. $\mathrm{N}^{\circ} 207 . \zeta$. -Frifcb. t. I 50.-Brif. i. p. 79. E.-Id. 8 vo. i. p. 15.-Brun. $\mathrm{N}^{\circ} 21$ 1.-Borowes. Nat. iii. p. 21 1. 6.-Rom. Orn. i. p. 19. t. 1 2.-Raii Syn. p. 60. 6.-Will. p. 132.6. t. 33.-Klein. Av. p. 118.5 .

Pigeon nonain, Buf. ii. t. 19 .

Jacobine Pigeon, Latb. Syn. iv. p. 6ro.-Alb. iii. t. 43 .

Roftrum brevifimum eft.

2. $x$.

hifpida. C. plumis minimis ereetis, per dorfum alafque difperfis.

Columba hifpida, Lin. Syft. i. p. 280.-Gmel. Syjt. i. p. 770.

- crifpa, Brif. i. p. 76. G.-Id. 8vo. i. p. 15.

Pigeon frifé, Buf. ii. p. 519.3 .

Laced Pigeon, Latb. Syn. iv. p. 6 ro.

Habitat in India.

C. pennis 
2. $\lambda .592$ A V E S C O L U M B E. Columba.

turbita. C. pennis in pectore recurvis.

Columba turbita, Lin. Syft. i. p. 280.-Gmel. Syft. i. p. 77.

p. 75. F. -Id. 8vo. i. p. 15.-Raii Syn. p. 60. 7:-Will. p. 132.

7.-Frifch. t. 147.-Brun. No216.-Borowfk. Nat. iii. p. 21 I. 7. Pigeon à cravate, Buf. ii. p. 5 1 3.t. 23.

Turbit Pigeon, Latb. Syn. iv. p. 611 . -Will. (Angl.) p. 182. reflexæ.

2. $\mu$.

laticauda.

C. cauda erecta multipenna patula.

Columba laticauda, Lin. Syft. i. p. 280.-Gmel. Syft. i. p. 770.-Borow/k. Nat. iii. p. 2 I 1. 8 - Brif. i. p. 80. P. - Id. 8vo. i. p. 18.-Raii Syn. p. 60. 3-Will. p. 13r. 3. t. 34.-Id. (Angl.) p. 18 1. 3.Frifch. t. I $51 .-K l e i n . A v$. p. 118.3 .

Le Pigeon Paon, Buf. ii. p. 5 I1. t. 22.

Columba tremula, Brif. i. p. 8 I. Q.-Raii. Syn. p. 6o. 4.-Will. p. 132. 4.-I . (Angl.) I 8 1. 4.-Brun. No 209 .

Broad and narrow-tailed thaker Pigeons, Lath. Syn. iv. p. 6 I I. tia caudæe.

2. $v$.

gyratrix. C. fub volatu fe gyrans.

Columba gyratrix, Lin. Syjt. i. p. 280.-Gmel. Syft. i. p. 77 1.-Brif. i. p. 79. N.-Id. 8 vo. i. p. 17.-Frifch. t. 148.-Raii. Syn. p. 61. 1.0.-Will. p. 132. 10.-Borowfk. Nat. iii. p. 212.9.

Columba vertaga, Brun. $\mathrm{N}^{\circ} 205$. et var.

Le Pigeon culbutant, Buf. ii. p. 517 .

Tumbler Pigeon, Latb. Syn. iv. p. 6 I 2.-Will. (Angl.) p. i 82.

Domeftica paulo minor.-Inter volandum miros motus in aere exhibet.

2. $\xi$.

galeata. C. capite remigibus rectricibufque concoloribus, a corpore difverficoloribus.

Columba galeata, Lin. Syft. i. p. $280 .-$ Gmel. Syft. i. p. 77 1.-Brif. i. p. 80. O. -Id. 8 vo. i. p. 18.-Raii Syn. p. 61. 1 1.-Will. p. 132. I1.-Brun. $\mathrm{N}^{\circ} 210$.

Pigeon cuiraffé, Buf. ii. p. 5 I 5 .

Helmet Pigeon, Latb. Syn. iv. p. 61 2.-Will. (Angl,) p. 182.

C. cera 
2. 0

turcica. C. cera papillofa rubra.

Columba turcica, Lin. Syft. i. p. 28 1.-Gmel. Syft. i. p. 77 1.-Brif. i.

p. 76. H. -Id. 8vo. i. p. 16.-Will. t. 33.-Frifch. t. 149.-

Klein. Av. p. I18.6.-Rom. Orn. i. p. 8 r.

Perfian or Turkifh Pigeon, Latb. Syn. iv. p. 6 I 2.-Will. (Angl.) t. 33。

Habitat in Perfia.-Roftrum flavum: oculorum ambitus et mem2. $\pi$.

branæ nares tegentes miniaceo colore tinguntur.

tabellaria. C. cera lata carunculata albida, palpebris nudis.

Columba tabellaria, Lin. Syft. i. p. 28 1. -Gmel. Syft. i. p. 77 1.-Brif. i.

p. 77. I.-Id. 8 vo. i. p. 16.-Raii. Syn. p. 60. 5.-Will. p. 1 32. 5.

t. 34.-Brun. $\mathrm{N}^{\circ} 21$ 3.-Klein. Av. p. I $18.4 .-$ Borow/k. Nat. iii.

p. 2 I 3. II.

Carrier Pigeon, Latb. Syn. iv. p. 6r 3.-Alb. ii. t. 45.-Will. (Angl.)

p. I81.-Hayes Br. Birds, t. 16.

Longiffime licet deportata feftinanter domum redit, hinc olim literas

2. $\rho$. affigerunt per cœlum eunti nuncio. A G. turcica non multum differt.

gutturofa. C. pectore inflato.

Columba gutturofa, Lin. Syft. i, p. 280.-Gmel. Syft. i. p. $771 .-$ Brif. i. p. 78. K. $-I d .8$ vo. i. p. 16.-Klein. Av. p. I $8.2 .-I d$. Ov.

p. 33. t. 16. f. 5.-Borowefk. Nat. iii. p. 2 10. 5.-Raii Syn. p. 60.

2.-Will. p. I31. 2. t. 34.-Frijch. t. 146.-Brun. $\mathrm{N}^{\circ} 2$ 1 2. et var.

Le Pigeon groffe-gorge, Buf. ii. p. 505. t. 17. 18.

Powter Pigeon, Latb. Syn. iv. p. 61 3.-Will. (Angl.) 181. 2. t. 34.

Habitat in Arabia felici.-PeCtus inflat magnitudine corporis.

2. $\sigma$.

Eques. C. pectore inflato, cera carunculata.

Columba Eques, Brif. i. p. 78 . L. -Id. 8 vo. i. p. 17.-Gmel. Syft. i. po 77 1. -Raii Syn. p. 61. 1 2.-Will. p. 132. 12.

Horfeman Pigeon, Latb. Syn. iv. p. 614.-Alb. ii. t. 45.-Will. (Angl.)

p. 182 .

Spuria eft hæc varietas altera parente $C$. gutturofa, altera tabellaria, adeoque participat de utraque.

2. $\tau$.

Percuffor. C. fub volatu fe gyrans, ac alas fortiter percufians.

Columba percuffor, Brif. i. p. 79. M.-Id. 8 vo. i. p. 17.-Gmel. Syft. i。

p. 77 1.-Raii Syn. p. 60. 9.-Will. p. I32. 9.-Brun. $\mathrm{N}^{\circ} 218$.

Smiter Pigeon, Lath. Syn. iv. p. 614.-Will. (Angl.) po x82. 9.

$$
4 \mathrm{G}
$$


594 A V E S C O L U M B 王. Columba.

Hæc inter volandum in orbem circumvolitat, et alas tam fortiter quatit, ut duorum afferum fimul colliforum fonitum fuperet, unde remiges penne femper fere fractæ confpiciuntur, ac quandoque etiam volare nequeat.

2. v.

jubata. C. cervice pennis jubæ equinæ inftar reverfis.

Columba jubata, Gmel. Syjt. i. p. 77 1. v.

Turner Pigeon, Lath. Syn. iv. p. 614.-Will. p. 132. 14.-Id. (Angl.) I 82.14 .15 .

2. $\varphi$.

frontalis. C. corpore albo, macula frontis caudaque concoloribus.

Columba fulicaria, Brun. $\mathrm{N}^{\circ} 206$. maculata, Gmel. Syft. i. p. $772 . \varphi$.

Spot Pigeon, Lath. Syn. iv. p. 615.-Will. p. 132. 17.-Id. (Angl.) I 82.17 .

3.

montana. C. orbitis nudis fanguineis, corpore rufo, fubtus flavo.

Columba montana, Lin. Syft. i. p. 28 1. 13.-Gmel. Syft. i. p. 772.

- rufa cayanentis, Brif. i. p. 131. 28. t. 12. f. 2.-Id. 8vo. i. p. 32 .

Perdix montana, Raii Syn. p. 180. 20.-Sloan. Jam. p. 302. t. 261 , f. 1.-Brown. Fam. p. 469.-Edw. t. 119.

Partridge Pigeon, Latb. Syn. iv. p. 615. 3.-Id. Sup. p. 197.

Habitat in Cayana, famaica, infula $S$. Helene $?-8 \frac{x}{2}$ pollices longa.

-Victitat baccis myrtilli.

Macula alba fub oculis, gula, et ad axillas: roftrum et pedes rubri.

4.

tetraoides. C. capite colloque nigris, margine nigro.

Columba tetraoides, $S \operatorname{cop}$. Ann. i. N $\mathrm{N}^{\circ}$ i 80.-Gmel. Syft. i. p. 772.

Tetraoid Pigeon, Latb. Syn. iv. p. 616.4.

Caput et collum nigra, nigredine albo margine cincta, ut in Tetraone rufo.

5. C. cærulefcens, orbitis verticeque albis, remigibus rectricibufque fufcis. phala. Columba leucocephala, Lin. Syft. i. p. 28 1. 14.-Gmel. Syft. i. p. 772 . -Raii Syn. p. 63. 16. p. 184. 24.-Klein. Av. p. 120.18.

Columba faxatilis jamaicenfis, Brif. i. p. 137.33.-Id. 8 vo. i. p. 34.Buf. ii. p. 529 .

Bald-pated Pigeon, Sloan. Fam. p. 303. t. 26r. f. 2,-Brown. Fam. p. 468 .

White- 
A V E S C L U M B 正. Columba.

White-crowned Pigeon, Cat. Car. i. t. 65.-ArE7. Zool. ii. No $189 .-$ Lath. Syn. iv. p. 616.5 .

6.

Haвiтat in America feptentrionali, Famaica.-Roftrum bafi rubrum.

Seucoptera, C. fufco-rufefcens, orbitis nudis cæruleis, rectricibus cinereis apice albis, intermediis fufcis.

Columba leucoptera, Lin. Syft. i. p. 617. 15.-Gmel. Syft. i. p. 773.facq. Vog. p. $3^{8 .} 27$.

Columba indica, Brif. i. p. 105. 15. -Id. 8 vo, i. p. 25.-Klein. Av. p. I 20. 26 .

Brown Indian Dove, Edw. t. 76.

White-winged Pigeon, Latb. Syn. iv. p. 617. 6.-Id. Sup. p. 197.Brown. Fam. p. 468 .

Habitat in India, et Cartbagena americana:-8-9 poll. longa.

Irides fulvæ: pedes rubri : corpus fubtus cinereo-cærulefcens: ftria infra aures nigra.

7.

martinica. C. fubviolacea, abdomine rufefcente, remigibus interius rufis.

Columba martinica, Lin. Syft. i. p. 283. 24.-Gmel. Syft. i. p. 78 r.

Columba violacea martinicana, Brif. i. p. 129. 27. t. I 2. f. 1.-Id. $8 \mathrm{vo}$. i. p. 32 .

Pigeon violet de la Martinique, Buf. ii. p. 525.-Pl. Enl. I62.

Martinico Pigeon, Lath. Syn. iv. p. 618. 7.

Habitat in Martinica. -9 pollices longa.

Palpebra papillis coccineis: roftrum pedefque rubicundi.

$\beta$. C. fufco-rufefcens, torque violaceo-aureo, alis nigro maculatis, rectricibus lateralibus nigro terminatis, apice fummo albo.

Columba martinicana, Brif. i. p. 104. 14. -Id. 8 vo. i. p. 25.

Le Pigeon roux de Cayenne, Buf. ii, p. 526.-Pl. Enl. 141,-Latb. Syn. iv. p. 618. 7. var. A.

8. Jamaicen- C. fufco-purpurafcens fubtus alba, rectricibus cæruleis linea alba termifis. natis.

Columba jamaicenfis, Lin. Syft. i. p. 283.25.-Gmel. Syjt. i. p. 782.Brif. i. p. 134. 31. $-I d$. 8 vo. i. p. 33 .

Pigeon de la Jamaique, Buf. ii. p. 529. t. 2 I. 


\section{A V E S C O L U M B E. Columba.}

Columba minor ventre candido, Raii Syn. p. 63. 16.-p. 183. 23.Sloan. Fam. p. 303. t. 262. f. 1.-Brown Fam. p. 469 .

White-bellied Pigeon, Lath. Syn iv. p. 619. 8.

HABITAT in famaice arboribus.-9 pollices longa.

Irides vertex corpus et fubtus alba.

9.

coronata. C. orbitis nigris, crifta erecta, corpore carulefcente, humeris ferrugineis. Columba coronata, Lin. Syft. i. p. 282. 17.-Gmel. Syft. i. p. 774. Pall. Adumb. 78.-Mill. Ill. t. 16. A.

mugiens, Scop. Ann. i. No 179 .

Phafianus criftatus indicus, Brif. i. p. 279.6. t. 26. f. 1.-Id. 8 vo. i. p. 78 .

Le Faifan couronné des Indes, Buf. ii. p. 354. 542.-Pl. Enl. I 8.

Le Goura de la nouvelle Guinée, Son. Voy. p. 169. t. 104.

Kronvogel, Naturf. xvii. p. 32.

Great crowred Pigeon, Edw. t. 338.-Damp. Vay. iii. part 2. p. 93. t. 3. -Latb. Syn. iv. p. 620.

Habitat in infulis Moluccis, nova Guinea. Magnitudo Gallopavonis. Roftrum pedefque fufci : capitis crifta amplifima, compreffa, erecta, radiis difcretis.

10.

criftata. C. fufco-rufefcens criftata, fubtus capite colloque nigris, dorfo caudaque viridibus, fronte fetis fex longiffimis erectis.

Columba criftata, Gmel. Syft. i. p. 774.

Le Rouloul de Malacca, Son. Voy. Ind. ii. p. 174. t. 100.

Phafianus criftatus, Muf. Carlf. fafc. iii. t. 64.

Uncommon Bird from Malacca, Pbil. Tranf. lxii. p. 1. t. I.

Leffer crowned Pigeon, Latb. Syn. iv. p. 622. 10.

Habitat in infula Malacca, Celebes, Macao, alibique in India; domeftice magnitudine; inter gramina arundinefque nidificans.

Roftrum nigrum, bafi flavicans, ubi myftaces aliquot albefcentes : orbite rubræ: irides flavæ: vertex albus : cauda brevis, rotundata, apice nigro : femora feminuda, tibiis longis, gracilibus, rubris vel flavis, digito poftico mutico.

Femina paulo minor: crifta nulla: remiges primores et tectrices alarum rufo-ferrugineæ. Pulli lanuginofi, atri.

Mas et femina voce fonora frequenter fibilant. 


\section{A VES COL U M B E. Columba.}

3. Leffer crowned Pigeon, Latb. Syn. iv. p. 623. 10. A. t. 58.

A priore variat coloribus obfcurioribus; fincipite abfque fetis erectis;

I1. digito poftico unguiculato.

albicapilla. C. viridis, vertice cano, colli lateribus rufefcente-aureis, remigibus primoribus caudaque nigris.

Columba albicapilla, Gmel. Syft. i. p. 775.

Le Pigeon vert à tête grife d'Antigue, Son. Voy. p. 11 2. t. 66.

Grey-headed Pigeon, Lath. Syn. iv. p. 623. II.

Habitat in infula Panay; magnitudine domefica.

Roftrum rubrum: irides flavæ : remiges fecundariæ viridi-aureæ.

12.

pompado- C. viridis, alis purpurafcentibus, remigibus nigris, genis gulaque flavis.

ra. Columba pompadora, Gmel. Syft. i. p. 775.

Pompadour Pigeon, Lath. Syn. iv. p. 624. 12.-Id. Sup. p. 198.Brown. Ill. t. 19. (Mas.)

Yellow-faced Pigeon, Brown. Ill. t. 20. (Femina.)

Habitat in Zeylona, India, arboribus.-Femine ale virides.

I3.

phonico- C. olivacea fubtus cinerafcens, capite colloque flavefcentibus, tectrici-

ptera. bus alarum minoribus purpurafcentibus, majoribus remigibufque fecundariis albo nigroque ftriatis.

Purple-hhouldered Pigeon, Latb. Syn. Sup. p. 201. 60. $\beta_{0}$

Habitat in India; magnitudine domeftica. Roftrum obfcurum: pedes flavi.

14.

afiatica. C. cinereo-viridis, capite cinereo, macula alarum corporeque fubtus albo, remigibus nigris albo extus marginatis.

Indian Pigeon, Lath. Syn. Sup. p. 202.60. $\%$.

Habitat in India.-II pollices longa.-Supra peztus torquis alba circumdat collum : pedes cærulefcentes; nonnullis flavi.

15.

erythro- C. granatina, fubtus nucha dorfo remigibufque nigris, fronte fuperci-

ptera. $\quad$ liifque albis, cauda a medio ad apicem nigra.

Columba erythroptera, Gmel. Syft. i. p. 775.

Garnet-winged Pigeon, Latb. Syn. iv. p. 624. 13.

HabItat in infula Eimeo maris pacifici, $-9 \frac{x}{2}$ pollices longa:

$\beta . C$. gutture 
398 AVES C O L U M B H. Collumba.

$\beta$. C. gutture et pectore albis, fuperciliis ferrugineis, remigibus cauda que nigricantibus.

Habitat in infula Otabeite.

$\gamma$. C. nigro-rubefcens, fuperciliis colloque fubtus albis, pedibus rubris. Habitat in infula Tanna.-Latera capitis alba.

16.

endica.

C. corpore purpureo, humeris viridibus, pileo cærulefcente, remigibus primoribus reEtricibufque nigris.

Columba indica, Lin. Syjt. i. p. 284. 29.-Gmel. Syft. i. p. 785-Klein. iv. p. 120.20.

Palumbus amboinenfis, Brif. i. p. I 50. 42 . t. 1 5. f. 1.-Id. 8 vo. i. p. 39. Green-winged Pigeon, Lath. Syn. iv. p. 625. 14.-Id. Sup. p. 198.Edw. t. I4.

Habitat in India, Amboina.- - 0 pollices longa.-Roftrum pedefque rubri : cera cærulefcens : flexura alarum nigra, albo punctata.

ß. C. tectricibus alarum violaceis, remigibus viridibus, uropygio $\mathrm{c}$ ruleo, Facq. Vog. p. 35. 29. t. 16.

Habitat in India,-Cauda viridis: criffum cæeruleum.

17.

purpurata. C. viridis, pileo coccineo, criffo fulvo, capite collo pectoreque albis. Columba purpurata, Gmel. Syft. i. p. 784 .

Purple-crowned Pigeon, Lath. Syn. iv. p. 626. 15.-Boug. Voy. pp. 247. 329 ?

Habitat in infulis Oceani pacifici, intra tropicos. - 9 poll. longa, Variat fronte pileoque minus faturatiore, et in quibufdam vertex abfque ulla rubedine : irides flavæ.

18.

Jambos. C. viridis, fronte rubra, pectore albo.

Columba Jambu, Gmel. Syft. i. p. 784 .

Pooni Jamboo, Marfd. Sumat. p. 84 .

Jamboo Pigeon, Latb. Syn. iv. p. 627. I6. Alave.

Habitat in Sumatra, Fava; Turture minor.-Roftrum et irides $+\quad$ C. atro- 
19.

rubrica- C. atro-violacea, pileo orbitifque nudis rubris, collo dorfo fuperiore

pilla. pectoreque grifefcentibus.

Columba rubricapilla, Gmel. Syft. i. p. 784.

Le Pigeon violet à tête rouge d'Antigue, Son. Voy. p. I 12. t. 67.

Red-crowned Pigeon, Lath. Syn. iv. p. 628. i 7.

Habitat in infula Panay; cucullate magnitudine.

- Roftrum bafi cera carnofa, ad oculos producta tectum.

20.

purpurea. C. viridis, capite colloque purpurafcentibus, pectore fulvo, criffo rubro.

Columba purpurea, Gmel. Syft. i. p. 784 .

Purple Pigeon, Brown. Ill. t. 18.-Lath. Syn. iv. p. 628. 18.

HАBITAT in Fava; anadis magnitudine.

$2 \mathrm{I}$.

eimenfis. C. fufco-virefcens, fronte colloque fubtus vinaceis, pectore tectricibufque alarum fufco-rubris, fafcia pectorali alba.

Columba eimenfis, Gmel. Syft. i. p. 784.

Purple-breafted Pigeon, Latb. Syn. iv. p. 629. I 9.

Habitat in infula Eimeo.-I 4 pollices longa.

22.

vernans. C. viridis fubtus flavens, alarum margine exteriore luteo.

Columba vernans, Lin. Mant. I77 1, p. 526.-Gmel. Syf. i. p. 789. viridis philippenfis, Brif. i. p. 143. 38. t. I 1. f. $2 .-1 d .8 \mathrm{vo}$.

i. p. 37 .

Pigeon vert des Philippines, Buf. ii. p. 528.-Pl. Enl. 138 :

Columba maderafpatana, Raii Syn. p. I96. 15. t. 2. f. 15.

Le Pigeon vert male de l'ifle de Luçon, Son. Voy. r 10. t. 64.

Parrot Pigeon, Lath. Syn. iv. p. 629. 20. (Mas.)

Le Pigeon vert femelle de l'ine de Luçon, Son. Voy. I I I. t. 65.

Parrot Pigeon, Lath. Syn. iv. p. 630. 20. (Femina.)

Habitat in Manilla et Panaya.- $9 \frac{1}{2}$ poll. longa.-Pectus azureum.

Femina viridi-grifefcens, fubtus viridi-flavicans.

23.
aromatica. C. viridi-olivacea, dorfo caftaneo, fafcia alarum duplici flavicante et nigra, remigibus nigris, margine flavis.

Columba aromatica, Gmel. Syft. i. p. 778 .

Columba viridis amboinenfis, Brif. i. p. 145.39 . t. Io. f. $2 .-I d .8 \mathrm{vc}$ 。 i. $\mathrm{p} .37$. 
600

A V E S C O L U M B 㞼. Columba.

Yigeon vert d'Amboine, Buf. ii. p. 528.-Pl. Enl. $16_{3}$.

Aromatic Pigeon, Lath. Syn. iv. p. 631. 21.

24.

Habitat in Amboina. - $10 \frac{x}{2}$ poll. longa.-Vertex grifeus.

S. Tho- C. viridis, tectricibus caudæ inferioribus flavis, remigibus et apice caumæ.

Columba viridis S. Thomæ, Brif. i. p. 147.40.-Id. 8 vo. i. p. 38.Klein. Av. p. I19. 11.-Gmel. Sy/t. i. p. 778.

- fylv. ex infula S. Thomæ, Raii Syn. p. 62. 7.-Will. I 34 . St. Thomas's Pigeon, Latb.Syn. iv. p. 631. 22.-Will. (Angl.) p. 183.

Habtтat in infula $S$. Thome; domeftice magnitudine.-Orbite cærulex.

25.

curvirof- C. viridis fubtus flavefcens, dorfo caftaneo, fafcia alarum duplici rec.

tra.

26.

tannenfis. C. viridis, tectricibus alarum albo maculatis, remigibus fecundariis ad apicem margine flavis, Latb. Syn. iv. p. 632.23. fect. ult.

Haв Iт Aт cum pracedente.- I I pollices longa.

Roftrum modice aduncum: pedes rubri : apex cauda pallidus. An varietas curviroftre?

27.

pacifica. C. dorfo fufco-virefcente, rapite collo pectore abdomineque cinereoalbis, cauda nigricante.

Columba pacifica, Gmel. Syft. i. p. 777.

Ferrugineous-vented Pigeon, Latb. Syn. iv. p. 633. 24.

Habitat in infulis Amicis Oceani auftralis.- $13^{\frac{1}{2}}$ poll. longa.

Nares gibbofæ: gula albicans : pectus vinaceum : pedes rubri aut fufci。

ß. C. capite collo pectore abdomineque albidis, dorfo tectricibus alarum caudaqu' fubviridibus, bafi roftri gibba.

HaBitat in inf lis Otabeite et Tongataboo.

C. fufca, 
28.

A V E S C O L U M B A. Columba.

mexicana. C. fufca, orbitis coccineis, pectore candido, alis extremis albis.

Columba mexicana, Brif. i. p. 99. 10.-Id. 8 vo. i. p. 23.-Gmel, Syft. i. p. 777 .

Pigeon du Mexique, Buf. ii. p. 525 .

Cehoilotl, Raii Syn. p. 63.14.

Mexican Pigeon, Latb. Syn. iv. p. 633. 25.

Навітат in Mexiro.-Irides nigræ: pedes rubri.

29.

nævia. C. fupra fufca nigro maculata, fubtus fulvefcens, tectricibus caudæ inferioribus cinereis.

Columba nævia, Gmel. Syft. i. p. 777.

CEnas mexicana, Brif. i. p. 100. I1.-Id. 8vo. i. p. 23.-Buf. ii. p. 525. Hoilotl, Raii Syn. p. 63.12.

Black-fpotted Pigeon, Lath. Syn. iv. p. 633. 26.

Habitat in $N$. Hifpania frigidioris fylvis; anadis magnitudine.

30.

Hoilotl. C. rufo-purpurea, tectricibus alarum minoribus albis.

Columba Hoilotl, Gmel. Syft. i. p. 777.

Columba montana mexicana, Brif. i. p. 130. 28. -Id. 8 vo. i. p. 32.

Hoilotl, Raii Syn. p. 63. 13.-Buf. ii. p. 525.

White-fhouldered Pigeon, Lath. Syn. iv. p. $654 \cdot 27$.

Haвiтат in Mexicanis montibus.-Variat corpore fulvo.

31 .

cærulea. C. cærulea fubtus teetricibufque alarum rubris, capite colloque rubro variegatis.

Columba cærulea mexicana, Brif. i. p. 140. 35.-Id. 8 vo. i. p. 35.Gmel. Syft. i. p. 776.

Tlacahoilotl, Raii Syn. p. 63. I 5.-Buf. ii. p. 525 .

Blue Pigeon, Latb. Syn. iv. p. 634.28.

Habitat in Mexico.

32.

Palumbus. C. cinerea, rectricibus poltice atris, remigibus primoribus margine exteriore albidis, collo utrinque albo.

Columba Palumbus, Lin. Syft. i. p. 282. 19.-Faun. Suec. N०208.Gmel. Syft. i. p. 776 . -Scop. Ann. i. $\mathrm{N}^{\circ} 178 .-B r u n . \mathrm{N}^{\circ} 204 .-$ Muller, $\mathrm{N}^{\circ} 228 .-K r a m . E l . p .359 .2 .-G e o r g i$, p. 173.-Frifch. t. $138 .-$ Faun. Arag. p. 83.-Sepp. Vog. t. 4. 5.-Brif. i. p. 89.6. -Id. 8vo. i. p. 20.-Borowjk. Nat. iii. p. 205. t. 75. A. 
602

A V E S C O L U M B 压. Columba.

Columba torquata, Klein. Av. p. II 9. 7.-Id. Stem. p. 27. t. 29. f. I. a-c. - Id. Ov. p. 33. t. I 5. f. 2.

Palumbus torquatus, Raii Syn. p. 62. A. 9.-Will. p. I35. t. 35.Rom. Orn. i. p. 84. t. 14.--Faun. Helv.

Le Pigeon ramier, Buf: ii. p. 531. t. 24.-Pl. Enl. 316.-Hift. Prov. i. p. 49 c.

Columbo Saffaiuolo, Cet. uc. Sard. p. I 39.

Colombaccio, Ziman. Uov. p. 32. t. 4. f. 14.-Olin. uc. p. 54 .

Ringel Tauben, Guntb. Neft. u. Ey. t. 32 .

Ring Pigeon, Br. Zool. i. $\mathrm{N}^{\circ}$ 102.-Id. fol. 8g. t. O.-Arct. Zool. ii. p. 329. B.-Will. (Angl.) p. 185.-Hayes Br. Birds, t. 15.Alb. ii. t. 46.-Lath. Syn. iv. p. 635. 29.-Id. Sup. p. 198.

Haвiтат per omnem Europam; in Sibiria rarior; fylvas frequentat, 33.

ænea. C. pedibus plumofis, roftro pedibufque virefcentibus, corpore æneo.

et in arboribus nidificat; omnibus bene nota avis. $-17 \frac{\pi}{2}$ poll. longa.

Columba ænea, Lin. Syft. i. p. 283.22.-Gmel. Syft. i. p. 780.

Palumbus moluccenfis, Brif. i. p. I48. 41.t. I3. f. 2. -Id. 8 vo. j. p. 38.

Pigeon ramier des Moluques, Buf. ii. p. 538.-Pl. Enl. I64.

Nutmeg Pigeon, Lath. Syn. iv. p. 636. 30.

Haвiтат in Moluccis; myriftica victitans.-I7 pollices longa.

B. Pigeon cuivre mangeur de mufcade, Son. Voy. p. 168.t. I02.-Lath. Syn. iv. p. 637.

$\mathrm{H}_{\mathrm{ABIT}} \mathrm{T}$ T in nova Zealandia. - Remiges caudaque nigra.

Variat copite cærulefcente, corpore fubtus grifeo-rufo, criffo flavefcente, pedilus incarnatis.

34.

alba.

C. corpore albo, remigibus primoribus caudaque ad apicem nigris.

Columba alba, Gmel. Syft. i. p. 780.

Le Pigeon blanc mangeur de mufcade, Son. Voy. p. I69. t. I03.

White nutmeg Pigeon, Lath. Syn. iv. p. 638. 31 .

HaвiтAт in nova Guinea; mediæ magnitudinis; myriftica potiffimum victitans; femina aromatis cum excrementis fpargens.

Variat cauda toto alba.

35.

guinea. C. orbitis nudis rufis, alis maculis albis triquetris, rectricibus apice nigris.

Columba 


\section{A V E S C O L U M B IE. Columba.}

Columba guinea, Lin. Syft. i. p. 232. 16.-Gmel. Syft. i. p. 774.-Brif. i. p. 132. 30.-Id. 8vo. i. p. 33.-Klein. Av. p. I 20. 25.

Pigeon de Guinée, Buf. ii. p. 538 .

La Tourterelle du Cap de B. Efperance, Son. Voy. Ind. ii. p. 179.

Triangular fpotted Pigeon, Edw. t. 75.-Latb. Syn. iv. p. 639. 32.

Habitat in Africa auffraliore; Palumbi magnitudine.

- Roftrum fufcum: irides flavæ: caput et collum cinereum, fupra vio36. laceo-purpurafcente nitens: uropygium et abdomen album.

caribæa.

C. cærulefcens, abdomine albo, capite collo inferiore pectoreque purpurafcentibus, cauda fafcia tranfverfa nigra.

Columba caribæa, Gmel. Syft. i. p. 773.

Columba cauda annulo cincta jamaicenfis, Brif. i. p. 138. 34.-Id. 8 vo. i. p. 35 .

Columba cauda fafcia notata, Raii Syn. p. 63. 17.-p. 183.22.-Sloan. fam. p. 302. 27.-Brown. Fam. p. 468.-Klein. Av. p. 120.19.

Ring-tailed Pigeon, Lath. Syn. iv. p. 639.33.

Habitat in famaica.- 15 pollices longa.

Roftrum virefcens, bafi rubrum: cera gibba: irides rubræ.

ß. C. cauda cuneata, orbitis denudatis flavefcentibus, corpore cærulefcente, Facq. Vog. p. 30. 24.-Liath. Syn. Sup. p. 199.

HabItat in infularum Coribearum fylvis; in caveis frequenter alitur; caro fapidiffima.

Roftrum rubro-virefcens : irides rubre : color pennarum fere toto cærulefcens : collum cupreo fplendens : cauda longitudine corporis abfque fafcia.

37.

zealandica. C. rubra, abdomine albo, uropygio cæruleo, cauda nigra.

Columba nova Seelandir, Gmel. Syft. i. p. 773.

New Zealand Pigeon, Lath. Syn. iv. p. 640. 34.

Haвiтат in nova Zealandia.- 18 poll. longa.

Collum inferius viridi-rubrum: roftrum, irides, orbita, pedefque rubra:

38.
brunnea. C. pileo collo fupra dorfo tectricibufque alarum brunneis, pectore collo fubtus uropygioque viridi-\{plendidis.

Habitat in nova Zealandia.-Roftrum pedefque fanguinei.

C. fufco- 
604 A V E S C O L U M B 死. Columba.

chalcopte- C. fufco-cinerea rufo-marginata, fronte gulaque albis, fafcia alarum

ra.

40.

madagaf- C. pedibus plumofis, cauda violacea, corpore cæruleo-nigro.

carienfis. Columba madagafcarienfis, Lin. Syft. i. p. 283. 21.-Gmel. Syft. i. p. 779.-Brif. i. p. 140. 36. t. 14. f. 1. $-1 d .8$ vo. i. p. 36.

Le Founingo, Buf. ii. p. 539 .

Pigeon ramier bleu de Madagafcar, $\mathrm{Pl}$. Enl. $\mathbf{x}$.

Madagafcar Pigeon, Lath. Syn. iv. p. 640.

$\mathrm{H}_{\text {AвIтAт in Madagafcaria. }}-10 \frac{x}{2}$ pollices longa.

Roftrum digitique rubri.

$4 \mathrm{I}$.

auftralis. C. viridis, abdomine crifo femoribufque maculatis, humeris violaceis. Columba auftralis, Lin. Mant. 1771. p. 526.-Gmel. Syft. i. p. 779.

Palumbus viridis madagafcarienfis, Brif. i. p. 142. 37. t. I4. f. 2.-Id. 8 vo. i. p. 36 .

Pigeon ramier verd de Madagafcar, Buf. ii. p. 540.-Pl. Enl. II I.

Madagafcar Pigeon, Latb. Syn. iv. p. 641. 35. var. A.

Haвitat in Madagafcaria. -12 fere pollices longa.

Roftrum plumbeum: oculi et pedes fanguinei : abdomen poftice et fen mora nigro maculata. An præcedentis varietas ?

42.

Franciæ, C. cærulea, orbitis nudis, uropygio caudaque rubris, pennis colli anguftis elongatis apice acuminatis.

Columba Francix, Gmel. Syft. i. p. 779.

Le Pigeon Hollandois, Son. Voy. Ind. ii. p. I75. t. I0I.

Hackled Pigeon, Latb. Syn. iv. p. 641. 36.

Habitat in infula Francic; Palumbo multo major.

Rofrum et irides rubri ; pedes nigri。

C. faturate 
43.

A V E S C O L U M B Æ. Columba. 605

maculata. C. faturate viridis, corpore fupra albido maculato, abdomine nigricante, cauda nigra apice ferruginea.

Columba maculata, Gmel. Syft. i. p. 780.

Spotted green Figeon, Lath. Syn. iv. p. 642. 37.

Longitudo $\mathrm{I} 2$ pollicum.-Pennæ colli ftrictiores elongatæ, ut in Gallo domeftico: pedes antice plumofi.

44.

nicobarica. C. cauda alba, corpore nigro, remigibus cæruleis, dorfo viridi-nitente, pennis colli elongatis.

Columba nicobarica, Lin. Syft. i. p. 283. 27.-Gmel. Syft. i. p. 783.Brif. i. p. 153. 44.-Id. 8vo. i. p. 40.-Klein. Av. p. 1 20. 23.

Pigeon de Nincombar, Buf. ii. p. 541.-Pl. Enl. 491.

Nicobar Pigeon, Edw. t. 339.-Alb. iii. t. 47. 48. (M. et Fem.)Lath. Syn. iv. p. $642.3^{8}$.

Навгтат in infulis Nicombarienfibus; domeftice magnitudine. Roftrum pedefque fufci.

45.

fpeciofa. C. ferruginea, cauda nigricante, collo inferiore pectoreque rufo albo purpureoque undulatis.

Columba fpeciofa, Gmel. Syft. i. p. 783 .

Le Ramiret, Buf. ii. p. 54 I.

Le Pigeon ramier de Cayenne, Pl. Enl. 213.

Scallop-necked Pigeon, Latb. Syn. iv. p. 643.39.

Habitat in Cayana; Turture minor.

46.

corenfis. C. cauda æquali, orbitis denudatis atro punctatis, corpore grifeo.

Columba corenfis, Facq. Vog. p. 31. 25.-Gmel. Syft. i. p. 78.3.

Grey Pigeon, Lath. Syn. Sup. p. 201.

Ha вiтат in America auftrali, prope Coro; domeftice magnitudine.

Pennæ colli inferioris, variante luce, verficolores, quafi fquammofæ.

47.

Turtur.

C. rectricibus apice albis, dorfo grifeo, pectore incarnato, macula laterali colli nigra lineolis albis.

Columba Turtur, Lin. Syft. i. p. 284. 32.-Gmel. Syjt. i. p. 786.-Scop. Ann. i. $\mathrm{N}^{\circ} 181 .-K r a m$. El. p. 359. 3.-Frifch. t. 140.-Georgi, p. 173.-Faun. Arag. p. 88.-Faun. Arab. p. 4. 14.-Sepp. Vog. t. p. I 1.-Borowes. Nat. iii. p. 21 2. t. 75. B.-Raii Syn. p. 6 I. A. 2. -Will. p. I 34. t. 35.-Brif. i. p. 92. 7.-Id. 8 vo. i. p. 2 I. Turtur auritus, Raii Syn. p. 184. 26.-Sloan. Fam. p. 304. t. 262.2.

Palumbus. 
Palumbus Turtur, Klein. Av. p. I 19. I2.-Id. Stem. p. 27. 29. f. 3. a. b. $-I d$. Ov. p. 33. t. I6. f. 3. 8.-Rom. Om. i. p. 89. t. I5.f. I. -Id. (albus.) p. 94.-Faun. Helvet.

Tourterelle, Buf. ii. p. 545. t. 25.-Pl. Enl. 394.

Tortora, Zinnan. Uov. p. 33. t. 4. f. 15.-Olin. uc. t. p. 34.-Cett. uc. Sard. p. 143.

Common Turtle, Br. Zool. No 103. t. 45.-Id. fol. 88. t. 88.-Alb. ii. t. 47.-Will. (Angl.) p. 183.-Ojl. Voy. i. p. 158.-Hayes $\mathrm{Br}$.

Birds, t. 14.-Lath. Syn. iv. p. 644. 40.-Id. Sup. p. 199.

Haвıтат in Europa, Cbina, India.-I 2 pollices longa.-In Anglia aftate fatis numerofa; nemoribus adificans.

Irides flave: orbite pedefque rubri: abdomen album.

Varietas finenfis ab Europacanon difcrepat, nifi corpore inferiore tots vinaceo.

ß. Spotted-necked Turtle, Lath. Syn. iv. p. 645.40. A.

Навıтат in Europa, Africa, Afia; in Anglia interdum reperitur.

A priore variat lateribus colli nigris, apicibus pennarum macula alba notatis.

$\gamma$. C. fufca, macula laterali colli albo nigroque varia, rectricibus cinereis, lateralibus latere exteriore omnibus apice albis.

Turtur lufitanicus, Brif. i. p. 98. 9.-Id. 8vo. i. p. 23.-Klein. Av. p. I I 9 . 14 .

Tourterelle de Portugal, Buf. ii. p. $55^{6 .}$

Portugal Dove, Alb. ii. t. 48.-Latb. Syn. iv. p. 646.

HaBITAт in Lufitania.

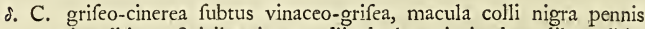
apice albis, rectricibus intermediis duabus nigris, lateralibus albis.

La Tourterelle grife de l'ille de Luçon, Son. Voy. p. 52. t. 22.

Luzonian Turtle, Latb. Syn. iv. p. 646.

Habitat in Luzonia.

48. orientalis.

C. fufco-grifea, lateralibus colli pennis nigris apice grifeo-cinereis, fafcia alarum flava.

La Tourterelle brune de la Chine, Son. Voy. Ind. ii. p. I77.

Chinefe Turtle, Lath. Syn. iv. p. 647.

Habitat in Cbina; Turturis magnitudine. 
Roftrum, irides, pedes rubri: ale fufce fafcia tranfverfa flava: uropygium et cauda cinereo-grifea: abdomen vinaceo-grifeum.

49.

regyptiaca. C. teftaceo-incarnata, gula maculata plumis nigris, apice bilobo truncatis ferrugineis, Forfk. Faun. Arab. p. 5. I5.

HaBitat in Agypto, frequens ad ades.

Roftrum nigrum: caput violaceo-incarnatum : orbite nudæ cxrulef. centes: gulc plumæ cuneiformes, nigra, apice divifa in uos lobos lineares, divergentes, truncatos, totos fere incarnato-ferrugineos : dorfum cinereum: pectus violaceo-incarnatum : abdomen albidum, et femora : ale magna ex parte fufcæ: rectrices 2 extimæ bafi cinerex, medio nigræ, reliquæ tota parte albæ; duæ utrinque fequentes bafi cinereæ, medio nigræ, reliqua parte cinereæ, extremo apice albidæ; quinta utrinque a margine numeranda fufca, medio obfolete nigra : duæ denique intermediæ totæ fufcæ: pedes incarnati.

50.

furinamenfis.

C. cinerea fubtus alba, gula viridi nigroque varia, roftro cæruleo. Columba furinamenfis, Gmel. Syft. i. p. 787 .

La Tourterelle, Defor. de Surin. ii. p. 165. Surinam Turtle, Latb. Syn. ii. p. 647.41 .

Habitat in Surinami fylvis.-Io poll. longa.-Caro deliciofa.

$5^{\mathrm{I}}$. riforia.

C. fupra lutefcens fubtus alba, lunula cervicali nigra.

Columba riforia, Lin. Syft. i. p. 285. 33.-Scop. Ann. i. $\mathrm{N}^{\circ} 182 .-$ Frifcb. t. 14. 1.-Brun. No 220.-Borowfk. Nat. iii. p. 214. I2.Gmel. Syft. i. p. 787 :

Turtur torquatus, Brif. i. p. 95. 8. $-I d$. 8 vo. i. p. 22.-Rom. Orn. i. 92. t. I 5 .

Turtur indicus Aldr. Raii Syn. p. 61. 3.-Will. p. 134. t. 35.-Klein. Av. p. 119.13 .

La Tourterelle à collier, Buf. ii. p. 550. t. 26.-Pl. Enl. 244.-Hift. Prov. i. p. 490.

Indian Turtle, Alb. iii. t. 45,-Will. (Angl.). p. 184,-Hayes Br. Birds, t. I 3 .

Collared Turtle, Latb. Syn. iv. p. 648. 42.

Habiтat in Europa, India.-Roftrum fufcum : pedes rubri.

ค.. C. fufca: 
$\beta$. C. fufca fubtus vinaceo-grifea, vertice grifeo, cervice lunula nigra maculis albis, rectricibus lateralibus nigris albo maculatis.

La Tourterelle grife de la Chine, Son. Voy. Ind. ii. p. I76. t. 102.

Chinefe grey Turtle, Lath. Syn. iv. p. 649.

Habitat in India, Cbina.-Regio oculorum alba.

$\gamma$. Turtur hybridus, Brif. i. p. 97. A.-Id. 8 vo. i. p. 22.

Hebridal Turtle, Latb. Syn. iv. p. 649.

Provenit hæc varietas ex conjugio $C$. Turturis maris et riforic femina. Caput, collum, pectus vinacea: dorfum rubro-cinereum: abdomen, ale fubtus, et cauda, ut in C. riforia.

52. finici.

C. fufca nigro fafciata, abdomine fubfanguineo, remigibus nigris, roftro
nigro.

Columba finica, Lin. Syft. i. p. 284. 28.-Gmel. Syft. i. p. $783 .-K l e i n$. Av. p. 120.22.

Turtur finenfis ftriatus, Brif. i. p. 107. 16.-Id. 8vo. i. p. 26.

Tourterelle rayée de la Chine, Buf. ii. p. 556.

Dove from China, Alb. iii. t. 46.

Striated Turtle, Lath. Syn. iv. p. 650.43 .

HABITAT in Cbina ; riforice magnitudine.-Roftrum cærulefcens : irides albæ: pedes rubri : teEtrices alarum majores intermediæ albæ.

ftriata. C. orbitis lorifque candidis, corpore cinereo nigro fafciato, fubtus rufo. Columba Atriata, Lin. Syft. i. p. 282. 18.-Gmel. Syft. i. p. 775.-Facq. Vog. p. 32. t. 15.-Klein. Av. p. 120.21.

Turtur indicus ftriatus, Brif. i. p. 109. 17.-Id. 8 vo. i. p. 26.

Tourterelle rayée des Indes, Buf. ii. p. 557.

Barred Turtle, Lath. Syn. iv. p. $650.44 .-I d$. Sup. p. 200.-Edw. t. I6.

Habitat in Malacca, infula $S$. Helene, America aufrali.- $9 \frac{x}{2}$ poll. longa.-Latera cærulefcentia : rectrices æquales lateralibus apice albis.

54. cyanocephala.
C. vinaceo-furca, capite gulaque cæruleis, fafcia fuboculari alba.

Columba cyanocephala, Lin. Syft. i. p. 282. 20.-Gmel. Syft. i. p. 778. - Jacq. Vog. p. 36. t. 17 .

Turtur jamaicenfis, Brif. i. p. 1 35. 32. t. 13. f. r. $-I d$. 8 vo. i. p. 34.Klein. Av. p. I 19.15 .

Tourterlle de la Jamaique, Buf. ii. p. 558.-Pl. Enl. I74. 
A VES C O L U M B $\mathbb{E}$. Columba.

609

Turtle Dove from Jamaica, $A l b$. ii. t. 49.

Blue-headed Turtle, Latb. Syn. iv. p. 65 1. 45.-Id. Sup. p. 100.

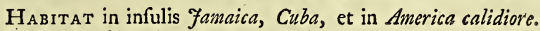

Roftrum bafi, pedes et ungues rubri.

In Cuba proftat venalis in foro hrec avis, et in deliciis habetur.

55.

furatenfis. C. grifea, collo fupra nigro, nucha alba, cervice rufo fafciata, teçricibus alarum cinereo-grifeis rachibus nigris.

Columba furatenfis, Gmel. Syyt. i. p. 778 .

La Tourterelle de Surate, Son. Voy. Ind. ii. p. 179.

HaBrTAT in India; riforie magnitudine.

Roftrum nigrum : irides et pedes rubri.

56.

cambayen- C. grifea fubtus alba, capite fubvinaceo, collo fubtus nigro rufo vario,

fis. rectricibus lateralibus nigro grifeoque dimidiatis.

Columba cambayenfis, Gmel. Syft. i. p. 779 .

La Tourterelle grife de Surate, Son. Voy. Ind. ii. p. 180.

Cambayan Turtle, Lath. Syn. iv. p. 652.47.

Habitat in Cambaya; magnitudine precedentis.

Colli inferioris penna nigra, extrema tertia parte rufefcentes: teärices alarum cinereo-grifex.

malabari- C. cinerea fubtus alba, alis medio maculis ovatis, rectricibus lateralibus

ca.

a bafi ultra medium nigris, reliqua parte albis.

Columba malabarica, Gmel. Syft. i. p. 779 .

Tourterelle de la côte de Malabar, Son. Voy. Ind. ii. p. 180.

Malabar Turtle, Latb. Syn. iv. p. 652.48.

Habitat in Malabaria; riforice magnitudine.

Roftrum et irides rubræ.

$5^{8}$.

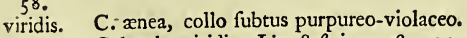

Columba viridis, Lin. Syft. i. p. 283. 23.-Gmel. Syft. i. p. 780.

Turtur viridis amboinenfis, Brif. i. p. 152.43 . to I5. f. 2. $-I d .8$ vo. i. p. 39 .

Le Turvert, Buf. ii. p. 555. (prima fpecies.)

La Tourterelle à gorge pourprée d'Amboine, Pl. Enl. i42.

Green Turtle, Latb. Syn. iv. p. 653. 49. 
610 AVES COLU M B E. Columba.

Habitat in Amboina. -8 fere pollices longa.

Roftrun rubrum: pedes rubent plumis femitecti : rectrices laterales. apice fulphurex.

59.

melano- C. viridis, capite cinerafcente, occipite nigro, gula abdomine imo crifcephala.

foque flavis, rectricibus tribus exterioribus purpureo-coccineis.

Columba melanocephala, Zool. Ind. p. 16. t. 7.-Gmel. Syjt. i. p. 78 r.

Turvert, Buf. ii. p. 555. (Ipecies fecunda.)

Tourterelle de Batavia, Pl. Enl. 2 I 4 .

Black-capped Pigeon, Lath. Syn. iv. p. 65.4, 50.-Ind. Zool. t. 7 .

Habitat: in fava. $-9 \frac{I}{2}$ pollices longa.

Roftrum nigrum : pedes rubri.

60.

javanica. C. viridis, capite collogue vinaceo-rubris, abdomine obfcuriore, remigibus primoribus fufcis.

Columba javanica, Gmel. Syst. i. p. 78 r.

Le Turvert, Buf. ii. p. 556 . (fpecies tertia.)

La Tourterelle de Java, Pl. Enl. 177.

Javan Turtle, Latb. Syn. iv. p. 654. 51 .

HaвiтAт in fava. -9 pollices longa..

Roftrum pedefque rubri: cera alba. .

$6 \mathrm{r}$.

exrulecce. C. viridis fubtus rubens, vertice caruleo, remigibus rectricibufque cæe-

p'ala.

ruleo-nigricantibus.

Columba cyanocephala, Gmel. Syft. i. p. $78 \mathrm{r}$.

Blue-crowned Turtle, Latb. Syn. iv. p. 655. 52.

Habitat in India, Cbina; præcedentis magnitudine.

$62:$

fenegalen. C. fufco-rufefcens fubtus alba, collo fubtus nigro maculato, rectricibus fis. tribus extimis ultima medietate albis.

Columba fenegalenfis, Lin. Syft. i. p. 283 3. 26.-Ginel. Syyt. i. p. $7^{82}$. Turtur. gutture maculato fenegalenfis, Brif. i. p. 125.25 . t. 8. f. 3-$I i^{2} .8$ vo. i. p. 3 I.

Tourterelle à gorge tachetée du Senegal, Buf. ii. p. 552 . Senegal Turtle, Latb.Syn, iv. p. 655. 53 .

Habitat in Senegala.-10 fere pollices longa.

C. grifeo : 
63.

vinacea. C. grifeo-fufca fubtus alba, collo fuperiore torque nigro, remigibus fufcis albido extus marginatis.

Columba vinacea, Gmel. Syjt. i. p. 782 .

Turtur torquatus fenegalenfis, Brif. i. p. 124.24. t. I1. f. I. $-I d$. 8 vo. i. p. 30.

Tourterelle à collier du Senegal, Buf. ii. p. 553-Pl. Enl. I6I.

Collared Senegal Turtle, Latb. Syn. iv. p. 656. 54 .

HАВітат cum fenegalenfi; ejufdem magnitudine.

64.

afra. C. grifeo-fufca fubtus albida, maculis tectricum alarum violaceo-azureis, rectricibus extimis bafi exteriore maculaque apicis albis.

Columba afra, Lin. Syft. i. p. 284. 31.-Gmel. Syft. i. p. 786.

Turtur fenegalenfis, Brif. i. p. 122. 23. t. Io. f. 1.-Id. 8 vo. i. p. 30.

Tourterelle du Senegal, Buf. ii. p. 553.-Pl. Enl. 160.

African Turtle, Lath. Syn. iv. p. 656. 55 .

HaвiтAт in Senegala.-8 poll. longa.-Roftrum et pedes rubri.

65.

cruenta. C. grifea, collo fubtus albo, cervice violacea, fafciis alarum tribus grifefcentibus, macula pectoris fanguinea.

Columba cruenta, Gmel. Syfr. i. p. 785 .

La Tourterelle grife enfanglantée, Son. Voy. Ind. p. 52. t. 21 .

Red-breafted Turtle, Lath. Syn. iv. p. $657 \cdot 56$.

Hавгтат in Manilla; afra magnitudine.

66.

Roftrum pedefque nigricantes.

fanguinea. C. corpore toto albo, macula pectorali roftro pedibufque fanguineis.

Columba fanguinea, Gmel. Syft. i. p. 785.

Tourterelle blanche enfanglantée, Son. Voy. p. 5 r. t. 20.

Sanguine Turtle, Latb. Syn. iv. p. 657. 57.

Habitat in Momilla.-Roftrum rubrum: irides purpurafcentes.

67.

pafferina. C. rectricibus remigibufque obfcurioribus, corpore purpurafcente, roftro pedibufque flavis.

Columba pafferina, Lin. Syft. i. p. $2850^{\circ} 34 .-G m o l$. Syft. i. p. $787 .-$ Scop. Anm. i. N $183 .-7 a c q$. Vog. p. 32. t. 26.

Turtur parvus americanus, Brif. i. p. I1 3. 19. t. 9. f. 1.-Id. -8vo. i. p. 27.

Columbus minimus, Klein. $A v$. p. 120. 24 . 
Turtur indicus, feu Cocotzin, Raii Syn. p. 6r. 62. No 4. 5. 6.-p. I84. 25.-Will. p. 135. t. 36.-Id. (Angl.) p. I 84 .

Cocotzin, Buf. ii. p. 559 .

Les petites Tourterelles, $\mathrm{Pl}$. Enl. 243. f. I. (mas.) f. 2. (femina.)

Ground Dove, Cat. Car, i. t. 26.-Sloan. Fam. ii. p. 305. 32. t. 26 r. f. 1. - Brown. Fam. p. 469.-Arct. Zool. ii. N i gr.-Latb. Syn. iv. p. 659.59.-Id. Sup. p. 100.

Habitat in America calidiore. $-6 \frac{1}{4}$ pollices longa.

68. Ale extus in tectricibus punctis 1 . maculis fufcis adfperfæ.

minuta. C. fufca, alis punctis 5 f. 7 chalybeis, rectricibus extimis apice albis. Columba minuta, Lin. Syft. i. p. $285 \cdot 35-$ Gmel. Syft. i. p. 788. Turtur parvus fufcus americanus, Brif. i. p. 116. 20. t. 8. f. 2.-Id. 8 vo. i. p. 28.

Cocotzin aliud genus, Tlapalcocotli, Will. p. 135.-Id. (Angl.) 1840 Pafferine Turtle, Latb. Syn. iv. p. 660.

Habitat in America. $-5 \frac{1}{2}$ pollices longa.

Pectus rufefcens: ale fubtus rufæ: rectrices 2 intermediæ fufcæ, latcrales in exortu cinerafcentes, poftea nigræ, paululum fufco definentes. Forte pefferine varietas.

69.

malaccen- C. nigro undulatim lineata, fupra cinereo-grifea fubtus cinerea, collo

fis. lateribus albo, rectricibus fufcis, lateralibus verfus apicem albis. Columba malaccenfis, Gmel. Syft. i. p. 788. La petite Tourterelle de Queda, Son. Voy. Ind. ii. p. 177. Malacca Turtle, Latb. Syn. iv. p. 661. 6o.

Habitat in Malacca.-Roftrum flavum, medio nigrum : pedes flavi.. Pulcherrima avicula; magnitudine pafjeris.

70.

migratoria. C. cauda cuneata, orbitis denudatis fanguineis, corpore cinereo, pectore rufo.

Columba migratoria, Lin. Syft. i. p. 285. 36.-Gmel. Syft. i. p: 789.Borow/k. Nat. iii. p. 205. t. 214.13.

Enas americana, Brif. i. p. 100. 12.-Id. 8 vo. i. p. 24.-Frifch. t. 142. Palumbus carolinienfis, Klein. Av. p. 119.16.

Pigeon de paffage, Buf. ii. p. 527.-Cat. Car. i. t. 23 .

Paffenger, 
Paffenger, or migratory Pigeon, Pbil. Tranf. lxii. p. 398.-Kalm. Tr. ii. t. p. 82.-ArEt. Zool. ii. $N^{\circ}$ 187.-Latb. Syn. iv. p. 661. 6 1.

HaвiтAт in America feptentrionali, copiofifima; victitat feminibus variis. - 14-16 pollices longa.-Caro eximia.

Collum cinereum æeneo fplendens : cauda longitudine corporis : redtrices 2 intermediæ nigræ, reliquæ ex albido cinereæ macula nigra, verfus apicem alba: roftrum nigrum : pedes rubri.

ß. C. cauda cuneata, corpore fufcefcente fubtus rufo-albido, collo antice fubvinaceo, rectricibus lateralibus medio intus macula rotundata nigra.

Habitat cum priore, et ejufdem fere magnitudinis.

Remiges primores fufcæ, extus et apice rufefcente marginatæ, fcapis caftaneis : restrices 2 intermediæ fufcæ, laterales cinereæ, verfus bafin intus. macula rotundata nigra ; extima extus et apice, fecunda apice tantum albida; fubtus omnes laterales a bafi ad medium intus nigræ, reliqua parte cinereæ. Forte varietas migratoria.

$7 \mathrm{x}$. carolinen-

fis.

C. cauda cuneata, corpore rufo-cinereo fubtus rufefcente, orbitis cæruleis.

Columba carolinenfis, Lin. Syft. i. p. 286. 37.-Gmel. Syft. i. p. 789 . Turtur carolinienils, Brif. i. p. 1 10. 18. t. 8. f. 1.-Id: 8 vo. i. p. 27. Picacuroba, Will.p. 134.-Klein. Av. p. I 19. 17.

Tourte, Tourterelle de la Caroline, Buf. ii. p. 557.-Pl. Enl. 175. (fem.)

Carolina Pigeon, Arqz. Zool. ii. p. 188: t. 14.-Cat. Car. i.t. 24.-Lath. Syn. iv. p. 663.62.

HabItat in America calidiore, et infulis adjacentibus.- $-10 \frac{1}{2}$ pollices longa.-Roftrum fufcum: pedes rubri: rectrices cinereæ, apice albo, medio macula nigra.

Mas pectore violaceo-aureo fplendente, et in utraque ala maculæ quædam nigræ.

72.

canadenfis. C. cauda cuneata, corpore grifeo-fufco fubtus albido, remigibus prìmoribus apice flavicantibus, rectricibus extimis albis.

Columba canadenfis, Lin. Syft. i. p. 284* 30.-Gmel. Syft. i. p. 785.Brif. i. p. 118.21 - Id. 8 vo. i. p. 29.

Tourterelle de Canada, Buf. ii. p. 552.-Pl. Enl.' 176.

Canada Turtle, Arct. Zool.ii. No 190.-Lath. Sym, iv, p. 658.58 . 
614 A VES COLU M B IE. Columba.

Habitat in Canada. - 13 pollices longa.

Recarices cinereæ, excepta utrinque extima alba ; omnes vero, duabus intermediis exceptis, verfus exortum in latere interiore magna præditæ funt macula rufa, infra quam magna altera macula fufço-nigricans adeft. Multum affinis carolinen/ti.

Femina fupra fordide albo-flavicante tranfverfim lineata.

73.

marginata. C. cauda cuneata, corpore fupra fufco fubtus fufco-cinereo, pectore rubro, rectricibus apice nigris albo marginatis.

Columba marginata, Lin. Syft. i. p. 286. 40.-Gmel. Syft. i. p. 79 ז.

Turtur americanus, Brif. i. p. Ior. 24.-Id. 8 vo. i. p. 24 .

Tourterelle d'Amerique, Buf. ii. p. 552.

Long-tailed Dove, Edw. t. I 5 .

Marginated Pigeon, Lath. Syn. iv. p. 664.63.

Habitat in Anterica.-10 pollices longa.

Macula fufca ad aures: orbitcloraque alba : pedes rubri : roftrum cinereum: reitrices laterales cinerex apicibus albis, inter quos colores tænia tranfverfa nigra. An diftincta fpecies?

74.

amboinen- C. cauda cuneata, corpore rufo, collo undulato-nigricante.

fis. Columba amboinenfis, Lin. Syft. i. p. $286.38 .-$ Gmel. Syft. i. p. 790. -Brif. i. p. I 27.26. t. 9. f. 3.-1d. 8vo. i. p. 3 I.

La Tourterelle d'Amboine, Buf. ii. p. 557.

Amboina Turtle, Lath. Syn. iv. p. 665.64.

Habitat in Amboina.- I 4 pollices longa.

Roftrum pedefque rubri: penna collum et peltus tegentes nigricante tranfverfim ftriatæ.

75 。

capenlis. C. cauda cuneata, corpore grileo-fufco fubtus albo, remigibus primoribus latere interiore rufis.

Columba capenfis, Lin. Syft. i. p. 286. 39.-Gmel. Syft. i. p. 790.Brif. i. p. 120.22 . t. 9. f. 2. (mas.) $-I d .8$ vo. i. p. 29.

La Tourtelette, Buf. ii. p. 554.-Pl. Enl. 140. (mas.)

Cape Pigeon, Lath. Syn. iv. p. 666.65.

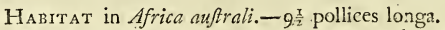

Ale macula chalybis fplendentis: rectrices longiffima fubtus nigræ, extima utrinque excepta, qua extus et apice alba eft.

Variat fincipite nigro. Maris jugulum atrum: rofrum et pedes rubri.

C. macroura, 
76.

A VES C O L U M B AE. Columba.

macroura. C. macroura, cauda cuneata, corpore cinnamomeo fubtus albido, rectricibus apice albis.

Columba macroura, Gmel. Syft.i. p. 790.

Lue Tourocco, Buf. ii. p. 553 .

La Tourterelle à large queue, $\mathrm{Pl}$. Enl: 329 .

Great-tailed Pigeon, Lath. Syn. iv. p. 667.66. .

Habrtat in Senegala.- I 2 pollices longa.

Roftrum et pedes rubri : roftrum bafi cera alba obductum : cauda lon-

77. gitudine corporis.

bantamen- C. cauda cuneata, orbitis denudatis carneis, collo pectore hypochonfis. driifque albo nigroque undulatis.

Columba bantamenfis, Muf. Carlf. fafc. iii. t. 67.

Навгтат in infula fava, juxta Bantam vulgatifima, ubi in fylvis palmarum melancholicis fuis cantilenis aures incolarum demulcet.

Corpus magnitudine $\Upsilon$. Torquilla, totum fupra cinereo-canum fubtus albidum, dorfo, alis, pectoreque maculis undulato-lunulatis nigris : cauda longitudine corporis, cuneata, rectricibus quatuordecim, intermediæ fex nigræ, reliquæ octo verfus apicem albæ: roftrum nigrum: pedes rubri.

78.

melano- C. cauda cuneata, corpore cxrulefcente, remigibus nigris.

ptera. Columba melanoptera, Molin. Cbil. p. 308.-Id. (ed. Gall.) p. 21 5.Gmel. Syjt. i. p. 790.

Habitat in Cbili.

79.

domini- C. cauda cuneata, corpore grifeo, capite fubtus albo, macula verticis senfis.

fafcia fub oculis et torque colli nigris.

Tourterelle de St. Domingue, $P l$. Enl. 487.

Hавгтат in Dominicenfi infula.- I I pollices longa.

Roftrum nigrum : pedes rubri : corpus fupra cinereo-grifeum, dorfo. fubundulato: alis maculis aliquot nigricantibus : pestus vinaceum: frons, gula, latera capitis, et inde torquis fub nucha alba: macula verticis, fafcia a naribus utrinque fub oculis poftice dilatata, torquis medio. colli nigra : criffum album: cauda grifea, reltricibus extimis albis.. 


\section{O R D O V. G A L L I N Æ.}

\section{GENUS XLIX. PA V O.}

Roftrum conico-incurvatum, fornicatum. Caput pennis revolutis tectum.

Penna uropygii elongatæ, latæ, expanfiles, ocellatæ.

I.

criftatus. P. capite crifta compreffa, calcaribus folitariis.

Pavo criftatus, Lin. Syft. i. p. 267. 1.-Faun. Suec. N॰ 197.-Gmel. Syft. i. p. $729 .-S c o p$. Ann. i. No 162.-Brun. p. 58.-Kram. El. p. 355. -Frifch. t. 118.-Raii Syn. p. 51. A. 2.-Will. p. I1 2. t. 27.-Id. (Angl.) p. 158.-Brif. i. p. 28 1. 7. t. 27.-Id. 8vo. i. p. 79. $-K l e i n . A v$. p. II 2. B.-Id. Ov. p. 32. t. 14. f. I. 2.-Borow/k. Nat. ii. p. 164.-Ger. Orn. ii. p. 73, t. 217.

Le Paon, Buf. ii. p. 288. t. Io.-Pl. Enl. 433.434 .

Pfau, Gunth. neft. u. Ey. t. 22.-Naturf. iv. p. 605.

Pavone, Zinnan. Uov. p. 25. t. I. N० I.

Crefted Peacock, Latb. Syn. iv. p. 668. I.

Habitat in Afia, Africa; in Europa, et apud nos in Anglia, paffim in hortis nobilium et curioforum cicur.

Mas remigibus primoribus ferrugineis, calcaratus, ejulans, vindicans, pertinax, fuperbus, pulcherrimus omnium : togam dorfalem gemmantibus ocellis, naturæ miraculo pictam, erigendamque, tertio anno acquirit, qua nihil pulchrius, quam fub canicula dejicit. Pernoctat in altis.

Femina curat pullos in proximas nuptias.

Ovum albo-flavefcens, punctulis impreffis.

B. Pavo varius, Brif. i. p. $288 .-$ Id. 8 vo. i. p. 81 . Frifch. t. 115.-Lath. Syn. iv. p. 671.-Borowe. Nat. ii. p. 166.

A præcedente differt genis, gutture, fupremo ventre, teclricibufque slarum albis. 
$\gamma$ Pavo albus, Brif. i. p. 288.-Id. 8 vo. i. p. 8 I. - Frifch. t. 120.Raii Syn. p. 51. A. 2.-Borow/k. Nat. ii. p. 167.-Ger. Orn. ii. p. 74. t. 218.

Le Paon blanc, Buf. ii. p. 323. -Lath. Syn. iv. p. 672.

Variat corpore toto albo.

2.

muticus. P. capite crifta fubulata, calcaribus nullis.

Pavo muticus, Lin. Syft. i. p. 268. 3.-Gmel. Syjt. i. p. 731.-Borow/k. Nat. ii. p. 167 .

- japonenfis, Brif. i. p. 28 g. 8.-Id. 8vo. i. p. 8i.-Aldr. Av. ii. t. $33.34 \cdot-70 b n f$. Av. t. 23 .

Le Spicifere, Buf. ii. p. 366.

Japan Peacock, Lath. Syn. iv. p. 672. 2.

Навітат in faponia; criftati magnitudine.

Orbita oculorum rubre: corpus fupra cæruleo et viridi varium, fubtus leucophæum maculis nigris: crifla fpicæ æmula: tectrices caudæe fuperiores macula præditæ in medio aurea, dein cærulea, marginibus viridibus. Femina fubtus nigra.

3.

bicalcara- P. capite fubcriftato, calcaribus binis.

tus. Pavo bicalcaratus, Zin. Syft. i. p. 268. 2.-Gmel. Syft. i. p. 730.-Borowfk. Nat. ii. p. 163. t. 26.

finenfis, Brif. i. p. 291 . $9 .-I d .8$ vo. i. p. 82.

Phafianus pavoneus, Klein. Av. p. I14. 6. (mas.)-Id. Ph. fufcus, p. I 14. 6. (femina.)

L'Eperonnier, Buf. ii. p. 368.-Pl. Enl. 492. 493.

Le petit Paon de Malacca, Son. Voy. Ind. ii. p. 173. t. 99.

Peacock Pheafani, Edw. t. 67.69.

Iris Peacock, Lath. Syn. iv. p. 673. 3.

Навітат in Cbina; $P b$. colcbico major.

Pennæ verticis reflexæ: pennæ pofterioris dorfi longæ ocellis binis.

4.

tibetanus. P. dorfo fuperiore tectricibufque caudæ maculis fplendide cæruleis, calcaribus binis.

Pavo tibetanus, Lin. Syft. i. p. 268. 2. 3.-Gmel. Syft. i. p. 731.-Brif. i. p. 294. 10. t. 28 . A. f. 2. -Id. 8 vo. i. p. 83 .

Le Chinquis, Buf. ii. p. 365 .

Thibet Peacock, Lath. Syn. iv. p. 675. 4. 
Habitat in Tibeti regno.-Maculæ cæruleæ violaceo et aureo variantes: tectrices caude fuperiores maculis quatuor concoloribus præditæ: calcaria bina, ut in præcedente, cui nimis affinis.

\section{GENUS L. ME LEA G R IS.}

Rofrum conico incurvum.

Caput carunculis fpongiofis tectum.

Gula caruncula membranacea longitudinali.

Cauda pennis numerofis, extenfilis.

Pedes calcarati.

I.

Gallopa- M. capite caruncula frontali gularique, maris pectore barbato.

vo. Meleagris Gallopavo, Lin. Syjt. i. p. 268. 1.-Foun. Suec. $N^{\circ} 198,-$ Gmel. Syft. i. p. 732.-Brif. i. p. 158. t. 16.-Id. 8 vo. i. p. 4 1.Raii Syn. p. 5 1. A. 3.-Id. p. 182. 16.-Will. p. I I 3. t. 27.Pbil. Trans. xviii. p. 992.-Id. lxxii. p. 67.-Faun. Arag. p. 80. -Borow/k. Nat. ii. p. I68.-Frifch. t. 122.-Ger. Orn. ii. p. 75. t. 222.-226.-Scbaf. El. Orn. t. 37.-Klein. Av. p. I1 2. 1.-Id。 Ov. p. 32. t. I 3. f. 4 .

Gallina indiana, Zimnan. Uov. p. 27. t. 2. f. 3.-Rom. Orn. i. p. 47. t. 5 . Il Gallinacio, Cett. uc. Sard. p. I I I.

Le Dindon, Buf. ii. p. 132. t. 5.-Pl. Enl. 97. American Turkey, ArEz. Zool. ii. N ${ }^{\circ}$ 78.-Latb. Syn. iv. p. 678. 1. Domeftic Turkey, Br. Zool. i. No 97.-Will. (Angl.) p. 159. t. 27.Alb. iii. t. 35.-Latb. Syn. iv. p. 679.

Habitat in America; ultra $3 \frac{t}{2}$ pedes longa; hofpitatur apud nos ubique culta, colore mire varians, non raro toto corpore candido : in America Septentrionali, dum fera, nigra femper eft.

Mas exæftuat inflato pectore, expanfa cauda, fanguinea facie, relaxata frontis caruncula; iræ tenax; barba pectoris nigra, tertio anno excrefcit : cauda rectricibus 18 : caro tenerrima, fapida. Ovum album lutefcente nævofum.

Pes poftice calcari donatur craffifimo, brevi et obtufo. Femina a mare difcrepat in eo quod calcari careat, et caruncula prædita fit minori multo et breviori, et caudam non geftat erectam.

M. capite 
Satyra. M, capite cornibus geminis, corpore rubro punctis ocellatis.

Meleagris fatyra, Lin. Syft. i. p. 269.-Borow/k. Nat. ii. p. 168. t. 27. Penelope fatyra, Gmel. Syft. i. p. 753 .

Phafianus cornutus, Brif, App. p. I $4-I d .8$ vo. i. p. 86.

Le Napaul, ou Faifan cornu, Buf. ii. p. 362 .

Horned Pheafant, Edw. t. I 16 .

- Turkey, Lath. Syn. iv. p. 680. 2. -Id. Sup. p. 203.

Habrtat in India; magnitudine fere Gallopavonis.

Nares, frons, orbite pennis, pilorum inftar, nigris tecta: vertex ruber: caruncula gularis dilatabilis cærulea, rufo variegata: cornua duo cærulea pone oculos enata, poftice vergentia: pedes albidi, calcarati : cauda pennis viginti.

Femina capite pennis recto, abfque cornibus et caruncula gulari : capitis et colli fuperioris pennæ cæruleo-nigræ, elongatæ, decumbentes : reliquum corpus, uti maris, rubrum, ocellato-maculatum, et pedes cal. caribus obtufioribus inftructi.

\title{
GENUS LI. PENELOPE。
}

\author{
Roftrum bafi nudum. \\ Caput pennis tectum. \\ Gula nuda. \\ Cauda rectricibus duodecim. \\ Pedes mutici.
}

I.

criftata. P. capite pennis ereetis criftato, temporibus violaceis。

Penelope criftata, Gmel. Syft. i. p. 733 .

Penelope Jacupema, Merrem. Ic. ii. p. 42. t. I I.

Meleagris criftata, Lin. Syft. i. p. 269. 2.-Borow/k. Nat. ii. p. I 70.

Gallopavo brafilienfis, Brif. i. p. 162 ?-Id. 8 vo. i. p. 43 .

Phafianus fufcus brafilienfis, Klein. Av. p. I1 2. 4.

Jacupema, Raii. Syn. p. 56. 2.-Will. p. I 1 8. t. 28.-Id. (Angl.) p. I65. Guan, or Quan, Latb. Syn. iv. p. 680. 3.-Edw. t. I3.

Habitat in Brafilia, Guiana; Galline magnitudine.-2 ped. 6. poll. longa.-Hofpitatur apud Brafilienfes. - Caro fapida.

Roftrum nigrum : irides aurantiæ : pedes rubri : orbite violaceæ: gula 


\section{AVES G A L L I N FE. Penelops:}

caruncula compreffa rubra, pilis rarioribus veftita : caput fupra crifta oblonga pennacea, ablque caruncula : corpus nigro-virefcens, dorjo fuf$\mathrm{co}$, collo antice peflore et abdomine albo maculatis.

Fomina vix criftata.

In hac ave prius fupra totum fternum afpera arteria extendatur, atque: reflectatur, quam pectus intret.

2.

pipile. Cr. caruncula gulari cærulea, ventre albo, dorfo fufco atro maculato,

Penelope pipile, Gmel. Sylt. i. p. 734 .

Crax pipile, focq. Vog. p. 26 . t. 2 1.

Piping Curaffow, Laib. Syn. Sup. p. 205:-

HАвітат cum priore; vox tenuis, pipilans.

Caput, cera, et orbite albæ: crifla nulla: tedtrices alartm albo variz.

3.

cumanen- P. nigricans, capite criftato, temporibus gulaque cæruleo-nigricantibus,

fis. Penelope cumanenfis, Gmel. Syyt. i. p. 734.-

- leucolophos, Merrem. Ic. p. 43. t. I2.

Crax cumanenfis, Facq. Vog.p. 25. 19. t. I 2.

Cumana Curaffow, Latb. Syn. Sup. p. 205 . :

Yacou, Mem. Sur Cay. i. p. 398. t. 5.-Buf. ii. p. 387.-Lath. Syn. iv. p. 68 I. t. $6 \mathrm{I}$.

Habitat in Cayana, Guiana; Gallopavonis femine magnitudine.Nidum vel terra, vel in arboribus trunco proximum ftruit, et ova $4-6$ ponit.-Roftrum nigrum : pedes rubefcentes : irides pallide rofex : orbite et gula nuda cæruleo-nigricans, pennis pilofis rarioribus veftita : crifta tectricefque alarum majores albæ, fcapo pennarum nigro, harum quoque apicibus nigris. - Caudam pennis I 2 conftantem expandit.

4.

Marail. P. capite fubcriftato, temporibus gulaque incarnatis carunculatis.

Penelope Marail, Gmel..Syf. i. p. 734.

Le Marail, Buf. ii. p. 390.

Faifan verdatre de Cayenne, Pl. Enl. $33^{8}$.

Maraye, Mem. Jur Cay. i. p. $3^{8}$ 3.t. 3. 4.-Defor. de Surin. ii. p. 149. Marail Turkey, Lath. Syn. iv. p. 682.

Haritat in Cayane et Guiane fylvis; gregaria.

Roftrusn nigrum: pedes rubri: corpus nigro-virefcens, collo infra albo vario: cauda plerumque pendula, at Gallopavonis inftar erigere et expandere poteft avis.

A priore 
A priore diftincta avis, ut docet anatomia.

In hac fpecie afpera arteria (utriufque fexus) extra cavum thoracis defcendit, ubi retroflexa, furfumque afcendens, cavum et pulmones intrat. .

\section{GEN US LII. N U M I D A.}

Caput collo compreffo colorato cornutum.

Palearia carunculacea, ad latera maxillæ inferioris.

Rofrum cera inftructum nares recipientes.

I.

Meleagris. N. nigra maculis rotundatis albis, remigibus extus albo tranfverfim ftriatis, vertice corneo.

Numida Meleagris, Lin. Syft. i. p. 273. 1.-Muf. Adolph. Fr. ii. p. 27. -Gmel. Syft. i. p. 744. -Scop. Ann. i. No 165.-Borow/k. Nat. ii. p. 182.t. 20.-Ger. Orn. ii. p. 79. t. 230.-Haffelq. It. p. 274.-Id. Voy. p. 274. 42.-Fricch. t. I 26.-Scbaf. El. Orn. t. 46.-Rom. Orn. i. p. 69. t. 10.-Brif. i. p. 176. t. 18.-Id. 8 vo. i. p. 49.Klein. Av. p. III. 2.-Id. Stem. p. 25. t. 26. f. I. a. b.-Id. Ov. p. 32. t. I3. f. 5.6.

Gallus et Gallina guineenfis, Raii Syn. p. 52.8.-Id. p. 182. 17.Will. p. II 5, t. 26. 27 .

Peintade, Buf. ii. p. 163.t. 4.-Pl. Enl. 108.-Voy. en. Barb. i. 268.Zinnan. Uov. p. 27. t. 2. $\mathrm{N}^{\circ} 4$.

Guinea Pintado, Will. (Angl.) p. 162.-Sparm. Voy. ii. p. 19.-Sloan. fam. p. 303.-Brown. Fam. p. 470.-Pitf. Mem. t. p. 174.Latb. Syn.iv. p. 685 . 1.-Id. Sup. p. 204.

Habitat in Africa; in Europa frequens in ornithone. - Carofapida. Pennæ colli a tergo reverfæ funt.

Caruncula Maris cærulefcens, Femine rubens.

B. Meleagris pectore albo, Brif. i. p. I8r. A. $-I d$. 8 vo. i. p. 50.

White-breafted Pintado, Latb. Syn. iv.p. 687.-Alb. ii. t. 35.-Brown. fam. p. 470 .

Variat peEtore albo.

d. Varietas corpore toto albo, Ger, Orn, ii. t. 23 I. 

622
A V E 5
GA I; I I N RE.
Cras:

2.

mitrata, N. nigra maculis albis, vertice corneo, gula carunculata.

Numida mitrata, Pall. Spic. iv. p. 18. t. 3. f. 1. (caput.)-Borowijk. Nat, ii. p. 184. 3.-Gmel. Syft. i. p. 745.

Mitred Pintado, Lath. Sjn. iv. p. 688.2.

Habitat in Madagafcaria, Guinea; meleagridis magnitudine.

Roftrum flavefcens: verticis cum capiftro rubri tuber conicum : collum fuperius nudum, cærulefcens; inferioris pennis tranfverfim undula. tis: corpus nigrum, guttis majoribus confperfum quam meleagris.

3.

criftata. N. nigra albo maculata, vertice criftato, collo cærulefcente fubtus fanguineo.

Numida criftata, Pall. Spic. iv. p. 15. t. 2.-Borowes. Nat. ii. p. 184. 2.-Gmel. Syft. i. p. 746.

Crefted Pintado, Lath. Syn. iv. p. 688. 3.t. 62.

Haвiтat in Africa.-Collum corpufque fubtus nigrum immaculatum: remiges fufca : maxilla inferior palearibus deftituta : cauda albo fafciata,

4.

agyptiaca. N. nigra cærulefcente maculata, vertice criftato, capite colloque rufis.

Meleagris altera, Ger. Orn. ii. p. 8๑. t. 232.

Meleagris hac, Gallina agyptiaca dicta, in aviario regio anno 1728 Verfaliis vivebat.

Roftrum rubefcens : pedes nigro-cærulefcentes : caput et collum rufum pilis rarioribus, vertice pennis longioribus erectiufculis : gene et caruncula maxillaris utrinque brevis cærulefcens : corpus nigrum, maculis majufculis cærulefcentibus. An a criftata fatis diftineta.

\section{GEN U S LIII. C R A X.}

Rofrum bafi cera obductum in utraque mandibula.

Nares in medio cera.

Penna caput tegentes revolutæ plerifque.

Cauda magna, recta, expanfilis.

Alector: Cr. cera flava, corpore nigro, ventre albo.

mas. Crax Alector, Lin. Syft. i. p. 269. 1. -Gmel. Syjt. i. p. 735.-Scop. Ann. i. No 163.-Frich. t. 121.-Klein. Av. p. 11 1. 3.-Borowesk. Nat. ii. p. I70. t. 28 . 
Crax guianenlis, Brif. i. p. 298, I2. t. 29.-Id. 8 vo. i. p. 84 .

Mituporanga, Raii Syn. p. 56.6.-183. 19.-Will. p. I 1 5.t. 28. (caput.)

Le Hocco de la Guiane, Buf. ii. p. 375. t. I 3.-Defcrip. Surin. ii. p. 149. Indian Cock, Pitfild's Mem. t. p. 190.-Pbil. Tranf. lvi. p. 215. f. 3 .

Peacock Pheafant of Guiana, Bancr. Guian. p. 173.

Crefted Curaffow, Brown. Fam. p. 470.-Sloan. Fam. p. 302. t. 260.Damp. Voy. ii. part 2. p. 67.-iii. part i. p. 75.-Lath. Syn. iv. p. 690. 1 .

Habitat in America calidiore; Gallopavonis minoris magnitudine.Hofpitatur in Europa calidiore, facile manfuefcens.-Caro admodum bona.

Roftrum a medio cera tectum, tam in fuperiori quam inferiori mandibula, ultra oculos protenfa: lingua integra: pilei pennæ revolutæ: tempora calva nigra : cauda rotundata pennis 14 : calcaria nulla.

Variat abdomine albo nigroque fafciato.

ß. Cr. cera rubra, corpore nigro, abdomine fufco.

Crax Mitu, Lin. Syft. i. p. $270.3 .-$ Raii Syn. p. 52. 4.-Will. p. I I4. t. 28. -Id. ( $\mathrm{Angl.}$ ) p. 138 .

- Brafilienfis, Brif. i. p. 296.1 I. $-I d .8$ vo. i. p. 83.

Crefted Curaffow, Latb. Syn. iv. p. 69r. A.

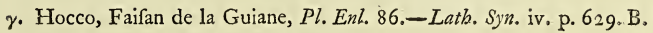

Priori fimillima, at cauda apice alba.

s. Cr. cera flava, corpore nigro, crifta alba apice nigra, collo albo nigroque fafciato, Latb. Syn. iv. p. 692. C.

In hac varietate collum inferius et femora fufca: criflum album.

r.

Alector. Cr. rubra, capite cærulefcente, crifta alba apice nigra.

femina. Crax rubra, Lin. Syft. i. p. 270. 2.-Gmel. Syft. i. p. $73^{6}$.

- peruvianus, Brif. i. p. 305 . 16.-Id. 8vo. i. p. 86.-Klein. Av. p. I12. 4 ?

Gallopavo brafilienfis, Ger. Orn. ii. p. 77. t. 227.

Hocco de Perou, Buf. ii. p. 375. t. 14.-Pl. Enl. 123.

Coxilitli, Raii Syn. p. 57 ?

Red peruvian Hen, Alb. iii. t. 40.

Crefted Curaffow, Lath. Syn. iv. p. 693.

Habitat in Peruvio. 
624 AVES GALIIIN IE. Crax.

$\beta$. $\mathrm{Cr}$. corpore rubro, collo albo nigroque annulato, abdomine albo, cauda fulca, Lath. Syn. iv. p. 693. A.

$\gamma$. Cr. corpore toto fufco-rubro lutefcenteque fafciato, Lath. Syn. iv. p. 693. B.

¿. Cr. corpore fufco-rubro, collo albo nigroque annulato, cauda fafciis novem luteis nigro marginatis, Lath. Syn. iv. p. 693. var..C. t. lxiii.

2.

globicera. Cr. flava, narium gibbere globofo, corpore nigro-cærulefcente, abdomine imo albo.

Crax globicera, Lin. Syft.i. p. 695. 4.-Gmel. Syft. i. p. 736.-Borows/k. Nat. ii. p. $17 \mathrm{r}$.

—. Curaflous, Brif. i. p. 300 . 13.-Id. 8 vo. i. p. 85.

Gallus indicus alius, Klein. Av. p. I I I. 3.-Raii Syn. p. 52. 7.-Will. p. I10. I 15.-Ii. (Angl.) p. 162.-Ger. Orn. ii. p. 79. t. 229.

Curaffow Cock and Hen, Alb. ii. t. 31. 32.-Edw. t. 295. f. I. Globofe Curaffow, Leth. Syn. iv. p. 695.2.

Habitat in Guiana; aleetoris magnitudine.-Pilei pennæ revolutæ, apice albæ: gibber fubglcbofus, luteus, cerafiformis inter nares.

Femina oblcure fuifca, ventre fupremo albo: cauda nigra, fafciis quatuor albis.

Pauxi. Cr. cera cærulea, narium gibbere criftato, corpore nigricante, abdomine apiceque caudx albis.

Crax Pauxi, Lin. Syft. i. p. 270. 5.-Gmel. Syft. i. p. 737.-Raii Syn. p. 52.5.-Will. p. I14.305.-Id. (Angl.) p. I6 I. 394.-Bororejk. Nat. ii. p. 172 .

Gallina indica alia, Will. p. 110.

Crax mexicanus, Brif. i. p. 302 . 14.- $-1 d$. 8vo. i. p. 85 .

Le Hocco du Mexique, Buf. ii. p. $34^{8}$.

La Pierre de Cayenne, Pl. Enl. 7.8 .

Cufhew Curaflow, Edw. t. 295. f. 2.-Latb. Syn. iv. p. 6g6. 4.

Habitat in Mexico.-Rofrum rubrum: caruncula criftata, pyrie formis, turcoidis colore, roftro longior, inter nares.

Femina fufca ubi mas niger, in cæteris mari fimilis.

4.

galeata. Cr. vertice corneo, corpore nigro, criflo albo.

Crax vertice cono corneo onulto, Brif. (ed. 8 vo.) i. p. 87.

Galeated Curafiow, Lath. Syn. Sup. p. 206. 
Habitat in Curafjao infula.-Magn. fere Gallopavonis.

5. Rofrum et pedes rubri.

weciferars. $\mathrm{Cr}$. fufca, roftro pectoreque cyaneis, abdomine albido.

Penelope vociferans, Gmel. Syft. i. p. 735 .

Chachalacametl, Raii Syn. p. 163.-Fern. Hift. N. Hi.p. ch. 41.

Chacamel, Buf. ii. p. 394 .

Crying Curaffow, Latb. Syn. iv. p.6g6. 4.

Habitat in Mexico, locis montofis; magnitudine Galline vulgaris ut et vox.-Avis eft admodum ftrepera et clamofa, unde nomen quod avis vociferans et clamitans fignificat.

\section{GENUS LIV. PHASI A NUS.}

Roftrum breve, robuftum.

Genee cute nuda lævigata.

Pedes plerifque calcarati.

T.

Gallus. Ph. caruncula compreffa verticis geminaque gulæ, auribus nudis, cauda compreffa adfcendente, pennis colli linearibus elongatis apice membranaceis.

Phafianus Gallus, Gmel. Syft. i.p. 737 .

Coq fauvage, Son. Voy. Ind. ii. p. 253 . t. 94. (mas.)-p. 160. t. 95. (femina.)

Wild Cock, Lath. Syn. iv. p. 698. 1.

Haвiтат in India.-3 ped. 4 poll. longus.

Caruncula verticis fpeciofa, dentata, et paleare maxillæ inferioris utrinque dependens, rubra: pone oculos area nuda reniformis, margaritacea : corpus grifeo, albo, rufoque varium: totius colli pennæ angurtæ, elongatæ, fcapo maculis 3 vel 4 cartilagineis flavis, apice cartilagineo: tectrices alarum rufo-caftaneæ apice dilatato, cartilagineo, fulvo: pectus rufefcens: cauda rectricibus violaceo nitentibus, intermediis elongatis, falcatis: pedes calcari magno incurvato armati.

Femina minor, abfque carunculis, corpore obfcuriore, fufco, grifeo, rufoque vario: pedes mutici.
4. L
Ph. caruncula 
1. $\beta$.

domefti- $\mathrm{Ph}$. caruncula compreffa verticis geminaque gulæ, auribus nudis, cauda cus.

z. $\gamma$. compreffa adfcendente, pennis colli linearibus elongatis.

Phafianus gallus, Lin. Syft. i. p. 270.-Faun. Suec. $\mathrm{N}^{\circ}$ 199:-Borow/k. Nat. ii. p. 177 .

Gallus domefticus et Gallina, Brif. i. p. 166. 1.-Id. 8 vo. i. p. 45.Raii Syn. p. 5 I. A. 1.-Will. p. 109. t. 26.-Scbaf. El. Orn. t. 38.-Rom. Orn. i. p. 56. t. 9. p. 59. t. 7.-Ger. Orn. ii. t. 207. 208.

Alector, Klein. Av. p. iा 1. A. 1.-Id. Ov. p. 31. t.. I3. f. I.

Coq commun, Buf. ii. p. II6. t. 2.-Pl. Enl. I.

Domeftic Cock, Alb. iii. t. 32.-Brown. Fam. p. 470.-Sloan. Fam. ii.

p. 301.-Will. (Angl.) p.1 54.-Pbil. Tranf. xii. p. 923.-Latb. Syn. iv. p. 700 .

criftatus. $\mathrm{Ph}$, crifta in vertice plumofa denfiffima.

Phafianus criftatus, Lin. Syft. i. p. 270. I. B.-Fatn. Suec. N${ }^{\circ}$ 199. B. --Raii Syn. p. 5 I. A. I. var. I.-Will. p. I ro.-Borow/k. Nat, ii. p. 178. a.-Rom. Orn. i. p. 6o.-Ger. Orn. ii. t. 2 I6.

Le Coq huppé, Buf. ii. p. I16.-Pl. Enl. 49.

Crefted Cock, Lath. Syn.iv. p. 703.-Will. (Angl.) p. 158 :

I. $\delta$.

In omnibus, crifta plumofa excepta, cum aliis convenit.

pentadac- Ph. domefticus quinque digitis in utroque pede.

tylus. Gallus pentadactylos, Brif. ii. p. 169.-Id. 8 vo. i. p. 46.-Frifch. to 127. $128 .-$ Rom. Orn. p. 62.

Le Coq à cinq doigts, Buf. ii. p. I 24 ..

Darking Cock, Lath. Syn. iv. p. 703.

$\mathrm{Ab}$ aliis differt folo numero digitorum; tres antici, poftici bini.

I. $\varepsilon$.

crifpus. Ph. pennis furfum reflexis.

Gallus crifpus, Lin. Syft. i. p. 27 1. n.-Brif. i. p. 173. t. 17. f. I.-Id.

8 vo. i. p. $47 .-$ Raii Syn. p. 51. A. 1. var. 4 .-Erifch. t. $135 \div$ Borow/k. Nat. ii. p. I 80 . F.

Gallus cincinnatus, Ger. Orn. ii. p. 7 1. t. 2 I5.

Gallina Frienandica, Will. p. I 10.

Le Coq frifé, Buf. ii. p. I 2 I.

Crifped or frizzled Cock, Lath. Syn. iv. p. 704.-Baner. Guian. p. 175. -Defcr. Surin. ii. p. I 59.-Will. (Angl.) p. 156.

Habitat in Afia, Java, Faponia.

Pennæ revolutæ: remiges ablque radiis.

Ph. cauda 
x. $\zeta$.

ecaudatus, Ph. cauda $\mathrm{f}$. uropygio carens.

Ph. Gallus ecaudatus, Lin. Syft. i. p. 27r. $\gamma$-Raii Syn. p. 51. A. I. var. 3.-Frifch. t. I 3 I. I 32.-Borowfk. Nat. ii. p. I 8 I. I.

Le Coq fans croupion, Buf. ii. p. 122.

Rumplefs or Perfian Cock, Latb Syn. iv. p. 705.-Will. (Angl.) p. 156.

I. $\eta$.

Hæc varietas uropygio et rectricibus prorfus caret.

Pumilio. Ph. pedibus brevifimis.

Gallus Pumilio, Brif. i. p. I7 1. 2.-Id. 8vo. i. p. 46.-Raii Syn. p. 5 I. A. r. var. 2,-Frif6h. t. 133. 134.-Will. p. r10. t. 26.-Ger. Orn. ii. p. 70. t. 214 .

Le Coq nain, Buf. ii. p. 118 .

Dwarf Cock, or Creeper, Latb. Syz. iv. p. 705.-Will. (Angl.) p. 156.

Habitat in Afia? - In omnibus convenit cum Gallo et Gallina vul.

r. $\theta$. gari, fed cruribus donatur brevifimis, unde nomen.

puffllus. Ph. tibiis pennatis, pennis pofticis elongatis.

Ph. Gallus pufillus, Lin. Syjt. i. p. 77 1. K.-Borow/k. Nat. ii. p. 179. c. Gallus banticus, Brif. i. p. 172. B.-Id. 8vo. i. p. 47.

Gallus plumipes, Rom. Orn. p. 6 I.

Le Coq de Bantam, Buf. ii. p. II 9 .

Bantam Cock, Lath. Syn. iv. p. 706.-Alb. iii. to 33. 34.-Brown. Fam. p. 47 1.-Hayes Br. Birds, t. 23.

Habitat in Bantam Afie.-Hac varietas pedes habet ad digitos ufque plumofos, fed in latere exteriore tantum.-Mas audacifimus.

x. ..

plumipes. Ph. pedibus ad digitos ufque plumofis.

Gallus plumipes, Brif. i. p. I72. A.-Id. 8 vo. i. p. 47.-Witl. p. 110. -Ger. Orn. ii. t. 212.

Gallus et Gallina minor, Frifch. t. 1 36 . 137 .

r. $x$.

Rough-footed Cock, Latb. Syn. iv. p. 706.-Will. (Angl.) p. 156.

turcicus. Ph. pulchris coloribus variegatus.

Gallus turcicus, Brif. i. p. I70. D.-Id. 8 vo. i. p. 46.-Aldrov. Av. ii.

t. p. 314. 315. 316.-Will. p. I10.-Borows. Nat. ii. p. I80. e. Turkifh Cock, Latb. Syn. iv. p. 707.-Will. (Angl.) p. $5_{5} 6$.

Colorum varietate et pulchritudine præcipue a noftratibus differt. 4 L, 2

$\mathrm{Ph}$, corpore 
1. $\lambda$.

patavinus. Ph. corpore duplo majore.

Gallus patavinus, Brif. i. p. 170. C.-Id. 8vo. i. p. 46.-Will. p. 110.Aldrov. Av. ii. t. p. 310.31 1. - Borowefk. Nat. ii. p. I 8 1. k.-Ger. Orn. ii. p. 66. t. 209. $210 .-$ Rom. Orn. p. 63.t. 8. et 9:

Lue Coq de Caux, ou de Padoue, Buf. ii. p. 125.

Paduan Cock, Lath. Syn. iv. p. 707.-Will. (Angl.) p. I56.

Magnitudine ab aliis diftinguitur; Gallo vulgari.duplo major. .

I. $\mu$.

Morio. $\mathrm{Ph}$. crifta et palearibus nigris.

Phafianus Gallus Morio; Lin. Syft. i. p. 27. I. d.-Borowes. Nat. iia p. I80. h.

Gallus mozambicanus, Brif. i. p. 174. 4.-Id. 8 vo. i. p. 48 -Will. p. 298. - Id. (Angl:) p. 387 .

Gallus perficus, epidermide nigricante, S. G. Gmel. iii. p. 285.

Le Coq negre, Brif. ii. p. I22.-Voy. de Siam, i. p. 279.

Rlackamoor Pullet, Fryer. Trov: p. 53.-Harris Coll. Voy. ii. 468.

Negro Cock, Lath. Syn. iv. p. 708 .

Habitat in Africa.-Hac avis ab aliis diferepat crifta, paleis, epidermide, et periofteo nigris, ita ut cocta in atramento elixa putetur.

I. ข.

tophaceus. Gallina vertice tuberofo, Pall. Spic. iv. p. 20 . t. 3. f. 2.

I. $\xi$.

cornutus. Ph. vertice cornibus donato, Ger. Orn. ii, t. 213 .

3. 0 .

lanatus. $\mathrm{Ph}$. pennis pilorum amulis.

Phafianus Gallus lanatus, Lin. Syfi. i. p. 271.-Borowes. Nai. ii. p. 180. G.

Gallus japonicus, Brif. i.p. 175. 6. t. 17. f. 2. (fem.)-Id. 8 vo. i. p. 48 .

Poule à duvet du Japon, Buf. ii. p. 121.-Pl. Enl. $9^{8}$.

S,ilk Cock; Lath. Syn: iv. p. 708.

HaвiтAт in Zaponia, et variat pennarum pinnulis disjunctis et pilosum amulis,-Pedes ad digitos ufque extus plumofi.

fuperbus. Ph. muticus rufus viridi cæruleoque varius, carunculis frontis fubrotundis, palearium fubulatis.

Phafianus fuperbus, Lin. Mant. I77 1. p. 526:-Gmel. Syft. i. p. 744. Superb Pheafant, Latb. Syn. iv. p. 709. 2. .

Haвitat in Cbina.-Corpus rubrum : callum poftice viride, utrinque ciliatum pennis longis variis extantibus, retroque fpectantibus: vertex viridis 
viridis, poftice excurrens crifa plicatili carulea: bumeri virides albo maculati: remiges primores cerulex: cauda elongata, cuneata, reftrici3. bus cæruleis rubrifque variis, tectricibus declinatis varicoloribus mixtis.

Argus. $\mathrm{Ph}$. luteus nigro punctatus, facie rubra, occipite criftato cæruleo.

Phafianus Argus, Lin. Syft. i. p. 272. 4.-Gimel. Syft. i. p. 742.-Borowefk. Nat. ii. p. 176. 3.

Argus or Luen, Pbil. Tranf. 1v. p. 88. t. 3.-Lond. Mog. 1766. t. p. 473.-Gent. Mag. 1768. t. p. 521.-Buf. ii. p. 36r.

Argus Pheafant, Latb.Syn. iv. p. 710.3 .

Haвıтат in Tataria cbinenfi.-Magnitudo Gallopavonis.

Orbita et nyyftaces nigræ: finciput gula et jugulum rubra : occiput criftatum et nucba crerulea : ale grifex punctis ocellatis : cauda cuneata alis concolor, rectricibus intermediis duabus tripedalibus, ad rachin ocellatis ocellis magnis : pedés calcarati.

4.

colchicus. Phr rufus, capite cæruleo, cauda cuneata, genis papillofis.

Phafianus colchicus, íin. Syft. i. p. 270. 3.-Gmel. Syft. i. p. 741.Scop. Ann. i. $\mathrm{N}^{\circ}$ 166.-Brun. p. 58.-Brif. i. p. 262 . 1. $-I d .8$ vo. i. p. 73.-Klein. Av. p. I I4. I.-Id. Stem. p. 25. t. 29. B.-Id. Ov. p. 32. t. 14. f. 7. 8.-Frijch. t. 123.-N.C. Petr. xvi. p. 45 1. 7.Raii Syn. p. 56. A. 1.-Will. p. 117. t. 28.-Sepp. Vog. t. p. 1590 -Borowerk. Nat. ii. p. 173 .

Faffan, Guntb. Neft. u. Ey, t. 16.

Le Faifan, Buf. ii. p. 328. t. I1.-Pl. Enl. 121. 122.

Fagiano, Zinnan. Uov. p. 28. t. 2. f. 5.-Olin. uc. t. p. 49.

Conmon Pheafant, Alb. i. t. 25. 26.-Hayes Br. Birds, t. 20.-Will. (Angl.) p. 163. t. 28. -Latb. Syn. iv. p. 712.4 .

- Habitat in Africa, Afia; hodie in Europa frequens, et in Anglia non rarus.

Gene nudæ, coccinex, papillofx : pedes calcaribus intructi.

Femina ex fufco, grifeo, rufefcente, et nigricante variegata. Ovum : perdicino fimile, at pallidius.

. . Ph. rufus, capite cæruleo, cauda cuneata, collo torque albo.

Phafianus torquatus, Gmel. Syft. i. p. 742.

Ring Pheafant, Latb. Syn. iv. p. 71 5.-Id. Sup. p. 208. .

Fiabitat in Cbina; in Anglia precedente minus frequens. -Pulcherrima avis.

$\gamma$ : Phafianus 
$\gamma$. Phafianus varius, Brif. i. p. 267 . A. t. 25 . f. $3 .-I d$ 8vo. i. p. 75. -Frijch. t. 124.-Borowes. Nat. ii. p. 175.-Gmel. Syft. i. p. 742. Ie Faifan panaché, Buf. ii. p. 352. Variegated Pheafant, Lath. Syn. iv, p. 267.-Hayes Br. Birds, t. 2 r.

A priore differt colore albo, maculis Phaf. vulgarium coloribus imbutis vario.

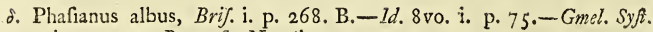
i. p. 742.-Borowes. Nat. ii. p. 175.

White Pheafant, Lath. Syn. iv. p. 716.

Weiffer Fafan, Goetz. Naturf. xvi. p. 127.

Corpus in hac ave album, maculis fparfis minimis nigro-violaceis verfus collum, et fcapularibus maculis paucis rufis notatis.

In quibufdam corpus totum album immaculatum.

£. Phafianus hybridus, Brif. i. p. 268. C.-Id. 8vo. i. p. 75.-Gmel. Syft. i. p. 742.-Frifch. t. I 25.-Borowe/k. Nat. ii. p. 175 .

Le Coquar, Buf. ii. p. 353. t. I2.

Hybridal Pheafant, Lath. Syn. iv. p. 7 r6.

Spuria avis hæc, forte ex $\mathrm{Pb}$. Gallo et colcbico.

Corpus rufo, fufco, albo, et nigricante obfcure varium.

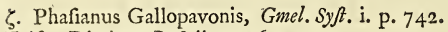

Faifan Dindon, Buf. ii. p. 160.

Turkey Pheafant, Edw. t. 377.-Pbil. Tranf. li. p. 883. t, 19.-Lath. Syn. iv. p. 717.

Hæc avis, uti præcedens, fpuria.

pictus. Ph. crifta flava, pectore coccineo, remigibus fecundariis cæruleis, cauda cuneata.

Phafianus pictus, Lin. Syft. i. p. 272. 5.-Am. Ac. i. p. 562. t. 1.Gmel. Syft. i. p. 743.-Borowek. Nat. ii. p. 173. t. 29. fanguineus, Klein. Av. p. 114. 3.

Phafianus aureus finenfis, Brif. i. p. 27 . . 4. $-I d .8$ vo. i. p. 76 .

Faifan doré de la Chine, Buf. ii. p. 355.-Pl. Enl. 217 . (M. et F.)

Gold Faffan, Guntb. Neft. u. Ey. t. 24. -Naturf. xiv. p. 204.

Painted Pheafant, Edw. t. 68. 69.-Alb. iii. t. 36.-Hayes Br. Birds, t. 22.-Latb. Syn. iv. p. 717.5 .

Habitat 


\section{A VES G A L L I N $\not 2$. Phafianus. 63I}

HaBITAT in Clina; colcbico minor.

Gena fub oculis nudæ: pedes calcaribus inftructi.

Femina furco-rufefcens fubtus fufco-flavefcens, pedibus muticis.

6.

Ovum colcbici fimile, rubedine tinetum.

ayctheme- $\mathrm{Ph}$. albus, critta abdomineque nigris, cauda cuneata.

rus. Phafianus nycthemerus, Lin. Syjt. i. p. 272. 6.-Gmel. Syf. i. p. 743. -Scop. Ann. i. N 167.-Bororevk. Nat. ii. p. 176. 4.

Phafianus albus finenfis, Brif. i. p. 276. 5. -Id. 8vo. i. p. 77.-Klein。 Av. p. 114. 4 .

Le Eaifan noir et blanc de la Chine, Buf. ii. p. 359.-Pl. Enl. I23. 124.

Silber Faffan, Guntb. Neft. u. Ey. t. 49.-Naturf. xvi. p. 122.

Black and white China Phealant, Edrw. t. 66.-Alb. iii. t. 37 .

Pencilled Pheafant, Lath. Syn. iv. p. 7 I 9.6.

Habitat in Cbina; colcbico paulo major.

Tempora nuda, rubra: maris crifta nigra: corpus album pennarum. marginibus nigris, fubtus nigrum : pedes rubri calcaribus inftructi.

Femina grifea, pedibus muticis. Ovum rufo-album.

$7 \cdot$

sriitatus. Ph. fulvo-fufcus, capite criftato, fafcia alarum duplici pallida, cauda apice lutea.

Phafianus criftatus, Gmel. Syft. i. p. 741.

Crax fufcus mexicanus, Brif. i. p. 304. 15.-Id. 8vo. i. p. 86.-Boe rowejk. Nat. ii. p. 172.

Hoatzin, Raii Syn. p. 163.-Will. p. 300-Id. (Angl.) p. 389.-mo. Buf. ii. p. 385 .

Faifan huppé de Cayenne, Pl. Enl. 337.

Crefted Pheafant, Latb. Syn. iv. 720.7. t. 64.

HaBitat in America aufrali.-I ped. Io poll. longus.

Roftrum validum: crifta e pennis elongatis pallidis fubtus nigris: pennæ collo medio albidæ: tectrices alarum apice luteo-albæ, unde faf-

8. ciæ duæ: cauda fubcuneiformis apice alba : pedes mutici.

africanus. Ph. corpore cæruleo-cinereo fubtus albo, capite criftato, rectricibus. duabus intermediis apice, lateralibus toto nigris.

African Pheafant, Lath. Syn. Sup. p. 2 ro.

$\mathrm{H}_{\text {ABITAT }}$ in Africa.- 19 pollices longus.

Roftrum flavum, vaiidum, ut in precedente : crifta e pennis elongatis, fufcis, lateribus albis: pennæ pectoris et abdominis albæ, rachibus nigris : cauda rotundata, vix cuneata. 
9.inct. Ph. fufcus fubtus rufefcens, cauda cuneata, rectricibus lateralibus rufis. Phafianus Motmot, Lin, Syft. i. p. 27 1. 2.-Gmel. Syft. i. p. 740.-Borowejk. Nat. ii. p. $18 \mathrm{r},-6$.

guianenfis, Brif. i. p. 270. 3. t. 26. f. 2.-Id. 8vo. i p. 76. Faifan de la Guiıne, $\mathrm{Pl}$. Enl. I46.

l. e Katraca, Buf. ii. p. 364 .

Motmot Pheafant, Latb. Syn. iv. p. 72 I. 8.-Seba. i. p. 103. t. 67. f. 2.

Habitat in Brofilia.-I 8 pollices longus. - Caret calcaribus.

- I ennx capitis elongata rufa.

Io.

mexica- $\mathrm{Ph}$. fulvo-albus, cauda èlongata, tectricibus viridi-nitentibus.

nus. Phafianus mexicanus, Gmel. Sy/t. i. p. 74I.

Hoitlallotl, Buf. ii. p. 395.-Hern. Hijp. ch. 3. p. 25-Raii Syn. p. I 58 ? -Will. p. 304 ?-Id. (Angl.) p. 393 ?

Courier Pheafant, Latb. Syn. iv. p. 723 . 10.

Habitat in Mexico.-Ad bafin caudæ maculæ alba.-Volatu tarda avis, fed adeo pernici curfu ut equorum velociffimorum agilitatem longe excedit.

I.

impejanus. $\mathrm{Ph}$. criftatus purpureus viridi-nitens fubtus niger, colli pennis aureo cupreo viridique verficoloribus, cauda integra rufa.

Impeyan Pheafant, Lath. Syn. Sup. p. 208. t. i 4 .

Habitat in India; Galli majoris magnitudine.

Orbite nudæ, carunculatæ, virefcentes: mandibula fuperior valde incurvata: pennæ colli elongatæ mucronatæ, ut in $\mathrm{Pb}$. Gallo: crifta verticis e pennis 18 erectis apice rhombeis : cauda apice fufca, restricibus 14 .

Femina corpore fufco undulato, cauda breviore, fub oculis fafcia alba.

I 2.

Parraqua. Ph. fubcriftatus fufcus fubtus fulvus, cauda elongata apice integra.

Le Parraqua, Mem. Jur Coy. i. p. 378. t. I. 2.-Buf. ii. p. 394.

Hannequaw, Bancr. Guian. p. 176 ?

Parraka Pheafant, Latb. Syn. iv. p. 722. 9.

Hавіт Aт in Cayana.-23 pollices longus.

Hæc avis caudam frequenter gerit erectam. Trachea maris fupra pectus decurrit, fimiliter ac in Pen. Marail.

Ph. criftatus 
33.

leucome- Ph. criftatus niger, corpore pennis albo marginatis,

lanos. Coloured Pheafant, Lath. Syn. Sup. p. 210.

Habitat in India. -22 pollices longus.

Roftrum albidum: tempora nuda, rubra: crifta occipitalis elongata, decumbens : pennæ corporis fupra margine angultiore fubtus latiore albo: jugulum, peetus, et abdonen pennis longiufculis mucronatis: pedes calcarati.

\section{GENUS LV. TINAMUS.}

Rofirum longiufculem, obtufum; nares in medio roftri. Rictus ampla.

Latera capitis fubdenudata.

Cauda breviufcula.

Pedes tetradactyli, digito poftico a terra elevato.

braflien- T. fufco-olivacea fufco maculata, abdomine albido vario, tibiis poftice

fis. fcabris.

Tetrao major, Gmel. Syft. i. p. 767 .

Perdix brafilienfis, Brif. i. p. 227.4 - -Id. 8 vo. i. p. 63 .

Perdix major brafilienfis, Brif. i. p. 227. 5.-Id. 8 vo. i. p. 64 ?

Macucagua, Raii Syn. p. 53. 9.-Will. p. I 16. t. 26.-1d. (Angl.) p. 163.-Klein. Av. p. 18. 4.

Jambu, Raii Syn. p. 57.4.-Will. p. 11 g.-Id. (Angl.) p. 167.

Le Magoua, Buf. iv. p. 507. t. 24.

Tinamou de Cayenne, Pl. Enl. 476.

Groffe Perdrix de la Guiane, Mem. Jur Cay, ii. p. $26 \mathrm{~g}$.

Great Partridge, Defcr. Surin. ii. p. I 88.

Great Tinamou, Latb. Syn. iv. p. 724. I.

Haв IтAт in Americe calidioris fylvis.-I 8 pollices longus, - Victitat feminibus, infectis. - Caro fapida. Ovum creruleo-viride.

Tibic poftice duplici ferie fcabræ, fquamis exftantibus ferratæ.

2.

cinereus. T. cinereo-fufcus, capite cerviceque rufefcentibus.

Tetrao cinereus, Gmel. Syft. i. p. 768 . 
634 A V E S G A L L I N E. Tetrao.

Le Tinamou cendré, Buf. iv. p. 5 10.

Cinereous Tinamou, Latb. Syn. iv: p. 726. 2.

3.

Habit at cum precedente. -12 pollices longus.

variegatus. T. rufo fufco nigricanteque fafciatus fubtus rufus, pileo nigro, guia abdomineque medio albis.

Tetrao variegatus, Gmel. Syft. i. 768.

Tinamou varié, Buf. iv. p. 41 I. - Pl. Enl. 828. -Mem. Cay. ii. p. 272 。 Variegated Tinamou, Lath. Syn. iv. p. 726. 3.t. 65.

HabItat in Guiana.-11 pollices longus.

Pileus cum nucba niger: remiges fufcæ. Ovun colore florum fyringe.

4.

Soui. T. fufco-nebulofus fubtus rufus, gula albo varia, capite fupra colloque poftice nigris.

Tetrao Soui, Gmel. Syft. i. p. 768.

Le Soui, petit Tinamou, Buf. iv. p. 51 2.-Pl. Enl. 829.

Little Tinamou, Latb. Syn. iv. p. 727.4.

Habitat in Guiana, Cayana.-9 pollices longus.

Ceuda brevis, rotundata. Ovum colombinum, album.

\section{G E N U LVI. TE TR A O.}

Roftrum conico-incurvum, fornicatum.

Macula fupra oculos nuda, papillofa.

Pedes plumofi.

* Pedibus tetradactylis.

I. lis albis.

Tetrao urogallus, Lin. Syft. i. p. 273. 1.-Faun. Suec. No 200.-Gmel. Syft. i. p. 746.-Scop.Ann. i. No 169.-Brun. $\mathrm{N}^{\circ}$ 194. 195.-Muller, $\mathrm{N}^{\circ} 221$. - Borowes. Nat. ii. p. 186. 2.-Scbaf. El.Orn. t. 42.-Scb. Hift. Lapl. p. 344. -Frijcb. t. 107. 108.-Kram. El. p. 356. 1.Georgi, p. 172.-Raii Syn. p. 53. A. 1.-Will. p. 123.t. 30. Urogallus major, Brif. i. p. $182 .-I d .8 v o$. i.p. $51-K l e i n$. Avep. 115. 1. $-I d$. Stem. p. 25 . t. 27 . f. x. a. b. $-1 d$. Ov. p. 33. t. I 5 . f. x.- 
A VES G A L L I N EE. Tetrao. 635

Scbaf. El. t. 42.-Haßelq. Voy. p. 16,-Ger. Orn. ii. p. 83. t. 236. 237.

Coq de Bruyere, ou Tetras, Buf. ii. p. I9 1. t. 5.-Pl. Enl. 73. 74.Hift. Prov. ii. p. 33I.

Capricalca, Sib. Scot. xvi, t. 14. I8.

Averhahn, Gunth. Neft. u. Ey. t. 8.-Naturf. iv. p. 58 g. t. 18. f. $2-5$.

Cock of the Wood, or Mountain, Raii Syz. p. 53. A. 1.-Will. (Angl.)

p. 172. t. 30. - Alb. ii. t. 29.30 .

Wood Grous, Br. Zool. i. No 92. t. $40.4 \mathrm{I}$-Id. fol. M. M. *,-ArEt. Zool. ii. p. 312. A.-Id. Sup. p. 62.-Tour in Scotl. 176g. t. p. 217. (mas.) -Id. t. I 1. f. 2. (fem.)-Id. 8vo. p. 79. t. I5. I6. (M. et F.) -Latb. Syn. iv. p. 729.1 .

Habrtat in Europe pinetis, Afia; in Scotia olim frequens, hodie fatis rarus.

Femine mare minor, rufo nigro et cinereo tranfverfim variegata: gule rufa: rectrices rufæe nigro fafciatæ. Nidificat in terra, o.sa pariens alba, flavefcente maculata.

2.

Phafianel- T. teftaceus nigticante varius, rectricibus duabus intermediis elongatis

lus. maculis ocellaribus notatis.

Tetrao Phafianellus, Lin. Syft. i. p. 273. 1. var. $\beta .-P b i l$. Tranf. Ixii. p. 42 5.-Gmel. Syft. i. p. 747 .

Coq de Bruyeres à longue queue, Brif. Sup. p. 9.-Buf. ii. p. 286. III. Sharp-tailed Grous, ArEt. Zool. ii. $\mathrm{N}^{\circ} \mathrm{I} 8 \mathrm{r}$.

Long-tailed Grous, Pbil. Tranf. 1xii. p. 394.-Latb. Syn. iv. p. 732. 2. -Id. Sup. p. $212 .-$ Edw. t. 117 .

Habitat in America Septentrionali. -17 pollices longus.

Inter roftrum et oculos macula alba : latera colli et teहtrices alarum maculis rotundatis albis: rectrices laterales apice albæ, intermedia 2 multo longiores.

Mas pectore caftaneo-fufco, et caruncula fuperciliari magis fpeciofa. Ovum album maculis obfcuris.

3.

Tetrix. T. nigro-violacea, cauda bifurca, remigibus fecundariis verfus bafin albis.

Tetrao Tetrix, Lin. Syft. i. p. 274. 2.-Faun. Suec. $\mathrm{N}^{\circ}$ 202.-Gmel. Syft. i. p. 748.-Scop. Ann. i. $\mathrm{N}^{\circ}$ 169.-Brun. $\mathrm{N}^{\circ}$ 196. 197.-Muller, $\mathrm{N}^{\circ}$ 222.-Frifch. t. 10g.-Kram. El. p. 356. 2.-Georgi, p. 172 . Sepp. Vog. t. p. I65.-Borowes. Nat. ii. p. 182.3.-Ger. Orn. ii. p. 82 . t. 233.234 .235 . 
Urogallus minor, Raii Syn.p. 53. A. 2.-Will. p. 124. t. 31 .-Brif. . p. 186. 2.-Id. 8vo. i. p. 52.-Klein. Av. p. I16. 2.-1d. Stem. p. 25. t. 27. f. 2. a. b. -Id. Ov. p. 33. t. 15. f. 3 .

Le $\mathrm{Coq}$ de bruyeres à queue fourchue, Buf. ii. p. 2 10. t. 6.-Pl. Enl: 172. 173.-Hifl. Prov. ii. p. $33^{6 .}$

Birckhahn, Gunth. Neft. u. Ey. t. 34 .

Black Grous, Black Cock, Black Game, Br. Zool. i. N 93. t. 42.-Id. fol. 85. t. M. 1.2.-ArC7. Zool. ii. p. 3i4. C.-Will. (Angl.)

p. 173.t. 31.-Alb. i. t. 22.-Latb. Syn. iv. p. 733. 3.-Id. Sup. p. 213 .

Habitat in Europa; in Anglice feptentrionalis et Scotice montofis non rarus. - Caro fapida, medii pectoris alba, deliciofa.

Femina a mare differt ut in pracedente fpecie. Ovum flavicans, ferrugineo-rubro maculatum.

ß. T. corpore nigro alboque variegato, macula pectorali maxima atro nitente.

Tetr. Tetrix mas, var. Muf. Carlf. fafc. iii. t. 65 .

Inter $\mathcal{T}$. Tetrices communes, qui quotannis, tempore hyemali, e Norlandia Holmiam folent transferri, varietas hæc a fecr. regio Törnros detecta, et pro Muf. Carlfon. communicata.

$\boldsymbol{\gamma}$. T. fordide alba ac obfolete ferrugineo-undulata, roftro nigro, pedibus ferrugineis.

Tetr. Tetrix femina, var. Muf. Carlf. fafc. iii. t. 66. - Act. Sc. Holm。 1785. p. 281 ? (alba.)

In focietate plurium varietatis communis prope Hademora interfecta hæc varietas.

ઈ. T. hybridus, cauda bifurca, fubtus albo maculatus.

Tetrao hybridus, Faun. Suec. $\mathrm{N}^{\circ}$ 201. - Mvf. Carlf. fafc. i. t. I 5 . Gallus fcreator, ACt. R. Ac. Sc. Suic. v. p. 18 1 ?

Lagopus hybridus, Klein. Stem. p. 25. t. 28. f. ז. a. b. c.-Id. Ov. p. 33. f. 2.

Urogallus minor punctatus, Brif. i. p. r9i. A.-Id. 8 vo. i. p. 53. Spurious Grous, ArEt. Zool. ii. p. 314. B.-Id. Sup. p. 62.-Lath. Syn. iv. p. 734.-Id. Sup. p. 214 .

Habitat paffim in Swecie et Finlandic fylvis; magnitudine Urogalli 
femina; originem ex T. Tetrice (patre) ac T. Urogallo (matre) trahere creditur. Sexum non niî̃ mafculinum, tam in Tetraonum quam Urogallorum fodalitio prodere vifus eft. Sparrmon.

4.

nemefia- T. corpore nigro rufoque vario, cauda rufa apice nigra nigroque macunus.

5. Tetrao nemefianus, Scop. Ann. i. $\mathrm{N}^{\circ}$ I 7 I.-Aldr. Orn. 1. xiii. cap. 8. -Gmel. Syjt. i. p. 748 .

Nemefian Grous, Latb. Syn. iv. p. 735. 4 .

Statura $\mathcal{T}$. Tetricis : remiges primæ fufcæ, latere externo rufis maculis variegato; fecundæ apice albæ.

Sexus unus maculis nigris tranfverfis ad bafin colli, abdomine rufo nigroque maculato.

Sexus alter collo, genis, pectore rufis et immaculatis. Scop.

betulinus. T. cauda nigra maculis rufis tranfverfis varia, uropygio albido nigro fafciato.

Tetrao betulinus, Scop. Ann. i. $\mathrm{N}^{\circ}$ i $72 .-$ Gmel. Syf. i. p. 749.

Grygallus minor, Aldr. Orn. 1. xiii. cap. 9 .

Birch Grous, Latb. Syn. iv. p. $735 \cdot 5$.

Supercilia non rubra : pectus cinerafcens : roftrum pedefque nigri : re-

6. miges apice alba: corpus nigro rufoque varium.

canadenfis. T. fulvus cinereo varius fubtus albus lunulis nigris, rectricibus nigris apice fulvis, lituris duabus albis ad oculos. (Mas.)

Tetrao canadenfis, Lin. Syft. i. p. 274. 3.-Gmel. Syft. i. p. 749.

Bonafa freti Hudfonis, Brif. i. p. 201. 6.-Id. Sup. p. 10.-Id. 8vo. i.

p. 56 .

- canadenfis, Brif. i. p. 203.7 . t. 20. f. x. $-I d .8$ vo. i. p. 57 :

Lagopus freti Hudfonis, Klein. Av. p. 117.6.

La Gelinote du Canada, Buf. ii. p. 279.-Pl. Enl. 131.

Black and fpotted Heathcock, Edw. t. 1 i 8.

Spotted Grous, or wood Partridge, Pbil. Tranf. 1xii. p. 38.9-Arct.

Zool. ii. $\mathrm{N}^{\circ}$ 182.-Lath. Syn. iv. p. 735.-Id. Sup. p. 214.

ß. T. cauda integra, macula alba pone aures narefque. (Femina.)

Tetrao Canace, Lin. Syft. i. p. 25. 7.-Gmel. Syft. i. p. 749. 3. b.

Bonafia canadenfis, Brif. i. p. 203. t. 20. f. 2.-Id, 8vo, i. p. 57. (fem.) Gelinotte du Canada, Pl. Enl. 132 . 
633 A $V$ ES GALLIN $1 \mathrm{~N}$. Terrao.

Brown and fpotted Heathcock, Edw. t. 7 1.-Ell. Hudf. Bay, i. t. p. 50. Spotted Grous, Lath. Syn. iv. p. 735. 6.

Habrtat in Canade juniperitis.-1 $3-16$ pollices longus.

Mari roftrum nigrum : orbito nuda carunculatæ: collum infra et pecius nigrum: pedes hirfuti, digito medio peetinato.

Femine roftrum fufcum; corpus nigro maculatum, fupra fufco-rubrum, fubtus albidum : cauda fufca nigro nebulofo fafciata, apice fulvo.

Nidificat in terra. Ovun nigro, flavo, alboque varium.

7.

Umbellus. T. fufco rufo nigroque variegatus fubtus fulvo-albus, re尺ricibus nigrofafciatis apice cinereis, cervicali umbone exftante. (Mas.)

Tetrao umbellus, Lin. Syft. i. p. 275. 6.-Gmel. Syft. i. p 752.-Borowfk. Nat. ii. p. 185. t. 31 .

Attagen Penfylvanix, Brif. i. p. 214 . Ir. $-I d .8$ vo. i. p. 59.

Coq de Bruyere à fraife, Buf. ii. p. $18 \mathrm{I}$.

Ruffed Heathcock, Pbil. Tranf. xlviii. p. 499. t. I 5.-Edw. t. 248.

Ruffed Grous, ArEt. Zool. ii. $\mathrm{N}^{\circ}$ 179.-Lath. Syn. iv. p. 738. 8.-Id. Sup. p. 215.

ß. $\mathrm{T}$. pennis axillaribus majoribus nigris azureis. (Femina) Tetrao togatus, Lin. Syft. i. p. 275.8.-Gmel. Syft. i. p. 752 . Bonafa major canadenfis, Brif. i. p. 207. 8. t. 21 . 1.-Id. 8vo. i. p. 57. L.a groffe Gelinotte de Canada, Buf. ii. p. 28 1. - Pl. Enl. ro4. Shoulder-knot Grous, Pbil. Tranf. lxii. p. 393.-Latb. Syn. iv. p. $737 \cdot 7$.

Habitat in America Septentrionali. - I 5-20 pollices longus.

Caput criftatum : cauda prope apicem fafcia latiore nigra, apice cinereo-alba: digitus medius pectinatus.

Femina abfque crifta et unbone, pennæ axillares majores pectorifque laterales nigræ azureæ.

8.

Cupido. T. fub-criftatus fufco-rufefcens nigro et albicante tranfverfim ftriatus, alis fuccenturiatis cervicalibus.

Tetrao Cupido, Lin. Syft. i. p. 274. 5.-Gmel. Syft. i. p. 75 1.-Borowfk. Nat. ii. p. 190.5 .

Attagen americana, Brif. i. p. 212 . 10.-Id. 8 vo. i. p. 59.

Urogallus minor fufcus, in cervice plumis alas imitantibus, Klein. Av. p. 117 . 7.-Cat. Car. App. t. r.

Pinnated Grous, Arct. Zool. ii. No $180 .-$ Lath. Syn. iv. p. 74c. 9. 
Habitat in America.-Color Tetricis femine.-Irides avellanex: vertex fubcriftatus : a tergo colli duæ parvæ alæ, fingulæ peunis quinque : cauda fafcia terminali nigra.

Femina abfque fafriculis pennarum cervicalibus.

9.

Lagopus. T. cinereo alboque varius, pedibus lanatis, remigibus albis, rectricibus nigris apice albis, intermediis albis.

Tetrao Lagopus, Lin. Syft. i. p. 274. 4.-Faun. Suec. No 203.-Gmel. Syft. i. p. 749.-Scop. Ann. i. No 170.-Brun. No 198. 199.-Muller, $\mathrm{N}^{\circ} 223 .-$ Pbil. Tranf. Ixii. p. 390:-1d. 1xiii. p. 224.-Frifch. t. I 10. I I I.-Kram. El. p. 356.-Faun. Groenl. No 80.-Georgi, p. $172 .-$ Faun. Arag. p. 80.-Raii Syn. p. 55. 5.-Will. p. I 27. t. 32. -Brif. i. p. 216 . 12. $-I d$. 8vo. i. p. 60.-Klein. Av. p. I 6 . 4.--Bororofk. Nat. ii. p. I8g. 4.-Ger. Orn. ii. 85. t. 24.0. (varius.) -Id. t. 239. (albus.)

Tetrao mutus, Martin Adt. Soc. Lund. iii. p. 55.

La Gelinote blanche, Pl. Enl. 129 (albus.)-494. (varius.).

Lagopede, Buf.ii. p. 264. t. 9. -Azt. Tolof. i. p. 1 I r.-Hift. Prov. ii. 335. White Game, Will. (Angl.) p. 176. t. 32 .

Ptarmigan, Br. Zcol. i. No 95. t. 43.-Id. fol. 86. t. M. 4. 5.-Arct. Zool. ii. p. 315. D.-Tour in Scotl. 176g. t. I I. f. I. -Id. 8 vo. t. 16. f. 1.-Gent. Mag. 1772. t. p. 74.-Lath. Syn. iv. p. 741. 10.

Habitat in Europe alpinis et Sibiria; in Anglie frigidioribus, et in Scotia non rarus. - 14-1 5 pollices longus. - Eittate corpus albo fufcoque cinereo-varium, hyeme fere toto album: in omni tempore rectrices laterales nigræ apice albæ: pedes lanati leporis, plantis tantum nudis, unde nomen Lagopus. Ovum pallide rufum maculis fufco-rubris.

10.

albus. T. aurantius fafiiis atris et lituris albis varius, digitis hirfutis, rectricibus atris apice albis, intermediis totis albis.

Tetrao albus, Gmel. Sy/t. i. p. 750.

Lagopede de la baie d'Hudfon, Buf. ii. p. 276.

Ripa major, Amsen. Ac. i. p. 349.--Scbaf. Hift. Lapl. t. p. 347.

White Partridge, Hift. Hudf. Bay, i. t. 1.-Edw. t. 72.-Kalm. Trav. iii. 58 .

White Grous, Arct. Zool. ii. No I 3.-Lath. Syn. iv. p. 743. I I.

HABIтAт ad fretum Hudfonis, et in Lapponic fylvis; præcedente multo major.- I $6 \frac{1}{2}$ pollices longus.-Hyeme corpus album, æitate albo fulvoque varium. An diftincta fpecies?

T. aurantius, 
II.

640 A VES G A L L I N IE. Tetrao.

rupeftis. T. aurantius, fafciis atris et lituris albis varius, digitis plumofis, rectricibus atris apice albis, intermediis totis albis, loris nigris.

Tetrao rupeftris, Gmel. Syfl. i. p. 751 .

Rock Grous, Arct. Zool. ii. N ${ }^{1}$ 1 84.-Lath. Syn. Sup. p. 217.

HaBitat ad finum Hudfonis; pracedente multo minor, et moribus fatis diftincta; fylvas non fiequentar, at rupibus infidens collo porrecto ftertentis hominis fontm frequenter emittit.

12.

Japponi- T. dorfo nigro ferrugineo vario, collo ferugineo nigro maculato, peccus. toré crifloque albis.

Tetrao lapponicus, Gmel. Syfr. i. p. 751.

Rehufal, Montin. in AEt. Soc. Lund. Goth. viii. p. 155. I.

Rehufak Grous, Arct. Zool. ii. p. 316. E.-Latb. Syn. Sup. p. 216.

Habitat in Lapponice alpibus.-Magnitudo Gallina.

Femina luteo maculata: remiges primores albæ: cauda nigra apice albida : femora alba maculis ferrugineis : pedes lanati. Orum rubefcens maćulis magnis fufcis varium.

13.

canus. T. corpore cano fufco undulato, roftro pedibufque nigris.

Tetrao canus, Muf. Carlf. fafc. i. p. 16.-Gmel. Syft. i. p. 753.

Helfingian Grous, Lath. Syn. Sup. p. 217.

Habitat in Suecia; in Helfingia frequens.-Plumæ totius fere corporis canæ, apicibus fufcis : tectrices alcrum fufcæ, extimo apice macula alba notatz: criffum candidum : cauda complicata in pagina fuperiore ex albo, fufco, canoque nebulofa ; in pagina inferiore lateribus fufca ; in medio autem ex criffo elongato, quafi macula triangulari candido

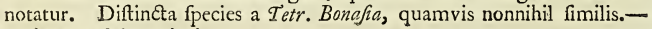
Roftrum pedefque nigni.

1.4.

Bonafia. T. ruftefens fufco maculatus, rectricibus cinereis punctis nigris fafcia nigra, exceptis intermediis duabus.

Tetrao Bonafia, Lin. Syft. i. p. 275. 9.-Faun. Suec. $\mathrm{N}^{\circ} 204 .-$ Gmel. Syft. i. p. 753.-Scop. Ann. i. No 173.-Brun. $\mathrm{N}^{\circ}$ 200.-Muller, N०224:-Kram. El. p. 356. 4.-Georgi, p. 175.-Brif. i. p. I91. 3. -Id. 8 vo. i. p. 53.-Bororefk. Nat. ii. p. 191.6.-Ger. Orn. ii. p. 84 . t. 238 .

Gallina corylorum, Raii Syn. p. 55.6.-Will. p. 126. t. 31.-Klein. Av. p. I 16. 3. -Id. Stem. p. 25 . t. 26. f. 3. a. b.-Id. Ov. p. 33 . t. I.5. f. 4 .

Gelinotte, 
Gelinotte, Buf. ii. p. 233. t. 7.-Pl. Enl. 474. 475.-Faun. Helvet. Hazel Grous, Ard7. Zool. ii. p. 317. F. -Will. (Angl.) p. 175. t. 31.Lath. Syn. iv. p. 744 .

HaвIтAT in Europe coryletis, vietitans amentis.

Macula alba pone. aurem fingulam: corpus rufefcens fufco maculatum: dorfum cinereo rufoque varium. Mas gula nigra: tibice antice - femitectæ: caro exquifita. Ovum columbino majus, rubiginofo-rubicundum, parum maculatum.

15 .

fcoticus. T. rufo et nigricante tranfverfim ftriatus, rectricibus 6 utrinque exterioribus nigricantibus.

Bonafa fcotica, Brif. i. p. 199. 5. t. 22. f. 1.-Id. 8vo. i. p. 55-Buf. ii. p. 242.

Attagen, Brif. i. p. 209. 9.-Id. 8vo. i. p. 58.-Buf. ii. p. 252,Frifch. t. I 12 ? - Faun. Helvet.

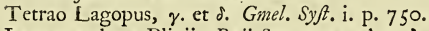

Lagopus altera Plinii, Raii Syn. p. 54. A. 3 ?-Will.p. 28 ?

Red Game, Moorcock, Gorcock, Raii. Syn. p. 54. A. 3.-Will. (Angl.) p. $177 .-A l b$. i. t. 23.24 .

Red Grous, Br. Zool. i. No 94. t. 43.-Id. fol. 85. t. M. 3.-Latb. Syn. iv. p. 746. 13.-Id. Sup. p. 216.

HABITAT in Scotice ericetis; invenitur etiam in montibus Anglie feptentrionalibus, et in Cambria.

Caruncula fuperciliaris lunata, coccinea, in mare magis fpeciofa: remiges majores fufcæ: cauda pennis 16 , intermedix 4 dorfo concolores, reliqua nigricantes. Ovum rufefcens, maculis anomalis faturate fan16. guineis, punctulis interjectis.

Alchata. T. olivaceo flavicante nigro rufoque varius, abdomine albo, rectricibus duabus intermediis duplo longioribus fubulatis.

Tetrao Alchata, Lin. Syyt. i. p. 276 . I I.-Haffelq. It. p. 28 r.-Id. Voy. p. 204.-Faun. Arag. p. 8 1. -Klein. Av. p. I 1 5. 5.-Borowe. Nat. ii. p. 129. t. 31. B.-Gmel. Syft. i. p. 754.

Bonafa pyrenaica, Brif. i. p. 195. 4. t. Ig. f. 1. 2. $-I d .8$ vo. i. p. 54. Perdix damafcena, Raii Syn. p. 55.7.-Will. p. 128.-Id. (Angl.) p. I78. t. 29.

Le Grandoule, Hift. Prov. i. p. 354.

Le Ganga, Buf. ii. p. 244. t. 8.-Pl. Enl. 105. 106.-Voy。 en Barb. i. p. 269 .

Tetrao caudacutus, Gmel. Reife. iii. p. 93. t. 18.

$$
4 \mathrm{~N} \quad \text { Kitiwiah, }
$$


Kitiwiah, Kata, Sbaw's Trav. t. p. 253.-Ruf. Alep. p. 64. t. $\dot{9}$ Pintailed Grous, Latb. Syn. iv. p. 748. 14.-Edw. t. 249.

Habitat Monspelii, in Pyreneis, Syria, Arabia.

Supercilia gulaque nigra: pectorale lunatum, latum, fulvum nigro marginatum: remiges primores cinereæ: tectrices ferrugineæ albo margine : cauda cuneiformis, lutea, fafciis fufcis: rectrices apice albo : orbite oculorum nigræ poftice producta: pedes antice hirfuti, unguibus pectinatis.

17.

Femine gula non nigra.

fenegalus. T. pedibus hirfutis teftaceus, rectricibus duabus mediis duplo longioribus.

Tetrao fenegalus, Lin. Mant. 1771. p. 526.

La Gelinotte du Senegal, Pl. Enl. I 30 .

Senegal Grous, Lath. Syn.iv. p. 749. 14. A.

Ha вiтAт in Senegala.

Corpus teftaceum: fafcia capitis lateralis cærulefcers : remiges laterales albæ: pedes antici hirfuti. An a præcedente fatis diftinctus?

18.

arenarius. T. torque abdomine et criffo atris, rectricibus fufco et grifeo fafciatis apice albis, intermediis 2 fulvefcentibus.

Tetrao arenaria, N. C. Petr. xix. p. 418. t. 8. - Pall. reife. iii. p. 699. 27.-Gmel. Syjt. i. p. 755 .

Tetrao fubtridactyla, Hafjelq. It. p. 250.

Sand Grous, Lath. Syn. iv. p. 75 1. 16.

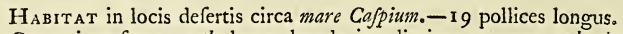

Caput cinerafcens : gula lutea, lunula juguli nigra: pennæ gula jugulique truncatæ, fplendentes : cauda fafciata, rectrices intermediæ apice fubulatæ: pedes hirfuci calcare minuto.

Femina flavefcens, capite colloque maculis nigris, dorfo nigro fafciato. Orum columbino majus ex albo pallidum.

19.
Namaqua. T. pedibus hirfutis, dorfo caftaneo, abdomine nigricante, rectricibus duabus mediis longioribus fubulatis.

Tetrao Namaqua, Gmel. Syft. i. p. 754.-Sparm. Voy. i. p. 153. Namaqua Grous, Lath. Syn. iv. p. $750.15 .-I d$. Sup. p. 215.

Habitat ad Caput Bone Spei.-9 pollices longus.

Caput collum et pectus cinereo-grifea: lunula pectoris alba: femora $x$ 


\section{A V E S G A L L I N E. Perdix.}

criffumque cinereo-alba: tedzrices alarum minores albæ margine caftaneo, majores caftaneæ apice macula cærulefcente-alba: pedes hirfuti, poftice calcare minuto inftructi.

Femina fupra nigro albo rufoque nebulofa, fubtus albo nigroque tranfverfim ftriata : pedes mutici.

20. * Pedibus tridactylis.

paradoxus. T. pedibus tridactylis hirfutis, dorfo grifeo nigroque undulak, abdomine nigro maculis pallidis, lateribus colli macula fulva. Tetrao paradoxa, Pall. It. ii. p. 712 . 25. t. F. -Gmel. Syjt. i. p. 755. Heteroclite Grous, Lath. Syn. iv. p. 753. 18.

Habitat in defertis Tatarie auftralioris; inter Tetraones et Otides ambiguus.

Roffrum gracilius quam in congeneribus : caput cæruleo-cinerafcens: gula flavefcens lineolis nigris: ad latera colli utrinque macula fulva : BeEtrices majores et remiges fecundaria albidæ medio nigræ: pedes plumofi, digiti tres antice politi, per totam longitudinem adnati, folo apice unguibufque diftincti : plante rugofe imbricatæ.

\section{GEN U S LVII. PE R D I X.}

Roftrum convexum, validiufculum.

Nares margine prominulæ.

Orbita papillofe.

Pedes nudi, plerifque calcarati.

I.

* Pedibus tetradactylis, maris calcaratis.

capenfis. P. fubbicalcarata cinereo-nigricans grifefcente tranfverfim lineata, pectore ftrigis albis, pedibus rubris.

Tetrao capenfis, Gmel. Syyt. i. p. 759 .

Cape Partridge, Latb. Syn. iv. p. 756 . r.

Habitat ad Caput Bone Spei.-1 9 pollices longa.

Roffrum validum, carneum: tibie poftice calcaribus duobus, fuperiore obtufo.

2.

bicalca- P. bicalcarata rufo fufco et albido varia, fuperciliis nigris.

rata. Tetrao bicalcaratus, Lin. Syft. i. p. 277. 15 . 


\section{A V E S G A L L I N AE. Perdix.}

Perdix fenegalenfis, Erif. i. p. 231. 8. t. 24. f. r.-Id. 8 vo. i. p. 65.

Le Bis-ergot, Buf. ii. p. 443.-Pl. Enl. I 37.

Senegal Partridge, Lath. Syn. iv. p. 757.2.

Habitat in Senegala. - Linea nigra utrinque fupra oculos lineola alba divifa : tibie calcaribus duobus obtufis.

3.

ceylonen- P. bicalcarata, capite collo corporeque antice albo nigroque vario, pof-

fis. tice itrugineo.

Tetrao zeylonenfis, Gmel. Syft. i. p. 759.

Perdix bicalcarata, Zool. Ind. p. 25. t. I4.

Ceylon Partridge, Latb. Syn. iv. p. $75^{8} .3$. (mas.)

Chittygong Partridge, Lath. Syn. Sup. p. 222. (femina?)

Habitat in Zeylona, India; magnitudine Gallina.

Roftrum et orbite nudæe rubre : coput albo nigroque varium : collum, peEtus, pars antica dorfin, et teetrices alarum nigra, maculis fagittatis albis; pars poftica dorfi ferruginea : cauda fufca: tibice et digiti rubri.

Feminc caput cinereum nigro-maculatum : pectus dorfum et ale fufcoferrugineæ: pennæ dorfi et alarum medio fulco-maculatx, pectoris luteo-marginatæ: pedes abfque calcaribus.

4.

fpadicea. P. bicalcarata fufco-rubra, roftro flavo, pedibus rubris.

Tetrao fpadiceus, Gmel. Syft. i. p. 759.

La Perdrix rouge de Madagafcar, Son. Voy. Ind. ii, p. 16g.

Brown african Partridge, Lath. Syn. iv. p. 759. 4.

HaвiтAт in infula Madagafcar; magnitudine cinerea. Irides et tibice rubræ.

5 .

nudicollis. P. bicalcarata, corpore variegato, collo antice nudo rubro.

Tetrao nudicollis, Gmel. Syft. i. p. 759.

Le Gorge-nue, Buf. ii. p. 444 .

Bare-necked Partridge, Latb. Syn. iv. p. 759. 5.

Corpus variegatum ut in fequente : cauda expanfa : tibice rubre.

6.

Francoli- P. calcarata, corpore vario, abdomine gulaque atris, cauda cuneata.

nus. Tetrao Francolinus, Lin. Syft. i. p. 275. 10.-Gmel. Syft. i. p. 756.Brif. i. p. 245 . I 3. t. 23. f. 2.-Id. 8 vo. i. p. 68.

Tetrao orientalis, Hajfelq. It. p. 278. 43.-Id. Voy. p. 203. 43.

Le Francolin, Buf. ii. p 438.-Pl. Enl. 147. 148,-Voy. en Barb. i. p. 270.

Francolino 
Francolino (Attagen Aldr.) Raii Syn. p. 54. 4.-WWill. p. 125.t. 31.Olin. uc. t. p. 33.-Zinnan. Uov. p. 23. t. 3. f. 6.

Francoline Partridge, Edvv. t. 246.-Tourn. Voy. 4to. i. t. p. 412.-Id.

8 vo. ii. t. I. P. I I I.-Gent. Mag. xlii. t. p. I I 2.-Latb. Syn. iv. p. 759.6 .

Habitat in Europa, Africa, Afia. -12 pollices longa.

Supercilia fubnuda non papillofa, ciliis brevifimis : corpus fupra ex nigricante et rufo-flavefcente varium, fubtus nigrum albo maculatum, torque dilute caftaneo : pedes rubri, calcare folitario inftructi.

Femina ex nigricante et rufo-flavicante toto varia : pedes mutici.

7 .

aragonica. P. calcarata, pedibus antice hirfutis, remigibus abdomine femoribufque nigris.

Tetrao pedibus, \&c. Faun. Arag. p. 8r. 3. t. 7. f. 2.

Aragonian Partridge, Lath. Syn. Sup. p. 223.

Habitat in Aragonia.

Corpus fufcum ferrugineo varium: pectus rufum, fafcia nigra: gula, remiges, abcomen, femoraque nigra: criffum album nigro maculatum : cauda cuneiformis, reltricibus lateralibus extimo apice albis : pedes antice hirfuti, poftice calcarati.

8.

madagaf- P. calcarata fupra varia, abdomine nigro maculis albis, fafcia per ocucarienfis. los alteraque infra nigris.

Tetrao madagafcarienfis, Gmel. Syft. i. p. $75^{6}$.

Le Francolin de l'inle de France, Son. Voy. Ind. ii. p. 166. t. 97.

Pintado Partridge, Lath. Syn. iv. p. 761. 7.-Id. Sup. p. 2 1 9.

HaвIтAт in Madagafcaria; rufi magnitudine.

Fafcia ocularis ad nucham fere protenfa poftice fubulata; fubocularis poftice dilatata: pennæ pectorales maculis albis fex: remiges majores albo fafciatæ : pedes moris calcarati.

cinerea. P. calcarata, cinereo rufo et nigro varia, macula nuda coccinea fub oculis, cauda ferruginea, pectore brunneo.

Tetrao Perdix, Lin. Syft. i. p. 276. 1 3.-Faun. Suec. $\mathrm{N}^{\circ} 205 .-$ Gmel. Syft. i. p. 757.-Scop. Ann. i. $\mathbf{N}^{\circ}$ 175.-Brun. $\mathbf{N}^{\circ} 201 .-$ Muller, $\mathrm{N}^{\circ} 225 .-$ Frifch. t. I 1 4.-Kram. El. p. 357.6.-Georgi, p. 173. - Scbaf. El. Orn. t. 54.-Faun. Arab. p. vii. 1 1.-Faun. Arag. p. 8.2.-Borow/k. Nat. ii. p. 193. 9.-Faun. Helvet.

Perdix cinerea, Raii Syn. p. 57. A. 2.-Will. p. I 18. t. 28.-Brif. i. 
p. 219.1 . $-I d .8$ vo. i. p. 61,-Klein. Av. p. 114.1 -Id. Stem. p. 25. t. 26. f. 2. a. b.-Id. Ov. p. 32. t. I5. f. 5 .

La Perdrix grife, Buf. ii. p. 401,-Pl. Enl. 27. (fem.)

Rephuhn, Gunth. Neft.u. Ey. t. 4.6.

Starna, Zinnan. Uov. p. 30. t. 3. f. 8.-Cet.uc. Sard. p. I I4.-Olin. uc.

t. p. 57 .

Common Partridge, Br. Zool. i. No 96.-Id. fol. 86. t. M.-ArEt. Zool. ii. p. 31 9. A. -Will. (Angl.) p. 166. t. 28.-Alb. i. t. 27. - Lath. Syn. iv p. 762.8 .

Habitat in Europa, Afaa.-I 3 poll. longa.-Hyeme habitat intra folfas nivis utraque extremitate apertas.

Area nuda fanguinea papillofa fub palpebra inferiore pone oculos ducta : facies lutefcens: pileus collumque cinereo-undulata: macula duæ caftaneæ in imo pectoris: cauda rectricibus 18. Mas obtufe calcaratus. Orum grifeo-virefcens.

ß. Perdix cinereo-alba, Brif. i. p. 22.3. A. $-I d .8$ vo. i. p. 62. Perdrix gris-blanche, Buf. ii. p. 415.-Frifch. t. I 15.-Latb. Syn. iv. p. 763 .

Colore a præcedente differt, pennæ enim in toto corpore cinereoalbæ, lineolis tranfverfis et undatis fufcis variæ cum aliqua rufefcentis mixtura.

Variat interdum corpore toto albo, corpore variegato, corpore brunneo; 10. mento gulaque rufis. Confer Lath. Syn. iv. p. 764.

damafce- P. cauda ferruginea, pectore brunneo, pedibus flavis.

na. Perdix damafcena, Brif. i. p. 223. B.-Id. 8vo. i. p. 62.-Raii Syn. p. 57. 3.-Will. p. 1 19. t. 29.-Id. (Angl.) p. 167.-Klein. Av. p. I 1 4. 2.-Gmel. Syf. i. p. $75^{8}$.

La petite Perdrix grife, Buf. ii. p. 4 I7.

Damafcus Partridge, Lath. Syn. iv. p. 764. 9.

Habitat in variis Gallie provinciis; cineree perfimilis, at multo minor eft, roftroque prolixiore; migratoria. An diftineta fpecies?

I I.

montana. P. dilute caftanea, capite et collo fupremo fulvis, rectricibus feptem extimis pallide caftaneis.

Tetrao montanus, Gmel. Syft. i. p. $75^{8}$.

Perdix montana, Brif. i. p. 224. 2, t. 2 I. f, 2, $-I d$. 8 vo. i. p. $62 .-$ Frifs. t. 114. B. 


\section{A VES GAL L I N 2 E. Perdix.}

La Perdrix de montagne, Buf. ii. p. 419.-Pl. Enl. 136.

Mountain Partridge, Latb. Syn. iv. p. 765. 10.

Habitat in Europe montibus; in campeftria loca quandoque defcendit, et cum cinereis cohabitat.-Cauda viginti rectricibus conftat; intermedia fex caftaneo-fufcæ apice grifex.

12.

rufa. P. pedibus calcaratis roftroque fanguineis, gula alba cincta fafcia nigra albo punctata.

Tetrao rufus, Lin. Syft. i. p. 276. т2.-Gmel. Syft. i. p. 756,-Klein. Av. p. 115. 4.-Kram. El. p. 357. 5.-Faun. Arag. p. 82.-Bororvelk. Nat. ii. p. 192. 8.-Faun. Helvet.

Perdix greca, Brif. i. p. 24 I. 12. t. 23 . f. 1.-Id. 8vo. i. p. 67.-Raii Syn. p. 57. A. 5.-Will.p. 121. t. 29.

La Bartavelle, Buf. ii. p. 420.-Pl. Enl. $23 \mathrm{r}$.

Pernice, Zinnan. Uov. p. 29. t. 3. f. 7.

Greek or red Partridge, Lath. Syn. iv. p. 767. 1 2.-Will. (Angl.) p. 169.-Alb. i. p. 27. (defcr.)

HАВІтAт in Europa auftraliore, arcbipelagi infulis.

Pennæ laterum trenia duplici nigra: rectrices 14 cinerex; extimæ 5 ultima medietate rufa. Calcaria obtufa mari.

ß. Tetrao rufus, Lin. Syft. i. p. $276 .-N$. C. Petr. xv. p. 448. t. 13.Scop. Ann. i. No 174.-Kram. El. p. 357. 5.-Faun. Arag. p. 82.

Perdix rubra, Brif. i. p. 236 . 10.-1d. 8vo. i. p. 66.-Klein. Av. p. I 1 5. 4.-Faun. Helvet.

ruffa, Raii Syn. p. 57. A. 5.-Will.p. 167.29.

Perdrix rouge, Buf. ii. p. 431. t. 15.-Pl. Enl. 150. (Mas.) -Voy. en Barb. i. p. 270.

Guernfey Parridge, Alb. i. t. 29.-Will. (Angl.) p. 167. t. 29.-Lath. Syn. iv. p. 768.-Id. Sup. p. 220.

Habitat in Europa, Afia, Africa, rarius in Anglia.

Pennæ laterum tænia fimplici nigra: rętrices 56 , quinque extimæ in utroque latere rufæ.

\%. Perdix rubra barbarica, Brif. i. p. 239. I1.-Id. 8vo. i. p. 67.Klein. Av. p. I I 5 . 4 .

Perdrix rouge de Barbarie, Buf. ii. p. 445.

Barbary Partridge, Edw. to 70.-Sbew's Trav. p. 300 ?-Lath. Syn. iv. p. 770 .

HABITAT 

648
A V E S
G A L L I N E
Perdix.

HABitat in Barbaria.-In hac ave fafcia, feu torquis colli, caftanea, maculis rotundatis albis varia: pennæ iaterum tænia fimplici nigra : rectrices cinereæ, intermediæ fufco tranfverfim ftriatæ, laterales in ultima medietate aurantiæ.

13.

rubricollis. P. calcarata, corpore fufco maculato, crifio albo, orbitis gulaque nudis rubris.

Tetrao rubricollis, Gmel. Syft. i. p. 758 .

La Perdrix rouge d'Afrique, Buf. ii. p. 444--Pl. Enl. 180.

Red-necked Partridge, Latb. Syn. iv. p. 77 I. I3.

HaBrtat in Africa.-I 3 pollices longa.-Supra et infra oculos ftriga alba: pedes calcare incurvato, roftrumque rubra.

14.

petrofa. P. fufca, roftro pedibus iridibufque rubris, macula pectoris ferruginea.

Tetrao petrofus, Gmel. Syft. i. p. $75^{8}$.

La Perdrix de la roche, Buf. ii. p. 446.

Rufous-breafted Partridge, Lath. Syn. iv. p. 77 I. I4.

Habitat ad Gambiom; rufo paulo minor.

15.

perlata. P. calcarata fufca albido et rufefcente maculata, dorfo rufefcente ftriato, gula alba, lateribus capitis fafciis duabus nigris, fuperciliis rufis.

Perdix perlatus, Gmel. Syft. i. p. 758.

Perdix finenfis, Brif. i. p. 234 . 9. t. 28. A. f. 1. $-I d .8$ vo. i. p. 65.

Perdrix perlée de la Chine, Buf. ii. p. 446.

Tetrao finenfis, Ofb. Voy. ii. p. 326.

Pearled Partridge, Lath. Syn. iv. p. 772.15.

Habrtat in Cbina.- $22 \frac{1}{2}$ pollices longa.

16.

afra. P. calcarata fufca fafciolis ftriifque albidis, fuperciliis colloque fubtus albo nigroque variis, remigibus caudaque lineolis tranfverfis albis. Pearled Partridge, Lath. Syn. iv. p. 773. I5. A.

Habrtat ad Caput Bone Spei.-PeEtus et latera ferrugineo, caftaneo, nigricante, et albido variegata.

gingica. P. rufo-grifea, fuperciliis albo nigroque variis, uropygio tectricibufque alarum mediis nigro minoribuis grifeo maculatis.

Tetrao gingicus, Gmel. Syft. i. p. 760. 


\section{A VES G A L L IN IE. Perdix.}

La Perdrix de Gingi, Son. Voy. Ind. ii. p. 167.

Gingi Partridge, Latb. Syn. iv. p. 773. 16.

Hавітат in regno Ginginiano; cinerea minor.

Collum inferius rufefcens, ftriis nigris : gula rufefcens : peczoris macula nigra, alteraque câtanea; inter has tertia alba.

18.

ponticeria- P. calcarata rufa nigro fafciata, fubtus alba lunulis nigris, rectricibus

na. duabus mediis fafciis quatuor albidis, lateralibus intus nigro fafciatis.

Tetrao ponticerianus, Gmel. Syft. i. p. 760 .

La Perdrix de Pondichery, Son. Voy. Ind. ii. p. 165.

Pondicherry Partridge, Latb: Syn. iv. p. 774. 17.

Haвıтат in India; cinerea magnitudine.

Capiftrum gulaque flavefcens: cervix, peitus, abdomen, et rettrices laterales nigro, dorfum, uropygium, remigefque minores albo fafciata: pedes calcarati. An mas?

P. mutica fufca nigro fafciata, collo pectoreque albo maculis nigris, rectricibus fafciis nigris.

Pondicherry Partridge, Lath. Syn. Sup. p. 221.

Habitat in India.-Orbite gulaque flava: fafcia pectoris e lineis albis nigrifque : cauda fafciis ro obliquis albis : pedes mutici. An femina?

19.

nævia. P. fufco pallente et fulvo varia, capite gutture et lateribus nigro maculatis, roftro pedibufque incarnatis.

Perdix nævia, Gmel. Syft. i. p. 760.

Perdix montana mexicana, Brif. i. p. 226. 3. -Id. 8 vo. i. p. 63.

Galgulus mexicanus criftatus, Brif. ii. p. 84. I0.-Id. 8vo. i. p. 177 .

Ococolin, feu Perdix montana, Raii Syn. p. 57. 1.-Buf. ii. p. 489.-

Seba, i. p. 100. t. 64. f. 1. - Klein. Av. p. $5^{8} .3$.

Mexican Partridge, Latb. Syn. iv. p. 775. 19.

Haвiтat in Mexico.-2 I pollices longa.

Roftrum pedefque pallide rubri.

20.

afiatica. P. rufo-flavefcens fufco nigroque variegata fubtus albida fafciolis nigris, pedibus obtufe calcaratis.

Habitat 
650 A V E S G A L L I N IE. Perdix.

HABIT A

Rofirum breve, obtufum, fufcum, mandibula inferiore pallida : capu cum gula fiavo-fufcum: corpus fuperius rufo flavo fufcoque varium, hinc inde nigro intermixtum; inferius albicans, pennis fingulis fafciis 2 nigris, coloribus verfus criffum obfoletioribus: remiges rufo-flavefcentes fufco-variegatæ: pedes rubicundi, medio poftice calcari brevi obtufo inftructi. Muf. Brit.

* Pedibus tetradactylis muticis.

21.

gtianenfis. P. rufo-fufca nigro maculata et varia, gula cinerea, per oculos vitta: fulva, remigibus extus maculis rufis.

Tetrao guianenfis, Gmel. Syft. i. p. 767 .

Le Tocro, ou Perdrix de Ja Guiane, Buf. iv. p. 513?

Guiana Partridge, Lath. Syn. iv. p. 776. 20.-Bancr. Guian. p. 177 ?

Habitat in Guiniza, Cayana.-I I pollices longa.

Orbite nudiufculæ, papillofx.

viridis. $P$. viridis, alis caltaneis nigro punctulatis, roftro pedibufque pallide rubris.

Tetrao viridis, Gmel. Syft. i. p. 761.

Green Partridge, Latb. Syn. iv. p. 777.21. t. 67.

Longituco I I $\frac{x}{2}$ pollicum.-Caput, cauda, femoraque obfcure viridia, digitus porticus muticus.

23. indica.

P. mutica rufa fafciolis nigris, fincipite albo lunula nigra, remigibus fecundariis albo nigroque alternatim fafciatis, medio rufis.

Tetrao indicus, Gmel. Syft. i. p. 755.

La Gelinotte des Indes, Son. Voy. Ind. ii. p. 164. t. $9^{6 .}$

Indian Grous, Lath. Syn. iv. p. 752.17.

Habitat in India; alchata magnitudine.

24. 2 . Putica nigro varia, fupra fufco-rufefcens fubtus flavefcens, fafcia nigra fupra et infra oculos, linea verticali fulva.

Tetrao virginianus, Lin. Syjt. i. p. 277. 16.-Gmel. Syfl. i. p. $761 .-$ Klein. Av. p. 1 i 5.6 ..

Perdix americana, Brif. i. p. 230. 7.-Id. 8.vo. i. p. 64. 
A VES G A L L I N FE. Perdix. 65I

La Perdrix d'Amerique, Buf. ii. p. 399.

Virginian Partridge, Cat. Car. iii. t. 12.-Lath. Syn. iv. p. 777. 22.

25 .

Habitat in America nemorofis, arboribus infidens; cinerea minor.

marilanda. P. rufa nigro varia fubtus albida undulatim lineata, fupercilis gulaque albidis.

Tetrao marilandus, Lin. Syft. i. p. 277. 17.-Gmel. Syft. i. p. 76 r.

Perdix novæ Angliæ, Brif. i. p. 229. 6.-Id. 8 vo. i. p. 64.-Klein. Av. p. II5.3.

Perdrix de la nouvelle Angleterre, Buf. ii. p. 447.

New-England Partridge, Alb. i. t. 28.-Brown. Jam. p. $47 \mathrm{I}$.

American Partridge, $P$ b. Tr. xvii. p. 992,-Du Pratz, ii. p. 86.

Maryland Partridge, Aret. Zool. ii. No 185.-Lath. Syn. iv. p. 778. 23 .

26.

Habitat in America; virginiane magnitudine, a qua non fatis diftincta.

ferruginea. P. rufo fufca, dorfo tectricibufque alarum lineis longitudinalibus flavefcentibus, pennis elongatis mucronatis.

Tetrao ferrugineus, Gmel. Syft. i. p. 76r.
La grande Caille de la Chine, Son. Voy. Ind. ii. p. I7 I.

Hackled Partridge, Lath. Syn. iv. p. 766 . I I. t. 66.

Habitat in Africa, Afa. - 2 pollices longa.

Pennæ colli fufcæ medio et margine flavefcentes.

Avis a Sonneratio defcripta, dorfo ftriis albidis, abdomine lateribus remigibufque exterioribus maculis nigris; cæeterum noftræ perfimilis; forte fexus alter.

27.

javanica. P. cinerea, lunulis obfcuris, genis nigris, fronte fincipite abdomineque fulvis, rectricibus maculis lunatis nigris.

Tetrao javanicus, Gmel. Syft. i. p. 76 r. Javan Partridge, Latb. Syn. iv. p. 775. 18.-Brown. Ill. p. 40. t. 17.

HaвtтAт in infula fava.-A gula fub genis utrinque fafcia fulva: criffum rubrum fafcia cinerea: pedes carnei.

28.

Coturnix. P. mutica, corpore grifeo maculato, fupercilis albis, rectricibus margine lunulaque ferruginea.

Tetrao Coturnix, Lin. Syft. i. p. 278. 20:-Faun. Suec. N'206.-Gmel. Syjt. i. p. 765.-Scop. Ann. i. No 176.-Brun. $\mathrm{N}^{\circ} 202,-$ Muller, $4 \mathrm{O}_{2}$

$\mathrm{N}^{\circ} 226$. 
$\mathrm{N}^{\circ} 226 .-K r a m . E l$. p. $357 \cdot 7 .-F r i f c h$. t. $117 .-$ Georgi, p. 173.Sepp. Vog. t. p. 143.-Faun. Arag. p. 83.-Hafelq. It. p. 279.44.Id. Voy. p. 203.-Raii Syn. p. 58. A. 6.-Will. p. I21. t. 29.Brif. i. p. $247.14 .-I d$. 8 vo. i. p. 69.-Klein. Av. p. I 15. 1.-Id. Stem. p. 25 . t. 27 . f. 3. a. b.-Id. Ov. p. 33. t. I 5. f. 6.-Bororesk. Nat. ii. p. 194. 10.-Faun. Helvet. Quaglia, Zinnan. Uov. p. 36. t. 5. f. I9.-Cet. uc. Sard. p. I 8. La Caille, Buf. ii. p. 449. t. I6.-Pl. Enl. 170.

Wachtel, Guntb. Neft. u. Ey. t. 35.

The Quail, Br. Zool. i. No 97.-Id. fol. 87. t. M. 6.-Arct. Zool. ii. p. 320. B. -Alb. i. t. 30.-Will. (Angl.) p. 169.-Latb. Syn. iv. p. 779. 24.-Id. Sup. p. 222.

HaBITAT per omnem orbem antiquum; migratoria. $-7 \frac{x}{2}$ poll. longa. Pennæ corporis ferrugineæ linea longitudinali alba: rectrices 12. Ovun luteo-aibidum maculis fanguineo-nigricantibus aliifque obfcuris notatum.

ß. Coturnix major, Brif. i. p. $251 .-I d .8$ vo. i. p. 70. Le Chrokiel, Buf. ii. p. 476. -Lath. Syn. iv. p. 782 .

Præcedenti fimilis eft in omnibus, excepta magnitudine qua eam an29. tecellit. Habitat pariter in fegetibus et pratis.

chinenfis. P. mutica, corpore grifeo maculato, jugulo nigro arcu albo.

Tetrao chinenfis, Lin. Syyt. i. p. 277. 19.-Gmel. Syft. i. p. 765 .

Coturnix philippenfis, Brif. i. p. 254. 17. t. 25. f. 1. $-J d$. 8 vo. i. p. 7 1. Fraife, ou Caille de la Chine, $B u f_{-}$ii. p. 478.-Pl. Enl. I 26. 2. ( $f e-$ mina.)

Chinefe Quail, Edw. t. 247. (mas.)-Latb. Syn. ii. p. 783.25 .

Habitat in China, Pbilippinis cum coturnice, quem vivum portant Cbinenfes, ut hyeme manus calefaciant. $-4-6$ pollices longa.-Cauda abbreviata.

30.

criftata. P. mutica, corpore variegato, crifta dependente gulaque fulvis.

Tetrao criftatus, Lin. Syft. i. p. 277. 18.-Gmel. Syft. i. p. 765.

Coturnix mexicana criftata, Brif. i. p. 260. 21 . t. 25 . f. 2.-Id. 8 vo. i. p. 72 .

Coturnix indica, Quauhtzonecolin, Raii Syn. p. 158.-Will. p. 304.Id. (Angl.) p. 393. 
Le Zonecolin, Buf. ii. p. 485 .

Caille huppée du Mexique, Pl. Enl. I26. I.

Crefted Quail, Lath. Syn. iv. p. 784. 26.

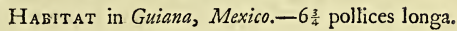

3 I.

mexicana. P. mutica, roftro pedibufque fanguineis, corpore tranfverfim ftriato, linea fuperciliari gulaque albis.

Tetrao mexicanus, Lin. Syft. i. p. 277. 14.-Gmel. Syft. i. p. 762.

Coturnix ludoviciana, Brif. i. p. 258. 20: t. 22 . f. 2.-Id. 8 vo. i. p. 72. Attagen americanus, Frifch. t. I 13 .

Colcuicuiltic, Coturnicis fimulacrum, Raii Syn. p. 1.58?-Will. p. 304. -Id. (Angl.) p. 393.

Le Colenicui, Buf. ii. p. 487.-Pl. Enl. 149.

Louifiane Quail, Lath. Syn. iv. p. 785.27.

Haвitat in Ludovicia, Mexico.-8 pollices longa.

Corpus fupra caftaneum nigro tranfverfim et undatim ftriatum, fubtus grifeum nigricante tranfverfim ftriatum : rectrices laterales cinerex.

In ave a Raio defcripta, pedes cruraque cyanea.

32.

falklandi- P. mutica, corpore fupra fufcefcente, juguloque flavefcente lunulis ca. fufcis, pectore imo abdomineque albis.

Tetrao falklandicus, Gmel. Sy/t. i. p. 762.

La Caille des ifles Malouines, Buf. ii. p. 477,-Pl. Enl. 222.

Malouine Quail, Lath. Syn. iv. p. 786.28.

Hавттат in infulis Falklandicis; Coturnicis magnitudine.

Latera capitis albo nebulofa: couda fufca fafciis pallidioribus.

33.

novæ Hif - P. mutica, capite criftato, corpore fulvo, remigibus apice albis.

paniæ. Tetrao novæ Hifpaniæ, Gmel. Syft. i. p. 763 .

Coturnix major mexicana, Brif. i. p. 257. 19.-Id. 8vo. i. p. 72.

Hoitlallotl, Raii Syn. p. 158.-Will. p. 304?-Id. (Angl.) p. 393 ?

Le grand Colin, Buf. ii. p. 485 .

Mexican Quail, Lath. Syn. iv. p. 786. 29.

34.

Habitat in Mexico. Confer Pbafianum mexicanum.

Coyolcos. P: mutica fulva, corpore fupra fulvo albo nigroque vario fubtus fulvo.

Tetrao Coyolcos, Gmel. Syft. i. p. 763 .

Coturnix mexicana, Brif. i. p. 256. 18.-Id. 8vo. i. p. 7 I.

Coyolcozque, 
654 A V E S G A L L I N E. Perdix.

Coyolcozque, feu Coli fonalis, Raii Syn. p. 158.-Will. p. 304,-Id. (Angl.) p. 393.-Buf. ii. p. 486.

Leffer Mexican Quail, Latb. Syn. iv. p. 786. 30.

Habitat in Mexico.

35.

Sufcitator. P. Alavicante rufo nigro et grifeo variegata, roftro longiore.

Tetrao fufcitator, Gmel. Syjt. i. p. $76_{3}$.

Coturnix javenfis, Brif. i. p. 25 I. 15.-Id. 8 vo. i. p. 70.

Coturnix indica Bontii, Raii Syn. p. 58. 7.-Will. p. 123.

Le Reveil-matin, Buf. ii. p. 479.

Indian Quail of Bontius, Will. (Angl.) p. I71. t. 29.

Noify Quail, Latb. Syn. iv. p. 787.31.

Hazitat in Jave fylvis; Turturis magnitudine; Coturnici in omnibus limilis, at roftro longiore.

36.

ftriata. P. mutica, corpore variegato, pectore nigro maculis albis, gula nigra, vitta fupra oculos maxillarique albis.

Tetrao ftriarus, Gmel. Syft. i. p. 763 .

Grande Caille de Madagafcar, Son. Voy. Ind. ii. p. 169. t. 98.

Madagafcar Quail, Latb. Syn. iv. p. 788. 32.

Habitat in Madagafcaria; Coturnice duplo major.

Corpus fupra caftaneo-ferrugineum fafciis lineifque longitudinalibus albidis : gula nigricans: pętus nigrum maculis rotundatis albis : bypocbondria ferruginea lineis flavefcentibus : cauda nigra fafciis albis.

37.

grifea. P. mutica fupra grifeo nigroque varia fubtus cinereo-grifea, jugulo pectore abdomineque fafciis nigris.

Tetrao grifeus, Gmel. Syft. i. p. 764 .

La Caille brune de Madagafcar, Son. Voy. Ind. ii. p. 171.

Grey-throated Quail, Latb. Syn. iv. p. 788. 33 .

Habitat in Madagafcaria; Coturnicis magnitudine.

$3^{8 .}$

coromal - P. mutica, corpore fafciolis lineifque pallidis, fupra caftaneo fubtus fladelica. vo, fafcia per oculos flavefcente, gula alba.

Tetrao coromandelicus, Gmel. Syft. i. p. 764.

La petite Caille de Gingi, Son. Voy. Ind. ii. p. 172.

Coromandel Quail, Lath. Syn. iv. p. 789 . 34.

Habirat in Coromandela; Coturnice tertia parte mino:.

P. mutica, 
39.

nez. Tetrao novæ Guineæ, Gmel. Syft. i. p. 764 .

Caille de la nouvelle Guinée, Son. Voy. Ind. ii. p. I70. t. 105.

New Guinea Quail, Latb. Syn. iv. p. 789. 35 .

40.

Haвттат in nova Guinea; Coturnice dimidio minor.-Remiges nigræ.

manillen- P. mutica, corpore fupra nigricante fubtus flavefcente fafciis nigrican-

fis.

- tibus, gula alba.

Tetrao manillenfis, Gmel. Syft. i. p. 764 .

La petite Caille de l'ifle de Luçon, Son. Voy. p. 54. t. 24.

Manilla Quail, Lath. Syn. iv. p. $790.3^{6 .}$

Habitat in Manilla; Paferis magnitudine.-4 pollices longa.

$4 \mathrm{I}$.

Tectrices alarum lineis grifeis infignitæ: bypocbondria rufefcentia.

hudfonica. P. mutica, corpore rufo-fufcefcente pallido, cervice albo maculata, alis dorfo caudaque lineis tranfverfis diftantibus albis.

Hudfonian Quail, Latb. Syn. Sup. p. 224.

Habitat ad finum Hudfonis.-Parva fpecies; 5 pollices longa.

Lineæ albæ corporis fuperioris latere inferiore nigro marginatæ.

42.

Kakelik. P. roftro palpebris pedibufque coccineis, pectore cinereo, dorfo albo et cinereo undulato.

Tetrao Kakelik, Gmel. Syft. i. p. T62.-Falk. It. iii. p. 390.

HABIтAT gregaria in Bucbaria, Cbiwa, Songoria; Columbe gutturofe magnitudine. Vox Kakerlik.

43:

fafpia. P. cinerea fpadiceo maculata, naribus orbitis et temporibus calvis pedibufque luteis.

Tetrao cafpius, Gmel. Syft. i. p. 762.-S. G. Gmel. It. iv. 67. t. 10,

Haвiтat prope Aftrabat in Perfia.

44.

cambaien- P. rufo-flavefcens nebulis faturatioribus, digito poftico mutico.

fis.

HaBiт at in India, regno Guzurat.-6 pollices longa.

Roftrum validum, breve, pallidum : corpus totum rufo-flavefcens fubtus pallidius, pennis omnibus coloribus faturatioribus nebulofis: pedes flavi, digito poftico mutico. Muf. Brit. 
45.

* * Pedibus tridaetylis.

gibraltari- P. tridactyla mutica, corpore fupra fufco nigro fafciato fubtus flavefcen-

ca. te-albo, tectricibus alarum maculis, pectore lunulis nigris.

Tetrao gibraltaricus, Gmel. Syft. i. 766.

Gibraltar Quail, Latb. Syn. iv. p. 790.37 .

Навітат in Gibraltaria. $-6 \frac{x}{2}$ pollices longa.

TeEtrices alorum macula nigra albo circumdata apiceque albo: gula 46. et jugulum albo nigroque fafciata: pedes pallidi.

andalufica. P. tridactyla mutica, corpore rufo nigro undulato fubtus flavefcente.

Tetrao andaluficus, Gmel. Syft. i. p. 766.

Andalufian Quail, Latb.Syn. iv. p. 79r. 38.t. in tit. præf.

Habitat in Andalufia.

47.

nigricollis. P. tridactyla mutica, corpore fupra cinereo rufo et nigro vario, gutture et collo inferiore nigris.

Tetrao nigricollis, Gmel. Syft. i. p. 767 .

Coturnix madagafcarienfis, Brif. i. p. 252. I6. t. 24. f. 2.-Id. 8 vo. i. p. 70.

La Caille de Madagafcar, Buf. ii. p. 479.-Pl. Enl. I7 I.

Black-necked Quail, Lath. Syn. iv. p. 791. 39.

Haвiтат in Madagafcaria. $-6 \frac{x}{2}$ pollices longa.

48.

luzonien- P. tridactyla mutica fupra fufca fubtus flava, capite albo nigroque va-

fis. rio, tectricibus alarum apice flavis macula nigra.

Tetrao luzonienfis, Gmel.Syft. i. p. 767.

Caille de l'inle de Luçon, Son. Voy. p. 54. t. 23.

Luzonian Quail, Lath. Syn. iv. p. 792. 40.

Haвiтат in Luzonia; Coturnice tertia parte minor.

fugulum et peIfus caftaneo-fulvum. 


\section{GENUS LVIII. PSOPH I A.}

Rofrum cylindrico-conicum, convexum, mandibula fuperiore longiore.

Nares ovatæ, patulæ.

Lingua cartilaginea, plana, apice laciniata.

Femora fupra genua denudata.

I.

crepitans. Pf. nigra, dorfo grifeo, pectore cæruleo-viridi fplendente, orbitis nudis rubris.

Pfophia crepitans, Lin. Syft. i. p. 263. 1.-Gmel. Syft. i. p. 720.-Borowjk. Nat. iii. p. 8 I.

Grus Pfophia, Pall. Spic. iv. t. I.

Phafianus Antillarum, Brif. i. p. 269. 2.-Id. 8vo. i. p. 75.-Raii Syn. p. 56. 2. fect. 2.

L'Agami, Buf. iv. p. 487. t. 23.-Pl. Enl. 16g.

Le Caracara, Buf. ii. p. 292 ? - Hift. des Ant. ii. cap. 5.\$. 8 ?

L'Oifeau Trompette, Defcript. de Surin. ii. p. I62.

Gold-brealted Trumpeter, Lath. Syn. iv. p. 793. t. 68.

Habitat in Brafilia, Guiana; magnitudine Galline, -20 poll. longa. Collum inferius et peEtus coloris funt cærulei fplendentis, nec minus pulchri quam Pavonis: dorfum totum e grifeo brunneum: ale et cauda

2. nigra : roftrum et pedes longiores virides. Ovum cæruleo-viride.

undulata. Pf. criftata undulata fubtus alba, pennis pectoralibus dependentibus elongatis nigris.

Pfophia undulata, Facq. Vog. p. 24. 18. t. 90-Gmel. Syft. i. p.72I.

Undulated Trumpeter, Lath. Syn. Sup. p. 225.

Haвiтat in Africa; Anferis magnitudine.

Corpus fupra fufcum nigro undulatum : occiput criftatum: ad latera colli utrinque linea longitudinalis nigra definens fupra pectus in cirrham elongatam dependentem. 


\section{Genus LIX. OTIS.}

Roftrum mandibula fuperiore fornicata.

Nares ovatæ.

Pedes curforii, tridactyli, femoribus in parte inferiore denudatis.

I.

Tarda. O. nigro rufoque undulato-maculata fubeus albida, capite (maris) juguloque utrinque criftato.

Otis Tarda, Lin. Syft. i. p. 264. 1.-Gmel. Syft. i. p. $722 .-S c o p$. Ann. i. $\mathrm{N}^{\circ}$ I 59.-Frifch. t. 106.-Kram. El.p. 354. 1.-Georgi, p. I72. -Faun. Arag. p. 79. - Raii Syn. p. 58. A. 1.-Will. p. 129. t. 32. Brif. v. p. 18. 1. -Id. 8 vo. ii. p. $216 .-K l e i n$. $A v$. p. 18. 1. $-I d$. Stem. p. 3. t. 2. f. 1.-3.-Id. Ov. p. 16. t. 3. f. 1.-Borowk. Nat. iii. p. II 5. t. 59.-Scbarf. El. Orn. t. 51 .

Outarde, Buf. ii. p. 1. t. 1.-Pl. Enl. 245.-Hift. Prov. i. p. 353.

'Trappe, Wirf. Vog. t. 33.-Guntb. Neft. u. Ey. p. 43.-Naturf. iii. 376. t. 8. f. 2.-Id. xi. p. I I.

Great Buftard, Br. Zool. i. $\mathrm{N}^{\prime}$ 98. t. 44.-Id. fol. 87. t. N.-Arct. Zool. ii. $\mathrm{N}^{\circ}$ 186.-Id. Sup. p. 63.-Will. (Angl.) p. 178. t. 32.Edw. t. 79. 80.-Aib. iii. t. 38.39.-Pitfield's Mem. t. p. 196.Latb. Syn. iv. p. $79^{6}$.

Habitat in Europe, Afie, Africa campis; victitans granis et herbis. -4 pedes longa.

Remiges primores nigræ: rectrices 20. Ovum olivaceo-flavefcens maculis rubro fufcis.

2.

chilenfis. O. capite juguloque lavi, corpore albo, vertice rectricibufque cinereis, remigibus primoribus nigris.

Otis chilenfis, Molin. Cbil. p. 231.-Id. (ed. Gall.) 241.-Gmel. Syjt. i. p. 725 .

Habitat in campis Cbilenfibus; gregaria; victitans herbis,-Ponit ova fex alba anferinis majora ; facile manfuefcit; magnitudine Tardam excedit.-Roftrum et pedes ut in congeneribus : caput et ala antice grifeæ: remiges nigræ; tota avis aliter alba : cauda brevis, rectricibus i 8.

O. nigro 
Tetrax. O. nigro rufo alboque variegata fubtus alba, capite juguloque lævi.

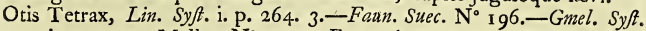
i. p. $725 .-$ Muller, $\mathrm{N}^{\circ} 220 .-$ Faun. Arag. p. 79.-Borow/k. Nat. iii. p. I 18.2.

Otis minor, Brif. v. p. 24. 2. t. 2. f. 1. 2.-Id. 8 vo. ii. p. 2 18.-Raii Syn. p. 59. 2.-Will. p. I 29. t. 32 .

Tarda nana, Klein. Av. p. 18. 2 .

Petite Outarde, Buf. ii. p. 40.-Pl. Enl. t. 25. (mas.)-10. (femina.)

Canapetiere, Hift. Prov. i. p. 353.

Gallina pratojuola, Cet. uc. Sard. p. 122.

Field Duck, $A l b$. iii. t. 4r.

Little Buftard, Br. Zool. i. N 99.-Arct. Zool. ii. p. 32 I. A.-Edw. t. 251.-Pbil. Tranf. xlviii. p. 502. t. I6.-Id. Ivii. p. 349.-Lath. Syn. iv. p. 759. 2.-Id. Sup. p. 226.

Haвitat in Europa auftraliore, Afia; in Anglia rarifima.- 7 pollices longa.

Mas collo nigro, torque albo : rętrices octodecim. Ovum fplendide viride.

4.

arabs. O. rufefcens nigricante ftriata fubtus alba, auribus erecto-criftatis.

Otis arabs, Lin. Syft. i. p. 264. 2.-Gmel. Syft. i. p. 725.-Brif. v. p. 3.. 3.-Id. 8 vo. ii. p. 2 19.-Klein. Av. p. 18. 3.-Borowjk. Nat。 iii. p. 120.3 .

Le Lohong, Outarde huppée d'Arabie, Buf. ii. p. 52.

Paon fauvage de Luçon, Son. Voy. p. 85. t. 49.

Arabian Buftard, Lath. Syn. iv. p. 80 I. 3.-Id. Sup. p. 226.-Edw.

t. $I 2$.

Habitat in Afia, Africa; Tarde magnitudine.

Corpus fupra fcolopacinum fubtus albidum: aures nigræ: cauda fafcia fufca.

5. 5 . O. nigra, dorfo cinereo undulato, auribus albis.

Otis afra, Gmel. Syjt. i. p. 724.-Bororefk. Nat. iii. p. I20. 4.

Otis atra, Lin. Syft.i. p. 264.4.

L'Outarde d'Afrique, Buf. ii. p. 54.

Knor-Cock, Kolb. Cap. ii. p. I39. t. 7. f. 2.-Sparrm. Voy. i. p. 153.

White-eared Buftard, Lath. Syn. iv. p. 802. t. 69. 4.-Id. Sup. p. 227.

Haвiтат ad Caput Bone Spei.-22 pollices longa.

Maris roftrum et pedes flavi : vertex cinereus: alarum area longitudi- 
nalis alba: collum imum pottice, et femora fupra genua torque albo cincta : couda rectricibus I 4 .

6.

Femina tota cinerea, exceptis femoribus abdomineque atris.

bengalen- $O$. nigra fupra fulvo-fufca, dorfo maculis cauda fafciis nigris, tectricifis. bus alarum albis.

Otis bengalenfis, Gmel. Syft. i. p. 724 .

Pluvialis bengalenfis major, Brif. v. p. 82 . 13. -Id. 8vo. ii. p. 23 I.

Le Churge, Buf. ii. p. $5^{6 .}$

Large Eyes, Adanf. Seneg. p. 77 ?

Indian Buftard, Lath. Syn. iv. p. 804. 5.-Id. Sup. p. 228.-Edw. t. 250.

Haвjтat in Bengala; præcedenti nimis fimilis.

7 :

aurita.

8.

Houbara. O. flavefcens fufco maculata, collo pennis elongatis albidis rachibus nigris, remigibus nigris medio macula alba.

Otis Houbara, Borowes. Nat. iii. p. I 21 . 5.-Gmel. Syft. i. p. 725.

Houbara, Buf. ii. p. 59.-Shaw's Trav. t. p. 252.-Gent. Mag. xix.

t. p. 499.-Voy. en Barb. i. p. 267.

Ruffed Buftard, Lath. Syn. iv. p. 805.6.

Habitat in Africa, Arabia; Caponis magnitudine.

Rhaad. O. criftata flavefcens fufco maculata fubtus alba, capite nigro, cauda fufca fafciis nigris.

Otis Rhaad, Gmel. Syft. i. p. 725 .

Rhaad, Buf. ii. p. 61.-Sbaw's Trav. p. 255. f. 2.-Voy. en Barb. i. p. 267 .

Rhaad Buftard, Latb. Syn. iv. p. 805. 7.

Habit a t cum priore.-Occiput crifta cærulea.

Variat oscipite non criftato. 
ro.

A V E S G A L L I N 死. Otis. 66r

indica. O. fufca nigro undulata fubtus fufco-albida, gula alba, vertice nigro, lateribus capitis fafcia nigra.

Otis indica, F. F. Mill. t. 33.-Gmel. Syft. i. p. 725.

White-chinned Bultard, Lath. Syn. iv. p. 806.8 .

Habitat in India; CEdicnemi magnitudine.

I.

QEdicne- O. grifea, remigibus primoribus duabus nigris medio albis, roftro acumus. to, pedibus cinereis.

Charadrius QEdicnemus, Lin. Syft. i. p. 255 10.-Gmel. Syft. i. p. 689. -Klein. Av. p. 20. 4.-Faun. Arag. p. 78.-Borowes. Nat. iii. p. II 6.6 .

Scolopax, Gmel. reife. iii. p. 87. t. I6.

Pluvialis major, OEdicnemus vulgo dicta, Brif. v. p. 76 . 12. t. 7. f. 1. -Id.8vo. ii. p. 230.-Raii Syn. p. 108. A. 4.-Will. p. 227 .t. 58. 77.-Schaf. El. Orn. t. $5^{8}$.

Fedoa noftra tertia, Raii Syn. p. 105. A. 6.-Will. p. 216.

Charadrius illyricus, It. Pofegan. p. 26. t. 3.

Le grand Pluvier, Buf. viii. p. 105. t. 7.-Pl. Enl. 919.

L'Eddinemo, Cett. uc. Sard. p. 260.

Stone Curlew, Alb. i. t. 69.-Will. (Angl.) p. 306. 293. t. 58.77.

Thick-kneed Buftard, Br. Zool. i. N ${ }^{\circ}$ 100.-Id, fol. I27.- Hift. Selb.

pp. 43. 88.-Lath. Syn. iv. p. 806. 9.

Haвiт Aт in Europa, Africa, Afia; in Anglie faxofis fatis frequens.

Roftrum nigrum : pedes luteo:virefcentes : palpebra inferior nuda luteola : lineola fupra infraque oculos flava : linea fufca a roftro fub oculis ad aures. Ovum cinerafcens maculis anomalis olivaceo-rubris. 
662 AVES STRUTHIONES. Didus.

\section{ORDOVI. STRUTHIONES.}

GENUS LX. D I D U S.

Rofrum medio coarctatum rugis duabus tranfverfis, utraque mandibula inflexo apice.

Nares obliqux, margini medii roftri propinqux.

Facies ultra oculos nuda.

Ala ad volandum ineptx.

Femora in parte inferiore plumis deftituta.

Pedes tetradactyli, breves, craffi.

I.

ineptus. D. grifeus, remigibus rectricibufque flavo-cinereis, capite cucullato.

Didus ineptus, Lin. Syft. i. p. 267.-Gmel. Syft. i. p. 728.-Borowjk: Nat. ii. p. 16r. t. 25.

Raphus, Brif. v. p. 1 5.-Id. 8vo. ii. p. 214.

Cygnus cucullatus, Raii Syn. p. 37. 4.-Will. p. 107. t. 27.

Gallus gallinaceus peregrinus, Cluf. Exot. 99. t. 10.-Olear. Muf. xxiii. t. I3. f. 5 .

Le Dronte, Buf. i. p. 480.-Bont. Ind. Or. t. p. 70.

Dod-eerfen, or Valgh-vogel, Herb. Tr. (ed. 1634.) t. p. 212.-Id. (ed. 1677.) t. p. 383 .

Hooded Dodo, Lath. Syn. v. p. I. t. 70.-Edw. t. 294.

Habitat in infulis Francice et Bourbon; Cygno major.-3 ped. long.

Corpus nigrum albido-nebulofum : ale impennes albida : cauda breviffima pennis incurvis, ut in Strutbione : roftrum cærulefcens, fupra apicem rubrum: pedes flavicantes.

2.

folitarius. D. grifeo fufcoque varius, alis abbreviatis, alulis gibbofis.

Didus folitarius, Gmel. Syft. i. p. 728. 
Le Solitaire, Buf. i. p. 485.-Leguat. Vuy. i. t. p. 98.-Bororvf. Nat. " ii. p. I62.

Solitary Dodo, Lath. Syn. v. p. 3.

HaBItat in infula Rodrigue; Gallopavonis magnitudine; 25 libras pondere æquans. - Ala fpuriæe tubere rotundo terminatæ.

Femina peשzore utrinque cirrho albo mammam æmulante.

3.

nazarenus. D. tơto corpore tomentofo nigro.

Didus nazarenus, Gmel. Syjt. i. p. 728.

Oifeau de Nazareth, O. de Naufée, Buf. i. p. 485.-Cauche Madag. p. I30.-Borowe. Nat. ii. p. I62.

Nazarene Dodo, Latb. Syn. v. p. 4 .

Habitat in infula Francie; Cygno major. - Nidum ex foliis ficcoque gramine in terra ftruit, ovum unum album pariens.

Roftrum ingens: pedes longi, fquammati, tridactyli.

\section{GENUS LXI. S T R U T H I O.}

Roftrum rectum, depreffum, apice rotundatum. Alce breves, volatui inutiles.

Femora fupra genua nuda.

Pedes didactyli, digitis duobus anticis, poftico nullo.

Camelus, Struthio.

Struthio Camelus, Lin. Syft. i. p. 265.-Gmel. Syft. i. p. 726.-Scop. Ann. i. $\mathrm{N}^{\circ}$ 160.-Raii Syn. p. 36. 1.-Will. p. 104. t. 25.-Brif. v. p. 3.-Id. 8 vo. ii. p. 209.-Seba, i. p. 83 . t. 6 r. f. $6 .-K l e i n$. Av. p. 16.-Id. Stem. p. 1. t. x. f. 1. 2.-Id. Ov. p. I5. t. 1.-Ger. Orn. ii. p. 29. t. 137. 138. 139.-Borowjk. Nat. iii. p. 122. t. 60.

L'Autruche, Buf. i. p. 398. t. 29.-Pl. Enl. 457. (fem.)

Black Oftrich, Brown. Ill. t. 16. (mas.)-Will. (Angl.) p. 149. t. 25. -Alb. iii. t. 53.-Gent. Mag. xviii. t. p. 580.-Pitf. Mem. t. p. 214.-Pbil. Tranf. xxxiii. p. 223.-Id. xxxiv. p. I 1 3.-Id. xxxvi. p. 275.-Cbefeld. Anat. cap. 5. (scelet.)-Sparrm. Voy. i. p. 130.ii. p. 81,-Lath. Syn. v. p. 6. t. 7 r. 
664 AVES STRUTHIONES. Cafuarius.

Habitat in Africa, Afa.-Corpus maximum omnium avium, hine volare nefcium, pennis decompofitis radiis difcretis : curfu facile omnibus animalibus antecellit: caput anferinum et colli pars maxima nuda, incarnata, pilis rarioribus hirta: palpebra utraque ciliata : irides avellanea : corpus nigrum, pennis quandoque albo grifeoque admixtis, remigibus primoribus reEtricibufque albis: Aternum callofum: Spine alarum 2 , altera ad alulam, altera in alæ apice: digiti 2 bafi membrana connexi, exteriore digito mutico. Femina fufca ubi mas niger, et ova ufque ad 50 candida in arena pariens.

\section{GENUS LXII. CASUARIUS.}

Roftrum depreffum, rectum, fubconicum. Nares ovatæ. Ala brevifimæ, volatui inutiles: Femora in parte inferiore denudata. Pedes tridactyli, digitis omnibus anticis. Cauda nulla.

I. Emeu.

C. niger, vertice galeato, corpore fetofo, capite colloque fupremo nudis. Struthio Cafuarius, Lin. Syft. i. p. 265.-Gmel. Syft. i. p. 726.

Cafuarius, Emeu, Brif. v. p. 10.-Id. 8 vo. ii. p. 21 2.-Raii Syn. p. 36. 3.-Will. p. 105. t. 25.-Frijch. t. 105.-Klein. Av. p. 17.-Id. Stem. p. 2.-Id. Ov. t. 2.-Ger. Orn. ii. p. 28. t. 136.-Borowefk. Nat. iii. p. 128.3 .

Le Cafoar, Buf. i. p. 464 . Pl. Enl. 3 r 3.

Galeated Caffowary, Latb. Syn. v. p. 1o. t. 72.-Alb. ii. t. 60.-Will. (Angl.) p. 151. t. 25.-F. F. Nill. Ill. t. 14.-Gent. Mag. xliii. t. p. 47 1.-Pitfield. Mem. t. p. 240.-Grew's Muf. t. 27. (Splancbn.)

Haвгтат in Afa orientali, intra zonam torridam.- $5 \frac{x}{2}$ pedes longus. Corpus magnitudine Strutbioni proximum, et æque avis volatus nefcia, celerrime currit : caput nudiufculum, cærulefcens : diadema vericis 3 pollices altum e collo elevato, flavo; antice fufco: irides topazinæ: palearia membranacea duo, rubro-cærulea, fub medio collo fupra nudo: pennæ corporis decompofitæ pinnulis a fe invicem disjunctis, utroque alveolo ut plurimum binis, omnibus magnopere ad pilorum 
formam accedentibus : remiges 5 hiftricis calamis fimiles abfque radiis : redtrices nullæ: fternum callofum : roftrum et pedes nigri. Ovum virens,

2. crebris lituris punctifque faturatioribus.

N. Hol- C. nigricans, vertice plano, corpore fetofo, capite colloque pennaceis, landiæ. New-Holland Caffowary, Pbill. Bot. Bay, t. p. 27 r.

HABIтAт in nove Hollandice variis partibus; pracedentem magnitudine excedens. -7 ped. 2 poll. longus.-Curfu velocifimus.-Caro fatis bona.

Roftrum nigrum : caput, collum, corpufque totum pennis fetaceis fufco et grifeo variegatis : jugulum nudiufculum, cærulefcens : corporis pennæ apice paulo incurvatæ: ale brevifimæ, vix confpicuæ: pedes fufci, poftice per totam longitudinem ferraturis extantibus exafperati.

\section{GENUS LXIII. RHEA.}

Roftrum rectum, depreffum, apice fubrotundato.

Ala volatui inutiles.

Crura in parte inferiore plumis denudata.

Pedes digitis tribus antice inftructi, poftice callo rotundato.

I.

americana. Rhea.

Struthio Rhea, Lin. Syft. i. p. 266. 3.-Gmel. Syft. i. p. 727.-Borow/k. Nat. iii. p. 1 27. 2.-Molin. Cbil. p. 232.-Id. (ed. Gall.) p. 241. Rhea, Brif. v. p. 8.-Id. 8vo. ii. p. $211 .-M o e b r$. Av. Gen. 55.

Struthio-camelus americanus, Nhandu-guacu, Raii Syn. p. 36. 2.Will. p. 105 .

Struthio nothus, Klein. Av. p. 17.

L.e Touyouyou, Bajon. Cay. ii. p. 263.

Le Touyou, Buf. i. p. 452.

L'Autruche, Ferm. Surin. p. I42.

American Oftrich, Will. (Angl.) p. r 50.-Clavig. Hift. Mexic. ii. p. 290. 293.-Falk. Patag. p. 52. 53. et alibi.-Wallis Voy. p. 373. Damp. Voy, iii, part r. p. 76. -Lath. Syn. iv. p. 23. *. 4. Q

HABITAE 
Habitat in Americe auftralioris variis locis, præfertim circa lacum Nabuelguspi, in Andorum vallibus; altitudine fere hominis; magnitudine a Strutbione vix fecunda. Ova ponere in arena ad $40 \mathrm{vel} 60$, fibiloque pullis acclamare fertur. Victitat fructibus, carne, mufcis. Rofirum Strutbionis æmulum, feu potius anferinum, depreffum: oculi nigri: palpebra ciliis inftructæ: caput parvum, rotundatum, plumis tectum : collum pedes 2 poll. 8 longum; ab extremo ad extremum alarum extenfarum pedes 8 ; harum pennæ decompofitæ pinnulis disjunctis, hinc volatui inutiles: color alarum et dorfi obfcure grifeus, reliqui corporis albus : uropygii pennæ elongatæ deflexæ caudam tegunt et abfcondunt.

Variat corpore toto albo, interdum nigro. Molina. 


\section{II. AVES A QUATICAE.}

\section{ORDO VII. GRAL L E.}

\section{GENUS LXIV. PLA T A L E.}

2

Roftrum elongatum, planiufculum, apice dilatato, orbiculato, plano.

Nares parvæ ad bafin.

Lingua brevis, acuta.

Pedes tetradactyli, femipalmati.

1.

leucorodia. Pl. corpore albo, gula nigra, occipite fubcriftato.

Platalea leucorodia, Lin. Syft. i. p. 231. 1.-Muf. Adolph. ii. p. 26.Faun. Suec. $\mathrm{N}^{\circ}$ 160.-Gmel. Syft. i. p. 61 3.-Scop. Ann. i. No 115.

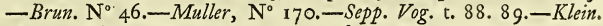
Av. p. 126. 1.-Id. Ov. p. 34. t. 18. f. 4.-Decouv. Ruff. i. p. I64. - Faun. Helvet.

Platea, five Pelecanus Aldr. Raii Syn. p. 102. 1.-Will. p. 2 1 2. t. 52 . -Brif. v. p. 352 . 1. -Id. 8 vo. ii. p. 300.-Borowejk. Nat. iii. p. 68. t. 45 .

La Spatule, Buf. vii. p. 448. t. 24.-Pl. Enl. 405.-Voy. en Barb. i. p. 277 .

Garza, o Beccarivale, Zinnan. Uov. p. 111 . t. 20. f. 99 . Spoon-bill, or Pelican, Alb. ii. t. 66.-Will. (Angl.) po 288. t. 5 ?Kolb. Cap. ii. p. 142. t. 7. f. 5.-Ray's T'rav. p. $3^{8}$.

White Spoonbill, Br. Zool. App. t. 9. -Arct. Zool, ii, p. 441. A.-Id. Sup. p. 66. -Lath. Syn. v. p. 13. I. 
Habitat in Europa, Afa ; in arboribus altiflimis nidificans, et ova pariens $3-4$ albida. - Tota avis 2 ped. 8 poll. longa.

Roftrum nigrum, in quibufdam fufcum aut varium: pedes nigri: pennæ occipitis elongatæ in criftam : orbite oculorum et gula nuda dilatabilis nigra.

ß. I a Spatule blanche de Luçon, Son. Voy. p. 89. t. 5 r.

Haвiтat in Pbilippinis.-Variat alis albo nigroque variegatis. Roftrum fufcum: pedes flavefcentes.

\%. La Spatule huppée de l'ifle de Luçon, Son. Voy. p. 9o. t. 52.

A præcedentibus differt corpore toto albo, capite crifta longiore.

Roftrum rufo-grifeum : pedes incarnati.

2.

Ajaja. Pl. corpore rofeo, tectricibus caudæ coccineis, rectricibus rofeis.

Platalea Ajaja, Lin. Syft. i. p. 231. 2.-Gmel. Syft. i. p. 614.-Raii Syn.

p. I02. 3.-Will. p. 2 I 3.-Klein. Av. p. 1 26. 2.-Borarejk. Nat.

iii. p. 69.2 .

Platea rofea, Brif. v. p. 356 . 2. t. $30 .-I d .8$ vo. ii. p. 302.

La Spatule couleur de rofe, Pl. Enl. 165.-Buf. vii. p. 456.-Pernet. Voy. i. p. 184 . t. 2. f. 3.-Hift. de la Louis. ii. p. I 16.

Bec à cuiller, Ferm. Surin. ii. p. I 53.- Mem. Sur Cay. ii. p. 257.

Brafilian rofeate Spoonbill, Lath. Syn. v. p. 16. t. 73.-Will. (Algl.)

p. 28 9.-Harris Coll. Voy. i. p. 728.

Habitat in America aufrali; pracedente paulo minor.

Caput anterius et guttur nuda, candicantia.

B. Pl. corpore fanguineo, collo candido, torque nigto, rectricibus coccineis.

Platalea Ajaja, Lin. Syft. i. p. 231. 2. $\beta$.

Platea coccinea, Brif. v. p. 359. 3.-Id. 8vo. ii. p. 303.

Platea mexicana, Tlauhquechul, Raii Syn. p. 102. 2.-189. 5.-Will. p. 2 I 3. -Klein. Av. p. 126. 3.

Scarlet Spoonbill, Lath. Syn.v. p. 16.-Sloan. Fam. ii. p. 316.-Bancr. Guian. p. 170.- Will. (Angl.) p. 289.2.

Habitat cum priore, cujus forte adulta avis.

Caput pene depile, et cum univerfo fere collo et parte pectoris candens: fafcia nigra latiufcula caput a collo diftinguit.

$\mathrm{Pl}$. corpore 
3.

A V E S G R A L L E. Palamedea.

pygmea. P1. corpore fupra fufco fubtus aibo.

Platalea pygmea, Lin. Syft. i. p. 231. 3.-Muf. Ad. ii. p. 26.-Gmel. Syft. i. p. 615.

Dwarf Spoonbill, Bancr. Guian. p. 17 1.-Latb. Syn. v. p. 17.3.

Habitat in Guiana, Surinamo.-Corpus magnitudine Paferis.

Rofrum nigrum, apice, uti in congeneribus, dilatatum : cauda brevis rotundata : remigum raches albæ: pedes fiff, longiufculi, nigri, $f_{c-}$ moribus feminudis.

\section{GENUS LXV. PA L A M D E A.}

Roftrum conicum, mandibula fuperiore adunca.

Nares ovatæ.

Pedes tetradactyli; fifi.

I.

cornuta. P. alulis bifpinofis, fronteque cornuto.

Palamedea cornuta, Lin. Syft. i. p. 232. 1.-Gmel. Syft. i. p. 61 5.-Borowek. Nat. iii. p. 69. t. 46 .

Anhima, Brif. v. p. 5 18. 1. - Id: 8 vo. ii.p. 349.-Raii Syn. p. 96. 7. -Will. p. 276. t. 47.

Le Kamichy, Buf. vii. p. 335. t. 1 8.-Pl. Enl. 45 1.

Aigle d'eau cornu, Defor. Surin. ii. p. 143.

Camoucle, Mem. Cayen. ii. p. 286 . t. 4.

Horned Screamer, Latb. Syn. v, p. 18. t. 74.

Навітат in Braflia, Guiana rarior; Cygno major:-3 ped. 4. poll. longa.-Mas et femina femper juncti. incedunt.-Nidus e luto, forma furni, fupra terram. - I erribili voce clamitat.

Roftrum et pedes nigri : irides aurea: corpus nigricans, albo variegatum: venter inferior albus : cornu in fronte ad bafin roftri recurvatum, 3 pollices longum, rotundum, albicans: Jpine duæ ad alulam rectæ, triangulares, flavæ.

2.

criftata. P..inermis, fronte criftata.

Palamedea criftata, Lin. Syft. i. p. 232. 2.-Gmel. Syft. i. p. 6 I6.

Cariama, Brif. v. p. 516.-Id. 8vo. ii. p. 348.-Buf. vii. p. 325.Raii Syn. p. 96. 6. - Will. p. 202. t. 51.-Id. (Angl.) p. 276. t. 5 1.

Crefted Screamer, Lath. Syn. v. p. 20, 2.

HABITAT. 
670 A V E S G R A L L \#. Mycteria.

Habitat in Brafilia; ardere magnitudine.-Voce Galloparonis cla. mans longe auditur.

Rofirum et pedes flavefcentes: crifta frontis erecta plumata: corpus griteum fufco et rufetcente varium: pollex obfoletus terram non attingens.

\section{GENUS LXVI. MYCTERIA.}

Rofirum fubafcendens, acutum, mandibula fuperiore triquetra.

Frons calva.

Nares lineares.

Pedes tetradactyli.

I.

americana. M. alba, remigibus rectricibufque nigro-purpurafcentibus.

Mycteria americana, Lin. Syft. i. p. 232. 1.-Gmel. Syft. i. p. 616. Borowfk. Nat. iii. p. 80.3 .

Ciconia brafilienfis, Brif. v. p. 37 1. 4.-Id. 8 vo. ii. p. 306.

Jabiru guacu, Raii Syn. p. 96. 5.-Will. p. 202. t. 47.-Id. (Angl.)

276.-Buf. vii. p. 282 . t. 13. - Pl. Enl. 8 I7.

Touycuyou, Mem. Jur Cayen. ii. t. 3 ?

Aouarous, Mem. Jur Cay. ii. p. 254?

Indian Stork's Head, Grew's Muf. t. 5. f. I.

American Jabiru, Lath. Syn. v. p. 22. t. 75.

Habitat in Americe calidioris paludofis.-Magnitudo CiconiceMigratoria, gregaria, arboribus infidens; victitat pifcibus.

Koftrum et pedes nigri : corpus album : collum fere totum nudum, hujufque medietas cum capite cute nigra tegitur, infra quam cutis rubra.

2.

afiatica. M. alba, fafcia per oculos dorfo infimo remigibus rectricibufque nigris. Indian Jabiru, Lath. Syn. Sup. p. 231.

HaBıтAт in India; cocbleis victitans.

Roftrum nigricans, mandibula fuperiore bafi fupra gibba, inferiore fubtus tumida : pedes incarnati. 


\section{GENUS LXVII. CANCROMA.}

Roftrun gibbofum, mandibula fuperiore cymbæ refupinatx forma.

Nares parvæ, ovatæ, in fulco roftri.

Lingua parva.

Pedes tetradactyli, fiffi.

I.

cochlearia. C. criftata cinerafcens, ventre rufo, vertice lunulaque cervicis nigra.

Cancroma Cochlearia, Lin. Syft. i. p. 233. 1.-Gmel. Syft. i. p. $617 .-$ Borowe. Nat. iii. p. 106. 2.

Cochlearius, Brif. v. p. 506. r. -Id. 8 vo. ii. p. 344 .

Le Savacou, Buf. vii. p. 443. t. 23.-Pl. Enl. 38.

Boat-bill, Brown Illuftr. p. 92. t. 36.-Latb. Syn. v. p. 26. t. 76.

Hавітат in America auftrali.-22 pollices longa.-Vietitat pifcibus, cruftaceis.

Roftrum fufcum: lora nuda, nigricans: crifa verticis e pennis longiffimis gradatim brevioribus: pedes fufco-flavefcentes, digitis ad bafin membrana connexis.

B. Cochlearius navius, Brif. v. p. 508. $-I d .8$ vo. ii. p. 346 . Spotted Boat-bill, Lath. Syn. v. p. 27.

Variat corpore fufco maculato.

$\%$. C. criftata rufo-fufca, abdomine albido, vertice nigro.

Cancroma cancrophaga, Lin. Syft. i. p. 233.2.-Gmel. Syft. i. p.618. - Borow/k. Nat. iii. p. 105 . t. 56 .

Cochlear us fufcus, Brif. v. p. 509. 2.-Id. 8 vo. ii. p. 345 .

Gallinula aquatica, Tamatia, Raii Syn. p. I16. 12.-Will. p. 238.Id. (Angl.) p. 318. t. 78.

La Cuilliere brune, Buf. vii. p. 443.-Pl. Enl. 869.

Brown Boatbill, Lath. Syn. v. p. 28.

HАВітат cum præcedente, cujus forte femina. 


\section{GENUS LXVIII. S C O P U S.}

Roftrum longum, craflum, compreffum, apice adunco. Nares lineares, obliqux. Pedes tetradactyli, fiffi.

I.

Umbretta. Scopus.

Scopus Umbretta, Gmel. Syft. i. p. 618.-Brif. v. p. 503. 1.-Id. 8vo. ii. p. 343 .

Ombrette, Buf. vii. p. 440.-Pl. Enl. 796.

Tufted Umbre, Lath. Syn. v. p. 30. t. 77.-Brown Illuftr. p. 90. t. 35 .

Haвitat in Africa; Cornicis magnitudine. -20 poll. longus.

Roftrum fufco-nigricans: mandibula fuperior pluribus partibus inter fe coadunatis confata videtur, apice parumper adunco, utrinque fulco longitudinali exarata, in quo nares fitæ funt; inferior verfus finem anguftior, fubtruncata : occiput criftatum : crifta tumida, denfiffima, floccofa, plumulis laxis conferta, in quibufdam ad dorfum ufque pendens. Avis tota fufca, terræ umbriæ æmula : cauda fafciis faturatioribus : pedes longiufculi, fufci, digitis bafi membrana connexis.

Femine caput non criftatum.

\section{G E N U LXIX. A R D E A.}

Roftrum rectum, acutum, longum, fubcompreffum, fulco e naribus verfus apicem exaratum.

Nares lineares.

Lingua acuta.

Pedes tetradactyli, fifi, bafi membrana connexi.

I.

* Criftatæ: roftro vix capite longiore.

pavonina.

A. cærulefcens, crifta fetofa erecta, temporibus palearibufque binis nudis.

Ardea pavonina, Lin. Syft. i. p. 233. 1.-Gmel. Syft. i. p. 6r g.-Borowfk. Nat. iii. p. 73. t. 48 .

Grus 


\section{A $\sqrt{ }$ E S G R A L L Æ.. Ardea.}

Grus balearica, Raii Syn. p. 95. 3.-Will. p. 201. t. 48.-Brif. v. p. 5 I 1. r. t. 4 I. (fem.) -Id. 8 vo. i. p. $346,-K l e i n$. Av. p. I 21 . III. Grus capenfis, Petiv. Gaz. t. 76. f. 9 .

L'Oifeau royal, Buf. vii. p. 317.t. 16.-Pl. Enl. 265. (mas.)

Grue tête de negre, Ferm. Surin. ii, p. I 50.

Peacock, Kolb. Cap. ii. p. 245 . t. 7 . f. 4.

Balearic Crane, Sloan. Fam. p. 314.-Will. (Angl.) p. 275 . t. 48.

Crowned African Crane, Edw. t. 192:-Voy. to Guinea, p. 250 . t. I I.

Crowned Heron, Latb. Syn. v. p. 34. i.-Gent. Mag. xx. t. p. 264.

Haвiтat in Africa.-2 ped. 9 poll. longa.

Caput nigrum: tempora nuda paleariaque rubra: crifa flavefcens ex fetis quaquaverfum diffutis, porcinis finilibus, apice nigris : ahe albe: cauda nigra, xqualis.

Femina nigra ubi mas cærulefcens : palearia exigua, vel nulla.

2.

Virgo. A. fuperciliis albis poftice retrorfumque longe criftatis.

Ardea Virgo, Lin. Syft. i. p. 234. 2.-Gmel. Syjt. i. p. 6rg.-Boroun. Nat. iii. p. 84. 3 .

Grus numidica, Brif. v. p. 388. 12.-Id. 8 vo. ii. p. 3 I r.-Klein. Av. p. I 2 I. 6.

La Grue de Numidie, ou Demoifelle, Buf. vii. p. 3r 3. t. I 5.-Pl. Enl. 241.-Dodart. Mem. iii. p. 3. t. 35. (Tracbea.)

Kurki, For/k. Faun. Arab. p. 9. 4?

Dancing Bird, Pocock Trav. ii. p. 207.

Demoifelle, or Numidian Crane, Lath. Syn. v. p. 35.-Alb. iii. t. 83 . -Edw. t. 134.-Pitfield. Mem.t.p. 204. (Tracbea.)-Pbil. Tranf. lvi. p. 210. t. 11. p. 215 . (Tracbea.)

Habitat in Africa, Afia.-3 ped. 3 poll. longa.

Corpus magnitudine Ciconia, cæruleo-cinereum; capito remigibufque primariis apice nigris : pennæ paleares nigræ, pendulæ: oculi rubri pupilla cinerea : pone oculos utrinque crifta pennacea recurvata longa alba: pedes nigri : roftrum bafi viride, medio luteum, apice rubrum.

In hac fpecie tricbea in fterni. cavitatem intrat, inibique reflectitur ; eodemque foramine egrediens ad pulmones tendit. 
3 .

* Grues: capite calvo.

gigantea. A. nivea, orbitis nudis, remigibus decem primoribus nigris, roftro pedibufque rubris.

Ardea gigantea, Gmel. Syft. i. p. 622.-Gmel. reife. ii. p. 189. t. 21. Grus leucogeranos, Pall. It. ii. p. 7 14. 30. t. I.-Georgi reife p. I71.-Dec. RufJ. ii. p. 145 .

Sibirian Crane, Arct. Zcol. ii. p. 455. C.-Id. Sup. p. 67.-Latb. Syn. v. p. $37 \cdot 3$.

Habitat in vaftifimis paludibus campifque lacuum maxima copia irrigatis, circa Ifcbimum, Irtin, et $O b$ fluvios, et in feptentrionalibus.Victitat ranis, pifciculis, lacertis.-Stans erecta $4 \frac{1}{2}$ pedes altitudine æquat.

Roftrum ferratum: facies ultra oculos nuda, rugofa, rubra: primi anni aves ochracex, roftro pedibufque fufcefcentibus. Ova 2 cinerea, anferinis aqualia ponit.

4.

Antigone. A. capite nudo collarique papillofo rubris, corpore cinereo, remigibus primoribus nigris.

Ardea Antigone, Lin. Syf. i. p. 235. 6.-Gmel. Syj. i. p. 622.

Grus orientalis indica, Brif. v. p. $378.7 .-I d$. 8 vo. ii. p. 308.-Klein: Av. p. 121.5 .

Indian Crane, Lath. Syn. v. p. 33.-Id. Sup. p. 232.-Edw. t. 45 .

Habitat in India et Mongolic defertis ; migrans ultra Baikalum.5 fere pedes alta.-Pone oculos macula parva alba, et vertex albus: roftrum flavo-virefcens : pedes rubri: rectrices cinereæ.

ß. Grue à collier, Buf. vii. p. 307.-Pl. Enl. 865.-Lath. Syn. v. p. 39.

$\mathrm{H}_{\mathrm{AB}} \mathrm{TT}$ A $\mathrm{T}$ in India.-A præcedente variat corpore carulefcente-cinereo, roftro nigro, capite colloque nudiufculo, incarnato, collari rubro: cauda nigra: pedes nigricantes.

5.

Grus.

A. occipite nudo papillofo, pileo remigibufque nigris, corpore cinereo, tectricibus intimis laceris.

Ardea Grus, Lin. Syft. i. p. 234. 4.-Foun. Suec. No 161.-Gmel. Syft. i. p. 620.-Scop. Ann. i. $\mathrm{N}^{\circ}$ 122.-Brun. p. 47.-Muller, p. 22. -Kram. El. p. 345.-Frifch. t. 194.-Brif. v. p. 374. 6. t. 33.Id. 8vo. ii. p. 307.-Raii. Syn. p. 95. A. 1.-Will. p. 200. t. 48.- 
Klein. Av. p. I 2 r. 1.-Id. Ov. p. 23. t. 17. f. 1.-Faun. Arag. p. 76.-Borowe. Nat. iii. p. 82. 2.-Faun. Helvet.-Block. berl. Befcb. iv. p. 586 . t. 16.

I. Grue, Buf. vii. p. 287. t. I4.-Pl. Enl. 769.-Cett. uc. Sard. p. 262. Common Crane, Br. Zool. ii. App. p. 629. t. 6.-Arct. Zool. ii. p. 453. A.-Will. (Angl.) p. 274. t. 48.-Kolb. Cap. ii. p. 141.-Alb. ii. t. 65.-RuJJ. Alep. p. 69.-Pbil. Tranf. xxvii. p. 464 ?-Id. lvi. 208. 2 I 5. t.I I. f. 4. - Arcboolog. ii. p. 172.-Lath. Syn. v. p. 50.5.

Habitat in Europas Afia, Africa.-Ultra 5 pedes longa.-Migratoria.-Victitat granis, ferpentibus, ranis.-In Anglia olim fatis frequens, hodie inter rariffimas numeratur. fero.

Mari tracbea fternum ingreditur, ibique varie inflectitur, ut in Cygno

$\beta$. A. occipite nudo papillofo rubro, corpore albo, collo inferiore remigibufque nigris.

Grus japonenfis, Brif. v. p. $3^{81}$. 9.-Id. 8 vo. ii. p. 309.-Klein. Av. p. I 2 I. 4.

Japan Crane, Lath. Syn. v. 42.

6.

Habitat in Faponia, Cbina, India.

americana. A. vertice nucha temporibufque nudis papillofis, fronte nucha remigibufque primariis nigris, corpore albo.

Ardea americana, Lin Syjt. i. p. 234. 5.-Gmel. Syft. i. p. 62 ז.

Grus americana, Brif. v. p. 382 . 10.-Id. 8 vo. ii. p. 309 .

Grue blanche d'Amerique, Buf. vii. p. 308.-Pl. Enl. $88 \mathrm{~g}$.

Hooping Crane, Catef. Car. i. t. 75.-Arct. Zool. $\mathrm{N}^{\circ}$ 339.-Id. Sup. p.

66. -Edw. t. 1 32.-Latb. Syn. v. p. 42. 6.

Habitat in America Septentrionali. $-4 \frac{x}{2}$ pedes longa.-Caput fubtus ad maxillam inferiorem rubrum eft: roftrum flavicans, apice ferratum : pedes nigri : rectrices candida.-Victitat infectis, mollufcis.-Ovum album.

7.

cinadenfis. A. fincipite nudo papillofo, corpore cinereo, alis extus teftaceis.

Ardea canadenfis, Lin. Syft. i. p. $234 \cdot 3 .-G m e l$. Syft. i. p. 620.

Grus freti Hudfonis, Brif. v. p. $3^{85}$. I1.-Id. 8 vo. ii. p. 310.

La Grue brune, Buf. vii. p 310.

Blue Crane, Pbil. Tranf. Ixii. p. 409.

Brown Crane, Arct, Zool. N $\mathrm{N}^{\circ} 340,-E d w$. t. 1 33.-Lath. Syn. v. p.43.7. 
Habitat in America feptentrionali.- $3^{\frac{\pi}{4}}$ pedes longa.-Migratoria.Vietitat fegetibus variis, infectis, vermibus.-Coro fapida : coput fuperius nudum, rubrum: dorfum, ale, fcapulares rufefcentes: fafcia alarum grifea.

ß. A. cinerea, capite fuperiore fubnudo rubro, remigibus majoribus nigris.

Grus mexicana, Brif. v. p. $380.8 .-I d$. 8 vo. ii. p. 309 .

- indica, Raii Syn. p. 95.2.-Will. p. 201.-Id. (Angl.) p. 275.Klein. Av. p. I 21.2.

Grue brune du Mexique, Buf. vii. p. 312.

\section{Habitat in Mexico.}

8.

Argala. A. cinerea, capite collo facculoque jugulari nudis, abdomine humerifque candidis.

Ardea dubia, Gmel. Sy,t. i. p. 624 .

Argill, or Hurgill, Ives Voy. p. I 83.

Boorong Cambing, Booring oolar, Marfd. Sumatr. p. 99.

Gigantic Crane, Lath. Syn. v. p. 45.-Id. Sup. p. 232. t. II 5.

Habitat in Africa, Afia.-5-7 pedes longa.--Monifrofa avis hæc forte omnium Ardearum maxima; gregaria; ad ora fluviorum regionis Bengalenfis fatis frequens; gulofa fpecies et omnivora, etiam ofla deglutiens et facile decoquens.

Roftrum album compreffum: riftus oris amplifimus : caput collumque fubnuda, rubra, pilis rarioribus obfita: in medio colli membrana conica, veficæ fimilis, rarius lanugine brevi confita : pedes nigri : remiges fufca: cauda pennis I2, tectricibus inferioribus lanuginofis, levif. fimis.

*** Ciconiæ: orbitis nudis.

9. A. alba, orbitis nudis remigibufque nigris, roftro pedibus cuteque fanguineis.

Ardea Ciconia, Lin. Syft. i. p. 235. 7.-Faun. Suec. $\mathrm{N}^{\circ}$ I 62.-Gmel. Syft. i. p. 622.-Scop. Ann。i. No $123 .-B r u n . N^{\circ}$ I $54 .-$ Muller, p. 22. - Faun. Arag. p. 76.-Raii Syn. p. 97. A. x.-Will. p. 210. t. 52. -Scbaf. El. t. 26.-Brif. v. p. 36.5. 2. t. 32.-Id. 8 vo. ii. p. 305. -Klein.Av. p. 125. 1.-Id. Ov. p. 34. t. 17. f. 2.-Borowe.Nat. iii. p. 78. 1.-Faun. Helvet.-It. Pojeg. p. 25 .

Cicogne. 


\section{A V E S G R A L L IE. Ardea.}

Cicogne blanche, Buf. vii. p. 253.t. 12.-Pl. Enl. 366.-Hift. Prov. i. p. $348 .-$ Voy. en Barb. p. 270.

White Stork, Arat. Zool. p. 455. C.-.Hafelq. Voy. p. 32.-Will. (Angl.) p. 286. t. 52.-Alb. ii. t. 64.-Tves Voy. pp. 299. 307.-Fryer. Tr. P. 25 I. -RuJ. Alep. p. 69.-Lath. Syn. v. p. 47.-Id. Sup. p. 234 .

Habitat in Europa, Aja, Africa.-Victitat amphibiis, reptilibus.Huic honos ferpentum exitio tantus, ut nefas occidere.-Migracoria.Rottro crepitat creberrimo mandibularum ad fe mutuo appulfu; quiefcit fuper unicum pedem, uti $A$. Grus: Ovum fordide ochroleucum.

10.

Maguari. A. alba, orbitis nudis coccineis, remigibus nigro-virefcentibus, tectricibus caudx fuperioribus nigris.

Ardea Maguari, Ginel. Syft. i.p. 623 .

Ciconia americana, Brif. v. p. $369.3 .-I d .8$ vo. ii. p. 305.-Klein. Av. p. $125 \cdot 3$.

Maguari, Raii Syn. p. 97.3.-Will. p. 21 1.-Id. (Angl.) p. 287.Buf. vii. p. 275 .

American Stork, Lath. Syn. v. p. 50. ro.

Habitat in America calidiore, præfertim in Brafilia.-Roftro crepitat ut præcedens.

I.

nigra. A. nigra, orbitis nudis, pectore abdomineque albo.

Ardea nigra, Lin. Syft. i. p. 235. 8.-Faun. Suec. $\mathrm{N}^{\circ}{ }_{1} 63 .-$ Gmel. Syft. $_{\text {. }}$ i. p. $623 .-S c o p$. Ann. i. $\mathrm{N}^{\circ}$ 124.-Brun. p. 46.-Muller, p. 22.Georgi reife. p. 17 1. - Borowelk. Nat. iii. p. 79.2.-Faun. Helvet.It. Pofeg. p. 25.

Ciconia nigra, Reii Syn. p. 37. 2.,Will. p. 2 I I. t. 52.-Klein. Av. p. 125. 2.-1d. Ov. p. 34. t. 18. 1.

Ciconia fufca, Brif. v. p. 362 . 1. t. 31.-Id. 8 vo. ii. p. 304.

Cicogne noire, Buf. vii. p. 271.-Pl. Enl. 399.-Dec. Ruff. ii. p. 77.

Aghiron nero, Cet. uc. Sard. p. 175.

Black Stork, ArEt. Zool. ii. p. 456. D. -Will. (Angl.) p. 286. t. 52.Alb. iii. t. 82.-Lath. Syn. v. p. 50. 11.

Haвгтат in Europa, $A f a$; alba rarior et minor; victitans ranis, pifcibus; migratoria.-Altifime volat, ut magnitudine pafferis fuperans non apparet.

Roftrum virefcens : pedes obfcure rubri: orbite nudæ: pennæ occipi- 
tis et fub collo longiores, corporis fuico-nigræ: collum et latera capitis I 2. azureo-nitentia. Ovum pallidi coloris.

bononien- A. nigricans, collo torque albo, roftro flavo, medio et apice macula

fis. nigra. Ardea bononienfis, Grnel. Syft. i. p. 639 .

Ardea nigra torquata, Brif. v. p. 440. 22.-Id. 8 vo. ii. p. 325 . Ardew congener, Raij Syn. p. 102. 19.-Will. p. 207. t. 50.-Id. (Angl.) p. 282 .

Collared Heron, Lath. Syn. v. p. 52. 12.

Habiтat circa Bononiam; Scol. arquate magnitudine.-Pedes nigri.

13. **** Ardeæ: ungue intermedio introrfum serrato.

Nyctico- A. crifta occipitis tripenni alba horizontali, dorfo nigro, abdomine flarax. vefcente. (Mas.)

Ardea Nycticorax, Lin. Syft. i. p. 235. 9.-Gmel. Syft. i. p. 624.-Scop。 Ann. i. No 1 16.-Kran. El. p. 347. 7.-Sepp. Vog. t. p. I $51 .-$ Brif. v. p. 493. 45. t. 39.-Id. 8vo. ii. p. 34t.-Raii Syn. p. 99. 3.-Will. p. 204. t. 49.-Faun. Arag. p. 76.-Borowfk. Nat. iii. p. 74. 2.-Faun. Helv.-Dec. Ruf. ii. p. 77 .

Ardea varia, Klein. $A v$. p. 123. 5.-Id. Stem. p. 29. t. 31. f. 1-4.-Id. Ov. p. 34. t. 18. f. 2 .

Ardea Kwaka, N. C. Petr. xv. p. 452 . t. 14.

Le Bihoreau, Buf. vii. p. 435. t. 12.-Pl. Enl. 758.-Pernet. Voy. ii. p. 26 .

Nitticorace, Cett.uc. Sard.p. 273.

Night Heron, Night Raven, Arct. Zool. ii. No 356.-Will. (Angl.) p. 279. t. 49.-Alb. ii. t. 67.-Ray's Trav. p. 38.-Lath. Syn. v. p. 52.-Id. Sup. p. 234 .

A. capite lævi fufco, corpore fufcefcente fubtus albo, remigibus primoribus apice macula alba. (Femina.)

Ardea grifea, Lin. Syft. i. p. 239. 22.-Gmel. Syf. i. p. 625.-Brif. v. p. 412 . 9. t. 36 . f. 1. $-I d$. 8 vo. ii. p. $317,-$ Faun. Helvet. $-D e c_{0}$ Ruff. ii. p. 146.-Sepp. Vog. t. p. 15 I. Bihoreau, la femelle, Pl. Enl. 759 .

Hавітат in Europa, Afia, America; in arboribus vel inter rupes nidificans. - Victitat pifcibus. -20 pollices longa. 


\section{A V E S G R A L L IE. Ardea.}

Mari frons fafcia alba : caput ufque ad medium colli nigrum: lora viridi-flavicantia, uti pedes : remiges rectricefque cinerex.

Femine vertex fufcus : crifta nulla: corpus grifeo-fufcum: collum fubtus linea ferruginea: remiges primores 18 apice macula alba : reEtrices albo marginatæ: lora alba : pedes fufci.

Hæc fpecies migratoria fluviorum et ftagnorum ripas frequentat; victitat pifcibus, reptilibus; infidet arboribus, in quibus etiam nidificat. Ovum albicans maculis tranflucentibus nonnullis rubentibus.

14. jamaicen- A. fubcriftata fufca, collo abdomineque fufco alboque ftriatis, tectricifis. Ardea jamaicenfis, Gmel. Syft. i. p. 625 . Jamaica Night Heron, Lath. Syn. v. p. 54. I4.

Haвттат in famaica.-Vix 2 ped. longa.

Rofrum nigro-fufcum: lora et orbit c nudæ virefcentes: gula crifJumque alba: remiges primores apice albæ. An diftincta a femina præcedentis?

15. caledoni-

ca.

A. fufco-ferruginea, fubtus fuperciliifque albis, vertice nigro, crifta occipitis tripenni alba.

Ardea caledonica, Gmel. syft. i. p. 626.

Caledonian Night Heron, Latb: Syn. v. p. 55. 1 5.-Cook's Voy. ii. p. I I I. t. 50 .

HABIT AT in nova Caledonia.-Roftrum nigrum: pedes Alavi.

Varietas forte maris Nycticoracis.

16.

obfcura. A. occipite criftato penna folitaria, corpore caftaneo fupra virefcente- aureo fubtus caftaneo albo ferrugineoque longitudinaliter liturato, remigibus apice macula alba.

Ardea obfcura, It. Pofeg. P. 24. t. ii.

Habitat in Sclavonia.-Statura et habitus fellaris.

Roffrum recurvum virefcenti-nigrum : occiput crifta dependente penna alba: frons, vertex, et nucba obfcure caftanea: dorfum et tectrices alarum obfcure caftaneæ atque aureo-virefcentes : collum fuperius caftaneoferrugineum; inferius et pectus abdomenque caftaneo albo ferrugineoque longitudinaliter liturata : remiges obfcurius caftaneæ apice macula aiba : xeEtrices caftanea: pedes breves, virefcentes. 
$680 \quad \triangle V E S G R \& L L E$. Ardea.

17.

cayanenfis. A. crifta fexpenni, corpore cæruleo-cinereo, dorfo ftriis nigris, capse nigro, pileo fáciaque fuboculari albis.

Ardea cayanenfis, Gmel. Syft. i. p. 626.

Le Bihoreau de Cayenne, Buf. vii. p. 439.--Pl. Enl. 899.

Cayenne Night Heron, Lath. Syn. v. p. 56. 16.

Haditat in Cayana.-2 I poll. longa.

Roffrum nigricans: lora virefcentia: crifta e pennis fex linearibus elongatis, quarumi tres albæ, tres nigræ: pennæ dor $f i$ et alarum medio longitudinaliter nigra: pedes flavi.

18.

ftellaris. A. capite lreviufculo, fupra teftacea maculis tranfverfis, fubtus pallidior maculis oblongis fulcis.

Ardea ftellaris, Lin. Syf. i. p. 239. 21.-Foun. Succ. No 164.-Gmel. Syft. i. p. 635.-Scop. Ann. i. No 125.-Brun. $\mathrm{N}^{\circ}$ 1 55.-Muller, p. 22.-Krom. El. p. 347.9.-Frifch. t. 205. - Georgi reife.p. 171 . -Sepp. Vog. t. p. 74.-Raii Syn. p. 100. A. 11.-IVill.p. 207. t. 50. 52.-Klein. Av. p. I23. 4.-Id. Sten. p. 29. t. 32. a. b. -Id. Ov. p. 34. t. 18. f. 3.-Fann. Arag. p. 76.-Borowej. Nat. iii. p. 76. 5.-Fanr. Helvet.

Botaurus, Brif. v. p. 444. 24. t. 37. f. r. -Id. 8 vo. ii. p. 327.

Le Butor, Buf. vii. p. 4 1 1. t. 21.-Pl. Enl. 789.-IIif. Prov. i. p. 349. Garza bionda o di color d'oro, Zinnan. Uov.p. I I2. t. 20 . f. 100.

Tarabufo, Cet. uc. Surd. p. $2 ; 4$.

Bittern, Br. Zool. ii. No $174 .-I d$. fol. 7 I 1. t. A. r.-Will. (Angl.)

p. 232.-Alb. i. t. 68.-Hayes Br. Bira's, t. i 9.-Latb. Syn. v. p. 56. 17.-Id. Sup. p. 234.

HABita] ubique in Eurcpe et Afie paludibus; victitans pifcibus, reptilibus. - Venatus olim falconum ope magnatibus placuit.-Mugitus fentorii impares; terrefacta fpiraliter athera fcandit - In terra nidificat inter arundines; ova 4-5 cinereo-virefcentia, feu aquæ lutofæ coloris, pariens.

Roftrum fubtus virefcens: pecies virides : lora viridia.

B. Botaurus freti Hudfonis, Brif. v. p. 449. 25.-Id. 8 vo. ii. p. 328. Buf. vii. p. 430 .

Hudfon's Bay Bittern, Edw. t. I 36.-Pbil. Tranf. Ixii. p. 410.-Lath. Syn. v. p. 58.-ArEz. Zool. ii. $N^{\circ} 357 .-$ Id. Sup. p. 67.

Habitat in America Septentrionali.-Nifi corpore minore, et colore pennarum faturatiore, vix a priore difcrepans.

A. nigricans, 
19.

folonienfis, A. nigricans fubtus rufefcens, capite colloque ferrugineis, uropygio albo, tectricibus alarum albo ferrugineoque variegatis.

Ardea folonienâs, Gmel. Syft. i. p. 637 .

Botaurus rufus, Brif. v. p. $45^{8}$. 29. $-I d$. 8 vo. ii. p. 330.

Ardeæ ftellaris tertium genus, Raii Syn. p. 100. 12.-Will. p. 208. Id. (Angl.) p. 283 .

Le Butor roux, Buf. vii. p. 425.

Quoimeau, Salern. Orn. p. 315.

Rufous Bittern, Latb. Syn. v. p. 60. I 9.

HaBitat in Italia, circa Bononiam.

20.

Marfigli. A. rufefcens fufco ftriata, rectricibus albicantibus, collo fubtus albo,

Ardea Marfigli, Gmel. Syft. i. p. 637 .

Botaurus minor, Brif. v. p. 452 2. 26.-Id. 8 vo. ii. p. 329.

Le petit Butor, Buf. vii. p. 425 .

Ardea viride-flavefcens, Klein. Av. p. I 24. I3.

Swabian Bittern, Lath. Syn. v. p. 60. 20.

Habitat ad ripas Danubii; fellari minor.-Lora pedefque flavi.

2 I.

danubialis. A. lineolis fufcis nigris et rufefcentibus ftriata, collo fubtus pectoreque albicantibus, roftro fufco fubtus flavo.

Ardea danubialis, Gmel. Syft. i. p. 637.

Botaurus ftriatus, Brif. v. p. 454. 27.-Id. 8 vo. ii. p. 329.

Le Butor brun rayé, Buf. vii. p. 424 .

Rayed Bittern, Lath. Syn. v. p. 61. 2 I.

HABITAT cum præcedente.

22.

undulata. A. rufo-grifea, pileo nigro, corpore fupra ftrigis undulatis fubtus angulatis nigris.

Ardea undulata, Gmel. Sygt. i. p. 637.

Le petit Butor de Cayenne, Buf. vii. p. 430.-Pl. Enl. 763 .

Zigzag Bittern, Latb. Syn. v. p. 61. 22.

HaBITAT in Cayana.-1 3 poll. longa.-Pulcherrima fpecies.

Roftrum fufcum: pedes flavi.

brafilienfis. A. capite lævi, corpore nigricante flavo punctato, remigibus reetricibus roftro pedibufque nigricantibus.

$4 \mathrm{~S}$

Ardea 
Ardea brafilienfis, Lin. Syft. i. p. 239. 23.-Gmel. Syft. i. p. 637.-Brif. v. p. 44 I. $23 .-I d$. 8 vo. ii. p. 326.

Soco, Raii Syn. p. 100. 14.-Will. p. 209. t. 5 I. -Id. (Angl.) p. 284. L'Onoré de Bois, Buf. vii. p. 433.

Clucking Hen, Brown. Jam. p. 478.-Damp. Voy. iii. part r. p. 75 .

Brafilian Bittern, Lath. Syn. v. p. 62. 23.-Brown. Ill. p. 88. t. 34.Gent. Mag. xxxiv. t. p. 209.

Haвiтat in Brafilia. -2 pedes 8 pollices longa.

Collum fubtus album maculis longitudinalibus nigris fufcifque : roftrum nigrum: pedes fufci.

24.

tigrina.

A. maculis nigris difformibus notata fupra rufa lubtus albida, vertice caudaque nigris, rectricibus fafciis quatuor albis.

Ardea tigrina, Gmel. Syft. i. p. $63^{8}$.

Heron tigré, Ferm. Surin. ii. p. 1 5 I.

L'Onoré, Buf. vii. p. 43 r.-Pl. Enl. p. 790.

Tiger Bittern, Latb. Syn. v. p. 63. 24 .

Habitat in Cayana, Surinamo.-2 pedes 6 poll. longa.

Roftrum rubro-virefcens: gula collique latera rufefcentia maculis nigris: pedes flavi.

25. lineata.

A. flavo fufco rufoque tranfverfim lineata fubtus albida, capite colloque rufis fafciolis fufcis, anterius linea longitudinali alba. Ardea lineata, Gmel. Syft. i. p. 638 .

L'Onoré rayé, Buf. vii. p. 432.- Pl. Enl. 860.

Lineated Bittern, Lath. Syn. v. p. 64. 25.

Habitat in Cayana, ad fluviorum ripas.

Roftrum loraque cærulefentia : pedes flavi: remiges rectricefque nigræ: linea colli anterioris alba, maculis nigris utrinque marginata.

26.

flava. A. Atriata fupra fufca fubtus alba, capite colloque rufefcentibus, rectricibus ftriis tranfverfis albis.

Ardea flava, Gmel. Syjt. i. p. $63^{8}$.

Botaurus brafilienfis, Brif. v. p. 460 . 30.-Id. 8 vo. ii. p. 331 .

Ardea brafilienfis roftro ferrato, Raii Syn. p. 101. 16.-Will. p.20g.Id. (Angl.) p. 285 .

Le. Butor jaune du Brefil, Buf. v. p. 460.

Yellow Bittern, Lath. Syn. v. p. 64. 26. 


\section{A V E S G R A L L E. Ardea.}

Habitat in Brafilia. -2 ped. 3 poll. longa.-Caro fapida.

Caput et collum fupra pennis longiufculis pallide flavis, nigro undulatis : collum fubtus pectus et abdomen imum alba fufco undulata : dorfum et ale fufcæ flavo undatæ: rectrices albo tranfverfim lineatz.

27.

minuta. A. capite lævi, vertice dorfo remigibus rectricibufque nigro-rirefcentibus, collo tectricibus alarum abdomineque pallide fulvis. (Mas.) Ardea minuta, Lin. Syft. i. p. 240. 26. 3.-Gmel. Syft. i. p. 646.-Kram. El. p. 348. 10.-Frijch. t. 206. 207.-Sepp. Vog. t. p. 57.-Borowejk. Nat. iii. p. 77.6.

Ardeola, Brif. v. p. 497.46 . t. 40 . f. r. $-I d .8$ vo. ii. p. 341 .

Le Blongios, Buf. vii. p. 395.-Pl. Enl. 323 .

Boo-onk, Long Neck, Shaw's Tr. t. p. 255.-RuJ. Alep. p. 7 r. to 10. -Edw. t. 275.-Gent. Mag. xix. t. p. 497.

Little Bittern, Br. Zool. App. p. 663. t. 8.-Arit. Zool. ii. No 359.Latb. Syn. v. p. 65. 27.-Id. Sup. p. 235.

A. capite lævi, corpore fufco, marginibus pennarum rufefcentibus, fubtus rufefcente, vertice dorfo remigibus caudaque nigris. (Femina.) Ardea minuta, Lin. Syft. i. p. 240. 26.-Faun. Helvet. Ardeola nævia, Brif. v. p. 500.47 t. 40. f. 2.-Id. 8 vo. ii. p. 342. Le Blongios tacheté, Buf. vii. p. 395 .

Little Bittern, Latb. Syn. v. p. 66.-Edw. t. 275.

Habitat in Europa, Afia, rariffime in Anglia.-1 5 pollices longa. Roftrun et pars nuda faciei flava: irides croceæ: pedes viridi-fufci. In terra nidificat. Ovum album.

28.

pumila. A. caftanea, tectricibus alarum mediis albo flavoque variis, collo antice ftria longitudinali abdomine caudaque albis.

Ardea pumila, N. C. Petr. xiv. p. 502. t. 14. 1.-Gmel. Syft. i. p. 644. Dwarf Heron, Latb. Syn. v. p. 77. 42.

Habitat ad mare Cajpium. -19 pollices longa.

Roftrum nigrum fubtus flavum : lora et irides flavæ: pedes nigricantes.

29. exilis.

A. rufo caftanea, collo rufo, antice abdomineque albo, lunula pectorali remigibus rectricibufque nigris. Ardea exilis, Gmel. Syft. i. p. 645 . Minute Bittern, Latb. Syn. v. p. 66. 28. 
HaBITAT in Famaica et America Septentrionali; fpecierum adhue notarum minima, vix corpore Turdum excedens. - I I , pollices longa.

Rofrum virefcens: irides pallide flavæ: vertex rufo-caftaneus : colluw anterius medio album, lateribus nigro ftriatum : pecius fufco-nigricans verfus dorfum utrinque extendens: tectrices alarum intermiedia 30. ferrugineæ lineis nigris : pedes virides.

fenegalen- A. fufca, abdomine alis caudaque albis, capite colloque nigro ftriatis,

fis. alarum medio fafcia longitudinali pallide rufa.

Ardea fenegalenfis, Gmel. Syft. i. p. 645 .

Le petit Butor du Senegal, Buf. vii. p. 4.26.

Petit Heron roux du Senegal, $P l$. Enl. 3 I 5 .

Senegal Bittern, Latb. Syn. v. p. 67. 29.

Habitat in Senegalo.- 12 pollices longa.

Roftrum fufcum : pedes flavi : pennæ colli laxæ totæ rufæ.

$3 \mathrm{r}$.

virefcens. A. occipite fubcriftato, dorfo viridi-nitente, pectore rufefcente, loris luteis, rectricibus viridi-aureis. (Mas.)

Ardea virefcens, Lin. Syft. i. p. 238. 20.-Gmel. Syft. i. p. 635 .

- ftellaris minima, Klein. Av. p. 123.6.

Cancrofagus viridis, Brif. v. p. 486 . 43 . t. 37 . f. r. $-I d .8$ vo. ii. p. 339. Le Crabier verd, Buf. vii. p. 404 .

Small Bittern, Cat. Car. i. t. 80.

Green Heron, Latb. Syn. v. p. 68. 30.

A. fufca viridi-aurea, corpore fubtus albido, collo rufefcente albo ftriato, tectricibus alarum remigibufque albo maculatis. (Femina.)

Cancrofagus viridis nævius, Brif. v. p. 490 . t. 38. f. 2.

Le Crabier verd tacheté, Buf. vii. p. 405.-Pl. Enl. 9i 2.-Latb. Syn. v. p. 68 .

Haвiтat in America calidiore infulifque vicinis. -18 pollices longa.

Roftrum fubtus flavicans: pedes fufco-flavi: vertex nigro-virefcens. Victitat ranis, pifciculis. Arboribus infidet.

Nias remigibus viridi-aureis, fecundariis ferrugineo marginatis.

Femine vix criftata, tectricibus alarum apice maculis rufo-albis triquetris; gulia alba maculis nigris.

B. A. criftata cinerea, collo antice albo ftriis rufis, tectricibus alarum virefcentibus rufo marginatis, vertice caudaque nigris. 
A V E S R A L L \#. Ardea.

Le Crabier gris à tête et que vertes, $B u f$. vii. p. 408 . de Cayenne, Pl. Enl. g03.-Latb. Syn. v. p. ho. 30. A.

HaBiтAт in Cayana.-Roftrum nigrum: pedes flavi : vertex et crifta nigro-virefcens.

$\gamma$. A. fufca fubtus dilutior, alis albo punctulatis, remigibus rectricibufque cxrulefcenti-cinereis.

Ardea fufca, Klein. Av. p. 124. 8.

Botaurus americanus nævius, Brif. v. p. $464 \cdot 32 .-I d$. 8 vo. ii. p. 332 . Ardea Atellaris minor, Raii Syn. p. 189.4 - -Sloan. Fam. p. 31 5. t. 236. f. 2.

L'Etoilé, Buf. vii. p. +28 .

Crab-caicher, Brown. Fam. p. 478.

Brown Bittern, Cat. Car. i. t. 78.-Latb. Syn. v. p. 70.

32.

HaBITAT in Famaica.

Gardeni. A. nigricans albo maculata fubtus albida fufco ftriata, remigibus margine apiceque albis, cauda fufca.

Ardea Gardeni, Gmel. Syft. i. p. 645 .

Botau us nævius, Brif. v. p. 462 . 31. $-I d$. 8 vo. ii. p. 332.-Frifch. ii.

t. 9 .

Butor tacheté, ou Pouacre, Buf. vii. p. 427.-Pl. Enl. 939.

Spotted Heron, Lath. Syn. v. p. 70. 31.

Gardenian Heron, Latb. Syn. v. p. 7 1. 32.-Arct. Zool. ii. N' 355.

33.

HABITAT in Carolina, Cayana.-1 8-22 pollices longa.

cyanopus. A. cinerea fubtus alba, remigibus partim nigris partim candidis, roftro: loris pedibufque creruleis.

Ardea cy.anopus, Gmel. Syft. i. p. 644 .

Ardea americana cinerea, Brif. v. p. $406.6 .-I d$. 8 vo. ii. p. 3 I6.

Le Crabier cendré, Buf. vii. p. 401 .

Cinereous Heron, Latb. Syn. v. p. 7 1. 33.

Habitat in America.-Cornice paulo major.

34.

novæ Gui- A. corpore toto nigro, iridibus flavis, roftro pedibufque fufcis.

neæ. Ardea novæ Guineæ, Gmel. Sy/t. i. p. 644 .

Crabier noir de la nouvelle Guinée, Pl. Enl. 926.-Buf. vii. p. 394.

New Guinea Heron, Lath. Syn. v. p. 7 1. 34.

HABITAT in nova Guinea.-Io pollices longa. - Irides flavæ.

A. caftanea 
philippen- A. caftanea fubtus albida, dorfo ftriis tranfverfis nigris, tectricibus ala-

fis.

36.

Squaiotta. A. criftata caftanea, pennis fcapularibus bafi albis, crifta medio alba lateribus nigra.

Ardea fquaiotta, Gmel. Syft. i. p. 634 .

Cancrofagus, Brif. v. p. 466. 33.-Id. 8vo. ii. p. 333 .

Squaiotta, Raii Syn. p. 99. 9.-Will. p. 207. t. 50.-Id. (Angl.) p. 28 r. Le Crabier Caiot, Buf. vii. p. $3^{8}$ g.

Squaiotta Heron, Lath. Syn. v. p. 72. 36 .

HABITAт in Italia, circa Bononiam.-1 8 pollices longa.

Crifta capitis e 30 pennis conftat, quarum qux medium locum tenent funt candidæ, qua vero ad latera politæ funt, nigræ.

37.

badia.

A. caftanea fubtus albida, tectricibus alarum cærulefcentibus, pedibus rubris.

Ardea badia, Gmel. Syft. i. p. 644 .

Cancrofagus caftaneus, Brif. v. p. 468 . 34. $-I d$. 8 vo. ii. p. 334 .

Le Crabier roux, Buf. vii. p. 390.

Chefnut Heron, Latb. Syn. v. p. 73. 37 .

Hавітат in Silefia.-Arboribus nidificat.-Cornicis magnitudine.

Roftrum fufcum : ftriga candida a gula ad peztus : remiges nigra.

$3^{8 .}$ erythropus.

A. criftata croceo-caftanea fubtus faturatior, roftro cæruleo, pedibus rubris.

Ardea erythropus, Gmel. Syft. i. p. 634 .

Cancrofagus rufus, Brif. v. p. $469.35 .-I d$. 8 vo. ii. p. 334 .

Ardea hæmatopus, feu Cirris, Raii Syn. p. 99. 7.-Will. p. 206. t. 50.

-Id. (Angl.) p. 281 . t. 50.

Le Crabier marron, Buf. vii. p. 390.

Red-legged Heron, Lath. Syn. v. p. 73. $3^{8}$.

Habitat circa Bononiam; virefcentis magnitudine.

$\beta$. Cancrofagus 
$\beta$. Cancrofagus rufus nævius, Brif. v. p. 47 I. $36 .-I d$. 8 vo. ii. p. $335^{\circ}$ Lath. Syn, v. p. 74.

A priore variat collo lateribus maculato, pedibus lutefcentibus.

39.

comata. A. criftata luteo-rufefcens, uropygio corpore fubtus alis caudaque aibis.

Ardea comata, Pall. reife. ii. p. 7 I 5. 31.-Gmel. Syft. i. 632.-It. Pofeg. p. 24 .

Cancrofagus luteus, Brif. v. p. 472 . 37.-Id. 8 vo. ii. p. 335 .

Sguacco, Raii Syn. p. 99. 8.-Will. p. 206.-Id. (Aingl.) p. $381 .-$ Buf. vii. p. 39 I.

Crabier de Mihon, Euf. vii. p. 393.-Pl. Enl. 348.-Fain. Helvet. Squacco Heron, Lath. Syn. v. p. 74. 39.

Habitat in Europa, Afia, circa maris Cafpii finus, et ad aquas pigras deferti auftralioris fatis frequens; minut e magnitudine.

Roftrum pedefque flavi : criffa e pennis valde elongatis albis nigro marginatis.

ß. A. alba, capite fuperiore cervice pectore dorfoque rufefcentibus, capite lavi.

Crabier de Coromandel, Buf. vii. p. 393.-Pl. Enl. 9.12.-Latb. Syn v. p. 75. 39. A.

Habitat in Coromandela.-An fexus alter præcedentis?

$\boldsymbol{\gamma}$. A. fronte colloque albido teftaceo nigroque ftriatis, alis teftaceis, uropygio abdomine femoribufque albis.

Ardea comatæ fimillima, It. Pofegani. p. 24.

Habitat in Pofegana; comate magnitudine et habitu.

Roftrum album apice nigrum: caput læve : frons et collium fupra infraque e pennis ex fordide albo in dilute teftaceum vergentibus, nigro marginatis : rectrices albæ, 2 intermediæ apice dilute teftacea. An folo. fexu a comata diverfa?

40.

eaftanea. A. criftata alba, lateribus capitis colloque caftaneo-flavis, dorfo caftaneo, remigibus intus rectricibus apice albo maculatis.

Ardea caftanea, N. C. Petr. xv. p. 454 . 9. t. 15.-Id. reife. iii. p. $253^{\circ}$ -Gmel. Syft. i. p. 633.-Dec. Ruf. i. p. 164. 
Ardea ralloides, Scop. Ann. i. $N^{\circ} 121$.

Caftaneous Heron, Latb. Syn. v. p. $75 \cdot 40$.

Haвiтat in Europa, Afac-22 pollices longa.

Roftrum bafi lividum, apice fufcum : lora virefcentia : crifta alba plumis margine fufcis : corpus compreffum ut in Rallis : lana flava, fericea ad hypochondria, certo anni tempore fuavem odorem fpirans: pedes croceo-rubri. An varietas comate?

$4 \mathrm{~T}$.

ferruginea. A. fubcriftata nigricans rufo maculata, fubtus rufo albido cinereo fufcoque variegata.

Ardea ferruginea, N. C. Petr. xv. p. 456. t. 16.-Gmel. reife. iii. p. 253.-Gmel. Syft. i. p. 634 .

Ferrugineous Heron, Lath. Syn. v. p. 76. 41.

Habitat in Europa, Afia, circa fluvium Tanaim fatis frequens; in arboribus nidificans. $-2 \mathbf{r}$ pollices longa.-Victitat pifcibus, infectis.

Roftrum pedefque virefcentes.

42.

torquata. A. occipite nigro criftato, dorfo fufco, collo et abdomine fordide albis, pectore nigro, lunulis flavefcentibus.

Ardea torquata, Mill. Ill. t. 36.-Gmel. Syft. i. p. 624.

$\mathrm{H}_{\mathrm{ABj}} \mathrm{T} \mathrm{T}$ in America meridionali.

43.

erythroce- A. occipitis crifta dependente rubra, corpore albo.

phala. Ardea erythrocephala. Molin. Cbil. p. 207.-Id. (ed. Gall.) p. 215.Gmel. Syst. i. p. 633 .

Навіт ат in regno Cbilenfi; cinerea magnitudine.

Crifta ad dorfum ufque elongata.

44.

Thula. A. occipitis crifta et toto corpore albis.

Ardea Thula, Molin. Cbil. p. 208.-Id. (ed. Gall.) 214.-Gmel. Syft. i. p. 633 .

Habitat in regno Cbilenfi.

45.

cyanocephala.

A. vertice criftato dorfoque cæruleis, alis nigris margine albis. Ardea cyanocephala, Molin. Cbil. p. 208.-Id. (ed. Gall.) p. 214.Gmel. Syft. i. p. 633 . 
A V E S. GR A L L E. Ardea.

Habitat in Cbili.-Roftrum nigrum: abdomen viridi-flavefcens: 46. cinnamo-

mea. cauda viridis: pedes flavi.

A. caftaneo-cinnamomea, collo antice fufco ftriato, gula macula maxillari criffoque albis.

Ardea cinnamomea, Gmel. Syft. i. p. 643 .

Cinnamon Heron, Lath. Syn. v. p. 77. 43.-Id. Sup. p. 235.

Habitat in China, India.-Magnitudo A. virefcentis.

Roftrum pedefcue flavi : cauda corpore obfcurior.

47.

malaccen- A: alba, dorfo fufco, collo fufco alboque triato, roftro pedibufque fis. flavis.

Ardea malaccenfis, Gmel. Syft. i. p. 643 .

Crabier blanc et brun de Malacca, Buf. vii. p. 394.-Pl. Enl. 9 I r.

Malacca Heron, Lath. Syn. v. p. 78. 44.

48.

Habitat in India, Malacca.-19 poll. longa.-Lora grifea.

cærulea. A. occipite criftato, corpore cæruleo, crifta colloque violaceis.

Ardea cærulea, Lin. Syjt. i. p. ${ }^{2} 38$. 17.-Gmel. Syft. i. p. 63 i.-Brif. v. p. 484. 42.-Id. 8vo. ii. p. 338.-Roii Syn. p. 189. 3.-Sloan。 fam. ii. p. 3 I 5. t. 263 . f. 3 .

Ardea plumbea, Brown. Fam. p. 478.

- cyanea, Klein. Av. p. x 24. 7.

Le Crabier bleu, Buf. vii. p. $39^{8}$.

Blue Heron, Latb. Syn. v. p. 78. 45.-Arit. Zool. ii. No 35 I.-Catef. Car. t. 76 .

Habitat in Carolina, famaica, et infulis maris Pacifici.-I 8 pollices longa.-Roftrum et lora cærulea : pedes virides.

Femina capite colloque obfcure purpureis; gula et jugulo medio albo; capite fubcriftato; dorfo plumbeo.

B. A. fubcriftata viridi-cærulea, gula juguloque albis.

Blue Heron, Latb. Syn. v. p. 79. 45. B.

Habitat in $N$. Zealandia.-i 8 pollices longa.

Roftrum, irides, pedefque flava.

$\boldsymbol{\gamma}$. A. fufco flavo cinereoque varia, fupra nigro-chalybea fubtus alba, remigibus rectricibufque virefcentibus.

$4 \mathrm{~T}$

Cancrofagus 
690

A VES G R A L L $\mathbb{E}$. Ardea.

Cancrofagus brafilienfis, Brif. v. p. 479. 40.-Id. 8 vo. ii. p. 337. Ardeola brafilienfis, Raii Syn. p. IOI. 18.-Will. p. $210 .-I d$. (Angl.) p. 285 .

Le Crabier chalybé, Buf. vii. p. 404. Blue Heron, Latb. Syn. v. p. 80. C.

HaBitat in Brefflia; Columbe magnitudine.-16 pollices longa. alba.

Roftrum fubtus album : lora pedefque flavi : remiges ad apicem macula

49.

creruler.

cens.

A. criftata, corpore obfcure cæruleo, capite colloque fufco-rufis, occipite pennis duabus elongatis.

Le Crabier bleu à cou brun, Buf. vii. p. 399.

Heron bleuâtre de Cayenne, Pl. Enl. 349 .

Blue Heron, Latb. Syn. v. p. 79. 45. A.

Habitat in Cayana.- 19 pollices longa.

Roftrum luteum : lora rubra : pedes fufci.

50.

violacea. A. occipite luteo. crifta alba, corpore albo nigroque ftriato fubtus cærulefcente, pedibus luteis.

Ardea violacea, Lin. Syft. i. p. 238. 16.-Gmel. Syft. i. p. 63r.

- ftellaris criftata americana, Klein. Av. p. I24. 9 .

Cancrofagus bahamenfis, Brif.v. p. 48r. 4I.-Id. 8vo. ii. p. 337 .

Ardea cæruleo-nigra, Raii Syn. p. 189. 3.-Sloan. Fam. ii. p. 314. t. 264. f. 5 .

Le Crabier gris-de-fer, Buf. vii. p. 399.

Grey-crefted Gaulding, Brown. Fam. p. 478.

Crefted Bittern, Catef. Car. i. t. 79 .

Yellow-crowned Heron, Lath. Syn. v. p. 80. 46.-Arct. Zool. ii. $\mathrm{N}^{\circ} 352$.

HaвítAт in Carolina, Famaica, Babamenfibus infulis numerofifima. -I 5 pollices longa.-Nidificat in fcopulis et inter arbufta.-Caro fapida. -Victitat cancris.

Rofrum nigrum : lora viridia : pedes lutei.

5 I.

Iudovicia- A. criftata cinerea, collo abdomineque rufis, vertice alis caudaque vi-

na, ridi-nigricantibus.

Ardea ludoviciana, Gmel. Syft. i. p. 630 .

Le Crabier roux à tête et queue vertes, Buf. vii. p. 407.

Crabier de la Louifiane, Pl. Enl. 909.

Louifiane Heron, Lath. Syn, v, p. 8I. 47.-ArE7. Zool. ii, $\mathrm{N}^{\circ} 350$.

HaBITAT 
A V E S G R A L L 2 A. Ardea. 6gr

Habitat in Louifiana.- 16 pollices longa.

Lora pedefque flavi : tectrices alorum fulvo marginatæ : remiges majo52. res apice albæ : collum antice albidum rufo ftriatum.

ftriata. A. occipite fubcriftato, dorfo cano ftriato, collo fubtus ferrugineo, re. migibus fecundariis apice albis.

Arcea ftriata, Lin. Syft. i. p. 238. 19.-Gmel. Syfl. i. p. 634.-Dec。 Ruf. ii. p. 146 .

Heron of Guiana, Bancr. Guian. p. 171 .

Striated Heron, Lath. Syn. v. p. 82. 48.

HabiтAт in Guiana, Surinamo; cinerea magnitudine.

53. caruncu-

lata.

54.

cinerea. A. occipite crifta nigra dependente, corpore cinereo, collo fubtus linea fafciaque pectorali nigris. (Mas.)

Ardea major, Lin. Syft. i. p. 236. 12.-Gmel. Syft. i. p. 627.-Scop. Ann。 i. $\mathrm{N}^{\circ}$ I $17 .-\mathrm{Kram}$. El. p. 346.4.-Frifcb. t. 199.-Raii Syn. p. 98. A. r.-Will. p. 203. t. 49.-Faun. Helvet.

Ardea criftata, Brif. v. p. 396. 2. t. 35.-Id. 8vo. ii. p. 313.-Klein. Av. p. 122. 2.-Id. Stem. p. 28. t. 30.-Id. Ov. p. 34. t. $17 . \mathrm{f}_{0} 3$. -Molin. Cbil. p. 207.-Id. (ed. Galli) p. 214.

Le Heron huppé, Buf. vii. p. 342.-Pl. Enl. 755.

Garza cinerizia grofla, Zinnan. Uov. p. I I 3. t. 2 I. f. IOI.

Crefted Heron, Alb. i. t. 67.

Common Heron, (male.) Lath. Syn. v. p. 83. 50.-Br. Zool. ii. N'173. -Id. fol. i r6. t. A.-Arct. Zool. ii. No 343 -Chefeld. Ofteog. Intr. ad finem. (Scelet.)

A. occipite nigro lævi, dorfo cærulefcente, fubtus albida, pectore maculis oblongis nigris. (Femina.)

Ardea cinerea, Lin. Syjt. i. p. 236. I I.-Faan. Suec. $\mathrm{N}^{\circ}$ I65.-Scop. $4 \mathrm{~T}_{2}$ Ann. 
Ann. i. $\mathrm{N}^{\circ}$ i 17.-Brun. $\mathrm{N}^{\circ}$ 156.-Muller, p. 22.-Frijcb. t. ig8. -Brif. v. p. 392. r. -Id. 8 vo. ii. p. 312.-Klein. Av. p. 122. I. -Borowefk. Nat. iii. p. 75. 4.-Faun. Helvet.-Scbaf. El. Orn. t. 2 t. Ardea thenana, Naturf. xiii. p. I95.

Heron, Buf. vii. p. 342. t. I9.-Pl. Enl. 787,-Defcr. Surin. ii. p. 15. I. - Hijt. Prov. i. p. 346 .

Reiger, Guntb. Nef. u. Ey. t. 44.

Common Heron, (fem.) Lath. Syn. v. p. 83.-Br. Zool. ii. $\mathrm{N}^{\jmath}$ 173. to

6r.-Id. fol. I 16.-ArEt. Zool. ii. No 343.-Alb. iii. t. 78.

Habitat in omnibus terris. -3 ped. 3 poll. longa.-In. Anglia: frequens et bene nota.

Roftrum favicans : lora flavicantia : pedes virefcentes.-Nidificant in arboribus plures fimul.

Mas crifta verticis nigra, poftice propendente, fronte pennis longis albis : collum fubtus nigro maculatum : pennæ dorfi elongatæ, laceræ.

Femine coput fubcriftatum, grifeum: pennæ dorfi. minus elongatæ, vix laceræ. Ovun aquæ marinæ colorem refert.

55.

xufa. A. cinereo-fufca fubtus caftaneo-ferruginea, crifta dependente. Ardea rufa, Scop. Ann. i. No 1 19.-Kram. El. p. 347.6.-Gmel. Syft. i. p. 642 .

Rufous Heron, Latb. Syn. v. p. 99. 72.

Habit at in Aufria, juxta paludes; rarius.-Vieticat pifcibus.

Nigra funt caput, crifta, abdomen, caude, remiges primæ: pectus rufum : ftria nigra ab oculo fingulo ad nucham : tempora ferruginea : colli bafis albida fufcis maculis varia: fupra dorfum ale fufco-cinerex: fomora ferruginea : pedes fufci.

variegata。 A. ferruginea fufco maculata fubtus pallidior, fronte nigra, gula alba. Ardea variegata, $S c o p$. Ann. i. № 120 .

Femora rufa : pedes fufci.

56.

Herodias. A. occipite criftato, dorfo fufco, femoribus rufis, pectore maculis oblongis nigris.

Ardea Herodias, Lin. Syyt. i. p. 237. 15.-Gmel. Syft. i. p. 630.-Scop. $A n n$. i. $\mathrm{N}^{\circ}$ II 8.

Ardea virginiana criftata, Brif,v, p. 416. 10,-Id. 8vo, ii, p. 318.Kleim, Av, p. 125,14 . 


\section{A V E S G R A L L F, Ardea.}

Le grand Heron d'Amerique, Buf. vii. p. $3^{8} 5$.

Largeft crefted Heron, Cat. Car. App. t. Io. f. I.

Great Heron, Arct. Zool. ii. N $\mathrm{N}^{\circ}$ 341.-Latb. Syn. v. p. 85. $5 \mathrm{r}$.

Habitat in America Septentrionali.-Ultra 5 pedes longa.

Capitis pennæ longiffimæ nigræ, unde poftice crifta evadit: collum fubtus albido-teftaceum : corpus fupra fufcum : roftri latera et lora fla. 57. vicantia: pedes fufci: remiges nigræ: rectrices fufcæ.

hudfonias. A. vertice criftato nigro, corpore fufcefcente fubtus albido, collo fúbtus nigro-rufefcente maculato.

Ardea hudfonias, Lin. Syft. i. p. 238. 1 8.-Gmel. Syft. i. p. 632.

- freti Hudfonis, Brif. v. p. 407: 7.-Id. 8 vo. ii. p. 3 I6.

Heron de la baie de Hudfon, Buf. vii. p. $3^{86 .}$

Afh-coloured Heron, Edw. t. 135 .

Red-fhouldered Heron, ArEt. Zool. ii. No $342 .-$ Lath. Syn. v. p. 86. 52.

Haвiтat cum præcedente, et paulo minor.

Capitis pileus niger criftatus: collum fubtus fufcum faturatius fafciatum : corpus fupra cinereo-fufcum fubtus albidum : femora rufefcentia : rectrices fufcæ: roftrum fubtus fulvum: lora flavo-virentia: pedes flavi. An Herodia femina?

58.

rubiginofa.

A. fubcriftata ferruginea, gula alba, abdomine albo nigro ftriato, collo fubtus lineis quatuor nigris.

Ardea rubiginofa, Gmel. Syft. i. p. 632 .

Rufty-crowned Heron, ArEt. Zool. ii. No 358,-Lath. Syn. v. p. 87. 53.

Haвiтат in America Septentrionali--Magnitudo fellaris.

Roftrum pedefque lutei : lineæ colli inferioris 4 e maculis nigris : dor a sum fparfim nigro maculatum : cauda plumbea.

59.

59. A. cinerea, collo fufco-cinerafcente, abdomine genis gulaque albis. Ardea cana, Gmel. Syft. i. p. 643 .

Afh-coloured Heron, Arct. Zool. ii. $\mathrm{N}^{\circ}$ 353.-Lath. Syn. v. p. 87. 54.

Habitat in America.-Roftrum nigrum: pedes flavefcentes.

60.

virgata. A. fufco-nigricans, collo fubtus albo, jugulo nigro ftriato, tectricibus: alarum flavefcente ftriatis. Ardea virgata, Gmel. Syjt. i. p. 643 .

Streaked Heron, ArEt. Zool. ii. No $354 .-L a t h . ~ S y n . v . ~ p .87 .55$. 
$6 \mathrm{I}$.

Habitat in America Septentrionali.-17 poll. longa.-Corpus gracile.

Variat linea fubmaxillari alba, pennis fcapularibus tectricibufque alarum albo maculatis. An femina?

rufefcens. A. cinereo-nigricans, capite collo dorfoque poftico fulvo-rufis.

Ardea rufefcens, Gmel. Syft. i. p. 628.

L'Aigrette rouffe, Buf. vii. p. 378.-Pl. Enl. 902.

Reddifh Egret, Ariz. Zool. ii. No 348. -Lath. Syn. v. p. $88.5^{6 .}$

HABIтAт in Louifiana. -2 fere pedes longa.

Roftrum flavum, apice pedibufque nigricantibus : pennæ dorfi poftici elongatæ rufa, cauda multo longiores.

62.

leucogaf- A. criftata cæruleo-nigricans, alis fubtus abdomine femoribufque albis.

ter. Ardea leucogafter, Gmel. Syft. i. p. 628.

La demi-Aigrette, Buf. vii. p. 378.

Heron bleuâtre à ventre blanc, $\mathrm{Pl}$. Enl. 350 .

Demi Egret, Lath. Syn. v. p. 88. 57.

Habitat in Cayana; præcedentis magnitudine.

Roftrum pedefque flavi : crifta occipitis e pennis 2. elongatis : dorfa poftici pennæ aliquot rufæ, laceræ, caudam tegentes.

Variat collo violaceo, crifta alba, collo fubtus rufo-albo maculato, pennis dorfi pottici grifeis. Forte femina.

63.

Egretta. A. occipite criftato, corpore albo, pennis fcapularibus longiflimis laceris, roftro pedibufque nigris.

Ardea Egretta, Gmel. Syjt. i. p. 629.

Guiratinga, Raii Syn. p. 101. 17.-189. 1 ?

La grande Aigrette, Buf. vii. p. 377.-Pl. Enl. 925 .

Great Egret, Arct. Zool. ii. No 346,-Bougain. Voy. p. 67.-Latb. Syn. v. p. $89 \cdot 5^{8}$.

Habitat in America aufrali, infulis $S$. Dominici et Falklandicis; Garzetta duplo major.-Corpus niveum: pennæ fcapulares eleganter laciniatæ multo caudam excedunt.

64.

Garzetta. A. occipite criftato, corpore albo, roftro nigro, loris pedibufque virefcentibus.

Ardea Garzetta, Lin. Syft. i. p. 937. 13.-Gmel. Syft. i. p. 628.-Krdm. El. p. 346.3.-Faun. Arag. p. 76,-Faun, Helvet,-It. Poseg. p. 25 . 
Egretta, Brif. v. p. 431. 16.-Id. 8vo. ii. p. 322.

Garzetta, Raii Syn. p. 99. 5.-Will. p. 206. -Id. (Angl.) p. 280.

L'Aigrette, Buf. vii. p. 372 . t. 20.-Pl. Enl. gor.-Defcr. Surin. ii. p. I5 5 。

Criel Heron, Harris Coll. Voy. ii. p. [468].

Little Egret, Br. Zool. App. t. 7.-Arct. Zool. ii. $\mathrm{N}^{\circ}$ 347.-Lath. Syn. v. p. 90.59 .

Habitat in omnium terrarum locis temperatis; olim in Anglia frequens, hodie inter rarifimas.-I 2 pollices longa.

Pennæ occipitis elongatæ, quarum 2 longifimæ; fcapulares longiffimæ catidam tegunt et abfcondunt. Pulli cinerei.

65.

alba. A. capite lævi, corpore albo, roftro fulvo, pedibus nigris.

Ardea alba, Lin. Syjt. i. p. 239. 24.-Faun. Suec. N॰ 166.-Gmiel. Syft. i. p. 639.-Scop. Ann. i. N I 26.-Kram. El. p. 346. 2.-Klein. Av. p. 122. 2.

Ardea candida, Brif. v. p. 428. I 5.-Id. 8vo. ii. p. 322.-Faun. Helv. Ardea alba major, Raii Syn. p. 99. A. 4.-Will. p. 205. t. 49.

Ardea egrettoides, Gmel. reife. ii. p. 193. t. 25.

Le Heron blanc, Buf. vii. p. 365.- Pl. Enl. 886.

Garza bianca, Cett. uc. Sard. p. 276.

Great white Gaulding, Brown. Fam. p. 478.-Sloan. Fam. p. 314. t: 266.-Raii Syn. p. 189. I ?

Great white Heron, Br. Zool. ii. p. 175. t. 62.-Id. fol. I 17.-Arct. Zool. ii. No $234 .-I d$. Sup. p. 66.-Will. (Angl.) p. 279. t. 49.Lath. Syn. v. p. 9r. 60.

Habitat in Europa, Afia, America, nova Zealandia; in Anglia ra. riffima fpecies. - Lora viridia.

66.

pileata. A. occipite criftato, corpore albo, vertice nigro.

Le Heron blanc à calotte noire, Buf. vî́. p. 380.

Luppé de Cayenne, Pl. Enl. 907.

Ardea brafilienfis candida, Brif. v. p. 434 . 17.-Id. 8 vo. ii. p. 323.

Black-crefted white Heron, Latb. Syn. v. p. 92.

Навгтат in Guiana, ubi fatis rara.

Roftrum fufcum: pedes lutei : vertex cum occipite niger: crifta e pennis 6 , quarum 2 longitudine fere capitis cum roftro; reliquæe per gradus breviores: lora grifeo-viridia. 
6.6 A VES GR A L L $\mathbb{E}$. Ardea.

Avis a Brifonio defcripta crifta caret, et caput fuperius abfque ma67.

nivea. A. criftata nivea, pennis occipitis colli dorfique longioribus.fetofis, digitis croceis.

Ardea nivea, N. C. Petr. xv. p. 45 8. t. 17.-Gmel. Syft. i. p. 640.Dec. Ruff. i. p. 164 .

Ardea candidifima, Gmel. Syf. i. p. 633.-Facq. Vog. p. 18. i 3 .

Ardea xanthedactylos, Gmel. reife. iii. p. 253 .

Snowy Heron, Latb. Syn. v. p. 92. 61.-Id. Sup. p. 236.

Habitat in Europa, Afia, America calidiore.-2 pedes longa.-Ad fluvium Tanaim vere frequens; in arboribus excelfis nidificat.

68.

Roftrum pedefque nigri, digitis croceis. Vox rauca ingrata.

Galatea. A. occipite fubcriftato, corpore lacteolo, roftro luteo, pedibus coccineis. Ardea galatea, Molin. Chil. p. 207.-Id. (ed. Gall.) p. $214 .-$ Gmel. Syft. i. p. 634 .

Habitat in Cbili.-Roftrum 4 pollices longum: pedes, prouti collum, $2 \frac{x}{2}$ pedes alti.

69.

facra. A. alba, capite lævi, tectricibus interioribus alarum rectricibufque nigro lineatis, pennis dorfalibus laceris albis.

Ardea facra, Gmel. Syft. i. p. 640.

Sacred Heron, Latb. Syn. v. p. 92. 62.

Habitat in Mare Pacifico, Otabeite; incolis facra. $-2 \frac{\mathrm{T}}{4}$ ped. longa. Medio verticis ftriæ aliquot nigricantes: roftrum fufcum: pedes flavi.

ß. A capite lævi, corpore albo nigro variegato, pennis dorfalibus laceris nigris.

Sacred Heron, Latb. Syn. v. p. 93. A.

Habitat cum pracedente, a quo differt vertice toto albo: $\int c a p u l a-$ ribus partim albis partim nigris : corpore nigro pulchre vario : cauda alba, rectrice unica toto nigra : pedes nigri.

70.

æquinoc- A. capite lævi, corpore albo, remigibus duabus primis margine extetialis. $\quad$ riore fufcis.

Ardea æquinoctialis, Lin. Syft. i. p. 240. 25.-Gmel. Syft. i. p. 64r. Ardea carolinenfis candida, Brif. v. p. 435. 18.-Id. 8 vo. ii. p. 324.Klein. Av. p. I24. Io. 
Le Crabier blanc à bec rouge, Buf. vii. p. 401.

Red-billed Heron, Arct. Zool. ii. Sup. p. 66.

Little white Heron, Lath. Syn.v. p. 93.63.-Cat. Car. i. t. 77.-Arct. Zool. ii. $\mathrm{N}^{\circ} 345$.

HaBITAт in America.-I 8 poll. longa.-Roftrum et lora rubra.

ß. A. capite lævi, corpore albo, vertice et pectore croceis, loris pedibufque flavo-croceis.

Ardea candida minor, Brif. v. p. 438. 20. Id. 8 vo. ii. p. 325 .

- alba tertia Aldr. Raii Syn. p. 99. 6.-Will. p. 206.-Id. (Angl.) p. 280.

La Garzette blanche, Buf. vii. p. 371.-Lath. Syn. v. p. 94. A.

Habitat circa Bononiam.

$\boldsymbol{\gamma}$. A. capite lævi, corpore albo, loris luteis, roftro purpureo, pedibus pallide purpurafcentibus.

Ardea mexicana candida, Brif. v. p. 437. 19.-Id. 8vo. ii. p. 324.Raï Syn. p. 102. 22.-Lath. Syn. v. p. 94. B.

\section{Habitat in Mexico.}

71.

atra. A, nigricans, tectricibus alarum cinereo-cærulefcentibus, rectricibus nigricantibus, roftro pedibufque nigris.

Ardea atra, Gmel. Syft. i. p. $64 \mathrm{I}$.

Ardea nigra, Brif. v. p. 439. 2 1. - Id. 8 vo. ii. p. $325 .-K l e i n$. Av. p. I23. 3 .

Le Heron noir, Buf. vii. p. 368.

Black Heron, Latb. Syn. v. p. 94. 64.

HaвiтAт in Silefia; majori æequalis.

72.

purpurea. A. occipite nigro, crifta dependente pennis duabus elongatis, corpore olivaceo fubtus purpurafcente.

Ardea purpurea, Lin. Syft. i. p. 236. ro.-Gmel. Syft. i. p. 626.-Borowes. Nat. iii. p. 74. 3.-Faun. Helvet.

_ criftata purpurafcens, Brif. v. p. 424 . 14. t. 36. f. 2, -Id. 8 vo. ii. p. 321 .

Le Heron pourpré, Buf. vii. p. $369 .-P l . E n l .788$.

Crefted purple Heron, Latb. Syn, v. p. 95.65. 
Habitat in $A f a$, ad mare Cafpium frequens; Helvetia. -2 ped. $10 \frac{\pi}{2}$ pollices longa.

Corpus cinereo-olivaceum : pectus et abdomen caftaneo-purpurafcentia, cárina nigra : caput fuperius fplendide nigrum: crifta concolor, in qua pennæ 2 longa: collum rufum ftriis tribus nigris: remiges cinereo-nigricantes : couda cinerea fubtus: roftrum fubtus et lora flavicantia : pedes virefcentes.

73.

cafpica. A. criftata corpore cinereo, collo pectore abdomineque ferrugineis, gula alba, collo lineis tribus nigris. Ardea cafpica, Gmel. reife. ii. p. I 95. t. 24.

African Heron, Latb. Syn. Sup. p. 237.

Haвгтат in Africa, Afla; rariffima in Anglia.-Magnit. A. cinerea. Roftrum et pedes lutei : crifta verticis e pennis nigris tres digitos longis : linea nigra latior colli poftici a nucba ad dor $\sqrt{i}$ initium, et altera utrinque lateribus : pennæ elongatæ pectoris et uropygii ferrugineo variæ. Vix a præcedente fatis diftincta. Nonne avis annotina?

74.

Botaurus. A. criftata cinereo-fufca fubtus rufa, vertice nigro, gula juguloque albo ftriis nigris.

Ardea Botaurus, Gmel. Syft. i. p. 636 .

Botaurus major, Brif. v. p. 455 . 28.-Id. 8 vo. ii. p. 330.-N. C. Petr. xv. p. 482 . 22. t. 24 ?

Ardea ftellaris major, feu rubra, Raii Syn. p. 100. 13.-Will. p. 208. Grand Butor, Buf. vii. p. $422 .-D e c$. Ruff. ii. p. 146. Greater fpeckled or red Heron, Will. (Angl.) p. 283.

Greater Bittern, Lath. Syn. v. p. 58. I8.

Hавітат in Italia; purpurea affinis. -3 ped. 9 poll. longa.

75.

purpurata. A. capite lævi colloque cinereo-nigricantibus, corpore fupra caftaneopurpureo fubtus cinereo.

Ardea purpurata, Gmel. Syft. i. p. 64r.

- purpurafcens, Brif. v. p. $420.12 .-I d .8$ vo. ii. p. 320.

Heron pourpré, Buf. vii. p 369.

Purple Heron, Lath. Syn. v. p. 96. 66.

HABIтA ad ripam Danubii.-Roftrum fupra viridi-flavicans, fubtus flavicans : cervix lineolis nigricantibus: pedes fufci.

A. caftaneo- 
76.

A V E S G R A L $\mathbb{E}$. Ardea.

fpadicea. A. caftaneo-purpurea, capite remigibufque fpadiceis, vertice nigro.

Ardea fpadicea, Gmel. Syft. i. p. 641 .

Ardea mexicana purpurafcens, Brif. v. p. 422. 13.-1d. 8 vo. ii. p. 320.

Avis Xoxouquihoactli, Seba, i. t. 64. f. 2.

Le Crabier pourpré, Buf. vii. p. 402.

Mexican Heron, Latb. Syn. v. p. 96. 67.

Haвiтат in Mexico.- 12 pollices longa.

77.

Cracra. A. rufefcente variegata, fupra cinereo-cærulefcens fubtus cinerea, collo fubtus pectoreque albis.

Ardea Cracra, Gmel. Syft. i. p. 642.

Cancrofagus americanus, Brif. v. p. $477 \cdot 39 .-I d$. 8 vo. ii. p. 336.

Cracra Heron, Lath. Syn. v. p. 96. 68.-Buf. vii. p. 403 .

$\mathrm{H}_{\mathrm{ABIT}} \mathrm{at}$ in America calidiore, juxta rivulorum ripas.

78.

leucoce-

phala.

A. nigro-violacea, vertice nigro, capite collo fuperiore criffo tectricibufque fubcaudalibus albis, roftro pedibufque fufco-rubris.

Ardea leucocephala, Gmel. Syft. i. p. 642.

Le Heron violet, Buf. vii. p. 370 .

Heron de la côte de Coromandel, $P l$. Enl. go6.

Violet Heron, Latb. Syn. v. p. 97. 69.-Id. Sup. p. 236.

HaBit at in India.-33 poll. longa.-Roftrum et pedes fufco-rubri.

79.

Agami. A. criftata cærulea, orbitis gulaque albis, collo fupremo corpore fubtus femoribufque rufis.

Ardea Agami, Gmel. Syft. i. p. 629.

Le Heron Agami, Buf. vii. p. 382.-Pl. Enl. 859.

Agami Heron, Latb. Syn. v. p. 97. 70.

Habit at in Cayana. - 31 pollices longa.

Roftrum nigricans: pedes flavi : pileus, criftaque occipitis e pennis 6 longiffima, cærulea : dorfum cæruleo-viride: nucba, collum imum, fca. pularefque laciniatæ, pallide cæruleæ: jugulum albo nigroque varium. Pulcherrima fpecies.

Femina, colore obfcuriore excepto, paucis variat.

80.

Cocoi, A. occipite crifta dependente dorfoque cinereis, collo fubtus nigro maculato, capitis lateribus nigris. 
Ardea Cocoi, Lin. Syft. i. p. 237. 14.-Gmel. Syft. i. p. 629.-Raii Syn。 p. 100. 15.-Will. p. 209. t. 51.-Id. (Angl.) p. 284 . Ardea cayanentis criftata, Brif. v. p. 400. 3. -Id. 8 vo. ii. p. 314. Le Soco, Buf. vii. p. 379.

Blue Heron, Alb. iii. t. 79 ?

Cocoi Heron, Lath. Syn. v. p. 98.71.

Haвiтат in Cayana.-3 pedes longa.

Corpus totum cinereum: caput ad latera nigrum: occiput crifte cinerea: remiges rectricefque cinerea: lora cinerea : roftrum flavo-virens:

81. pedes cinerei.

finenfis. A. fufca ftriis pallidioribus fubtus dilutior, remigibus rectricibufque nigris.

Ardea finenfis, Gmel. Syft. i. p. 642.

Chinefe Heron, Latb. Syn. v. p. 99. 73.

82.

Haвiтат in Cbina; parva.-Roftrum flavefcens : pedes virides.

Johannæ. A. crifta occipitis nigra, corpore fupra grifeo fubtus albo, collo antice maculis remigibufque nigris.

Ardea Juhannæ, Gmel. Syft. i. p. 629.

Johanna Heron, Latb. Syn. v. p. 100. 74.

Haвiтат in infula fobanne.

83.

fufca. A. crifta capiris nigricante, corpore fufco-nigricante fubtus albo, pectore maculis fufcis elongatis.

Le Heron brun, Buf. vii. p. $3^{81}$ 1.-Pl. Enl. $85^{8}$.

HaBitat in Cayana. $-2 \frac{x}{2}$ ped. longa. - Roftrum fufcum : pedes flavi。

84.

Hoactli. A. crifta capitis nigra, corpore nigro-virefcente fubtus albo, alis caudaque cinereis.

Ardea Hoactli, Gmel. Syft. i. p. 630.

Ardea mexicana criftata, Brif. v. p. 2 I8. I1.-Id. 8vo. ii. p. 319.

Hoactli, Raii Syn. p. 178. 8.-Will. p. 300.-Id. (Angl.) p. 389.Buf. vii. p. 382 . (Mas.)

Hoacton, Will. p. 302.-Id. p. 391. (Femina.)

Dry Heron, Lath. Syn. v. p. 100. 79.

Habitat in Mexico; inter arundineta nidificat, et pifcibus victitat. 3 ped. 3 poll. longa. 


\section{A VES GR A L L $\mathbb{E}$ Ardea. 701}

85.

Femina a mare difcrepat corpore fupra fufco albo vario, fubtus albo fufco variegato; in reliquis fatis bene convenit.

Hohou. A. criftata cinerea, fronte albo nigroque varia, alis albo cinereo et cya. neo variis, pedibus variegatis.

Ardea Hohou, Gmel. Syft. i. p. 630.

Ardea mexicana cinerea, Brif. v. p. 404.5 . Id. 8 vo. ii. p. 315.

Xoxoukqui Hoactli, Raii Syn. p. I02. 2 I.

Houhou Heron, Latb. Syn. v. p. 101. 76.-Buf. vii. p. $3^{8} 4$.

Haвгтат in paludibus Mexicanis, et inter rariores numeranda.

Roftrum nigrum: pedes fufco, nigro, et flavefcente variegati : crifta

86.

7 purpurafcentibus plumis conftat.

indica. A. fufca viridi varia, remigibus fecundariis viridibus, cauda nigra, tec. tricibus alarum remigibus primoribus corporeque fubtus albis.

Lohaujung Heron, Latb. Syn. Sup. p. 238.

Haвıтат in India; cineree magnitudine.-3 ped. longa.

Roftrum nigrum: pedes incarnati: vertex, collum, dorfumque poftice

87. maculis viridibus. In quibufdam dorfum totum album.

fiavicollis. A. crifta occipitis corporeque nigris, collo lateribus flavefcente, anterius caftaneo pennis albo nigroque marginatis.

Yellow-necked Heron, Lath. Syn. Sup. p. 239.

88.

Haвiтat in India.-Magnitudo carulea.-2 ped. longa.

novæHol- A. fubcriftata plumbeo-cinerea fubtus rufo-ferruginea, facie ultra oculandiæ. los gula juguloque albis. White-fronted Heron, Pbill. Bot. Bay. t. p. $16_{3}$.

Haвit at in nova Hollandia. -28 pollices longa.

Roftrum nigrum bafi fubtus flavefcens : lora et orbite nudre virefcentes: pedes flavo-fufci : corpus fupra plumbeo-cinereum : vertisis pennæ elongate nigra: frons, gene, gula, collum antice ad medium alba: tboo racis pennæe elongatæ: abdomen, femora rufa.

89.

fcolopacea. A. cupreo-fufca, collo pectoreque ftriis albis, gula nigra.

Ardea fcolopacea, Gmel. Syjt. i. p. 647.

Le Courlan, ou Courliri, Buf. vii. p. 442.-Pl. Enl. 848.

Scolopaceous Heron, Lath. Syn. v. p. 102. 79. 
702 A VES G R A L L E. Tantalus.

Habitat in Cayana.- Roftrum fufco-rubrum apice cærulefcens, declive: pedes albidi, digitus intermedius bafi connexus, intus pectinatus. Species intermedia inter Ardeas et Numenios pendens.

go.

***** Roftro in medio hiante.

pondice- A. cinereo-grifea, remigibus nigris, roftro lateribus glabro apice muriana.

\section{1.}

coroman- A. alba, facie dorfo fupremo remigibus caudaque nigris, roftro laterideliana. Ardea pondiceriana, Ginel. Syft. i. p. 646.

Le Bec-ouvert, Buf. vii. p. 409.-Pl. Enl. 932.

Pondicherry Heron, Lath. Syn. v. p. ror. 77.

HaвIт Aт in India.- $4 \frac{1}{2}$ pollices longa.

Roftrum flavum, ab utraque parte recurvum, medio dehifcens, bafi validum, apice acutum: fpatium inter roftrum et oculum pennis tectum: digitus medius abfque ferraturis : roftrum et pedes lavi. bus ferrato apice dentato.

Ardea coromandeliana, Gmel. Syjt. i. p. 646.

Le Bec-ouvert des Indes, Son. Voy. Ind. ii. t. p. 219.

Coromandel Heron, Lath. Syn. v. p. 102. 78.-Id. Sup. p. 237.

Habitat in Coromandela autumno tempore; victitans pifcibus, reptilibus.- Roftrum ut in præcedente, at lateribus a medio ad apicem ferratum, apice dentatum : caput fuperius lineis nigris notatum : lora et gula nuda nigra: roftrum et pedes flavefcentes, digitis bafi connexis : irides rubre.

\section{Genus LXX. TA N T L U S.}

Rof trum longum, fubulatum, teretiufculum, fubarcuatum. Facies nuda.

Lingua brevis.

Sacculus jugularis nudus.

Pedes tetradactyli, bafi palmati.

Ioculator. T. facie cærulefcente, roftro rubefcente, pedibus remigibus rectricibufque nigris, corpore albo.

Tantalus 
Tantalus loculator, Lin. Syft. i. p. 240. 1.-Gmel. Syft. i. p. $647-$ Klein. Av. p. 1 27. C. - Borowejk. Nat. iii. p. 7 1. t. 47.

Numenius americanus major, Brif. v. p. 335 . 8.-Id. 8 vo. ii. p. 295.

Numenius niger, Klein. Av. p. 109. 6.

Couricaca, Buf. v. p. 276.-Pl. Enl. 868.-Damp. Voy. iii. p. 96. f. 2. Wood Pelican, Cat. Car. i. t. 8 r.

-- Ibis, ArEt. Zool. ii. $\mathrm{N}^{\circ}$ 36c.-Latb. Syn. v. p. 104. I.

$\mathrm{H}_{\mathrm{AB}}$ itat in America calidiore, Carolina, $N$. Hollandia.-Victitat amphibiis, pifcibus.-Arboribus infidet, et in iis nidulatur.-Caro fatis bona.-Magnitudo fere anferis.

Mas capite et collo nudis, rugofis, nigro-cærulefcentibus.

Femina capite et gula nudis, collo grifeo tomentofo.

ß. T. capite et collo albis flavo variegatis, corpore nigro, dorfo capite ventreque cinereis.

Curicaca, Raii Syn. p. 103. 4.-Will. p. 2 18. t. 54.-Id. (Angl.) p. 295.

Haвitat in Brafilia.-Forte junior avis.

$\boldsymbol{\gamma}$. T. albus, alis fere totis caudaque nigris.

In hac varietate tectrices alarum albæ, medio area magna nigra : re2. miges toto nigra.

ruber. T. facie roftro pedibufque rubris, corpore fanguineo, alarum apicibus nigris.

Tantalus ruber, Lin. Syft. i. p. 241. 5.-Gmel. Syft. i. p. 651.-Scop. Ann. i. $\mathrm{N}^{\circ}{ }_{1} 30$.

Numenius brafilienfis coccineus, Brif. v. p. 344. 12. t. 29. f. 1. 2.Id. 8 vo. ii. p. 298.

Guara, Raii Syn. p. 104. 6.-Will. p. 21 9. t. 54.-Sloan. Gam. p. 317. -Pernet. Voy. i. p. 183.-Harris Coll. Voy. i. 728.-Ulloa Voy. ii. p. 228 ?

Avis porphyrio, Seb. i. p. 98. t. 62. f. 3.-Klein. Av. p. I24. I I.

Le Courlis rouge, Buf. viii. p. 35.-Pl. Enl. 80. $8 \mathrm{I}$.

Red Curlew, Cat. Car. i. t. 84.-Hift. Guian. p. 172.

Scarlet Ibis, Arct. Zool. ii. N N $^{\circ}$ 1.-Lath. Syn. v. p. 106. 2.

Hав втат in America meridionali, Carolina, Famaica.-Arboribus infidet, fed in terram ova virefcentia ponit.-Victitat pifciculis, infectis. -2 I pollices longus. 

704
A V E S G R A L L E. Tantalus.

3.

Avis adulta tota coccinea, apicibus pennarum exceptis : primum exclufa coloris eft nigricantis, et coccineum illum colorem ætate paulatim acquirit : remiges et rectrices fcapis albis.

cayanenfis. T. viridi-nigricans, remigibus rectricibufque faturatioribus, roftro nigricante, pedibus flavefcentibus.

Tantalus cayanenfis, Gmel. Syft. i. p. 652 .

Le Courlis de bais, Buf. viii. p. 42.

Cayt de Cayenne, Pl. Enl. 820.

Cayenne Ibis, Lath. Syn. v. p. 107.3.

Habitat in Cayana.-22 pollices longus.-Facies ultra oculos nuda, rubefcens. Variat vertice nucbaque pennis medio atris.

4.

mexica- T. purpureo viridi et nigricante varius, fubtus fufcus rubro variegatus, nus.

Tantalus mexicanus, Gmel. Syjt. i. p. 652.

Numenius mexicanus varius, Brif. v. p. 335 . 7.-Id. 8 vo. ii. p. 295.

Acacalotl, Raii. Syn. p. 104. 5.-Will. p. $218 .-I d$. (Angl.) p. 296.Buf. viii. p. 45.

Mexican Ibis, Lath. Syn.v. p. 108. 5 .

Habitat in Mexico. -3 pedes longus.

5.

melanopis. T. dorfo alis fafciaque pectorali cinereis, capite colloque fulvis, remigibus reetricibus femoribus criffoque nigris.

Tantalus melanopis, Gmel. Syft.i. p. 653 .

Black-faced Ibis, Lath. Syn. v. p. 108. 5. t. 79.-Forft. Voy. ii. p. 521 .

Habitat in infula Novi Anni aufralis; in fcopulis nidificans.-28 pollices longus.

Roftrum longum nigrum: facies tota ultra oculos nuda, rugofa : faccus gularis fpeciofus nudus, plicatus, niger : pedes rubri : pennæ capitis. et colli pofterioris elongatæ.

6.

albicollis. T. fufcus grifeo undulatus, capite colloque rufo-albis, tectricibus alarum majoribus albis.

- Tantalus albicollis, Gmel. Syft. i. p. 653 .

Le grand Courlis de Cayenne, Buf. viii. p. 47.

Courly à col blanc, Pl. Enl. 976.

White-necked Ibis, Lath. Syn, v. p. 109. 6.

HABITAT 


\section{A VES G R A L L E. Tantalus.}

HaBitat in Cayana.-27 pollices longus.

Roftrum nigrum : pedes rubri : fpatium inter roftrum et circa oculos nudum : vertex rufefcens.

7.

grifeus. T. albidus, capite pofteriore colloque grifeis, uropygio remigibus rectricibufque nigro-virefcentibus.

Tantalus grifeus, Gmel. Syft. i. p. 653 .

Numenius americanus minor, Brif. v. p. 337. 9. -Id. 8vo. ii. p. 296.

Matuiti, Will. p. 218.-Id. (Angl.) p. 296.-Buf. viii. p. 46.

Grey Ibis, Latb. Syn. v. p. I 10. 7.

8.

Habitat in Brafilia; Galline magnitudine.

fufcus. T. roftro apice inflexo, corpore nigro albo nebulofo, uropygio alifque fubtus albis.

Tantalus fufcus, Lin. Syft. i. p. 242.7.-Gmel. Syft. i. p. 65 r.

Numenius brafilienfis fufcus, Brif. v. p. 341. 11.-Id. 8 vo. ii. p. 297.

-Klein. Av. p. 10g. 4 .

Courly à front rouge, Buf. viii. p. 42.

Brown Curlew, Cat. Car. i. t. 83 .

- Ibis, Arct. Zool. ii. $\mathrm{N}^{\circ} 362 .-$ Latb. Syn. v. p. 110.8.

Habitat in Cayana, Carolina.-Vix 2 ped. longus.

Roftrum, lora, pedes pallide rubri.

9.

T. facie roftro pedibufque rubris, corpore albo, alarum apicibus viridibus. Tantalus albus, Lin. Syft. i. p. 242.6.-Gmel. Syft. i. p. 65 1.-Klein. Av. p. 109. 3.

Numenius brafilienfis candidus, Brif. v. p. 339. 10.-Id. 8 vo. ii. p. 296. Le Courly blanc du Brefil, Buf. viii. p. 41.-Pl. Enl. 915.

White Curlew, Cat. Car. i. t. 82.

- Ibis, ArCz. Zool. ii. No 363.-Latb. Syn. v. p. III. g.

Habitat in Caroline aquofis frequens.

Roftrum, facies nuda, pedefque pallide rubri.

ß. T. facie roftroque flavo-carneis, pedibus ex carneo pallentibus, corpore albo, remigibus 3 extimis apice nigris.

Tantalus Coco, facq. Vog. p. 24. 18.-Gmel. Syft. i. p. 652.

Coco Ibis, Latb. Syn. Sup. p. 24I. 
706 A VES GRALL E. Tantalus.

HabItat in Caribbeis infulis.-Victitat pifcibus.-Syllabas $\mathrm{Ko}_{0}, \mathrm{Ko}_{\mathrm{p}}$ 10. voce rauca continuo edit; unde nomen.

leucoce- $T$. facie roftroque flavis, corpore albo, tectricibus alarum remigibufque phalus. nigris, uropygii pennis longiffimis pedibufque rofeis.

Tantalus leucocephalus, Zool. Ind. p. 20. t. 10.-Gmel. Syft. i. p. 649. White-headed Ibis, Ind. Zool. p. I 1. t. I0.-Lath. Syn. v. p. I 16.1 f. -Id. sup. p. 240.

Haв rт at in India. - Species maxima.-In altero fexu tectrices alarum albo marginatæe et fufco variegatæ: fafcia pectoralis lata nigra,-Clangit roftro, ut Ciconia noftras, et quod obfervatu dignum, tempeftate anni. pluvia ingruente, omnes pulchras plumas rofei coloris quotannis perdidit.

II.

Ibis. T. facie rubra, roftro luteo, pedibus grifeis, remigibus nigris, corpore rufefcente-albido.

Tantalus Ibis, Lin. Syft. i. p. 241. 4.-Haffelq. It. p. 248. 25.-Id. Voy. p. 198.-Scop. Ann. i. N' 128.-Borowjk. Nat. iii. p. 72. 3.Gmel. Syjt. i. p. 650 .

Ibis candida, Brif. v. p. 349. 14.-Id. 8vo. ii. p. 299.

L'Ibis blanc, Buf. viii. p. I4. t. 1.-Pl. Enl. $3^{8} 9 .-H i f f$ de l'Acad. iii. p. 3. pag. 6r. t. I3.

Emfeefy, or Ox-bird, Sbaw's Tr. p: 255 .

Egyptian Ibis, Lath. Syn. v. p. II I. IO.

Habitat in Egypto, regionis purificator poft inundationem tranfactam.-Corpus magnitudine A. Ciconia.-Caput anterius ultra oculos. nudum rubrum.

12.

T. albus, capite colloque fuperiore fufcis, dorfo poftico remigibufque nigris.

Abou Hannes, Bruce's Trav. App. t. p. 172.

Haвiтat in Etbiopia.-Stans erecta a dorfo ad terram 19 pollices altitudine æquat.

Roftrum a bali ultra medium rectiufculum, cæterum, ut in congeneribus, declive, fuperius viride, inferius nigrum: oculi magni : color pennarum albus : caput et collum pofterius fere ad dorfum fufcum: dor fum pofticum, remiges, coudaque nigra : pedes nigri. 
13.

niger. T. niger, capite anteriore nudo rubro, rectricibus nigris, roftro pedibufque rubris.

Tantalus niger, Gmel. Syft. i. p. 650.

Ibis nigra, Pbil. Tranf. Ivii. p. 349 .

Ibis, Brif. v. p. 347 . I3.-Id. 8 vo. ii. p. 299.-Raii Syn. p. 98.-Will. p. 2 12. t. 49.-Buf. viii. p. 17.

Numenius holofericeus, Klein. Av. p. 1 10. 9.

Black Ibis, Latb. Syn. v. p. I 12. I1. -Will. (Angl.) p. 288. t. 49.

Haвiтat copiofe in Volge paludofis; gregatim degens. $-30-40$ pollices longus.-Ranis, lacertis, et ferpentibus victitant hæ aves, ideoque divini honores iis habiti funt.

I4.

Falcinel- T. facie nigra, pedibus cæruleis, alis caudaque violaceis, corpore caflus. taneo.

Tantalus Falcinellus, Lin. Syft. i. p. 241. 2.-Gmel. Syft. i. p. 648.Scop. Ann. i. No 1 1. -Kram. El. p. 350. 2.-Borow/k. Nat. iii. p. 72. 2. - Faun. Helvet.

Numenius viridis, Brif. v. p. 326. 4.-Id. 8 vo. ii. p. 293. fubaquilus, Klein. Av. p. 1 10. 8.

Falcinellus, Raii Syn. p. 103. 3.-Will. p. 218 . t. 54.-Id. (Angl.) p. 295.

Le Courlis verd, Buf. viii. p. 29.

Bay Ibis, Lath. Syn. v. p. $113.12 .-$ Arct. Zool. ii. p. 460. A.-Id. Sup. p. 67.

Habitat in Europa, Afia.-2 I pollices longus.

Corpus caltaneum, maculis parvis fufcis albifque in capite et collo antico : facies nuda nigra : roftrum nigrum : pedes cyanei : ale, rectrices, uropygium violacea.

B. T. fpler.dide caftaneus, pectore viridi.

Numenius caftaneus, Brif. v. p. 329. 5. - Id. 8 vo. ii. p. 294. Arcuata minor, puniceo colore, pectore virefcente, Marf. Dan. v. p. 40. t. 18. -Buf. viii. p. 31. (r.) -Latb. Syn. v. p. I14. I2. A.

Habitat in Europa, juxta Danubii ripas.

15.

viridis. T. viridis aureo fplendens, capite collo corporeque fubtus nigricantibus, facie nuda colloque anterius fafciis tribus nigris.

$$
4 X^{2}
$$

Tantalus 
708 A V E S G R A L L E. Tantalus.

Tantalus viridis, Gmel. Sy $\ell$. i. p. 648 .

Numenius viridis, N. C. Petr. xv. p. 462. t. 19.-Gmel. It. i. p. 167.

Green Ibis, Lath. Syn. v. p. 114. I3.

Haвгтат in Rufia, ad ripas fluviorum Tonais et Cboperi.-Victitat pifcibus et infectis; gregatim volat, et arboribus nidificat.- $19 \frac{x}{2}$ poll. longus.-Roftrum fufco-plumbeum: pedes nigri: fupra oculos fafcia alba : vertex maculis duabus vel tribus albis.

16.

igneus. T. corpore nigricante cæruleo viridi et vinaceo variegato-nitente, capite colloque nigris pennis albido fimbriatis.

Tantalus igneus, Gmel. Syft. i. p. 649.

Numenius igneus, N. C. Petr. xv. p. 460 . t. 18.

Glofly Ibis, Latb. Syn. v: p. I 15 . 14.

Habitat cum pracedente, cui moribus accedit; in Anglia, comitatu Cornubii femel occifa $\in \mathbb{f}$.

17.

calvus. T. capite colloque fupremo nudis, corpore nigro viridi fplendente, pileo roftro pedibufque rubris.

Tantalus calvus, Gmel. Syft. i. p. 649.

Courly à tête nue, Buf. viii. p. 32.-Pl. Enl. 867.

Bald Ibis, Latb. Syn. v. p. 116.16.

Haвitat in Africa, ad Caput Bone Spei.-32 pollices longus.

Capitis latera, et pars nuda co!li grifea : caput fupremum rubrum, oc-

18. cipite tuberculato.

manillen- T. rufo-fufcus, roftro laterıbufque capitis nudis virefcentibus, pedibus

fis. rubris.

Tantalus manillenfis, Gmel. Syft. i. p. 649.

Courly brun de Luçon, Son. Voy. p. 85. t. 47.-Buf. viii. p. 3 1.

Manilla Ibis, Latb. Syn. v. p. I 17.17 .

HАBıтат in Pbilippinis; arquate magnitudine.-Irides rubræ.

I9.

minutus. T. facie roftro pedibufque virefcentibus, corpore ferrugineo fubtus albo.

Tantalus minutus, Lin. Syft. i. p. 241. 3.-Gmel. Syft. i. p. 650.

Leffer Ibis, Lath. Syn. v. p. I 17 . 18.-Edw. t. 356 .

Habitat in Surinamo.-Magnitudo fere Pbropodis.

Facies virefcens: pectus, abdomen, femora, uropygiumque alba.

T. criftatus, 
20.

A V E S G R A L L E. Tantalus.

criftatus. T. criftatus ferrugineus, capite criffo caudaque nigris, alis albis.

Tantalus criftatus, Gmel. Syft. i. p. 650 .

Courlis huppé de Madagafcar, Buf. viii. p. 33.-Pl. Enl. 84 r.

Crefted Ibis, Latb. Syn. v. p. I 18 . 19.

HaвIт Aт in Madagafcaria.-20 pollices lorgus.

Roftrum et pedes flavi: regio oculorum nuda incarnata : crifta e pennis valde elongatis partim nigris partim albis : caput et collum fupremum nigra.

$2 \mathrm{I}$.

melanoce- $T$. albus, roftro capite pedibufque nigris.

phalus. Black-headed Ibis, Latb. Syn. Sup. p. 240.

HaBitat in India.-2 I pollices longus.

Roftrum valde incurvatum: nucba et cervix maculis nigris minutis: irides fufcæ.

22.

Pillus. T. facie roftro pedıbufque fufcis, corpore albo, remigibus rectricibufque nigris, Molin. Cbil. p. $215 .-$ Id. (ed. Gall.) p. 224.-Gmel. Syft. i. p. 652 .

Habitat ad fluvios et lacus regni Cbilenfis; anferis magnitudine.Terram frequentat, vix arboribus infidens; amphibiis victitans. - Nidum ftruit inter arundineta, ova 2 albo-cærulefcentia ponens.

Collum 3 pedes longum: roftrum magnum, acutum, convexum, 4 pollices longum, bafi nudum: gula faccofa, nuda: plumæ totius avis alba nigro variegatæ: cauda brevis apice integra : pedes, cum femoribus, 2 ped. 8 poll. longi.

23.

Hagedafh. T. cinereus, dorfo viridi flavoque vario, alis cæruleo-nigris, tectricibus minoribus violaceis. Hagedafh, Hadelde, Sparm. Voy. i. p. 28 I.

Habitat ad Caput B. Spei; Gallinam magnitudine excedens.-Arboribus nocte quiefcit; radicibus, potiffinum bulbofis, victitat.

Roftrum 5 pollices longum, fuperius rubrum, inferius cum apice nigrum : collum et femora cinerea: dorfum cinereum viridi et pauco flavo variegatum : ale fubtus obfcuræ, fupra cæruleo-nigræ, tectricibus minoribus violaceis : cauda cuneiformis, roftro duplo longior : pedes nigricantes. Confer Num. leucocepbalum. 
710 AVES GiN A L L A. Numentus.

\section{GEN U S LXXI. NUM E N I US.}

Roftrum longum, incurvum.

Facies pennis tecta.

Nares lineares juxta bafin.

Lingua brevis, acuta.

Pedes tetradactyli, digitis bafi connexis.

I.

Arquata. N. cinerafcente nigroque varius, pedibus cærulefcentibus, alis nigris maculis niveis.

Scolopax Arquata, Lin. Syft. i. p. 242. 3-Faun. Suec. $\mathrm{N}^{\circ}$ 168.-It. Scan. 333.-Gmel. Syjt. i. p. 655.-Brun. p. 22.-Kram. El. p. 350. 1.-Frifcb. t. 229.-Sepp. Vog. t. p. 109.-Borowfk. Nat. iii. p. 86. t. 51.-Faun. Helvet.

Numenius, Brif. v. p. 31 1. 1. $-I d$. 8 vo. ii. p. 289.-Raii Syn. p. 103. A. 1.-Will. p. 216 . t. 54.-Klein. Av. p. 109. 1.-Id. Stem. p. 24. t. 24. f. 3.-Id. Ov. p. 31. t. II. f. 5.--Schaf. El. t. 50.

Le Courlis, Buf. viii. p. 19.-Pl. Enl. 818.-Voy. en Barb. i. p. 278. Common Curlew, Br. Zool. ii. $\mathrm{N}^{\circ}$ 176. t. 63.-Id. fol. $118 .-$-ArEz. Zool. ii. p. 462 . A.-Will. (Angl.) p. 294. t. 54.-Alb. i. t. 79. Collin. Anat. ii. t. 21.-Cook's laft Voy. i. p. 220.-Latb. Syn. v. p. II g. I.-Id. Sup. p. 242.

Habitat in Europa, Africa, Afia; ad littora Anglice hyberno tempore gregatim frequentius obfervatur; in paludofis nidificans. Ovum olivaceum maculis fufco-rubris, in zonam confluentibus verfus extremitatem obtufiorem.

$\beta$. N. rufo nigroque varius, corpore fubtus pallide rufefcente, pedibus nigris, alis nigris maculis rufefcentibus.

Habitat in America Septentrionali.-Corpus huic minus, et roftrum longius quam in noftra ave.

2.

madagaf- $\mathrm{N}$. roftro pedibufque rufefcentibus, maculis dorfi rhomboidalibus.

carienfis. Scolopax madagafcarienfis, Lin. Syft. i. p. 242. 2.-Gmel. Syft. i. p. 655 . Numenius madagafcarienfis, Brif.v. p. 32 I. 3. t. $28 .-I d$. 8vo. ii. p. 292. 
Le Courly de Madagafcar, Pl. Enl. 198.

Madagafcar Curlew, Lath. Syn. v. p. I 21.2.

Habitat in Madagafcaria; Arquate magnitudine æqualis et affinis, at rottro minus incurvato.-Gula candida: maculæ corporis magis diftinctx.

3.

Iuzonien- $\mathrm{N}$. albus, capite colloque ftriis abdomine caudaque fafciis nigris, dorfo fis. fufco maculis albis, vertice nigro.

Scolopax luzonienfis, Gmel. Syft.i. p. 656.

Le Courlis tacheté de Luçon, Son. Voy. p. 85. t. 48.-Buf. viii. p. 32. Luzonian Curlew, Lath. Syn. v. p. 122.3 .

Habitat in Luzonia; Arquata multo minor.

4.

tahitienfis. N. albo-rubefcens, collo ftriis nigris, dorfo tectricibufque alarum nigricante et albido undulatis, cauda bafi maculis ad apicem fafciis nigris.

Scolopax tahitienfis, Gmel. Syft. i. p. 656 .

Otaheite Curlew, Lath. Syn. v. p. I 22. 4.

HaBITat in Otabeite. -20 pollices longus.

Roftrum fufcum bafi rubrum : pedes cærulefcentes : Supercilia albida.

5.

leucoce- N. cyaneus, capite et collo fupremo grifeo-albis, remigibus nigris, rof-

phalus. tro rubro.

Scolopax leucocephala, Gmel. Syft. i. p. 656.

White-headed Curlew, Latb. Syn. v. p. 123.t. 80.-Id. Sup. p. 242.

Habitat ad Caput B. Spei.-Corpus intenfe caruleum : caput et collum ad dimidium ufque cinereo-alba: pedes grifeo-cinerei. Confer Tant. Hagedafp.

6.

Phæopus. N. roftro nigro, pedibus cærulefcentibus, maculis dorfalibus fufcis rhomboidalibus, uropygio albo.

Scolopax Phropus, Lin. Syft. i. p. 243. 4.-Faun. Suec. No 169.Gmel. Syft. i. p. 657. -Scop. Ann. i. N ${ }^{\circ}$ 132.-Brun. N $159 .-$ Muller, p. 22.-Kram. El. p. 350.-Georgi reife. p. 17 1.-Borowjk. Nat. iii. p. 87.2.-Faun. Helvet.

Numenius minor, Brif. v. p. 317. t. 27. f. 1.-Klein. Av. p. 109. 2.Id. Stem. p. 24. t. 24. f. 4.

Arquata minor, Raii Syn. p. 103. A. 2.-Will. p. 217.

Corlièu, 
Corlieu, ou petit Courlis, Buf. viii. p. 27.-Pl. Enl. 842 .

Whimbrel, Lath. Syn. v. p. 123.-Br. Zool. ii, $N^{\circ}$ I77.-Id. fol. I1 9 . - Tour in Scotl. 4 to. p. I 30.-Id. 8 vo. p. I08.-ArEt. Zool. ii. p. 462. B. -Will (Angl.) p. 294.-Edw. t. 307.-Flor. Scot. i. p. 32.

Habitat in Europa; Arquate dimidio minor, et in omnibus fere, magnitudine excepta, convenit. Ovum fimiliter olivaceum, fufco-rubro pictum, et zona coloris ejufdem cinctum.

hudfoni-

\section{pictum, et zona coloris juftem cindum.}

cus.

N. roftro nigro, pedibus cæruleis, corpore fufco albo maculato, abdomine albo, vertice caft anco-fufco, medio linea longitudinali alba. Efkimaux Curlew, Arct. Zool. ii. $\mathrm{N}^{\circ} 3^{64}$.t. 19.

Hudfonian Curlew, Lath. Syn. Sup. p. 243.

Habitat in finu Hudfonis.-Magnitudo Pbocopi, a quo tamen differt verticis linea, et fuperciliis albis: uropygium dorfo concolor, minime

8. album.

Guarauna. N. roitro flavicante, corpore fufco albo ftriato, pedibus fufcis.

Scolopax Guarauna, Lin. Syft. i. p. 242. 1.-Raii Syn. p. 104. 7.-Will. p. 2 1 5. t. 53.-Buf. viii. p. 44.-Gmel. Syft. i. p. 654 . Numenius americanus fufcus, Brif. v. p. $330.6 .-1 d$. 8 vo. ii. p. 294. Brafilian Whimbrel, Lath Syn. v. p. I25.7.

Haвiтat in America auftrali.-2 I pollices longus.

Uropygium caudaque fufca viridi micantia.

9.

borealis. N. roftro pedibufque nigris, corpore fufco grifeo maculato, fubtus ochroleuco.

Scolopax borealis, Pbil. Tranf. 1xii. p. 431.-Faun. Am. Sept. p. 14.Gmel. Syft. i. p. 654 .

Enkimaux Curlew, Latb. Syn. v. p. 125--Pbil. Tronf. lxii. p. 41 I.

HABIтAт in finus Hudfonis inundatis et pratis humidis; victitans infectis et vermibus; Lrquatce affinis, fed differt corpore triplo minore, roftro ratione corporis breviore, colore in dorfo faturate fufco, in abdomine ochroleuco.

10.

africanus. N. cinereus, facie collo fubtus abdomine uropygio tectricibus alarum. mediis apice albis, pectore cineraicente ferrugineo maculato.

Scolopax africana, Gmel. Syft. i. p. 655 .

Cape Curlew, Lath. Syn. v. p. I26. 9 . 


\section{A V E S G R A L L E. Scolopax.}

Habitat ad Caput Bone Spei; gregarius.-Corpus vix magnitudine Gallinaginis : roftrum pedefque nigricantia.

I I.

pygmeus. N. fufco ferrugineo alboque variegatus, corpore fubtus uropygioque albo, remigibus rectricibufque exterioribus albo marginatis.

Scolopax pygmea, Gmel. Syft. i. p. 655 .

Pygmy Curlew, Lath. Syn. v. p. I 27. 10.-Id. Sup. p. 291. nota 0.Gen. of Birds, p. 64. t. I I.-Boys's Sandwich. t. p.

Haвiтат in Europa, rarius in Anglia.-Magnitudo Alauda. Roftrum pedefque nigri.

\section{GENUS LXXII. S C O L O P A X.}

Roftrum teretiufculum, obtufum, capite longius. Nares lineares.

Lingua acuta.

Pedes tetradactyli, fifi.

I.

Rufticola. Sc. caftaneo nigro grifeoque varia, fubtus rufefcens fafciolis nigris, fafcia capitis nigra, femoribus tectis.

Scolopax rufticola, Lin. Syft. i. p. 243. 6.-Faun. Suec. N¹70.-Gmel. Syft. i. p. 660.-Scop. Ann. i. $\mathrm{N}^{\circ}$ 1 34.-Brun. $\mathrm{N}^{\circ}{ }_{1} 64 .-$ Muller, p. 23.-Frifch. t. 226. 227.-Scbaf. El. t. 61.-Georgi reife. p. 171.-Faun. Arag. p. 77.-Borowes. Nat. iii. p. 88. 3.-Faun. Helvet.

Scolopax, Brif. v. p. 292. 1.-Id. 8vo. ii. p. 284.-Raii Syn. p. 104. A. 1. -Will. p. 2 1 3. t. 53.-Klein. Av. p. 99. 1.-Id. Stem. p. 20. t. 20. f. r. a.-c. $-I d$. Ov. p. 30. t. I I. f. I. 2.

La Becaffe, Buf. vii. p. 462. t. 25.-Pl. Enl. $885 .-$ Voy. en Barb. i. p. 278.

Wald-fchnepff, Gunth. Neft. u. Ey. t. 18. Accegia, Beccagia, Cet. uc. Sard. p. 248. Woodcock, Br. Zool. ii. No 178. t. 65.-Id. fol. 119.-Flor. Scot. i. $\mathrm{N}^{\circ}$ 142.-ArEt. Zool. ii. p. 470. A.-Id. Sup. p. 68.-Will. (Angl.) p. 28g. t. 53.-Borlaf. Corn. p. 245. t. 24. f. r2.-Alb. i. t. 70.-Bradly Nat. t. I 1. f. 2.-Latb. Syn. v. p. 129. I. 


\section{A V E S G R A L L E. Scolopas.}

Habitat in Europa, Afia, Africa.-I 5 pollices longa.-Hybernat in Anglia.-Victitat lumbricis.

Roftrum bafi rufum : lora nigra : corpus totum maculatum : uropygium. varium : collum fubtus ferrugineum lineis tranfverfis nigricantibus : caudes. nigra, apice fupra cinerea, fubtus nivea: pedes fufci.

Ovum rubiginofum maculis fufcis.

ß. Sc. candida, Brif. v. p. 295. A.-Lath. Syn. v. p. 13x。

$\gamma$. Sc. pallidiffime Itraminea, Id.

d. Sc. capite rubefcente, corpore albo, alis fufcis.

๕. Sc. corpore ufitato, alis totis niveis.

2.

minor. Sc. caftaneo nigro rufoque varia fubtus flavefcens, occipite nigro fafciis quatuor tranfverfis flavefcentibus, cauda nigra.

Scolopax minor, Gmel. Syjt. i. p. 661.

Little Woodcock, Lath. Syn. v. p. I 31. 2.-Arc7. Zool. ii. No 365. t. I 9.

HАвІтАт in America Septentrionali.- I I $\frac{\mathrm{T}}{2}$ pollices longa.-Habitus Rufticola.-Mandibula inferior multo brevior: frons cinerea: gula alba: lora obfcura: sauda nigra apice fufco: pedes fufci.

3. que nigris.

Scolopax paludofa, Gmel. Syft.i. p. 66r.

Becaffe des Savanes, Buf. vii. p. 48 r.-Pl. Enl. 895.

Savannah Woodcock, Lath. Syn. v. p. I33. 3 .

Haвiтat in Cayana; Rufticola minor.

Roftrum pedefque fufci : gula albida.

4 . major.

Sc. nigro maculata fupra teftacea fubtus albida, linea verticis teftacea, altera utrinque nigra.

Scolopax major, Gmel. Syjt. i. p. 66 I.

Scolopax media, Frifcb. t. 228.

Great snipe, Br. Zool. ii. $N^{\circ}$ 188.-Arct. Zool. ii. p. 470. B.-Latb. Syn. v. p. $133 \cdot 4$.

Hав тт Aт in Sibiria, rarior in Anglia -16 pollices longa. 6 
Corpus fupra teftaceum, nigro maculatum, pennis margine albis, fubtus flavefcens lineís undatis nigris: abdomen maculis cordatis: cauda 5 . ferruginea, reitricibus exterioribus nigro fafciatis.

cayanenfis. Sc. cinereo-fufca teftaceo varia, corpore fubtus uropygioque albo, tectricibus alarum majoribus remigibufque primoribus bafi albidis. Scolopax cayennenfis, Gmel. Syft. i. p. $66 \mathrm{r}$. Cayenne Snipe, Lath. Syn. v. p. I 34.5.

HaBitat in Cayana. $-\mathrm{r} 3$ poll. longa. - Cauda fafciis obfcuris.

6.

Gallinago. Sc. roftro tuberculato, corpore nigricante et fulvo vario fubtus albos frontis lineis fufcis quaternis.

Scolopax Gallinago, Lin. Syft. i. p. 244. 7.-Faun. Suec. $\mathbf{N}^{\circ} 173 .-$ Gmel. Syjt. i. p. $662 .-$ Scop. Ann. i. $\mathrm{N}^{\circ} 138 .-B$ run. $\mathrm{N}^{\circ} 160.16 \mathrm{r}$. (i62. var.)-Muller, p. 23.-Kram. El.p. 352.6.-Borow/k. Nat. iii. p. 89. 4.-Frifch. t. 229.-Georgi reife. p. 182.-Raii Syn. p. I05. A. 2.-Will. p. 2 I 4. t. 53.-Brif. v. p. 298. 2.-Id. 8 vo. ii. p. 28 5.--Faun. Arag. p. 77.-Faun. Helvet.

Scolopax media, Klein. Av. p. 99. 2.-Id. Stem. p. 20. t. 20. f. 2. a.-c. Becaffine, Buf. vii. p. 483. t. 26. -Pl. Enl. 883.-Cet. uc. Sard. p. 248. Moos-fchneppe, Scbrank. Naturf. xviii. p. 68.

Snipe or Snite, Br. Zool. ii. N $\mathrm{N}^{\circ} 87$. r. 68.-Id. fol. I21.-Fl. Scot. i. $\mathrm{N}^{\circ}$ 144.-ArEt. Zool. ii. $\mathrm{N}^{\circ}$ 366.-Will. (Angl.) p. 290. t. 53.Alb. i. t. 7 1.-Ilift. Selb. p. 29.-Collins's Anat. ii. t. 24.-Latb. Syn. v. p. I 34.6 .

Haвгтат ubique in paludibus. -12 fere pollices longa.

Caput lineis 4 fufcis, inter quas 3 ferrugineæ: lora fulca: gula ferruginea : pectus et abdomen alba immaculata: reitrices bafi nigræ: roftrum pedefque fufci: uropygium varium. Ovum fufco-olivaceum maculis ru. fefcentibus.

7.

gallinaria. Sc. roftro tuberculato, corpore variegato, capite grifeo, pedibus flavis. Scolopax gallinaria, Müller, $\mathrm{N}^{\circ}$ 1 8 3.-Gmel. Syft. i. p 662 .

Finmark Snipe, ArEt. Zool. ii. p. 47 I. D.-Lath. Syn. v. p. I36. 7.

Habitat in Finnia; præcedenti affinis.

8.

Gallinula. Sc. roftro tuberculato, corpore variegato, uropygio violaceo vario, pedibus virefcentibus, loris fufcis. 
Scolopax Gallinula, iin. Syft. i. p. 244. 8.-Gmel. Syft. i.p. 662.-Scop. Ann. i. $\mathrm{N}^{\circ}{ }_{1}$ 39.-Brun. $\mathrm{N}^{\circ}{ }_{163 .-M u l l e r, \mathrm{~N}^{\circ} 189 .-F r i f c b .}$ t. $23 \mathrm{I}$. - Borowes. Nat. iii. p. 90.-Faun. Helvet.

Gallinago minima, Raii Syn. p. IO5. A. 3.-Will. p. 214.-Klein. Av. p. 100. 4.-Id. Stem. p. 20. t. 20, f. 4. a. b.

minor, Brif. v. p. 303 . 3. t. 26. f. $2 .-I d .8$ vo. ii. p. 287. La petite Becaffine, Buf. vii. p. 490.-Pl. Enl. 884 . Jack Snipe, Gid, Judcock, Br. Zool. ii. No 189. t. 68.-Id. fol. I 2 I.Flor. Scat. 145.-Arct. Zool. ii. No 367.-Will. (Angl.) p. 291. -Alb. iii. t. 86.-RuJ. Alep. p. 65.-Latb. Syn. v. p. 136.8.

Haвiтат in Europa, Afia, America; Gallinaginis fubdupla eft. $-8 \frac{r}{2}$ pollices longa.-Corpus varium e teftaceo nigro violaceo viridique nitente: caput lineis luteis nigrifque a roftro ad occiput ductis : !cra nigricantia: roftrum fufcum: pedes virefcentes: pectus maculatum: uropygium violaceum albo varium.

9:

belgica. Sc. roftro rectifimo apice nigro, capite collo et pectore ferrugineis, abdomine albo, dorfo alis cauda pedibufque nigris, Sepp. Vog t. 27. p. $51 .-$ Gmel. Syft. i. p. $66_{3}$.

HaBitat in Belgio, infectis terreftribus vietitans.

10.

capenfis. Sc. roftro lineaque verticis rufefcentibus, fafcia pectorali nigra, lineas utrinque dorfali alba.

Scolopax capenfis, Lin. Syft. i. p. 246. 14.-Gmel. Syft. i. p. 666.

Gallinago capitis B. Spei, Brif. App. p. 141. t. 6. -Id. 8 vo. ii. p. 288 . La Becaffine du Cap de B. E.-Buf. vii. p. 494.-Pl. Enl. 270.

Keuvitt, Sparrm. Voy. cap. i. p. 153 .

Cape Snipe, Lath. Syn. v. p. 1 38. 9.-Id. Sup. p. 244.

Habitat ad Cap. B. Spei.-10 pollices longa.

Dorfum cinereum, nigro undulatum: lineola albido-rufefcens a roftro ad occiput: orbit.e albæ, poftice in fafciam productæ: collum antice rufum : pectus fafcia nigra, a qua fafcia alba utrinque per dorfum ad uropygium : abdomen album : pedes nigri.

ß. Sc. olivaceo-viridis, collo nigro, vertice juguloque ferrugineis, orbitis fcapularibus abdomineque albis, remigibus caudaque maculis fulvis.

Cape Snipe, Latb. Syn. v. p. 138. 9. var. A. t. 8 I. 


\section{A V E S G R A L L F. Scolopax.}

$\gamma$. Sc. cinereo grifeo nigroque undulata, capite colloque rufis, orbitis gula fcapularibus abdomineque albis, fafcia pectoris fuperciliifque nigris, remigibus caudaque maculis ovatis flavis.

Becafline de Madagafcar, Buf. vii. p. 495.-Pl. Enl. 922.-Lath. Syn. v. $\mathrm{N}^{\circ}$ I 39. C.

§. Sc. albus, capite colloque nigro, alis dorfoque viridibus, remigibus primariis rubro-maculatis.

Rallus benghalenfis, Lin. Syft. i. p. 263.8.-Gmel. Syft. i. p. $715 .-$ Klein. Av. p. 104. 5.

Totanus bengalenfis, Brif. v. p. 209. 9.-Id. 8 vo. ii. p. 266 .

Le Chevalier vert, Buf. vii. p. 520.

Bengal Water Rail, Alb. iii. t. 90.-Lath. Syn. v. p. 140. var. D.

๘. Sc. fupra maculis lunulifque nigris, dorfo cærulefcente, alis caftaneis, pectore imo nigro, abdomine genis gulaque albis, orbitis lineaque fcapulari flavis.

Cape Snipe, Latb. Syn. Sup. p. 244. var. E.

Haвitat in India.

I.

finenfis. Sc. cærulefcente fufco rufo nigroque variegata, fuperciliis linea verticis gula abdomineque albis.

La Becaffine de la Chine, Buf. vii. p. 495.-Pl. Enl. 88 I.

Cape Snipe, Latb. Syn. v. p. I 39. var. B.

HaBitat in Cbina.- - 10 pollices longa.

Roftrum longum, ut in Ruficola, fufco-flavum: corpus fupra pulcherrime undulatum : collum fupra fufcum lineis tranfverfis nigris, fubtus albidum ftriis longitudinalibus albis: remiges caudaque maculis rufefcentibus : pedes grifei.

12.

maderaf- Sc. nigricante fulvoque varia fubtus alba, capite fafciis tribus, dorfo patana. duabus fufco-nigricantibus, pectoris unica nigra.

Scolopax maderafpatana, Gmel. Syjt. i. p. 667.

Gallinago maderafpatana, Brif. v. p. 308. 4.-Id. 8 vo. i. p. 287.

La Becafline de Madras, Buf. vii, p. 496.

Partridge Snipe, Raii Syn. p. 193. t. 1. f. 2.

Madras Snipe, Lath. Syn. v. p. I41. IO. 
13.

indica. Sc. grifea fufco undulata fubtus alba, capite albido, collo fubtus ftriis vitta per oculos alteraque fubtus grifeis, roftro pedibufque nigris.

Scolopax indica, Gmel. Syjt. i. p. 667 .

La Becaftine blanche des Indes, Son. Voy. Ind. ii. p. 2 r 8 .

White Indian Snipe, Latb. Syn. v. p. 141، I I.

14.

Habitat in India. An fpecies diflineta?

Fedoa. Sc. roftro flavicante, corpore rufo nigroque fubtus albido, pedibus fufcis, remigibus fecundariis rufis nigro punctatis.

Scolopax Fedoa, Lin. Syft. i. p. 244. 9.-Gmel. Syft. i. p. 663.

Limofa americana rufa, Brif. v. p. 287. 7.-Id. 8vo. ii. p. 282.

Barge rouge de la baie d'Hudfon, Buf. vii. p. 507.

American Godwit, ArEt. Zool. ii. N'371.-Edw. t. 137.-Lath. Syn. v. p. 142 . 12 .

HaBitat ad finum Huajonis. - I 6 pollices longa.

Corpus grifeum: remiges primores fufcæ: gena, gula, et Jupercilia alba : uropygium rufum nigro fafciatum.

15.

lapponica. Sc. roftro flavefcente, pedibus nigris, fubtus tota rufo-ferruginea.

Scolopax lapponica, Lin. Syft. i. p. 246. I 5.-Faun. Suec. $N^{\circ} 174 .-$ Gmel. Syft. i. p. 667.-Brun. $\mathrm{N}^{\circ} 165 .-$ Muller, $\mathrm{N}^{\circ}$ 186.-Pbil. Tranf. lxii. p. $41 \mathrm{I}$.

Limofa rufa, Brif. v. p. 28 I. 5. t. 25 . f. x. $-I d .8$ vo. ii. p. 28 r.

I a Barge rouffe, Buf. vii. p. 504.-Pl. Enl. 900.

Red Godwit, Br. Zool. ii. N I $^{\circ}$ 1. t. 67.-1d. fol. tab. add.-ArEz. Zool. ii. $\mathrm{N}^{\circ} 372 .-E d w$. t. $138 .-$ Lath. Syn.v. p. 142.13.

Habitat in Europa maritimis, America; in Anglia rarior--i 8 poll. longa.-Roftrum fubafcendens, rubefcens, apice nigricante: corpus nigricans maculis ferrugineis, fubtus ferrugineum immaculatum : uropygium albido-ferrugineum maculis oblongis nigris : Jupercilia ferruginea a roftro fupra oculos per collum defcendentia : rectrices fufcæ albo-fafciatre: pedes fufci.

In quibufdam abdomen medium album.

ß. Sc. fufca, 
$\beta$. Sc. fufca, capite colloque cinereis, gula fupercilis abdomineque albis, pectore ferrugineo nebulofo.

Red Godwit, Latb. Syn. v. p. 143. I3. A.

16.

Habitat ad Calpen.

IEgoce- Sc, roftro flavo-rubente, pedibus virefcentibus, capite colloque rufefphala. centibus, remigibus tribus nigris bafi albis.

Scolopax ægocephala, Lin. Syft. i. p. 246. 16.-Gmel. Syft. i. p. 667. l.imofa rufa major, Brif. v. p. 284. 6.-Id. 8 vo. ii. p. 282.

IEgocephalus Bellonii, Raii Syn. p. 105. A. 4.-Will. p. 215.-Id.

(Angl.) p. 294.-Marjgl. Dan. v. p. 36. t. 16.-Klein. Av. p. 102. II.

La grande Barge rouffe, Buf. vii. p. 505.-Pl. Enl. 916.

Barbary Godwit, Sbarw's Trav. p. 255.

Godwit, Latb. Syn. v. p. 145. 14. A.-Alb. ii. t. 70.-Br. Zool. fol. t. B. B.

Habitat in Europa, Africa, rarius in Anglia.-Reetrices albæ nigricante ftriatæ.

17.

leuco- Sc. fufca albido marginata, collo albido maculis parvis fufcis, gula abphra. domineque albis, rectricibus albis nigro fafciatis.

Limofa grifea major, Brif. v. p. 272 2. 3. t. 24. f. 2.-Id. 8 vo. ii. p. 279. Common Godwit, Br. Zool. ii. No 179.-Id. fol. 120. t. B.-ArEt. Zool. ii. $\mathrm{N}^{\circ}$ 373.-Lath. Syn. v. p. 144. 1 5.-Id. Sup. p. 245.

Habitat in Europa; frequens in Anglia.-16 pollices longa.

Roffrum fubafcendens, fufcum, bafi purpureum: rectrices albæ, 2 intermediæ totæ, reliquæ latere exteriore fufco fafciatæ: uropygium quibufdam album. An precedentis varietas?

18.

Limofa. Sc, roftro fubrecurvato bafi rubro, corpore grifeo-fufco rufo variegato fubtus albo, remigibus bafi albis, quatuor primis immaculatis, cauda bafi alba.

Scolopax limofa, Lin. Syft. i. p. 245. 12.-Faun. Suec. N॰172.-Gmel. Syft. i. p. 666.-Faun. Groenl. $\mathrm{N}^{\circ} 72 .-$ Muller, $\mathrm{N}^{\circ} 190 .-$ Georgi reife, p. 17 1.-Brif. v. p. 262. 1.-Id. 8vo. ii. p. 277.-Faun. Arag. p. 77.-Faun. Helvet..

Scolopax rufticola Aldr. Klein. Av. p. 100. 5 .

Fedoa 
Fedoa noftra fecunda, Raii Syn. p. 105. A. 5.-Will. p. 216.-Id. (Angl.) p. 293. \$II.

La Barge, Buf. vii. p. 500. t. 27.-Pl. Enl. 874.

Leffer Godvit, Br. Zool. ii. No 182.-Id. fol. I 20.

Jadreka Snipe, Lath. Syn. v. p. 146. 17.-ArEt. Zool. ii. N'375.Olaf. Ifl. ii. p. 201 . t. 48.

Habitat in Europa, Anglia.- I 7 pollices longa.

Dorfum fufcum: gence rufefcentes: remiges nigricantes; $I-3$ fcapo albo, $5^{-1} 3$ bafi in medium albæ: rectrices bafi albæ, magis exteriores : roftri bafis rubra, quam ambiunt pennæ albo-rufefcentes : irides albidæ.

Ig.

marmora- Sc. nigricante pallideque rufo maculatim varia, abdomine medio fuper-

ta.

20.

ciliis gulaque albidis, pectore fufco undulato, remigibus rufefcentibus, quatuor primis extus apiceque nigris.

Marbled Godwit, Lath. Syn. Sup. p. 245.-Arct. Zool. Sup. p. 68.

HaBITat ad fretum Hudfonis. - Corpus magnitudine Fedoc: roftrum fubafcendens nigrum, bafi rufum: pedes nigri: cauda fafciis fufco-nigricantibus.

hudfonica. Sc. fufca maculis albis, fubtus caftaneo-ferruginea fafciis fufcis, fuperciliis gula uropygio rectricibufque bafi albis.

Hudfonian Godwit, Latb. Syn. Sup. p. 246. - ArEt. Zool. Sup. p. 68.

HaBITat cum pracedente, cui magnitudine cedit.-Roftrum et pedes nigricantes: cauda brevis : rectrices nigræ bafi albæ.

$2 \mathrm{r}$.

Glottis. Sc. grifeo-fufca maculis nigricantibus varia, fuperciliis dorfo infimo corporeque fubtus albis, rectricibus albis fafciis fufcis.

Scolopax glottis, Lin. Syft. i. p. 245. 10.-Faun. Suec. $\mathrm{N}^{\circ} 17$ 1.-Gmel.

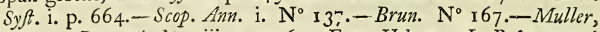
p. 23.-Borow/k. Nat. iii. p. 90. 6,-Faun. Helvet.-It. Pofeg. p. 23 ? Limofa grifea, Erif. v p. 267.2 . t. 23 . f. I. $-I d$. 8 vo. ii. p. 278. Klein. Av. p. 102. I2 ?

La Barge variée, Buf. vii. p. 503 ?

Pluvialis major, Raii Syn. p. 106. A. 8.-Will. p. 220. t. 55-If. (Angl.) p. 298. ch. iv. \$ 1.-Raii Syn. p. I90. 6.-Sloan. Fam. $317 \cdot 9 \cdot$ t. 268 .

Green-legged Horfeman, Alb. ii. t. 69 .

Greenfhank 
Greenßhank, Br. Zool. ii. No I83.-Id. fol. 12.1. t. C. r.-Arct. Zoolo ii. N'379.-Lath. Syn. v. p. 147. 18.-Id. Sup. p. 249.

Haвгтат in Europa, Afa, America; in Anglia maritimis non rara. 14 poll. longa.-Roftrum gracile, mandibula fuperiore apice deorfum, 22. inferiore furfum inclinante: pedes fufco-vireifcentes.

canefcens. Sc. cinereo alboque varia, gula pectoreque albis, cauda fafciis pectoreque maculis cinereis.

Scolopax canefcens, Gmel. Syjt. i. p. 668.

Cinereous Godwit, Br. Zool. ii. No 180. t. 66.-Latb. Syn. v. p. 145. I 5 .

Habitat in Anglize agro Lincolnienfi; Glottidi magnitudine et coloribus fimilis, at roftro validiore: pedes cinerei.

23.

cantabri- Sc. cinereo-fufca fubtus alba, tectricibus alarum rectricibufque nigro gienfis. fafiatis, roftro rubro.

Scolopax cantabrigienfis, Gmel. Syft. i. p. 668.

Cambridge Godwit, Br. Zool. ii. No 18 5,-Lath. Syn. v. p. I46. 16.

Ha вгт a in Anglia; Calidri major.-Tectrices alarum minores fufcæ margine albo, nigro fafciatæ: remiges nigricantes intus albæ, fecundariæ albo fafciatæ: cauda cinereo nigroque fafciata.

24.

Totanus. Sc. nigricans maculis albis fubtus alba, pectore lineolis rectricibus lateralibus fafciis nigricantibus, pedibus rubris.

Scolopax Totanus, Lin. Syf. i. p. 245. I 2 ? -Brun. N N $^{\circ} 7$ ?-Faun. Arag. p. 77.-Muller, 187 ?-Georgi reife, p. I7 1 ?'-Faun. Helvet. -Gmel. Syft. i. p. 665.-Borow/k. Nat. iii. p. 9 1. 7.

Totanus alter, Raii Syn. p. ro6. 11.-Will. p. 22 1. - Id. (Angl.) p. 299. Glareola, Klein. Av. p. 102 ?

Barker, Alb. ii. t. 7 r.

Spotted Redfhank, Br. Zool. ii. No 186.

Spotted Snipe, Latb. Syn. ii. p. 148. I9.

Habitat in Europa; in Anglia rarius occurrit.

ß. Spotted Woodcock, Pbil. Tranf. lxii. p. 410.

Snipe, ArIt. Zool. ii. No 374.-Latb. Syn. v. p. I49. var. A.

Habitat in America boreali.-A præcedente differt corpore paula majore, maculis alarum albis trıquetris diftinctis.

$$
4 \mathrm{Z} \quad \text { Sc. roftro }
$$


25. 722 A V E S G R A L L IE. Scolopax.

Calidris. Sc. roftro rubro, pedibus coccineis, corpore cinereo, remigibus fecundariis albis.

Scolopax calidris, Lin. Syft. i. p. 245. 11.-Gmel. Syft. i. p. 664.Muller, $\mathrm{N}^{\circ}$ 186.-Kram. El. p. 353. 5.-Frifch. t. 240.-Faun. Helvet.

Scolopax Totanus, Faun. Suec. N*167.-Erif. v. p. 188. 3. t. 17. f. 1. -Id. 8 vo. ii. p. 26 1. - Raii Syn. p. 107. A. 1.-Will. p. 221.

Glareola, Klein. Av. p. ror. 1. -Id. Stem. p. 2 1. t. 2 r. f. Il. a. b.

Chevalier aux pieds rouges, Buf. vii. p. 5 r 3. t. 28,-Koy. en Barb. i. $_{\text {. }}$ p. 27.8 .

L.a Gambette, Pl. Enl. 845 .

Redhank, or Pool Snipe, Br. Zool. ii. No 184. t. 65.-Id: fol. 124, ArEt. Zool. ii. No 377.-Will. (Angl.).p. 299.-Alb. iii, t. 87:Latb. Syn. v. p. I $50.20 .-$ Id. Sup. p. 225.

Habitat in Europa, America; in Anglia frequens.-12. poll. longa. Roftrum rubicundum: pedes rubri : uropygium varium : reEtrices faf. ciis numerofis nigris. In quibufdam uropygium et abdomen alba.

Ovum albidum maculis ftriis purpureis.

ß. Chinefe Redßhank, Latb. Syn. v. p. 15.1. 20. var. A.

A præcedente non multum differt : corpus fupra grifeum fubtus candidum : collum fubtus et peđtus lateribus nigricante maculatum : uropy gium et cauda albo nigroque fafciata.

26.

candida. Sc. roftro recto, pedibufque aurantiis, corpore albicante, rectricibus candidis grifeo fafciatis.

Scolopax candida, Gmel. Syft. i. p. 668.

Totanus candidus, Brif. v. p. 207. 8. $-I d .8$ vo. ii. p. 266.

Le Chevalier blanc, Buf. vii. p. 5 I9.

White Redhank, Latb. Syn. v. p. I 5 1. 2 1. $-E d w . ~ t . ~ 139$.

HaBItAT ad fretum Hudfonis. An præcedentis varietas.

27. mata. fafcia, fecundariis rectricibufque extimis toto albis.

Scolopax femipalmata, Gmel. Syft. i. p. 659.

Semipalmated Snipe, Arct. Zool. ii. N³80.-Lath. Syn. v. p. 152.22.

Habitat in America Septentrionali.- 4 pollices longa.

Corpus fupra cinereum maculis fagittatis nigris, fubtus album: caput collumque 


\section{A V E S G R A L L E. Scolopax.}

collumque ftriis, pectus maculis rotundatis nigris : rectrices mediæ cinereo nigroque fafciatæ, excimæ albæ: pedes nigricantes, digitis femipalmatis.

28.

melano- Sc. corpore maculis, uropygio caudaque fafciis albis nigrifque, remigileuca.

29. bus primoribus nigricantibus, pedibus flavis. Scolopax melanoleuca, Gmel. Syft. i. p. 659 .

Stone Snipe, Arct. Zool. ii. N ${ }^{\circ}$ 376.-Latb. Syn. v. p. 152. 23.

Habitat in America Septentrionali; Gallinagine duplo major.

flavipes. Sc. albida nigro maculata, alis fufcis, collo fubtus pectoreque albo nigroque maculatis, abdomine tectricibufque caudx albis, rectricibus albis fafciis fufcis.

Scolopax flavipes, Gmel. Syft. i. p. 659 .

Yellowhank Snipe, ArEt. Zool. ii. N $\mathrm{N}^{\circ} 378 .-$ Latb. Syn. v. p. 152. 24.

Habitat autumno in Noveboraco.-I I pollices longa.

Roftrum nigrum, gracile, apice nonnihil incurvatum.

30.

nutans. Sc. cinerea ferrugineo varia, abdomine uropygio caudaque albis, collo fubtus pectore femoribus uropygioque maculis, cauda fafciis nigris. Scolopax nutans, Gmel. Syft. i. p. 659 .

Nodding Snipe, Arct. Zool. ii. N' 370.-Latb. Syn. v. p. 153. 25.

HaBitat in Labradore littoribus.-Magnitudo Gallinaginis.

Roftrum nigrum : pedes virefcentes, digitis membrana marginatis.

nigra. Sc. corpore toto aterrimo, roftro pedibufque rubris.

Scolopax nigra, Gmel. Syft. i. p. 659 .

Black Snipe, Arct. Zool. ii. No 38 1.-Latb. Syn. v. p. 153. 26.

Habitat in infulis inter Afiam borealem et Americam intermediis.

32.

novebora- Sc. nigro cinereo rubroque varia, dorfo abdomineque albis, alis cinecenfis. reis, cauda albo nigroque fafciata.

Scolopax noveboracenfis, Gmel. Syft. i. p. 658 .

Red-breafted Snipe, Arct. Zool. ii. N 368.-Latb. Syn. v. p. 153. 26.

Habitat in Noveboraci maritimis; Gallinaginis magnitudine.

Roftrum pedefque fufci : collum antice ferrugineum maculis nigris.

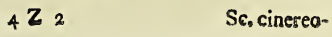


33. albis, uropygio rectricibufque nigro fafciatis.

Scolopax grifea, Gmel. Syft. i. p. $65^{8}$.

Brown Snipe, Arc7. Zcol. ii. No 369.-Lath. Syn. v. p. 154.28.

Haвiтат cum pracedente.- I I pollices longa.

Roftrum pedefque fuifi : lora et macula fupra oculos aiba.

34 .

incana. Sc. cinerea, jugulo abdomine medio maculaque ante oculos albis.

Scolopax incana, Gmel. Syft. i. p. $65^{8}$.

Afh-coloured Snipe, Lath. yn. v. p. 154.29.

Haв IтAт in infulis Eimeo et Palmerfon.- I pollices longa.

Roftrum apice nonnihil inflexum, nigrum: pedes flavo-virefcentes.

35.
fufca. Sc. roftro apice inflexo, corpore nigro albo nebulofo, uropygio alifque fubtus albis.

Scolopax fufca, Lin. Syft. i. p. 243. 5.-Gmel. Syft. i. p. 657.-Faun. Helvet:

Limofa fufca, Brif. v. p. 276 . 4. t. 23. f. 2.-Id. 8 vo. ii. p. 280.

La Barge brune, Buf. vii. p. 508.-Pl. Enl. 875 .

Dufky Snipe, Arct. Zool. ii. p. 47 I. C.-Id. Sup. p. 68.-Lath. Syn. v. p. $155 \cdot 30$.

Hавітат in Europa boreali.-Migratoria.-1 2 pollices longa.

Roftrum nigrum: pedes fufci : cauda albo nigroque fafciata : remigis primæ fcapus albus.

36.

Terek. Sc. cinerea fufco maculata fubtus alba, collo fubtus pectoreque cinereo nebulofis, fafcia alarum remigibufque fecundariis apice albis.

Scolopax cinerea, N. C. Petr. xix. 6. t. 19.-Gmel. Syjt. i. p. 657 .

Terek Avofet, ArE7. Zool. ii. p. 502. A.

Terek Snipe, Lath. Syn. v. p. 155 . 31 .

НАвітат ad mare Cafpium; gregatim volans. -9 pollices longa. Roftrum fubrecurvatum, apice deorfum inclinans, nigrum: pedes fufco-rubri, digitis fubpaimatis: rectrices laterales albido nebulofæ.

37 .
curonica. Sc. grifeo-maculata, alis nigricantibus, roftro nigricante, mandibula inferiore fubtus a bafi ad medium coccinea, pedibus lateritiis, Naturf. Gef. vii. p. $462 .-$ Gmel. Syft. i. p. 669.

HaBitat in Curonia.

Sc. corpore 
Helias. Sc. corpore nigro fulvo alboque fafciato, abdomine ftrigifque capitis albis, collo rufo lineis tranfverfis nigris, cauda nebuiofa fafcia nigra.

Ardea Helias, Pall.n. Nord. Beytr. ii. p. 48. t. 3.-Gmel. Syft. i. p. 640. Caurâle, ou petit Paon des Rofes, Buf. viii. p. 169. t. 14.-Pl. Enl. 782. Caurale Snipe, Lath. Syn. v. p. 156.32 .

HaвIтAт in Guiana, inter rariores.

Roftrum pedefque flavefcentes: caput nigrum: fuperciliis, ftriga a maxilla inferiori ad nucham, et gula albis : ale albo, nigro, fufco, flavo, ferrugineoque fafciatæ. Pulcherrima fpecies.

\section{GENUS LXXIII. T R I N G A.}

Rofrum teretiufculum, longitudine capitis.

Nares parvæ.

Pedes tetradactyli, fifii; digito portico a terra frequentius elevato.

pugnax. Tr. roftro pedibufque rufis, rectricibus tribus lateralibus immaculatis, facie papillis granulatis carneis.

Tringa pugnax, Lin. Syst. i. p. 247. 1.-Faun. Suec. N' 175.-Gmel. Syjt. i. p. 669.-Scop. Ann. i. $\mathrm{N}^{\circ}$ 140.-Brun. $\mathrm{N}^{\circ}$ 168. 169.Kram. El. p. 35 2. 1. 2.-Frifch. t. 232. 235.-Georgi reife. p. I72. -Sepp. Vog.t. p. 29.-Brif. v. p. 240. 18. t. 22. f. I. 2. -Id. 8vo. ii. p. 273.-Raii Syn. p. 107. A. 3.-Will. p. 224. t. 56.-Klein. Av. p. 102. 10.-Id. Stem. p. 2 1. t. 2 I. f. 1. a. b.-Borowejk. Nat. iii. p. 92. t. 52.-Faun. Helvet.

Combattant, ou Paon de Mer, Buf. vii. p. 521 . t. 29. 30.-Pl. Enl. $3 \circ 5.306$.

Pavoncella, Cet. uc. Sard. p. 253.

Ruff and Reeve, Br. Zool. ii. No 192. t. 69.-Id. fol. 123. t. E.-Arct. Zool. ii. p. 479. A.-Will. (Angl.) p. 302. t. 56.-Alb. i. t. 72 . 73. - Lath. Syn. v. P: I59. I.

Habitat in Europa, Sibiria.-Pedem longa.-Mares pugnacifimi, pennis colli longifimis torquem referentibus vernalibus diffi niles. - Mira eft in maribus colorum diverfitas, ut ne duæ per omnia fibi mutuo fimiles inveniantur. 
inveniartur.-In paluftribus Lincolnienfibus Anglia et alibi nidificat.Tempore autumno Mas, torque decidente, a femina vix diftinguitur.

In quibufdam roftrun grileum aut fufcum, at in omnibus pedes rubri aut flavi. Ovum cinerafcens maculis fufco-rubris, potifimum ad an2. gulum obtufiorem, confperfum.

Vanellus. Tr. pedibus rubris, crifta dependente, pectore nigro.

Tringa Vanellus, Lin. Syft. i. p. 248. 2.-Faun. Suec. N' 176.-Gmel. Syft. i. p. 670.-Scop. Ann. i. N ${ }^{\circ}$ 141.-Brun. $\mathrm{N}^{\circ}$ 170.-Muller, $\mathrm{N}^{\circ}$ 192.-Kram. El. p. 353 . 4.-Frifch. t. 213 .-Olin. uc. t. p. 21.-Georgi reife. p. 172. - Gmel. reije. i. t. 15. p. 75.-Sepp. Vog. t. p. 65.-Faun. Helvet.-Brif. v. p. 94. 1. t. 8. f. 1. -Id. 8 vo. ii. p. 236.-Raii Syn. p. 1 10. A. 1.-Will. p. 228. t. 57.-Faun. Arag. p. 77.-Borowes. Nat. iii. p. 93. 2.-Schaf. El. t. 69.

Gavia vulgaris, Klein. Liv. p. 19. 1.-Id. Stem. p. 3. t. 3. f. 5. a. b.Id. Ov. p. 16. t. 6. f. 2. 3.

Le Vanneau, Buf. viii. p. 48. t. 4.-Pl. Enl. 242.-Hift. Prov. i. p. 352.-Voy. en Barb. i. p. 299.

Kybiz, Gunth. Neft. u. Ey. t. 31.-Wirfing. Vog. t. 35 .

Lapwing, or Baftard Plover, Br. Zool. ii. N' $190 .-$ Id. fol. 122. t. C. *.

f. 1.-Fl. Scot. i. N ${ }^{\circ}$ 146. - ArEt. Zool. ii. p. 480. D.-Will. (Angl.) p. 307 . t. 57.--Alb. i. t. 74.-Hayes Br. Birds, t. 1 1.-Latb. Syn. v. p. 161.2.

Hавітат in Europa, Afie, Africe pratis apricis depreffis.- $13 \frac{1}{2}$ pollices longa.

Roftrum nigrum : pedes rubri : uropygium virefcens : corpus fupra viridi-aureum tubtus album: pennæ occipitales longiffinæ criftam elegantem efficientes : reEtrices intermediæ decem a bafi ad medium albæ, extima tota alba. Ovum olivaceum lituris maculifque fubrotundis ex atro fufcis; in menfarum deliciis habetur.

3.

bononien- Tr. nigra fubtus albida, capite et collo fuperiore caftaneis, jugulo et fis. Tringa bononienfis, Gmel. Syft. i. p. 670 . Vanellus bononienfis major, Brif. v. p. 110. 5.-Id. 8 vo. ii. p. 239. Greater Lapwing, Latb. Syn. v. p. 163.3.

Habitat circa Bononiam; Vanello major. Roftrum flavicans apice nigro: pedes lutei. 
4. Tr. fufco-cinerea, abdomine fuliginofo, fronte rufa, rectricibus albo-

erythro- Tr. fufco-ciniea, abdomine fuliginofo, fronte rufa, reetricibus albopus.

5. Tringa erythropus, Scop. Ann. i. N $146 .-$ Gmel. Syft. i. p. 670.

Red-legged Sandpiper, Lath. Syn. v. p. 163. 4.

Pugnace major.-Rofrum nigrum : pedes rubri : remiges primores nigræ, fecundariæ albæ: femorum pars major nuda: pedes rubri.

cayanenfis. Tr. criftata, alis armatis, dorfo viridi-purpureo, collo rufefcente, fronte gula fafcia pectoris caudæque nigris, margine alarum extus abdomine bafique caudæ albis.

Parra cayennenfis, Gmel. Syft. i. p. 706.

Vanneau. armé de Cayenne, Buf. viii. p. 66.-Pl. Enl. 836.-Ferm. Surin. ii. p. 193.

Cayenne fandpiper, Latb. Syn. v. p. 164. 5 .

HaвtтAт in Cayane paludofis; Vanello minor.-Vietitat infectis.

Roftrum et pedes nigri : ad flexuram als calcar notabile.

6.

ludovicia- Tr. carunculata, alis armatis, corpore grifeo-fufco, fubtus bafique cauna. $\quad d \mathfrak{a l b o - r u f e f c e n t e , ~ p i l e o ~ r e m i g i b u s ~ f a f c i a q u e ~ r e f t r i c u m ~ n i g r i s . ~}$

Parra ludoviciana, Gmel. Syft. i. p. 706.

Vanellus ludovicianus armatus, Brif. v. p. I14. 7. t. 8. f. 2.-Id. $8 \mathrm{va}$. ii. p. 24 .

Vanneau armé de la Louifiane, Buf. viii. p. 65.-Pl. Enl. 835 .

Armed Sandpiper, ArEz. Zool. ii. N: 395. 6.

Louifiane. Sandpiper, Latb. Syn. v. p.. $16_{4}$. 6.

HaBitat in Luuifiana:- I I pollices longa.

Membrana utrinque roftrum inter et oculum luteo-aurantia fuppra ocilos ducta et deorfum dependens : roftrum et pedes flavi.

. Tr. carunculata, alis armatis, corpore fulvo fubtus rofeo, rectricibus fulvis, roftro pedibufque flavis.

Parra dominicana, Lin. Syft. i. p. 259. 1.-Gmel. Syft. i. p. 705.

Vanellus dominicus armatus, Brif. v. p. 1 1 8.8.-Id. 8vo. ii. p. $24 \mathrm{I}$ \% -Latb. Syn.v. p. 165 . 6. var. A.

Habitat in infula $S$. Dominici,

7. oenfis. Tr. carunculata armata fufca, capite collo remigibus fafciaque caudae nigris, linea longitudinali colli pectore abdomine fafcia alarum bafique cauda_albis. 
Parra goenfis, Gnel. Syfi. i. p. $7 c 6$.

Vanneau armé des Indes, Buff. viii. p. 64.

- de Goa, Pl. Enl. 807.

Goa Sandpiper, Lath. Syn. v. p. 165. 7 .

Haвiтat in India.-I 3 pollices longa.

Roftrum obfcure rubrum apice nigrum : inter roftrum et oculos orbi8. tæque carunculatæ rubræ: pedes flavi: ad flexuram alæ calcar acutum.

fenegalla. Tr. carunculata armata fufca, gula remigibus fafciaque caudæ nigris, fafcia alarum longitudinali abdomine bafi apiceque caudæalbis. Parra fenegalla, Lin. Syft. i. p. 259. 2.-Gmel. Syft. i. p. 706. Vanellus fenegalenfis armatus, Brif. v. p. I I I.6. t. Io. f. 2.-Id. 8 vo. ii. p. 240.

Le Vanneau armé du Senegal, Buf. viii. p. 62.-Pl. Enl. 362. Uett, Uett, Adanf. Seneg. p. 78. Senegal Sandpiper, Lath. Syn. v. p. 166.8.

Habitat in Senegala.-Caruncula frontis laxa lutea, deorfum utrinque dependens: roftrum luteum : pedes rubri: ad flexuram alæ fpina acuta nigra.

Gambetta. Tr. roftro pedibufque rubris, corpore luteo cinereoque variegato, fubtus albo.

Tringa gambetta, Lin. Syft. i. p. 248. 3.-Faun. Suec. No 177.-Scop. Ann. i. $\mathrm{N}^{\circ}$ 142.-Gmel. Syft. i. p. 67 r.

Tringa variegata, Brun. $\mathrm{N}^{\circ}$ 1 $81,-$ Muller, $\mathrm{N}^{\circ} 204$.

Totanus ruber, Brif. v. p. 192. 4.-Id. 8vo. ii. p. 262.

Gambetta, Raii Syn. p. 107.2.-Will. p. 222.-Id. (Angl.) p. 300.Klein. Av. p. го ı. 1. (alia.)

Red-legged Horfeman, Alb. ii. t. 68.

Gambet Sandpiper, Br. Zool. ii. No 198. t. 70.-Arct. Zool. ii. $N^{\circ} 394$. Latb.Syn. v. p. 167.9.

Habitat in Europa, America; Glottidis magnitudine.

Roftrum rubrum apice nigro: pedes flavi : cauda femipalmaris, quam alæ complicatæ excedunt et occultant.

IO.

helvetica. Tr. roftro pedibufque nigris fubtus nigra, abdomine albo, rectricibus albis nigro fafciatis.

Tringa helvetica, Lin. Syjt. i. p. 250 . 12.-Pbil. Tranj. Ixii. p. 412.Gmel. Syft.i. p. 676.-Faun. Helvet. 
Vanellus helveticus, Brif. v. p. 106. 4. t. 10. f. 1. $-I d$. 8 vo. ii. p. 239. Charadrius hypomelus, Pall. reife. iii. p. 699. 26.

Vanneau de Suiffe, Buf. viii. p. 6o.-Pl. Enl. 853 .

Swifs Sandpiper, Aret. Zool. ii. No 396 .--Lath. Syn. v. p. 167. 10.-. Id. Sup. p. 248.

Habiтat in Europa, America.-I I pollices longa.

Corpus nigricans maculis albis : frons alba: gula, collum fubtus, pec-

I 1 . tufque nigra : cauda alba fafciis anguftis nigris: uropygium variegatum: linea lateralis alba a fronte ad alas: digitus pofticus minutus.

Squataro- Tr. roftro nigro, pedibus virefcentibus, corpore grifeo fubtus albido.

la. Tringa fquatarola, Lin. Syft. i. p. 252. 23.-Faun. Suec. $\mathrm{N}^{\circ} 186$. Gmel. Sy.t. i. p. 682.-Scop. Ann. i. N $\mathrm{N}^{\circ}$ 144.-Brun. $\mathrm{N}^{\circ} 176$. Muller, p. 25.-Georgi reife. p. 172.-Faun. Arag. p. 77.-Faun. Helvet.

Vanellus grifeus, Brif. v. p. 100. 2. t. 9. f. 1.-Id. 8 vo. ii. p. 237.

Pluvialis cinerea, Raii Syn. p. I I I. A. 3.-Will. p. 229. t. 57.-Klein. Av. p. 20. 3.-Id. Stem. p. 3. t. 3. f. 2. a.-c.

Vanneau pluvier, Buf. viii. p. 68.-Pl. Enl. 854 .

Grey Plover, Alb. i, t. 76.-Will. (Angl.) p. 309. t. 57.-Brown. Fam. p. 478 .

Grey Sandpiper, Br. Zool. ii. No 191.-Id. fol. I 22.-Arct. Zool. ii。 $\mathrm{N}^{\circ}$ 393.-Lath. Syn. v. p. 168. I 1.-Id. Sup. p. 248.

Habitat in Europa, America; hyberno tempore in Anglia gregatim volans. - 12 pollices longa.

Remiges nigricantes, exceptis 2 primis, puneto albo notatæ : rectrices albæ fafciis fufcis plurimis : uropygium album: roftrum nigrum: pedes virefcentes, digito poftico valde exiguo.

$\beta$. Tr. roftro pedibufque nigris, corpore fufco albo variegato, abdomine albo, rectricibus fufco fafciatis.

Tringa varia, Lin. Syft. i. p. 252. 21.-Gmel. Syft. i. p. 682.

Vanellus varius, Brif: v. p. 103. 3. t. Io. f. 2.-Id. 8 vo. ii. p. 238.

Vanneau varié, Pl. Enl. 923.-Latb. Syn. v. p. I69. I1. var. A.

НАВІта с cum priore.-Uropygium variegatum : rectrix extima alba; tænia lateris interioris fafcia longitudinali.

I 2.

Ochropus. Tr. roftri apice punctato, pedibus virefcentibus, dorfo fufco-viridi, abdomine rectricibufque extimis albis. 
Tringa Ochropus, Lin. Syft. i. p. 250 . I 3.-Faun. Suec. $\mathrm{N}^{\circ}$ 1 80.-Gmel. Syft. i. p. 676.-Brun. $\mathrm{N}^{\circ}$ 183.-Muller, p. 25.-Frifch. 239.Borowf. Nat. iii. p. 95. 5.-Faun. Helv. - Schaf. El. t. 67.

Tringa Aldrov. Raii Syn. p. 108. A. 7. 8.-Will. p. 222. 223. t. 55.Id. (Angl.) p. 300.301 t. 55.-Brif. v. p. 177. 1. t. 16. f. 1.Id. 8 vo. ii. p. 259 .

Glareola, Klein. Av. p. 101. p. 4. 7.

Gambettola, Giarola, Pivinello, Zinnan. Uov. p. 116. t. 22. f. 105.

11 Culbianco, Cett. uc. Sard. p. 257.

Becaffeau, ou Cul-blanc, Buf. vii. p. 534.-Pl. Enl. 843.

Green Sandpiper, $B r$. Zool. ii. N $\mathrm{N}^{\circ}$ 201. $-I d$. fol. 125. t. F. 2. f. 3.Arct. Zool. ii. $\mathrm{N}^{\circ} 3^{8}$ 9.-Lath. Syn. v. p. 170.12.

Habitat in Europa, America; folitaria.-ro pollices longa.-Morchum olet.-Pariendi tempore mas et femina individui comites.

Roftrum virefcens : uropygium varium : fupercilia alba.

B. Tr. cinerea, fupra maculis albidis varia fubtus albida, fronte fuperciliifque albis, pectore nebulofo, rectricibus lateralibus extus nigro fafciatis.

Green Sandpiper, Lath. Syn. v. p. I 7 1. var. B.

Haвiтat in America boreali.-Roftrum nigrum : pedes virefcentes.

13.

Glareola. Tr. roftro lævi, pedibus virefcentibus, corpore fufco albo punctato, pectore albido.

Tringa Glareola, Lin. Syft. i. p. 250 . I3. 3.-Faun. Suec. $\mathrm{N}^{\circ} 184 .-$ Gmel. Syft. i. p. 677.

Wood Sandpiper, Arct. Zool. ii. p. 482. G.-Lath. Syn. v. p. 172. I3.

Habiтat in Suecia fylvis uliginofis; Sturni magnitudine.

Dorfum fufcum albido punctatum: uropygium album: remiges fufcæ, prima rachi nivea, fecundariæ apicis margine albæ: rectrices fafciis albis fufcifque, laterales magis albæ minufque fafciatæ: abdomen albidum.

14.

equeftris. Tr. pedibus virefcentibus, dorfo fufco vario, abdomine uropygioque albis.

Le Chevalier commun, Buf. vii. p. $511 .-P l$. Enl. 844 .

Haвiтат in Europa. -12 pollices longa.

Corpus grifeo rufefcente fufcoque nebulofum : gula, abdomen, criffum, femora, et uropygium alba: cauda rufo-fufca, rectricibus 2 intermedirs nigro fafciatis : roftrum et pedes nigricantes.

Tr. roftro 
I5.

A V E S G R A L L R. Tringa.

litcorea. Tr. roftro lævi pedibufque cinereis, remigibus fufcis rachi primæ nivea. Tringa littorea, Lin. Syjt. i. p. 251 . 17.-Faun. Suec. $\mathrm{N}^{\circ} 185 .-$ Brun. $\mathrm{N}^{\circ} 177$. 178.-Muller, $\mathrm{N}^{\circ}$ 200.-Gmel. Syft. i. p. 677 .

Totanus cinereus, Brif. v. p. 203.7 . t. 17. f. $2 .-I d$. 8 vo. ii. p. 265. Le Chevalier varié, Buf. vii. p. 517.-Pl. Enl. 300.

Mr. Oldham's white Heron, Alb. iii. t. 89 .

Shore Sandpiper, Arct. Zool. ii. p.48 I. F.-Lath. Syn. v. p. 17 I.

HaBITAT in Europa.- - I f fere pollices longa.

Regio oculorum aibicat : linea inter oculos et roftrum fufca : vertex nigricans : collum fufcum lineis obliquis nigricantibus : dorfun fufcum maculis punctifve ferrugineis: uropygium album pennis tamen verfus bafin nigricantibus : pectus, abdomen, tectrices caude fubtus albæ: rectrices fufco et albo undulato-maculatæ, exterioribus maxima parte fufcis.

16. grenovi- Tr. corpore fupra vario, collo fubtus cinereo, abdomine criffo uropycenfis. giique lateribus albis.

Greenwich Sandpiper, Lath. Syn. Sup. p. 249.

Habitat in Anglia rarius; præcedentis magnitudine et facie.

Roftrum nigrum : pedes virefcentes : vertex fufcus nigro ftriatus : collum fubtus cinerafcens: dorfum, tectrices alarum fufco-ferrugineæ albido marginatæ: dorfum pofticum, uropygium, tectrices alarum minores cinereæ : cauda cinerea, rectricibus ad apicem nebulofis, apice ipfo pallide ferrugineo. A præcedente vix fatis diftincta, forte fexu varians?

17.

leucoptera. Tr. fufca, corpore fubtus fuperciliis uropygioque rufis, cauda rufo maculata, humeris albis.

Tringa leucoptera, Gmel. Syft. i. p. 678.

White-winged Sandpiper, Lath.Syn. v. p. 172. 14. t. 82.

Habitat in infulis Maris pacifici, Otabeite, Eimeo; Cinclo major.

Roftrum cinereum: pedes virefcentes : rectrices intermediæ inmaculatæ, laterales nigro rufoque fafciatæ.

18.

maritima. Tr. grifeo nigroque varia fubtus alba, jugulo caudaque obfcuris, rectricibus lateralibus quatuor albo marginatis.

Tringa maritima, Brun. $\mathrm{N}^{\circ}$ 182.-Muller, $\mathrm{N}^{\circ} 206 .-$ Leems Lap. $\mathrm{N}^{\circ}$ 254.-Gmel. Syft. i. p. 678 .

Selninger Sandpiper, Arct. Zool. ii. p. 480. C.-Latb. Syn. v. p. 173. 15. 
732 A VES G R A L L E. Tringa.

Habitat in Norvegice et Iflandie maritimis; Sturni magnitudine. Pedes flavi : rectrices laterales 4 utrinque brevifimæ, margine albæ.

I9.

undata. Tr. obfcura luteo alboque undulata, tectricibus alarum et remigibus fecundariis apice uropygioque albis, cauda cinerea apice nigro marginata.

Tringa undata, Brun. p. 55. 183.-Gmel. Syft. i. p. 678.

Tringa fordide flava fubtus alba, \&c. Naturf. Gef. vii. p. 463 .

Waved Sandpiper, Arit. Zool. ii. p. 48 1. E.-Latb. Syn. v. p. 173. 16.

Habitat in Dania et Norvegia.

20.

uniformis. Tr. roftro brevi nigro, tota dilute cinerea, Muller, $\mathrm{N}^{\circ} 205$.

Tringa uniformis, Gmel. Syft.i. p. 678.

Uniform Sandpiper, Arct. Zool. ii. p. 482. H.-Latb. Syn.v. p. 173. I7.

HABITAT in Iflandia.

2.1.

Calidris. Tr. roftro pedibufque nigricantibus, corpore fubtus olivaceo, uropygio variegato.

Tringa Calidris, Lin. Syft. i. p. 252. 19.-Gmel. Syft. i. p. 68 1.-Brif. v. p. 226. 14. t. 20 . f. r.-Id. 8vo، ii. p. 270.-Faun. Helvet.

La Maubeche, Buf. vii. p. 529. t. 31 .

Dufky Sandpiper, Latb. Syn. v. p. 174. 18.

Hавітат in Europa.- $-9 \frac{\pi}{+}$ pollices longa.

Roftri bafis grifea : corpus fupra fufco-nigricans, pennis margine caftaneis, fubtus caftanea : cauda grifeo-fufca, rectricibus lateralibus albo marginatis. Variat corpore fubtus albo.

22.

nævia. Tr. cinereo rufo violaceoque nigro varia fubtus caftaneo-albida, rectricibus lateralibus fufcis, extima latere exteriore linea longitudinali alba.

'Tringa nævia, Gmel. Syft. i. p. 681 .

Calidris nævia, Brif. v. p. 229. 15.t. 2 I. f. 1.-Id. 8 vo. ii. p. 27 1.

Glareola caftanea, Klein. $A v$. p. 101. 5 .

Maubeche tachetée, Buf. vii. p. 531.-Pl. Enl. 365.

Freckled Sandpiper, Arct. Zool. ii. p. 480. B.-Latb. Syn. v. p. 174. I 9 .

HaRltat in Europa,-9 pollices longa.

Tr. grifea 
grifea. Tr. grifea fubtus alba, collo fubtus uropygio et pectore fufco undatis, rectricibus margine albo.

Tringa grifea, Gmel. Syft. i. p. 681 .

Calidris grifea, Brif. v. p. 233. 16. t. 2 1. f. 2.-Id. 8 vo. ii. p. $272 .-$ Faun. Helvet.

Maubeche grife, Buf. vii. p. 531.-Pl. Enl. 366.

Grilled Sandpiper, Latb. Syn. v. p. 175. 20.

24.

Habitat in Europa; nevie magnitudine.- $9^{\frac{1}{4}}$ pollices longa.

ftriata. Tr. roftro bafi pedibufque flavis, rectricibus albis fufco fafciatis, remigibus plurimis albis.

Tringa ftriata, Lin. Syft. i. p. 248. 5.-Gmel. Syft. i. p. 672.-Muller, No 1 94. - Faun. Groenl. N ${ }^{\circ}$ 73.-Ström. Act. Nidrof. iii. p. 440. t. 6. ${ }^{*}$--Borowfk. Nat. iii. p. 94. 3.-Faun. Helvet.

Totanus ftriatus, Brif. v. p. I96. 5. t. 18. f. I. $-I d$. 8 vo. ii. p. 263.

Le Chevalier rayé, Buf. vii. p. 5 16.-Pl. Enl. 827 .

Striated Sandpiper, ArC7. Zool. ii. N³83.-Lait. Syn. v. p. I76. 21.

HaвiтA ' in Europa et America boreali ; Sturni magnitudine.

Corpus cinereo et nigricante undulatum : pectus et abdomen alba : uropygium album.

$\beta$. Tr. nigricans rufo-grifeo marginata, pectore abdomine uropygioque albis, rectricibus albo nigroque fafciatis.

Totanus nævius, Brif. v. p. 200. 6. t. 18. f. 2.-Id. 8 vo. ii. p. 264.-Lath.Syn. v. p. I77. 21, var. A.

25.

cinerea. Tr. nigro cinereo alboque lunato-varia, pectore et abdomine albis, tectricibus caudæ albo nigroque fafciatis, rectricibus margine albo.

Tringa cinerea, Brun. $\mathrm{N}^{\circ}$ 179.-Muller, $\mathrm{N}^{\circ}$ 202.-Frifch. t. 237.Gmel. Syft. i. p. 673 .

Afh-coloured Sandpiper, $B r$. Zool. ii. No 194.-Id. fol. I24. t. E. I. f. 1. -Arcz. Zool. ii. $\mathrm{N}^{\circ} 236 .-$ Latb. Syn. v. p. 177. 22.

Habitat in Europa, America.- -10 pollices longa.

Roftrum nigrum: pedes obfcure virides, digitis membrana dentata lateribus inftructis.

26.

fufca. Tr. pallide fufca nigro maculata fubtus alba, collo antice nigro ftriato, cauda cinerea, tectricibus alarum albido marginatis.

Brown Sandpiper, Br. Zool. ii. No $195 .-$ Lath. Syn. Sup. p. 250. 
724 A V E S G R A L L E. Tringa.

Habitat in Anglia.-Magnitudo Sc. Gallinule.

Rofrum pedefque nigri.

27.

lincolnien- Tr. alba, fupra maculis grifeis fufcifque varia, fubtus maculis oblongis

fis. fufcis et nigris, rectricibus duabus intermediis toto nigris.

Black Sandpiper, Br. Zool. ii. N 197.-Lath. Syn. Sup. p. 25 I.

Habitat in Anglie agro Lincolnicinf.

28.

Hypoleu- Tr. roftro lævi, pedibus cinereis, corpore cinereo fubtus albo.

cos. Tringa hypoleucos, Lin. Syft. i. p. 250 . 14.-Faun. Suec. $\mathrm{N}^{\circ} 182 .-$ Gmel. Syft. i. p. 678.-Scop. Ann. i. $\mathrm{N}^{\circ}$ 1 43.-Brun. $\mathrm{N}^{\circ}$ 174.Muller, p. 25.-Kram. El. p. 353. 3.-Borowe. Nat. iii. p. 95.6. -Faun. Helvet.

Guinetta, Brif. v. p. 183. 2. t. 16. f. 2.-Id. 8 vo. ii. p. 260. Tringa minor, Raii Syn. p. 108. A. 6.-Will. p. 223. t. 55 .

La Guignette, Buf. vii. p. 540 .

Petite Alouette de mer, Pl. Enl. 850.

Common Sandpiper, Br. Zool. ii. N $\mathrm{N}^{\circ}$ 204. t. 7 1. - Id. fol. 125.-ArEt. Zool. ii. No 388.-Will. (Angl.) p. 301. t. 55.-Lath. Syn. v. p. 178. 23 .

Habitat in Europa, America; in Anglie littoribus fabulofis æeftate frequens.

Corpus cinereum fufco nitens, lituris undulifque fufcis : orbite, gula, abdomen alba: collum antice album lituris fufcis. Ovum incarnatum, maculis parvis rotundatis, in zonam confluentibus verfus extremitatem obtufiorem.

29.

macularia. Tr. roftro bafi pedibufque incarnatis, corpore undique maculato, fuperciliis fafciaque gemina alarum albis.

Tringa macularia, Lin. Syft.i. p. 249.7.-Gmel. Syft. i. p. 672.

Turdus aquaticus, Brif.v. p. 255. 20.-Id. 8 vo. ii. p. 275 .

La Grive d'eau, Buf. viii. p. 140 .

Spotted Tringa, Edw. t. 277. f. 2.

Spotted Sandpiper, Br. Zool. ii. N 196.-Id. fol. 124.-ArEt. Zool. ii. $\mathrm{N}^{\circ} 38$.-Lath. Syn. v. p. 179. 24.

Habitat in America; in Anglia rarius. -8 pollices longa. Roftrum obfcurum : pedes incarnati.

Femina corpore fubtus immaculato.

Tr. nigricans 
30.

A V E S G R A L L \&. Tringa.

novebora- Tr. nigricans pennis margine albidis fubtus alba, tectricibus caudæ albo cenfis. nigroque fafciatis, cauda cinerea.

Tringa noveboracenfis, Gmel. Syft. i. p. 673 .

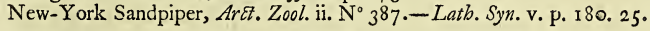

Habitat in Noveboraco. - PeEtus fufco maculatum: latera fub alis ftriis fufcis.

31.

virgata. Tr. fufca albo marginata fubtus alba, fcapularibus maculis ferrugineis, capite colloque albis fufco longitudinaliter ftriatis.

Tringa virgata, Gmel. Syft. i. p. 674 .

Streaked Sandpiper, Lath. Syn. v. p. 180. 26.

HaBitat in finu Sanduicenfi; Gallinaginis magnitudine.

Rofrrum obfcurum : pedes obfcure flavi : teetrices caude alba.

32.

borealis. Tr. cinerea, collo lateribus pectoreque pallidiore undulatis, fuperciliis gula tectricibus caudre corporeque fubtus albis.

Tringa borealis, Gmel. Syft. i. p. 674 .

Boreal Sandpiper, Latb. Syn. v. p. I81. 27.

Haвiтат in finu Regis Georgii.-Roftrum, pedes, remiges, et cauda obfcura.

33.

novæ Ter- Tr. nigricans fufco marginata fubtus cinereo-alba, roftro pedibus alula

re. $\quad$ remigibus caudaque nigris.

Tringa novæ Terra, Gmel. Syft. i. p. 674 .

Newfoundland Sandpiper, Lath. Syn. v. p. 181, 28.

Habitat in infula nove Terra.

variegata. Tr. roftro pedibufque nigris, corpore fupra fufco nigro et rufo variegato fubtus albo, pectore nigro maculato, cauda fufca.

Tringa variegata, Gmel. Syft. i. p. 674 .

Variegated Sandpiper, Lath. Syn. v. p. 18 r. 29.

Habitat in finu Nootka.

35 .

Cinclus. Tr. roftro pedibufque nigris, loris albis, corpore uropygioque grifeis fufcifque.

Tringa cinclus, Lin. Syft. i. p. 25 1. 18.-Gmel. Syft. i. p. 680.-Georgi reife. p. 172.-Bororefk. Nat. iii. p. 96. 8.-Faun. Helvet.-Brif.

v. p. $2 I$ I。 
v. p. 2 Ir. Io. t. I g. f. r.-Id. 8vo. ii. p. 267.-Raii Syn. p. I10. A I3.-190. II.

L'Alouette de Mer, Buf. vii. p. 548.-Pl. Enl. 85 r.

Leaft Snipe, Sloan. Fom. p. 320 . I4. t. $265.4 .-$ Brown. Fam. p. 477 . Wagtail, Kolh. Cap. ii. p. I 52 ?

Sanderling, Alb. iii. t. 88.

Purre, or Stint, Br. Zool. ii. $\mathrm{N}^{\circ}$ 206. t. 7 1. -Id. fol. I 26.-ArEt. Zool. ii. $\mathrm{N}^{\circ}$ 390.-Will. p. 226.-Id. (Angl.) p. 305.-Lath. Syn. v. p. I82. 30.

Habitat in Europa, Africa, America; in Anglia hyeme frequens. - Gregaria.

Corpus magnitudine Alaude fubtus albicans : collum fubtus albidum maculis fufcis: remiges primores fcapo albo verfus apicem : rettrices intermediæ binæ acuminatæ, laterales expanfæ utrinque in concavum tendunt : roftrum nigrum: pedes obfcure virides. Variat pennis corporis fupra ferrugineo marginatis. An fequenti affinis?

36.

ruficollis. Tr. cinerea fubtus ferruginea, capite colloque ferrugineo nigroque ftriatis.

Tringa ruficollis, Pall. reife. iii. p. 700. 3r.-Gmel. Syft. i. p. 680.

Red-necked Sandpiper, Lath. Syn. v. p. 183. 3 I.

Habrtat circa lacus falfos Daunria; campeftris; vere gregaria; Cincli magnitudine et fimilitudine. An varietas.

37.

alpina. Tr. teftaceo-fufca, pectore nigricante, rectricibus cinereo-albidis, pedibus fufcefcentibus.

Tringa alpina, Lin. Syft. i. p. 249. 11.-Faun. Suec. $\mathrm{N}^{\circ}$ 1 8 1.-Gmel. Syft. i. p. 676.-Brun. $\mathrm{N}^{\circ}$ i67? 173.-Muller, $\mathrm{N}^{\circ}$ 197.-Frifch. t. 24r.-Faun. Groenl: No 77.- - Faun. Helvet.

Cinclus torquatus, Brif. v. p. 2 16. I 1. t. I g. f. 2. -Id. 8 vo. ii. p. 268. Gallinago anglicana, Brif. v. p. $3 \circ 9 \cdot 5 \cdot-I d .8$ vo. ii. p. 288.

Le Cincle, Buf. vii. p. 553.-Pl. Enl. 852 .

La Brunette, Buf. vii. p. 493 .

Dunlin, Br. Zool. ii. $\mathrm{N}^{\circ} 205 .-I d$. fol. 126. t. E. I. f. 2.-ArEt. Zool. ii. $\mathrm{N}^{\circ} 39$ r. -Raii Syn. p. rag. A. I r.-Will. p. 226.-Id. (Angl.) p. 305.-Lath. Syn. v. p. $185.33 .-$ Id. Sup. p. 249.

Habitat in Europa, Afia, America; in Anglie feptentrionali regione verfatur. $-9 \frac{3}{4}$ pollices longa.

Corpus grifeo fufcoque intime mixtis maculatum: fternum nigrum: 
38.

abdomen album: remiges primores fufcæ rachi alba, fecundariæ majores apice margine exteriore latereque interiore albæ : rectrices cinereæ.

pufilla.

Tr. roftro pedibufque fufcis, corpore fubtus rufefcente, reetricibus extimis fcapo albo, uropygio variegato.

Tringa pufilla, Lin. Syft. i. p. 252. 20.-Gmel. Syft. i. p. 68 1.

Cinclus dominicenfis minor, Brif. v. p. 222. 13. t. 25. f. 2.-Id. 8 vo. ii. p. 269 .

Little Sandpiper, Br. Zool. ii. N' 207,-Gen. Birds, p. 65. t. r2.ArEt. Zool. ii. N $\mathrm{N}^{\circ}$ 397.-Latb. Syn. v. p. 184.32.

Habitat in Europa boreali, finu America Nootka; rarius in Anglia.

Corpus magnitudine Paferis, fufco ferrugineoque varium, fubtus albido-rufefcens : rętrices 3 extimæ rachi alba, intermediæ acuminatæ.

inlandica. Tr. roftro pedibufque fufcis, corpore fubtus ferrugineo, remigibus fecundariis margine albis.

Tringa inandica, Lin. Syft. i. Addend.-Gmel. Syft. i. p. 682.

- ferruginea, Brun. $\mathrm{N}^{\circ} 180 .-$ Muller, $\mathrm{N}^{\circ} 205$.

Scolopax fubarquata, N. C. Petr. xix. p. 47 1. t. 18.-Gmel. Syft. i. p. 658.

Red Sandpiper, Br. Zool. ii. No 202. t. 72.-ArEt. Zool. ii. $N^{\circ} 393$.

Aberdeen Sandpiper, Br. Zool. ii. $\mathrm{N}^{\circ} 203$.

Red Sandpiper, Latb. Syn. v. p. 186. 34.

Habitat in Europa, America, Iflandia, et ad mare Cajpium; interdum in Anglia.-Corpus magnitudine Turturis, 8-10 pollices longum, totum fcolopacinum, f. e nigro ferrugineoque confertim maculatum, fubtus vero totum rufo-ferrugineum : alarum tectrices margine exteriore albæ, at fub alæ tectrices albæ, notatæ nigro: uropygium albidum nigro undulatum : crifum albidum ftriis aliquot nigris : remiges omnes nigræ rachi alba, fecundariæ infuper margine exteriore etiam alba : rectrices cinereæ rachi alba, nullæ harum acutæ.

Femina pectore ferrugineo-fufco, abdomine albo.

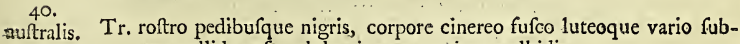
tus pallide rufo, abdomine uropygioque albidis.

Tringa auftralis, Gmel. Syft. i. p. 679 .

Southern Sandpiper, Latb. Syn.v. p. 187. 35.-Id. Sup. p. 249.

Habitat in Cayana et ad fretum Hudjonis. - I I pollices longa.

Uropygium fafciis obfcuris: remiges et cauda obfcura. 
$\begin{array}{cc}4 \text { T. } & 73^{8} \\ \text { fafciata. } & \text { Tr. roftro vertice occipite tania pone oculos et abdomine nigris, fronte }\end{array}$ caudaque rotundatd albis, $F$. G. Gmel. It. ii. p. 194, t. 26.-Gmel. Syft. i. p. 67 1.

Haвitat in Afraconia.

42.

Keptufch- Tr. corpore cinereo, vertice nigro, abdomine nigricante ad exitum ru.

ca. fefcente, Lepecb. It. ii. p. 229.-Gmel. Syft. i. p. 673.

Habitat in Sibirice paludibus.

43. Tr. capite colloque nigris, dorfo alifque fufcefcentibus nigro mixtis,
atra. pectore et abdomine cinereis, uropygio cinereo albo nigroque undulato, Naturf. xiii. p. 193.-Gmel. Syf. i. p. 673.

Habitat ad Rbeni ripas.

44.

Canutus. Tr. roftro lævi, pedibus cinerafcentibus, remigibus primoribus ferratis, rectrice extima alba immaculata.

Tringa Canutus, Lin. Syft. i. p. 25 1. 1 5.-Faun. Suec. $\mathrm{N}^{\circ}$ 1 83.-Gmel. Syft.i. p. 679.-Brun. N. I 82.-Brif. v. p. $25^{8}$. 21.-Id. 8 vo. ii. p. $276 .-$ Raii Syn. p. 108. A. 5.-Will. p. 224. t. $5^{6}$.

Le Canut, Buf. viii. p. 142.

Knot, Br. Zool. ii. No 193.-Id. fol. 123. t. E. 2. f. 1.-Flor. Scot. i。 p. 34. t. 3.-Arct. Zool. ii. $\mathrm{N}^{\circ}$ 384.-Will. (Angl.) p. 302.Edw. t. 276.-Lath. Syn. v. p. $187 \cdot 36$.

Habitat in Europa, Afia, America; in Anglice comitatu Lincolnienfo arenofis maris littoribus frequens; gregaria.-9 pollices et ultra longa. - Caro in deliciis habetur.

Supercilia, fafcia alarum, corpus fubtus, rectrix extima alba: uropygium album lunulis fufcis: rofrum pedefque fufci. Variat fronte, gula, jugulo cinereo-fufcis.

Ovum incarnatum, maculis confertis aurantio-rubris. .

45.

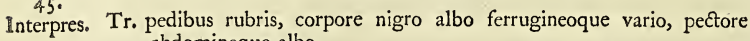
abdomineque albo.

Tringa Interpres, Lin. Syf. i. p. 248. 4.-Faun. Suec. $\mathrm{N}^{\circ}$ 178.-Gmel. Syft. i. p. 671.-Brun. $\mathrm{N}^{\circ}$ 175.-Muller, $\mathrm{N}^{\circ}$ 193.-Faun. Helvet. Arenaria, Brif. v. p. I32. I. -Id. 8vo. ii. p. 246.-Klein. Av. p. 21.9. Morinellus marinus, Raii Syn. p. 112. A. 5.-Will. p. 23 1. t. 58. Le Tournepierre, Buf, viii. p. I30. to, 10 .

Coulon 
A VES G R A L L BE. liringa.

Coulon-chaud, $P l . \bar{E} n l .856$.

Stein-dreher, AEt. Soc. Hall. i. p. I I r.

Hebridal Sandpiper, Br. Zool. ii. N $\mathrm{N}^{\circ} 200 .-$ Flor. Scot. $\mathrm{N}^{\circ}$ 1 52.t. 3.ArEZ. Zool. ii. $\mathrm{N}^{\circ} 3^{82}$.

Turnftone, or Sea Dotterel, Edw. t. 141.-Will. (Angl.) p. 311.Lath. Syn. v. p. 188. 37.-Id. Sup. p. 249.

Habitat in Anglia et America maritimis.-9 pollices longa.

Roftrum apice fubafcendens, nigrum: gene collumque fubtus nigra: cauda bafi et apice alba, medio nigra. Femina obfcurior capite fufco albidoque vario, collum fubtus nigricans. In terra nidificat. Ovum olivaceum nigro maculatum.

ß. Tr. pedibus rubris, rectricibus nigricantibus bafi albis, corpore grifeo, pectore nigro.

Tringa Morinella, Lin. Syft. i. p. 249.6.-Gmel. Syft. i. p. 671. 4. 3.Faun. Helvet.

Arenaria cinerea, Brif. v. p. 137. 2. t. I I. f. 2.-Id. 8 vo. ii. p. 247. Turnftone, or Sea-Dotterel, Br. Zool. ii. $\mathrm{N}^{\circ}$ 199.-Id. fol. I25. t. E. 2. f. 2.-Catef. Car. i. t. 72.-Lath. Syn. v. p. 190. 37. var. A.

Habitat in Scotia, America Septentrionali.

Corpus fupra cinereo-fufcum, fubtus, gula, uropygium, bafifque rectricum alba : collum fubtus et peEtus faturate fufcum : roftrum fufcum.

$\gamma$. Tr. fufco alboque varia, gula jugulo abdomine fafciaque alarum gemina albis, remigibus caudaque obfcuris.

Coulon-chaud de Cayenne, Pl. Enl. 340.-Lath. Syn. v. p. I90. B.

Habitat in Cayana.-Roftrum flavum apice nigrum: pedes rubri.

§. Tr. fufco alboque varia fubtus alba, pectore maculis fufcis, remigibus caudaque fufcis, rectricibus exterioribus margine, omnibus apice albis.

Coulon-chaud gris de Cayenne, Pl. Enl. 857.-Lath. Syn. v. p. 191.

HaBitat in Cayana.-Roftrum nigrum: pedes fufci. 


\section{GENUS LXXIV. CHARADRIUS.}

Rofrum teretiufculum, rectum, obtufum.

Nares lineares.

Pedes curforii, tridactyli.

I.

Pluvialis. Ch. corpore nigro viridique maculato fubtus albido, pedibus cinereis.

Charadrius pluvialis, Lin. Syf. i. p. 254. 7.-Faun. Suec. $\mathrm{N}^{\circ}$ 190.-

Gmel. Syft. i. p. 688.-Brun. $\mathrm{N}^{\circ}$ 187.-Kram. El. p. 354. 1.-

Frifcb. t. $217 .-$ Brif. v. p. 43. 1. t. 4. f. 1.-Id. 8 vo. ii. p. 222.-

Faun. Arag. p. 78.-Borow/k. Nat. iii. p. I I I. 4.-Faun. Helvet.

Gavia viridis, Klein. Av. p. I 9. 2.-Id. Stem. p. 3. t. 3. f. I. a.-c.

Pluvialis viridis, Raii Syn. p. I I 1. A. 2.-190. 9.-Will. p. 229. t. 57.

Kleiner Braach Vogel, Wirfing Vog. t. 34

Le Pluvier doré, Buf. viii. p. 8 r.-Pl. Enl. 904.-Hift. Prov. i. p. 353. Piviere, Cet. uc. Sard. p. 257.

Golden or green Plover, Br. Zool. ii. N'208. t. 72.-Id. fol. 128.Flor. Scot. i. $\mathrm{N}^{\circ}$ 1 56.-RuJ. Alep. p. 7 1.-Arct. Zool. ii. $\mathrm{N}^{\circ} 399$. -Will. (Angl.) p. 308. - Sloan. Fam. 318. t. 269. 1.-Alb. i. t. 75. - Lath. Syn. v. p. 193. r.-Id. Sup. p. 252.

HaвiтAт fere per omnem terrarum orbem.- $-10 \frac{r}{2}$ pollices longus. In Anglice montofis et ericetis nidificat.

Roftrum pedefque nigricantes : pectus grifeum maculis nigricantibus. Tempore incubationis pectus nigrum vel nigro maculatum : ungue minutiffimo poftico quandoque gaudent individua. Caro fapidiffima. Ovum albidum maculis parvis rotundis purpureis.

ß. Ch. corpore nigricante flavefcenteque vario fubtus albo, collo inferiore et pectore dilute grifeis.

Pluvialis dominicenfis aurea, Brif. v. p. 48. 3. t. 6. f. I.-Id. 8 va ii. p. 224.

Habitat in Dominicenfi infula.

2.

rubidus. Ch. rutilus pulveratim albo varius maculis nigris, rectricibus duabus intermediis fufcis margine ferrugineis, lateralibus albis.

Charadrius 


\section{A V E S G R A L L $\mathbb{E}$. Charadrius.}

Charadrius rubidus, Gmel. Syft. i. p. 688.

Ruddy Plover, Arct. Zool. ii. No 404. - Lath. Syn. v. p. 195. 2.

HaBitat ad finum Hudjonis.

$3 \cdot$

Himanto- Ch. albus, dorfo nigro, roftro nigro capite longiore, pedibus longifimis.

pus. Charadrius himantopus, Lin. Syjt. i. p. 255 . I I. -Scop. Ann. i. N ${ }^{\circ} 248$. -Gmel. reife, i. p. I 52. t. 32.-Gmel. Syft. i. p. 690.-Borowes. Nat. iii. P. I I 3. 7.-Faun. Helvet.

Charadrius autumnalis, Haffelq. Ii. p. 253. 29.-Id. (ed. Angl.) I 99. Himantopus, Brif. v. p. 33. 1. t. 3. f. 1.-Id. 8vo. ii. p. 220. 1.Raii Syn. p. 106. 9.-190, 7.-193. I. t. I. f. 3.-Will. p. 219. t. 54.-Klein. Av. p. 22.-Id. Stem. p. 3.

L'Echaffe, Buf. viii. p. I I4. t. 8.-Pl. Enl. 878 .

Long-legged Plover, $\mathrm{Br}$. Zool. ii. $\mathrm{N}^{\circ}$ 209. -Id. fol. I 28. Addenda.Flor. Scot. i. No i 57. t. 4.-Arct. Zool. ii. No 405.-Latb. Syn. v. p. 195. 3.-Id. Sup. p. 252,-Sibb. Hift. Scot. iii. I 8. t. I I. I 3.

Habitat in Europa auftrali, Africa, Afia, et America; ad maris littora interdum in Anglia.

Roftrum nigrum apice craffius: corpus album, fed nigricans dorfo, occipite, tectricilus alarum. Sexus alter albus, alis dorfoque ufque ad uropygium nigris.

ß. Himantopus mexicanus, Brif. v. p. 36. 2,-Id. 8 vo. ii. p. 220 \%

Comaltecatl, Raii Syn. p. I77.

Habitat in Mexico hyeme.-Corpus candidum: ale albo et nigro variæ : caput fuperius nigrum : rectrices candidæ.

$4 \cdot$

Calidris. Ch. roftro pedibufque nigris, loris uropygioque fubgrifeis, corpore fubtus albo immaculato.

Charadrius calidris, Lin. Syft. i. p. 255. 9.-Georgi reife p. 172.-Bo. rowesk. Nat. iii. p. I 1 2. 5.-Gmel. Syft. i. p 689.

Tringa arenaria, Lin. Syft. i. p. 251. 16.-Raii Syn. p. I09. A. I 1.Will. p. $225 .-$ Borowfk. Nat. iii. p. 96. 7.-Gmel. Syjt. i. p. 680. Calidris grifea minor, Brif.v. p. 236 . 17. t. 20. f. 2. -Id. 8 vo. ii. p. 272. Le Sanderling, Buf. vii. p. 532.

Sanderling, or Curwillet, $B r$. Zool. ii. N $\mathrm{N}^{\circ} 212$. t. 73.-Id. fol. I 29. Addend. -ArEz. Zool. ii. No 403.-Will. (Angl.) p. 3०3.-Alb. ii: t. 74. -Lath. Syn. v. p. 197.-Id. Sup. p. 253.

Habitat 
742 A V E S G R A L L IE. Charadrits.

Habitat in Europa, Afsa, America; in Anglia fatis frequens, in maris littoribus arenofis gregatim volans. -8 pollices longus.

Corpus grifeo varium: Facies, colltm, pegius, et abdomen nivea : remiges primores fcapo candido. Ovum fufco-lutefcens, purpureo maculofim maculis veríus apicem obtufiorem confuentibus.

ß. Ch. fronte et corpore fubtus ex cinereo albis, Latb. Syn. v. p. 197 . 4. A.

Variat corpore cinereo fufco vario, fronte et fubtus cinereo-alba : tectricibus alarum nigris margine cinereo, majoribus cinereis margine albo: remigibus caudeque obfcuris.

In adulta ave corpus fupra pallide caruleo-grifeum, minime fufco varium.

5.

apricarius. Ch. pectore abdomineque nigro, corpore fufco albo luteoque punctato, pedibus cinereis.

Charadrius apricarius, Lin. Syft. i. p. 254. 6.-Fann. Suec. $N^{\circ} 189 .-$ It. Oeland. 72.-Brun. $\mathrm{N}^{\circ}$ 186.-Muller, $\mathrm{N}^{\circ} 212,-$ Faun. Groenl. N*79.-Georgi reije, p. 172.-Gmel. Syft. i. p. 687.-Borow/k. Nat. iii. p. 109. t. 58. - Faun. Helvet.

Pluvialis aurea freti Hudfonis, Brif. v. p. 5 I. 4. $-I d$. 8 vo. ii. p. 224 . Le Pluvier doré à gorge noire, Buf, viii. p. 85 .

Spotted Plover, Edw. t. 140.-Bancr. Guian. p. 173.

Alwargrim Plover, Ariz. Zool. ii. No 398.-Id. Sup. p. 6g.-Lath. Syn。 v. p. 198.5 .

Habitat in Europa, Anerica, et Sibiria ; pluvialis magnitudine.

Frons, supercilia, palpebra inferior, bypocbondria, crifjumque alba: gula, abdomen, linea fub collo nigra : rofrum pedefque nigricantia. Mas

6. temporibus albis; femina fufcis.

vaciferus. Ch. fafciis pectoris colli frontis genarumque nigris, cauda lutea fafcia nigra, pedibus flavis.

Charadrius vociferus, Lin. Syft. i. p. 253. 3.-Gmel. Syft. ii. p. 68 5.Borowe/k. Nat. iii. p. II3. 8.

Pluvialis virginiana torquata, Brif. v. p. 68. 9. -Id. 8vo. ii. p. 228.Klein. Av. p. 21.8.

Kildir, Buf. viii. p. 96.

Chattering Plover, Kill-Deer, Cat. Car. i. t. $7 \mathrm{~s}$.

Noify Plover, Arct. Zool. ii. N 400 -Lath. Syn. v. p. x99. 6. 
A V E S G R A L L FE. Charadrius.

Habitat in America Septentrionali.-Species inquieta, garrula, migratoria. $-9 \frac{3}{4}$ pollices longa.

Corpus fupra grifeo-fufcum fubtus album : roftrum nigrum : pedes lutei.

$\beta$. Ch. pectore grifeo-variegato, fronte alba, vertice collarique nigro, roftro pedibufque cærulefcentibus.

Charadrius torquatus, Lin. Syft. i. p. 255. 9.

Pluvialis dominicenfis torquata, Brif. v. p. 7o. ro. t. 6. f. 2.-Id. 8 vo. ii. p. 229.

Pluvier à collier de St. Domingue, Pl. Enl. 286.-Lath. Syn. v. p. 200.

Haziт a in Dominicenfi infula.-8 $\frac{3}{4}$ pollices longus. - Facies et magnitudo Hiaticule : uropygium rufum: rectrices 3 extimæ apice albæ.

7.

jarraicen- Ch. obfcure fufcus fubtus albus, pectore nigris maculis vario, torque fis.

albo, rectricibus albidis rufo et nigricante variegatis.

Charadrius jamaicenfis, Gmel. Syft. i. p. 685 .

Pluvialis jamaicenfis torquata, Brif. v. p. 75. I1. $-I d$. 8vo. ii. p. 230. - ex fufco et albo varia, cauda longiore, Raii Syn. p. I90. Io. -Sloon. Jam. p. 318. t. 265 . f. 3 .

Large grey Snipe, Brown. Fam. p. 477.

Collared Plover, Lath. Syn. v. p. 20 1. 7.

HaBITAт in Jamaica, ad ripas fluviorum frequens. -8 poll. longus.

8.

Hiaticula. Ch. grifeo-fufcus fubtus albus, pectore nigro, fronte nigricante fafciola alba, vertice fufco, pedibus luteis.

Charadrius Hiaticula, Lin. Syft. i. p. 253. 1.-Faun. Suec. $\mathrm{N}^{\circ}$ 187.Gmel. Syst. i. p. 683.-Scop. Ann. i. No 147.-Brun. No 184.Muller, $\mathrm{N}^{\circ}$ 209.-Kram. El. p. 354. 2.-Frifch. t. 214.-Georgi reife, p. 172.-Faun. Groenl. N. 78.-Raii Syn. p. I 1 2. A. 6.-190. 1 3.-Wili. p. 230. t. 57.-Borowg. Nat. iii. p. 109. 2.-Faun. Helvet.

Pluvialis torquata minor, Brif. v. p. 63. 8. t. 5. f. 2.-Id. 8 vo. i. p. 227. Gavia littoralis, Klein. Av. p. 2 I. 6.-Id. Stem. p. 3. f. 4. a. b. Petit Pluvier à collier, Buf. viii. p. 90. t. 6.-Pl. Enl. 921 . Iaticula, Cett. uc. Sard. p. 259.

Sea Lark, Alb. i. t. 80.-Will. (Angl.) p. 310. t. 57.-Sloan. Fam. p. 319. t. 269. f. 2.

Ringed Plover, Br. Zool. ii. No 2 I r. -Id. fol. I29. t. Addenda.-Arat. Zool. ii. $\mathrm{N}^{\circ} 401 .-L a t b . S y n$. v. p. 201.8. 


\section{A VE S G R A L L F. Charadrius.}

Haвiтat in Europa, America; ad ripas curfitans; primo vere ad nos venit, autuinno migrat.

Roftrum rubrum apice nigro: irides avellaneæ: pedes rubri. Ovum albo-cærulefcens, maculis rotundatis parvis purpurafcentibus.

ß. Ch. grifeus, collari abdomineque albis, Faun. Arag. p. 78 .

Habitat Cefaraugufa, circa Epila.

Frons grifea: remiges fufcæ: peEtus grifeum: orbite flavæ: roftrun nigrum et pedes rufi : rectrices fuicæ, 6,6 , immaculatæ; $3,4,5$, apicibus albis; 2 extimæ albæ, macula intermedia furca. Avis primi anni? In quibufdam roftrum et pedes nigri.

$\gamma$. Ch. grifeo-cinereus, fronte collarique albis, caudæ ultima medietate nigra apice ferrugineo, Latb. Syn. v. p. 203.

Habitat in America auftrali et Septentrionali, et in infula Oribybee Maris pacifici.-Rqfrum nigrum : pedes pallidi.

9. alexandri- $\mathrm{Ch}$. fufcus, fronte collarique dorfali abdomineque albis, rectricibus lanus. teralibus utrinque candidis, pedibus nigris.

Charadrius alexandrinus, Lin. Syft. i. p. 253. 2.-Gmel. Syft. i. p. 683. -Hafelq. It. p. 255 . 30.-Id. ( $\mathrm{ed}$. Angl.) p. 190.-Brun. App. p. 77.- Muller, $\mathrm{N}^{\circ} 210$.

Pluvialis torquata, Brif. v. p. 60. 7. t. 5. f. r.-Id. 8 vo. ii. p. 226.

L.e Pluvier à collier, Buf. viii. p. 90.-Pl. Enl. 920.

Alexandrine Plover, Lath. Syn. v. p. 203. 9.

Habitat ad Agypti ex Nilo canalem.

Roftrum pedefque nigri: rectrices 1,2 , utrinque candidæ; 3,4 , utrinque fordide albæ apicibus fufcis; 5,6 , fufco-nigricantes reliquis paulo longiores: remiges e grifeo nigricantes, I rachi alba; 5-8 macula alba oblonga in margine exteriore; fecundariæ apice albæ: tedtrices apice albæ.

ß. Ch. fafcia pectorali nigra, fuperciliis albis, rectricibus apice albis fafcia nigra, pedibus caruleis.

Charadrius ægyptius, Lin. Syft. i. p. 254. 4-Haffelq. It. 256. 31.Id. (ed. Angl.) p. 190.-Lath. Syn. v. p. 204.

Haвiтat in Egypti apricis.-Vietitat infectis.

$\gamma$. Ch. vertice 
A V E S GR A L L $\mathbb{R}$. Charadrius.

$\gamma$. Ch. vertice nigro, pedibus rubris, Lath. Syn. v. p. 204. 9. B.

Variat vitta alba a fronte fupra oculos ad nucham ufque ducta, infra oculos altera nigra; corpore fupra pallide fufco fubtus albo, fafcia pectoris nigra : cauda alba fafcia ad apicem nigra: roftrum et pedes ut in Hiaticula.

10.

atricapil- Ch. cinereo fufcus, pileo nigro, fuperciliis gula abdomineque albis,

lus. cauda alba fafcia ad bafin nigra.

Charadrius atricapillus, Gmel. Syft. i. p. 686.

Black-crowned Plover, Arct. Zool. ii. N402.-Latb. Syn. v. p. 2 10. I 5.

Haвiтат in Noveboraco.- - Io pollices longus.

Roftrum pede/que rubri : inter pecius et abdomen fafcia tranfverfa fufca.

II.

philippi- Ch. fufcus, regione oculorum torque colli caudaque nigris, fronte cornus. pore fubtus rectricibufque apice albis. Petit Pluvier à collier de Luçon, Son. Voy. p. 84. t. 46.-Latb. Syn. va p. 205. C:

Habitat in Pbilippinis; alexandrini magnitudine. Roftrum pedefque nigricantes.

I 2.

novæ Zea- Ch. cinereo-viridis, facie et torque colli nigris, vitta annulari capitis landiæ. fafcia alarum corporeque fubtus albis.

Charadrius novæ Seelandiæ, Gmel. Syft. i. p. 684.

New-Zealand Plover, Lath. Syn. v. p. 206. 10. t. 83.

Haвiтat in nova Zealendia; Hiaticula paulo major.-8 poll. long.

Facies ultra oculos nigra ad collum pofticum utrinque producta.

I3.

gregarius. Ch. cinereus fubtus albus, pectore lunula nigra poftice rufa, rectricibus albis fafcia nigra.

Charadrius gregarius, Pall. reife, i. t. 456. 9.-Gmel. Syjt. i. p. 684. Gregarious Plover, Lath. Syn. v. p. 206. I I.

Навгтат copiofe in campeftribus ad Volgam, Jaickum, et Samarum. -Magnitudo et habitus Tr. Vanelli, quocum et roftro et pedibus fubtetradactylis convenit.

Frons alba fafciaque a fronte lata fupraciliaris in nucham coiens : lore nigra ultra oculos producta.

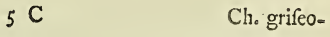


I4.

746 A V E S G R A L L F E. Charadrius.

afiaticus. Ch. grifeo-fufcus, fronte fuperciliis gula abdomineque albis.

Charadrius afiaticus, Pall. reife, ii. p. $715 \cdot 32 .-$ Gmel. Syft. i. p. 684.

Afiatic Plover, Latb. Syn. v. p. 207. I2.

HaBITAt ad lacus falfos Tataric deferti auftralioris; rarior atque folitaria avis.-Magnitudo fupra Hiaticulam.

fugulum a medio collo ferrugineum terminatum fafcia pectorali tranfverfa fufca.

I5.

tataricus. Ch. collo cinereo, pectore ferrugineo, fafcia gulæ pectorifque nigra, abdomine albo, alis caudaque fufcis.

Charadrius tataricus, Pall. It. ii. p. 7 I 4. 32. *-Lath. Syn. v. p. 210. $14 . \mathrm{B}$.

Habitat in auftralioribus deferti Tatarici, circa lacus falfos.

16 .

mongolus. Ch. cinereo fufcus, fronte fubtufque albus, jugulo pectoreque ferrugineis, gula lunula nigra.

Charadrius mongolus, Pall. reife, iii. p. 700. 29.-Gmel. Syft. i. p. 685. Mongolian Plover, Latb. Syn. v. p. 207. I 3.

Habitat circa lacus falfos, verfus Mongolie fines non infrequens; folitarius.-Magnitudo et forma Morinelli.

17.

Morinel- $\mathrm{Ch}$. pectore ferrugineo, fafcia fuperciliorum pectorifque lineari alba,

lus. $\quad$ pedibus nigris.

Charadrius Morinellus, Lin. Syft. i. p. 254. 5.-Faun. Suec. N॰ I 88.Gmel. Syft. i. p. 686.-Brun. $\mathrm{N}^{\circ}$ I 85.-Muller, $\mathrm{N}^{\circ} 211$.-Brif. v.

p. 54. 5. t. 4. f. 2. -Id. 8 vo. ii. p. 225.-Raii Syn. p. II I. A. 4.Will. p. 230. t. 55. 57.-Klein. Av. p. 2 I. 5.-Id. Stem. p. 3. t. 3. f. 3. a. b.-Borozojk. Nat. iii. p. I Io. 3.-Faun. Helvet. Petit Pluvier, ou le Guignard, Buf. viii. p. 87.-Pl. Enl. 832 . Dotterel, Br. Zool. ii. N 2 I0. t. 73:-Id. fol. 129. t. D.-ArEt. Zool. ii. p. 487. A.-Will. (Angl.) p. 309.-Alb. ii. t. 62:-Latb. Syn. v. p. 208. 14 .

Habitat in Europe campeftribus locis; in Anglia migratoria; in Nortbumbria et Scotia nidificans.

Mas ad fcrobiculum abdominis niger. Femina vitta fuperciliari obfcura. Vertex, roftrum, pedefque nigricantia : linea pectoris alba : abdomen albo nigroque varium: cauda fufca, ad apicem fafcia nigricans apice albo,

ß. Morinellus 
ß. Morinellūs anglicanus, Brif. v. p. 58. 6. $-I d$. 8 vo. ii. p. 226.

Gavia morinella altera, Klein. Av. p. 2 r. 7 .

Dotterel, Alb. ii. t. 63.-Latb. Syn. v. p. 209. 14. A.

A priore differt vertice albo, grifeo-fufco, flavefcenteque vario; cora pore fubtus flavefcente alboque mixto; rectricibus duabus intermediis 18. fufcis, lateralibus albis.

falklandi- Ch. fufco-nebulofus, fronte collo fubtus abdomineque albis, vitta ancus. nulari capitis ferruginea, fafcia verticis pectoreque nigris. Rufty-crowned Plover, Portlock Voy. t. p. 36. M. et $F$.

Habrtat in infulis Falklandia. $-7 \frac{\frac{5}{2}}{2}$ pollices longus.

Roftrum et pedes nigricantes: corpus fupra cinereo-fufcum nebulofum, fubtus album: verticis medio fafcia nigra ad latera colli utrinque defcendens ufque ad peEtus : circulus ferrugineus coronæ inftar caput porterius cingit.

Femina omnibus mari fimillima, fed caput corona non cingitur.

If I9. $\quad C h$. fronte ex albo et nigro varia, vertice nigricante fafciato, pectore fufco fafcia alba terminato, abdomine ferrugineo, Lepecb. It. ii. t. 6 .

Charadrius fibiricus, Gmel. Syft. i. p. 690.

Habitat in Sibiria.

20.

obfcurus. Ch. nigricans fubtus ochraceus, fronte gulaque albidis, collo obfcuriore ftriis pallidis.

Charadrius obfcurus, Gmel. Syft. i. p. 686.

Dufky Plover, Lath. Syn. v. p. 2 1. 16.

Habitat in nova Zealandia.-Roftrum nigrum: pedes cærulefcentes.

$2 I$.

fulvus. Ch. niger fulvo marginatus fubtus albidus, pectore fulvo maculis nigris, fafcia alarum alba.

Charadrius fulvus, Gmel. Syft. i. p. 687.

Fulvous Plover, Lath. Syn. v. p. 2 i 1.17.

Habitat in infulæ Otabeite paludofis; Vanello minor. - I 2 pollices longus.-Roftrum nigrum : pedes cærulei : tectrices alarum minores et mediæ nigræ fulvo maculatæ, majores fufco-nigricantes apice albæ, unde fafcia alarum: remiges et cauda fufca, rectricibus fafciis albicantibus.

$$
{ }_{5} \mathrm{C}_{2} \quad \text { B. Ch. fufcus }
$$


A V E S G R A I, L E. Charadrius.

$\beta$. Ch. fufcus fulvo marginatus fubtus albus, pectore obfcuro, cauda fufca, rectricibus utrinque maculis pallidis, Lath. Syn. v. p. 21 I. 17. var. A.

Variat corpore minore: roftro fufco; pedibus flavefcentibus; alis abf22.

leucogal- $\mathrm{Ch}$. fufcus, corpore fubtus fronte vitta fupra et infra oculos remigibus ter.

23. que fafcia alba.

rubricollis. Ch. cinereus, corpore fubtus albo, capite colloque nigris, lateribus colli utrinque macula quadrata caftaneo-rufa.

Charadrius rubricollis, Gmel. Syft. i. p. 687.

Red-necked Plover, Latb. Syn. v. p. 212 . 19.

Habitat in terra Van Diemen; Tr. Cincli magnitudine.

Roftrum incarnatum apice nigrum : pedes incarnati.

24. Charadrius leucogafter, Gmel. Syft. i. p. 687.

Longitudo 6 pollicum.-Pedes pallide cærulei : rectrices 6 intermediæ fufcæ, 3 laterales utrinque albæ; 1, I, immaculatæ; 2, 2, macula fufca intus ad apicem; 3,3 , apice nigro; 4 , 4, apice albo.

fpinofus. Ch. remigibus pectore pedibufque atris, occipite criftato, rectricibus dimidiato-albis, alulis fpinofis.

Charadrius fpinofus, Lin. Syft. i. p. 256. 12.-Haffelq. It. 260. 261.Id. (ed. Angl.) p. 200. 33.-Gmel. Syft. i. p. 690.-Borow/k. Nat. iii. p. 114 . 9 .

Pluvialis fenegalenfis armata, Brif. v. p. 86. I 5. t. 7. f. 2. $-I d .8$ vo. ii. p. 233.

Le Pluvier à aigrette, Buf. viii. p. 99.

Spur-winged Plover, Lath. Syn.v. p. 21 3. 20.--Ruff. Alep. p. 72. t. I1.

HABITAT in Egypto.- I 2 pollices longus.

Roftrum pedefque nigri : collum et corpus fupra grifeum fubtus album: fafcia pectoris nigra : bumeri fpinofi ut in Parris : tectrices albæ apice nigræ.

B. Ch. corpore fupra caftaneo, collo abdomineque imo albis, collo antice pectore capite fupra remigibus caudaque apice nigris, alulis fpinofis.

Charadrius 
Charadrius fpinofus, Lin. Syft. i. p. 256 . 1 2. $\beta$.

Pluvialis perfica criftata, Brif. v. p. 84. 14.-Id. 8vo. ii. p. 232.

Gavia, f. Vanellus indicus, Klein. Av. p. 22, 10.

Pluvier armé du Senegal, $\mathrm{Pl}$. Enl. 801.

Pluvier huppé de Perfe, Buf. viii. p. $9^{8}$.

Black-breafted Indian Plover, Edw. t. 47. (Mas.)

Spur-winged Plover, Edw.t. 280. (Fem.)-Latb. Syn.v. p. 2 I 4. A.

$\mathrm{H}_{\mathrm{AB}}$ ITAT in Europa, Afal.-Variat collo toto albo; gula nigra; rec.

25. tricibus exterioribus apice albis.

cayanus. Ch. capite collo poftico fafciaque pectoris nigris, fafcia occipitis annulari collo antice abdomine bafique caudæ albis, alulis fpinofis.

L.e Pluvier armé de Cayenne, Buf. viii. p. 102.--Pl. Enl. 833. Spur-winged Plover, Lath. Syn. v. p. 215. 20. B.

НАВітAт in Cayana.- 9 pollices longus.

Roftrum nigrum : pedes flavi : corpus fupra fufcum : occiput fufco-variegatum, vitta alba annulari circumdatum : fcapulares, remiges, cauda-

26. que apice nigra.

pileatus. Ch. criftatus, fronte carunculata, corpore fupra rufo-grifeo fubtus albo, vertice gula remigibus caudaque apice nigris.

Charadrius pileatus, Gmel. Sy/t. i. p. 69 r.

Pluvier coiffé du Senegal, Buf. viii. p. Ioo.-Pl. Enl. 834.

Hooded Plover, Lath. Syn. v. p. $215 \cdot 26$.

Habitat in Senegala.- $10 \frac{1}{2}$ pollices longus.

Roftrum flavum apice nigrum : pedes rubri : frons et palpebre membrana rugofa flava: occipitis pennæ longiores dependentes criftam for-

27. mantes : collum fub gula nigro cingitur.

coronatus. $\mathrm{Ch}$. fufcus, capite fuperiore nigro, occipitis annulo abdomine fafcia alarum caudaque albis, remigibus fafciaque rectricum ad apicem nigris.

Charadrius coronatus, Gmel. Syft. i. p. 691.

Pluvier couronné du Cap de B. Efp. Buf. viii. p. Ior.-Pl. Enl. 800.

Wreathed Plover, Latk. Syn. v. p. 216.22.

Habitat ad Caput Bone Spei.-I 2 pollices longus.

Roftrum rubicundum: pedes ferruginei. 
28. 750 A V E S G R A L L E. Charadrius.

bilobus. Ch. rufo-grifeus, fuperciliis abdomine fafciaque alarum albis, pileo res migibus fafciaque rectricum nigris, caruncula frontis dependente. Charadrius bilobus, Gmel. Syft. i. p. $69 \mathrm{I}$. Le Fluvier à lambeaux, Buf. viii. p. 102. de la côte de Malabar, Pl. Enl. 880.

Wattled Plover, Latb. Syn. v. p. 2 I6. 23.

HabItat in Malabaria; Pluvialis magnitudine. $-9 \frac{x}{2}$ poll. longus. Rofrum pedefque flavi : caruncula frontis flava elongata, dependens, 29. apice acuta : rectrices exteriores et apices omnium alba.

melanoce- Ch. cxruleo-grifeus, capite collo pontico et dorfo nigris, fuperciliis collo phalus. antice pectoreque pallide rufis.

Charadrius melanocephalus, Gmel. Syjt. i. p. 692.

Le Pluvian du Senegal, Buf. viii. p. 104.-Pl. Enl. 9 1 8.

Black-headed Plover, Lath. Syn. v. p. 217.24.

Habitat in Senegala. -7 pollices longus.

Roftrum fufcum : pedes grifei : remiges nigræ albo variæ : rectrices laterales verfus apicem nigræ, fummo apice albo.

30.
indicus. Ch. fufcus fubtus albus, pectore fafciis duabus fufcis, rectricibus bafi albis.

Le petit Pluvier des Indes, Brif. Orn. 8vo. ii. p. 234. 16.

Indian Plover, Lath. Syn. Sup. p. 254.

$3 \mathrm{I}$.

Haвiтat in India.-Magnitudo Alauda.-6 poll. longus.

curonicus. Ch. albus, roftro nigricante, cervicis fafcia et lunula frontis nigra, verticis pileo cinereo, fafcia oculari nigricante-undulata, dorfo alis caudaque cinereis, pedibus rubefcentibus, Befeke Sch. der Berl. Naturf. Gef. vii. p. 463 .

Charadrius curonicus, Gmel. Syft. i. p. 692.

Habitat in Curonia.-Orbita citrinæ.

32.

nævius. Ch. fupra ex cinereo nigro alboque varius fubtus albus, fafcia infra oculari nigro punctata, roftro pedibufque nigricantibus, Naturf. Gef. vii. p. $464 .-G m e l$. Syft. i. p. 692 . 


\section{GENUS LXXV. CURSORIUS.}

Rofrum teretiufculum, apice incurvato, acuto. Rictus ampliffimus.

Nares ovatæ.

Lingua acuta.

Pedes curforii, tridactyli.

I.

europæus. C. fufcefcens, ftriga per oculos pallida, remigibus macula pone oculos et ad apicem rectricum lateralium nigris.

Charadrius gallicus, Gmel. Syft. i. p. 692.

Le Coure-vite, Buf. viii. p. 128.-Pl. Enl. 795 .

Pluvialis morinellus flavefcens, Ger. Orn. t. 474 .

Cream-coloured Plover, Latb. Syn. v. p. 217.25 .

Haвiтat in Europa rariffimus; in Gallia femel deprehenfus.-Io pollices longus.

Rof rrum nigrum : pedes flavefcentes: color totius fere avis grifeobrunneus: latera capitis per oculos et gula albida: pone oculos ftriga gemina nigra ad nucham tendens: vertex rufus: remiges primores nigra : cauda grifeo-brunnea, rectricibus 2 mediis exceptis, verfus apicem macula nigra, apice fummo albo.

ß. C. flavo-rufefcens, lateribus capitis gula abdomineque pallidioribus, pone oculos macula obfcura, remigibus rectricibufque lateralibus ad apicem nigris.

Cream-coloured Plover, Latb. Syn. Sup. p. 254. t. I 6.

Haвiтat in Anglia rariffimus; unus fcloppo necatus eft prope Wingbam, comitatu Cantii; prioris magnitudine, a quo non multum variat.

In hoc fpecimine corpus rufo-flavefcens ftrigis rarioribus undatis obfcuris : pileus ferrugineo-fufcus maculis minutis nigricantibus: remiges 4 primores apice tenerrime rufæ: cæterum fere ut in præcedente ave, at ftriga ad latera capitis magis obfcura. Forte fexus alter?

2.

afiaticus. C. fufcus fubtus rufus, fuperciliis gula abdomine imo uropygio caudaque apice albis, remigibus fafciaque oculari nigris.

Charadrius coromandelicus, Gmel. Syft. i. p. 692.

Coure-vite 
Coure-vite de Coromandel, Buf. viii. p. 129.-Pl. Enl. 892. Coromandel Plover, Latb. Syn. v. p. $217 \cdot 26$.

Haвгтат in Coromandela; præcedentis magnitudine.

Roftrum fufcum: vertex, jugulum, pectus, et abdomen anterius rufa: fpatium inter femora nigricans : femora alba: cauda fufca apice alba: pedes flavicantes.

\section{GENUS LXXVI. H E MA T OPUS.}

Roftrum compreffum, apice cuneo æquali.

Nares lineares.

Lingua brevis.

Pedes curforii, tridactyli, fiffi, digitis bafi membrana connexis.

1 .

oftralegus. H. niger, corpore fubtus fafcia gulari et alarum uropygio caudaque bafi albis.

Hæmatopus oftralegus, Lin. Syft. i. p. 257.-Faun. Suec. No 192.Gmel. Syft. i. p. 694.-Brun. $\mathrm{N}^{\circ} 189 .-$ Muller, $\mathrm{N}^{\circ} 215 .-$ Sepp. Vog. t. p. 5 1. - Raii Syn. p. 105. A. 7,-Will. p. 220. t. 55.-Barowefk. Nat. iii. p. 106. t. 57.-Faun. Helvet.

Scolopax Pica, Scop. Ann. i. N 135 .

Pica marina, N. C. Petr. iv. 425 .

Oftralega, feu Pica marina, Brif. v. p. $3^{8}$ t. 3. f. 2.-Id. 8 vo. ii. p. 221.-Klein. Av. p. 23.

L'Huitrier, Buf. viii. p. I 19. t. 9. $-P l$. Enl. 929.

Auftermann, Wirfing. Voy. t. 36 .

Sea-Pie, Pied Oifter-catcher, Br. Zool. ii. p. 2 I 3. t. 74.-Id. fol. I 27. t. D. 2.-Arct. Zool. ii. p. 406.-Will. (Angl.) p. 297.-Alb. i.

t. 78.-Catef. Car. i. t. 85.-Hayes Br. Birds, t. I 2.-Lath. Syn. v. p. 2 Ig. t. 84 .

Haвitat ubique ad maris littora, ibique maximam oftrearum copiam devorat; victitat etiam patellis, ad quas fubruendas roftrum valde accommodum nactus eft. - I $6^{\frac{1}{4}}$ pollices longus.

Roftrum pedefque rubri : macula parva lunata infra oculos.

Variat roftri apice nigro. In quibufdam fafcia gularis et macula fub oculis non confpicua.

Ovum alivaceo-flavum maculis anomalis purpurafcentibus.

ß. H. corpore 
B. H. corpore toto nigro, Forft. Voy. i. p. 453.-Park. Voy. p. 488.Hawkefw. Voy. ii. 333.-Cook's laft Voy. i. p. 151.-ii. p. 378 .

HaBItat in infulis nova Hollandia et Zealandia, alibique in mare auftrali.

\section{GENUS LXXVII. GLAREOLA.}

Rofrum bafi rectiufculum, validum, verfus apicem compreffum, apice incurvum.

Nares lineares obliqux.

Rictus amplus.

Pedes tetradactyli, digitis bafi membrana connexis.

Cauda forficata, rectricibus duodecim.

I.

auftriaca. Gl. grifeo-fufca fubtus rufo-alba, linea gulari incurvata nigra, rectricibus quatuor exterioribus bafi albis.

Hirundo Pratincola. Lin. Syft. i. p. 345. 12.-Gmel. Syft. i. p. 695.Kram. El. p. 38 1. t. p. $400 .-$ Gmel. reife, i. p. 77. t. 16.-Borowes. Nat. iii. p. 158 .

Glareola, Brif. v. p. 14I. t. 12. f. 1.-Id. 8 vo. ii. p. 248.-Faun. Helvet. Hirundo marina, Raii Syn. p. $72 .-$ Will. p. $156 .-I d$. (Angl.) p. 214. Hirundo riparia, Marf. Dan. v. p. 96. t. 46 .

La Perdrix de Mer, Buf. vii. p. 544.-Pl. Enl. 882 .

Auftrian Pratincole, Lath. Syn. v. p. 222. t. 85 .

Habitat ad littora Europe auftralioris, in Auftrie pratis apricis.

Roftrum nigrum bafi coccineum: gulam albam cingit linea nigra, per oculos ad aures ducta : remiges fufce, longa : cauda fufca, maxime forficata, redtrice extima latere exteriore alba: pedes plumbei, quibufdam fanguinei.

B. Gl. grifeo-fufca fubtus albida, fronte nigra utrinque macula alba, linea gulari incurvata fufca.

Glareola torquata, Brif. v. p. I45. 2. -Id. 8 vo. ii. p. 249.-Gmel. Syft. i. p. 696.-Klein. Av. p. 1о1. 6.

La Perdrix de mer à collier, Buf. vii. p. 546 .

Collared Pratincole, Latb. Syn. v. p. 223.

Habitat in Germanie arenis, ad littora fluviorum. 
$\gamma$. Gl. grifeo-fufca, fubtus uropygioque albo, gula ftriis nigris lineaque incurvata nigro cincta.

Perdrix de mer, Son. Voy. p. 216.

Maldivian Pratincole, Lath. Syn. v. p. 224.

§. Gl. fufca, corpore fubtus uropygio bafique caudæ albis, linea gulari incurvata nigra.

Coromandel Pratincole, Lath. Syn. v. p. 224.-Son. Voy. p. 216.

๕. Gl. rufo-grifea, femoribus criffo uropygio cauda bafi rectricibus lateralibus ad apicem lunula albis.

Madras Pratincole, Latb. Syn. v. p. 224.-Son. Voy. p. 216.

2.

fenegalen- Gl. roftro pedibufque fufcis, corpore fufco immaculato.

fis. Glareola fenegalenfis, Gmel. Syft. i. p. 696.

Tringa furca, Lin. Syft. i. p. 252. 22.-Falck. It. iii. p. 376. t. 26.

Glareola fenegalenfis, Brif. v. p. 148. 4.-Id. 8 vo. ii. p. 250.

La Perdrix de mer brune, Buf. vii. p. 544.

Senegal Pratincole, Lath. Syn. v. p. 225.2.

Habitat in Senegalenfi regione, et in provincia Sibirice Ifettenfi.-. $9 \frac{1}{2}$ pollices longa.

3.

nævia.

Gl. maculis fufcis et albicantibus varia fupra fufca fubtus rufa, abdomine imo bafique caudæ candicantibus.

Glareola nævia, Brif. v. p. 147. 3.-Id. 8 vo. ii. p. 250.-Gmel. Syft. i. p. 696.

Gallinula melampus, Raii. Syn. p. 109. 9.-Will. p. 225. t. 56.-Id. (Angl.) p. 304.-Klein. Av. p. 101.9.

La Giarole, Buf. vii. p. 545 .

Spotted Pratincole, Lath. Syn. v. p. 225.3.

Habitat in Germania; aufriace magnitudine.

Rofrum et pedes nigri. 


\section{GENUS LXXVIII. RALLUS.}

Roftrum compreffum, paulifper incurvatum.

Lingua apice rugofa.

Corpus compreffum.

Cauda brevis.

Pedes tetradactyli, fifí.

I.

aquaticus. R. alis grifeis fufco maculatis, hypochondriis albo maculatis, roftro fubtus fulvo.

Rallus aquaticue, Lin. Syft. i. p. 262. 2.-Faun. Suec. No 195.-Gmel. Syjt. i. p. 7 12.-Scop. Ann. i. $\mathrm{N}^{\circ}$ 1 55.-Brun. $\mathrm{N}^{\circ}$ 193.-Muller, $\mathrm{N}^{\circ} 2$ 19.-Kram. El. p. 349. 2.-Klein. Av. p. 103. 2.-Id. Sitem. p. 22. t. 23. f. 1. a. b.-Faun. Arag. p. 79.-Brif.v. p. I51. I. t. 12. f. 2.-Id. 8 vo. ii. p. 25 1. - Raii Syn. p. I I 3. A. 2.-Id. 19o. 12.-Borowefk. Nat. iii. p. IO2. 2.-Faun. Helvet.-Scbaf. El. t. 6o. (caput.) -Will. p. 234 . t. 56 .

Gallina ferica Gefneri, Raii Syn. p. I 14.4 ? -Will. p. 235.

Gallinula aquatica, AEZ. Nidrof. ii. p. 340. f. 12.-Marf. Dan. v. p. 68. t. 32 .

Le Rale d'eau, Buf. viii. p. I 54. t. 1 3,-Pl. Enl. 749. Velvet Runner, Will. (Angl.) p. 313 ?

Water Rail, Bilcock, Brook-ouzel, Br. Zool. ii. $\mathrm{N}^{\circ}$ 214. t. 75.-Id. fol. r3o. t. E. E.-Sloan. Fam. p. 32 I. 16.-Alb. i. t. 77.-Will. (Angl.) p. 314.-Lath. Syn. v. p. 227. I.

HaBitat in Europa, juxta aquas degens; celerrime currit; ambulat potius quam natat in aquis.

Roftri balis fubtus fulva: palpebre rubræ, plumæ hypochondriorum nigræ lineis tranfverfis albis notatæ: pedes virefcentes. Ovum Aavicans maculis obfcurioribus fufcis.

ß. R. fuperne fufcus infra fufco-rufefcens, rectricibus fufcis, fuperciliis gulaque albis.

Rallus virginianus, Lin. Syft. i. p. 263. 12.-Gmel. Syft. i. p. 7 16.Brif. v. p. 175 . 8.-Id. 8 vo. ii. p. 257.

Rallus penfilvanicus, Brif. Sup. p. r $38 .-I d .8$ vo. ii. p. 257. 
American Water Rail, Edw. t. 279.

Virginian Rail, Arct. Zool. ii. N $\mathrm{N}^{\circ}$ 408.-Lath. Syn. v. p. 228.

Haвitat in Penfilvania.-Plumæ hypochondriorum albo nigroque

2. tranfverfim lineatæ ut in præcedente, cujus forte mera varietas.

crepitans. R. olivaceo-fufcus, gula alba; collo fubtus pectoreque fufco-flavefcentibus, hypochondriis cinereo alboque tranfverfim lineatis.

Rallus crepitans, Gmel.Syft.i. p. 7 I3.

Clapper Rail, Arct. Zool. ii. N $\mathrm{N}^{\circ}$ 407.-Lath. Syn. v. p. 229.2.

$\mathrm{H}_{\mathrm{AB} 1 \mathrm{~T}} \mathrm{~T}$ in America Septentrionali-14-16 pollices longus.

3.

auftralis. R. cinereo-ferrugineus, alis caudaque faturate brunneis, pennis nigro fafciatis.

Rallus auftralis, Muf. Carlf. fafc. i. No 14,-Gmel. Syft. i. p. 7 I7.

troglodytes, Gmel. Syft. i. p. 7 I 3 .

Troglodyte Rail, Latb. Syn. v. p. 229. 3.-Id. Sup. p. 25.5.

Habrtat in nova Zealondia, ad cujus littora meridionalia refluente mare frepius occurrit. - Magnitudo circiter Galline vulgaris.-I 5-17 pollices longus.

Roftrum et pedes flavicant : coxpus fupra ferrugineo-fufcum, fubtus cinereo-ferrugineum : remiges rectricefque ferrugineo-rufefcentes, fafcüs plurimis nigris fubundulatæ. In quibufdam fupercilia albida.

4.

philippen- R. fufcus fubtus grifeo fafciatus, fuperciliis albis, collo fubtus rufefcente.

fis, Rallus philippenfis, Lin. Syft. i. p. 263. 7.-Gmel. Syft. i. p. $7140-$ Brif. v. p. 163 . 4. t. 14. f. 1.-Id. 8 vo. ii. p. 254.

Le Rale des Philippines, Buf. viii. p. 160.-Pl. Enl. 774.

Philippine Rail, Latb. Syn. v. p. 230.4.

Habitat in Pbilippinis.- I 1 pollices longus.

Corpus fupra nigricans, ferrugineo-varium: roftrum pedefque grifei.

3. R. rubro-fufcus nigro alboque maculatus et ftriatus, capite caftane⿰, corpore fubtus fuperciliifque cinereis.

Philippine Rail, Latb. Syn. v. p. 23 I. 4. var. A. t. 86.

Habitat in Otabeite.

$\gamma$. R. nigricans albo undulatus, pedibus flavis.

Rallus ftriatus, Lin. Syft. i. p. 262. 5.-Gmel. Syft. i. p. 714.

Rallus 
Rallus philippenfis friatus, Brif. v. p. I67. 5. t. I4. f. 2. $-I d$. 8 vo. ii. p. 255 .

Ee Tiklin rayé, Buf. viii. p. $16 \mathbf{r}$.

Philippine Rail, Latb. Syn. v. p. 232. 4. var. C.

Habitat in Pbilippinis. $-8 \frac{\pi}{4}$ pollices longus.

Roftrum cornei coloris : pedes fubfufci : corpus fufcum albo-maculatum et fafciatum, fubtus cinereum : collum poftice caftaneum : gula atbida : abdomen, latera, et cauda fufco alboque fafciata.

§. R. fufcus albo maculatus et ftriatus fubtus albus, fuperciliis grifeis, cauda fufco alboque fafciata.

Philippine Rail, Lath. Syn. v. p. 232. 4. var. B.

Habitat in infula Tongataboo.

8. R. fupra fufcus fubtus cinerafcens, dorfo alifque albo maculatim lineatis, abdomine imo albo fafciis nigricantibus.

Philippine Rail, Latb. Syn. Sup. p. 255 . 4. var. D.

Habitat in India.-Roftrum rubrum apice albo: pecies virefcentes. Variat abdomine immaculato.

5 .

torquatus. R. furcus fubtus albo undulatus, linea infra oculos alba.

Rallus torquatus, Lin. Syft. i. p: 262. 6.-Gmel. Syft. i. p. 714.-Brifo v. p. 170. 6. t. 15. f. x.-Id. 8vo. ii. p. 255--Bororefk. Nat. iii. p. 102.4 .

I.e Tiklin à collier, Buf. viii. p. 162:

Banded Rail, Latb. Syn. v. p. 233. 5.

HaBITAT in infulis Pbilippinis. -12 pollices longus:

6. Roftrum pedefque fufci.

fufcus. R. fufcus, criffo albo undulato, pedibus flavis.

Rallus fufcus, Lin. Syft. i. p. 262. 4.-Gimel. Syft. i. p. 7r 3-Brif. v'. p.

173. 7. t. 15. f. 2. -Id. 8 vo. ii. p. 256.

Le Rale brun des Philippines, $\mathrm{Pl}$. Enl. 773.

Le Tiklin brun, Buf. viit. p. I6.1.

Brown Rail, Latb. Syn. v. p. 233. 6.

HaBitat cum precedentibus. -7 pollices longus.

Gorpus fubtus caftaneo-fufcum: cauda fubtus albo nigroque fafciata.

R. nigricans: 
A V E S R A L L IE. Rallus.

ferrugi- R. nigricans fubtus cinereus, collo peEtoreque ferrugineis, hypochon-

neus. driis albo tranfverfim lineatis, fuperciliis pallidıs.

Rallus fersugineus, Gmet. Syft. i. p. 7 I6.

Red-breafted Rail, Lath. Syn. v. p. 234. 7.

8.

Magnitudo aquatici; longitudo 9 pollicum.

capenfis. R. ferrugineus fubtus albo nigroque fafciatus.

Rallus capenfis, Lin. Mant. 1771. p. 525.-Gmel. Syft. i. p. 716.

The Rail, Brown. Ill. p. 94. t. 38 ?

Cape Rail, Lath. Syn. v. p. 234.8.

Habitat ad Caput Bona Spei; Cregis magnitudine.

Ferruginea funt caput, collum, pectus anterius, dorfum: nigro alboque undulata, f. fafciata, peEtus pofteritis, abdcmen, femora, crifum, remiges, couda, exceptis mediis duabus rectricibus ferrugineis : pedes fanguinei : roftrum nigrum.

9.

cærulef- R. fufco-ruber, corpore fubtus albo, collo antice pectoreque pallide cens.

IO. cæruleis, hypochondriis albo nigroque tranfverfin lineatis.

Rallus cærulef́cens, Gmel. Syft. i. p. 716.

Blue-necked Rail, Latb. Syn.v.p. 234. 9.

Haвiтат ad Caput B. Spei.-7 pollices longus.

Roftrum et pedes rubri: crifum album immaculatum.

zeylanicus. R. ferruginers fubtus pallide ruber fufco nebulofus, capite nigricante, roftro pedibufque rubris.

Rallus zeylanicus, Gmel. Syft. i. p. 7 I 6.

Ceylon Rail, Lath. Syn. v. p. 235. 10.-Brown. Ill. p. 96. t. 37.

Habitat in Zeylona; aquatico major.

II.

pacificus. R. niger albo punctatus, alis fafciatis, corpore fubtus albido, capite fufco, pectore cinereo-cærulefcente.

Rallus pacificus, Gmel. syft. i. p. 717 .

Pacific Rail, Lotb. Syn. v. p. 235. I I.

Haвitat in infula Otabeite et vicinis.

Rofrum fanguineum: pedes incarnati : gula alba : Jupercilia albida: rucba ferruginea.

R. corpore 
12.

A V E S G R A L L F. Rallus.

tabuenfis. R, corpore toto nigro fubtus pallidiore, palpebris iridibufque rubris.

Rallus tabuenfis, Gmel. Syfl.i.p. 717.

Tabuan Rail, Lath. Syn. v. p. 235. I2.

HaBItat in infulis Societatis Oceani pacifici.

Roftrum nigricans: pedes rubefcentes: cauda brevifima, vix confpicua.

$\beta$. R. fufco-nigricans criffo albo nigroque fafciis nigris, pedibus rubris, Habitat in infula Tama.

13.

niger. R. corpore toto fufco-nigricante, roftro flavo, pedibus rubris.

Rallus niger, Gmel. Syft. i. p. 717 .

Black Rail, Lath. Syn. v. p. 236. i 3 .

Habitat in Africa; pracedente major. Variat pedibus fufcis.

I4.

fanduicen- R. pallide ferrugineus, fupra maculis obfcuris, roftro pedibufque ci-

fis. nereis.

Rallus fandwichenfis, Gmel. Syft. i. p. 7 I 7 .

Sandwich Rail, Lath. Syn. v. p. 236.14.

Habitat in infulis Sanduicenfibus et in Tanna.

Variat corpore obícuriore, rofiro pedibufque flavefcentibus.

I5:

taitienfis. R. cinereus, corpore fupra rubro-fufco, gula remigibufque latere exteriore albis, cauda nigra.

Rallus tahitienfịs, Gmel. Syft. i. p. 717 .

Otaheite Rail, Latb. Syn. v. p. 236. 15.

Haвiтat in Otabeite, infulis Amicis. -6 pollices longus.

Roftrum nigrum: pedes flavi, unguibus nigris.

I6.

obfcurus. R. fufco-ferrugineus ftriis nigris fubtus ferrugineo-fufcefcens, pedibus rubro-fufcis.

Rallus obfcurus, Gmel. Syft. i. p. 7 I 8.

Dufky Rail, Latb. Syn. v. p. 237.16.

Habitat in infulis Sanduicenfibus, -6 pollices longus.

longirof- R. corpore fupra cinereo fufco maculato, fubtus ferrugineo-albo, hypo-

tris. chondriis albo tranfverfim undatis, roftro elongato ferrugineo. 
Rallus longiroftris, Gmel. Syft. i. p. 7 I 8 ,

Le Rale à long bec de Cayenne, Buf. viii. p. $\leq 6_{3},-P$. Enl. 849 .

Long-billed Rail, Lath. Syn. v. p. 237.17.

HaBrTar in Cayana.-9-12 pollices longus.

18.

Roftrum apice fufcum: pedes flavefcentes.

barbaricus. R. fufcus, alis albo macularis, uropygio albo nigroque vario, criffe albo.

Rallus barbaricus, Gmel. Syjt. i. p. 7 I 9 .

Barbary Water Hen, Sbaw's Trav. p. 255 .

Barbary Rail, Lath. Syn. v. p. 240. 22.

HaBITAT in Barbaria; Pluviali minor.

19.

dubius. R. fufco ferrugineoque lituratus, abdomine albo, hypochondriis fufcis ferrugineo-cinerafcente fafciatis, remige prima extus longitudinaliter alba.

Rallus dubius, It. Pofeg. p. 26.

Habitat in Pofegana.-Magnitudo fere G. Cbloropi.

Facies obfolete ferruginea : gula fordide alba, collari fufco lato cincta: latera corporis fufca : roftrum et pedes nigro-virefcentes.

20.

yariegatus. R. nigro alboque maculatim variegatus, remigibus caudaque fufcis, teetricibus alarum fufcis albo ftriatis.

Rallus variegatus, Gmel. Syft. i. p. 718.

Le Rale tacheté de Cayenne, Buf. viii. p. 165.-Pl. Enl. 775.

Variegated Rail, Lath. Syn. v. p. 237.18.

HabiтAт in Cayana.-I I pollices longus.

Roftrum fulvum: pedes flavi : gula alba: bypocbondria tranfverfim albo undulata, ut in aquatico.

2 I.

cayanenfis. R. olivaceo-fufcus, vertice fubtufque rufus, genis nigricantibus, remigibus nigris.

Rallus cayennenfis, Gmel. Syft. i. p. 7 18.

Le Kiolo, Buf. viii. p. I64.

Le Rale de Cayenne, $\mathrm{Pl}$. Enl. p. 368.

Cayenne Rail, Latb. Syn. v. p. 238.19.

HавIтAт in Cayana. -8 fere poll. longus. - Roftrum pedefque fufci.

R. R. fufcus, 
$\beta$. R. fufcus, corpore fubtus et vertice caftaneo, genis cinereis, gula criffoque albidis.

Rale à ventre roux de Cayenne, Pl. Enl. 753.-Latb. Syn。 v. p. 238.

Pracedente paulo minor.

22.

jamaicen- R. fufco-rufefcens tæniis nigricantibus, collo fubtus pectoreque cærulef-

fis.

23. cente, capite nigro, abdomine femoribus hypochondriifque fufco alboque undatis.

Rallus jamaicenfis, Brif. Sup. p. 140.-Id. 8 vo. ii. p. 258.-Gmel. Syft. i. p. 718 .

Le Rale Bidi-bidi, Buf. viii. p. I66.

Leatt Water-Hen, Edw. t. 278.-Brown. Fam. p. 479 .

Jamaica Rail, Lath. Syn. v. p. 239. 20.

Hавітат in Famaica. -6 pollices longus.

minutus. R. fufcus fubtus flavefcens, dorfo alifque maculis ftriifque pallidis, fu:perciliis fafciifque hypochondriorum et caudx albis.

Rallus minutus, Gmel. Syjt. i. p. 7 I9.

Le petit Rale de Cayenne, Buf. viii. p. 167.-Pl. Enl. 847.

Little Rail, Lath. Syn. v. p. 239.21.

Habitat in Cayana; minuta fpecies; magnitudine vix Paferem excedens.

$\beta$. R. fufcus, dorfo fafciolis albis, corpore fubtus albido, abdomine et hypochondriis albo nigroque undulatis.

Little Rail, Latb. Syn. v. p. 240. 21 . var. A. flavi.

24.

pufillus. R. ferrugineo nigroque lituratus, corpore fubtus nigro fafciolis albis, juo gulo pectoreque cærulefcentibus.

Rallus pufillus, Pall. reife, iii. p. 700. 30.-Gmel. Syft. i. p. 7 I 9. -It. Pofeg. p. 26.

Habitat circa Dauurie lacus falfos et arundineta frequens; Alaude magnitudine colore et forma, perquam fimilis aquatico.

Facies, collum fubtus, et pętus medium longitudinaliter cærulefcenticana : media gula candicat : litura per oculos longitudinalis obfolete ferruginea : dorfum lineolis longitudinalibus albis vagis : abdomen crifumque nigra tæniolis albis tranfverfis : caudam inter alas erectam frequenter gerit: pedes virefcentes. 


\section{G E N U LXXIX. P A R R A.}

Roftrum acutum, ad apicem tumidiufculum, bafi carunculatum.

Nares fubovatx in medio roftri.

Alule fpinofæ.

Pedes tetradactyli, fifi ; digitis et unguibus rectis, longiflimis.

Jacana. P. caftaneo-purpurea, capite collo fubtufque ex nigro violacea, remigibus olivaceo-viridibus, apice fufco marginatis, rectricibus apice nigro-violaceis.

Parra Jacana, Lin. Syft. i. p. 259. 3.-Gmel. Syjt. i. p. 707.-Borowfk. Nat. iii. p. 99. 2.

Jacana armata fufca, Brif.v. p. I25. 4. t. I I. f. x.-Id. 8vo. ii. p. 244. Gallinula brafilienfis quarta Marcgr. Raii Syn. p. I 15. I I.-Will. p. 237. Yohualquachili, Raii Syn. p. 178.5 .

Le Jacana, Buf. viii. p. 185. t. 16.-Pl. Enl. 322.

The fourth Brafilian Water Hen of Marcgrave, Will. p. 318.

Le Chevalier, Ferm. Surin. ii. p. 193.

Spur-winged Water Hen, Edw.t. 357.

Chefnut Jacana, Lath. Syn. v. p. 241 . I.

Habitat in Americe aufratis infulæque S. Dominici aquofis.-10 pollices longa.

Roftrum fulvum : caruncula bipartita aurantia, cui lacinia dependens utrinque adhæret: corpus nigro-violaceum, dorfo purpurafcente: Jpine alarum robuftæ, flavæ: remiges nigræ margine albo: pedes virefcentes.

Variat corpore maculis aliquot albis.

nigra, P. nigra fubtus fufca, remigibus viridibus apice fufcis, rectricibus nigris.

Parra nigra, Gmel. Syft. i. p. 708.

Jacana armata nigra, Brif. v. p. I 24. 3.-Id. 8 vo. ii. p. 243 .

Gallinula tertia Marcgr. Raii Syn. po II5. 10.-Will. p. 237.-Id. (Angl.) p. 318. 


\section{A V E S G R A L L E, Parra.}

l.e Chirurgien noir, Buf. viii. p. 189 .

Black Jacana, Lath. Syn. v. p. 242. 2.

Haвiт at in Brafilia.-Ad fexuram ala fpinula flava.

3.

brafilienfis. P. nigro-viridans, alis ad fufcum vergentibus, reetricibus nigro-viridantibus.

Parra brafilienfis, Gmel. Syft. i. p. 708.

Jacana armata, Brif. v. p. 123. 2.-Id. 8 vo. ii. p. 243.

Aguapecaca, Reii Syn. p. I I 5. 9.-Will. p. 237.-Id. (Angl.) p. 317.

Le Jacana-peca, Buf. viii. p. I 90.

Brafilian Jacana, Latb. Syn. v. p. 243.3.

Haвiтat in Braflia, Guiana; gregaria.-Victitat pifciculis, infectis.

- Facane magnitudine.-Spine alarum luter.

4.

viridis. P. nigro-viridans, capite collo pectoreque violaceo-variantibus, rectricibus nigro-viridantibus, tectricibus fubtus albis.

Parra viridis, Gmel. Syft. i. p. 708.

Jacana, Brif. v. p. 121. 1. -Id. 8 vo. ii. p. 242.

Gallinula brafilienfis, Jacana diEta, Raii Syn. p. 11 5. -Will. p. 237.Id. (Angl.) p. 317. t. 59.

Le Jacana vert, Buf. viii. p. I 89.

Green Jacana, Latb. Syn. v. p. 243. 4.

Hавгтат in Brafilie paluftribus; Columbe magnitudine.

Roftrum pedefque lutei : caput anterius membrana Turcoidis colore obducitur.

5 .

variabilis. P. caftaneo-purpurea, fubtus fuperciliifque albis, remigibus viridibus, fafcia per oculos nigra.

Parra variabilis, Lin. Syft. i. p. 260. 4.-Ginel. Syft. i. p. 708.-Borowefk. Nat. iii. p. 98. t. 54 .

Rallus digitis triuncialibus, \&c, Klein. Av. p. 104. 7.

Jacana armata varia, Brif. v. p. I29. 5.-1d. 8 vo. ii. p. 245 .

Le Jacana varié, Buf. viii. p. 192.

Lu Brefil, Pl. Enl. 846 .

Spur-winged Water Hen, Edw. t. 48.-Bancr. Guian. p. 173.

Variable Jàcana, Latb. Syn. v. p. 244. 5.

Haвiтат in Cayana, Brafilia. -9 pollices longa.

Roftrum fulvo-rubrum: frons membrana aurantia tegitur: caput et collum fuperius nigra: pedes cinereo-cærulefcentes.

${ }_{5} \mathrm{E}_{2}$

P. fufcas 

6. 764 .
A V E S
G R A L L $\mathbb{E}$.
Parra.

Juzonien- P. fufca, fubtus fuperciliis tectricibus alarum minoribus remigibufque

fis. fecundariis albis, lateribus colli fafcia cinerea, remigibus prinoribus tribus elongatis denudatis apice rhombeis.

Parra luzonienfis, Gmel. Syft. i. p. 709.

Le Chirurgien de l'ifle de Luçon, Son. Voy. p. 82. 4.5 .

Luzonian Jacana, Lath. Syn. v. 245. 6.-Id. Sup. p. 256.

Haвгтат in infulis Pbilippinis, India; Vanello minor.

Rofrum pedefque pallide virides : teltrices alarum majores fufco nigroque fafciatæ: pectus fufcum : alule fpinofx.

$7 \cdot$

finenfis. P. caftaneo-vinacca, capite collo anteriore tectricibufque alarum albidis, collo poftico lutefcente, remigibus duabus rectricibufque intermediis elongatis.

Parra finenfis, Gmel. Syft. i. p. 709.

Chinefe Jacana, Lath. Syn. v. p. 246. 8.-Id. Sup. p. 256 . t. 117 .

Habitat in Cbina.-Magnitudo Pbaf. pizti.-2 I pollices longa.

Roftrum cærulefcens: pedes virides : fafcia occipitis nigra, lateribus colli utrinque ad pectus defcendens : tectrices alarum majores albo marginata.

8.

africana. P. cinnamomea, collo fubtus albo, pectore flavefcente nigro vario, vitta

per oculos collo poftice remigibufque nigris.

Parra africana, Gmel. Sygt. i. p. 709.

African Jacana, Latb. Syn. v. p. 246. 7. t. 87.

HАВIтAт in Africa.- $9 \frac{\pi}{2}$ pollices longa.-Roftrum pedefque nigricantes: frons nuda cærulea : fpinula alarum brevis.

9. nigris, temporibus gulaque albis, alulis fpinofis.

Parra Chavaria, Lin. Syft. i. p. 260. 9.-Gmel. Syft. i. p. 709.-Borow/k. Nat. iii. p. 99. 3.

Faithful Jacana, Latb. Syn. v. p. 246. 9.

HaBitat circa Cartbagenam indicam, in fluviis, lacubus, et inundatis.-Vefcitur herbis.-Facile manfuefcit, et cum reliqua Gallinarum turba per vicina pergit, nunquam deferit, etfi volare poffit, et domum. ad vefperam revertitur.-Galli magnitudine.

Corpus fefquipedale a terra altum: roftrum albicans : membrana ad: bafin utrinque rubra ad tempora extenditur, in cujus media parte funt oculi, 

A $V$ E S
G R A L L Æ. Parra.
765

oculi, iride fufca : crifta e 12 circiter pennis tripollicaribus nigricantibus, orta in infima parte occipitis : genua craffifima, f. nodofa : tibie longæ, flavo-rubræ, validæ: pedes tetradactyli, fifli, concolores : digiti craffi, omnium longiffimi, unde maxime decuffent fub inceffu : calcaria in alis fingulis 2 . 3 , craffa, durifima, femipollicaria, acuta, occultata nifi quando alis, quas longiffimas fortifimafque habet, quantum fieri poteft, extenfis, hoftem aggreditur, et ictibus fortifimis trucidat.

ro.

indica. P. cæruleo-nigricans, dorfo alifque fufcis, fuperciliis albis, ad rictum oris macula rubra.

Indian Jacana, Lath. Syn. Sup. p. 257.

Habitat in Indice paludofis, nidum natantem ex herbis ad ripas ftruens.-Magnitudo Cbloropi.

Roftrum flavum, bafi fupra cærulefcens: pẹdes luteo-fufci.

I I.

chilenfis. P. unguibus modicis, pedibus fufcis, occipite fubcriftato.

Parra chilerfis, Molin. Cbil. p. 229.-Id. (ed. Gall.) 239.-Gmel. Syft. i. p. 707 .

Habitat in Cbili campis; vietitans infectis, vermibus; vocifera avis. - Mas et femina individui focii.-Nidum inter gramina ttruit, et ova 4 fulva nigro punctulata ponit.-Caro fapida. - Magnitudo Pice, at pedibus longioribus.

Roftrum conicum, ad apicem paulo incurvum, 2 pollices longum: irides flavæ: frons caruncula biloba rubra : caput nigrum fubcriftatum: collum fupra, dorfum, et alarum pars antica violacea : collum fubtus ad pectus medium nigrum : abdomen album : remiges et cauda brevis fufca : fpina alarum femipollicaris, flavefcens, conica: pedes fupra genua denudati, digitis quam in congeneribus minus elongatis. 


\section{GENUS LXXX. GALLINULA.}

Roftrum bafi craflum, apice declive, fronte denudata membranacea.

Corpus compreffum.

Gauda brevis.

Pedes tetradactyli, fifi.

I. Crex. G. grifea pennis medio nigricantibus, alis rufo-ferrugineis, corpore fubtus albo-rufefcente.

Rallus Crex, Lin. Syft. i. p. 261. 1.-Faun. Suec. $\mathrm{N}^{\circ}$ 1 94.-Gmel. Syft. i. p. 7 I I.-Scop. Aun. i. $\mathrm{N}^{\circ}$ 154.-Brun. $\mathrm{N}^{\circ}$ 192.-Muller, $\mathrm{N}^{\circ}$ 218.-Frifch. t. 21 1. - Georgi reife, p. 172.-Faun. Arag. p. 79.Borowfk. Nat. iii. p. 100. t. 55.-Faun. Heliet.-Scbaf. El. Orn. t. 60 .

Ortygometra, Raii Syn. p. 58. A. 8.-Will. p. 122. t. 29.-Brif. v. p. 159. 3.-Id. 8 vo. ii. p. 253.-Kram. El. p. 349. 1.-Klein. Av. p. IO2. 1. -Id. Stem. p. 22. t. 23. f. 2. a. b.-Id. Ov. p. 31. t. 12 . f. 1 .

Porphyrio rufefcens, Brif. v. p. 533. 5.-Id. 8vo. ii. p. 353-Will. p. 236.

Rale de Genet, ou Roi des Cailles, Buf. viii. p. 146. t. I2.-Pl. Enl. 750 .

Re delle Quaglia, Zinnan. Uov. p. 36. t. 5. f. 18.-Cet. uc. Sard. p. 277. Land Hen, Will. (Angl.) p. 316.

Wiefen Schnarre, Wachtel Koenig, Gunth. Neft. u. Ey.t. 45. Daker Hen or Rail, Alb. i. t. 32.-Will. (Angl.) p. I70. t. 29.

Crake Gallinule, $B r$. Zool. ii. $\mathrm{N}^{\circ} 2$ 16. t. 75.-Id. fol. 131.-Flor. Scot. i. $\mathrm{N}^{\circ}$ 162.-Dec. RuJ. i. p. 470.-ArEt. Zool. ii. No 412.-RuJ. Alep. p. 64.-Latb. Syn. v. p. 250. I.

Навітат in Europa, Afia agris, carectis.-Victitat granis, infectis, et vocem edit Crek, Crek.-In Anglia non rara; in Hibernia frequentiffima; corpore valde compreffo.-Curfitat inter gramina.; nidificat in agris.-Roftrum pedefque grifei. Ovum lutefcens lituris rufis. 
$\beta$. G. corpore rufo-fufco fubtus pallidiore, remigibus caudaque faturatioribus, gula crifoque albidis, Lath. Syn. v. p. 25 I. I. var. A.

HaBitat in famaica.-Corpus magnitudine præcedentis: roftrum majus, nigrum: pedes obfcure rubri.

$\gamma$. G. corpore fupra rufo-grifeo, fubtus tectricibufque alarum ferrugineo-fufcis, pedibus obfcuris.

Crake Gallinule, Latb. Syn. v. p. 252 . x. B.

2.

Habitat in Cbina.

carthage- G. fronte cærulea, corpore rufo.

na. Fulica carthagena, Ein. Syft. i. p. 258. 6.-Gmel. Syft. i. p. 700.

Carthagena Gallinule, Lath. Syn.v. p. 252.2.

3.

Habitat Cartbagene in America; atre magnitudine.

cayanenfis. G. grifeo-fufca, pectore abdomineque fuperiore rufis, dorfo alifque olivaceis, gula albida.

Fulica cayennenfis, Gmel. Syft. i. p. 700.

Grande Poule d'eau de Cayenne, Buf. viii. p. 182.-Pl. Enl. 352.

Cayenne Gallinule, Lath. Syn. v. p. 252. 3.

Habitat in Guiane, Cayane paludoîs frequens.-Victitat pifciculis, infectis.-18 pollices longa.-Roftrum luteum: pedes rubri.

4.

suficollis.

G. corpore fubtus nigro, dorfo fufco-viridi, collo fubtus pectoreque rufis.

Fulica ruficollis, Gmel. Syft. i. p. 700.

Black-bellied Gallinule, Latb. Syn. v. p. 253. 4 .

Habitat in Cayana.- 17 pollices longa.

Roftrum bafi rubrum, apice flavum: pedes rubri : vertex fufcus : collum fupra cinereo-fufcum: gula alba: abdomen, femora, criffum, uropygium nigra: corpus ad latera, et ale fubtus nigro rufoque falciatæ. An varietas, aut texus alter præcedentis.

5. maderaf- G. cinerea fubtus alba, collo fubtus et pectore maculis lunulatis nigris.

patana. Fulica maderafpatana, Gmel. Syft. i. p. 700.

Crex indica, Madras Rail Hen, Raii Syn. p. 194. t. I. f. 4.

Porphyrio maderafpatanus, Brif. v. p. 543. 10.-Id. 8vo. ii. p. 357. 
768 A V ES G R A L L FE. Gallinuli.

L'Angoli, Buf. viii. p. 205 .

Madras Gallinule, Latb. Syn. v. p. $253 \cdot 5$.

Habitat circa Maderafpatanum.-Frontis calvities alba.

6.

Porphyrio. G. fronte ribra, armillis multis, corpore viridi, fubtus violaceo.

Fulica Porphyrio, Lin. Syft. i. p. 258. 5.-Gmel. Syft. i. p. 699.-Scopo Ann. i. $\mathrm{N}^{\circ}$ 152.-Brif. v. p. 522 . r. t. 42 . f. r.-Id. 8 vo. ii. p. 351.-Raii Syn. p. Ix6. 13.-Will. p. 238.-Klein. Av. p. I04 6.-Cluf. exot. 370. f. 84.-Aldr. iii. p. 437. t. p. 439-Borow/k. Nat. iii. p. 97 . t. 53 .

La Poule-Sultane, Buf. viii. p. 194. t. 17.

Chloropus, Acbac, Pbil. Tranf. xxiii. p. 1395. 19.

La Taleve de Madagafcar, Pl. Enl. 8 io.

Der Blau-Vogel, Gmel. reife, iii. p. 7y. t. 12.

Kaloe, Cook's laft Voy. App.?

Purple Water Hen, Edw. t. 87.-Alb. iii. t. I I.

Purple Gallinule, Latb. Syn.v. p. 254. 6.

Haвıтат ubique in locis temperatis et calidioribus. -Victitat granis, pifcibus. -15 pollices longa.

Roftrum validum compreffum rubrum: pedes rubri: tectrices fubcuudales albæ.

ß. G. nigro-violacea, collo fubtus cyarieo, fronte pedibufque rubris.

Porphyrio alter, Aldr. iii. p. 438. t. 440.-Faun. Arag. p. 78.

Hæc avis tota e nigro violacea : crifum album. Infignis G. Porpbyrionis varietas, forte nova fpecies?

7.

melanoce- G. fronte fulva, corpore cæruleo, capite colloque nigris.

phala. Fulica melanocephala, Gmel. Syft. i. p. 699.

Porphyrio melanocephalos, Brif. v. p. 526 . A. $-I d$. 8 vo. ii. p. 352. Gallinula paluftris, Feuill. Fourn. p. 288. (ed. 1725.)-Buf. viii. p. 20g. Black-headed Gallinule, Latb. Syn. v. p. 257. 10.

Habitat in America; Porphyrionis magnitudine. Nonne varietas?

8.

alba. G. fronte roftro pedibufque rubris, corpore toto albo.

White Gallinule, Pbil. Bot. Bay, t. p. 273. 


\section{A V E S G R A L L IE. Gallinula.}

Habitat in infula Norfolk, ejufque vicinis maris auftralis; fatis nu. merofa; Porphyrionis magnitudine. -2 pedes longa.

Rofirum validum, breviufculum, rubrum: irides rubefcentes: calvities frontis lata totum fere pileum tegens: area oculorum papillis rubris obfita : plumæ totius avis aibæ: pedes rubri, ungues nigri.

9.

In quibufdam dorfum et interfcapulium caruleo maculatum.

martinica. G. fronte cærulea, armillis concoloribus, corpore fufco-cærulefcente. Fulica martinica, Lin. Syft. i. p. 259. 7.-Facq.Vog. p. x 2. $N^{\circ}$ 9. t. 3.Gmel. Syft. i. p. 700.

Porphyrio minor, Brif. v. p. 526. 2. t. 42. f. 2.-Id. 8 vo. ii. p. 352. La petite Poule-fultane, Buf. viii. p. 206.

Martinico Gallinule, Latb. Syn.v. p. 255. 7. t. 88.-Id. Sup. p. 258.

HA AIT A T in infularum Antillarum et Cayana inundatis. - I 2 poll. long. Roftrum modicum flavum, bafi rubrum : pedes flavi: tedrices fub-

10. caudales albæ: caro fapida.

flaviroftris. G. fronte rubra, corpore fupra cæruleo fubtus uropygioque albo, remigibus caudaque fufcis.

Fulica flaviroftris, Gmel. Syft. i. p. 699 .

La Favorite de Cayenne, Buf. viii. p. 207.-Pl. Enl. 897.

Favourite Gallinule, Latb. Syn. v. p. 256. 8.

Habitat in Cayana.- 2 pollices longa.-Rofrum pedefque flavi.

I.

purpurea. G. fronte roftroque rubente, corpore faturate purpureo albo vario.

Fulica purpurea, Gmel. Syft. i. p. 699.

Quachilto, Porphyrio americanus, Raii Syn. p. x16. 14.-Will. p. 238. - Id. (Angl.). P. 319.

L'Acintli, Buf. viii. p. 208.

Crowing Gallinule, Latb. Syn. v. p. 257. 9.

Habitat in Mexico.-Inter noctu canit Galli gallinacei modo.

12.

viridis. G. corpore fupra obfcure viridi fubtus albo, fronte roftro pedibufque viridi-flavefcentibus.

Fulica viridis, Gmel. sy/f. i. p. 698 .

Porphyrio viridis, Brij. v. p. 529 . 3. -Id. 8 vo. ii. p. 352 。

La Poule-fultane verte, Buf. viii. p. 204.

Green Gallinule, Lath. Syn. v. p. 257. II.

Habit at in India.-I I poll. longa.

G. fronte 
oropus. G. fronte fulva, armillis rubris, corpore nigricante, crifo albo. Fulica chloropus, Lin. Syft. i. p. 258. 4.-Gmel. Syft. i. p. 698.-Scop. Ann. i. No 153.-Brun. No I 91.-Muller, p. 27.-Kram. El.p. 358. 1.-Frifch. t. 209.-Sepp. Vog. t. p. 7 1.-Faun. Arag. p. 79. -Faun. Helvet.

Gallinula chlorepus major, Raii Syn. p. II3. A. I.-Id. 190. I5.Will. p. 233 . t. $5^{8 .-B r i f . ~ v i . ~ p . ~ 3 . ~ I . ~ t . ~ 1 .-I d . ~} 8$ vo. ii. p. $35^{8}$. -Klcin. Av. p. i०3. 2 ?

Poule d'eau, Buf. viii. p. 171. t. 15.-Pl. Enl. 877.-Hift. Prov. i. 352. Gallinelle, Cet. uc. Sard. p. 377.

Common Water-Hen, or More-Hen, Alb. ii. t. 72.-iii t. 91.-Will. (Angl.) p. 312 . t. $5^{8}$.

Gallinella aquatica, Porzanone, Zinnan. Uov. p. 109. t. 29. f. 98.Scbas. El. t. 36.

Common Gallinule, Br. Zool. ii. No 2 I 7. t. 77.-Id. fol. I3 т. t. L. I. Arst. Zool. ii. $\mathrm{N}^{\circ} 4 \mathrm{I} 1 .-I d$. Sup. p. 69.-Flor. Scot. i. $\mathrm{N}^{\circ} 6_{3}$. Hayes Br. Birds, t. 30.-Lath. Syn. v. p. 258. 12.

Habitat in Eurcpa, America; communis avis; flumina et itagna frequentans.-Victitat pifcibus, feminibus, infectis. - I 4 pollices longa. Roftrum flavum, bafi femicoccincum: irides rubre: pedes flavo-virefcentes: criffum utrinque album, quod internatandum crebro oftentat: abdomen cinereum pennis albido marginatis. Variat gula alba. Ovun albidum, maculis fanguineo-fufcis.

14. phœnicu. G. fronte incarnato, corpore nigro, vertice fubtus genifque albis, criffo $\mathrm{ra}$ caudaque ferrugineo-rubris.

Rallus phœnicurus, Zool. Ind. p. ig. t. 9.-Gmel. Syft. i. p. 7 I 5.

Red-tailed Water Hen, Ind. Zool. p. Io. t. 9.

- Gallinule, Lath. Syn. v. p. 259. I3.

Habitat in Zeylona. $\rightarrow 9$ pollices longa.

Roftrum et pedes viridefcentes : remiges maculis cærulefcentibus notatæ.

ß. G. fronte rubra, corpore cinereo-nigricante fubtus albo, abdomine imo criffoque rufis.

La Poule-Sultane brune, Buf. viii. p. 204. de la Chine, Pl. Enl. 896.-Latb. Syn. v. p. 259.

Habitat in Cbina. 
$\gamma$. G. fronte alba, corpore fupra nigro nitente fubtus albo, criffo rubro, Lath. Syn. v. p. $260.13 . \mathrm{B}$.

15.

Habitat ad Caput Bonce Spei.

fufca. G. fronte flavefcente, armillis concoloribus, corpore fufcefcente.

Fulica fufca, Lin. Syft. i. p. 257. 1.-Gmel. Syf. i. p. 697.-Faun. Arag. p. 78.-Faun. Helvet. - albiventris, Scop. Ann. i. $\mathrm{N}^{\circ}$ I 50 .

Gallinula minor, Brif. vi. p. 6. 2.-Id. 8 vo. ii. p. 359 .

Rallus Italorum Aldr. Raii Syn. p. I 16. 15.-Will. p. 238.

Gallinula alia Aldr. Will. p. 234.-Id. (Angl.) p. 314. 319.

La Poulette d'eau, Buf. viii. p. 177.

Waffer huhn, Guntb. Neft.u. Ey. t. 20.-Naturf. xviii. p. 70.

Brown Gallinule, Latb. Syn. v. p. 260. I4.

HaвiтAт in Europa.-12 pollices longa.

Corpus fufco-olivaceum, fubtus cinereum albo-undulatum : margines alarum candidæ: rętrix extima utrinque candida.

$\beta$. G. fronte flavicante, corpore fupra caftaneo fubtus cinereo, marginibus pennarum albis, capite et collo nigricantibus, itmo ventré albo.

Gallinula major, Brif. vi. p. 9. 3. $-I d .8$ vo. ii. p. 360.

Gallina chloropus altera, Raii Syn. p. $114.3 .-W i l l$. p. 233.-Id. (Angl.) p. 313.

Grande Poule d'eau, ou Porzane, Buf. viii. p. 178.

Brown Gallinule, Latb. Syn. v. p. 26 1. 14. var. A.

16.

novebora- G. fufca, fcapularibus margine flavefcentibus, pectore flavo, abdomine cenfis.

Fulica noveboracenfis, Gmel. Syft. i. p. 70 r.

Yellow-breafted Gallinule, Arct. Zool. ii. No 410.-Lath. Syn. v. p. 262. 15 .

Habitat in Noveboraco; coturnice minor.

Vertex collumque fuperius olivaceo-fufca albo maculata.

17.

carolina. G. grifea, capiftro nigro, pectore plumbeo, roftro flavo, pedibus virefcentibus.

Rallus carolinus, Lin, Syft, i. p. 263. 9.-Gmel. Syft. i. p. 7 I 50

$$
5 \mathrm{~F}_{2}
$$

Rallus 
Rallus terreftris americanus, Klein. Av. p. 103. 4.

Porphyrio freti Hudfonis, Brif. v. p. 541. 9. $-1 d$. 8 vo. ii. p. 356 .

Le Rale de Virginie, Buf. viii. p. I65.

Little American Water Hen, Edw. t. I 4.4.

Soree Gallinule, ArEz. Zool. ii. No 409.-Catef. Car. i. t. 70.-Burn. Tr. p. 16. 42.-Latb. Syn. v. p. 262. I6.

18.

Haвıтат in America Septentrionali; inigratoria; gregaria.-7-8 pollices longa.

nævia. G. frontē crocea, corpore rufefcente nigro maculato, collo fubtus cinereo-cærulefcerite maculis nigris, fuperciliis albidis.

Fulica nævia, Gmel. Syft. i. p. 701.

Porphyrio nevius, Brif. v. p. 438 . 8.-Id. 8 vo. ii. p. 355 .

Poliopus, Gallinula minor, Raii. Syn. p. 1 14. - Will. p. 235 . t. $5^{8}$.

La Grinette, Buf. viii. p. 179 .

Small Water Hen, Alb. ii. t. 73 .

Grinetta Gallinule, Lath. Syn. v. p. 263.-Will (Angl.) p. 315.

Habitar circa Bunoniam.-9 poll. longa.-Porzane valde affinis.

19.

Porzana. G. fufco-olivacea nigro albidoque variegata et maculata, fubtus cinerea albido varia, rectricibus duabus intermediis albo marginatis.

Rallus Porzana, Lin. Syft. i. p. 262. 3.-Gmel. Syft. i. p. $712 .-$ Scop. Ann. i. $\mathrm{N}^{\circ}$ 144.- Frifch. t. $211 .-$ Borowes. Nat. iii. p. 102. 3.Faun. Helvet.

Rallis aquaticus minor, five Maruetta, Brif. v. p. 155. 2. t. I3. f. I.Id 8 vo. ii. p. 252.

Rallus alter, Klein. Ov. p. 3r. t. 12. f. 2 ?

Gallinula ochra Gefneri, Raii Syn. p. I I 5. 7.-Will.p. 236.-Id. (Angl.) p. 316.

Petit Rale d'eau, ou le Marouette, Buf. viii. p. 157.-Pl. Enl. 75 1.Argenv. Litbol. 533. t. 25.

Spotted Gallinule, Br. Zool. ii. N $\mathrm{N}^{\circ}$ 2 $5 .-I d$. fol. I 30. t. L. *. I. Arct. Zool. Sup. p. 69.-Lath. Syn. v. p. 264. I 8.

Habitat in Europa, fmerica boreali, ad ripas fluviorum; Crege multo minor; vix 9 pollices longa. Ovum maculis atro-fufcis.

20.

maculata. G. fronte flava, corpore fufco-rufefcente fupra maculis nigris candidifque adfperfo, genis gula colloque fubtus albis. 
Fulica maculata, Gmel. syft. i. p. 701 .

Porphyrio punctulatus, Brif. v. p. $536.7 .-I d .8$ vo. ii. p. 354 .

Gallinula erythra Gefn. Raii Syn. p. I09. 10...Will. p. 226. t. 56.

Matkneitzel, Matkern, Will. (Angl.) p. 304.-Klein. Av. p. Iог. 8.

Speckled Gallinule, Latb. Syn. v. p. 266. I 9.

Haвiтat in Germania; Cregis magnitudine.-I I pollices longa. albæ.

Roftrum flavicans: pedes grife1: rectrices intermediæ 2 nigræa apice

21.

flavipes. G. fronte flava, corpore fupra rufo maculis nigricantibus vario fubtus albo, capiftro genifque candidis.

Fulica flavipes, Gmel: Syjt. i. p. 702.

Porphyrio rufus, Brif. v. p. 534. 6.-Id. 8 vo. ii. p. 354 .

Gallinula ochropus major, Raii Syn. p. I15. 6.-Will. p. 236.-Id. (Angl.) p. 316.-Klein. Av. p. Ior. 2.

La Smirring, Buf. viii. p. 180 .

Yellow-legged Gallinule, Lath. Syn. v. p. 266. 20.

Hавітат in Germania; Cbloropodis magnitudine.

Roftrum pedefque flavi : rectrices rufæ nigricante maculatæ.

22.

fiftulans. G. fronte viridi-flavicante, corpore fufco fubtus albo, genis candidis.

Fulica fiftulans, Gmel. Syft.i. p. 702.

Porphyrio fufcus, Brif. v. p. 531. 4.-Id. 8vo. ii. p. 353 .

La Glout, Buf. viii. p. I $8 \mathrm{I}$.

Piping Gallinule, Lath. Syn. v. p. 267.21.

23.

Habitat in Germania, ibique lacuum et pifcinarum ripas frequentat.

criftata. G. fronte criftata rubra, corpore fupra cinereo-virefcente, fubtus capite colloque cinereis, abdomine medio albo.

Fulica cinerea, Gmel. Syft. i. p. 702 .

Crefted Gallinule, Lath. Syn. v. p. 267. 22.

Habitat in Cbina, India. - 8 pollices longa.

Frons et vertex calva, carunculata, gibbofa, rubra. 
774 A VES GR A L L IE. Vaginalis.

\section{GENUS LXXXI. VA G I A L I S.}

Roftrum robuftum, craffum, conico-convexum, comprefium, mandibula fuperiore fupra vagina mobili cornea tecta.

Nares parvæ, vix ante vaginam confpicuæ.

Lingua fupra teres, fubtus complanata, apice acuminata. Facies nuda, papillofa.

Ala fub flexura nodo obtufo munitæ.

Pedes robuft, tetradactyli, parumper fupra genua nudi, digito exteriore medio bafi membrana connexo.

I.

Chionis. Vaginalis.

Vaginalis alba, Gmel. Syft. i. p. 705. (Chionis Forfteri.)

White Sheathbill, Latb. Syn. v. p. 268. t. 89.-Penn. Syft. Index, t. præf. tit.

HabiтAт in $N$. Zealandice aliarumque maris auftralis infularum maritimis; gregaria ; teftaceis et cadaveribus victitans.-Magnitudo Columbe majoris.- $15^{-1} 8$ pollices longa.

Roftrum validum, fupra bafi lamella cornea flava vel nigra mobili tectum, et nares tegente : irides plumbeæ: gene nudæ verrucis flavis obfitæ: color pennarum toto niveus : ad flexuram alarum calcar obtufum, 1. nodus nigricans: pedes rubefcentes; -in quibufdam fufci, aut albidi. Caro ingrata. 
A VES PINNATIPEDES. Phalaropus. 775

\section{ORDO VIII. PINNATIPEDES.}

\section{GENUS LXXXII. PHALAROPUS.}

Roftrum teretiufculum, rectum, apice fubinflexo. Nares minutæ.

Pedes tetradactyli, fifi, digitis ad latera membranis pinnatis $f$. dentatis infructi.

1.

hyperbo- Ph. cinereus, fubtus uropygio fafciaque alarum albis, pectore cinereo, reus. colfi lateribus ferrugineis. (Mas.)

Tringa hyperborea, Lin. Syft. i. p. 249. 9.-Faun. Suec. No 179. (defcr. pofterior.) - Brun. 172.-Muller, No 196.-Faun. Groenl. No 75 . -Gmel. syjt. i. p. 675 .

Phalaropus cinereus, Brif. vi. p. 15. 2.-Id. 8vo. ii. p. 362.

Larus fidipes alter noftras, Raii Syn. p. 132. A. 7.-Will.p. 270.

Le Phalarope cendré, Buf. viii. p. 224--Pl. Enl. 766.

Cock Coot-footed Tringa, Edw. t. 143 .

Red Phalarope, Br. Zool. ii. N' 21 9. t. 76.-Latb. Syn. v. p. 270 . I. (Mas.)

$\mathrm{Ph}$. corpore grifeo fubtus rufo, uropygio fafciaque alarum alba, fuperciliis re etricibufque bafi rufefcentibus. (Femina.)

Tringa fulicaria, Lin. Syft. i. p. 249. 10.-Faun. Groenl. No 76.-Gmelo. Syft. i. p. 676.6.

Phalaropus rufefcens, Brif. vi. p. 20. 4.-Id. 8 vo. ii. p. $3^{6} 3$.

Le Phalarope rouge, Buf. viii. p. 225.

Red Coot-footed Tringa, Edro. t. 142 .

Red Phalarope, Lath.Syn.v. p. 271. (Femina.)

Haвттат in Europa boreali et America ; migratorius.-8 poll. longus.

- Per paria plerumque incedunt hæ aves; hyeme gregaria.

Mas roftro nigro, fafcia per oculos nigricante: uropygio fafciis nigricantibus. 


\section{$77^{6}$ A VES PIN N A T I PEDES. Phalaropus.}

Femina roftro flavefcente, fafcia fupra oculos rufefcente : uropygio nigricante maculato.

$\beta$. Ph. fufco-nebulofus, gula abdomine fafciaque alarum albis, lateribus colli macula difformi rufa.

Red Phalarope, Lath. Syn. v. p. 272. t. in tit. (maris var.) fuit.

Hæc avis in montibus glacialibus Afre et America interjectis capta

2.

lobatus. Ph. cinereo carulefcens fubtus albus, tectricibus alarum remigibus rectricibufque nigricantibus margine cinerafcente-albis.

Tringa lobata, Lin. Syft. i. p. 249. 8.-Faun. Suec. $\mathrm{N}^{\circ}$ 179.-Gmel. Syft. i. p. 674.-Brun. No 17 1.-Muller, No $195 .-$ Faun. Groenl. $\mathrm{N}^{\circ} 75,-N$. C. Petr. xiv. p. 501. 3. t. I 3. f. 3 ?-Borowjk. Nat. iii. p. 94. 4.-Faun. Helvet.

Phalaropus, Brif. vi. p. I 2. I. -Id. 8 vo. ii. p. 36 I.

Le Phalarope à fettons dentelés, Buf. viii. p. 226.

Grey Coot-footed Tringa, Edw. t. 308.-Pbil. Tranf. 1. p. 255. t. 6. Grey Phalarope, Br. Zool. ii. $\mathrm{N}^{\circ}$ 218. t. 76.-Id. fol. I 26 t. E. 1. f. 3 . -Arct. Zool. ii. $\mathrm{N}^{\circ} 4 \mathrm{I} 2$. -Lath. Syn. v. p. 272. 2.

Habitat in Europa, Afia, America; rarius in Anglia; procellofa tempeftate gregarius lacubus innatat, tranquilla in paludibus folitarius.

Roftrum nigrum: pedes cinerei.

3. glacialis. Ph. fupra nigricans pennis margine flavefcentibus fubtus albus, genis colloque fubtus flavicantibus, alis caudaque cinereis.

Tringa glacialis, Gmel. Syft. i. p. 675 .

Plain Phalarope, Arct. Zool. ii. No 41 5.-Latb. Syn. v. p. 173. 3.

Haвiт at in Mare byperboreo inter glaciem.

Roftrum nigrum apice dilatatum: per oculos fafcia nigra : pedes flavicantes.

4 .

fufcus. Ph. fufcus marginibus pennarum dilutioribus fubtus albus, capite fupra nigro, collo cinereo, fafcia alarum alba.

Tringa fufca, Gmel. Syft. i. p. 675.

Phalaropus fufcus, Brif. vi. p. 18. 3.-Id. 8 vo. ii. p. 363 .

Fulica fufca, roftro tenui, Klein. Av. p. I 5 1. 3.

Coot-footed 
A VES PIN NATIPEDES, Fulica.

Coot-footed Tringa, Edze. t. 46 .

Brown Phalarope, Arcz. Zool. ii. No 4r 4.-Latb. Syn. v. p. 2\%4. 4.

Habrtat in America Septentrionali.-Rofrum pedefque nigri.

s.

cancella- $\mathrm{Ph}$. fufcus marginibus pennarum albis fubtus albus fafciolis obfcuris,

tus.

Tringa cancellata, Gmel. Syjt. i. p. 675 .

Barred Phalarope, Lath. Syn. v. p. 274. 5.

$H_{\text {ABIт }}$ at in infula Nativitatis Cbriffi. $-7 \frac{x}{2}$ pollices longus.

Remiges et reitrices nigricantes apice fufcæ, marginibus pallidis.

\section{GEN U S LXXXIH. F U L I C A.}

Roftrum conicum, compreffiufculum, bafi fronte calva. Nares oblongæ, perviæ.

Corpus compreffum.

Cauda brevis.

Pedes tetradactyli, digitis per totam longitudinem mem.

branis fiffis emarginatis.

i.

atra. F. fronte incarnata, armillis luteis, corpore nigricante.

Fulica atra, Lin. Syft. i. p. 257. 2.-Faun. Suec. $\mathrm{N}^{\circ}$ i 93.-Gmel. Syft. i. p. 702.-Scop. Ann. i. $\mathrm{N}^{\circ}$ 149.-Brun, $\mathrm{N}^{\circ}$ 190.-Muller, $\mathrm{N}^{\circ}$ 2 16.-Kram. El. p. 357. 1.-Frifch. t. 208.-Georgi reife, p. 172. Hajelq. Voy. p. 200. 34.-Sepp. Vog. t. p. 61.-Brif. vi. p. 23. t. 2. f. $2 .-I d .8$ vo. ii. p. $365 .-$ Raii Syn. p. 116. A. 1. -Will. p. 239. t. 59.-Brown. Fam. p. 479.-Scbaf. El. t. 34.-Klein. Av. p. 150. I.-Id. Stem. p. 40 . t. 40 . f. x. a. b. -ld. Ov. p. 36. t. I 2. f. 3.-Borow/k. Nat. iii. p. 97. 2.-Faun. Helvet.

Le Foulque, ou Morelle, Buf. viii. p. 2 I . t. 18.-Pl. Enl. 197.Hift. Prov. p. 352.

Folaga, o Polon, Zinnan. Uov. p. 108. t. 19. f. 96.-Cet.uc. Sard.p. 282. Kleiner Blœfsling, Gunth. Neft. u. Ey. t. 29.

Common Coot, Br. Zool. ii. No 220. t. 77.-Id. fol. 132. t. F. -Arct. Zool. ii. N 4 I6. -Will. (Angl.) p. 319. t. 59.-Alb. i. to 83.Lath. Syn. v. p. 275. I. -Id. Sup. p. 259. 
Habitat in Europa, Afia, America.- - 5 pollices longa.-In Anglie aquofis frequens. - Natat curritque fupra aquas; nidificat inter arundinem, nido ex ejus foliis confeEto et arundinibus affixo. Ovum fordide album punctulis obfcuris maculifque diftantibus purpureis.

$\beta$. Fulica nigra, alis albis.

Fulica leucoryx, Muf. Carlf. fafc. i. No 1 2.-Latb. Syn. Sup. p. 259.Gmel. Syj. i. p. 703 .

Habitat ad Holmiom; magnitudine et ftatura $F$. atra.

Palpebra pallidæ: alorum tedirices et remiges omnes candidæ, rachibus remigum primariarum nigricantibus.

$\gamma$. F. tota nigra.

Fulica rethiops, Muf. Carls. fafc. i. No 13.-Latb. Syn. Sup. p. 259.Gmel. Syjt. i. P. 704:

Habitat in Suesia?-Magnitudo et ftatura atra, fed ab hac præcipue differt alarum plumis omnibus nigris, pectore abdomineque ferrugineo fufcoque undulatis.

ઈ. F. fufca, gula abdomine remigibufque primoribus albis. Fulica albiventris, Scop. Ann. i. p. 105 .

Sub gula eft macula fubovata fufca : caput albo maculatum : mandibula fuperior rubra: plumæ fub cauda albæ.

\&. F. alba, Br. Zool. ii. $\mathrm{N}^{\circ} 220$. var.

Corpus huic album, capite et alis fparfim maculatis.

2.

sterrima. F fronte alba, armillis rubris, corpore nigricante.

Fulica aterrima, Lin. Syft. i. p. 258. 3.-Gmel. Syft. i. p. 703.-Borowfk. Nat. iii. p. 98 . 3 .

fuliginofa, $S_{c o p}$. Ann. i. $\mathrm{N}^{\circ} 150$.

Fulica major, Brif. v. p. 28. 2. t. 2. f. 2.-Id. 8 vo. ii. p. $366 .-F a u n$. Helvet.-Raii Syn. p. I $17.2 .-W i l l$. p. 239. t. 5 1.-Klein. Av. p. 15 1. 2.-Id. Stem. p. 40. t. 40. f. 2.-Id. Ov. p. 36. t. 12. f. 3 ?

La grande Foulque, ou la Macroule, Buf. viii. p. 220.

Groffer Blœfsling met der weiffen Blaze, Gunth. Neft. u. Ey. t. 36.

Greater Coot, Br. Zool. ii. N²21.-Will. (Angl.) p. 320.-Lath. Syn. v. 277.2 .

A præcedente 
A precedente differt ftatura majore, corpore anguftiore, maculis nullis, tonfura duplo minore, roftro longiore, lobis digitorum duplo majoribus, $S c o p$.

3.

criftata. F. caruncula rubra bifida erecta, armillis tricoloribus, corpore cæruleonigricante.

Fulica criftata, Gmel. Syft. i. p. 704 .

Grande Foulque de Madagafcar à crête, Pl. Enl. 797.-Buf. viii.p. 222. Crefted Coot, Latb. Syn. v. p. 278. 3. t. 90.

Haвiтат in Madagafcaria, Cbina; corpore prioribus major.

Roftrum albidum, bafi rubrum : femora annulis tribus, fc. rubro viridi et flavo cineta.

mexicana. F. fronte coccinea, corpore pallide virefcente cyaneo et fulvo variegato, fubtus capite et collo purpureis.

Fulica mexicana, Brif. vi. p. 31. 3.-Id. 8vo. ii. p. 367.--Gmel. Syft. i. p. 704 .

Fulicæ Mexic. altera fpecies, Yohoalcoachillin, Raii Syn. p. II7.

Mexican Coot, Lath. Syn. v. p. 278. 4.

Habitat in Mexico; aterrime magnitudine.

Roftrum niveum, prope apicem luteum.

5.

americana. $\mathrm{F}$. fronte albida, corpore cinereo, gula abdomineque medio albis.

Fulica americana, Gmel. Syft. i. p. 704.

Cinereous Coot, Lath. Syn. v. p. 279. 5.

Habitat in America feptentrionali; atra minor.

Roftrum pallide viride: pedes cærulefcentes: membrana frontalis et digitorvin lateralis anguftior quam congeneribus. 
$7^{80}$ AVES PINNATIPEDES. Podiceps:

\title{
GenUS LXXXIV. POD I E P S.
}

\author{
Rofrum rectum, acutum. \\ Nares lineares. \\ Lora nuda. \\ Lingua fubbifida. \\ Corpus depreffiufculum. \\ Cauda obfoleta. \\ Pedes tetradactyli, compreffi, tibiis poftice duplici ferie \\ ferratis. \\ Digiti lateribus lobo fimplici inftructi, bafique connexi; \\ unguibus humanorum inftar planis rotundatis.
}

r.

criftatus. P. fufcus fubtus albus, capite rufo tumido, collari nigro, remigibus fecundariis albis. (Adulta Avis.)

Colymbus criftatus, Lin. Syff. i. p. 222. 7.-Faun. Suec: $\mathrm{N}^{\circ}$ I I I. -Scop. Ann. i. $\mathrm{N}^{\circ}$ 99.-Brun. $\mathrm{N}^{\circ}$ 135.-Muller, $\mathrm{N}^{\circ}$ 57.-Frifch.to.1 8 3.-

Sepp. Vog. t. p. 169.-Borowjk. Nat. iii. p. 56. t. 43.-Faun. Helv. Colymbus major criftatus et cornutus, Raii Syn. p. 124.A. 2.-Will. p. 257. t. 61.-Klein. Av. p. I49. i.

Colymbus cornutus, Brif. vi. p. 4.5 -4..t. 5. f. r. $-I d .8$ vo. ii. p. 370. Ardea exotica aurita, Pet. Gaz. t. 43. f. I 2.

Le Grebe cornu, Buf. viii. p. 235. t. 19.- Pl. Enl. 400.

Smergo, Fifolo marino, Zinnan. Uov. p. 1c7. t. 19. f. 95 .

Greater crefted and horned Ducker, Will. (Angl.) p. 340. \$. 5. t. 6r. f. 1.-Plot's Hift. Staf. p. 229. t. 22.-Alb. i. t. 81 .

Crefted Grebe, Br. Zool. ii. No 223.-Id. fol. 132. t. K.-ArCt. Zool. ii. p. 498. A.-Lath. Syn. v. p. 281 . 1.

$P$. fufcus fubtus albus, gutture fafciculo plumofo utrinque longiore, remigibus fecundariis albis. (Avis biennis?)

Colymbus criftatus, Brif. vi. p. 38. 2. t. 4. -Id. 8vo. ii. p. 368 .

- major criftatus, Klein. Av. p. 149. 2. ii. t. 75 .

$$
\text { cinereus major, Raii Syn. p. 124. A. 1.-Will. p. 257.-Alb. }
$$

Grey 
Grey or afh-coloured Loon, Will. (Angl.) p. 340. \$. 4. t. 61. f. 4 . Le Grebe huppé, Buf. viii. p. 233.-Pl. Enl. 94.4.

P. fufcus fubtus albus, capite levi, macula alarum alba. (Pullus annuus.)

Colymbus urinator, Lin. Syft. i. p. 223. 9.-Ginel. Syjt. i. p. 593.-Scop. Ann. i. No 102.-Borowek. Nat. iii. p. 61. 7. - Faun. Helvet.

Colymbus, Brif. vi. p. 34. I. t. 3. f. 1. -Id. 3 vo. ii. p. 368.

major Aldrov. Raii Syn. p. 125. 6. -Will. P. 256 . t. 51.Klein. Av. p. 150.3 .

Le Grebe, Buf. viii. p. 227.-Pl. Enl. 941.

Greater Loon or Arfefoot, Will. (Aigl.) p. 339. t. 51. $-E d w$. t. 360. f. 2 .

Tippet Grebe, Br. Zool. ii. N ${ }^{\circ}$ 222. t. 78. -Id. fol. 133.-Latb. Syn. v. p. 283.2 .

Habitat in Europa boreali.- 23 pollices longus. - In Anglie paludofis invenitur; paluftribus Lincolnienfibus et Ceftrienfibus copiofe, alibi rarius, nidificans. - Nidum natantem ex gramine et plantis aquaticis magnum, pedem crafun, ftruit. - Ovum fufco-cinerafcens.

Roftrum nigricans bafi rubente vel albida : lora nigricantia : pedes viridi-nigricantes. Hæc avis æetate potius quam fexu nire variat; at omni tempore corpus fupra fufcum, fubcus fafciaque alarum alba. Pulli, primo veftitu, colli lateribus nigricante frriatis. Ad finem anni pri$\mathrm{mi}$, caput et collum totum levia, fuica. Ad initium fecundi anni caput tumidiufculum, verticis plumulis fenfim elongatis, gutture et genis rubro vel nigro paululum contaminatis, aut ftriatis. Avis denique completa capite criftato et cornuto gaudet, plumulis circa verticem et colluin fupremum eminentibus, fuperius nigris, ad latera rufis.

2.

cayanus. P. fufco-nigricans fubtus albus, collo fubtus rufo.

Colymbus cayennenis, Gmel. Syft. i. p. 593.

Le grand Grebe, Buf. viii. p. 242.

Grebe de Cayenne, Pl. Enl. 404. f. x.

Cayenne Grebe, Latb. Syn. v. p. 284. 3.

HaBitat in Cayana.-1 $9 \frac{\mathrm{T}}{2}$ pollices longus.

3. auritus.

P. fufco-nigricans fubtus albus, capite nigro, auribus criftato-ferrugi-
neis. Colymbus auritus, Lin. Syft. i. p. 222. 7.-Faun. Suec. $N^{\circ}{ }_{1} 5_{2} .-$ Scop. Ans, 
Ann. i. $\mathrm{N}^{\circ}$ 100.-Brun. $\mathrm{N}^{\circ}$ '36. 137.-Nuller, p. 20.-Brif, vi. p. 54. 6.-Id. 8vo. ii. p. 37 2.-Borowejk. Nat. iii. p. 61.6.-Faun. Helvet.

Le petit Grebe huppé, Buf. viii. p. 235.

Eared Dobchick, Edw. t. 96 . f. 2.

Eared Grebe, Br. Zool. ii. N 224. t. 79.-Id. fol. 133.-Arct. Zool. ii. p. 499. B.-Boug.Voy. p. 6 I ? - Lath. Syn. v. p. $285 \cdot 4$.

Habitat in Europa, et in infulis Falklandicis?-I2 pollices longus. -In paluftribus Lincolnienfibus Anglice nidificat, nidum natantem inter arundines conficiens. - Lora rubra.

ß. Colymbus criftatus minor, Brif. vi. p. 42. 3. t. 3. f. 2.-Id. 8vo. ii. p. 369 .

Colymbus nigricans, Scop. Ann. i. $\mathrm{N}^{\circ}$ Ior ?

Eared Grebe, Lath. Syn. v. p. 286. 4. var. A.

Variat corpore minore; capite crifta duplici; collo fubtus maculis caftaneis vario.

4.

obfccurus. P. fufco-nigricans fubtus albus, macula utrinque inter roftrum et oculum, marginibus alarum remigibufque intermediis candidis.

Colymbus obfcurus, Gmel. Syft. i. p. 592 .

Colymbus minor, Brif. vi. p. 56. 7.-Id.8vo. ii. p. 373.-Klein. Av. p. $150.4 .-F a u n$. Helvet.

Le petit Grebe, Buf. viii. p. 232.-Pl. Enl. 942.

Black and white Dobchick, Edw. t. 96. f. 1 .

Durky Grebe, Br. Zool. ii. $N^{\circ} 225$. t. 78 . 1. $-I d$. fol. 133. t. K. 1.Ariz. Zool. ii. $\mathrm{N}^{\circ} 420 .-$ Lath. Syn. v. p. 286. 5.

Habitat in Europa, America; in Anglia interdum invenitur.-I I pollices longus. - Caput læve: lora et irides rubræ: pedes purpureo-incarnati.

5. cornutus. P. criftatus, collo fubtus pectoreque fulvis, capite nigro tumido, per oculos fafcia cirrhata flava.

Colymbus cornutus, Gmel. Syft. i. p. 59 г.

Eared or horned Dobchick, Edw. t. 145.

Horned Grebe, Arct. Zool. ii. No 417.--Lath. Syn. v. p. 287. 6. t. 9 I.

Habitat ad fretum Hudfonis, Noveboraco hybernans. -12 pollices longus.

Corpus 
A V E S P I N N A T I P E DES. Podiceps. 783

Corpus fupra fufcum fubtus album : remiges fecundariæ albæ. Ovum album.

$\beta$. P. criftatus, collo fubtus caftané, capite colloque fupremo nigro. virefcentibus, fafciculo pone oculos aurantio-rufefcente.

Colymbus cornutus minor, Brif. vi. p. 50. 5- - Id. 8 vo. ii. p. 37 I.

Colymbus, five Podiceps minor, Raii Syn. p. 19c. 14.-Slocn. Jain. p. 322. t. 27 I. f. 1. - Klein. Av. p. 150.4 ?

I.e petit Grebe cornu, Buf. viii. p. 237.

Grebe de l'Efclavonie, Pl. Enl. 404. f. 2.-Lath. Syn. v. p. 288. 6. var. A.

6.

Habitat in Sclavonia.

rubricollis. P. fubcriftatus fufcus, gula genis regioneque aurium cinerafcentibus, collo fubtus pectoreque ferrugineo-rubris, abdomine remigibufque fecundariis albis.

Colymbus rubricollis, Gmel. Syft. i. p. 592.

fubcriftatus, facq. Vog. p. 37. t. 18.-Gmel. Syft. i. p. 590. -Faun. Suec. p. 54. I 52. (ALIA.)-Brun. $\mathrm{N}^{\circ} 138$.

Colymbus urinator, It. Pofeg. p. 25 ?

Colymbus grifeus, Fann. Helvet.--Scbaef. El. Orn. t. 29.

roftro nigro collo badio, Naturf. Gef. 7. p. 460 ?

Le Grebe à joues grifes, Jougris, Buf. viii. p. 24I.-Pl. Enl. 931.

Red-necked Grebe, Latb. Syn. v. p. 288. 7.-Id. Sup. p. 260. t. I 18.Arct. Zool. ii. p. 499 . C.-Id. Sup. p. 69.

Habitat in Europa; in Anglia inter rariores.-1 8 pollices longus.

Roftrum nigrum, lateribus ad bafin fulvum: irides fulvæ: pedes nigricantes: caput fupra oculos nigrum, poftice lateribus pennis elongatis quafi fubcriftatum: gene et gula cinereo-alba, in quibuifdam alba.

$\beta$. P. capite lævi nigro, gulæ aurium et fubocularibus regionibus albidis nigro lineatis.

Colymbus Parotis, Muf. Carlf. fafc. i. t. 9.-Gmel. Syft. i. p. 592.Brun. 139. 283. nota $t$.

A priore variat capite lævi minime criftato: regiones fuboculares, gularis, parotideæque albæ, lineis 3 vel 4 fubparallelis nigris, anterioribus 
$7 \$ 4$ AVES PIN N TIPEDE; Fodireps,

riorbus interruptis : dorfum nigrum: bypochondvia, femora, crifum fultw ginofa.

7.

cafpicus. P. capite lavi, corpore fupra ex fufco nigricante infra ex argenteo albo, roftro plumbeo, gula genifque albis, tectricibus alarum fufcis, S. G. Gmel. It. iv. p. 137.-N. Nord. Beytr. iv, p. 9.-Ginel. Syjt. i. p. 593 .

8.

HaBITAT in mari Cafpio. - An a precedentis juniore fatis diftinctus? thomenfis. P. fufcus, fubtus albus maculis grifeis, remigibus pallide rufis, macula pećtoris nigra.

Colymbus thomenfis, Gmel. Syft. i. p. 592.

- infula S. Thomæ, Brif. vi. p. 58. 2.-Id. 8 vo. ii. p. 374.

Le Grebe Duc-laart, Buf. viii. p. 240 .

Black-breafted Grebe, Latb. Syn. v. p. 289. 9.

Habitat in infula Sti. Thome in America; Gallina minor.

Roftrum nigrum apice pallidum: irides et macula inter roftrum et oculum alba.

minor. P. fulvo-fufcus, corpore fubtus macula remigum uropygioque infimo albo-argenteis, collo fubtus grifeo-fulvo.

Colymbus minor, Gmel. Syft. i. p. $59 \mathrm{r}$.

Colymbus criftatus, Lin. Syjt. i. p. 223. $\gamma$. -Faun. Suec. $N^{\circ} 152$ ?Frijch. t. 184 .

Helvet.

Podiceps minor. Raii Syn. p. 125. A. 3.-Will. p. 258. t. 6I.

Yacapitzahoac, Raii Syn. p. 177.

Le Grebe de la riviere, ou le Caftagneux, Buf. viii. p. 244. t. 20.Pl. Enl. 905 .

Little Grebe, Br. Zool. ii. No 226.-Id. fol. 134. t. F. -Will. (Angl.)

p. 340. t. 61.-Lath. Syn. v. p. 289 . 10.

Habitat in Europa, America; in Anglia communis avis, flumina pifcinafque frequentans. - Victitat pifciculis, infectis, plantis.-Nidum conficit natantem in ipfa aqua inter carecta et arundines.-Egregie urinatur.- -10 pollices longus.

B. Le Caftagneux des Philippines, Buf. viii. p. 246.-Pl. Enl. 945.Lath. Syn. v. p. 290 . 10. var. A.

Habitat 
10.

A VES PIN N A T I P E D S. Podiceps. 785

HaвIтAт in Pbilippinis infulis.

A priore differt corpore paulo majore, fupra purpureo-fufco; genis lateribufque colli rufefcentibus.

dominicus. P. capite lavi, corpore fubtus confertim maculato.

Colymbus dominicus, Lin. Syft. i. p. 223. 10.-Gmel. Syft. i. p. 593.Brif. vi. p. 64. 11. t. 5. f. 2.-Id. 8 vo. ii. p. 376.

Le Caftagneux de St. Domingue, Buf. viii. p. 248.

Le Plongeon, Defc. Surin. ii. p. 155 .

Twopenny Chick, Hugb. Barb. p. 72.

White-winged Grebe, Lath. Syn. v. p. 291. I I.

Hавıтат in Antillarum infulis, Surinamo.-vix 8 pollices longus.

Corpus fubtus cinereo-argenteum maculis fufcis adfperfum: remiges ab octava ad undecimam ufque cinereo-albre. Variat corpore fubtus fufco medio albo, nonnullis toto fufco.

I.

hebridicus. P. nigricans, gula nigra, jugulo ferrugineo, abdomine cinereo argenteo vario.

Colymbus hebridicus, Gmel. Syft. i. p. 594 .

Black-chin Grebe, Br. Zool. ii. $\mathrm{N}^{\circ} 227$. t. 79.-Arct. Zool. ii. $\mathrm{N}^{\circ} 227$. Lath. Syn. v. p. 292. 12.

Habitat in infula Tirée; minore paulo major.

12.

carolinen- P. corpore fufco, roftro fafcia fefquialtera, gula nigra.

fis. Colymbus Podiceps, Lin. Sy/t. i. p. 223. 11.-Gmel. Sy/t. i. p. 594.

- fluviatilis carolinenfis, Brif. vi. p. 63. 10.-Id. 8vo. ii. p. 375.

- fufcus, Klein. Av. p. 150.5 .

Le Caftagneux à bec cerclé, Buf. viii. p. 247.

Pied-bill Grebe, Arct. Zool. ii. $\mathrm{N}^{\circ}$ 418. t. 22.-Cat. Car. i. t. 91.Lath. Syn. v. p. 292.93.

Habitat in America feptentrionali.-I 4 pollices longus.

Roftrum gallinaceum apice incurvatum, medio fafcia nigra: gula nigra albo circumdata : corpus fubtus argenteum, pectore cinereo-nebulofo: remigibus fecundariis apice albis.

Femina fafcia roftri guleque nigredine caret.

ludovicia- P. fufcus, lateribus colli et corporis ferrugineis, corpore fubtus albo

nus. maculis tranfverfis nigricantibus.

Colymbus 
786 A VES PALMIPEDES. Recurviroftra.

Colymbus ludovicianus, Gmel. Syft. i. p. 592.

Le Grebe de la Louifiane, Buf. viii. p. 240.-Pl. Enl. 943.

Louifiane Grebe, ArEt. Zool. ii. No 419.-Lath. Syn. v. p. 289. 9.

HaBItat in Louifiana.-Roftrum ut in precedente ave, apice paulo incurvato, fed abfque fafcia nigra : abdomen medium albo-argenteum. An a carolinenfis femina fatis diftinctus?

\section{ORDOIX. PALMIPEDES. * Pedibus longioribus.}

GENUS LXXXV. RECURVIROSTRA.

Roftrum depreffo-planum, fubulatum, recurvatum, acuminatum, apice flexili. Nares oblongæ, perviæ.

Lingua brevis.

Pedes tetradactyli, palmati; digitus pofticus brevis, folutus, a terra elevatus.

1.

Avocetta. R. albo nigroque varia.

Recurviroltra Avocetta, Lin. Syft. i. p. 256. r.-Faun. Suec. No I 9 r.Amon. Acad. iv. p. 591.-It. Oeland. 89.-Gmel. Syft. i. p. 693.Scop. Ann. i. $\mathrm{N}^{\circ}$ 1 29.-Brun. $\mathrm{N}^{\circ}$ 188.-Muller, $\mathrm{N}^{\circ}$ 214.-Kram. El. p. 348.-Georgi reife, p. 172.-Sepp. Vog. t. p. 69.-Brif. vi. p. 538 . t. 47 . f. 2.-Id. 8 vo. ii. p. $504 .-$ Raii Syn. p. I17. A. I. -Will. p. 240. t. 6o.-Id. (Angl.) p. 321.-Borow/k. Nat. iii. p. 8 5. t. 50.-Faun. Helvet.

Plotus recurvirofter, Klein. Av. p. 142. I.

L'Avocette, Buf. viii. p. 466. t. 38.-Pl. Enl. 353-Voy. en Barb. i. p. 280.-Salern. Orn. p. 359.-Cett. uc. Sard. p. 287.

Scooping Avofet, Br. Zool. ii. No 228. t. 80.-Id. fol. 1 34. t. C. -ArZt. Zool. ii. p. 503. B. - Alb. i. t. 101.-Latb. Syn. v. p. 293. 1.-Id. Sup. p. 263 . 


\section{A VES PALMIPEDES. Corrira.}

Habitat in Europa auftraliori ad maris littora.-Vietitat lumbricis, infectis. - 18 pollices longa.-In Anglia hæc avis fatis verfatur, paludofis nidificans. Ovum cinereo-grifeum maculis nigricantibus anomalis.

Dorfum, uropygium; reEtrices alba, ut et macula parva fub oculo: 2. roftrum capite triplo longius, nigrum: pedes cærulei.

americana. R. roftro nigro, corpore albo nigroque vario, capite collo pectoreque rufefcentibus.

Recurviroftra americana, Gmel. Syft. i. p. 693.

Avofetta, Damp. Voy. iii. t. p. I23. f. 3.

American Avofet, ArEt.Zool. ii. N²4 24 . t. 21.-Latb. Syn. v. p. 295. t. 92.

Habitat in nova Hollandia, America feptentrionali; Avocetta paulo major.

3 .

alba. R. roftro aurantio, corpore albo, remigibus rectricibufque flavicantibus, pedibus fufcis.

Recurviroftra alba, Gmel. Syft. i. p. 694 .

Scolopax alba, Lin. Syft.i. p. 247 . 17.

Limofa candida, Brif. v. p. $290.8 .-1 d .8$ vo. ii. p. 283 .

La Barge blanche, Buf. vii. p. 508.-Pl. Enl. 875 .

White Godwit, Edwo. t. r 39 .

White Avofet, ArEt. Zool. ii. p. 502.-Latb. Syn. v. p. 296. 3.

HaBITAT in America feptentrionali.-An præcedentis varietas?

\section{GEN U S LXXXVI. C O R R I R A.}

Roftrum edentulum, breve, rectum, rictu amplo. Crura corpore longiora. Pedes tetradactyli, palmati, digito poftico foluto.

1.

italica. C. fupra ferruginea fubtus alba, rectricibus binis intermediis candidis apice nigris.

Corrira italica, Gmel. Syft. i. p. 653 .

Corrira, Brif. vi. p. 542.-Id. 8 vo. ii. p. 505 .

'Trochilus, vel Corrira, Aldr. Av. iii. p. 288. t. p. 289 .-Raii Syn. p.

118. 3.-Will. p. 240 . t. 60.-Id. (Angl.) p. 321 . Italian Courier, Latb. Syn. v. p. 298. 
Haвıтат in Italia; celerrime currit, unde nomen.

Crura habet inter palmipedes, exceptis Pbanicoptero et Recurviroftra, longiffima : roftrun rectum, luteum, in fine nigrum, rictu magno: oculorum iridibus albis et fpadiceis, duplici circulo.

\section{GENUS LXXXVII. PHOENICOPTERUS.}

Roftrum denudatum, infracto-incurvatum, denticulatum. Nares lineares, longitudinales, perviæ.

Lingua carnofa, apice cartilaginea, acuta.

Collum longiffimum.

Crura corpore multo longiora.

Pcdes tetradactyli, palmati, membranis antice lunatis, digito poftico parvo, foluto.

1.

ruber. Ph. ruber, remigibus nigris.

Phœnicopterus ruber, Lin. Syft. i. p. 230.-Gmel. Syft. i. p. 6r 2.-Scop. Ann. i. $\mathrm{N}^{\circ}$ II 4.-Brif. vi. p. 532. t. 47 . f. 1.-Id. 8 vo. ii. p. 502. -Raii Syn. p. I 17. 2.-190. 1.-Will. p. 240. t. 60.-Sloan. Fam. p. 321 . 17.-Brown. Fam. p. 480.-Seb. Muf. i. p. 123. t. 67. f. I.-Pbil. Tranf. xxix. No 350. t. 2. p. 523.-Grew. Muf. p. 67.

t. 5. (Roftrum.)-Klein. Av. p. 126. B.-Borow/k. Nat. iii. p. 66. t. 44 .

Le Flammant, Buf. viii. p. 475. t. 39.-Pl. Enl. 63.-Hift. Prov. i. p。 345.-Voy. en Berb. i. p. 288.

Il Fenicottero, Cet. uc. Sard. t. p. 294.

Red Flamingo, Arct. Zool. ii. No 422.-Cat. Car. i. t. 73. 74.-Alb. ii. t. 77.--Kolb. Cap. ii. p. 1 37.-RufJ. Alep. p. 69.-Gent. Mag. xx. t. p. 264.-Sparrm. Voy. i. p. 30.-Dillon's Trav. p. 374.Latb. Syn. v. p. 299. t. 93.-Id. Sup. p. 263.

Habitat in Africa, America, rarius in Europa.-Longitudo ab apice roftri ad caudam extremam 4 ped. 4 poll. aquat, et ad extremos ungues 6 pedes.-Dum tdat, collum ita contorquet, ut mandibulæ fuperioris dorfum planum terram attingat, caputque utrinque motitat, et fic cibum arripit. Nidum ftruit in aquis ex limo monticuli forma, fupra depreffum, in quo ova deponit, eique infidet, ut pedes exfertos habeat, uno in uno latere, altero in altero.-Color pennarum fecundum atatem variat, trienni avi conftans coccineus; annuse cinereo-albus; 
bienni rofeus alis et interfcapuliis rubris: mandibula fuperior anguftior, antice plana incurva, utrinque marginata; mandibula inferior in medio triplo latior, fed canaliculato-compreffa, refpondens fuperiori, apice fubtus plicata utrinque fulcis 6 : margo utriufque lamellato-dentatus. Ovum anferino æquale, albunı. Hujus avis linguam inter præcipuas delicias veteres numerant.

2.

chilenfis. Ph. ruber remigibus albis.

Phœenicopterus chilenfis, Molin. Cbil. p. 2 14.-Id. (ed. Gall.) p. 222. -Gmel. Syft.i. p. 613.

HaвıтAт in regni Cbilenfis aquis dulcibus; habitu rubri; a roftro ad extremos ungues 5 pedes longitudine rquans.

Roftrum 5 pollices longum, cute rubefcente tectum: caput quafi vitta cinctum, feu potius fubcriftatum : color pennarum in omni ætate albus, dorjo et tectricibus alarum flammeo-rubris : remiges albr.

\section{* Pedibus brevioribus.}

\section{GEN U LXXXVIII. DIOMEDEA.}

Roftrum rectum, mandibula fuperiore apice adunca, inferiore truncata.

Nares ovatæ, patulæ, prominulæ, laterales. Lingua obfoleta.

Pedes tridactyli palmati, digitis omnibus antice pofitis.

r.

exulans. D. fupra fufco-rufefcens nigricante ftriata et maculata fubtus alba, collo fupra et lateribus fufco tranfverfim ftriatis, remigibus majoribus nigris, minoribus rectricibufque plumbeo-nigricantibus.

Diomedea exulans, Lin. Syft. i. p. 214 1.-Gmel. Syft. i. p. 566.Borow/k. Nat. iii. p. 27. t. 37 .

Plautus albatrus, Klein. $A v$. p. I 40. 13.

Albatrus, Brif. vi. p. 126.-Buf. ix. p. 339. t. 24.-Pl. Enl. 237.

Tchaiki, Pall. Spic, fafc. v. p. 28.-Hift. Kamtfch. p. 154.

Man of War Bird, Alb. iii. t. 8 I. (Caput.)-Grew. Muf. t. 6. f. ז。 - (Caput.)

Wandering 
Wandering Albatrofs, ArEt. Zool. ii. N'423.-Edw. t. 83.-Latb. Syn. v. p. 304. 1 .

Habitat in Pelago ubique, precipue inter tropicos; migratoria; gregaria ad Kamtfcbatkam ufque, infulifque vicinis menfe Julii obfervata. $-3 \frac{x}{2}-4$ pedes longa.-Pifcibus, potifimum Triglis volitantibus, et mollufcis victitat.

Corpus Cygno majus : roftrum flavicans: pedes incarnati : cauda, rec. tricibus 14 , rotundata: femora denudata: alc longiffimx, ab extremo ad extremum 10-1 3 pedes extendunt. Ovum, anferino majus, album.

$\beta$. D. fufca fupra nigricans, roftro rubro apice nigricante, lanugine cinerea, verfus caput albida, Gmel. Syft. i. p. $567 . \beta$.

g. D. alba, interfcapulio remigibus rectricibufque ex fufco nigricantibus, capite fummoque collo intenfe ftramineis, mandibula fuperiore alba vel rubicunda, inferioris rubræ carina alba, Gmel. Syjt. i. p. $567 \cdot \gamma$.

2.

fpadicea. D. roftro albido, corpore faturate caftaneo fufco, abdomine pallido, facie alifque fubtus albis.

Diomedea fpadicea, Gmel. Syft. i. p. 568.

Chocolate Albatrofs, Cook's Voy. ii. p. I 16. I $50 .-$ Forft. Voy. i. p. 258. -Park. Voy. p. 83. 84 ?-Latb. Syn. v. p. 308. 2.

HABITAT in Mare pacifico; fuliginofa major.

Roftrum albo-flavefcens: fedes albo carulefcentes, unguibus albis.

ß. D. tota grifeo-fufca, roftro pedibufque pallidis.

Albatros de la Chine, Pl. Enl. $9^{6} 3$.

HaBIt AT in Cbina. $-2 \frac{x}{2}$ pedes longa.

chloro- D. roftro nigro fupra bafique flavo, corpore fupra atro-cæruleo, fubtus shynchos.

Diomedea chlororhynchos, Gmel. syft. i. p. 568.

Yellow-nofed Albatrofs, Latb. Syn. v. p. 309. 3. t. 94.

Habitat in more Pacifico et ad Caput B. Spei.-Magnituco Anjeris. Roftrum nigrum, mandibula fuperiore fupra per totam longitudinem, inferiore bafi flavis: pedes albo-flavefcentes, antice nigricantes: caput grifeum : macula inter roftrum et oculos alteraque fupra nigricantibus.

D. roftro 
fuliginofa. D. roftro nigro, corpore fuliginofo-fufco, pone oculos lunula alba.

Diomedea fuliginofa, Gmel. Syft. i. p. 568 .

Albatrofs with a white eye-brow, Cook's Voy. i. p. 38.

Sooty Albatrofs, Forft. Voy. i. p. 91.-Lath. Syn. v. p. 309. 4.

Haвiтат Oceano, intra circulum antarcticuin. -3 fere pedes longa.

Corpus fufcum: caput, remiges, et cauda fuliginofo-atra : roftrum totum nigrum: pedes plumbei.

\section{GeNus LXXXIX. A L C A.}

Roftrum edentulum, breve, compreffum, convexum, tranfverfe fæpius fulcatum.

Nares lineares.

Lingua fere longitudine roftri.

Pedes tridactyli palmati, digito portico nullo.

I.

impennis. A. roftro compreffo-ancipiti fulcato, macula ovata utrinque ante oculos. Alca impennis, Lin. Syft. i. p. 2 10. 3.-Faun. Suec. $\mathbf{N}^{\circ}$ 140.-Gmel. Syft. i. p. $550 .-$ Brun. $\mathrm{N}^{\circ}$ 105.-Muller, p. 17.-Faun. Groenl. $\mathrm{N}^{\circ}$ 52.-Borowfk. Nat. iii. p. 32. 3 . Alca major, Brif. vi. p. 85 . 1. t. $7 .-I d$. 8 vo. ii. p. 382 . Penguin, Raii Syn. p. I1 8.-Will. p. 242. t. 65.-Id. (Angl.) p. 322. t. $65 .-E d w$. t. 147 .

Le grand Pingoin, Buf. ix. p. 393. t. 29.-Pl. Enl. 367 . Great Auk, Br. Zool. ii. No 229. t. 81.-1d. fol. 136.-ArEz. Zool. ii. $\mathrm{N}^{\circ}$ 424.-Latb. Syn. v. p. 31 I. I.

Habitat in Europe et Americe borealis alto mari.-Corpus duplo majus reliquis, impenne, $f$. non volitans. - Avis tota 3 pedes longa.

Roftrum fulcis 8-10 nigrum: remiges fecundaria apice albæ: pedes nigri. Ovum album lineis maculifque purpurafcentibus notatum, 6 pollices longum.

2.

cirrhata. A. roftro compreffo-ancipiti fulcato fulcis tribus, fuperciliis albis, portice flavis elongatis cirrhatis.

Alca cirrhata, Pall. Spic. v. p. 7. t. I, et 5.-Borowefk. Nat. iii. p. 30. t. 38.-Gmel. Syft. i. p. 553 . 
Le Macareux de Kamtfchatka, Buf. ix. p. 368.-Pl. Enl. 76 r. Igilma, Hift. Kamt ch. p. 183 . Tufted Auk, Arct. Zool. ii. No 432.-Cook's laft. Voy. ii. p. 4 I I, Lath. Syn. v. p. 313.2. t. 95. f. 1. (Coput.)

HaвiтAт in Kamtfchatka et infulis vicinis.-Nidificat in cuniculis ; victitat cancris, teftaceis; arftica moribus et facie affinis, at major.19 pollices longa.

Roftrum et pedes rubri : corpus nigricane, frcnte, capitis lateribus, $g u$ laque albis. Femina mare minor, roftri fulcis 2, cirrbo breviore. Ovum album.

3.

arctica. A. roftro comprefio-ancipiti fulcato fulcis quatuor, oculorum orbita temporibufque albis, palpebra fuperiore mucronata.

Alca arctica, L.in. Syft. i. p. 2 I I. 4.-Faun. Suec. No 14 I.-Gmel. Syft. i. p. 549.-Brun. $\mathrm{N}^{\circ}$ 103.-Muller, $\mathrm{N}^{\circ}$ 140.-Frifcb. t. 192.Borowofk. Nat. iii. p. 31. 2.--Sibb. Scot. ii. p. 20. t. I6. f. I.Olear. Muf. t. I5. f. 5.-Pall. Spic. v. p. I.

Fratercula, Brif. vi. p. 8 r. г. t. 6 . f. 2.-Id. 8 vo. ii. p. 380.

Alca deleta, Brun. $\mathrm{N}^{\circ}$ ro.4. (Avis annotina.)

Anas arctica, Raii Syn p. 120. A. 5.-Will. p. 244. t. 65.

Plautus arcticus, Klein. Av. p. 146.3.

Le Macareux, Buf. ix. p. 358. t. 26.-Pl. Enl. 275.

Lunda, Oelig. Muf. ii. f. I I. t. I I. f. 2 I.

I parka, Hift. Kamilch. p. 153 .

Puffin, Br. Zool. ii. $\mathrm{N}^{\circ} 232 .-I d$. fol. 135. t. H.-Arct. Zool. ii. N* 427.- Tour in Wales, t. 20.-Will. (Angl.) p. 325.-Hift. Greenl. ii. t. 1. - Alb. ii. t. 78. 79.-Edw. t. 358. f. 1.-Lath. Syn. v. P. 3I4. 3.

Habiтат in Europa, America.-Nidificat in cuniculis, ut pracedens. -Victitat pifciculis, cancris, herbis; gregaria.-12 pollices longa.

Corpus nigrum: genc, peetus, et abdomen alba: roftrunt rubrum bafi nigrum, in adultioribus fulcis $3 \mathrm{f} .4$ exaratum, in junioribus unico vel nullo: palpebra fuperior apice acuto carnofo: ad finum oris macula alba: pedes rubri, in pullis flavi. Ovum, pro mole corporis maximum, album, maculis ceruleo-nigricantibus obfcuris.

ß. A. nigra vertice cinereo, genis pectore abdomineque albis, Latb. Syn. v. p. 318. 3. A.

Habitat in infula Avium, inter Afiam et Americam.

A. roftro 
labradora. A. roftro carinato, mandibula inferiore gibba, ad apicem macula nigra, oculorum orbita temporibufque albidis, abdomine albo.

Alca labradora, Gmel. Syjt. i. p. 550.

Labrador Auk, ArEz.Zool. ii. No 428:-Lath. Syn. v. p. 318. 4.

HaBITAт in Labradora.-Magnitudo præcedentis.

Roftrum mandibula fuperiore rubefcente, inferiore albida, infra apicem gibba ut in Laro: color corporis fere ut in arctica: pedes rubri.

5.

Torda. A. roftro fulcis quatuor, linea utrinque alba a roftro ad oculos. (Avis adulta.)

Alca Torda, Lin. Syft. i. p. 2 10. 1.-Faun. Suec. No 139.-Gmel. Syft. i. p. 55 1. -Scop. Ann. i. $\mathrm{N}^{\circ}$ 94.-Brun. $\mathrm{N}^{\circ}$ I00.-Muller, p. I6. -Pall. spic. v. p. 3.-Brif, vi. p. 892. t. 8. f. I.-Id. 8vo. ii. p. 383. - Borowe/k. Nat. iii. p. 33 .

Plautus Tonfor, Klein. Av. p. 147. 5.-Id. Stem. p. 37. t. 38. f. 2. Alca Hoieri, Raii Syn. p. 119. A. 3.-Will. p. 243. t. 64. 65. Le Pingoin, Buf. ix. p. 390 . t. 27.-Pl. Enl. 1003. Razor-bill, Auk, Murre, Br. Zool. ii. No 230. t. 82.-Id. fol. I36.Edw. t. 358. f. 2.-Latb. Syn. v. p. 319.-Id. Sup. p. 264.

Haвiт at in Europa, America boreali.-i 8 pollices longa.-In rupibus inacceffis et clivis præruptis Anglie incubat. Ovum fufco-albidum, Havefcente varium, maculis purpureis anomalis.

Roftrum nigrum fulcis tranfverfis 4 , maximo albo: corpus nigrum fubtus a medio jugulo album: fafcia alarum e remigibus fecundariis apice albis : pedes nigri.

ß. A. roftro lævi compreffo unifulcato, corpore toto fubtus apicibufque remigum pofticarum albis. (Funior avis.)

Alca Pica, Lin. Syft. i. p. 2 1 o. 2.-Gmel. Syft. i. p. 55 I.-Faun. Groenl. $\mathrm{N}^{\circ} 5 \mathrm{I}$.

Alca unifulcata, Brun. $\mathrm{N}^{\circ}$ I02.-Muller, $\mathrm{N}^{\circ} 13^{8}$.

- minor, Brif. vi. p. 923. t. 8. f. 2.-Id. 8 vo. ii. p. $3^{8} 3$.

Mergus Bellonii, Utamania, Raii Syn. p. I 19. 2.-Will. p. 243. t. 64. -Id. (Angl.) p. 324.

Le Petit Pingoin, Buf. ix. p. 396.-Pl. Enl. 1004.

Black-billed Auk, Br. Zool. ii. $\mathrm{N}^{\circ} 23$ 1. -Id. fol. 1 37.-Arct. Zool. ii.

$\mathrm{N}^{\circ}$ 426.-Latb. Syn. v. p. 320. 6.

Habitat cum priore, cujus.incompleta avis. 


\section{4}

A VES PALMIPEDES. Alca.

Rofrum ruga unica obfoleta : corpus fupra nigrum fubtus a gula ad anum album: a roftro ad oculos ftriga albida : linea alarum tranfverfa alba.

$\gamma$. A. præcedenti fimillima, fed fubtus tota a roftro ad caudam candida, linea a roftro ad oculos nulla. (Pullus.)

6. Alca balthica, Brun. No 101.-Pall. Spic. v. p. 4?

criftatella. A. roftro compreffo fubfulcato, corpore nigricante, dorfo maculis ferrugineis, crifta frontali antrorfum inclinante.

Alca criftatella, Pall. Spic. v. p. 18. t. 3. et 5.-Borowfk. Nat. iii. p. 34. 6.-Gmel. Syft. i. p. 552 .

Black Stariki, Hift. Kamt fch. p. 156 .

Crefted Auk, ArEt. Zool. ii. No 434.-Latb. Syn. v. p. 323. 7. t. 95.f. 4.

Habitat in infulis faponievicinis, et inter Afram et Americam; nidificans in cuniculis et fiffuris rupium; incauta et ftolida avis. -12 pollices longa.-Magnitudo Turdi iliaci.

Roftrum rubrum : frontis plumulæ longiufculæ, at 6 vel 7 cæteris multo longiores, incurvatæ, antrorfum fpectantes: pone oculos utrinque fafcia alba: pedes lividi.

7.

tetracula. A. roftro lævi compreffo, corpore nigro fubtus cinerafcente, nucha maculis rectricibulque lateralibus apice ferrugineis, fronte fubcriftata. Alca tetracula, Pall. spic. v. p. 25. t. 4. et 5.-Gmel. Syft. i. p. 552. Dufky Auk, Arct. Zool. ii. No 435.-Ellis's Narr. ii. p. 252?-Lath. Syn. v. 324. t. 95 . f. 3 .

Haвitat in Oceano inter Faponiam et Kamtfchatkam, et ad littora; gregaria. - Nidificat in fcopulis. - I I pollices longa.

Roftrum luteo-fufcum, carina albida: irides albæ, circulo nigro: facies producta, plumofa, pennis reflexis : pone oculos ftriga alba : pedes lividi.

8.

pfittacula. A. roitro compreffo fubfulcato, corpore nigricante, abdomine albo, fa. cie producta, ad bafin roftri coarctata.

Alca pfittacula, Pall. Spic. v. p. 13. t. 2. 5.-Gmel. Syft. i. p. 553. Stariki, Hift. Kamt fch. p. I 55 .

Perroquet Auk, ArEz. Zool. ii. N 433.-Lath. Syn. v. p. 325. t. 95. f. 2.

Habitat cum pracedente,-Habitus A. Alle, at paulo major. 
Roftrum rubrum: pedes flavi : nares pervia: fupra oculos macula lunata parva, poftice ftriga alba. Ovum gallinacei fere magnitudine, for9. dide album, fufco maculatum, in fcopulo nudo aut arena ponit.

antiqua. A. roftro nigro bafi albido, corpore nigricante, abdomine albo, pennis cervicalibus linearibus elongatis albis.

Alca antiqua, Gmel. Syft. i. p. 554 .

Ancient Auk, Arct. Zool. ii. N $\mathrm{N}^{\circ}$ 240.-Lath. Syn. v. p. 326. Io.

Habitat in America boreali ad occafum, Kamtfcbatka, infulifque intermediis; præcedentis magnitudine.

Caput totum cum gula nigrum : pone oculos utrinque pennæ aliquot lineares, 2 vel 3 pollices longæ, incurvatæ, albæ: abdomen albu.n: cauda nigra.

10.

Alle. A. roftro lævi conico, abdomine toto fubtus remigumque pofticarum apicibus albis, pedibus nigris.

Alca Alle, Lin. Syjt. i. p. 211 . 5.-Faun. Suec. No 142.-Gmel. Syft. i. p. 554.-Brun. $\mathrm{N}^{\circ}$ 106.-Faun. Groenl. $\mathrm{N}^{\circ}$ 54.-Aiz. Nidr. i. p。 261. t. 6.-Martin Spitfb. p. 61. t. M. C.

Uria minor, Brif. vi. p. 73. 2.-Id. 8 vo. ii. p. 378 ,

Plautus columbarius, Klein. Av. p. I46. I.

Mergulus melanoleucos roftro acuto brevi, Raii Syn. p. I25. A. 5Will. p. 26r. t. 59.

Le petit Guillemot, Buf. ix. p. 354.-Pl. Enl. 917.

Small black and white Diver, Will. (Angl.) p. 343.-Edw. t. 9 I. Greenland Dove, Alb. i. t. 85 .

Little Auk, Br. Zool. ii. $\mathrm{N}^{\circ}$ 233. t. 82. $-I d$. fol. I37. t. H. 4. f. I.ArEt. Zool. ii. t. 429.-Latb. Syn. v. p. 327. 1 I.

Habitat in Europe et America, prefertim arcicice, pelago, inter glaciei fragmenta.-Corpus magnitudine Turdi, vix 9 pollices longum, atrum, pectore abdomineque albis : dorfum lineolis aliquot albis : remiges fecundariæ apice albæ: punctum album fupra oculos: roftri ruga obfoleta. In quibufdam gene, gula, et corpus totum fubtus alba, forte femina, vel pullus.

3. Alca candida, Brun. $\mathrm{N}^{\circ} 107$.

Habitat in Groenlandia, tota alba, cæterum quoad magnitudinem et omnia, folo colore excepto, Alle fimillima. An varietas?

A. roftro 


\section{AVES PALMIPEDES. Uria。}

pygmea. A. roftro carinato bafi depreffo, corpore atro fubtus cinereo.

Alca pygmea, Gmel. Syft.i. p. 555.

Pygmy Auk, Arct. Zool. ii. N $43 \mathrm{r}$.

Flat-billed Auk, Latb. Sym. v. p. 328. 12.

Habitat in infula Avium inter Afram et Americam; gregaria.-7. pollices longa.

Roftrum nigrum dorfo carinatum, apice fubincurvatum, bafi depreffum : facies producta ut in Pfittacula : corpus fuliginofo-atrum : abdomen medium et gula albida: pedes nigricantes.

\section{GEN US XC. U R I A.}

Rof trum rectum, fubulatum, apice deorfum inclinans;. bafi fubplumofa.

Nares lineares ad bafin roftri.

Lingua longitudine fere roftri.

Pedes compedes, tridactyli, digito poftico nullo.

Troile. U. corpore nigro, pectore abdomineque niveo, remigibus fecundariis apice albis.

Colymbus Troile, Lin. Syft. i. p. 220. 2.-Faun. Suec. $\mathrm{N}^{\circ}$ 149.-Gmel. Syft. i. p. $5^{8} 5$.

Uria, Brif. vi. p. 70. ז. t. 6. f. 1. $-I d$. 8 vo. ii. p. 377.-Scop. Ann. i. $\mathrm{N}^{\circ} 103$.

Lomwia Hoieri, Raii Syn. p. 120. A. 4.-Will. p. 244, t. 65.-N. C. Petr. iv. 414.-Klein. Av. p. 148.8.-Id. p. 168.3.-Brun. $\mathrm{N}^{\circ}$ 108. 109. - Muller, $\mathrm{N}^{\circ} \mathrm{I} 52$.

Je Guillemot, Buf. ix. p. 350. t. 25.-Pl. Enl. 903.

Lumme, Mart. Spitf. 57. t. M. f. A.-Frifch. t. 185.

Foolifh Guillemot, Br. Zool. ii. No $234 .-1 d$. fol. 1 38. t. H. 3.-ArG. Zool. ii. N॰436.-Pbipps's Voy. p. 187.-Cook's laft Voy. ii. p. 352. -Will. (Angl.) p. 324.-Alb. i.t. 84.-Edw. t. 359. f. 1.-Latb. Syn. vi. p. 329. 1.-Id. Sup. p. 265.

Haвiтat in Europa; in Anglia præruptis rupibus et inacceffis fatis frequens; gregaria.-17 pollices longa.

Rofrum 
Roftrum et pedes nigri : cauda fufco-nigricans. Ovum anferinum craffitie æquat, pallide virefcens ftriis flexuofis et maculis nigricantibus varium.

$\beta$. U. fupra nigra, fubtus genis fafciaque alarum alba.

Colymbus minor, Gmel. Syft. i. p. 585 .

Uria Swarbag, Ringuia, Brun. No I10. Irr.

Leffer Guillemot, Br. Zool. ii. INo 235. t. 83.-Id. fol. I38.-Ara. Zool. Sup. p. 69.-Latb. Syn. vi. p. 332. 2.

Junior avis hæc. -16 pollices longa.-Pone oculum utrinque fafcia nigra.

భ. Uria alga, Brun. $\mathrm{N}^{\circ}$ i 12.

2.

Pracedenti fimillima, exceptis rectricibus totis nigris.

Grylle. U. corpore atro, teetricibus alarum albis.

Colymbus Grylle, Lin. Syjt. i. p. 220. 1.-Faun. Suec. No 148.-Gmel. Syft. i. p. $5^{84 .}-$ Brun. $\mathrm{N}^{\circ}$ I 1 3.-Muller, $\mathrm{N}^{\circ}$ I5 1.-AE. Nidr. i. p. 258 . t. 4.-Frich. t. $185 .-N$. C. Petr. iv. 418.-Mart. Spitzb. 56. t. L. f. B.-Borowe/k. Nat. iii. p. 57. 2.

Columbus groenlandicus, Klein. Av. p. 168.2.

Uria minor nigra, Columba groenlandica, Brif. vi. p. 76. 3. $-I d .8$ vo.

ii. p. 379.-Raii Syn. p. I 2 1. 6.-Will. p. 245.-Ray's Trav. 18 .

I 92.-N. Ait. Stock. 178 1. 3. $\mathrm{N}^{\circ}$ 4. P. 224.

Le petit Guillemot noir, Buf. ix. p. 354 .

Kaiaver, vel Kaior, Hijt. Kamtscb. p. I 57 .

Greenland Dove, Sea Turcle, Alb: ii. t. 80.-Will. (Angl.) p. 326.-

t. 78. (Mas.)-Anderf. Groenl. ii. t. I.

Black Guillemot, Br. Zool. ii. $\mathrm{N}^{\circ} 236 .-I d$. fol. 138 . to H. 4.-ArEt. Zool. ii. N ${ }^{\circ}$ 437.-Lath. Syn. vi. p. 332. 3.

Habitat in Europa, America; in rupibus Anglice borealis frequens; in infulis Sançi Kilde, Farne nidificans.

Rofirum nigrum, fauce rubra : pedes rubri : tectrices alarum fuperiores . mediæ, et inferiores totæ albæ.

ß. U. fuliginofa, fafcia alarum gemina alba, Lath. Syn. vi. p. 333. 3. var. A.

Habitat in Aoonalaßka. 
$\gamma$. U. fupra nigricans ftriis tranfverfis faturationibus, fubtus alba tæanis cinereis varia, tectricibus alarum fuperioribus mediis candidis nigro variegatis,

Uria minor ftriata, Brif, vi. p. 78, 4, -Id. 8vo, ii. p. 379.-Klein. Av. p. I46. I?

Uria balthica, Brun. $\mathrm{N}^{\circ}$ i 16.

Spotted Greenland Dove, Edw. t. 50.-Latb. Syn. vi. p. 333. 3. var. B.

Haвiтат in Groenlendia.

§. U. dorfo alis caudaque nigris, capite collo corpore fubtus maculaque alarum albis.

Uria balthica, Brun. $\mathrm{N}^{\circ}$ I 15 .

Haвıтат in Cbriftionsöe.-Caput, collum, pectus alba maculis fparfis albis, pennis dorfi nigri margine albis.

\&. U. nigra, vertice albo nebulofo, teçtricibus alarum majoribus corporeque fubtus albo nigroque variis, gula tota alba, Latb. Syn. vi. p. . 334. 3. var. D.

Habitat in Kemtfchatka.

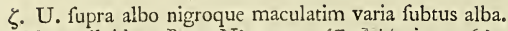

Uria grylloides, Brun. $N^{\circ}$ I I 4-ACT. Nidr. i. p. 268.

Spotted Guillemot, Br. Zool. ii. t. 83. f. 2.-Latb. Syn. vi. p. 334. 3. var. E.

lacteola. U. nivea, dorfo alis bafique caudæ pallide grifeis, remigibus fecundariis medio fufcefcentibus.

Cepphus lacteolus, Pall. Spic. v. p. 33.-Gmel. Syft. i. p. $5^{8} 3$.

White Guillemot, Latb. Syn.vi. p, 335.4. .

Habitat in occidentali Belgii littore; Grylle magnitudine. Roftrum et pedes fufco-incarnati: irides fuicæ.

$\beta$. U. macula nigra utrinque pone oculos, interfcapuliis et areis alarum nigris, mandibula fuperiore nigra, inferiore flavefcente, Naturf. xiii. p. $192 .-$ Gmel. Sjst. i. p. 584 .

HABItAт ad Rbenum; Querquedule magnitudine.

U. fuprs. 
A VES PALMIPEDES. Colymbus. 799

4. U. fupra caftaneo fufcoque undulata fubtus fufco alboque nebulofa, ror-

ta. tro nigro, pedibus fulvis.

Marbled Guillemot, Lath. Syn. vi. p. 336. t. 96.-ArEt. Zool.ii. p. 438. t. 22 .

Habitat in Kamtfchatka, et America occidentali.-10 poll. longa.

\section{GENUS XCI. COL YMBUS.}

Roftrum rectum, acutum, mandibulis lateribus coarctatis. Nares lineares.

Lingua longa, acuta, bafi lateribus denticulata.

Crura compreffa.

Pedes tetradactyli, compedes, palmati, digito exteriore longiore, poftico parvo interiori membranula coadunato.

Cauda brevis, viginti pennis conftans.

acialis. C. capite colloque nigro-violaceo, fafcia gulæ cervicifque alba interrupta.

Colymbus glacialis, Lin. Syft. i. p. 221. 5.-Gmel. Syft. i. p. 588.Muller, $\mathrm{N}^{\circ}{ }_{1} 55 .-$ Frifch. t. 185 . A.--Faun. Groenl. $\mathrm{N}^{\circ}$ 62, -Pbil. Tranf. Ixii. p. 420. 22. - Faun. Aner. $\mathrm{N}^{\circ}{ }_{1} 6$.

Colymbus torquatus, Brun. $\mathrm{N}^{\circ}{ }_{1} 34$.

Mergus major nævius, Brif. vi. p. I20.6. t. II. f. 2. (adulta.)-Id. 8 vo. ii. p. 392.

Mergus nævius, Brif. vi. p. 118. 5. (junior.) -Id. 8vo. ii. p. 391.

Colymbus maximus caudatus, Raii Syn. p. I25. A. 4.-Will. p. 259.

$-K l e i n . A v$. p. I4r. x.

Colymbus maximus ftellatus, Sibb. Scot. ii. p. 20. t. 15. f. I.

L'Imbrim, Buf. viii. p. 258. t. 22. $-P l$. Enl. $95^{2}$.

Greateft fpeckled Diver, or Loon, Alb. iii. t. 93.-Will. (Angl.) p. 34I. Northern Diver, Br. Zool. ii. No 327. t. 84.-Id. fol. I39. t. K. 2.Arct. Zool. ii. No 439.- Lath. Syn, vi. p. 337. I.

Habitat in Mari ardtico, America boreali; in Anglia rarus; congenerum maximus. $-3 \frac{x}{2}$ pedes longus.

Roftrum pallidum : caput et collum atro-violacea : gula fafcia alba interrupta : cervix in medio fafcia alba lata, antice non coiens : dorfum nigrum maculis quadratis albis : alaruin teetrices punctis albis.

Ovum fufcefcens.

C. corpore 
2.

800 AVES PAIMIPEDES. Colymbus.

Immer. C. corpore fupra nigricante albo undulato fubtus toto albo.

Colymbus Immer, Lin. Syf. i. p. 222. 6.-Gmel. Syjt. i. 588.-Brun. 129.-Muller, p. 29.-Borowfk. Nat. iii. p. 60. 5.-Adt. Nidr. i. p. 246. t. 13.-Faun. Helvet.

Mergus major, Brif. vi. p. 105. 1. t. xо. f. 1.-Id. 8vo. ii. p. 38 \%.Scbaf. El. t. 48.

Colymbus maximus Gefneri, Raii Syn. p. 126.8.-Will. p. 26o. §. IIf. -Klein. Av. p. I 50.6 .

Le grand Plongeon, Buf. viii. p. 251.-Pl. Enl. 914.

Ember Goofe, Sibb. Scot. 21.-Wallace Orkn. 16.-Debes. Ferr. If. 138. -Pontop. Norw. ii. 80.

Imber Diver, $\mathrm{Br}$. Zool. ii. $\mathrm{N}^{\circ}$ 238. t. 84.-Will. (Angl.) p. 342.Arct. Zool. ii. . $\mathrm{N}^{\circ} 440 .-$ Lath. Syn. v. p. 340. 2.

Habrtat in Oceano arctico; nifi afperitate hyemis compulfus vix in Anglia videtur. -2 pedes et ultra longus.

Corpus fupra nigricans marginibus pennarum albidis, fubtus album, fafcia nigra inter femora.

Mas fronte lateribufque capitis et colli fufco maculatis.

3. Atellatus.

C. cinereo-fufcus lineolis albidis varius fubtus albus, capite et collo fuperioribus cinereis, pennis ad latera cinereo-albo fimbriatis.

Colymbus ftellatus, Brun. $\mathrm{N}^{\circ}$ I 30.-Muller, $\mathrm{N}^{\circ}$ I $59 .-$ Gmel. Syft. i. p.

$\frac{587 .}{258}$ maximus caudatus, Raii Syn. p. 125. A. 4. var.?-Will. p. 258. t. 61.-Klein. Av. p. 141. 1.

Mergus minor, Brif. vi. p. 108. 2. t. 10. f. 2.-Id. 8 vo. ii. p. 389. Faun. Helvet.

Plotus claudicans, Scop. Ann. i. No 93.-Klein. Stem. t. 37. f. 2. a. b. Colymbus caudatus ftellatus, N. C. Petr. iv. p. 424.-Will. t. 62.

Le petit Plongeon, Buf. viii. p. 254. t. 21.-P!. Enl. 992.

Speckled Diver or Loon, Br. Zool. ii. No 239 -Id. fol. I 39. t. K. ".Alb. i. t. 82.-Arct. Zool. ii. $\mathrm{N}^{\circ} 44 \mathrm{1}$.-Latb. Syn. vi. p. 341.3.

Habitat in Europa, America; in fluviis mari vicinis Anglic non rarus. -27 pollices longus. - Roftrum corneum: pedes fufci.

Ovum anferino fimile, maculis rarioribus nigris.

4.

arcticus. C. capite cano, collo fubtus atro-violaceo, fafcia alba interrupta.

Colymbus arcticus, Lin. Syft. i. p. $221.4 .-$ Fann. Suec. $\mathbb{N}^{\circ} 150 .-$ Gmel. Syft. i. p. 587. -It. Goth. 341.-Brun. N०133.-Muller, $N^{\circ} 154$. 
AVES PALMIPEDES. Colymbus. 80s

No 154.-Befl. Muf. 31. t. 17.-Raii Syn. p. 125. 7.-Will. p. 259. t. 62. -Id. (Angl.) p. 343. t. 62.-AEt. Nidr. i. p. 140. t. 2. f. 1.-Facq. Vog. p. 22. t. 7.-Borow/k. Nat. iii. p. 59. 4.-Faun. Helvet.

Mergus gutture nigro, Brif. vi. p. I I 5. 4.-Id. 8vo. ii. p. 391 . arcticus, Klein. Av. p. 141. 2.-Id. Ov. p. 35. t. 2 I. f. 1.

Lumme, Buf. viii. p. 262,-Worm. Muf. 304. t. Q. Q.-Muf. Haffn. i. t. I. $\mathrm{N}^{0} 2$.

Rlack-throated Diver, Br. Zool. ii. $N^{\circ}$ 24r. t. 85. f. 2.-ArEz. Zool. ii. $\mathrm{N}^{\circ}$ 444.-Edw. t. 146.-Lath. Syn. vi. p. 343. 4.

Habitat in Europa, America boreali, et Afia; in Anglia, nifi hyeme rigidiore, inter rariores habetur. -2 pedes longus.

Caput fupra canum immaculatum, fubtus a gula ad medium atroviolaceum, fafcia gulari alba interrupta: dorfum nigrum fafciis interruptis, $f$ maculis albis quadratis : alarum tectrices albo punctatæ. Ovum album 4 aut 5 variolis inftructum, Klein.

5.

feptentrio- C. corpore fupra nigricante fubtus albo, collo antice macula fcutiformi nalis. ferruginea.

Colymbus feptentrionalis, Lin. Syjt. i. p. 220. 3.-Brun. $\mathrm{N}^{\circ}$ 132.Muller, $\mathrm{N}^{\circ}$ i $53 .-$ Borowfk. Nat. iii. p. 58. 3.

Colymbus areticus collo rufo, $A E t$. Nidr. i. p. 244. t. 2. f. 2.

Mergus gutture rubro, Brif. vi. p. I I I. 3. t. I I. f. I. -Id. 8vo. ii. p. 390.-Klein. Av. p. 142. 3 .

Le Plongeon à gorge rouge, $\mathrm{Pl}$. Enl. 308.-Buf. viii. p. 264.

Red-throated Diver or Loon, Br. Zool. ii. N 240. t. 85 . I. $-I d$. fol. 140.-ArE7. Zool. ii. $\mathrm{N}^{\circ} 44 \mathrm{j}^{\circ}-E d w$. t. 97.-Lath. Syn. vi. p. 344. 5 .

Habitat in Europe, Afie, Americe borealis lacubus, et mari.2 ped. 5 poll. longus. - In Anglia rarius obfervatur, huc tamen cum præcedentibus afperitate hyemum interdum advolat.

Corpus fupra fufcum punctis minutis albis : collum fupra lineolis albidis, fubtus macula fcutiformi ferruginea immaculata, a jugulo ad gulam. extenfa.

6.

borealis. C. corpore fupra nigricante maculis ftellatis albis innumeris fubtus albo, collo antice rufo vix maculato, Brun. $\mathrm{N}^{\circ} \mathbf{I} 3 \mathbf{I}$. 
8Q2

A VES PALMIPEDES. Rhynchops.

Stellato colore, magnitudine, et flatura fimilis, fed in parte colli prona pennæ aliquot ferrugineæ, - Occifus circa Hafniam. An diftincta fpecies.

7.

friatus. C. nigricans fubtus albus, capite colloque grifeis nigro lineatis.

Colymbus ftriatus, Gmel. Syjt. i. p. 586 .

Striped Diver, Latb. Syn. vi. p. 345. 6.-ArEz. Zool. ii. No 442 .

8.

Habitat in America borealis lacubus. $-2-3$ libras pondere aquans.

finenfis. C. fufco-virefcens maculis faturatioribus, pectore et abdomine rufo-albis maculis rufis.

Colymbus finenfis, Gmel. Syft. i. p. $5^{86 .}$

Chinefe Diver, Lath. Syn. vi. p. 34.5. 7. t. 97.

Habitat in Cbina.-Rofrum obfcurum : irides pedefque cinerei.

\section{GENUS XCII. RHYNCHOPS.}

Rofrum rectum, mandibula fuperiore multo breviore, inferiore apice truncato.

Nares lineares, perviæ.

Pedes tetradactyli, palmati, graciles, digito poftico minuto. Cauda forficata.

I. nigra.

Rh. nigricans fubtus alba, roftro bafi rubro.

Rhynchops nigra, Lin. Syjt. i. p. 228. 1.-Gmel. Syft. iv p. 61 1.-BErowjk. Nat. iii. p. 26 . t. 36 .

Avis maderaf. major Novaculæ facie, Raii Syn. p. 194. 5. t. r. f. 5 .

Rygchopfalia, Brif. vi. p. 223. 1. t. 21. f. 2.-Id. 8 vo. ii. p. $42 \mathrm{I}$.

Avis carolinenfis roftro cultriformi, Pet. Gaz. t. 76. f. 2. (Roftrum.)Edw. t. 28 I. (Roftrum.)

Plotus roftro conico inæquali, Klein. Av. p. 142. 2.

Le Bec en cifeaux, Buf. viii. p. 454 . t. 36.-Pl. Enl. 357 .

Coupeur d'eau, Defcr. Surin. ii. p. 291 .

Bec de hache, ou Pied-rouge, Hift. Louif. ii. p. 117.

Cutwater, Cat. Car. i. t. 90.

Black Skimmer, Lath. Syn.vi. p. 347. to in tit.-Arct. Zool. ii. $\mathrm{N}^{\circ} 445$. 
A VES PALM I PEDES. Sterna. $80_{3}$

Habitat in America, Afia.-Volando aquæ fuperficiem radit, ex illa infecta pifciculofque nandibula inferiore introducta extrahit ; victitat etiam conchilis. -20 pollices longa.

Roftrum nigrum bafi rubrum : pedes rubri : frons alba.

$\beta$. Rh. fulva roftro nigro.

Rhynchops fulva, Lin. Syft. i. p. 229.-Borowes. Nat. iii. p. 262.

Rygchopfalia fulva, Brif. vi. p. 227 . A.-Id. 8 vo. ii. p. 422. - Latb. Syn. vi. p. 348 .

Haвiтat in Guiana; a priore difcrepans corporis fuperioris colore fulvo in omnibus partibus in quibus pracedens nigricat; roftro penitus nigro.

\section{GENUS. XCIII. S T E R N A.}

Roftrum fubulatum, fubrectum, acutum, comprefliufculum.

Nares lineares.

Lingua acuta.

Ala longiffimæ.

Pedes tetradactyli, palmati, debiles, digito portico minuto foluto.

Cauda forficata plerifque.

I.

cafpia. St. curpore fupra plumbeo-cinereo fubtus colloque albo, roftro coccineo, capillitio pedibufque nigris.

Sterna cafpica, Muf. Carlf. fafc. iii. t. 62.-N. C. Petr. xiv. 582. t. 22.

f. 2.-AEt. Holm. 1782. 3. p. 221 .-Gmel. Syft. i. p. 603 .

Sterna Tfchegrava, N. C. Petr. xiv. p. 500. 2. t. 13. 2.

Larus atricilla, N. C. Petr. xv. p. 478 . t. 22. f. 2.

Cafpian Tern, Arct. Zool. ii. p. 526. B.-Id. Sup. p. 70.-Latb. Syn. vi. p. 350 . 1 .

Навгтат in mari Cajpio et Sudermanic maritimis. $-22 \frac{1}{2}$ poll. longa. Roftrum rubrum : cauda brevis forficata : remiges apice nigræ: pedes fufco-rubefcentes. 
804 AVES PALM I PDES. Sterna.

ß. St. cinereo-cana, corpore fubtus colloque albis, vertice nigro albo maculato, rectricibus ad apicem fafciis fufcis, Lath. Syn. vi. p. 35I. I. var. A.

Habitat in India, Bombay.-2 $\mathrm{r}$ pollices longa.

Rofirum 1 uorum : pedes nigri.

$\gamma$. St. cineren-cana, corpore fubtus colloque albis, vertice nigro, occipite fubcriftato, rectrice extima a medio ad apicem alba.

Cafpian Tern, Pbill. Voy. p. 160. t. p. 177.-Latb. Syn. vi. p. 35 r. 1. var. B.

Habitat in Cbina, infulis Sanduicenfibus, Suecia. Rofrum flavicans: pedes nigri.

ঠ. St. roftro albo, capillitio nigro alboque vario, aurium regionibus nigris, dorfo et alis cinereis, plumarum remigum primariarum apicibus nigris, Muf. Carlf. fafc. iii. $\mathrm{N}^{\circ} 62$. (var.)

2.

cayana. St. grifea pennis rufo marginatis, occipite nigro, corpore fubtus albo.

Sterna cayennenfis, Gmel. Syft. i. p. 604.

La grande Hirondelle de mer de Cayenne, Buf. viii. p. 346.-Pl. Enl. $9^{88 .}$

Cayenne Tern, Lath. Syn. vi. p. 352. 2.

Hавіт ат in Cayana. - 16 pollices longa.

3. St. cinerea fubtus alba, roftro capite collo pectoreque nigris, pedibus menfis. rubris.

Sterna furinamenfis, Gmel. Syft. i. p. 604.

Greater Tern, Hift. Surin. ii. p. 187.

Surinam Tern, Lath. Syn. vi. p. 352. 3 .

HABIt Aт in Surinamo.-Corpus magnitudine folida.

fuliginofa. St. fuliginofo-atra, fronte corporeque fubtus albis, ftriga per oculos nigra.

Sterna fuliginora, Gmel. Syft. i. p. 605.

L'Hirondelle de mer à grande envergure, Buf. viii. p. 345 .

Egg-bird, Forft. Voy. i. p. 11 5.-Cook's Voy. i. p. 66. 275.

Noddy, Damp. Voy. iii. part I. p. 142. t. p. 123. f. 5.-Hawkefw. Voy. iii. p. 652 .

Sooty Tern, ArEt. Zool. ii. N $N^{\circ} 447 .-$ Lath. Syn. vi. p. 352. 4.

HABITAT 
Habitat in infulis Maris atlantici et antaretici.-16 pollices longa. Ovum flavicans maculis fufcis et pallide violaceis notacum.

5.

Roftrum et pedes nigri : rectrix extima margine exteriore, apice excepto, alba.

africana. St. alba, corpore fupra cærulefcente, vertice nigro, alis fufco maculatis.

Sterna africana, Gmel. Syft. i. p. 605.

African Tern, Latb. Syn. vi. p. 354. 5 .

Habiтat in Africa; præcedentis magnitudine.-Roftrum et pedes nigri.

6.

stolida. St. corpore nigro, fronte albicante, fuperciliis atris.

Sterna ftolida, Lin. Syft. i. p. 227. 1.-Aman. Ac. iv. p. 420.-Borowe/k.

Nat. iii. p. 5 1. t. 42.-Gmel. Syft. i. p. 605.

Paffer ftultus, Raii Syn. p. 154.-Will. p. 297.-Id. (Angl.) p. 385.

Gavia fufca, Brif. vi. p. 199. 15. t. 18. f. 2.-Id. 8 vo. ii. p. 414.Klein. Av. p. 139. 15.

La Mouette brune, Pl. Enl. 997.

Le Fou, Hift. de la Louif. ii. p. 119.

Noddy, ArEt. Zool. ii. N $\mathrm{N}^{\circ} 46 .-$ Buf. viii. p. 46 I. t. 37.-Sloan. Gam.

i. p. 31. t. 6. f. 2.-Brown. Fam. p. 48 1.-Catef. Car. i. t. 88.-

Damp. Voy. iii. part 1. t. p. 123. f. 6.-Latb. Syn. vi. p. 354.6.

HaBitat in Oceano, imprimis inter tropicos.-I 5 pollices longa,

7. Roftrum pedefque nigri.

philippina. St. vinaceo-grifea, pileo albo, vitta per oculos remigibus cauda roftro pedibufque nigris.

Le petit Fouquet des Philippines, Son. Voy. p. 125. t. 85 .

Philippine Tern, Lath. Syn. Sup. p. 267.

Habitat in infulis Pbilippinis ; Hirundine duplo major.

Vitta a roftri bafi per oculos ducta poftice in acutum definens.

8.

fimplex. St. plumbefcens fubtus alba, vertice albido, tectricibus alarum mediis et majoribus albis.

Sterna fimplex, Gmel. Syft. i. p. 606.

Simple Tern, Lath. Syn. vi. p. 355. 7.

Навітат in Cayana.-Magnitudo folide:

Roftrum rubicundum : pedes rubri : pone oculos macula nigra.

ß. St. cinereo. 
$\beta$. St. cinereo-nigricans, fronte collo corpore fubtus tectricibufque alarum inferioribus albis, Lath. Syn. vi. p. 356 .

Roftrum pedefque nigri.

9. nilotica. St. cinerea fubtus alba, vertice colloque fuperiore maculis nigricantibus, orbitis nigris albo maculatis.

Sterna nilotica, Haffelq. It. p. 273.-Id. Voy. p. 202. 41.-Gmel. Syft. i. p. 606 .

Egyptian Tern, Lath. Syn. vi. p. 376.8 .

Haвiтат in Egypto; Columber magnitudine.

Roftrum nigrum : pedes incarnati.

IO.

Boyfii. St. alba, dorfo alifque canis, pileo nigro, fronte maculis albis, remigibus nigricantibus fcapo albo.

Sterna cantiaca, Gmel. Syft. i. p. 6.06.

Sandwich.Tern, Lath. Syn. vi. p. 356. 9.-Id. Sup. p. 266.-Boys's Sandwich, t. p.

Haвiтat in maritimis Anglia, praefertim ad littora Cantii prope Sanduicum; Hirundine major.-1 8 pollices longa.

Roftrun nigrum apice flavefcente: pedes nigri : ale caudam multo longitudine excedunt. Ovum olivaceo-fufcum maculis confertis purpurafcentibus.

$\beta$. St. cauda emarginata, corpore variegato, macula aurium nigra.

Sterna nævia, Lin. Syft. i. p. 228. 5.-Gmel. Syft. i. p. 609.-Brif. vi. p. 216. 6. t. 20. f. 2.-1d. 8vo. ii. p. 418.-Borow/k. Nat. iii. p. 54. 4.-Faun. Helvet..

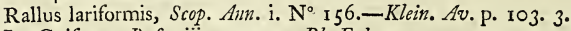

La Guifette, Buf. viii. p. 339.-Pl. Enl. 924.

Cloven-footed Gull, Alb. ii. t. 82 .

Kamtfchatkan Tern, Arct. Zool. ii. p. 525. A.-Latb. Syn. vi. p. $35^{8}$. 9. var. A.

Навітат cum præcedente, cujus forte pullus.-Cauda vix forficata.

$\gamma$. St. fupra nigro albo cinerafcenteque varie fufca fubtus alba, cauda forficata, roftro pedibufque nigris.

Sterna nubilofa, Muf. Carlf. fafc. iii. t. 63. (Pullus.)

Habitat in Finlandia. 
I.

A VES PALMIPEDES. Sterna.

ftriata., St. alba, occipite nuchaque nigris, corpore fupra alifque ftriis tranfverfis nigris.

Sterna ftriata, Gmel. Syft. i, p. Gog.

Striated Tern, Lath. Syn. vi. p. 358. 10. t. 93.

Haвiтat in nova Zealandia.-Roftrum nigrum: pedes plumbei.

12.

vittata. St. cinerafcens, capite fuperiore nigro vitta alba circumdato, uropygio criffo caudaque albis.

Sterna vittata, Grinel. Syft. i. p. 609 .

Wreathed Tern, Lath. Syn. vi. p. 359. I 1 .

Habitat in infula Nativitatis Chrifi.- I 5 pollices longa.

Roftrum fanguineum : pedes fulvi : rectrix extima cinerafcens.

Variat cauda tota cinerea, rachibus albis.

I3.

Ipadicea. St. fufco-rubefcens, criffo albo, dorfi pennis tectricibufque alarum margine albidis, fcapularibus remigibufque fecundariis apice albis.

Sterna fpadicea, Gmel. Syft. i. p. 6 го.

Brown Tern, Lath. Syn. vi. p. 359. I 2.

Hавіт Aт in Cayana.-I 5 pollices longa.-Roftrum nigrum: pedes fufco-rubefcentes.

In quibufdam collum et pectus pennis margine fufeis.

I4.

fufcata, St. cauda emarginata, corpore nigricante immaculato, pedibus rubris, roftro fufco.

Sterna fufcata, Lin. Syft. i. p. 228. 6.-Gmel. Syft. i. p. 6 I a

- fufca, Brif. vi. p. 220 . 7. t. 21. f. I. -IJ. 8 vo. ii. p. 420.

Dufky Tern, Latb. Syn. vi. p. 360. 13.

H.

I5.

Hirundo. St. cauda forficata, rectricibus duabus extimis albo nigroque dimidiatis. Sterna Hirundo, Lin. Syft. i. p. 227. 2.-Faun. Suec. $\mathrm{N}^{\circ}$ I 58.-Gmel. Syft. i. p. 6o6.-Hafelq. It. p. 272, 40.-Scop. Ann. i. No I I I.Brun. $\mathrm{N}^{\circ}$ 151. 152.-Muller, p. 21.-Faun. Groenl. No 69.Faun. Arag. p. 76.-Kran. El. p. 345. (Larus.) - Frifch. t. 219. Borowjk. Nat. iii. p. 52. 3.-Faun. Helvet.-Sepp. Vog. to Io5. $M$. et $F$.

Hirundo marina, Raii Syn. p. I31. A. 1.-Will. p. 268. t. 68. Sterna major, Brif. vi. p. 203 . I. t. Ig. f. I.-Id. 8 vo. ii. p. 415. 
Larus albicans, Klein. Av. p. I 38. I0.-1d. Stem. p. 32. t. 36. f. 3. a-c. -Marf. Dan. v. t. 42 .

La grande Hirondelle de mer, Buf. viii. p. 331. t. 27.-Pl. Enl. $9^{87}$. Sea Swallow, Alb. ii. t. 88.-Will. (Angl.) p. 352 .

Greater Tern, Br. Zool. ii. $\mathrm{N}^{\circ} 254$. t. 90.-Id. fol. I44. t. L. *.Lath. Syn. vi. p. 36r. 14.

Habitat in Europa, Afia, America; in maritimis Anglice xtate frequens.

Roftrum pedefque fanguinei : caput fuperius totum nigrum: dorfum aleque fupra canæ: remiges grifeæ: cauda maxime forficata in adultis, rectrice extima latere exteriore tota nigra. Ovum fubolivaceum maculis purpureo-nigris.

$\beta$. St. pedibus nigris, reetricibus extimis toto albis.

16.

Sterna Hirundo, var. Pbil. Tranf. Ixii. p. 421 . (Forfter.)

ganaya. St. fubtus alba, vertice nigro maculato, cervice grifeo-nigricante, alis caudaque fufcis.

Sterna panayenfis, Gmel. Syft. i. p. 607.

L'Hirondelle de mer de l'inle de Panay, Son. Voy. p. I25. t. 84.-Buf. viii. p. 344 .

Panayan Tern, Lath. Syn. vi. p. 363. 15.

Habitat in Pbilippinis infulis, Panaya.-Roftrum pedefque nigri.

17.

cinerea. St. cinerea, capite nigro, marginibus alarum et tectricibus caudæe inferioribus nigris.

Sterna cinerea, Brif. vi. p. 2 10. 3.-Id. 8vo. ii. p. 417.-Gmel. Syft. i. p. 607 .

Larus niger fidipes alter, alis brevioribus, Raii Syn. p. 131. 5.-Will. p. $270 . \$$ vi.-Id. (Angl.) p. 354 .

Cinereous Tern, Latb. Syn. vi. p. 363.16.

Hавітат in Italia. - 13 pollices longa.

Roftrum nigrum: pedes rubicundi.

18.

alba. St. corpore toto albo, roftro pedibufque nigris.

Sterna alba, Muf. Carlf. fafc. i. t. 1 1.-Gmel. Syft. i. p. 607.

- candida, Gmel. Syft. i. p. 607.

White Tern, Lath. Syn. vi. p. $3^{6} 3.17 .-I d$. Sup. p. 266.-Portlock's Voy. t. p. 3I2. 
Habitat in India orientali, ad promontorium Cap. B. Spei, infulifI9. que maris auftralis variis; nigra magnitudine.

thinuta. St. cauda forficata, corpore albo, dorfo cano, fronte fuperciliifque albis. Sterna minuta, Lin. Syft. i. p. 228.4,-Gmel. Syft. i. p. 608.-Borowes. Nat. iii. p. 55. 5 .

- bicolor, Scop. Ann. i. N० 110.

Kinor, Brif. vi. p. 206. 2. t. 19. f. 2.-Id. 8 vo. ii. p. $416 .-$ Klein. Av. p. 1 38 . т1.

Larus pifcator Aldr. Raii Syn. p. r 3 r... A. 2.-Will. p. 269. \$ II. La petite Hirondelle de mer, Buf. viii. p. 337.-Pl. Enl. 996. Leffer Sea-Swallow, Alb. ii. t. 90.-Will. (Angl.) p. 353. t. 68. Leffer Tern, Br. Zool. ii. $\mathrm{N}^{\circ} 255$. t. 90.-Id. fol. I 44. t. L. 2.-Flor. Ssot. i. No 196.-Arct. Zool. ii. $\mathrm{N}^{\circ}$ 449.-Latb. Syn. vi. p. 364. 18.

Habitat in Europa, America; Hirundine minor.- $8 \frac{x}{2}$ poll. longa.

Caput pileo nigro, fronte et temporibus albis : per oculos fafcia nigra: roftrum flavum apice nigrum: pedes flavi. Ovusn luteo-fufcum maculis purpureis.

20.

finenfis. St. alba, dorfo cinereo, alis caudaque fubforficata grifeo-canis, fafcia verticali nigra.

Sterna finenfis, Gmel. Syft. i. p. 608.

Chinefe Tern, Latb. Syn. vi. p. 365.19.

Habitat in Cbina; parva fpecies. -8 pollices longa.

Roftrum nigrum: pedes fulvi: fafcia verticis nigricans, per oculos utrinque defcendens, poftice ad nucham producta: dorfum cinereum pernis margine fufco-rubris: tectrices alarum canx, ftriis longitudinalibus nigricantibus.

21.

aufralis. St. cinerea fubtus grifea, fronte albo-flavefcente, remigibus albis.

Sterna auftralis, Gmel. Syft. i. p. 608.

Southern Tern, Latb. Syn. vi. p. 365. 20.

Habitat in infula Nativitatis Cbrifti. $\rightarrow \frac{\mathrm{T}}{2}-9$ pollices longa.

Roftrum nigrum : pedes nigricantes membranis intermediis fulvis.

22.

metopo- St. capite colloque nigris, dorfo cano-nigricante, remigibus cinereis, leucos. fronte corpore fubtus caudaque forficata albis.

Sterna metopoleucos, N. C. Petr.xv. p. 475.t. 22,-Gmel. Syft. i. p. 608. Hooded Tern, Lath. Syn. vi. p. 36.5. 21. 
HabıтAт in Rufia et Sibiria auftrali; per paria incedens. $-8 \frac{2}{2}$ poll. 23. longa.-Roftrum flavum, bafi rubrum: pedes crocei.

Gifipes. St. cauda emarginata, corpore nigro, dorfo cinereo.

Sterna fiffipes, Lin. Syft. i. p. 228. 7.-Gmel. Syft. i. p. 610.-Brun. No 153.-Scbaf. El. Orn. t. 63.-Faun. Helvet.

Larus merulinus, Scop. Ann. i. N 108 ?

Sterna nigra, Brif. vi. p. 211 . 4.-Id. 8 vo. ii. p. 417.-Sepp. Vog.t. p. i $3 \mathrm{I}$.

Larus niger Gefneri, Raii Syn. p. 131. A. 3.-Will. p. 269. \$III.Klein. Av. p. 1 38 . 12.

Larus niger fidipes alis longioribus Aldr. Raii Syn. p. 1 31. 4.-Will. p: 270. \$ V. t. 68.

Larus minor fidipes noftras, Raii Syn. p. 132. A. 6.-Will. p. 270. $\S$ IV.

Hirondelle de mer noire, ou l'Epouventail, Buf. viii. p. 341.-Pl. Enl. 333.

Black Tern, Br. Zool. ii. No $256 .-I d$. fol. 145. t. L. *. I. f. r.-Arzt.

Zool. ii. $\mathrm{N}^{\circ} 450$. -Lath. Syn. vi. p. 366. 22.-Id. Sup. p. 267.

Habitat in Europa, America-1o pollices longa.-In Anglie paludofis et ad fluviorum ripas frequens; ibique nidificans.

Roftrum nigrum: pedes obfcure rubri. Mas macula gulari alba. In quiburdam abdomen medio album.

Ovum fordide viridi-fufcefcens, maculis purpurafcentibus.

24.

nigra. St. cauda fubforficata, corpore cano, capite roftroque nigris, pedibus rubris.

Sterna nigra, Lin. Syft. i. p. 227. 3.-Faun. Suec. $\mathrm{N}^{\circ} 1$ 59.-Gmel. Syft. i. p. 608.-Muller, $\mathrm{N}^{\circ}$ 171.-Georgi reife, p. 171 .-Borow/k. Nat. iii. p. 52. 2 .

Sterna atricapilla, Brif. vi. p. 214.5 . $-I d$ 8vo. ii. p. 418.

Hirondelle de mer à tête noire, ou le Gachet, Buf. viii. p. 342 .

Leffer Sea-Swallow, Alb. ii t. 89.-Latb Syn. vi. p. 367. 22. var. A.

A filipede variat abdomine, femoribus, alis fubtus, criffoque albis. Forte mera varietas.

25.

bbfcura. St. fupra fufca fubtus alba, alis fufco cinereoque variis, capite nigro.

Sterna obfcura, Gmel. Syjt. i. p. 608.

Sterna fufca, Raii Syn. p. 131. A. 1 5.-Will. p. 268. \$ VIII. 
AVES PALMIPEDES. Larus. 8Ix

Brown Tern, Br. Zool. ii. No 253.-Id. fol. 143.-Will. (Angl.) po 352.-Latb. Syn. vi. p. 368. 23.

Obfcura fpecies, forte precedentium pullus.-Cauda non forficata.

\section{GEN U S XCIV. L A R U S.}

Roftrum rectum, compreflum, apice adunco, mandibula inferiore infra apicem gibba.

Nares lineares, antice latiores, perviæ, in medio roftri fitæ; in quibufdam cera obtectæ.

Lingua fubbifida.

Pars crurum infima plumis denudata.

Pedes tetradactyli, palmati, digito poftico foluto.

I.

* Naribus abfque cera.

ithyætus. L. capite colloque fupremo nigris, dorfo alifque grifefcentibus, remigibus primoribus albis, exterioribus quinque apice nigris, palpebris caudaque albis.

Larus icthyætus, Pall. reife, ii. p. 713. p. 27.-ART. Holm. iv. p. I 19.7. Gmel. Syft. i. p. 599 .

Die groffe Lachmoeve, Gmel. reife, i. p. 152. to 30.3 r. Great Gull, Latb. Syn. vi. p. 370. 1.

Habitat ad mare Cafpium; a $L$. ridibundo omnino diverfa.-Vox inter volandum gravis, coracina.-Magnitudo Anatis erytbropi, imo fæpe major.

Roftrum coccineum, bafi apiceque flavum, prope apicem macula fufca: os intus rubrum : pedes fufco-rubefcentes. Ova in arena nuda, ovato-oblonga, guttis crebris fufcis et obfoletis afperfa.

2.

ridibun- L. albidus capite nigricante, roftro pedibufque rubris.

dus. Larus ridibundus, Lin. Syjt. i. p. 225. 9.-Gmel. Syjt. i. p. 601.-AEz. Holm. iv. p. $120.9 .-$ Schaef. El. Orn. t. 44.-Sepp. Vog. t. p. 153. $M$. et $F$.

Gavia ridibunda phœnicopos, Brif. vi. p. 197. 14.-Id. 8 vo. ii. p. 413 Larus albus erythrocephalus, Klein. Av. p. 138. 8. - Id. Stem. p. 32. 36. f. 2. $a-c$. 
Larus cinereus, Raii Syn. p. 128. A. 5.-Will. p. 264.-Scop. Ann. i. $\mathrm{N}^{\circ}$ 105.

La Mouette rieufe, Buf. viii. p. 433--Pl. Enl. 970.

Brown-headed Gull, Alb. ii. t. 86.

Black-headed Gull, Br. Zool. ii. No $252 .-I d$. fol. 143. t. L. 5.-ArEt:

Zool. ii. $\mathrm{N}^{\circ} 455 \cdot-$ Flor. Scot. i.t. 5. f. 1.-Will. (Angl.) p. 347.

t. 66.-Lath. Syn. vi. p: 380. 9.-Id. Sup. p. 268.

Habitat in Europe maritimis et inundatis; in Anglia plerumque migratorius. - I 5 poll. long.; 3 ped. lat.-Voce cachinnos æmulatur.

Roftrum, pedes, et cilia rubra : caput totum, in nonnullis partim, nigro-fufcum: dorfum et ale cano-cinerea: collum et corpus fubtus alba : cauda alba: remiges primores Io exteriores margine et apice nigræ. Ovum olivaceo-flavefcens maculis rotundatis fufco-rubris.

ß. L. albus, dorfo cano, macula pone aures fufca.

Larus cinerarius, Lin. Syft. i. p. 224. 4.-Gmel. Syft. i. p. 597.-Faun。. Helvet.

- canus, Scop. Ann. i. No ro4.

Gavia cinerea minor, Brif. vi. p. 178. 9. t. 17. f. I. $-I d$. 8 vo. ii. p. 409 . Larus albus major, Raii Syn. p. 129. 9.-Will. p. 264.

La petite Mouette cendrée, Buf. viii. p. 430.

Le petit Goiland, Pl. Enl. 969 .

Dingla, Fork. Faun. Arab. p. 8. 17.

Greater white Gull of Belon, Will. (Angl.) p. 348.-Br. Zool. ii. N? 252. A.

Red-legged Gull, Latb. Syn. vi. p. $3^{8}$ 1. 10.

HaBitat cum priore, cujus forte avis incompleta.-Roftrum et pedes fimiliter rubra : caput fufco varium : reliqua fere ut in ridibundo.

$\gamma$. L. albidus, capite fufco maculis albis, dorfo cano, rectricibus decem intermediis fafcia nigra.

Larus erythropus, Gmel. Syft. i. p. 597.

Red-legged Gull, ArEz. Zool. ii. p. 533. E.

Brown-headed Gull, Lath. Syn. vi. p. $3^{8} 3.1$.

Magnitudo præcedentium.- 14 pollices longus.

Roftrum, cilia, et pedes rubri : caput et jugulum coloris murini albo maculata : collum et abdomen alba : ale fufco-nigricantes : remiges 4 prie mores apicibus margine nigris : rectrix extima utrinque alba. 
3.

atricilloi- L. ex rubicundo albus, capite orbitis colloque nigris, dorfo alifque cides. nereis, p dibus coccineis, Falck. It. iii. p. 355 .t. 24. - Gmel. Syft. i. p. 601.

Habitat in Sibirice auftralis lacubus fallis.

4.

atricilla. L. albus, capite nigricante, roftro rubro, pedibus nigris.

¿arus atricilla, Lin. Syft. i. p. 225. 8.-Gmel. Syjt. i. p. 600.-Faun. Helvet. -N. C. Petr. xv. p. 478. t. 22. f. 2. (pullus.)-Act. Hohm iv. p. 120.8 .

Gavia ridibunda, Brif. vi. p. 192. B. t. I8. f. 1. $-I d$. 8 vo. ii. p. 413 . Larus albus, Scop. Ann. i. No 106.

Larus major cinereus Baltneri, Raii Syn. p. I 29. 8.-Will. p. 263. t. 67. Larus minor capite rigro, Klein. Av. p. 139. 16.

Baltner's great afh-coloured Sea-Mew, Will. (Angl.) p. 346. t. 67. Laughing Gull, Cat. Car. i. t. 89.-Arct. Zool. ii. N 454.-Lath. Syn. vi. p. $3^{8} 3 \cdot 12$.

Habitat in America, Europa; præcedente paulo major, a quo vix variat nifi pedibus nigris.

Roftrum, ut in ridibundo, fanguineum : corpus cinereum fubtus album.

S.

minutus. L. niveus, capite nigro, alis leucophæis, pedibus coccineis.

Larus minutus, Pall. reife, iii. p. 702. 35-Gmel. Syjt. i. p. 595.Nov. AE. Stock. 1783 . ii. N ${ }^{\circ}$. p. I 20.

Little Gull, Lath. Syn. vi. p. 391..17.

Habitat circa alveos majorum Sibirice fluviorum; in Ruffia quoque auftraliori paffim, fed rarius obfervatur ; magnitudine Turdi vifcivori.

Roftrum fufco-rubrum : irides cærulefcentes : caput totum cum initio colli atrum: corpus niveum, dorfo alifque leucophæis: remiges apice albæ nigredine nulla : cauda æqualis alba : pedes coccinei.

6.

marinus. L. albus, dorfo nigro.

Larus marinus, Lin. Syjt. i. p. 225: 6.-Faun. Suec. $\mathrm{N}^{\circ}$ 1 55.-Gmel。 Syjt. i. p. 598.-A8. Holm. iv. p. Ior. 3.-Faun. Groenl. $\mathrm{N}^{\circ} 66$. Brun. $\mathrm{N}^{\circ}$ 145.-Muller, $\mathrm{N}^{\circ}{ }_{16} 6 .-$-Bororefk. Nat. iii. p. 48. 4. Larus niger, Brif. vi. p. 158 . 1.-Id. 8 vo. ii. p. 403.

Larus maximus ex albo et nigro varius, Raii Syn.p. 127. A. 1.-Will.

p. 261 . -Klein. Av. p. 136. I.

Le Goéland noir, Buf. viii. p. 405. t. 31.-Pl. Enl. 990.

Great black and white Gull, Will. (Angl.) p. 344. t. 67.-Alb. iii. t. 94. 
Black-backed Gull, Br. Zool. ii. No 242,-Id. fol. I40. t. L.-Flor. Scot. i. t. 5. f. 2.-Arit. Zool. ii. $\mathrm{N}^{\circ} 45$ 1. -Latb. Syn. vi. p. 37 1. 2.

Habitat in Europa et Americe maritimis, ad Cap. B. Spei, N. Hollandia; inter rupes nidificans; ova 3 grifeo-nigricantia maculis purpureo-nigris anomalis ponens. - Victitat pifcibus aviumque pullis.-Magnitudo fere Anferis. - 29 pollices longus.

Rofrum flavum : ad apicem mandibula inferioris macula rubra, medio nigra: dorfum fuperus et ale nigra: remiges apice albo: pedes incarnati.

$\beta$. L. albus, dorfo alifque canis, remigibus primoribus verfus apicem nigris.

Larus argentatus, Brun. N $\mathrm{N}^{\circ}$ 49.-Gmel. Syft. i. p. 600.

Gavia cinerea major, Brif. vi. p. I82, 10. t. I6. f. 2 ? $-I d$. 8 vo. ii. p. 410 ?

La grande Mouette cendrée, Buf. viii. p. 428.-Pl. Enl. 977.

Silvery Gull, ArEt. Zool. ii. p. 533. C.-Id. Sup. p. 70.-Lath. Syn. vi. p. $375 \cdot 5$.

Habitat cum priore, a quo parum difcrepat, præterquam quod color totus pallidior fit, et eadem avis eft ætate provecta.

\%. L. albus, dorfo cinereo, rectricibus apice nigris.

Larus nævius, Gmel. Syft. i. p. 598.

- varius, Brun. $\mathrm{N}^{\circ} 150 .-B r i f$. vi. p. 167.5 . t. 15.-Id. 8 vo. ii. p. 406 .

-_ grifeus maximus, Klein. Av. p. 1 37, 6.-Id. Stem. t. 36. f. r. a. b. Wagellus Cornubienfium, Raii Syn. p. I30. A. 1 3.-Will. p. 266. t. 66. Le Goéland varié, Grifard, Buf. viii. p. 41 3. t. 33.-Pl. Enl. 266.

Wagel Gull, Br. Zool. ii. No 247. A. t. 88.-Id. fol. ii. 422.-ArEt. Zool. ii. $\mathrm{N}^{\circ}$ 453.-Id. Sup. p. 70.-Will. (Angl.) p. 349. t. 66.Latb. Syn. vi. p. 375.6.

Magnitudo marini, cujus eft pullus primi anni.

Roftrum nigricans : pedes obfcure incarnati : corpus totum fufco, cinereo, alboque varium : remiges nigra: cauda prope apicem fafcia nigra.

L. albus, dorfo alifque canis, remigibus apice albis, roftro flavo angulo croceo.

Larus glaucus, Brun. $\mathrm{N}^{\circ}$ 148.-Muller, $\mathrm{N}$ ×69.-Faun. Groenl. $\mathrm{N}^{\circ} 64$. -Acz. Holm. iv. p. 97. 1.-Gmel. Syft. i. p. 600. 
Larus cinereus, Brif. vi. p. $160.2 .-I d .8$ vo. ii. p. 404 . albus, Ifl. reife, pp. $356.572 .75^{6}$.

Le Goéland à manteau gris, Buf. viii. p. 406. t. 32 .

Burgermeifter, Mart. Spitzb. p. 6o. t. L.-Raii Syn. p. $127 \cdot 3$.

Le Bourgmeftre, Buf. viii. p. 418 .

Glaucous Gull, Arct. Zool. ii. p. 532. B.-Id. Sup. p. 70.-Lath. Syn. vi. p. $374 \cdot 4$.

HaBitat in Europa, Suecia; hyeme migrans in Iflandiam; vorax; pullos Col. Troile aliorumque predans; magnitudine fufcum antecellit.

Ovum virefcens, ad apicem minorem elongatum, maculis 6-8 diffor-

8. mibus nigris.

fufcus. L. albus, dorfo fufco, pedibus flavis.

Larus fufcus, Lin. Syft. i. p. 225. 7.-Faun. Suec. No r 54.-Gmel. Syft.

i. p. 599.-Scop. Ann. i. No 107 ?-Brun. $\mathrm{N}^{\circ} 142 .-1 d$. 143. (var.) -Id. 144. (pullus.)-Muller, $\mathrm{N}^{\circ}$ 164.-Georgi, p. 171.-Frifch. t. 21 8. - Borowes. Nat. iii. p. 49. 5.-AIt. Holm. iv. p. 105. 4.-

Faun. Helvet.

Larus varius, Brun. $\mathrm{N}^{\circ} 150$. (pullus.)

grifeus, Brif. vi. p. 162. 3.-Id. 8vo. ii. p. $405-$-Klein. Av. p. I37. 2.

Gavia grifea, Brif. vi. p. I7 I. 6. (junior avis.)-Id. 8 vo. ii. p. 407. Larus cinereus maximus, Raii Syn. p. 127. A. 2.-Will. p. 262.Sloan. Fam. p. 322.

Herring Gull, Br. Zool. ii. $N^{\circ}$ 246. t. 88.-Id. fol. 141.-ArEz. Zool. ii. $\mathrm{N}^{\circ} 452 .-$ Will. (Angl.) p. 345.-Latb. Syn. vi. p. 372. 3.

Habitat cum præcedente, quo minor, et præcipue differt dorfo fufco, pedibus flavo-aureis. Ovum faturate grifeum, ad fufcum inclinans, maculis nigris crebrioribus.

9.

canus. L. albus, dorfo cano, remigibus primoribus extremitate nigris, quarta et quinta macula apicis nigra, extima extus nigra.

Larus canus, Lin. Syft. i. p. 224. 3.-Faun. Suec. $\mathrm{N}^{\circ}$ 153.-Gmel. Syf。 i. p. 596.-Sepp. Vog.t. 56.-Brun. $\mathrm{N}^{\circ} 141 .-$ Muller, $\mathrm{N}^{\circ} 162$. Georgi, p. 170.-Faun. Arag. p. 75.-Borowek. Nat. iii. p. 47. 3. - AEt. Holm. iv. p. 109. 5.-Faun: Helvet.

Larus canefcens, Hafjelq. It. p. 272. 39.-Id. Voy. p. 202.

Gavia cinerea, Brif. vi. p. 175 . 8. t. 16. f. 1. $-I d$. 8 vo. ii. p. 408. Larus roftro nigro, Klein. $A v$. p. 137. 5 ?-Id. Ov. p. $35 . t_{i} 20$. f. $^{2}$. 
Larus cinereus minor, Raii. Syn. p. 127. A. 3.-Will. p. 262. t. 76.

Gabbiano minore di color cinerizio, Zinnan. Uov. p. II 5. t. 22. f. 104. White web footed Gull, Alb. ii, t. 84 .

Common Gull, Br. Zool. ii. No 249. t. 89. f. 2.-Id. fol, 142.-ArEt.

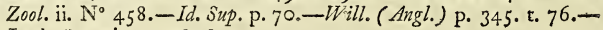
Lath. Syn. vi. p. 378. 8.

Haвiтат in Europa, America; in Anglie maritimis maxime frequens. -17 pollices longus.

Roftrum flavum: irides avellanex: caput, collum, corpus fubtus, et couda alba: remiges 5 primores apice nigræ, extima extus nigra, quarta et quinta macula alba apice notatæ: pedes albo-virefcentes. Ovum pallide olivaceo-fufcum, ttriis maculifque fufco-purpurafcentibus.

$\beta$. L. cinereus fubtus niveus, capite albo maculis fufcis vario, collo fupra fufco, alis variis, rectricibus albis fafcia nigra.

Larus hybernus, Gmel. Syft. i. p. 596.

Gavia hyberna, Brif. vi. p. 189. 12.-Id. 8vo. ii. p. 4 I I.

Larus fufcus, f. hybernus, Raii Syn. p. 130. A. 14.-Will. p. 266. t.

66.-Klein. Av. p. I $3^{8} .9$.

Mouette d'hyver, Buf. viii. p. 437.

Larus maculatus, Brun. $\mathrm{N}^{\circ} 146.147$.

Guaca-guacu, Raii Syn. p. I 30. 12.-Will. p. 268.-Id. (Angl.) 352. Winter-Mew, Coddy Moddy, Br. Zool. ii. No 248. t. 86. 1. -Id. fol. 142. t. L. 2.-Will. (Angl.) p. 35c. t. 66.-Alb. ii. t. 87.Lath. Syn. vi. p. $384,13$.

$\mathrm{Hæc}$ avis, præcedentis pullus, veftitu primo eft, et cum adultioribus fluviorum ripas, prata humida, paludefque frequentat.

IO.

cburneus. L. corpore toto niveo, roftro pedibufque plumbeis.

Larus eburneus, Pbipps's Voy.p. 187.-Gmel. Syft. i. p. 596.

- niveus, Azt. Holm. iv. p. 10o. 2.-Mart. Spitzb. t. L. f. A.

-- candidus, Faun. Groenl. p. 67.-Muller, p. 8.

L.a Mouette blanche, Buf. viii. p. 422.-Pl. Enl. 994.

Rathfher, i. e. Senator, Raii Syn. p. I26. I.-Nart. Spitz. p. 77.Adel. 359. 41 5. t. I3. f. 4.-Salern. Orn. p. 382.

Ivory Gull, ArEt. Zool. ii. N' 457.-Lath. Syn. vi. p. 377. 7 .

Habitat in Groenlandia et Spitzbergio, et in Mari glaciali.-16 pollices longus. 
Roftrum plumbeum apice pallido: pedes plumbei : ala caudam longitudine excedunt. Pulli maculis nigricantibus, prafertim dorfo et alis, varii. Ovum album.

I. छridacty- L. dorfo canefcente, rectricibus albis, digito poftico mutico.

lus. Larus Riffa, Lin. Syft. i. p. 224. 1.-Gmel. Syft. i. p. 594.-Brun. N* 140.-Muller, $\mathrm{N}^{\circ}$ 160.-Ijlo reife, 356. t. 23.-Faun. Grosnl. $\mathrm{N}^{\circ} 6_{3}$.

Kutiegef, Adel. 361. t. 14. f. 6.-Gmel. reife, ii. p. I91 ?

Le Goiland cendré, Pl. Enl. 253.-Brif. vi. t. I4 ?

Kittiwake, Br. Zool. ii. N $\mathrm{N}^{\circ}$ 50. t. 89.-Sibb. Scot. 20.-ArEt. Zool. ii. $\mathrm{N}^{\circ}$ 456.-Tour in Scotl. 1769. (4to. ed.) p. 145.-Phipps's Voy. p. 187.-Lath. Syn. vi. p. 393. 19.

Habitat in Europa, Afia, America; cano paulo minor.-r 4 pollices longus.

Roftrum flavefcens: os intus croceum: caput, collum, abdomen, et cauda nivea: dorfum et ale canæ, remigibus 4 f. 5 apicibus, exteriore extus, nigris: pedes obfcuri, loco digiti poftici gibbofitas exigua : vix a cano diftinctus, nifi abfente digito poftico. Ovum incarnatum maculis faturatioribus.

$\beta$. L. albicans, dorfo canefcente, reftricum apicibus excepto extimo nigris, pedibus tridactylis.

Larus tridactylus, Lin. Syft. i. p. 224. 2.-Faun. Suec. $\mathrm{N}^{\circ}$ I $57 .-G m e l$. Syft. i. p. 595.-Muller, $\mathrm{N}^{\circ}$ 161.-Ifl. reife, 572. t. 24. 25.-Faun. Groenl. p. 98. 63.-Faun. Helvet.-Borowe/k. Nat. iii. p. 47. 2.

Larus navius, Lin. Syjt. i. p. $225 \cdot 5$.

Gavia cinerea nævia, Brif. vi.p. 185. I I. t. I7. f. 2.-Id. 8 vo. ii. p. 410 . La Mouette cendrée tachetée, Buf. viii. p. 424. - Pl. Enl. $3^{8} 7$. Larus cinereus Bellonii, Raii Syn. p. I 28. A. 4.-Will. p. 263. t. 68.

- albo-cinereus torque cinereo, Aldr. iii. t. p. 77.-Will. p. 266. t. 66 .

Larus cinereus pifcator, Klein. Av. p. I 37. HI-Id. p. I48. 9.-169. 4. Kuutge-Gef, Klein. Av. p. 148. 9.-p. 169. 4. Tarrock, Br. Zool, ii. No 25 I.-Id. fol. 142. t. L. 3.-ArEt. Zool. ii. p. 533. D.-Id. Sup. p. 70.-Flor. Scot. i. p. 4 1. 1 93.-Will. (Angl.) p. 346. t. 68.-Lath. Syn. vi. p. 392. 18.-Id. Sup. p. 268.

Habitat cum priore, cujus incompleta avis; magnitudine aqualis. Roftrum et pedes obfcuri : caput, collum, et corpus fubtus alba: macula $5 \mathrm{M}$ auriuม* 
818

A VES PALMIPEDES. Larus.

aurium et gule, lunulaque nucbe nigra : dorfum cano-cæruleum : ale albo nigroque variæ: cauda alba apice nigro.

$\boldsymbol{\gamma}$. L. albus, dorfo canefcente, rectricum apicibus extimo excepto nigris, fafcia alarum obliqua nigra, Laib. Syn. vi. p. 393. 18. A.

Ab ultima ave variat corpore majore, gula alba : rectrix extima alba.

12.

\section{> * Naribus cera obte尺̂is.}

Catarrac- L. grifefcens, remigibus reetricibufque bafi albis, cauda fubæquali.

tes. Larus Cataraetes, Lin. Syft. i. p. $226.11 .-G m e l$. Syjt.i. p. 603.-Borowf. Nat. iii. p. 50.6 .

Catharacta Skua, Brun, $\mathrm{N}^{\circ}$ 1 25.-Muller, $\mathrm{N}^{\circ}$ 16\%.

Catarractes et Catarracta, Raii Syn. p. 128. A. 6.-Id. 129. 7.-Will.

p. 265.-Ii. (Angl.) p. 348. 349. t. 67.-Sibb. Scot. pars 2. 1. iii.

p. 20 . t. 14. 2.

Larus fufcus, Brif. vi. p. 165. 4.-Id. 8vo..ii. p. 405.-IKlein. Av. p.

137.7.

Le Goéland brun, Buf. viii. p. 408.

Gabbiano, Cuccale, Zinnan. Uov. p. 114. t. 2 1. f. 102.

Port Egmont Hen, Hawks. Voy. ii. 283.-Cook's Voy. i. pp. 44. 272.Forft. Voy. i. pp. 109. 118. et alibi.

Sea Crow, Kolb. Cap. ii. p. 141?

Brown Gull, Alb. ii. t. 85 .

Skua Gull, Br. Zool. ii. No 243.-Id. fol. 140. t. L. 6.-Arct. Zool. ii. $\mathrm{N}^{\circ} 531$. A.-Latb. Syn. vi. p. $3^{8} 5.14$.

Habitat in Europa, Afia, Africa; coracis magnitudine.-2 pedes. longus.-Avis rapax, ferox, congeneres minores exagitans, et captos. pifces rejicere cogens, illis aufert.

Roftrum cera nigra ultra medium tectum, et pedes obfcuri, unguibus validis : irides luteo-avellaneæ : corpus fufcum fubtus cinereo-ferrugineum : remiges et reftrices bafi albæ. Qvum fufco-cærulefcens, maculis, f. nebulis rubro-fufcis.

33.

Keeafk. L. fufcus, tectricibus alarum albo variegatis, cauda nigra albo maculata apice albo.

Efquimeaux Keeank, Latb. Syn. vi. p. 389.-ArEt. Zool. ii. p. 7 I.

Habitat in America ad finum Hudfonis; magnitudinis majoris:-22.

poilices 
14.

pollices longus.-Aprili adventans. - Nidum ex gramine confruit, wo a 2 ponens pallide ferruginea maculis nigris.

Roftum nigrum, 3 pollices longum: pedes nigri, digitis cum membranis albo nigroque dimidiatis.

crepidatus. L. luteo fufcoque varius fubtus pallidior, macula alarum alba.

Larus crepidatus, Gmel. Syft. i. p. 602.-Hawkfw. Voy. i. p. 1 5.-Buf. viii. p. 439 .

Catarra\&ta Cepplius, Brun. p. 36. $\mathrm{N}^{\circ}$ 1 26. t. in $\mathrm{D}^{\circ}$.-Muller, p. 2 1. Pbil. Tranf. lii. p. 1 35.--Raii. Syn. p. 129.11 .-Will. p. $267 .-$ Id. (Angl.) p. 35 1. t. 67.

Stercorarius ftriatus, Brif. vi. p. 1 52 2. 2. t. 13. f. 2.-Id. 8 vo. ii. p. 40 r. L'Abbe, ou Stercoraire, Buf. viii. p. 441. t. 34. - Pl. Enl. 99 r.

Black-toed Gull, Br. Zool. ii. N ${ }^{\circ} 44$. t. 86.-ArEt. Zool. ii. No 460 . -Lath. Syn. vi. p. 387. 1 5.-Id. Sup. p. 268.

Haвiтat fparfim in Europa.- -16 pollices longus.

Roftrum nigrum : caput et collum ferrugineo fufcoque longitudinaliter varia: corpus fufcum pennis plus minufve apice ferrugineis, fubtus pallidius, pectore albo vario: cauda fufca rotundata : remiges et rectrices bafi albæ: pedes cærulefcentes, digitis cum membranis nigricantibus bafi albis.

$\beta$. L. grifeo et albo varius fubtus albus, remigibus primoribus rectricibufque nigricantibus albo terminatis, harum lateralibus intus ma. xima parte albis.

Gavia grifea minor, Brif. vi. p. 173. 7.-Id. 8vo. ii. p. 408 .

Larus maculatus, Marf. Dan. v. p. 94. t. 45.-Klein. Av. p. ${ }_{138 .}{ }^{8} 4$. -Latb. Syn. vi. p. $3^{82}$. 10. A.

Longitudo $15 \frac{3}{4}$ pollicum.-Roftrum aurantium apice nigro : irides albidæ : pedes aurantii. An varietas crepidati?

15 . parafiti- L. fupra niger, collo pectore et abdomine albis, rectricibus duabus incus. termediis longiffimis.

Larus parafiticus, Lin. Syft. i. p. 226. 10.-Faun. Suec. N $156 .-$ Pbil. Tranj. lxii. p. 421. 23.-Faun. Amer. p. 16.-Muller, $\mathrm{N}^{\circ}$ 166.Borow/k. Nat. iii. p. 45. t. 41.-Faun. Helvet.-Gmel. Syf. i. p. 601 .

Catharakta parafitica, Brun. $\mathrm{N}^{\circ}$ I 27. I 28.-Faun. Groenl. N॰ 68. Larus fubfuícus major, vertice nigro, \&c.-Brown. Fam. 482. 
Stercorarius longicaudus, Brif. vi. p. 155. 3. (Mas)-Id. 8vo. ii. p. 402 .

Stercorarius, Brif. vi. p. 1 50. 1. (Fem.) -Id. 8 vo. ii. p. 40 r.

Sterna rectricibus maximis nigris, It. Wgoth. 182.-AZ7. Holm. 1753. p. $29 \mathrm{I}$.

L'Abbe à longue queve, Buf. viii. p. 445.-Pl. Enl. 762 .

Strundt-jager, i. e. Kompoońgns, Raii Syn. p. 127. 2.-Adel. 364. t. 13. f. 5o - Mart. Spitz. 87.

Arctic Birds, Edvo. t. 148. 149. M. et $F$.

Aretic Gull, Br. Zool. ii. N 245 . t. 87. M. et Fem.-ArEt. Zool. ii. $N^{\circ}$ 459.-Latb. Syn. vi. p. 389. 16. t. 99.

Habitat in Europa, Afia, America, tam alto mari quam finubus; vicus præcipue eft aliarum avium rapina evomita, quam fub cafu roftro prehendit; hinc Laros aliofve continuo perfequitur, illos evomere cogens. -2 I pollices longus.

Rofrum et pedes fufcefcentes: vertex nigricans: dorfum, alc, cauda. plumbeo-nigricantia, cætera alba.

Variat corpore fubtus fufco; forte fexus alter. Pullus totus grifeofufcus, fubtus dilutior. Ovum Gallinacei magnitudine, cinereum, maculis nigris.

\section{GENUS XCV. PROCELLARIA.}

I.

Roftrum edentulum, fubcompreffum, apice adunco. Nares cylindro fupra bafin roftri decumbente, truncato: in quibufdam difcretæ.

Pedes palmati, ungue poftico feffili, acuto, abfque digito.

* Naribus tubulofis.

gigantea. Pr. fufco-nebulofa fubtus albida, remigibus rectricibufque nigricantibus, roftro pedibufque flavis.

Procellaria gigantea, Gmel. Syft. i. p. $5^{6} 3$.

Quebrantahueflos, Boug. Voy. p. 63.-Forft. Voy. ii. p. 516.-Buf. ix. p. 3ig.

Ofprey Petrel, Forft. Obf. p. 202.

Mouton, Pernet. Voy. i. p. 1 5. t. 8. f. 3. (Roftrum.)

Glupifha, Hift. Kamtf. p. ${ }_{5} 6$.

Offifraga . $_{3}$ 
AVES PALMIP'EDES. Procellaria. 821

Ofifiraga, or Break-bones, Ulloa Voy. 8 vo. ii. p. 214.

Mother Cary's Goofe, Cook's Voy. ii. p. 205.

Giant Petrel, ArEZ. Zool. ii. Sup. p. 7 1. -Cook's laft Voy. ii. p. 258.-Id. 299. - Lath. Syn. vi. p. 396. t. 100.

HABIтAT in Oceano ardtico et antarctico; migratoria; gregatim vo2. lans. -Victitat pifcibus, balænifque occifis mortuifve -40 poll. longa. Corpus magnitudine Anferis.

brafiliana. Pr. fufco-nigricans, collo inferiore flavo, rectricibus fufco-nigricantibus. Procellaria brafiliana, Gmel. Syft. i. p. $5^{6} 4$.

Puffinus brafilienfis, Brif. vi. p. 138. 4.-Id. 8 vo. ii. p. 397.

Le Puffin du Brefil, Buf. ix. p. 337. IV.

Maiague, Raii Syn. p. 133. 3.-Will. p. 252. t. 62.-1d. (Angl.) P. 334.

HaвiтAт in Brafilia ; circa fluviorum oftia in mari vivit, et in littore nidificat.-Magnitudo Anferis.

3.

æquinoc* Pr. fufca immaculata, roftro flavo, pedibus fufcis.

tialis. Procellaria æquinoctialis, Lin. Syft. i. p. $213.4 .-G m e l$. Syft. i. p. 564 .

Puffinus Capitis Bonæ Spei, Brif. vi. p. 137. 3.-Id. 8 vo. ii. p. 397.

Plautus albatrofs fpurius major, Klein. Av. p. 148. 14.

Avis Diomedea, Redi. Differt: 1674. Amftel.

Le Petrel-puffin brun, Buf. ix. p. 326.

Shearwater, Brown. Fam. p. 482 .

Great black Petrel, Latb. Syn. vi. p. 398. 3.-Edw. t. 89 .

Habitat ad Caput Bona Spei, nova Zealandia.-Corpus magnitudine C. Coracis. -23 poll. longa. Variat gula alba.

ß. Kuril Petrel, Lath. Syn. vi. p. 399. 3. A.-Arc7. Zool. ii. p. 536. A. -Pall. Spic. v. p. 28.

Haвiтат in Kamtscbatka; priore multo major; pedibus rubro-nigricantibus.

4

grifea. Pr. fuliginofo atra, tectricibus alarum inferioribus albis, roftro fufco, pedibus antice cærulefcentibus.

Procellaria grifea, Gmel. Syft. i. p. 564 .

Dark grey Petrel, Cook's Voy. i. p. 258.-Latb. Syn. vi. p. 399. 4.

HАBIтAт in bemifpberio auftrali, $-14-15$ pollices longa.

Pr. cinereQ. 
5. $822 \quad$ A VES P A L MIPEDES. Procellaria,
gctida. Pr. cinereo-cerulefcens, dorfo nigricante, gula jugulo pectoreque albis, roftro flavo, pedibus caruleis.

Frocellaria gelida, Gmel. syft. i. p. $5^{64}$.

Glacial Petrel, Latb. Syn. vi. p. 399. 5 .

I IABITAT Oceano antarEtico inter glaciem.-rg pollices longa.

Narium tubus, mandibularum margines, dorfum fuperioris, et apex inferioris nigra.

6.

alba. Pr. fufco-nigricans, peetore abdomine criffoque albis. .

Procellaria alba, Gmel. Syft. i. p. $5^{6} 5$.

White-breafted Petrel, Lath. Syn. vi. p. 400. 6.

Habitat in infulis Maris pacifici.-i6 pollices longa.

Gula albida : cauda rotundata: roftrum nigrum : pedes fufci, digitis antice cum membranis nigris.

$\beta$. Pr. fuliginofa fubtus cinerea, facie albo fufcoque varia, pedibus $\mathrm{Ala}_{\text {- }}$ vefcentibus, digitis dimidiato-nigris.

Norfolk-inand Petrel, Pbil. Voy. t. p. I6r.

Hав ттат in infula Norfolcie; cuniculis luci quiefcens; vefperi gregatim volitans. - I 6 pollices longa.

Rofrun nigrum valde compreffum, aduncum : remiges caudam longitudine multo excedunt: pedes flavefcentes, digitis cum membranis antice dimidiato-nigris.

7.

antaretica. Pr. fufca fubtus albo-cærulefcens, remigibus fecundariis uropygio caudaque albis, rectricibus apice nigris.

Procellari. antarctica, Gmel. Syft. i. p. $5^{6} 5$.

Le Petrel antaretique, ou Damier brun, Buf. ix. p. $3 \mathrm{Ir}$.

Brown and white Petrel, Boug. Voy.i. p. 42 ?

Antarctic Petrel, Lath. Syn. vi. p. 400. 7.-Forft. Voy. i. p. 108.Cook's Voy. i. p. 257.

Habitat in Oceano antarctico; gregaria.-Magnitudo Palumbi.16 pollices longa.

Rofrum fufcum apice nigrum : irides avellaneæ: pedes plumbei.

8.

capenfis. Pr. albo fufcoque varia.

Procellaria capenfis, Lin. Syft. i. p. 213.5 -Amaen. Ac. iv. p. 240.Gmel. Syft. i. p. $565 .-0 / 6$. It. p. 76.-Id. Voy. 109.-Borowfk. Nat. iii. p. $37 \cdot 3$.

Procellaria 
A V E PALM I PEDES. Procellaria. 823

Procellaria nævia, Brif. vi. p. 146. 3.-Id. 8 vo. ii. p. 4co.-Klein. Av. p. 148. 14. (minor.)

Le Petrel tacheté, ou le Damier, Buf. ix. p. 304. t. 21.-Pl. Enl. 964.

-Pernet. Voy. ii. p. 72.-Forft. Voy. i. p. 489.

Pardela, Ulloa's Voy. p. 304 .

White and black fpotted Peteril, Edw. t. 90.-Hawksw: Voy. i. 556.

Plntado Petrel, Lath. Syn. vi. p. 401. 8.-Damp. Voy. iii. t. p. 96. f. r.

Ha вIтAт ad Cap. B. Spei et variis bemijpberii aufralis partibus. - 14 pollices longa; gregaria.

Corpus album, fuperne maculis nigricantibus varium : caput et collum fuperius nigricantia: rectrices laterales in exortu, candidæ, in extremitate nigricantes.

ß. Pr. lutefcente fuícoque varia, Lath. Syn. vi. p. 402. var.

9.

glacialis. Pr. albicans, dorfo canefcente, roftro pedibufque flavicantibus.

Procellaria glacialis, Lin. Syft. i. p. $213.3 .-F a u n$. Suec. $\mathrm{N}^{\circ}$ 144.Gmel. Syft. i. p. 562.-Brun. $\mathrm{N}^{\circ} 1$ 1 8.-Muller, $\mathrm{N}^{\circ}$ 144.-Faun. Groenl. $\mathrm{N}^{\circ}$ 55.-Borow/k. Nat.:iii. p. 36. 2.

Procellaria cinerea, Brif. vi. p. I43. 2. t. I2. f. 2. -Id. 8 vo. ii. p. 399. -AEz. Nidr. i. p. 182 . t. r.

Fulmar, ou Petrel-Puffin gris-blanc, Buf. ix. p. 325. t. 22.-Pl. Enl. 59. Wagellus Cornubienfium, Mallemucke, Raii. Syn. p. 130. A. I3. Haffhert, feu Equus marinus, Will. p. 306.-Id. (Angl.) p. 395. Fulmar Petrel, Br. Zool. ii. $\mathrm{N}^{\circ} 257 .-I d$. fol. 145. t. M. 2.-ArEt: Zool. ii. N $\mathrm{N}^{\circ} 46 \mathrm{1} .-$ Flor. Scot. i. No 197.-Martin's St. Kilda. 30. iv. t. 82.-Martin's Spitzb. t. v. f. C.-Pbipps's Voy. p. 186.-Latb. Syn. vi. p. 403. 9.

Habit at in Maribus auftralibis et feptentrionalibus, ad circulos arcti: cum et antarEticum ufque; in infulæ Sti. Kilde rupibus nidificat.-I 7 pollices longa:

Narium tubus conftat unico cylindro biloculari, nec duobus diftinctis $s_{r s}$ fufcus in roftro rufefcente: pedes rubro-flavicantes.

$\beta$. Pr.alba, dorfo medio canefcente, alis nigricantibus.

Fulmar Petrel, Latb. Syn. vi. p. 405. var. A.

Hавітат in Oceano antarctico.-Pedes obfcuri. 
10.

824 AVES PALMIPEDES. Procellaria.

cinerea. Pr. fupra cinerea fubtus alba, cauda nigricante, roftro flavo, pedibus cinerafcentibus.

Procellaria cinerea, Gmel. Syft. i. p. $5^{6} 3$.

Cinereous Petrel, Lath. Syn. vi. p. 405. ro.

HaBITAT intra circulum antarEficum. $-20 \frac{1}{4}$ pollices longa.

Cauda rotundata fupra nigra fubtus cinerafcens : pedes pallidi, mem. branis flavefcentibus.

Variat roftro cærulefcente, pedtore abdomineque nigricantibus.

I.

Puffinus. Pr. corpore fupra nigro fubtus albo, pedibus rufis.

Procellaria Puffinus, Lin. Syft. i. p. 213.6.-Gmel. Syft. i. p. 566.Brun. No 119.-Muller, p. 18.-Faun. Groenl. No $56 .-$ Brif. vi. p. 131. 1.-Id. 8 vo. ii. p. 395.-Klein. Av. p. 139. 18.-Brown. Fam. p. $482 .-$ Borowjk. Nat. iii, p. 37.4.

Avis Diomedea, Shearwater, Raii Syn. p. 133. x. et A. 2.-Will.p. 25 I. -Id. (Angl.) p. 332. 334.

Puffinus Anglorum, Raii Syn. p. 1 34. A. 4.-Will. p. 252.

Le Puffin, Buf. ix. p. $321,-$ Pl. Enl. 962.

Manks Puffin, Edw. t. 379.-Will. (Angl.) p. 333.

Shearwater Petrel, Br. Zool. ii. $\mathrm{N}^{\circ}$ 258.-Id. fel. 146. t. M. $-A r E$. Zool. ii. $\mathrm{N}^{\circ} 462 .-$ Flor. Scot. i. $\mathrm{N}^{\circ}$ 198.-Latb. Syn. vi. p. $406 . \mathrm{I}$. -Id. Sup. p. 269.

Habitat in Oceano tam aufrali quam arctico, in boreali Anglia, in infulis Orcadibus et Mone; in cuniculis nidificat, unum ovum album ponens. - I 5 pollices longa.

Corpus fupra nigrum fubtus album : remiges primores et rectrices extrorfum fufcæ, introrfum albæ: genæ cærulefcentes : roftrum nigrum: pedes nigri rubrique fimul.

ß. Pr. fupra cinerea fubtus alba, rectricibus candidis.

Puffinus cinereus, Brif. vi. p. 134. 2. t. 12. fo 1.-Id. 8 vo. ii. p. 396.

Le Petrel cendré, Buf. ix. p. 302. to 20.

Brown Shearwater, Kalm. Trav. i. p. 23?

Shearwater Petrel, Latb. Syn. vi. p. 407. Ix. var. A.

HABITAт in Jeptentrionalibus regionibus.

32.

melano. Pr. cinereo-nigricans, capitro gulaque grifeis maculis minutis nigrican-

pus. tibus, roftro toto digitifque dimidiato-nigris.

Procellaria 
Procellaria melanopus, Gmel. Syft. i. p. 562.

Black-toed Petrel, Lath. Syn. vi. p. 408. 1 2.-ArEZ. Zool. Sup. p. 73.

Haвiт at in America Septentrionali.-1 3 pollices longa.

Corpus fupra nigricans fubtus cinerafcens: roftrum nigrum: pedes: pallidi, digitis cum membrana intermedia albido nigroque dimidiatis.

13.

nivea. Pr. alba, rachibus pennarum nigris, roltro pedibufque cæruleis

Procellaria nivea, Gmel. Syjt. i. p. 562 .

Le Petrel blanc, ou Petrel de neige, Buf. ix. p. 314.

Snowy Petrel, Latb. Syn. vi. p. 408. I3.-Forft. Voy. i. p. 96.-Cook's Voy. i. p. 33.

Hав1тат in frigidioribus Maris antarczici; gregaria.-12 poll. long. Roftrum et pedes cæruleo-nigricantes, membranis pallidis.

14.

defolata. Pr. cinereo-cærulefcens fubtus alba, rectricibus apice fafciaque alarum expanfarum nigricantibus.

Procellaria defolata, Gmel. Syft. i. p. $5^{6} z$.

Brown-banded Petrel, Lath. Syn. vi. p. 409. 14.

Habitat in infula Defolationis. - I I pollices longa.

Roftrum nigrum apice flavefcens: corpus fupra cinerafcens, fubtus et gene candidæ: cauda apice faturate fufca: pedes fufci, palmis flavis.

15 .

fuliginofa. Pr. fuliginofo-fufca, capite collo remigibus rectricibufque nigris, cauda: emarginata.

Procellaria fuliginofa, Gmel. Syft. i. p. 562.

Sooty Petrel, Latb. Syn. vi. p. 409. I5.

HaBIтAт in infula Otabeite; præcedentis magnitudine.

Roftrum pedefque nigri : cauda fubforficata, rectricibus apice quadratis.

16. furcata.

Pr, argenteo-griféa, gula pallida, criffo albo, remigibus caudaque forficata nigricantibus, rectrice extima extus alba:

Procellaria furcata, Gmel. Syft. i. p. 56r.

Fork-tail Petrel, Latb. Syn. vi. p. 4 IO. I6.-Arct. Zool. ii. No $\mathrm{N}^{6} 3$.

Haвiтat in glacie inter Afiam et Americam. - ro pollices longa. Roftrum pedefque nigri.
5. $\mathrm{N}$
Pronigra 
17.

Fregata. Pr. nigra fubtus alba, pedibus nigris.

Procellaria Fregata, Lin. Syft. i. p. 212. 2.-Gmel. Sy/t. i. p. 561.

Hirundo americana, Rocbef. It. I 34. t. I 35 .

I 8.

Habitat in Oceano, Pelago; avis paulo minor pelagica.

marina. Pr. dorfo tectricibus alarum fufcis, vertice et cervice carulefcenti-cinereis, uropygio cærulefcente, genis corporeque toto fubtus albis.

Frigate Petrel, Lath. Syn. vi. p. 410.17.

Haвiтat in Mari aufrali ; latitudine $37 .-8 \frac{5}{2}$ pollices longa.

Pileus totus cum cervice ad dorfum ufque cinereo-carulefcens : capitis latera et corpus totum a gula ad anum alba: fub oculo utrinque ftriga cinerafcens : cauda emarginata : pedes nigri, palmarum medio macula flavefcente. Variat uropygio pallido.

19.

pelagica. Pr. nigra, uropygio albo.

Procellaria pelagica, Lin. Syf. i. p. 2 I2. 1.-Faun. Suec. No I43.Amon. Ac. iv. p. 587.-AEt. Stock. 1745. p. 93.-Gmel. Syf. i. pi 56 1.--Scop. Ann. i. No 95.-Brun. $\mathrm{N}^{\circ} 117:-$ Muller, $\mathrm{N}^{\circ} 143 .-$ Anderf. Ifl. ii. p. 54. t. I.-Brif. vi. p. I40. 1. t. I3. f. 1. $-I d$. 8 vo. ii. p. $398 .-$ Borow $/ k$. Nat. iii. p. 35. t. 39 .

Oifeau de tempête, Buf. ix. p. 327. t. 23.-Pl. Enl. 993.

Stormfinch, Will. p. 306.-Id. (Angl.) p. 395.

Stormy Petrel, Br. Zool. ii. $\mathrm{N}^{\circ}$ 259. to $91 .-I d$. fol. 146. to L. 5.Arct. Zoul. ii. $\mathrm{N}^{\circ}$ 464.-Flor. Scot. i. No 1.99--Cat. Car. App. t. 14.-Edw. t. 90.-Borlaf. Cornw. p. 247 . t. 29.-Alb. iii. t. 92. -Damp. Voy. iii. p. 97.-Hafelq. Voy. p. 174.-Lath. Syn, vi. po 411. 18.-Id. Sup. p. 269.

Habitat ubique in Oceano, currens fuper undas maris.-Inftante procella arcte naves appropinquat, unde præfagia nautarum de inftante tempeftate, quam avicula evitare conatur.-In rupibus nidificat.Magnitudo Alauda. - 6, pollices longa.

ReEtrices 3 exteriores bafi albidæ: nares prominentes, cylindro foraminibus membranula feparatis.

ß. Pr. nigra purpureo cærulefcenteque varia, tętricibus alarum uropygioque albo maculatis.

Stormy Petrel, Lath. Syn. vi. p. 41 3. 18. var. A,-Salern. Orn. p. $3^{8} 3^{\circ}$

HaßITAT in Mari italico, littora fugiens.

Pr. fufco- 
20.

A VES PA L.M I P E D S. Procellaria.

urinatrix. Pr. fufco-nigricans fubtus alba, gula plicata nigra, calcare obfoleto. Procellaria urinatrix, Gmel. Syjt. i. p. 560.

Diving Petrel, Lath. Syn. vi. p. 4.13. 19.-Forft. Voy. i. 189. 483. 503.

Habitat in Mari pacifico, nova Zealandia. $-8 \frac{1}{2}$ pollices longa.

Corpus robuftun, magnitudine Alce Alle: roftrum nigrum: pedes cærulefcentes palmis nigris, abfque calcare poftico.

27.

* Naribus difcretis.

Eorfteri. Pr. cærulefcens fubtus alba, remigibus rectricibus apice fafciaque alarum expanfarum fufco-nigris, roftro bafi dilatato.

Procellaria vittata, Gmel. Syft. i. p. 560.

Le Petrel bleu, Buf. ix. p. 316.

Vittated Petrel, Forft. Voy. i. p. I 53.-Id. Obf. p. 199.

Blue Petrel, Cook's Voy. i. p. 29.

Broad-billed Petrel, Lath. Syn. vi. p. 414.-20.

Habitat in Mari antartico; in nove Zealandie rupibus et cuniculis nidificans; gregatim noctu volans. -12 pollices longa.

Roftrum cæruleo-grifeum, bafi valde dilatatum, lateribus pectinatum, apice incurvo: fub oculis macula nigra: rectrices 6 intermedix apice nigricantes: nares patentes abfque tubulo.

Femina mari fimilis, roftro minus dilatato.

22.

cærulea. Pr. cano-cærulefcens, corpore fubtus et rectricibus apice albis, fafcia pectoris alarumque expanfarum obfcuris.

Procellaria cærulea, Gmel. Syft. i. p. 560.

Another blue Peteril, Cook's Voy. i. p. 32.

Blue Petrel, Latb. Syn. vi. p. 41 5. 21.-Forft. Voy. i. p. 91.

Habitat in Oceano aufrali; præcedentis magnitudine, a qua differt roftro modico minime dilatato.-Roftrum et pedes cærulefcentes : rectrix extima toto, fecunda intus, reliqua apice alba.

23.

pacifica. Pr. atra fubtus obfcura, roftro plumbeo, pedibus pallidis.

Procellaria pacifica, Gmel. Syjt. i. p. 560.

Pacific Petrel, Latb. Syn. vi. p. 416.22.

Habitat in Euopoa, aliifque infulis Maris pacifici; catervatim volans et urinans. -22 pollices longa. 
Rofrum apice valde aduncum: nares elevata at diftinctæ, ovatæe, oblique pofitæ: pedes pallidi, ad tarfum maculæ aliquot nigræ.

obfcura. Pr. nigricans fubtus alba, collo lateribus fufco nebulofo, tectricibus alarum inedio albido variegatis.

Procellaria obfcura, Gmel. Syft. i. p. 559.

Dufky Petrel, Lath. Syn. vi. p. 416. 23.-ArEt. Zool. Sup. p. 73.

Habıтат in infula Nativitatis Cbrifti, America boreali?-1 3 pollices longa.-Roftrum nigrum lateribus corneum, naribus diftinctis minime eminentibus : pedes extus nigri intus pallidi, palmis fulvis.

\section{GENUS XCVI. MER GUS.}

Rofrum denticulatum, fubulato-cylindricum, bafi depreffiufculum, apice adunco.

Nares in medio roftri, parva, ovatx.

Pedes tetradactyli, palmati, digitus externus reliquis longior.

I. Merganfer. M. fubcriftatus albus, capite collo fupremo dorfo remigibufque nigro.
nitentibus, cauda cinerea.

Mergus Merganfer, Lin. Syjt. i. p. 208. 2.-Faun. Suec. No 135Gmel. Syft. i. p. 544. - Pall. Befic. der Berl. Naturf. ii. p. 55 1.Otto. 1b. iii. p. $457 .-$ Nov. Act. Stock. 1785 . iv. $\mathrm{N}^{\circ} 5$ p. $237 .-$ Brun. $\mathrm{N}^{\circ}$ 92.-Niuller, $\mathrm{N}^{\circ}{ }_{13}$ 33.-Krom. El. p. 343. 1.-Georgi reife, p. 169.-Gmel. reife, ii. p. 188. t. 20.-Borowerk. Nat. iii. p. 21. t. 33.-Frijch. t. 49.-Faun. Groenl. No 49.-Brij. vi. p. 23 I. t. 32. (Mas.)-Id. 8vo. ii. p. 423.-Raii Syn. p. I34. A. 1.IVill.p. 253. t. 64--Faun. Helvet.-Scbaf. El. t. 47.

Serrator, Klein. Av. p. 140. 1.-Becbman Bejcb. der Berl. Naturf. Gef. i. 170 .

Mergus IEthiops, Scop. Ann. i. N" 90 .

Le Harle, Buf. viii. p. 267. t. 23.-Pl. Enl. 95 r.

Tauchergans, Block. Befch. der Berl. Naturf. Gef. iv. p. 594. t. 18. f. 3. Goofander, or Merganfer, Br. Zool. ii. No 260. t. 92. f. I.-Id. fol. 147.-Arit. Zool. ii. No $465 .-$ Id. Sup. p. 73.-Flor. Scot. i. p. 42 . No 200.-Will. (Angl.) p. 335. t. 64.-Latb. Syn. vi. P. 418.1. 
Habitat in borealibus Europe, Afic, Americe; in Anglia hyberno tempore invenitur; in infulis Orcadibus nidificans. -28 pollices longus. Roftrum pedefque rubri. Variat corpore fubtus flavefcente-carneo: ampullam feu labyrintbum in tracbea habet magnum, offeum, atque infuper arteria afpera ipfa in duplicem ventrem turgefcit.

2.

Caftor, M. criftatus cinereus, capite colloque fupremo fpadiceis, gula remigibus intermediis abdomineque albis.

Mergus Caftor, Lin. Syft. i. p. 209. 4.-Gmel. Syft. i. p. 545. B.-Faun. Helvet.

- Merganfer, fem. Faun. Suec. p. 48,-Brif. vi. p. 23I. I.

- gulo, Scop. Ann. i. No 88.

- ferratus, Brun. $\mathrm{N}^{\circ} 96$.

- cinereo-albus capite caîtaneo, Kram. El. p. 343. 2.

- cirratus longirofter, Raii Syn. p. 1 34. A. 2.-Will. p. 253.t. 64. (caput.)

Merganfer cinereus, Brif. vi. p. 254. 7.t. 25.-Id. 8 vo. ii. p. 428 . Anas rubricapilla, Brun. $\mathrm{N}^{\circ} 93$.

L.e Harle femelle, $P l$. Enl. 953.-Buf. viii. p. 236.

Dun-diver, Sparling Fowl, Br. Zool. ii. N ${ }^{\circ} 60$. t. 92. f. 2.-ArEt. Zool. ii. $\mathrm{N}^{\circ} 465 .-A l b$. i. t. 87.-Will. (Angl.) p. 333. t. 64.-Latb. Syn. vi. p. $420.42 x$. A.--Id. Sup. p. 270.

Hæc avis boreales partes, uti præcedens, frequentat; in Anglia hyeme non rarus. $-23^{-27}$ pollices longus.-Abdomen nonnullis incarnatum.

In quibufdam tracbeam ampullaceam detexi, quod maribus proprium; et in aliis teftes confpicuos vidit Dom. Heyßam; unde avem diftinctam effe a Merganfere fufpicor.

3.

imperialis. M. ex nigro fufco et grifeo varius, capite lævi, remigibus primoribus nigris, fpeculo nullo, roftro pedibufque ex rufefcente albis. Mergus imperialis, Gmel. Syft. i. p. 547.-Cet. uc. Sard.p. 326.

Habrtat in Sardinia; Anferis magnitudine et forma.-Lingua ciliata.

4.

Serrator. M. crifta dependente, pectore rufefcente variegato, collari albo, rectricibus fufcis cinereo variegatis.

Mergus Serrator, Lin. Syft. i. p. 208. 3.-Faun. Suec. No $136 .-$ It. Gott. 166. 27 1.-It. Oel. 27 1.-Bororefk. Nat. iii. p. 22. 2.-Muller, $\mathrm{N}^{\circ}$ 1 34.-Georgi reife, p. 169.-Faun. Groenl. $\mathrm{N}^{\circ} 48 .-$ Faun. Helvet. 
Serrator cirrhatus, Klein. Av. p. 140.2.-Id. Stem. p. 33. t. 37. f. 1. a-c. Mergus criftatus, Brun. No 94. 95.-Brif.vi.p. 237.2. t. 23.-Id. 8vo. ii. p. 424 .

- albellus; Scop. Ann. i. N०89.

- cirrhatus fufcus, Raii Syn. p. 135. A. 4.-Will. p. 255 . t. 64 . (minor.)

Le Harle huppé, Buf. viii. p. 273.-Pl. Enl. 207.

Red-breatted Merganfer, Br. Zool. ii. No26r. t. 93.-Id. fol. 147.ArCt. Zool. ii. $\mathrm{N}^{\circ}$ 466.-Edw. t. 95.-Alb. ii. t. 101.-Lath. Syn。 vi. p. $4.23 \cdot 3$.

Habitat in Europa, Afia, Anerica; in Anglie borealibus non rarus. -2 I pollices longus.

Rofirum fubtus pedefque rubra: lateribus pectoris pennæ majufculæ, candidæe, nigro marginatæ, alarum complicatarum partem anteriorem obtegentes. Mas occipite criftato elongato, capite et collo fupremo viridi-atris. Femina vix criftata, capite collique initio rufis. Ovum anatino æquale album.

Avis mafcula tracbea ampullacea gaudet.

ß. M. fupra niger fubtus albus, remigibus majoribus nigris, rectricibus furcis.

Merganfer leucomelanus, Brif. vi. p. $250.4 .-I d$. 8 vo. ii. p. 427. Harle à manteau noir, Buf. viii. p. 277.-Lath. Syn. vi. p. 425. A. .

Varietas maris præcedentis.

$\gamma$. M. fupra niger fubtus albus, collo fpadiceo, tænia tranfverfa in alis candida, remigibus majoribus rectricibufque nigris.

Merganfer niger, Brif. vi. p. 25 1. 5.-Id. 8 vo..ii. p. 427.-Lath. Syn。. vi. p. 426 . B.

Varietas femine.

5.

cucullatus. M. crifta globofa utrinque alba, corpore fupra fufco fubtus albo.

Mergus cucullatus, Lin. Syft. i. p. 207: 1.-Gmel. Syft. i. p. 544 .

Merganfer virginianus criftatus, Brif. vi. p. 258. 8.-Id. 8 vo. ii. p. 429.

Ecatototl, Ecatototl altera, Raii Syn. p. 175.-Will. p. 301 .

Serrator cucullatus, Klein. Av. p. 140. 3.

Le Harle couronné, Buf: viii. p. 280.-Pl. Enl. $935 \cdot 936$.

Wind-Bird, Will. (Angl.) p. $3^{8} \mathrm{~g}$.

Round. 


\section{A VES PALMIPEDES. Mergus.}

Round-crefted Duck. Cat. Car. i. t. 94.-Edwo. t. 360.

Hooded Merganfer, Lath. Syn. vi. p. 426. 4. t. CI.-ArEt. Zool. ii. No 4.67 .

Habitat in America, a Carolina ad finum Hizdjonis.- 17 poll. long.

Roffrum et pedes nigri : irides aurea: corpus fupra nigricans fubtus albicans : criffa capite major, lateribus alba, margine nigro.

Femina in toto corpore fufca, crifta orbiculari minore concolore.

6. Ovun albunı.

Albellus. M. crifta dependente, occipite nigto, corpore albo, dorfo temporibur. que nigris, alis variegatis. (Mos.)

Mergus albellus, Lin. Syft. i. p. 209. 5.-Faun. Suec. $N^{\circ}$ 137.-Brif. vi. p. $245 \cdot 3$. t. 24. f. r. -Id. 8vo. ii. p. $425 .-K l e i n . A v$. p. 135 . 30.-Brun. No 97.-Frijcb. t. 172.- Kram. El. P. 344. 3.Fobnfon. Av. t. 47.-Faun. Helvet.-Decouv. Ruf. ii. p. 145.Befch. der Berl. Naturf. Fr. iv. p. 496. t. 18. f. 7.-Act. Stock. nov. 1780. iii. $N^{\circ}$ 8. p. 224.

Mergus major cirrhatus, Raii Syn. p. 135. A. 3.-Will. p. 254. t. 64. Rheni, Raii Syn. p. 135. 5.-Will. p. 255.

albulus, Scop. Ann. i. No 91 .

Smew, or white Nun, Br. Zool. ii. $\mathrm{N}^{\circ} 262$. $-I$ Id. fol, 148. t. N. 1. Latb. Syn. vi. p. 428. 5. -Id. Sup. p. 27 I.

M. capite lævi grifeo, fafcia oculari nigra, macula fuboculari alba. (Femina,)

Mergus minutus, Lin. Syf. i. p. 209.6.

Merganfer ftellatus, Brif. vi. p. 252. 6. -Id. 8vo. iio p. 4.28.-Bruiv $\mathrm{N}^{\circ}$.98.-Klєin. Av. p. 135.29.

Le Harle étoilé, Buf. viii. p. 278 .

Weefel Coot, $A l b$. i. t. 88.

Red-headed Smew, Br. Zool. ii. N॰ 263.-Id. fol. 148. t. N. 2.

Habitat in Europa, America; in Anglia hyeme non raro invenitur. I6-17 pollices longus.

Rofirum pedefque nigri : speculum alarum album. In mare nigra funt nucba, macula ovata a roftro oculos ambiens, dorfum, linee 2 arcuatæ utrinque prope alarum initia. - Tracbea in labyrinthum dilatata.

Femina, abfque criffa aut labyrintbo, fupra fufco-nigricans, fubtus al. ba; capite fuperiore fpadiceo; gula candida; macula ovata inter rofiruis et oculos, ut in mare. 
minutus. M. cinereo-fufcus, fubtus gulaque candida, capite et collo fuperiore ferrugineo, macula alarum ante et pone alba. Mergus minutus, Faun. Suec. $\mathrm{N}^{\circ}$ 138.-Kram.El. p. 344. 4. - Tinus, Haffelq. 1t. p. 269. 37.-Id. (Angl.) p. 201. - glacialis, Brun. No 99.-Raii Syn. p. 135.A. 3.-Will. p. 254. Mergus pannonicus, Scop. Ann. i. No 92 .

Merganfer criftatus minor, (fem.) Brif. vi. p. 243. 3. t. 24. f. 2.-Id. 8vo. ii. p. 426.

La Piette femelle, $\mathrm{Pl}$. Enl. 450.

Lough-Diver, Will. (Angl.) p. 338.-Br. Zool. ii. p. 560.-Id. fol. 144. t. Addend.-Arez. Zool. ii. p. 540. A.-Id. Sup. p. 741. Minute Merganfer, Latb. Syn. vi. p. 429.6.

HaBITat cum præcedente, cujus feminæ valde fimilis, at macula ovata nigra oculari caret. An a juniore Albello fatis diftinctus ?

ß. M. capite lævi, dorfo nigro, abdomine albo, roftro pedibufque fanguineis, remigibus primoribus nigris, cauda cinerea.

Mergus afiaticus, Gmel. Syft. i. p. 5.48. 6. $\beta .-S$. G. Gmel. It. ii. p. 188. t. 20 .

Habitat in Afracania. $-14 \frac{x}{2}$ pollices longus.

8.

furcifer. M. niger capite lavi, collo ano abdomine et rectricibus. lateralibus albis, fronte genifque dilute fufcis, cauda furcata.

Mergus furcifer, Gmel. Syft. i. p. 548.-Bef, Scbr. der Berl. Naturf. vii. p. $45^{8}$.

Habitat in Curonia.-Rofrum nigrum, medio.lateritium : ab auribus utrinque per latera colli ad pectus tænia nigra.

9. M. criftatus fufcus fubtus albus, gula pectoreque nigro maculatis, alis nigris fafcia alba.

Brown Merganfer, ArEt. Zool. ii. Sup. p. 74.

Habitat ad fretum Hudjonis. $-\mathrm{I} 7 \frac{\mathrm{T}}{2}$ pollices longus.

Occiput criftatum : pone oculos fafcia albida ad nucham extendens : srifta inferiori parte nigra: pectus carulefcens, albido-nebulofum: pedes flavefcentes.

M. criftatus 
10.

AVES. PAI, I PEDES. Anas.

cæruleus. M. criftatus cæruleus, vertice caudaque nigris, gula abdomine maculaque alarum albis.

Blue Merganfer, ArEt. Zool. ii. Sup. p. 74 .

HaBITAT ad finum Hudfonis. - 14 pollices longus.

Roftrum elongacum nigrum: pedes cærulei. Confer Lath. Syn. vi. p. 504. 50. A.

\section{GENUS XCVII. A N A S.}

Roftrum lamellofo-dentatum, convexum, obtufurm.

Nares ovatæ.

Lingua ciliata, obtufa.

Pedes palmati, digitis tribus anticis membrana coaduna= tis, poftico foluto.

1.

Cygnus. A. roftro femicylindrico atro, cera flava, corpore albo.

Anas Cygnus, Gmel. Syft. i. p. 501.

Anas Cygnus (ferus), Lin. Syft. i. p. 194.-Faun. Suec. No 107.-Scop. Ann. i. $\mathrm{N}^{\circ}$ 66.-Brun. $\mathrm{N}^{\circ} 44 .-$ Muller, $\mathrm{N}^{\circ} 106 .-\mathrm{Kram}$. El. p. 338. 2.-Georgi reije, p. 165.-Borowe/k. Nat. iii. p. I4. 10.Faun. Helvet.

Cygnus ferus, Brif. vi. p. 292. 12. t. 28.-Id. 8vo. ii. p. 439.-Raii Syn. p. 136. A. 2.-Will. p. 272. t. 69.-Klein. Av. p. I 28. 1.Id. Stem. p. 3r. f. 33 .

Cygne fauvage, Buf. ix. p. 3.-Pl. Enl. 9r 3.-Hift. Prov. i. p. 340. Wild Swan, Br. Zool. ii. $\mathrm{N}^{\circ}$ 264.-Id. fol. 149. t. in Addend. -Will. (Angl.) p. 356. t. 69. (caput.)-Edw. t. 150.-Pbil. Tranf. Ivi. t. X. p. 2 I 5. f. I. 2.

Whiftling Swan, Arct. Zool. ii. No 469.-Id. Sup. p. 75.-Flor. Scot. i. $\mathrm{N}^{\circ}$ 204.-Lath. Syn. vi. p. 433.-Id. Sup. p. 272.

Habitat in Europa, Afia, America.-Longitudo fere 5 pedum.Afperitate hyemis compulfus interdum in Anglia videtur.-Ajpera arteria mirabili prorfus modo fternum ingreditur, inibique reflectitur, et poft, digreffum ad divaricationem in anguftum fpatium coarctatur, non annulis fed lata et offea cartilagine, deinde in duos ramos divifa, ad pulmones tendit. 
2.

834 AVES PALMIPEDES. Anas,

Olor. A. roftro rubro, bafi tuberculo carnofo nigro, corpore albo. Anas olor, Gmel. Syft. i. p. 501 .

Anas Cygnus (manfuetus), Lin. Syft. i. p. 194.-Foun. Suec. $\mathrm{N}^{\circ}$ 107. $\beta$. -Brun. $\mathrm{N}^{\circ} 44,-$ Kram. El. p. 338. 2. 3.-Frich. t. 152.-Brif. vi. p. 288 . I I. $-I d$. 8 vo. ii. p. $438 .-$ Raii syn. p. 136. A. 1.Will. p. 27 1. t. 69.-Klein. Ao. p. 128. 1.

Le Cygne, Buf. ix. p. 3. t. 1.-Pl. Enl. 91 3.-Cett. uc. Sard. p. 3 I6.

Tame Swan, Alb. iii. t. 96.-Edw. t. 150. (caput.) - Er. Zool. ii. No 265. t. 6c. -Id. fol. 149.t. in Addend.-Will. (Angl.) p. 355. to 69.-Flor. Scot. i. $\mathrm{N}^{\circ}$ 205.-Cbefeld. Ofteog. cap. 5. ad finem. (fcelet.)

Mute Swan, ArEz. Zool. ii. N $\mathrm{N}^{\circ}$ 470.-Lath. Syn. vi. p. 436. 2.

Habitat in Europa, Afia ; ubique hofpitatur in pifcinis magnatum. -A Cygno externe differt roftro; interne quod larynx fternum non ingreditur. Ovum albidum.

nigricollis. A. roftro rubro, corpore albo, capite colloque nigris.

Anas nigricollis, Gmel. Syst. i. p. 502.

- melanocephala, Gmel. Syft. i. p. 502.

melancorypha, Molin. Chil. p. 207.-Id. (ed. Gall.) p. 213.

Black necked Swan, Boug. Voy. p. 59.-Pernet. Voy. ii. p. 26. ch. 9.Lath. Syn. vi. p. 438.3 .

Habitat in infulis Falklandicis, ad fretum Magellanicum, et in Chili. - Cygno aqualis.

4.
atrata.

5.

brachy- A. roftro fulvo, corpore cinereo, alis abbreviaris, crifo fafciaque alarum ptera. albis.

Anas cinerea, Gmel. Syft. i. p. 506.

Oifeau gris, ou Oie de plein, Pernet. Voy. if. ch. I g. p. 21.

Racehorfe Duck, Pernet. Fourn. p. 21 3. 214 .-Buf. ix. p. 4I4. III.

Loggerhead Duck, Pbil. Tranf. Ixvi. p. 104.-Penrofe Falk. Ifl. p. 35. -Forft. Voy. ii. p. 492.-Lath. Syn. vi. p. 439. 4.

Habitat in infulis Falklandicis.-Magnitudo inter Cygnum et Anferem.

Rofrum 
Roftrum fulvum apice nigro: remiges et restrices nigre: alce valde 6. Bybrida. A. roftro femicylindrico, cera rubra, cauda acutiufcula, Molin. Chil. p. 213.-Id. (ed. Gall.) p. $221 .-$ Gmel. Syft. i. p. 502.

Habitat in mari circa Cbilö̈; Anferi æqualis; per paria incedens. Ova 8 parit in arena.

Mas totus albus, roftro pedibufque flavis. Femina nigra ftrigis aliquot: albis, pennis albo marginatis : roftrum pedefque rubri.

7.

Cofcoro- A. roftro extremo dilatato rotundato, corpore albo.

ba. Anas Cofcoroba, Mol. Cbil. p. 207.-ld. (ed. Gall.) p. 213 -Cmel. Syjt. i. p. $5 \circ 3$.

Habitat in Cbili; fpecies magna; facillime manfuefcens.

8.

Roftrum pedefque rubri: oculi nigri.

antaretica. A. corpore toto albo, roftro nigro, pedibus flavis. (Mas.) Anas antarctica, Gmel. Syft.i. p. 505.

Antardic Goofe, Latb. Syn. vi. p. 442. 7.-Forft. Voy. i. p. 495.518. -Pernet. Voy. ii. p. a 3.-Cook's Voy. ii. p. 186.

A. (magellanica) corpore variegato, abdomine crifo uropygio femoribus albis, fpeculo alartm viridi, Muf. Carlf. fafc. ii. t. 37. (fem.)

Habrtat in infulis Falklandicis. $-24-26$ pollices longa.

Mas totus eft niveus. Femina roftrum cinereo-fiavicans: corpus fupra fufcum: capillitium cinereum : collum fufco-grifeum: peztus et $a b$ domen nigra fafciis albis: ale albx, medio fpeculum viride, remigibus primoribus fuccis: criffum, femora, cauda alba.

Utrique fexui ad flexuram alarum calear obtufum.

9 .

Lucoptera. A. corpere albo, fupra nigro tranfverfim lineato, fpeculo alarum viridi, roftro pedibufque nigris.

Anas leucoptera, Gmel. Syjt. i. p. 505.

L.'Oie des Malouines, Buf. ix. p. 69 .

Outarde, Hifl. de la Louif. ii. p. Ir 3 ?

White-winged antaretic Goofe, Brown. Ill. t. 40.

Sea Goofe, Pbil. Tranj. lxvi. p. 104.

Buftard Goofe, Latb. Syn. vi. p. 440. 5.-Boug. Voy. P. 59. 


\section{AVES PALM I PEDES. Anas.}

Habitat cum pracedente. $-32-40$ pollices longa.

Caput, collum, teEtrices alarum minores, et corpus fubtus alba : collum pofticum inum, dorfum anterius, et latera fupra femora lineis numerofis nigricantibus : remiges nigræ, fafcia alba : Jpeculum faturate viride : recirices duæ intermediæ nigræ, laterales albæ: ad flexuram ale calcar obtufum.

I0.

variegata. A. corpore variegato, capite collo tectricibufque alarum albis, fpeculo alarum viridi, roftro pedibufque nigris.

Anas variegata, Gmel. Syf. i. p. 505 .

Variegated Goofe, Lath. Syn. vi. p. 44I. 6.

Haeitat in nova Zealandia; Anatis majoris magnitudine.

Coput., collum ufque ad medium, teltricefque alarum alba: collum a medio et corpus fubtus fufco-rubrum, albo nebulofum: dorfum nigricans, albo-nebulofum : uropygium criffumque ferruginea: remiges fecundariæ virides, unde $\int p e c u l u m$; remiges primores et rectrices nigræ: ad flexuram ala calcar obtufum.

II.

magella- A. ferrugineo-fufca, corpore anteriore fubtufque tranfverfim variegato, nica. tectricibus fafciaque alarum albis. Anas magellanica, Gmel. Syft. i. p. 505 . 1.'Oie des terres Magellaniques, Buf. ix. p. 68.-Pl. Enl. 1006. Magellanic Goofe, Latb. Syn. vi. p. 443.

Haвitat in terra Magellanica.-24 pollices longa.

Caput, collum, et dorjum pofticum ferrugineo-fufca : pectus, dorfum anticum, et corpus fubtus ferrugineo fufcoque tranfverfim lineata: ale coudaque nigra: tedirices alarum et fafcia remigum alba: roftrum nigrum: pedes flavi.

12.

picta. A. cinereo-nigricans nigro tranfverfim lineata, capite collo abdomine medio teetricibus fafciaque alarum albis.

Anas picta, Gmel. Syft. i. p. 504.

Painted Goofe, Lath. Syn. vi. p. 443. 9.-Cook's Voy. i. p. 96.

Habitat in Statenlandia. -28 pollices longa.

Roftrum, pedes, remiges primores, reetricefque nigra : ad flexuram ale calcar obtufum. An magellanice fexus alter?

13.

cærulef- A. grifea fubtus alba, tectricibus alarum dorfoque poftico cærulefcens. centibus. 
Anas carulefcens, Lin. Syft. i. p. 198. 12.-Gmel. Syft. i. p. 513. Anfer fylveftris freti Hudfonis, Brif. vi. p. 275. 5. -Id. 8 vo. ii. p. 434 . L'Oie des Efquimaux, Buf. ix. p. 80. Blue-winged Goofe, Arct. Zool. ii. $\mathrm{N}^{\circ}$ 474.-Id. Sup. p. 75.-Edwo. t. I 52.-Pbil. Tranf. lxii. p. 414. 2.-Lath. Syn. vi, p. 469.28.

Habitat in Canada.-Magnitudo circiter Anferis.

Roftrum et pedes rubri : caput et collum alba : vertex flavicans : cervix nigro maculata : collum imum, pectus, latera fub alis, et dorfum faturate fufca: tętrices alarum caudeque cinereo-cærulefcentes : fcapulares et cauda albo nigroque ftriata: abdomen, femora, criffum alba.

B. A. alba, collo poftice imo interfcapulio fcapularibufque plumbeis, tectricibus alarum caudæque cærulefcentibus.

$\boldsymbol{\gamma}$. A. grifea fufco varia, capite colloque fupremo albis portice nigro variis, tectricibus alarum caudæque cærulefcentibus.

I 4 .

hyperbo- A. corpore niveo, fronte flavefcente, remigibus decem primoribus nirea. gris, roftro pedibufque rubris.

Anas hyperborea, Gmel. Syft. i. p. 504 . Anfer niveus, Brif. vi. p. 288 . 10.-Id. 8 vo. ii. p. $43^{8},-$ Klein. Av. p. I30. II.

hyperboreus, Pall. Sfic. vi. p. 26.-Borowfk. Nat. iii. p. 14. 9. White Brant, Lawf. Car. p. 147.

Snow Goofe, Arct. Zool. ii. No 479.-Pbil. Tranf. lxii. p. 41 3. 443.Faun. Amer. Sept. p. 16.-Latb. Syn. vi. p. 445. 10.

Habitat in Europa, America boreali, ad finum Hudfonis; gregatim migrans gregibus numerofifimis. -32 pollices longa.

Roftrum luteum: irides pedefque rubri : corpus magnitudine Anferis. domeftici.

I5.

grandis. A. corpore nigricante fubtus albo, roftro nigro, pedibus coccineis. Anas grandis, Gmel. Syft. i. p. 504. Great Goofe, Latb: Syn. vi. p. 446. i r.-Arct. Zool. ii. p. 570. A.

Habitat in Sibiria; Cygni magnitudine; 30 libras roflicas pondere

16. fere æquans.

cygnoides. A. roftro femicylindrico, cera gibbofa, palpebris tumidis.

Anas cygnoides (auftralis), Lin. Syf. i. p. 194. 2. a.-Faun. Suec. $\mathrm{N}^{\circ}$ 
108.-Gmel. Syft. i. p. 502.-Frifcl. t. I53. I 54.-Pall. reife, iii. p. 700 .

Anfer guineenfis, Brif. vi. p. $230.7 .-1 d$. 8 vo. ii. p. 435.-Klein. Av.

p. 129. 4.-Raii Syn. p. 138. 8.-Will. p. 275.

L'Oie de Guinée, Buf. ix. p. 72. t. 3.-Pl. Enl. 347.

Spanifh Goofe, Swan Goofe, Alb. i. t. 91 .

Chinefe Goofe, Arä. Zool. ii. p. 57 I. B.-Brown. Fann. p. 480.-Ell. Narr. ii. p. 143 ?--Lath. Syn. vi. p. 447. 12.

Hавітат in Europa, Afia, Africa; frequens circa lacus majores et flumina Sibirice orientalis. - Corpus magnitudine inter Cygnum et Anferem. -3 pedes et ultra longa.

Roftrum nigrum verfus frontem rugofum, adfcendens, gibbofum: ftruma gule nigricans: vertex fafciaque fupra per collum album longitudinalis teftaceo-fufca: dorfum et bypocbondria cinereo-fufca marginibus plumarum grifeo-albidis: fubtus corpus albidum: linea circa bafin roftri ferrugineo-alba : crifum tectricefque caude alba: pedes fulvi.

ß. Anfer cygnoides (fpontaneus), Pall. reife, iii. p. 700.

Habitat cum priore; frequens.

Rofrum nigrum, verfus frontem rugofum, afcendens, et biangulatum, non in tuber gibbum elevatum: ftruma gula nulla : pedes coccineo-rubri : color pennarum vix aliter quam in priore.

$\gamma$. A. roftro luteo cera magna nigra, uccipite atro, facco gulari. A. cygnoides (orientalis), Lin. Syft. i. p. 194. 2. ß.-Pbil. Tranf. Ivii。 p. 347 . 17:-Dec.RufJ. i. p. 466. Anfer mufcoviticus, Brif. vi. p. 277. 6.-Id. 8 vo. ii. p. 435 .

- ruflicus, Klein. Av. p. 129.5 .

Crop Goofe, Kolb. Cap. ii. p. 139 . Mufcovy Gander, Alb. ii. t. 91. 92.-Latb. Syn. vi. p. 447. 12. A.

A primo variat corpore minore.- Roftrum fulvum, cera magna nigra: corpus grifeo-luridum albo mixtum: pedes luteo-rubicundi.-Paflim ut A. domefica circa Volgam alitur.

17.

canadenfis. A. cinerea, capite colloque nigris, genis gulaque albis.

Anas canadenfis, Lin. Syfl. i. p. I98. 14.-Pbil. Tranf. Ixii. p. 414.46. Faun. Amer. Sept. p. 16.-Gmel. Syft. i. p. 5 14.-Brif. vi. p. 272. 4. t. 26.-Id. 8 vo. ii. p. 433.-Raii Syn. p. 39. 10.-Id. 191. 9. 
A VES PALMI PEDES. Anas. 839

Will. p. 276 . t. 70.7 1. f. 3.-Klein: Av. p. I 29. 6.-Borowfk. Nat. iii. p. 10. c.

L'Oie à cravate, Buf. ix. p. 82.-Pl. Enl. 346.

Canada Goofe, ArEt. Zool. ii. No 47 s.-Will. (Angl.) p. 36 r. t. 79.Cat. Car. i. t. $92 .-$ Sloan. Fan. ii. p. 323.6.-Edw. t. 151.Lath. Syn. vi. p. 450 . 14.

Haвıтат in America Septentrionali. $-3 \frac{1}{2}$ ped. longa.

18.

Roftrum nigricans : pedes plumbei : uropygium rectricefque nigra.

melano- A. roftro bafi gibbo compreffo, corpore albo, capite colloque nigro notos. maculatis, dorfo alis caudaque nigris.

Anfer melanonotos, Zool. Ind. p. 2 1. t. 1 1.-Gmel. Syft. i. p. 503.

L'Oie bronzée de Coromandel, Buf. ix. p. 77.-Pl. Enl. 9.37.

Black backed Goofe, Ind. Zool. p. I 2. t. I I. - Latb. Syn. vi. p. 449. I3. -Id. Sup. p. 272.

Haвiтat in Zeylona, Coromandela.-3.3 pollices longa.

Roftruw pallidum, bafi gibbum, compreffum, dorfo carinato fere ut in fpectabili : dorfum nigrum viridi purpureoque nitens: ad flexura $\mathrm{n}$ alarum calcar validum, acutum: pedes nigricantes.

Femina bafi roftri minus gibba quam in mare, at calcari alari æque gaudet.

I9.

gambenfis. A. roftro bafi gibbo, corpore nigro fubtus albo, dorfo purpurafcente, roftro pedibufque rubris.

Anas gambenfis, Lin. Syft. i. p. 195.3.-Gmel. Syft. i. p. 503.-Brif.

vi. p. 283 . 8.-1d. 8vo. ii. p. 436.-Raii Syn. p. 138 . 9.-Will. p.

275. t. 7 I.

Anfer chilenfis, Klein. Av. p. 129. 7 .

L'Oie armée, Buf. ix. p. 76.

Gambo Goofe, Will. (Angl.) p. 360. t. 7 I ?

Spur-winged Goofe, Lath. Syn. vi. p. 452. t. 102.

Habitat in Africa, Gambia; Anferis magnitudine.

Roftrum et facies ante oculos gibbofa, carunculata, rubra: color plumarum niger, dorfo purpureo-nitente; genis, gula, abdomine albis: ad flexuram alarum calcar notabile flavefcens.

20.

indica. A. grifea fubtus pallide cinerea, capite colloque albis, lunula occipitis maculaque fubtus nigris, uropygio criffoque albis.

Barred-headed Goofe, Latb. Syn. Sup. p. 177.

HaBitat 
\$40 AVES PALMIPEDES. Anas.

HABrTAT in India; hyeme gregaria; e Tbibeto forte veniens : coro fapida.

Rofrum fulvo-flavum, ungue nigro: caput, gula, et collum pofterius alba: lunula occipitis nigra furfum ad oculos utrinque incurvata, infra hanc altera, maculæque aliquot denique cervicis coloris ejufdem : dorfun grifeum marginibus pennarum pallidioribus: collum imum fubtus, pectus, abdomen late cinerafcentia: abdomen pofterius fufcum albo marginatum: cauda grifea apice albo: pedes fulvi.

$2 \mathrm{I}$.

xgyptiaca. A. roftro fubcylindrico, corpore undulato, vertice albo, fpeculo alari candido fafcia nigra.

Anas ægyptiaca, Lin. Syf. i. p. 197. 10.-Gmel. Syft. i. p. 512.-Brif. vi. p. 284 . 9. t. $27 .-I d$. 8 vo. ii. p. 437.

L'Oie d'Egypte, Buf. ix. p. 79.-Pl. Enl. 379.

Gambo Goofe, Will. t. 7 I. f. I ?

The Ganfer, Alb. ii. t. 93 .

Egyptian Goole, Lath. Syn. vi. p. 453. 16.

Haв1тат in Africa. -27 pollices longa.

Corpus undulıtum e fufco ferrugineoque : tempora caftanea : macula ferni caftanea : speculum alarum magnum : roftrum rubefcens : pedes rubri : ad flexuram alarum calcar obtufum.

Femina pallidior, macula pectorali obfcura.

ß. L'Oie fauvage du Cap de Bonne Efperance, Son. Voy. Ind. ii. p. 220. Pl. Enl. 982. 983.-Latb. Syn. vi. p. 454. 16. A.

HaBitat ad Caput B. Spei.-Rofrum grifeum: macula pectoris nigra ; dorJo, alis, uropygioque caftaneis.

22.

cana.

A. ferrugineo-rufa, capite colloque grifeis, fpeculo alarum viridi, humeris albis.

Anas cana, Gwel. Syft. i. p. 510.

L'Oie fauvage à tête grife de Coromandel, Son. Voy. Ind. ii. p. 220 ?

Grey-headed Goofe, Brown. Ill. t. 41. 42.-Lath. Syn. vi. p. 458. 19. -Id. Sup. p. 273 .

Habitat ad Caput Bone Spei, Coromandela? Bernicla minor.

Caput et collum pallide grifea: gene albæ: dorfum, peztus, abdomen ferruginea lineis tranfverfis faturatioribus . tectrices alarum albre: remiges fecundariæ virides, primores nigræ: ad flexuram alæ calcar obtufum: criffum fulvum fafcia nigra: roftrum, pedes, caudaque nigra.

Femine 
AVES PALMIPEDES. Anas. $84 \mathrm{r}$

Femina pallidior; gene cum capite grifex. Variat corpore fupra abf23 . que ftriis.

ruficollis. A. fupra nigra, collo rufo, corpore fubtus macula ante oculos ftrigaque longitudinali colli utrinque albis.

Anfer ruficollis, Pall. Spic. vi. p. 21. t. 4.-Id. reije, iii. p. 70r. 33.Gmel. Syft. i. p. 51 1.-Dec. RufJ. ii. p. 19.

Red-breafted Goofe, ArEZ. Zool. ii. p. 57 r. C.-Latb. Syn. vi. p. 455.

Habiтat in Rufia; in boreali ora Sibirie paffim vulgaris; in Anglia rariffime inventa.-Magnitudo et facies canadenfis.

Rof trum parvulum nigrum: macula utrinque inter roftrum et oculun ovalis alba : fafcia pectoris alba fubtus nigra : gula nigra : ftriga collaris alba medio rufa: pedes nigri.

24.

Cafarca. A. rufa, remigibus rectricibufque nigris, fpeculo alari albo. Anas Cafarca, Lin. Syft. iii. App. p. 224.-Gmel. Syft. i. p. 511 .

— rutila, N. C. Petr. xiv. p. 579. 4. t. 22. f. 1.-Georgi reife, p. 167. -Gmel. reife, ii, p. 182. t. 1 5.-Lepech. It. i. p. 180.-Dec. Ruff. i. 417.464 .

Collared Duck, Gent. Mag. xlii. t. p. 161.

Ruddy Goofe, Latb. Syn. vi. p. 456. 18.-Id. Sup. p. 273.

Habitat in Aftracanenf regno; clamitat fono gratiffimo; per paria incedens.-Corpus Bofchadem fuperat, totum late rufum: caput dilutius fulvum: uropygium fufcum undulatum lineis fulvis: nigra funt oculi, roftrum, pedes, remiges, catida: alba funt tedtrices remigum, et alarum facies interior. Femina collari nigro caret.

25.

montana. A. capite collo alarumque pennis rubro-viridibus,

Anas montana, Gmel. Syft. i. p. 5 ro.

Hill or Mountain Goofe, Kolb. Cap. ii. p. 139-Latb. Syn. vi. p. 458 . 20.

Habitat in Cap. B. Spei montofis; anfere domefico major.

26.

Anfer. A. roftro femicylindrico, corpore fupra cinereo fubtus pallidiore, collo ftriato.

Anas Anfer (ferus), Lin. Syft. i. p. 197. 9.-Faun. Suec. No $114 .-$ Gmel. Syjt. i. p. 5 10.-Brun. $\mathrm{N}^{\circ}$ 53.-Muller, $\mathrm{N}^{\circ} 112 .-$ Kram. El. p. 338. 4. a.-Frijcb. t. I55.-Georgi reije, p. 166,-Faun. 5 Arag. 
Arag. p. 74.-Klein. Av. p. 274. t. 69.-Id. Stem. p. 31. t. 34. f. I. a-c.-Id. Ov. p. 34. t. 19. t. 2.-N. C. Petr. iv. p. $418 .-$ Scbaf. El. t. 20.-Raii Syn. p. 136. A. 4.-138. A. 3.-Will. p. 274. 2. t. 69.-Borow/k. Nat. iii. p. 9. 2. a.-Faun. Helvet. Anfer fylveftris, Brif. vi. p. 265. 2.-Id. 8vo. ü. p. 432 . Oie fauvage, Buf. ix. p. 30. t. 2., Pl. Enl. $985-$-Hift. Prov. i. p. 343. Uæs Araki, Fork. Faun. Arab. p. 3. N 6. Oca falvatica, Zinnan. Uov. p. 104. t. 17. f. 9 1. Wild Goofe, Albin. i. t. 9o.-Will. (Angl.) p. $35^{8}$. Grey-lag Goofe, Br. Zool. ii. N ${ }^{\circ}$ 266.-Id. fol. I 50.-ArE7. Zool. ii. $\mathrm{N}^{\circ} 473 .-$ Pbil. Tranf. xv. $\mathrm{N}^{\circ} 175$. p. 1 160. 5.-Latb. Syn. vi. p. 459. $3 \mathrm{I}$.

Haвiтat in paludofis fere pafim; in Anglia fatis frequens, ubi vix migratoria; hyeme gregaria.-33 pollices longa.

ß. Anas Anfer (domefticus), Lin. Syft. i. p. 197.-Faun. Suec. $N^{\circ} 114$.

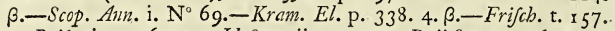
-Brif. vi. p. 262 . 1. $-I d .8$ vo. ii. p. $432 .-$ Raii Syn. p. 136. A. 3 . -Id. 191. 8.-Will. p. 273. t. 75.-Klein. Av. p. 129. 2.-Id. Ov. p. 34. t. 19. f. 1.-Borow/k. Nat: iii. p. 8. 2 .

Oca domeftica, Zinnan. Uov. p. 103. t. 17. f. 90.-Cet.uc. Sard.p. 317. Tame Goofe, Lath. Syn. vi. p. 46r. 21 . var. A.-Id. Sup. p. 273.Will. (Angl.) p. 358.-Flor. Scot. i. N $\mathrm{N}^{\circ}$ 206.-Tour in Scotl. 1769. (4to. ed.) p. 10.-Id. 8 vo. p. 8.

Manfueta ave color, ut in aliis domefticis, variat, fufco aut cinereo et albo plus minufve mixtus.

Roftrum et pedes in junioribus lutei, in adultis rubri. Femina inter27. albifrons. A. cinerea, fronte alba. dum, mas plerumque albus eft.

Anas albifrons, Gmel. Syft.i. p. 509 .

Anas erythropus, Faun. Suec. $\mathrm{N}^{\circ} 116$. (FEM.) -Brun. $\mathrm{N}^{\circ}$ 53. 54.Muller, $\mathrm{N}^{\circ}$ I I 3.-Kram. El. p. 339. 6.-Georgi reife, p. 166.Borow/k. Nat. iii. p. Io. b.

Anfer feptentrionalis fylveftris, Brif. vi. p. 269. 3. -Id. 8vo. ii. p. 433. L'Oie rieufe, Buf. ix. p. 81.

Laughing Goofe, Edw. t. 153.-Pbil. Tranf. lxii. p. 414. 3.

White-fronted Goofe, Br. Zool. ii. $\mathrm{N}^{\circ}$ 268. t. 94. 1. (caput.)-Id. fol. 50.-Arct. Zool, ii. No 476. -Lath. Syn. vi. p. 463. 22. 
Habitat in feptentrionali Afia, Europa, America; migratoria; in Anglice paludofis hyeme gregatim volans. -28 pollices longa:

Pectus et abdomen candida, macula in fterno nigricantes: roftrum et 28. pedes rubri.

Segetum. A. cinereo-fufca fubtus albida, alis grifeis, teetricibus majoribus remigibufque fecundariis apice albis. Anas fegetum, Gmel. Syft. i. p. $5 \mathbf{I} 2$. Bean Goofe, Br. Zool. ii. No 267. t. 94. f. 2.-Arct. Zool. ii. $\mathrm{N}^{\circ} 472$. -Latb. Syn. vi. p. 464.23 .

Habitat in Europe, Americe feptentrionalibus; in agri Lincolnienfis paludibus, alibique in Anglia hyeme invenitur. $-30-36$ pollices longa.

Roftrum nigrum parvum, medio pallidum: uropygium album: pedes rubri.

29.

Beringii. A. roftro gibbo, corpore albo, alis nigris, regione aurium virefcentialba.

Anas Beringii, Gmel. Syjt. i. p. 508.

Bering Goofe, Arct. Zool. ii. $\mathrm{N}^{\circ}$ 475.-Lath. Syn. vi. p. 465. 24.

Habitat in infula Beringii; Anferis magnitudine.

Gibber ad roftri bafin flavum medio pennis carulefcenti-nigris radia. tum : cervix cærulefcens.

30.

borealis. A. roftro angufto, capite viridi nitente, pectore abdomineque albis.

Anas borealis, Gmel. Syft. i. p. 512.

Gulaund Duck, Arct. Zool. ii. N 572 . E. -Lath. Syn. vi. p. 465.25.

Haвттат in Iflandice paludibus.-Magnitudo inter Anferem et Bofcbadem.

$3 \mathrm{I}$. erythro-

pus.

A. cinerea fupra nigro alboque undulata, collo nigro, facie abdomineque albis.

Anas erythropus, Lin. Syft. i. p. 197. I1.-Fann. Suec. No I 16. (Mas.) -Frifcb t. $189 .-$ Gmel. Syft. i. p. 512.

Bernicla, Brif. vi. p. 300 1 14. -Id. 8vo. ii. p. 41 1. - Raii Syn. p. I37. A. 5.-Will. p. 274 .

Anas Helfingen, Olaff. Ifl. ii. t. 33 .

Anfer Brenta, Klein. Av. p.. I 30. 8.-Id. p. 170. I2"

La Bernache, Buf. ix. p. 93. t. 5.-Pl. Enl. $855^{\circ}$ 
844 AVES PALMIPEDES. Anas.

Canada Goofe, Alb. i. t. 92.

Bcrnacle, or Clakis, Br. Zool. ii. $\mathrm{N}^{\circ}$ 269.-Id. fol. 1 50.-Aret. Zoo\%. ii. $\mathrm{N}^{\circ}$ 479.-Will. (Angl.) p. 359.-Pbil. Tranf. ii. p. 853.-Id. xii. p. 923.-Gerard. Herb. p. 1587. - Hayes Br. Birds, t. 24.Lath. Syn. vi. p. 466.26.

Habitat in Europa; rarior in America; hyeme in maritimis Anglie magna copia. -25 pollices longa.

Rofirum breve, nigrum, utrinque macula incarnata: frons, tempora, gula alba: inter oculum et roftri bafin macula nigra : dorf $\_$pennæ cinereæ apicibus nigris, margine albo: pectus, abdomen, et cauda fubtus alba: pedes nigricantes.

ß. A. cinerea marginibus pennarum albidis, fubtus et uropygio alba, capite anteriore et gutture fulvis, vertice et cervice nigricantibus, co:lo fubtus et pectore fufcis.

Bernicla minor, Brif: vi. p. 302. 1 5. -Id. 8 vo. ii. p. 442 .

Brenthus, Raii Syn. p. I 37. A. 7.-Id. 139. I I ?-Will. p. 276. t. 76. Anfer Brenta, Klein. Av. p. r 30.8.

Rat Goofe, or Road Goole, Will. (Angl.) p. $36 \mathrm{r}$.

Præcedente minor.-Cauda lateribus alba : roftrim et pedes nigri.

32.

Bernicla. A. fufca, capite collo pectoreque nigris, collari albo.

Anas Bernicla, Lin. Syjt. i. p. I98. I 3.-Faun. Suec. $\mathrm{N}^{\circ}$ I $15 .-$ Gmel. Syft. i. p. $513 .-S \operatorname{sop}$. Ann. i. $\mathrm{N}^{\circ} 84 .-$ Brun. $\mathrm{N}^{\circ}$ 52.-Muller, $\mathrm{N}^{\circ}$ I $15 .-$ Frifch. t. $156 .-$ Fatn. Groenl. N N $^{\circ}$.-Borowes. Nat. iii. p. I.I. 3 .

Brenta, Brif. vi. p. 304. 16. t. 31.-Id. 8 vo. ii, p. 442.-Raii Syn. p. 130. 8.-Will. p. 275. t. 69.-Klein. Av. p. I 30.8.

Le Cravant, Buf. ix. p. 87.-Pl. Enl. 342.

The Brent, Brand-Goofe, Br. Zool. ii. $\mathrm{N}^{\circ}$ 270.-Id. fol. I 5 1. Addend. t. Q.-Arct. Zool. ii. $\mathrm{N}^{\circ} 478$.-Id. Sup. p. 75.-Alb. i. t. 93.Will. (Angl.) p. 360.-Hayes. Br. Birds, t. 25.-Collins's Anat. ii. t. 20.-Lath. Syn. vi. p. 467.27 .

Habitat in Europa boreali, America; frequens in Anglia tempors hyberno.-Roftrum et pedes nigricantes: alba funt macula colli utrinque, abdomen pone pedes, reltrices inferiores caudæ, et latera uropygii.

Junior avis abfque macula lateribus colli. 
33 .

torrida. A. capite albo, collo fupra nigro fubtus caftaneo.

Branta torrida, Scop. Ann. i. No 86.-Ginel. Syft. i. p. 516 .

34. Statura Fuligule.

albicans. A. fupra fufca, fronte fubtufque alba, capite colloque fufco-rufis. Branta albifrons, Scop. Ann. i. N ${ }^{\circ} 87 .-$ Gmel. Syjt. i. p. $5 \mathrm{I} 6$.

Statura Galli: peftoris regio fuperior plumis cinereis margine pallide ferrugineis, fub apice fafcia rufa : remiges intus et apice albæ.

35.

mollifima, A. roftro cylindrico, cera poftice bifida rugofa.

Anas mollifima, Lin. Sy.f. i. p. $198.15 .-$ Faun. Suec. No 1 i $7 .-$ Gmel.

Syft. i. p. 514.-Brun. $\mathrm{N}^{\circ}$ 57-66.-Id. Monogr. t. 1. 2.-Muller;

$\mathrm{N}^{\circ}$ I 16.-Borowjk. Nat. iii. p. 5. t. 32.-Klein. Av. p. 130. 10.Muf. Carlf. fafc. i. t. 6.

Anfer lanuginofus, Brif. vi. p. 294. 1 3.t. 29. 30.-Id. 8 vo. ii. p. 440. Anas S. Cutberti, Raii Syn. p. 141. A. 3: F.-Will. p. 278. t. 77. F. Eidergans, Waullbaum Monogr. Lubec. 1778.

Oie à duvet, Eider, Buf. ix. p. 103. t. 6.-Pl. Enl. 209. M. 208. F. Great black and white Duck, Edw. t. 98. $M$. et $F$.

Eider or Cuthbert Duck, Br. Zool. ii. N 27 I. t. 95.-Id. fol. I 52 . t. Q.

-Arct. Zool. ii. No 480.-Tour in Scotl. (4to.ed.) 1769. t. p. 46.

-Id. 8 vo. t. p. 35.-Flor. Scot. i. $\mathrm{N}^{\circ}$ 209.-Von Troil. Icel. p.

144-146.6-Will. (Angl.) p.36.2. t. 76.-Latb. Syn. vi. p. 470 .

29.-Id. Sup. p. 274.

Habitat in feptentrionalibus Europe, Afice, Americe; rarius in Anglia; Anfere minor. -22 pollices longa.

Plumæ mollifimæ, præftantifimæ, pretiofifimæ: roftrum et pedies nigri. Mas albus, fubtus pofticeque niger, capitis poftica parte juxta pileum virefcente. Femina grifea ferrugineo varia, alis fafciis 2 albis. Ovum fufco-virefcens nitens.

36.

fpectabilis. A. roftro bafi gibbo compreffo, carina pennacea nigra, capite canefcente.

Anas fpectabilis, Lin. Syfi. i. p. 195.5.-Faun. Suec. $\mathrm{N}^{\circ}$ I 12.-Muf.

Ad. Fr. ii. p. 25.-Gmel. Syft. i. p. 907.-Muller, $\mathrm{N}^{\circ}$ 108.-Muf.

Carls. fafc. ii. t. 39. (mas.) 40. (femina.)-Faun. Groenl.

Anas freti Hudfonis, Brif. vi. p. 365 . 15.-Id. 8 vo. ii. p. 458.

Le-Canard à tête grife, Buf. ix. p, 253.

Greys 
846 AVES PALMIPEDES. Anas.

Grey-headed Duck, Edw. t. I54.

King Duck, ArCz. Zool. ii. No 48 1. - Lath, Syn. vi. p. 473. 30.

Habitat in boreali Europa et America.--2 fere pedes longa.

Corpus nigrum : bumeri albidi : pectus albo-flavefcens : macula alba oblonga in medio tectricum alæ: latera poftice verfus caudam alba : caput canum : tempora virefcentia : oculi macula parva nigra cincti : gula nigra divaricata: remiges nigricantes, fecundariæ antrorfum falcatæ: pedes rubicundi.

Femine roftrum vix gibbum : oculi albedine cincti : corpus ferrugineofufco nigroque maculatum: apices alarum caudaque cinerea : linea tranfverfalis alarum alba: pedes nigri. Ovum albidum.

37.

mofchata. A. facie nuda papillofa.

Anas mofchata, Lin. Syft. i. p. 199. 16.-Faun. Suec. No I 18.-Gmel. Syjt. i. p. 51 5.-Scop. Ann. i. N 85.-Frifch. t. I 80.-Pbil. Tranf. lvii. p. 348.-Brif. vi. p. 3I3. 3.-Id. 8vo. ii. p. 446.-Borowjk. Nat. iii. p. I I. 4.-Cett. Uc. Sard. p. 323 .

Anas fylveftris brafilienfis, Raii Syn. p. 148. 1. 2.-150. 3.-Will. p. 294. t. 75.-Id. p. 294 .

Anas indica Gefneri, Will. p. 295.-Klein. Av. p. ז3 1.2.

_ lybica, Will. p. 294.

Le Canard mufqué, Buf. ix. p. 162. t. 9.-Pl. Enl. $9^{8} 9$. Anitra muta, Zinnan. Uov. p. 105. t. 18. f. $9^{2}$. Turkifche Ente, Bl. Sch. der Berl. Nat. iii. p. 372. t. 7. f. r. Mufcovy Duck, Cairo, Guinea, India Duck, Will. (Angl.) p. 38r. 382.-Alb. iii. t. 97. 98.-Defcr. Surin. ii. p. 156.-Latb. Syn. vi. p. 476.31 .

Habitat in America aufrali, Afia.-2 pedes longa.

Corpus nigrum viridi cæruleove nitens, tectricibus alarum albis: ad flexuram alæ tuberculus niger : roftrum rubrum, nigro fafciatum : circum oculos cutis rubra: pedes rubri. Nidificat in arboribus, manfuefcens. Variat corpore plus minufve albo variegato, et in quibufdam corpus totum album. Ovun virefcens.

$3^{8 .}$

silotica. A. albida maculis canis, pectoris lateribus et abdomine cano lineatis, callo roftri marginali et caruncula purpureo-fanguineis.

Anas nilotica, Haffelq. p. $365 \cdot 36 .-I d$. Voy. 201.-Gmel. Syjt. i. p. 508. Bauk, Baw-Goofe, Pocock. Trav. i. p. 2 ro?

Nilotic Goofe, Lath. Syn. vi. p. 488.42.-Bruce's Trav. App. p. I 54 ? 
AVES PALMIPEDES. Anas.

Habitat ad Nilum Egypti fuperioris.-Irides flavæ: pedes rubri.Nonne Mojcbate affinis ?

39.

regia. A, caruncula compreffa frontali, corpore cæruleo fubtus fufco, collari albo, Molin. Cbil. p. 206.-Id. (ed. Gall.) p. 21 2.-Gmel. Syjt. i. p. 508 .

HaвiтAт in Cbili; Bofcbade paulo major.

Corpus fupra caruleum fubtus grifeum : crifta capitis magna, rubra: collare album collun circumdat.

40.

Monacha. A. albo nigroque varia, roftro flavefcente apice nigro, fpeculo alarum. viridi-violaceo.

Anas Monacha, Scop. Ann. i. No 86.-Gmel. Syft. i. p. 516.

Bofcbade major: lora grifea : roftrum, caput, et pectoris initium nigro maculata : remiges primæ albæ, apicibus fufco variegatis: rętrices albæ, ad apicem macula fufca, lanceolata, media.

$4 \mathrm{r}$.

georgica. A. cinereo-nebulofa, teEtricibus alarum cinerafcentibus, fpeculo alarum viridi albo marginato, remigibus rectricibufque nigricantibus.

Anas georgica, Gmel. Syjt. i. p. 516 .

Georgia Duck, Latb. Syn. vi. p. 478.34.

HaвtтAт in infula Georgice aufralis.-2o pollices longa.

Rofrum flavum apice fubrecurvato: pedes cinerafcentes : Speculum pallide viride.

\section{2.}

perfpicilla- A. nigra, vertice nuchaque albis, macula nigra roftri pone nares.

ta. Anas perfpicillata, Lin. Syft. i. p. 20r. 25.-Gmel. Syft. i. p. 524.Pbil. Trans. Ixii. p. 417.-Faun. Amer. Sept: p. I6.

— nigra major freti Hudfonis, Brif. vi. p. 425 . 30.-Id. 8 vo. ii. p. 472 .

Macreufe à large bec, Marchand, Buf. ix. p. 244.-P!. Enl. 995 .

Black Duck, ArEz. Zool. ii. No 48 3. - Edwo. t. 155 -Cook's laft Voy. iio. p. 378.-Latb. Syn. vi. p. 479. 35.

Habitat in America septentrionali.-2I pollices longa.

Roftrum rubrum macula quadrata nigra ad bafin : pedes rubri : macula alba triangularis in vertice et in nucba.

Femina minor, fuliginofa, abfque macula nucbe : gene maculis 2 albidis. Ovum album.

A. roftro: 
43 .

nigra, A. roftro bafi gibbo, corpore toto nigro.

Anas nigra, Lin. Syft. i. p. 196. 7.-Faun. Suec. N 1 10.-Gmel, Syft. i.

p. 508.-Muller, $\mathbb{N}^{\circ}$ i 10.-Brif. vi. p. 420.28 .t. 38.f. 2. (mas.) -Id. 8vo. ii. p. $47 \mathrm{I}$.

Anảs niger minor, Raii Syn. p. I4.1. A. 5.-Will. p. 230 . t. 74 . I. a Macreufe, Buf. ix. p. 234. t. 16.-Pl. Enl. 978 .

Whilk, Pbil. Tranf. xv. N० 175. p. I160. 4.

Scoter, black Diver, -Br. Zool. ii. No 273.-Id. fol. I 53.-Arct. Zcol. ii. No 484.-Id, Sup. p. 76.-Will. (Angl.) p. 366. t. 74.-Ray's Letters, p. 160. 161. - Lath. Syn. vi. p. 480.36.

Habitat in Eurcpa, America feptentrionali ; in mari perpetuo verfatur. - Victitat bivalvis. -22 pollices longa.

Roftrum nigrum medio luteum: frontis gibbofitas carnofa rubra, divifa linea flava: cauda fubcuneiformis: pedes fufci: nullus in afpera arteria labyrinthus.

Femina gibbofitate roftri caret: corpus ei fufcum, abdomine albedine variegato; gula et jugulo utrinque ufque ad aures cinerafcenti-albis.

44.

fufca. A. nigricans, palpebra inferiore fpeculoque alarum albis.

Anas fufca, Lin. Syft. i. p. 196. 6.-Faun. Suec. $\mathrm{N}^{\circ}$ 109. - Gncl. Syft. i.

p. 507.-Scop. Ann. i. No68.-Brun. No 48.49.-Muller, No 109.

-Frifch. t. 165.-Georgi reife, p. I 66.-Facq. Vog. p. 30. 1 5. t. 6.

- N. Aq7. Stock. 1785 . iii. No6. p. I88.-Borowek. Nat. iii. p.

17. 12.

Anas nigra major, Brif. vi. p. 423. 29.-Id. 8vo. ii. p. 472.-Raii Syn.

p. I '1. A. 4.-Will. p. 278 . t. 70.-Klein. Av. p. I33. 12.-ALt.

Nidr. i. t. 5 .

Turpan, N. C. Petr. iv. p. 420.-Buf. ix. p. 291.-Bell. Trav. p. 42 ? Grande ou double Macreufe, Buf. ix. p. 242.-Pl. Enl. 956.

Great black Duck, Will. (Angl.) p. 363. t. 70.

Velvet Duck, $\mathrm{Br}$. Z0.ol. ii. $\mathrm{N}^{\circ} 272$. t. 96.-Id. fol. 152. tab. add.Arct. Zool. ii. No 482.-Id. Sup. p. 75.-Hift. Kaintfch. p. 160.Ell. Nar. ii. p. $43-$-Latb. Syn. vi. p. $482 \cdot 37 .-$ Id. Sup. p. 274.

Habitat in Europie et Amèrice feptentrionalibus, Kamtfchatka.20-22 pollices longa.

Roftrum maris luteum medio nigrum, ad bafin gibbofitate notatum: pedes rubri : afpera arteria huic bafi tumefcens, offea: circum medium longitudinis ampulla rotundata, compreffiufcula.

Femina abfque gibbofitate roftri, corpore fufco ubi mas niger. In quibufdam regio aurium albida. Ovum album. 
4.5 .

AVES PALMIPEDES. Anas. 849

hiftrioni- A. fufca albo caruleoque varia, auribus, temporibus linea gemina, col-

ca. lari fafciaque pectorali albis. (Mas.)

Anas hiftrionica, Lin. Syfl. i. p. 204. 35.-Gmel. Syft. i. p. 534.-Brun. $\mathrm{N}^{\circ} 84.85 .-$ Muller, $\mathrm{N}^{\circ}$ I 27.-Fiaun. Groenl. $\mathrm{N}^{\circ} 46 .-$-Georgi reife,

p. 166.-Pbil. Tranf. 1xii. p. 417.-Frifch. t. 157.-Faun. Amer. p. 16.

Anas torquata, Brif. vi. p. 362. 14.-Id. 8 vo. ii. p. 457 .

Anas Brimond, Olaff. Ifl. ii. t. 34 .

Le Canard à collier, Buf. ix. p. 250.-Pl. Enl. 798.

Stone Duck, Hift. Kamtfch. p. 160.

Päinted Duck, Ell. Narr. ii. p. 43.

Dufky and fpotted Duck, $E d w$. t. 99 .

Harlequin Duck, (male) ArEt. Zool. ii. $N^{\circ} 490 .-L a t h$. Syn. vi. p. 485.38.

A. grifea, auribus albis, remigibus primoribus nigricantibus. (Femina.) Anas minuta, Lin. Syft. i. p. 204. 36.-Gmel. Syft. i. p. 534.-Brun. $\mathrm{N}^{\circ} 86 .-$ Faun. Groenl. $\mathrm{N}^{\circ} 46$.

Querquedula freti Hudfonis, Brif. vi. p. 469.4 I. $-I d$. 8 vo. ii. p. $4^{8} 3$. Le Canard brun, Buf. ix. p. 252.-Pl. Enl. 1007 .

La Sarcelle brune et blanche, Buf. ix. p. 287.-Pl. Enl. 799.

Little brown and white Duck, Edw. t. 157.-Cat. Car. i. t. 98.

Harlequin Duck, (female) Latb. Syn. vi. p. $485 \cdot 3^{8}$.

HaBITAт in America, Europa.-17 pollices longa.-Speculum alarum cæruleum linea alba tranfverfa : roftrum pedefque nigri.

Femina parva admodum tota grifea : punctum album ad aures utrinque : bafis mandibulæ fuperioris alba. Ovum columbinum album.

ß. A. nigra, temporibus fafcia oculari fuboculari et torque albis, lateribus colli caftaneis.

Anas torquata, Gmel. Syft. i. p. 514.-S. G. Gmel. reife, ii. p. 180. t. 14 .

Hавітат ad littora maris Cajpii; Hiftrionice maris varietas; folum difcrepat uropygio albo.

46.

fufcefcens. A. fufcefcens capite colloque dilutiore, alis cinereis, fpeculo cæruleo margine albo, cauda obfcura.

Anas fufcefcens, Gmel. Syft. i. p. 534 .

Brown Duck, Arct. Zool. ii. Nं 499.-Lath. Syn. vi. p. 486.39.

HaBITAT 
IJABтA $\mathrm{x}$ in infula nove Terra.-16 pollices longa.

Roftrum bafi crafum, cærulefcens, apice nigro: pectus ferrugineoundulatum.

47. poecilo. shyncha.

A. nigra, genis cum parte juguli cinereis, alarum fpeculo viridi fupra albo fubtus albo nigroque cincto, remigibus fecundariis candidis. Anas poecilorhyncha, Zool. Ind. p. 23. t. 13.-Gmel. Syft. i. p. 535. Spotted-billed Duck, Latb. Syn. vi. p. 487. 40.

Habitat in Zeylona communis.

Roftrum elongatum, nigrum, bafi lateribus macula rubra, apice album: fafcia per oculos nigra : criffum nigrum : pedes rufo-flavi.

48. damiatica.

A. alba, capite collo fuperiore humeris caudæque apice albis, nuchæ lunula ferruginea, remigibus virefcenti-atris.

Anas damiarica grifea, Heffelq. It. p. 264.-1d. Voy. p. 201. 35.-Gmelo Syft. i. p. 535 .

Black-headed Duck, Sbaw's Trav. p. 254?

Damietta Duck, Lath. Syn. vi. p. 487. 41.

Habitat in Egypti littoribus, Barbaria; Bofchade major.

49 .

Bofchas.

A. cinerea, rectricibus intermediis (maris) recurvatis, roftro recto, torque alba.

Anas Bofchas, Lin. Syft. i. p. 205.40.-Faun. Suec. $\mathrm{N}^{\circ}$ 131.-Gmel. Syft. i. p. 538.-Pbil. Tranf. lxii. p. 419.-Scop. Ann. i. No $77 .-$ Brun. $\mathrm{N}^{\circ} 87 .-$ Muller, $\mathrm{N}^{\circ}$ 128.-Kram. El. p. 341. I r.-Frifch. t. I 58. 1 59.-Georgi reife, p. 166.-Faun. Groenl. N $\mathrm{N}^{\circ}$ 47:-Faun. Arab. p. 3. 9.-Faun. Arag. No 75. 7.-Borowejk. Nat. iii. p. I8. -Faun. Helvet.-Cet. uc. Sard. p. $32 \mathrm{I}$.

Anas fera, Brif. vi. p. 318. 4.-Id. 8 vo. ii. p. 447.

Anitra, Zinnan. Uov. p. 105. t. 18. f. 93.-106. t. 19. f. 94.

Wilde Ente, Guntb. Neft. u. Ey. t. 37 .

Canard fauvage, Buf. ix. p. I 15. t. 7. 8.-Pl. Enl. 776. 777.-Ferm. Surin. ii. 156.

Wild Duck, Br. Zool. ii. N• 279. t. 97.-Id. fol. 175-Will. (Angl.) p. 308. t. 72. 75-Alb. ii. t.'IO.-Id. i. t. 99.-ArEz. Zool. ii. $\mathrm{N}^{\circ}$ 494.-Lath. Syn. vi. p. 48 9. 43.

Habitat in Europe, Afie, Americe paludibus; victitans variis.-2 pedes fere longa. 
A VES PALMIPEDES. Anas. 8,5

Mas caput collumque viridi-nitentia, torquc alba : jcapulares albæ lineis undulatis fufcis : dorfum fufcum : uropygium viridi-nigrum : peEtus caftaneum: abdomen grifeum : Speculum alarum violaceo-viride, fupra fafcia nigra alteraque alba marginatum: rectrices 2 intermedix viridiatræ, recurvatæ: labyrintisus ad tracbea divaricationem parvus offeus.

Feminc corpus totum fufco-rufefcens nigro maculatum: Speculum ut in mare, at pennæ caude non recurvantur. Orvm albo-cærulefcens.

B. Anas domeftica, Lin. Syft.i. p. 206. 40. 3.-Brun. N॰ 88.-Borowfk. Nat. iii. p. 17. 13.-Klein. Av. p. 13r. x.-Id. Ov. p. 34. t. 20. f. 1.-Raii Syn. p. 150. 1.-Id. 19r. 10.-Will. p. 293. t. 75.Brown. Fam. p. 480.-Sloan. Fam. p. 323. 7.-Brif. vi. p. 308. 1. -Id. 8 vo. ii. p. 43 I.

Tame Duck, Alb. iii. t. 99.-Latb. Syn. vi. p. 494.

Variat corpore verficolore.

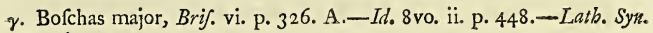
vi. p. 495 .

Anas fera fecunda, Klein. Av. p. r31. 3 .

Præcedente paulo major. - Dorfum fuliginofum. $-2 \frac{1}{2}$ poll. longa.

s. Bofchas major grifea, Brif. vi. p. 326. B.-Id. 8 vo. ii. p. 448.

Magnitudine et forma fatis præcedenti fimilis, fed cinereo colore tingitur.

\&. Bofchas major nævia, Brif. vi. p. 727 , C.-Id. 8vo. ii. p. 449.

A Bofclade majore difcrepat dorfo nigro flavicante maculato.

$\zeta$. A. rectricibus intermediis (maris) recurvatis, roftro incurvato. Anas adunca, Lin. Syft. i. p. 206. 41 . - -Gmel. Syjt. i. p. $53^{8}$. Anas roftro incurvo, Brif. vi. p. 3 I I. 2. -Id. 8 vo. ii. p. 445 .-Borowek. Nat. iii. p. 19. 14.-Raii Syn. p. 150. 2.-Will. p. 280. t. 75. Klein. Av. p. 133.17.

Hook-billed Duck, Alb. ii. t. 96. 97.-It. iii. to 100.-Will. (Angl.) p. 381 . t. 75.-Lath. Syn. vi. p. 495 . D.

In omnibus cum domefica convenit; roffro incurvato.

$$
5 Q_{2} \quad \text { A. atra, }
$$




\section{A.VES PALMIPEDES. Anas.}

50.

tra. alba, roftro incurvo.

Anas curviroftra, Pall. Spic. vi. p. 33.-Gmel. Syjt. i.p.537.

Curve-billed Duck, Lath. Syn. vi. p. 496. 44 .

Capta in Belgio.-Roftrum ut in Bofcbade $\zeta$ : irides fulvæ: color fere totius avis niger : caput, collum, uropygium grifeo fpJendens : remiges 5 exteriores albæ: gula alba : Speculum alarum cæruleo-nigro-nitens. An diftincta fpecies?

51.

fupercilio- A. cinereo-fufca, fafcia fupra et infra oculos gula juguloque albis, fpe-

fa. culo alarum viridi-cærulefcente nigro marginato.

Anas fuperciliofa, Gmel. Syft. i. p. 537 .

Supercilious Duck, Lath. Syn. vi. p. 497.45.

Habitat in $N$. Zealandia.-2 I pollices longa.-Roftrum plumbeum.

52.

autumna- A. grifea, remigibus cauda ventreque nigris, fpeculo alarum fulvo al-

lis. boque.

Anas autumnalis, Lin. Syft. i. p. 205.39.-Gmel. Syft.i.p. 537.-Facq. Vog. p. 6. 4 .

Anas fritularis americana, Brif. vi. p. 400.23 .t. 38. f. I.-Id. 8 vo. ii. p. 466 .

Anas fera mento cinnabarino, Marf. Dan. 108. t. 52 ?-Klein. Av. p. I35. 25 .

Siffleur à bec rouge et narines jaunes, Buf. ix. p. 183.-Pl. Enl. 826 . Red-billed whiftling Duck, Edw. t. I 94.-Lath. Syn. vi. p. 498.47.Id. Sup. p. 274 .

HaBITAT in America meridionali; arboribus infidens; intra tropicos frequens cicuratur, at valde pugnax. -2 I pollices longa.

Roftrum rubrum apice nigrum, in junioribus toto nigrum : irides avellanea: vertex, dorfum, et fcapulares caftanea : pectus et axille flavocinereæ : tectrices alarum cinereæ: pedes flavi.

53.

arborea. A. grifea, capite fubcriftato, abdomine albo nigroque maculato.

Anas arborea, Lin. Syft. i. p. 207. 44.-Gmel. Syft. i. p. 540.-Lawes, Carol. 149 .

Anas fiftulans jamaicenfis, Brif. vi. p. 403. 24. -Id. 8 vo. ii. p. $467 .-$ Raii Syn. p. Ig2. 12.-Sloan. Fam. 324. t. 273.-Brown. Fam. p. 480 。

Black- 
Black-billed whiftling Duck, Edw. t. 193.-ArEz. Zool. ii. $\mathrm{N}^{\circ} 492 .-$ Catefb. App. xxxvii.-Lath. Syn. vi. p. 499. 48.

Habitat in famaica, Guiana; in Carolinam hyeme migrans; arbo, ribus infidet et nidificat; præcedentis magnitudine.

Roftrum plumbeum ungue nigro: irides avellaneæ : collum elongatum : occiput cum nucba nigricans: cervix et dorfum fufcum pennis margine rufis : gene et gula alba : collum antice album maculis nigris, fub54. tus et pectus rufefcens maculis nigris : pedes longiores, plumbei.

Marila. A. nigra, humeris cinereo-undulatis, abdomine fpeculoque alari albis. (Mas.)

Anas Marila, Lin. Syft. i. p. 196. 8.-Faun. Suec. $\mathrm{N}^{\circ}$ I 1 1.-Pbil. Tranf. lxii. p. 413.-Gmel. Syft. i. p: 509.-Brun. 50. 51.-Muller, $\mathrm{N}^{\circ}$ I1 1. -Frifch. t. 193.-Georgi reife, p. 166.-Kram. El. p. 342. 17. (Fem.)

Anas fubterranea, $\operatorname{Sccp}$. Ann. i. $\mathrm{N}^{\circ} 83$ ?

Anas nigra ultima nova, Ström. Söndm. 230.

Glaucium minus ftriatum, Brif. vi. p. 4 16. 26 . A. $-I d$. 8 vo. ii. p. 470. Fuligula Gefneri, Raii Syn. p. 142. A. 6.-Will. p. 279.

Bergente, Befch. der Berl. Naturf. Fr. iv. p. 602. 12. t. 17. f. 3. 4.

Scaup Duck, Br. Zool. ii. No 275. t. 100.-Id. fol.p. 1 53. t. Q.-ArEz. Zool. ii. $\mathrm{N}^{\circ} 49^{8}$. - Lath. Syn. vi. p. 500.49.

A. fufco-ferruginea, fpeculo alarum abdomine capitifque annulo ad roftri bafin albis. (Femina.)

Anas frenata, Muf. Carlf. fafc. ii. t. $3^{8}$.

Duck with a circle of white feathers about the bill, Ray's Letiers, p. 6 r.

Haвiтat in Europa et Afa boreali; in America quoque fatis numerofa; in Anglia hyberno tempore gregatim volans; teftaceis victitans. -18-20 pollices longa.

Mari roftrum latum et pedes cærulei : irides aureæ: caput et pars colli nigro-virefcens : collum fubtus et pectus nigrum: abdomen album: dorfum et fcapulares grifefcentes lineolis tranfverfis nigris : dorfum pofticum, uropygium, et criffum nigra : tectrices alarum pulveratim fufco alboque maculatæ, fafcia alarum alba. Coloribus variat præfertim capitis et colli, adeo ut in grege 40 aut 50 vix duas invenias per omnia tibi mutuo fimiles.

Femina fufca : roftrum nigrum, ad bafin babena f. capiftro late cinctum : caput brunneum : collum ferrugineum: interfcapulium, dorfum, cauda fufco-ferruginea : abdomen et fafcia alarum alba: pedes nigri. 
ß. A. capite colloque purpureo-viridibus, dorfo humerifque cinereo undulatis, abdomine fpeculoque alarum albis.

Millouinan, Pl. Enl. 1002.-Buf. ix. p. 221. -Latb. Syn. vi. p. 502.

Longitudo 2 I pollicum.-Remiges, uropygium, cauda nigra.

55 . diffcors.

A. tectricibus alarum cæruleis, remigibus fecundariis extus viridibus, fafcia frontali alba. (Mas.)

Anas difcors, Lin. Syft. i. p. 205. 37.-Gmel. Syjt. i. p. 535 .

Querquedula americana, Brif. vi. p. $452.35 .-I d$. 8 vo. ii. p. 478. Klein. Av. p. 134. 24.-Brown. Fam. p. $48 \mathrm{r}$.

Sarcelle foucrourou, Buf. ix. p. 279.-Pl. Enl. 966.

Blue-wing, Burnab. Trav. p. 16.

White-faced Duck, ArEt. Zool. ii. No $503 .-$ Cat. Car, i.t. 100.-Brown. Jam. p. 48 1.-Lath. Syn. vi. p. 502. 50.

A. tectricibus alarum cæruleis, corpore grifeo-fufco fubtus grifeo, fpeculo alarum viridi, fafcia fuperius alba. (Femina.)

Querquedula virginiana, Brif, vi. p. $455 \cdot 36 .-I d$. 8 vo. ii. p. 479.

Anas quacula, Klein. Av. p. I 34. 23 .

Sarcelle foucrourette, Buf. ix. p. 280.-Pl. Enl. 403.

Blue-winged Teal, Cat. Car. i. t. 99.-Lath. Syn. vi. p. 503.

Habrtat in America; migratoria; oryza avenaque victitans.-I 5 pollices longa.

Mari caput et collum violaceum, pileo nigro: ante oculos fafcia utrinque alba: corpus fufcum grifeo-undulatum : pectus teftaceum : Speculum viride, fuperius albo marginatum: roftrum nigrum : pedes lutei.

Femine caput, collum, corpufque grifeo fufcoque varium: ala, roftrum, pedes ut in mafcula ave.

$\beta$. A. pileo caudaque nigris, tectricibus alarum cæruleis, majoribus macula alba, remigibus fecundariis extus gula abdomineque albis, Lath. Syn. vi. p. 504. 50. A.

HABITAT ad finum Hudfonis; nidificat in cavis arborum, ova io alba pariens.-14 pollices longa.

56.

Roftrum nigrum: pectus, crifum, pedefque cærulei.

Tadorna. A. roftro fimo, fronte comprefla, capite nigro-virefcente, corpore albo variegato. 
Anas Tadorna, Lin. Syf. i. p. 195. 4.-Faun. Suec. No 11 3.-Gmel. Syft. i. p. 506. 4.-Brun. $\mathrm{N}^{\circ} 45 \cdot 45.47 .-$ Muller, $\mathrm{N}^{\circ}$ 107.Frich. t. 166.-Georgi reife, p. 165.-Gmel. reife, ii. p. 185. t. I9. -Bl. scb. der Berl. Naturf. iii. p. 373. t. 7. f. 3. 4.-Borow/k. Nat. iii. p. I6. I 1.-Raii Syn. p. 140. A. 1.-Will. p. 278 . t. 70. 7 1. -Brif. vi. p. 344 . 9. t. 33 . f. 2.-Id. 8 vo. ii. p. 4,7 .

Vulpanfer, Klein. Av. p. I 30.9 .

Tadorne, Buf. ix. p. 205. t. 14.-Pl. Enl. 53.-Dec. RuJ. i. p. 472.

Shieldrake, Br. Zool. ii. No $278 .-I d$. fol. 1 54. t. Q.-ArEz. Zool. ii. p. 972. D.-Ald. i. t. 94.-Will. (Angl.) p. 363. t. 70.7 1.-Hayes Br. Birds, t. 28. (Mas.)-Lath. Syn. vi. p. 504. 51.-Id. Sup. p. 275 .

Habiтat in Europe et Afie maritimis; cuniculis nidificans, ova 15-16 alba pariens.

Roftrum rubrum bafi compreffa carnofa : pedes rubri : caput et collum violaceum : collum medium albo annulatum : pętus fulvo-brunneum : abdomen album linea carinali nigra: dorfum album: remiges primores primæ nigræ, proximæ violaceæ, interiores ferruginex, ultimæ albæ: Speculum violaceum viridi et cupreo fplendens : cauda alba apice nigra. Ampullam labyrintheam velut geminam obtinet ad tracbece divaricationem.

Femina mari omnibus fimillima, coloribus minus vividis.

$5 \%$ erythrorhyncha.

$5^{8}$.

bahamen- A. grifea, roftro plumbeo macula laterali fulva, macula alarum viridi fis.
A. fufca fubtus alba, pectore lateribus maculis fufcis, fafcia alarum alba alteraque fubtus lutefcente, cauda nigra.

Anas erythrorhyncha, Gmel. Syft. i. p. 5 I 7.

Crimfon-billed Duck, Lath. Syn. vi. p. 507. 52.

Habitat ad Caput B. Spei.-I 5 pollices longa.

Roftrum, ut in Tadorna, furfum reflexum coccineum : pedes nigri. luteaque.

Anas bahamenfis, Lin. Syft. i. p. 199. 17.-Gmel. Syft. i. p. 516.-Brif. vi. p. $35^{8}$. 12. -Id. 8 vo. ii. p. 456. -Klein. Av. p. 134 . I 8.

Mareca prima Aldr. Raii Syn. p. 149. 4.--Will. p. $29^{2}$.

Le Marec, Buf. ix. p. 256.

Ilathera Duck, Catef. Car. i. t. 93.--Arct. Zool. ii. No 495--Latb. Syn. vi. p. 507. 53.-Will. (Angl.) p. 379. \$ 1 I.

Habitat in infulis Babamenfibus, Brafilia.- I7 pollices longa. Vertex rufo-grifeus: collum fupra, corpus, et ale rufo-fufca: gene, 
collum fubtus alba: pectus, abdomen, femora rufo-grifea maculis nigris: 59. Speculum viride, antice flavum, poftice nigrum : pedes plumbei.

brafilienfis.

60. clypeata. A. roftri extremo dilatato rotundato, ungue incurvo.

Anas clypeata, Lin. Syft. i. p. 200. 19.-Faun. Suec. N॰ II 9.-Gmel. Syft. i. p. 5 18.-It. Gott. 167.-Scop. Ann. i. $\mathrm{N}^{\circ} 70 .-$ Brun. $\mathrm{N}^{\circ}$ 67. 68.69.-Muller, $\mathrm{N}^{\circ}$ 1 17.-Kram. El. p. 342. 15.-Frijcb. t. 161. 162. 163.-Brif. vi. p. 329. 6. t. 32. f. 1. (Mas.)-Id. 8vo. ii. p. 450.-Georgi reife, p. 166.-Borowes. Nat. iii. p. 12. 5. -Faun. Helvet.

Anas platyrynchos altera, Raii Syn. p. 143. A. 9.-Will. p. 283. (Mas.) Anas platyrynchos, Raii syn. p. 144. 13.-Will. p. 283 . \$xv.-Id. 284, xvi. (Femina.)

Anas virefcens, Marf. Dan. v. p. 120. t. $5^{8}$.

Avis latiroftra, Klein. Av. p. 134. 20.-Id. Stem. p. 31, t. 35. f. r. a-c. Souchet, Buf. ix. p. 191,-Pl. Enl. 971. 972.

Loeffelente, Bloch. Scbr. der Berl. Naturf. Fr. iii. p. 373. 17. t. 7. f. 2. Shoveler, Br. Zool. ii. No $280 .-I d$. fol. 155. t. Q. 4.-ArEt. Zool. ii. $\mathrm{N}^{\circ} 485$. -Will. (Angl.) p. 370. 15. (Mas.)-Id. 37 1. 16. 17. (Fem.)-Alb. i. t. 97. 98,-Cat.Car. i. t. 96. (Fem.)-Hayes Br. Birds, t. 27. (Mas.)-Latb. Syn. vi. p. 509.55.

Habitat ubique in Europa, Afia, et feptentrionali America.-2I pollices longa.

Roftrum lateribus pectinatum, nigrum : irides flavæ : caput et collum ad medium viridi-violaceum : collum imum antice, et pectus fupremum alba : abdomen caftaneum: criffum nigrum: tectrices alarum cæruleæ, majores fufc $x$, apice cærulex, fafciam efformantes; infra hanc- $\int p e c u l u m$ e mediis remigibus viride : pedes fulvi: ad divaricationem tracbec labyrintbus parvus. 
Femina, alis folummodo exceptis, $A$. domeftica feminæ funillima eft. Ovum rufum.

ß. A. macula alari purpurea utrinque nigra albaque, pectore rufefcente. Anas mufcaria, Lin. Syft. i. p. 200. 3.-Faun. Suec. $N^{\circ}$ I 20.-Raii Syn. p. $146 .-W$ ill. p. $287 .-$ Frifch. t. 162.

Anas clypeata ventre candido, Brif. vi. p. 337. A.-Id. 8vo. ii. p. 45 I. A prioris femina tantum difcrepat ventre candido.

y. Anas fera, Bofchas mexicana, Brif. vi. p. 327. 5. Id. 8 vo. ii. p. 449. Tempatlahoac, Raii Syn. p. $176 .-W i l l$. p. 299.-Id. (Angl.) p. $3^{87}$. Lath. Syn. vi. p. 5 I 1 .

Hавітат in Mexico.-Corpus fupra nigro-virefcens, tæniis arcuatis fordide albis varium, fubtus fulvum: caput et collum fupremum nigrum viridi et purpureo nitens : pectus album : tectrices alarum minores cyaneæ, mediæ candidæ, majores viridi-aureæ: pedes rubent.

61 .

mexicana. A. fupra nigro fulvo alboque varia fubtus fulva, tectricibus alarum minoribus albis, macula alarum viridi-aurea.

Anas clypeata mexicana, Brif. vi. p. 337.7.-Id. 8 vo. ii. p. 452.0 Gmel. Syft. i. p. 519 .

Yacapatlahoac, Raii Syn. p. 176.

Mexican Shoveler, Lath. Syn. vi. p. 5 I I. 56.

Habitat in Mexico; domeftica minor.

Roftrum apice dilatatum fufco-rubrum : pedes pallide rubri.

62.

rubens. A. fufca, jugulo et pectore rubro-fufcis, fpeculo alarum purpureo albo marginato, cauda brevi alba.

Anas rubens, Gmel. Syft. i. p. 519.

Barbary Shoveler, Sbaw's Trav. p. 254?

Red-breafted Shoveler, Br. Zool. ii. $\mathrm{N}^{\circ} 28$ r. -Latb. Syn. vi. p. 5 1 2. 57.

In Anglie agro Lincolnienfi aliquando capta eft hæc avis; domeftice magnitudine.-Roftrum fufco-flavefcens: irides flavæ: pedes graciles, rubro-fufci.

63. jamaicen-

fis.

A. fufco croceo ferrugineoque varia, dorfo alis caudaque fufcis, capite fuperiore nigro, fubtus cum gula albo maculis nigris.

Anas jamaicenfis, Gmel. Syjt.i. p. 519 . 


\section{$85^{8}$ AVES P A L I PEDES. Anas.}

Teal of Guiana, Bancr. Guian. p. 170?

Jamaica Shoveler, Lath. Syn. vi. p. 513.58.

Habitat in famaica.-I6 pollices longa.

Roftrum dilatatum cærulefcens, lateribus aurantium: irides fufcæ: cauda cuneiformis : pedes aurantii.

64. leucocephala.

65.

viduata. A. fufca, capitis antico albo poftico nigro, pedibus cæruleis.

Anas viduata, Lin. Syft. i. p. 205. 38.-Gmel. Syft. i. p. 536.-7acq. Vog. p. 3. 2. t. I.

Spanilh Duck, Gen. Birds, p. 65. t. 13.-Lath. Syn. vi. p. 525.69.Id. Sup. p. 275.

HaBITAT in Cartbagene amer. lacubus; autumnali minor.

Roftrum oculique nigri: corpus fufcum: caput dimidia antica parte cum gula album, poftice vero nigrum: pectus et collum imum rufa: abdomen lineolis tranfverfis interruptis e grifeo nigroque varium : junioribus totum caput nigrum. An leucocepbale varietas?

ß. A. rufefcente nigricanteque undatim varia, capite colloque antice dimidia 
dimidia parte albis, pectore rufo, cervice collari fub gula alis caudaque nigris.

66.

Canard à face blanche de Maragnon, Buf. ix. p. 255.-Pl. Enl. 808.

dominica- A. grifeo-cinerea, facie gulaque albis, fafcia oculari occipite collo pec-

na. toreque nigris. Anas dominicana, Gmel. Syft. i. p. 536 .

Canard dominicain du Cap de B. E. Son. Voy. Ind. ii. p. 22.

Dominican Duck, Latb. Syn. vi. p. 525. 70.

67. nigri.

Haвiтat ad Cap.B.Spei; Bofchadis magnitudine.-Rofrum pedefque

labradora. A. dorfo alis et abdomine fufcis, capite collo fcapularibus remigiburque

fecundariis albis, torque fafciaque pectoris nigris.

Anas labradora, Gmel. Syft. i. p. 537 .

Pied Duck, ArEz. Zool. ii. N ${ }^{\circ}$ 488. t. in tit.-Lath. Syn. vi. p. 497.46.

-Laweon's Car. p. 148 ?

HABiтAт in Labradora.- 19 pollices longa.

Roftrum bafi aurantium: a vertice ad nucham ftria nigra : caput et collum ad rufum inclinant: pedes flavi.

68.

Femina fufco varia fubtus albida, macula alarum alba: pedes nigri.

fcandiaca. A. fpadiceo-fufca, roftro ampliato, corpore fupra nigro, linea alari pectore et abdomine albis.

Anas fcandiaca, Gmel. Syft. i. p. 520.

Anas latiroftra, Brun. $\mathrm{N}^{\circ}$ 91.-Muller, $\mathrm{N}^{\circ}$ i 30 . (Skoora.)

Lapmark Duck, Arct. Zool. ii. p. 57 6. M. - Latb. Syn. vi. p. 5 I 5.60.

Habitat in Danie et Norvegie maritimis; Bofchadis magnitudine. Roftrum latum pedefque nigri : bypocbondria ferruginea.

69.

Atrepera. A. fpeculo alarum rufo nigro albo.

Anas ftrepera, Lin. Syft. i. p. 200. 20.-Fawn. Suec. N' 1 $21 .-G m e l$. Syft. i. p. 520.-Brun. p. $21 .-$ Muller, $\mathrm{N}^{\circ}$ i $18 .-$ Frifch. t. 168.Georgi reije, p. 166.-Gmel. reise, ii. p. 183. t. 17.-Borowe. Nat. iii. p. 12. 6.-Faun. Helvet.-Brif. vi. p. 339. 8. t. 33. f. 1.-Id.

8vo. ii. p. $452 .-K l e i n$. Av. p. 132. 6.-Cet. uc. Sard. p. 325.

Anas platyrhynchos, Raii Syn. p. 145. A. 2.-Will. p. 287.

Chipeau, Buf. ix. p. 187.t. 12. (Fem.)-Pl. Enl. $95^{8}$.

$5 \mathrm{R} 2$

Gadwall, 
Gadwall, or Grey, Br. Zool. ii. $N^{\circ}$ 288.-Id. fol. I 57. t. Q. 3.-ArEF. Zool. ii. p. 575. I.-Will. (Angl.) p. 374. t. 72.-Lath. Syn. vi. p. $5 \mathrm{I} 5.6 \mathrm{I}$.

Habitat in Europa et in feptentrionali Afa - I 9 pollices longa.

Roftrum planum nigrum: pedes fulvi : Speculum nigrum margine antico rufo, poftico albo: uropygium nigrum : dorfum fufcum pallido undulatum: pectus et abdomen grifeo alboque varium.

Femine perfus ex rubefcente fufcum maculis nigris: uropygium non nigrum: dorfum non undulatum.

70.

falcaria. A. criftata, corpore cano fufcoque variegato, pectore fquammato-undulato, fronte gula torque colli fafciaque alarum albis. Anas falcaria, Pall. reife, iii. p. 701. $\mathrm{N}^{\circ} 34 .-$ Gmel. Syft. i. p. 521. Anas falcata, Georgi reife, p. 168.

Falcated Duck, Arct. Zool. ii. p. 574. I. t. 23.-Latb. Syn. vi. p. 516.62.

Habit at in aquis Sibirice orientalis, prafertim Dauurice frequens, ex auftro migrans. - I 8 pollices longa.

Roftrum nigrum: vertex teftaceus; reliquum caput viridi-fericeum, macula frontis minuta alba: gula alba, continuaque fafcia collum cingens infra criftam, in qua torquis virefcenti-atra : criffum medio atrum utrinque nigrum: speculum alarum chalybeo-atrum albo marginatum : remiges 5 interiores elongatæ, deorfum falcatæ, violaceo alboque virgatæ: pedes plumbei.

B. Sarcelle de Java, Buf. ix. p. 275.-Pl. Enl. 930.-Lath. Syn. vi. p. 517.62 . A.

Hавітат in Fava infula.-Caput vix criftatum : remiges falcatæ nulle: crifum fufcum abfque albedine: femora alba.

$7 \mathrm{~T}$.

Penelope. A. cauda acutiufcula, criffo nigro, capite brunneo, fronte alba, dorfo cinereo undulato.

Anas Penelope, Lin. Syft. i. p. 202. 27.-Faun. Suec. N० I24.-Gmel.

Syft. i. p. 527.-Brun. $\mathrm{N}^{\circ}$ 72. 73.-Muller, $\mathrm{N}^{\circ}$ 121.-Kram. El.

p. 342. 16.-Georgi reife, p. 166.-Raii Syn. p. 146. A. 3.-Will.

p. 288. t. 72.-Borowjk. Nat. iii. p. 13. 7.-Faun. Arag. p. 75. 2.

-Faun. Helvet.-Cet. uc. Sard. p. 326.

Anas filtularis, Brif. vi. p. 391. 21. t. 35. f. 2.-Id. 8 vo. ii. p. 464.Klein, Av. p. 132. 7.-Id. Ov. p. 35. t. 2 I. f. 3 . 
Canard fiffleur, Buf. ix. p. 169. t, 10. I1.-Pl. Enl. 825 .

Pfeifente, Bl. Bef. der Berl. Nat. iv. p. 6or. t. 18. f. 5 .

Wigeon, Whewer, Whim, Br. Zool. ii. $\mathrm{N}^{\circ} 286 .-I d$. fol. 157. Addend. t. Q. 157.-Arct. Zool. ii. p. 574. K.-Will. (Angl.) p. 375.t. 72. -Alb. ii. t. 99.-Latb. Syn. vi. p. 518.63.

Habitat in Europe, Afle, et Africe maritimis; hyeme in Anglia. -Vox fiftulans. - 20 pollices longa.

Roftrum plumbeum ungue nigro: caput et collum fuperius rubra maculis nigricantibus : vertex roftrum verfus dilatiore eft colore, $f$. luteoalbido: pectus vinaceum: corpus fupra cinereo nigricanteque undulatum: Speculum alarum cæruleo-viride, antice et poftice nigrum : tectrices alarum fufco alboque variæ, in quibufdam toto albæ: abdomen album: pedes plumbei. Ad divaricationem tracbec labyrintbus parvus.

Femina fufco-nebulofa, pedtore pallidiore, cæterum cum mare bene convenit. Ovum pallide fufcum parumper nebulofum.

$\beta$. A. gutture cinereo-undulato, alarum fpeculo argenteo, Bef. $s c b$. der。 Berl. Nat. vii. p. $45^{8}$.

Anas kogolka, N. C. Petr. xv. p. 468.15.t. 21 .

72.

melanura. A. cinerea roftro pedibufque teftaceis, vertice dorfoque rufis, remigibus rectricibufque nigris.

Anas melanura, Scop. Ann. i. N $\mathrm{N}^{\circ}$ 2.-Gmel. Syft. i. p. 516.

Bofcbade paulo minor.-Tempora cinerafcentia: uropygium nigrum albo maculatum.-Præcedenti affinis.

73.

capenfis. A. cinerafcens, dorfo ex rubefcente fufco, pennis margine flavefcentibus, fpeculo alarum cæruleo-virefcente albo marginato.

Anas capenfis, Gmel. Syft. i. p. 527.

Cape Wigeon, Lath. Syn. vi. p. 519.64.

HaвiтAт ad Cap. B. Spei.-I 5 pollices longa.-Roftrum et pedes rubri : caput caruleo-cinerafcens, maculis minutis obfcuris notatum.

74 .

americana. A. ferrugineo nigroque undulata, abdomine albido, capite albo nigroque maculato, pone oculos ftriga utrinque ad nucham nigro-virefcente, tectricibus alarum medio albis.

Anas americana, Gmel. Syft. i. p. 526.

Canard Jenfen, Buf. ix. p. 174.-Pl. Enl. 955.

American Wigeon, Arct. Zool, ii, N 502. -Lath. Syn. vi, p. 520.65. 
75 .

glocitans. A. fubcriftata fufca nigro undata, capite viridi, macula ante poneque oculos ferruginea, pectore maculis nigris, fpeculo alarum viridi albo marginato.

Anas glocitans, Act. Stock. 1779. xl. t. 33. f. I.-Gmel. Sy/t. i. p. 526. Bimaculated Duck, Br. Zool. ii. $\mathrm{N}^{\circ} 287$. t. Ioo. f. 2.-Lath. Syn. vi. p. 521.66.

Hавітат in Sibiria orientali, ad fluvium Lenam et lacum Baikalum; rarifime in Anglia.-Vox glocitans, - 20 pollices longa.

Rofrum plumbeum apice nigro: vertex et irides fufca: macula inter roftrum et oculum rotunda, et altera pone aures oblonga, ferruginea : abdomen lineato-granulatum : ale cinerex : tectrices ultima ferrugineo ftriatæ: remiges fecundariæ virides: rectrices 12,2 intermediæ nigræ, reliquæ fufce margine albo: pedes flavi.

76. malacorhynchos.

A. cæruleo-cinerea, roftri apice flexili membranaceo, vertice viridi-cinereo, alarum macula tranfverfa alba.

Anas malacorhynchos, Gmel. Syft. i. p. 526 .

Blue-grey Duck with a foft bill, Cook's Voy. i. p. 72. 97.-Forft. Voy. i. p. 157.

Soft-billed Duck, Latb. Syn. vi. p. 522.67 .

Habitat in nova Zealandia.-Vox fiftulans.-I 8 pollices longa.

Roftrum cinerafcens apiçe nigro: pectus ferrugineo adumbratum : pedes faturate plumbei.

77.

ferina.

A. cinereo-undulata, capite brunneo, fafcia pectorali crifto uropygioque nigro.

Anas ferina, Lin. Syft. i. p. $203 \cdot 31$.-Faun. Suec. $N^{\circ}$ 127.-Gmel. Syft. i. p. 530.-Brun. $\mathrm{N}^{\circ} 80 .-$ Muller, $\mathrm{N}^{\circ} 124 .-$ Frifch. t. $171 .-$ Faun. Helvet.-Forfk. Faun. Arab. p. 4. K. I3. (Batt.)

Anas fera fufca, Raii Syn. p. 143. A. 10.-Will. p. 288. t. 72.-Id. p. 282. 12. Fem.?-Klein. Av. p. I32. 5 .

Anas erythrocephala, N. C. Petr. xv. p. 465. 14. t. 20. Penelope, Brif. vi. p. 384 . r9. t. 35. f. 1. $-1 d$. 8 vo. ii. p. 462.

Millouin, 
Millouin, Buf. ix. p. 216.-Pl. Enl. 803.

Rothhals, Bl. Bef. der Berl. Nat. iv, p. 6o3. t. 17. f. 5. 6.-Id. iii. p. 374. t. 8. f. $x$.

Poker, Pochard, red-headed Wigeon, Br. Zool. ii. $\mathrm{N}^{\circ}$ 284.-Id. fol. 156. t. Q.5.-Will. (Angl.) P. 367.t. 72.-Arcz. Zool. ii. No 49 I. - Alb. ii. t. 98. - Lath. Syn. vi. p. 523.68.

Habitat in America, Afia, et Europa feptentrionali; hyeme apud nos in Anglia paludibus.-19 pollices longa.

Roftrum latum, validum, cæruleum, apice nigro: irides fulvæ: caput et collum rufo-caftaneum : pectus et dorfun fuperius nigrum : $\int c a p u-$ lares et teetrices alarum interiores albido et nigricante undulatim lineatæ: abdomen albidum lateribus lineis obfcuris : pedes plumbei.

Femine color pennarum obfcurior: caput pallide fufco-rubefcens: tectrices alarum et abdomen cinerea : in reliquis cum mare fatis convenit.

$\beta$. A. nigricans, capite colloque caftaneis, pectore et abdomine fufco cinereoque variis, alis albo grifeoque variis.

Penelope nigra, Brif. vi. p. 389 . A. -Id. 8 vo. ii. p. 463.-Latb. Syn。 vi. p. 524. 68. A.

78.

Variat etiam corpore fufco.

rufa. A. cinerea, capite et collo rufis, roftro pectore pedibufque nigris. Anas ruficollis, Scop. Amn. i. N' 8 r. -Gmel. Syft. i. p. 515. (rufa.) Rufous-necked Duck, Latb. Syn. vi. p. 477. 32.

Statura fere Bofcbadis.-Dorfum lineis fufcis repandis varium : caudc brevis, fed elongata ultra alas fedentis volucris. - Ferine nimis affinis, an diftincta?

79 .

fulva. A. fulva, corpore fuperiore et alis fulvo fufcoque ftriatis, cauda albo nigroque varia.

Anas fulva, Gmel. Syft. i. p. 530 .

Penelope mexicana, Brif. vi. p. $390.20 .-I d .8$ vo. ii. p. 464.

Mexican Pochard, Latb. Syn. vi. p. 524.

Habitat in Mexico.-Rofrum et pedes cinerei.

80.

Jacquini. A. fpadicea, dorfo nigricante, roftro pedibufque nigris, facq. Vog. p. 5. 3.-Gmel. Syjt. i. p. $53^{6}$. fima.

Habrtat in infula S. Dominici; viduate magnitudine; voce acutif-

A. cauda 
31.

864 A VES P A L I PEDES. Anas.

acuta. A. cauda acuminata elongata fubtus nigra, occipite utrinque linea alba, dorfo cinereo undulato.

Anas acuta, Lin. Syft. i. p. 202. 28.-Faun. Suec. No 126.-Gmel. Syft. i. p. 528.-Scop. Ann. i. $\mathrm{N}^{\circ}$ 73.- Brun. in App.-Muller, $\mathrm{N}^{\circ} 122$. -Kram. El. p. 340 . 9.-Georgi reife, p. 166.-Faun. Arag. p. 75. 3.-Faun. Helvet. - Decouv. RuJ. i. p. 162.

Anas caudacuta, Raii Syn. p. 147. A. 5.-Id. 192. 13.-Will. p. 289.

t. 72.-Frijch. t. 160.-Klein. Av. p. 133. 15.-Id. 136. 32. -

Slocn. Fam. p. 324. xi.

Anas longicauda, Brif. vi. p. 369. I6. t. 34. f. r. 2.-Id. 8 vo. ii. p. 459. Canard à longue queue, Buf. ix. p. 199. t. 13.-Pl. Enl. 954.

Tzitzihoa, Raii Syn. p. 175 .

Sea Pheafant or Cracker, Will. (Angl.) p. 376.t. 73.-Alb. ii. t. 94. 95. Pintail, Br. Zool. ii. $N^{\circ} 282 .-$ Id. fol. i 56 t. Q. 8. (Mas.)-Q. (Fem.) -ArE7. Zool. ii. No 500.-Lath. Syn. vi. p. 526. 72 .

Habitat in Europa, America, et Afra boreali; hyeme in Anglia verfatur, at non copiofe; 28 pollices longa.

Roftrum elongatum et pedes nigricantes : caput purpureo-fufcum : corpus fupra grifeum tæniolis nigricantibus : collum antice et corpus fubtus album : alæ fufcæ, $\int p e c u l o$ violaceo, antice ferruginen, poftice albo nigroque : fcapulares anguftæ nigræ, albo marginatæ: criffum nigrum : rectrices fulcæ, 2 intermediæ longiffimæ apice acutæ, nigræ: labyrinthus parvus ovatus.

Femina rufo-fufco et obfcuro varia: tectrices alarum fufcefcentes grifeo marginatæ, jpeculo alarum pallide fufco, fupra albo inf́ra albo marginato. Gunior mas, primo anno, femine fimillimus.

82.

glacialis, A. cauda acuminata elongata, corpore nigro fubtus albo. (Mas adultus.) Anas glacialis, Lin. Syft. i. p. 203. 20.-Gmel. Syft. i. p. 529.-Scop. Ann. i. $\mathrm{N}^{\circ}$ 74.-Brun. $\mathrm{N}^{\circ}$ 75.76.-Muller, $\mathrm{N}^{\circ} 123 .-$ Pbil. Tranj. lxii p. 418.

Anas longicauda ex infula N. Terræ, Brif. vi. p. 382. 18.-Id. 8 vo. ii. p. $46 \mathrm{I}$.

Canard à longue queue, Buf. ix. p. 202.

de Miclon, Pl. Enl. 1008 .

Swallow-tailed Shieldrake, Will. (Angl.) p. 364.

Long-tailed Duck, Br. Zool. ii. $\mathrm{N}^{\circ} 283$. -Id. fol. I 56. t. Q. 7.-Edw. t. 280.-Arct. Zool. ii. No $501 .-I d$. Sup. p. 76.-Lath. Syn. vi. p. 528. 73 .

HABITAT 
Habitat in Europa, Afie, et America borealibus; in infulis Orcadibus gregatim hyeme migrans; in Anglia feptentrionali rarius obfervata. -Nidificat ad finum Hudfonis et in Groenlandia.-Ovum al bo-cærulefcens

Roftrum nigrum medio rubrum : caput anterius et lateribus rufo-grifeum, cæterum cum collo, pectore, et abdomine album: fcapulares elongatæ, mucronatæ, albæ: lateribus colli macula nigra: peøtus imum, dorfum, alc, cauda nigra, in quibufdam fufca: reatrices 4 media nigra, 2 intermediis longiffimis; reliquæ albæ: pedes obfcure rubri, aut rubronigricantes,

ß. A. cauda cuneata, rectricibus intermediis longis, corpore albo, temporibus pectore dorfo alifque nigris. (Junior mas.)

Anas hyemalis, Lin. Syjt. i. p. 202. 29. - Faun. Suec. $\mathbb{N}^{\circ} 225$. Anas caudacuta, Havelda, Raii Syn. p. 145. 14.-Will. p. 290. Anas longicauda illandica, Brif. vi. p. 379 . 17.-Id. 8 vo. ii. p. 460 . Long-tailed Duck, Edw. t. 1 56.-Will. (Angl.) p. 364. \$ 5.-Lath. Syn. vi. p. $529 \cdot 73$.

Rofrum ut in priore: latera capitis alba : occiput cinereum : collum, pe\&tus, dorfum nigricans: pectus inferius, fcapulares caftanex : abdomen album.

$\gamma$. A cauda cuneata, corpore nigricante rufo et grifeo vario, dorfo nigro, collari abdomineque imo albis. (Femina.)

Long-tailed Duck, female, ArEt. Zool. ii. App. p. 76.

Roftrum nigrum, aut circulo pallido cinctum: vertex et latera colli partim nigricantia: dorfum et uropygium nigrum tranfverfim grifeo varium : cauda brevis, cuneiformis.

Funiori femine vertex et collum nigra albo confperfa : orbite cinereæ: gula, pectus inferius, abdomen alba: dorfum obfcure cinereum: cauda obfcura, lateribus alba.

§. A. fufco-nigricans fubtus alba, capite lateribus dilute grifeo, orbitis candidis, occipite gula collo maculis fúfis; macula alarum fufcorufefcente.

Querquedula ferroenfis, Brif. vi. p. 466.40 . t. 40. f. 2.- $-I d$. 8 vo. ii. p. 482 .

Sarcelle de Ferroe, Buf. ix. p. 278.-Pl. Enl. 999.-Latb. Syn. vi. p. 53. 
Haвıтат in Ferroenfli infula fub nomine Oëdel. Forte varietas pra83.

difpar. A. alba fubtus ferruginea, occipitis macula fronteque virefcentibus, orbitis gula jugulo collari dorfoque nigris.

Anas difpar, Mus. Carlf. fafc. i. t. 7. 8.-Gmel. Syft. i. p. 535. Anas Stelleri, Pall. Spic. vi. p. 35.t. 5.-Gmel. Syft. i. p. 518. Weftern Duck, Arct. Zool. ii. No 497. t. 23.-Lath. Syn. vi. p. 532. 74.-Id. Sup. p. 275.

Habitat in America, Suecia, Kamtscbatka.-I7 pollices longa.

Occiput fubcriftatum pennis fubvirefcentibus : fafcia ab oculo ad oculum frontali concolore: orbite nigræ: remiges fecundariæ albo nigroque dimidiatæ, apice rotundatæ incurvæ: $\int$ capulares concolores, elongatæ, acuminatæ: roftrum et pedes nigri.

Femine totum corpus ferrugineo et fufco fcolopacinum: remiges omnes rectæ, nigricantes : macula major e tectricibus alarum apicibus al-

84. bis, et altera minor.

ferruginea. A. fufco-rufa, abdomine albo, roftro dilatato pedibufque pallide cæruleis.

Anas rufa, Faun. Suec. N $\mathrm{N}^{\circ} 34$.

Anas ferruginea, Gmel. Syft. i. p. 528.

Red Duck, Arct. Zool. ii. N 576. N.

Ferruginous Duck, Br. Zool. ii. $\mathrm{N}^{\circ} 285$. t. 99.-Latb. Syn. vi. p。 526.71 .

Habitat in Suecia, Dania; in Anglia femel occifa.-An difparis femine?

85.

caryophyl- A. fufco-badia, roftro capite colloque fupremo caryophyllaceis, fpeculo lacea. ferrugineo, pedibus cæruleis. Pink-headed Duck, Latb. Syn. Sup. p. 276.

Haвiтat in India; per paria incedens; facile manfuefcit.-21 pollices longa.

Roftrum elongatum, apice potius adunco: caput et collum ad medium ufque caryophyllaceum, pennis curtis: irides rubra: tectrices alarum

86. majores elongatæ, incurvatæ, ut in præcedente: pedes cæruleo-grifei.

albeola. A. alba, dorfo remigibufque nigris, capite colloque cærulefcente fericeo nitente, occipite albo. (Mas.) 
Anas albeola, Lin. Syft. i. p. 199. 18.-Pbil. Tranf. 1xii. p. 416. 18.Gmel. Syft. i. p. 517 .

Anas bucephala, Lin. Syft. i. p. 200. 2 1. $-G m e l$. Syft. i. p. 52 I. Querquedula ludoviciana, Brif. vi. p. 46 1. 38. t. 4 1. f. I. $-I d$. 8 vo. ii. p. $48 \mathrm{I}$.

Anas hyberna, Brif. vi. p. 349. 10.-Id. 8 vo. ii. p. 454.

Sarcelle blanche et noire, ou la Religieufe, Buf. ix. p. 284.-Pl. Enl. - 948 .

Petit Canard à groffe tête, Buf. ix. p. 249.

Little black and white Duck, Edw. t. 100.

Spirit Duck, Arct. Zool. ii. $\mathrm{N}^{\circ} 487$.

Buffel-headed Duck, ArEt. Zool. ii. No 489.-Cat. Car. i. t. 95--Lath. Syn. vi. p. 533.75 .

A. fufco-cinerea, macula aurium alarumque alba. (Fenina.)

Anas ruftica, Lin. Syft. i. p. 201. 24.-Gmel. Syft. i. p. 524.

Querquedula carolinenfis, Brif. vi. p. $464.39 .-I d$. 8 vo. ii. p. 482.

Sarcelle de la Caroline, Buf. ix. p. 286.

Little brown Duck, Cat. Car. i. t. 98.-Lath. Syn. vi. p. 524.

Habitat in America; a Carolina ad finum Hudfonis migratoria; ni. dificans in arboribus. - I 6 pollices longa.

Roftrum nigrum : pedes aurantii : caput et collum, fere ad medium, fericeo-nigra, viridi et purpureo varia : occipitis fafcia ab oculo ad oculum alba: cauda cuneata, cinerea, rectricibus 3 exterioribus albis.

Femina minor : roftrum et pedes nigri : irides avellanex : caput et corpus fupra fufcum : pone oculos utrinque macula ovata alba : gula et corpus fubtus alba : ale fufcæ, medio macula alba.

Clangula. A. nigro alboque varia, capite tumido violaceo, finu oris macula alba. Anas Clangula, Lin. Syft. i. p. 201. 23.-Faun. Suec. $N^{\circ} 192 .-G m e l_{0}$ Syft. i. p. 523.-Scop. Ann. i. $\mathrm{N}^{\circ} 71 .-$ Brun. $\mathrm{N}^{\circ} 70.71 .-$ Muller, I 1 9.-Klein. Av. p. 1 33. I 3.-Id. 1 35. 27.—Kram. El. p. 341. I 3. -Frijch. t. 1 83 . 184.-Georgi reise, p. 166.-Faun. Groenl. N 43. -Brif. vi. p. 4 I6. 27. t. 37. f. 2.-Id. 8vo. ii. p. 470.-Raï Syn。 p. 142. A. 8.-Will. p. 282.13 . t. 73. -Pbil. Tranf. lxii. p. 417. 48.-Faun. Helvet.-MarS. Dan. v. p. 114 . t. 55.

L.e Garrot, Buf. ix. p. 222.-Pl. Enl. 802 .

Quakerente, Bl. Bef. der Berl. Nat. Fr. iv. p. 499. 9. t. 17. f. ז. 2. Golden-eye, Br. Zool. ii. $\mathrm{N}^{\circ} 276 .-I d$. 1 54. t. Addend.-ArCt. Zool. ii. ${ }_{5} \mathrm{~S}_{2}$ 
$\mathrm{N}^{\circ}$ 486.-Alb. i. t. 96.-Lath. Syn. vi. p. 535.76.-Will. (Angl.) p. 368. t. 73 .

Habitat in Europa, Afia, et America feptentrionali ; in cavis arborum nidificans, ova ponens $7-10$ alba. $\rightarrow$ I 9 pollices longa.

Roftrum nigrum : irides aureæ: caput et collum dimidium viridi-violaceo-nigra: pedes rubri: trachea ad divaricationem labyrintbo donatur, et præterea fuperius in ventrem intumefcit.

Feminc caput rubro-fufcum : collum grifeum : pectus et abdomen alba: tectrices alarum obfcuro et cinerafcente variæ: remiges mediæ albæ, re. liquæ cum cauda nigræ: pedes obfcuri.

88.

Glaucion. A. corpore nigricante, pectore nebulofo, fpeculo alarum albo lineari.

Anas Glaucion, Lin. Syft. i. p. 401 . 26.-Faun. Suec. No 123.-Gmel. Syjt. i. p. 525.-Scop. Ann. i. No 72.-Brun. No 89.-Muller, $\mathrm{N}^{\circ}$ I 20.-Raii Syn. p. 143. I 1.-Id. p. I44.-Will. p. 282. \$ ix. x. xi. xii.

Anas peregrina, S. G. Gmel. It. ii. p. I83. t. 16. Morillon, Brif. vi. p. 406.25 . t. 36. f. r. 2.-Id. 8 vo. ii. p. 468. Glaucium, or Morillon, Br. Zool. ii. $\mathrm{N}^{\circ} 277 .-$ ArEz. Zool. ii. p. 573. F. -Will. (Angl.) p. 367. \& xii.-Latb. Syn. vi. p. 537. 77 .

Haвiтат cum præcedente, a cujus juniore paucis differt.

Caput ferrugineum: irides aureæ : collum albo circumdatum, infra collare latius grifeum: corpus fupra grifeum, lineis fparfis albis : remiges. primores nigræ; fecundariæ, pectus, abdomen alba: color corporis in variis variat. In quibufdam macula ad angulum mandibulæ inferioris albida, nonnullis quoque ad divaricationem tracbec labyrintbus eft.

89. nova Hif- A. alba nigro maculata, capite fulvo nigricante et viridi-cærulen vario, pania. tectricibus alarum et criffo cæruleis, macula inter roftrum et oculum fafciaque alarum alba. Anas novæe Hifpaniæ, Gmel. Syft. i. p. 525 . Querquedula mexicana, Brif. vi. p. $45^{8}$. $37 .-I d .8$ vo. ii. p. 480 . Toltecoloetli, Metzcanahachtli, Raii Syn. p. 175. Sarcelle du Mexique, Buf. ix. p. 285.-Defcr. Surin. ii. p. $15^{8 .}$ Mexican Duck, Lath. Syn. vi. p. 539. 78.

Habitat in Mexico; Querquedule magnitudine.

Roftrum cæruleum fubtus nigrum : pedes pallide rubri : remiges intermedia extus virides apicibus fulvis.

Femina 
Femina capite et corpore fupra nigris fubtus albo nigroque varia : ma90. cula alarum viridi ut in mare: pedes cinerei.

Fuligula. A. crifta dependente, corpore nigro, abdomine fpeculoque alarum albis. Anas Fuligula, Lin. Syft. i. p. 207. 45. - Faun. Suec. $\mathrm{N}^{\circ}$ i 32.-Gmel. Syft. i. p. 543.-Scop. Ann. i. No 78.-Kram. El. p. 341. T2.Georgi reije, I67.-Brun. $\mathrm{N}^{\circ} 90 .-M u l l e r, \mathrm{~N}^{\circ}$ I 29.-Frifch. t. I7 I. -Klein. Av. p. 133. I1.-Will. p. 280. t. 73.-Borowe/k. Nat. iii. p. I9. I 5.- Faun. Helvet. Anas crittata, Raii Syn. p. 142. A. 7.-Ferm. Surin. ii. p. I 56. 3. Glaucium minus, Brif. vi. p. 4 II. 26. t. 37. 1. -1 Id. 8 vo. ii. p. 469. Morillon, Buf. ix. p. 227. 23r. t. 15.-Pl. Enl. Ioor. Europaeifche Haubenente, Bl. Bef. der Berl. Nat. iv. p. 6o3. Tufted Duck, Br. Zool. ii. N ${ }^{\circ}$ 274.-Id. fol. 1 53.-ArEt. Zool. ii. p. 573. G. - Alb. i. t. 95.-Will. (Angl.) p. 365. t. 73.-Hayes Br: Birds, t. 26. -Lath. Syn. vi. p. 540.79 .

Habit at in Europe et borealis Afie maritimis.-I6 pollices longa. Roftrum intenfe cæruleum, apice nigrum : irides aureæ: caput aliquo virore nitens: Scapulares ad fufcum inclinantes maculis minutis vix confpicuis flavefcentibus : pedes obfcure carulei : tracbea ad divaricationem tumida, planiufcula, offea, fupra rotundata, infra fubbifida.

Femine occiput læve, et color totius corporis ad fufcum inclinat.

Funiori avi caput, collum, et pellus caftanea: pennæ ad bafin roftri flavefcentes: dorfum, ala, cauda nigra : abdomen lineaque alarum alba.

$\beta$. A. criftata fufca, capite violaceo-nigro, uropygio fuliginofo albo vario, roftro pedibufque nigris, Scop. Ann. i. 78 . var. I.

$\gamma$. A. fubcriftata nigra, dorfo fufco, capite ac initio colli rufis, remigibus albis, ad bafin alarum fafcia alba, Scop. Ann. i. 78. 2 .

ঠ. A. criftata fubtus alba, capite rufo, temporibus viridi-nitidis, alis fafcia rufa, poftea viridi-nitente, denique nigra, remigibus fufcis, Scop. Ann。 i. $\mathrm{N}^{\circ} 78 \cdot 3$.

91. Nyroca.

A. atro-olivacea, capite collo pectoreque caftaneis, uropygio nigro, abdomine criffo maculaque alarum albis.

Anas Nyroca, N. C. Petr. xiv. p. 403.-Gmel. Syft. i. p. 542. Tufied Duck, Lath. Syn. vi. p. 54I, 79. var, A.

HABITAT: 


\section{AVES PALMIPEDES. Anas.}

Habitat circa Tanain, intra latit. 54 et $55 \mathrm{~N},-16 \frac{x}{2}$ pollices longa.

- Monogama, 6-8 ova albida in terra elevata Maii menfe ponens.

Mari caput pone tumidiufculum, non criftatum : irides albidæ.

Femina minor, fordide ferruginea ubi mas caftaneus : abdomen albido

92. nebulofum: dorfum magis ad rufum vergens. An Fuligule varietas?

N. Zea- A. nigra viridi nitens fubtus cinerafcens, capite colloque poftice cælandia. ruleo et purpureo nitente, fafcia alarum alba.

Anas novæ Zealandiæ, Gmel. Syft. i. p. 54I.

Hepatek, Forft. Voy. i. p. r68.-Cook's Voy. i. p. 72 ?

New Zealand Duck, Latb. Syn. vi. p. 543.80.

HABItAт in $N$. Zealandia; Fuligule affinis.-I 5 pollices longa.

Roftrum albo-cærulefcens apice nigro: irides aureæ: pedes cinerafcentes.

93.

criftata. A. criftata cinerea, fronte genis colloque poftico cinerafcentibus, gula juguloque flavefcentibus maculis ferrugineis, fpeculo alarum cæruleo fubtus albo.

Anas crittata, Gmel. Syft. i. p. 540.

Crefted Duck, Lath. Syn. vi. p. 543. 8 I.

Ha вгт Aт in Statenlandia.-28 pollices longa.

Roftrum, remiges, et cauda nigra: irides rubræ.

94.

rufina. A. nigra, dorfo et alis fufcis, capite colloque teftaceo-rubris, vertice rufefcente, fpeculo albo nigro marginato.

Anas rufina, Pall. reife, ii. p. 7 1 3. 28.-Gmel. Syjt. i. p. 54 I.

Anas fiftularis criftata, Brif. vi. p. $398.22 .-I d$. 8 vo. ii. p. 465 .

Anas criftata flavefcens, Marf. Dan. p. 108. t. 52.-Klein. Av. p. 135. 26.

Canard fiffleur huppé, Buf. ix. p. i 82.-Pl. Enl. 928.

Anas capite ruffo major, Raii Syn. p. 140. 2.-Will. p. 27.9.

Great red-headed Duck, Will. (Angl.) p. 364. 7.

Barbary Shoveler, Sbaw's Trav. p. 254?

Red.crefted Duck, Latb. Syn. vi. p. 544. 82.

Haвiтat in mari Cafpio, lacubufque vaftiffmis deferti Tatarici; folitaria; Italia quoque et Barbaria inventa.-2 pedes longa.

Roftrum cinnabarinum : irides fufcæ: crifta rotundata tumida: pedes fufci antice rubri. Femina fufca, roftro rubefcente, capite abfque crifta.

A. criftata 
95.

A VES PAL I PEDES. Anas.

inlandica. A. criftata nigra, jugulo pectore abdomineque albis, pedibus croceis. Anas illandica, Gmel. Syft. i. p. 54 I.

Hrafn-ond, Muller, N० I 31.-Ifl. reife, 688.-Arct. Zool. ii. p. 574. H. Iceland Duck, Lath. Syn. vi. p. 545.83.

HABITAT in Ifandia.

96.

obfcura. A. fufca, collo ftriis longitudinalibus obfcuris, fpeculo alarum cæruleo nigro marginato, rectricibus albo marginatis.

Anas obfcura, Gmel. Syft. i. p. 54r.

Dufky Duck, Latb.Syn. vi. p. 545. 84 .

Habitat in Noveboraco.-2 pedes longa.-Roftrum cæruleo-obfcurum : remiges primores obfcuræ: pedes obfcure flavi.

97.

fponfa. A. crifta dependente duplici viridi cæruleo alboque varia.

Anas fponfa, Lin. Syft. i. p. 207. 43.-Gmel. Syjt. i. p. 539.-Borowej. Nat. iii. p. 20.16.

Anas æettiva, Brif. vi. p. 35 I. I I. t. 32. f. 2.-Id. 8 vo. ii. p. 455.

Yztacton Yahauhqui, Raii Syn. p. 176.-Will. p. 299.-Klein. Av. p.

I 34. 2 I.

Beau Canard huppé, Buf. ix. p. 245.-Pl. Enl. 980.98 r.

American wood Duck, Brown. Fam. p. $48 \mathrm{r}$.

Summer Duck, Cat. Car. i. t. 97.-Edw. t. ror.-ArEt. Zool. ii. No 493.-Lath. Syn. vi. p. 546.85 .

Habitat in Americe calidioribus et temperatis, Antillarumque infulis; migratoria; in cavis arborum nidificans.-19 pollices longa.

Roftrum et pedes rubri : irides flammex : gula alba : collum et pectus vinacea maculis albis triquetris: dorfum fufcum : fcapulares cæruleovirides : bypocbondria albido nigroque lineata. Femina minor : corpus fufcum fubtus fordide album fufco varium, maculis triquetris pallidis.

98. galericulata.

A. crifta dependente dorfoque poftico utrinque penna recurvata compreffa elevata.

Anas galericulata, Lin. Syft. i. p. 206. 42.-Gmel. Syft. i. p. 539. Querquedula finenfis, Brif. vi. p. $450.34 .-I d$. 8 vo. ii. p. 478 . Kinmodfui, Kampf. Fapan. p. 129. t. 10. f. 3 .

Sarcelle de la Chine, Buf. ix. p. 276. t. 19.-Pl. Enl. 805.806. Chinefe Teal, Edw. t. 102.-Lath. Syn. vi. p. 548. 86.

Habitat in Cbina et Faponia; Penelope paulo minor. 
Roftrum rubrum: irides avellaneæ: crifta occipitis viridis et rubra: pedes fulvi : dorfum fufcum cæruleo-viridi micans : Speculum cæruleoviride, inferiore margine album : remiges fufca, intima claufis alis altero margine erigitur fupra dorfum rufa, antrorfum falcata : abdomen album: pedes fulvi. Femina feminæ $\int p o n f e$ fimilis, at capite fubcriftato, ftriga pone oculos gulaque alba: corpus fubtus album : pętus fufco-vinaceum maculis rotundato-ovatis albis.

99.

Querquedula.

I00.

Crecca.

A. macula alarum viridi, linea alba fupra oculos.

Anas Querquedula, Lin. Syft. i. p. 203. 32.-Faun. Suec. No 128.Gmel. Sift.i. p. 531.-Scop. Ann. i. p. 75.-Brun. No8 I.-Muller, $N^{\circ}$ I 25.-Kram. El. p. 343. 18. - Frifch. t. 176.-Brif. vi. p. 427. 31. t. 39. f. I. 2.-Id. 8 vo. ii. P. 473.-Raii Syn. p. 148. 8.Will. p. 291. t. 74.-Klein. Av. p. I 32. 8.-Faun. Arag. p. 75. 5. - Faun. Helvet.

Phafcas forte Gefnero D. Johnfon, Raii. Syn. p. 147. A. 4. (Fem.)Will. p. 289 .

Sarcelle, Buf. ix. p. 260.-Pl. Enl. 946. (Mas.)

Winterhalbente, Bl.Bef. der Berl. Nat. iv. p. 600. t. I8. f. 6. Garganey, Br. Zool. ii. No 289. t. Ior.-Id. fol. 158. t. Q. 9.-Arct. Zool. ii. p. 576. O.-Will. (Angl.) p. 377. 7. t. 74.-Latb. Syn. vi. p. 550.87 .

Habitat in Europe et Afia aquis dulcibus: hyeme in Anglia verfatur.- 17 pollices longa.

Roftrum et pedes nigri: pone oculos ad nucham linea alba : caput inferius et collum purpureo-caftanea ftriis albis : pectus concolor lunulis albis : abdomen album : tedtrices alarum grifeo-cinereæ; Speculum fordide viride, fupra et infra album: Scapulares nigræ cinerafcente marginatæ fcapis albis : ad tracbea divaricationem labyrintbus parvus.

Femina mare minor, magis decolor: fupra oculos macula alba: ale abfque fpeculo viridi.

A. fpeculo alarum viridi, linea alba fupra infraque oculos.

Anas Crecca, Lin. Syft. i. p. 204. 33.-Faun. Suec. No $\mathrm{N}^{\circ} 29 .-$ Gmel. Syft. i. p. 532.-Brun. No 82. 83.-Muller, N 1 26.-Kram. El. 343. 19.-Frifch. t. 174.-Georgi reife, p. 166.-Sepp. Vog. t. p. 147.-Klein. Av. p. I33. 14.-Id. I 36. 31.-Id. 1 32. 8. - Id. Stem. p. 31. t. 35. f. 2. a. b.-Faun. Arag. p. 75. 6.-Borowfk. Nat. iii. p. 1 3. 8.-Scbof. El. t. 19.-Faun. Helvet.-Pbil. Tranf. 1xii. p. $4 \mathrm{I} 9 \cdot 5 \mathrm{I}$.

Querquedula 
Querquedula fecunda Aldr. Raii. Syn. p. 147. A. 6.-Id. 192. 14.Id. 148. 9. (Fem.) -Will. p. 290. t. 74 .

Querquedula minor, Brif. vi. p. $43^{6 .} 3^{2}$.t. 40 . f. r. $-I d$. 8 vo. ii. p. 475 . Petite Sarcelle, Buf. ix. p. 265. t. 17. 18.-Pl. Enl. 947.

Krikente, Bl. Bef. der Berl. Nat. iv. p. 600.

Common Teal, Br. Zool. ii. $\mathrm{N}^{\circ}$ 290.-Id. fol. t. Addend.-Arct. Zool. ii. p. 577. P.-Will. (Angl.) p. 6. t. 74.-Alb. 1. t. 100.-Hayes Br. Birds, t. 29.-Latb. Syn. vi. p. 551. 88.-Id. Sup. p. 276.

Habitat in Europa, Afia.-1 4 pollices longa.-In Anglie boreali parte et in Scotia nidificat; hyeme auftraliores petens. $-N i d u m$ ad aquas fluviatiles magnum ftruit, ova 6-7 alba maculis avellaneis ponens.

Roftrum nigrum : irides avellanex : caput et collum rubefcenti-badia : pone oculos ad nucham fafcia lata viridis, fubtus linea alba marginata: linea fupra oculos alba: corpus albidum, fupra lineis tranfverfis nigricantibus : collum antice et pectus maculis rotundis nigris : Jpeculum viride albo fubtus marginatum fupra oblique nigrum: crifjum medio nigrum: tracbea labyrintbo donatur.

Femine caput et collum albido fufcoque varia : ale ut in mare: criffum totum album.

ß. A. fpeculo alarum varii coloris, linea alba fuperciliari roftro pedibufque cinereis.

Anas Circia, Lin. Syjt. i. p. 204. 34.-Faun. Suec. N 130.-Gmel. Syft. i. p. 533. -Scop. Ann. i. $\mathrm{N}^{\circ} 76 .-$ Brun. $\mathrm{N}^{\circ} 83 .-$ Raii syn. p. I48. 7.-Will. p. 291 . t. 76.-Klein. Av. p. 132. 8.

Querquedula æeftiva, Brif. vi. p. $445.33 .-I d .8$ vo. ii. p. 477. Sarcelle d'été, Buf. ix. p. 268.

Sommerhalbente, Bl. Bef. der Berl. Nat. iv. p. 604. t. 18. f. 4. Summer Teal, Will. (Angl.) p. 378. t. 76.-Alb. ii. t. 103. 104.Lath. Syn. vi. p. 552.89 .

Habitat in Europa.- $13 \frac{x}{2}$ pollices longa.

Corpus fupra fufco-cinereum, dor $\sqrt{2}$ pennis apice albicantibus, fubtus rufo-album, abdomine maculis nigris: Jupercilia alba: gene et gula caftanea : collum antice rufum pennis margine fufcis: Speculum alarum ut in Crecca.

$\gamma$. Variat dor $f 2$ marginibus pennarum rufis ; genis, gula, et corpore fubtus rufo-albis; $\int p e c u l o$ abfque nigredine.

$$
5 \mathrm{~T} \text { s. A. roftro }
$$


ঠ. A. roftro nigro, fpeculo alarum fupra oblique viridi, infra oblïque nigro.

Anas Balbul, Fork. Faun. Arab. p. 4. No 12.-Gmel. Syft. i. p. 543.

Habitat Kabire vulgaris.-Corpus cinereum albo undulatum fubtus albidius : caput brunneum macula magna et longa viridi-rubente utrinque ad tempora : in collo pone macula atro-cærulea, quæ maculas virides conjungit : ad bafin roftri fubtus macula nigra,

Femine caput cinereum undulatum.

IOI.

carolinen- A. nigro alboque undulata, capite colloque fupra caftaneis, fafcia pone

fis. oculos fpeculoque alari viridibus, humeris lunula alba, infra oculos linea obfolete alba.

Anas carolinenfis, Gmel. Syft. i. p. 533.

Anas Crecca, var. Pbil. Tranf. lxii. p. 419. 5 1.-Faun. Amer. p. 17. American Teal, Arct. Zool. ii. No 504.-Lath. Syn. vi. p. 554. 90.

Ha BItat in America a Carolina ufque ad finum Hudfonis.

Femina rubefcenti-cinereo-fufca maculis nigris. An fatis diftineta a Crecca.

102.

dominica, A. rufa, capite anteriore fuliginofo, fpeculo alarum candido, rectricum fcapis aterrimis.

Anas dominica, Lin. Syft. i. p. 201. 22.-Gmel. Syft. i. p. 521.

Querquedula dominicenfis, Brif. vi. p. 472 . 42. t. 41 . f. 2. $-I d$. 8 vo. ii. p. 484 .

Sarcelle rouffe à longue queue de la Guadeloupe, Buf. ix. p. 283.Pl. Enl. 968.

Chilcanauhtli, Raii Syn. p. 177.-Colcanauhtli, 1d. 176. (Fem.)

St. Domingo Teal, Latb. Syn. vi. p. 554. 91 .

Habitat in Dominicenfi infula et Aquarum Lupiarum. - I 2 pollices. longa.-Cauda elongata cuneata, rectricibus acuminatis : roftrun nigrum: pedes fufci.

103.

I03.
finofa. A. fufco-nebulofa, genis gulaque albis, vertice fafcia per oculos alteraque maxillari utrinque nigris, rectricibus mucronatis.

Anas fpinofa, Gmel. Syjt. i. p. 522 .

Sarcelle à queue épineufe, Buf. ix. p. 282.-Pl. Enl. 967.

Spinous-tailed Teal, Latb. Syn. vi. p. 555. 92.

Habitat in Cayana, Guiana. $\mathrm{x} \mathrm{I}-\mathrm{I} 2$ pollices longa. 
Rofrum nigrum : pedes incarnati : remiges reetrice/que nigra : macu104. africana. la tectricum alba.

ro5. madagafcarienfis.

106. coromandeliana.

107. manillen- A. fufca, capite anteriore gula jugulique parte fuprema albis, abdomifis.

A. obfcure viridis, facie ultra oculos gula abdomineque albis, jugulo imo pectore et lateribus ferrugineis fufco undulatis, infra aures macula ovata viridi.

Anas madagafcarienfis, Gmel. Syft. i. p. 522.

Sarcelle male de Madagafcar, Buf. ix. p. 274.-Pl. Enl. 770.

Madagafcar Teal, Lath. Syn. vi. p. $55^{6 .}$.94.

Habitat in Madagafaria.-12 pollices longa。

Roftrum flavum apice nigro: irides flavæ : ftria alarum longitudinalis et abdomen medium alba: latera corporis fub alis ferrugineo varia: pedes obfcuri。

A, alba, vertice dorfo alis caudaque æneo-fufcis, collo maculis friifque nigricantibus, macula alarum alba.

Anas coromandeliana, Gmel. Syft. i. p. 522 .

Sarcelle de Coromandel, Buf. ix. p. 274.-Pl. Enl. 949. 950.

Coromandel Teal, Latb. Syn. vi. p. 556. 95 .

$\mathrm{H}_{\text {ABITAT }}$ in Coromandela; 2uerquedula quarta parte minor.

Crifum lateribus pallide ferrugineum. Femina mari fimillima, at magis decolor, abdomine grifeo varia, collique lineis minus diftinctis.

ne albo lunulis nigris, remigibus reetricibufque fchifti colore.

A. dorfo alis caudaque nigris, capite collo pectore fupremo abdomineque fufco-rufis, macula pectoris inferioris fafciaque alarum albis. Anas africana, Gmel. Syft. i. p. 522. Sarcelle d'Egypte, Buf. ix. p. 273.-Pl. Enl. 1000. African Teal, Latb. Syn. vi. p. 555.93.

HaBitat in Egypto; Querquedula paulo major, rofto longiore.$x 6$ pollices longa.

Femine color pennarum fere ut in mare, at obfoletior, et macula pectoris fufco undulata.

Anas manillenfis, Gmel. Syft. i. p. 523 .

Sarcelle de l'ille de Luçon, Son. Voy. p. 9r. to 54.

Manilla Teal, Lath. Syn。 vi. po 523. 96. 
Habitat in Manilla; Querquedula minor.

Roftrum longiufculum et pedes nigri : pennæ $\operatorname{dor} f$ flavefcentes, nigro 108. formofa. A. fufca, vertice nigro albo marginato, gula rufefcente nigro maculata, alarum fpeculo nigro teftaceo marginato, anterius macula obliqua viridi-nitente infignito.

Anas formofa, Georgi reife, i. p. 168.-Gmel. Syft. i. p. 523.

Baikal Teal, Lath. Syn, vi. p. 557. 97.

Habitat circa lacum Baikalum. - I 5 pollices longa.

Roftrum nigrum : pedes obfcure rubri: ab oculo ad gulam macula incurvata nigra, poftice pallida, viridi marginata: nucba collumque lateribus undulatum : criffum nigrum lateribus ferrugineum, fafcia alba.

ß. A. fufca vertice nigro, capite lateribus fufco-flavefcentibus, pone oculos viridi macula incurvata nigra.

HАBiтAT in Cbina.

109.
Hina. A. regione oculorum viridi, Oß6. $V_{0 y}$. ii. p. 33.-Gmel. Syft. i. p. 523. Hina Teal, Lath. Syn. vi. p. 558. $9^{8}$.

HaBiтAт in Cbina.-Roftrum molle, grifeo-nigricans : caput et collum fufcum : fub oculis linea alba; fupra oculos color viridis: collum dorfumque fuperius nigro maculatum: uropygium cinereum : pectus et $a b$ domen alba poftice nigro maculata.

Femine caput grifeo-albidum : gula alba : corpus fupra nigrum rubefcenti-albo varium, fubtus album maculis nigris.

IIO.

Sparrman- A. fubtus fordide alba, fupra nigro ferrugineo alboque varia, fcapulani. ribus nigris margine lineifque difci albo-ferrugineis, antice in angulum coalefcentibus variegata.

Anas alandica, Muf. Carlf. fafc. iii. t. 60.

HaвiтAт in Alandia verfus Aboam. -23 pollices longa.

Roftrum et pedes nigri : cauda ferruginea, nigro fubfafciata.

111.

Gmelini. A. nigra, capite fpadiceo, pectore lineis rubris tranfverfis, S. G. Gmel. reife, i. p. 70.-ii. p. I82. t. 16.-Gmel. Syft. i. p. 53 I.

Habitat in mari Cajpio et reliqua Rufja auftrali; Cresca major. 


\section{A VES PALMIPEDES. Anas. 877}

Sinus oris macula alba : abdomen albidum nigricante maculatum; ad latera cum criffo niveum: remiges $1-4$ extus nigræ intus cinerex; 5-10 utrinque cinerex; I I-I9 albæ: 20 anterius partim alba partim nigricans, polterius cinerea; omnes apice nigræ; $21-25$, cum tectricibus, II 2. totæ nigræ: rectrices 12 nigræ.

Kekufch- A. ochracea fubtus nivea, dorfo cinereo, uropygio caudaque nigerrimis, ka.

I 3 . remigibus $15^{-1} 9$ apice albis, S. G. Gmel. reife, iii. p. 249. t. 26 . 27.-Gmel. Syft. i. p. 53 I.

HABITAT ad mare Cafpium; ultra I9 pollices longa; carne rancida.

arabica. A. grifeo maculata, fubtus et uropygio albida maculis cinereis, alarum fpeculo nigricante anterius et pofterius albo. Anas Scar chir, Fork. Faun. Arab. p. 3. 7. Anas arabica, Gmel. Syft. i. 542 .

Haвıт at in Arabia.-Roftrum flavum medio nigrum: pedes cinereoflavicantes.

114.

alexandri- A. roftro criffoque nigris, collo cinereo femicirculis nigris, abdomine

na. albo, pedibus cinereo-flavis.

Anas Sau Sarai, Fork. Faun. Arab. p. 3. 8.

- alexandrina, Gmel. Syft. i. p. 542.

Habitat Alexandrice.

II5.

Gattair. A. fufca, alis nigris fubtus albis margine fufcis, remigibus 4-20 medio albis

Anas Gattair, Forfk. Faun. Arab p. 3. 10.-Gmel. Syft. i. p. 542.

HABITAт in Alexandria.-Roftrum fufcum fubtus nigrum: gula ni116. gra : abdomen et tectrices caudæ alba: pedes cæruleo-cinerei.

Sirfæir. A. roftro fubtus flavo, fpeculo alarum oblique dimidiato, fupra fericeo-viridi fubtus nigro, antice et poltice albo, Fork. Faun. Arab. p. 3. I I. - Gmel. Syft. i. p. 524 .

Haвiтат in Arabia.-Roftrum plumbeum: gula alba: vertex fufcus: dorfum fufcum pennis margine albidis : abdomen albidum: pedes grifei。 


\section{GENUS XCVII. APTENODYTES.}

Roftrun rectum, compreffum, fubcultatum, mandibula fuperiore longitudinaliter oblique fulcata.

Nores lineares.

Lingua aculeis retroflexis.

Ala pinniformes, volatui inutiles, remigibus nullis.

Pedes compedes, tetradactyli, palmati.

I.

chryfoco- A. roftro rufo-fufco, pedibus flavefcentibus, crifta frontali erecta, auris me. culari deflexa fulphurea.

Aptenodytes chryfocome, Com. Goett. iii. p. 135. t. 1.-Gmel. Syft. is p. 555 .

Manchot fauteur, Buf. ix. p. 409.-Pl. Enl. 984 .

Hopping Penguin, Boug. Voy. p. 64. 65.-Pbil. Tranj. lxvi. p. 103. Crefted Pinguin, Lath. Syn. vi. p. 561. 1.-Cook's laft Voy. i. p. 88.

Habitat in infulis Falklandicis et Defolationis, etiam in terra Van Diemen nova Hollandia. -23 pollices longa.-Incauta avis; in aqua agilis, et egregie urinans; inter natandum ex aqua profiliens; irata criftas erigit; gregatim inter Pelecanos nidificans, ovum unicum in fovea terræ ponens.

Corpus cxruleo-atrum, fubtus album: ale fubtus albx.

Femina ftriga fuperciliari flavefcente, at non poftice elongata.

2.

patacho- A. roftro pedibufque nigris, macula ad aures utrinque flavo-aurea colnica. lum ambiente.

Aptcnodytes patachonica, Com. Goetz. iii. p. 137. t. 2.-F. F. Mill. Ill. t. 20. -Gmel. Syjt. i. p. 556.

Manchot de la nouvelle Guinée, Son. Voy.p. 179. t. I13.

Grand Manchot des ines Malouines, Buf. ix. 399. t. 30-Pl. Enl. 975. Firft clafs of Penguins, Boug. Voy. p. 64 .

Patagonian Pinguin, Pbil. Trans. Iviii. p. 91. t. 5.-Gen. of Birds, p. 66. t. 4.-Gent. Mag. xxxix. t. p. 489.-Lath. Syn. vi. p. 563.2。 -Forft. Voy. ii. p. 2 I4. 528.

Habitat in infulis Falklandie, Defolationis, nove Georgia, et novee Guinea: 
Guinea ; facile manfuefcens; inter congeneres maxima.-4 pedes 3 pol. lices longa.

Roftrum elongatum, gracile, nigrum, verfus apicem flavefcens, mandibula inferiore bafi fulva : irides avellaneæ: caput collumque pofterius fufcum : dcrfum creruleo-nigrum: peitus et abdomen alba; porrecto collo, macula aurium utrinque lateribus colli oblique ad pectus producta : fes3. fili capite, collum quafi collari aureo cinctum evadit.

papua. A. roftro pedibufque rubicundis, macula occipitali alba.

Aptenodytes papua, Com. Goett. iii. p. 143. t. 3.-Gmel. Syft. i. p. 556. Le Manchot papou, Son. Voy. p. 181. t. II 5.

Papuan Pinguin, Latb. Syn. vi. p. 565. 3.-Cook's laft Voy. i. p. 88.

Habıtat cum precedente. $-2 \frac{I}{2}$ pedes longa.

Irides flav1 vel rubicundi; caput et collum cæruleo-nigricans: dorfum et cauda atra: pectus, abdomen, criffum, et macula verticalis ab oculo ad oculum, alba.

4.

antarctica. A. roftro atro, pedibus rubicundis, linea gulari nigra.

Aptenodytes antarctica, Com. Goett. iii. p. 141. t. 4.-Gmelo Syft. i。 p. 557:

Antarctic Pinguin, Lath. Syn. vi. p. 565. 4.-Forft. Voy. i. p. 98.

Ha BITA'T in Mari auftrali.--25 pollices longa.

Irides flavefcentes : caput fupra atrum fubtus albo-fericeum : fafcia a gula ad aures nigra: pedes incarnati, plancis nigris.

5 .

demerfa. A. roftro pedibufque nigris, fuperciliis albis, fafcia pectorali nigra. Aptenodytes denterfa, Gmel. Syjt. i. p. $55 \%-N$. Cim. Goett. iii. p. 144. Diomedea demerfa, Lin. Syft. i. p. 2 I 4. 2.-Borowejk. Nat. iii. p. 28. 2. Sphenifcus, Brif. vi. p. 97. 1. Id. 8 vo. ii. p. 385 .

Anfer magellanicus Clufii, Will. p. 242.-Id. (Angl.) p. 322.

Plautus pinguis, Klein. Av. p. 147. 4.

Black-footed Penquin, Ed v. t. s4. f. 2.-Kolb. Cap. ii. p. 144.

Leffer Pingu,n, Pbil Tranf. Iviii. p. 97. 2.-Sparrm. Voy. i. p. 24.

Cape Pinguin, $L^{\text {th }}$. Syn. vi. p. 566. 5 .

Habitat in Mari atlantico et antarefico, potiffimum circa Cap. $B$. Spei et ad fretum Nagellanicum.-Nidificat in fcopulis, ova 2 alba ponens. -2 I pollices longa.

Roftrum fufco-nigricans, verfus apicem fafcia pallida, mandibula fuperiore 
periore adunca, inferiore truncata : corpus fupra nigricans fubtus album : lateribus capitis gulaque grifeis: pedes nigri, vel rubicundi.

$\beta$. A. roftro nigro fafcia alba, fuperciliis albis, fafcia pectorali nigra. Sphenifcus nævius, Brif. vi. p. 99. 2. t. ix. $-I d$. 8 vo. ii. p. 386 . Manchot à bec tronqué, Buf. ix. p. 4 I I. t. 31.-Pl. Enl. 380 . Black-footed Penguin, Edw. to 94. f. r.-Lath. Syn. vi. p. 567. 5. A.

Roftum precedentis : corpus fupra nigricans grifeo maculatum, fubtus album : latera capitis fub oculis, et gula fufco-nigricantia: fafcia fupra oculos alba: fafcia fupra peetus arcuata fufco-nigricans, utrinque fecundum latera ad pedes ufque protenfa: pedes nigri.

$\gamma$. A. roftro nigro fafcia alba, mento orbitifque nigris.

Pinguin à lunettes, Pernet. Voy, ii. p. 17. t. 7. f. 3.-Id. (ed. Angl.) p. 243. t. 15 .

Corpus fere ut in præcedente, a qua differt orbitis et mento tantum,

6. non gula tota, nigris.

magella- A. roftro nigro fafcia purpurafcente, fuperciliis albis, fafcia pectorali nica. et torque medio colli nigris.

Aptenodytes magellanica, Com. Goett. iii. p. 143. t. 5.-F. F. Mill. Ill. t. 34.-Gmel. Syft. i. p. 557 . Magellanic Pinguin, Latb. Syn. vi. p. 569. 6.

Навітат in terra Magellanica, Statuum, et del Fuego, infulifque Falklandicis; numerofiflima; antarctice magnitudine.

Roftrum nigrum fafcia purpurafcente: irides rubro-fufcæ: pedes incarnati maculis nigricantibus. A demerfa $\beta$. præcipue variat torque medio colli nigro. An diftincta fpecies?

7.

torquata. A. roftro pedibufque nigris, areis oculorum nudis fanguineis, femitorque albo.

Aptenodytes torquata, Com. Goett. iii. p. 146.-Gmel. Syft. i. p. 558. Manchot à collier de la nouvelle Guinée, Son. Voy. p. 181. t. 114. Collared Pinguin, Lath. Syn. vi. p. 571 . 7.

Haвiтат in nova Guinea, terra Kerguelen, et infula nove Georgie.I 8 pollices longa.

Roffrum elongatum, nigrum: caput, corpus fupra, ale, pedes nigra : pectus, abdomen, femora, criffum alba: medio collo fafcia alba: orbite nudæ, rugofe, fanguinex.

A. roftro 
8.

Catarrac- A. roftro pedibufque rubris, capite fufco.

tes. Aptenodytes Catarractes, Forft. Goett. iii. p. 145.-Gmel. Syft. i. p. 558. Phacton demerfus, Lin. Syfl. i. p. 219.-Borowefk. Nat. iii. p. 24. 2. Catarractes, Brif. vi. p. 102.-Id. 8 vo. ii. p. $387 .-$ Pl. Enl. 1005? Red-footed.Penguin, Edw. t. 49.-Pbil. Tranf. lviii. p. 98.-Lath. Syn. vi. p. 572.8 .

Habiтat in Oceano aufrali; Anferis magnitudine.

Mandibula fuperior apice nonnihil adunca, inferior rotundata : caput antice fufcum, poftice et corpus fupra fordide purpureum, fubtus album, quibufdam undulatum.

$9 \cdot$

minor.

A. roftro nigro, pedibus albidis.

Aptenodytes minor, Cum. Goett. iii. p. 147.-Gmel. Syft. i. p. $55^{8}$.

Small Penguin, Cook's laft Voy. i. p. I 5 I.

Little Pinguin, Latb. Syn. vi. p. 572. 9. t. 103.

HaвIтA in littore cuniculorum initar fodit. - I 3-1 5 pollices longa.

Roftrum, fere ut in Catarracta, nigricans : irides lividæ : corpus fupra cinereo-cæruleum fubtus album: latera capitis fufco-cinerea : pedes rubefcentes.

10.

chiloenfis. A. corpore lanuginofo cinereo.

Aptenodytes chiloenfis, Gmel. Syft. i. p. 559.-Buf. ix. p. 4I5. IV.

Diomedea chiloenfis, Molin. Cbil. p. 2 10.-Id. (ed. Gall.) p. 219.

Haвгтат in archipelago Cbiloenfi; communis; Anatis magnitudine. -Plumæ corporis elongatæ, lanuginof $x$, crifp $x$, et ab incolis ad vefti-

II. menta conficienda ufurpantur.

Molinæ. A. cinereo cæruleoque varia fubtus alba, pedibus tridactylis.

Aptenodytes chilenfis, Gmel. Syft. i. p. 559 .

Diomedea chilenfis, Molin. Chil. p. 2 10.-Id. (ed. Gall.) p. 217:

HaBITAT in Cbili; praecedentis magnitudine, at collo longiore.-In arena ova 6-7 alba, nigro punctata, parit.

Caput parvum, compreffum: corpus pilofum, fupra grifeo caruleoque varium : pectus et abdomen alba. 


\section{GENUS XCIX. PELECANUS.}

Rofrum rectum, apice adunco, unguiculato.

Nares rima obliterata.

Facies nudiufcula.

Pedes æquilibres, digitis omnibus quatuor fimul palmatis.

\section{1.}

* Roftro edentulo.

Onocrota- P. albus, gula faccata.

lus. Pelecanus onocrotalus, Lin. Syft. i. p. 215. 1.-Gmel. Syft. i. p. 569.N. C. Petr. xv. p. 47 1. 16.-Scop. Arn. i. No 97.-Hafjelq. It. p. 288.-Georgi reife, p. 169.-Kram. El. p. 345.-Brif. vi. p. 5 rg. J.-Id. 8 vo. ii. p. 497.-Borow/R. Nat. iii. p. 40. 2.-Faun. Helv. -Dodaert. Mem. iii. p. 189. t. 26.-Raii Syn. p. 121. 1.-Will. p. 246. t. 63.-Pbil. Tranf. Ixvi. p. 291.-Id. Ivii. p. 348 ?

Pelican, Buf. viii. p. 282. t. 25.--Pl. Enl. 87.-Hift. Prov. i. p. 342. Il grotto offia Pellicano, Cet. uc. Sard. t. p. 329 . f. 2.

Baba, Bell's Trav. p. 41 .

Tubano, Wheeler's Trav. t. p. 304.

Tacab Mife Perfis, Cbordin. It. iii. p. 40 ?

White Pelican, Edw. t. 92.-Will. (Angl.) p. 327.-Arc7. Zool. ii. N* 505.-Gen. Birds, p. 67. t. I 5.-Lath. Syn. vi. p. 575. I.

Habitat in Africa, Afia, America auftraliore; rarius in Europa; pifcibus victitans. - Nidificat ad ripas fluviorum inter arundineta, $\mathrm{Ca}$ recta, et ova 2 alba parit.-Interdum in defertis ficcis nidum ftruit, ibique facco gulari aquam fiticulofis pullis adfert. - Cygno major. -5 pedes longus.

Rofrum I 5-i6 pollices longum, coloris rubri, in junioribus flavi: mandibula fuperior depreffa, lata, apice adunco; inferior bifurca, burfa gulari membranacea, flaccida, valde diftenfili : irides avellaneæ: rictus amplifimus: caput lateribus nudum, cute incarnata tectum : occipus fubcriftatum : corpus incarnato-album: alula remigefque primores nigræ: pedes plumbei. 
2.

tofeus. P. rofeus, gula faccata.

Pelecanus rofeus, Gmel. Syft. i. p. 570.

Pelican rofe de l'inle de Luçon, Son. Voy. p. gr. t. 54.-Pl. Enl. 965.

Rofe-coloured Pelican, Lath. Syn. vi. p. 579. 2.

Habrtar in infula Manilla; Anferis magnitudine.

Roftrum nigrum: area oculorum nuda, flava: faccus gularis flavus.

3.
fuicus. P. cinereo-fufcus, gula faccata.

Pelecanus fufcus (occidentalis,) Lin. Syft. i. p. 21 5. 1. $\beta .-G m e l$. Syft.

i. p. 570.-Georgi reife, p. 169 .

Onocrotalus fufcus, Brif. vi. p. 524. 2.-Id. 8 vo. ii. p. 499.-Raii Syn.

p. 191. 3.-Sloan. Fam. p. 322. 1.-Brown. Fam. p. $480 .-K l e i$. Av. p. I 42 . I.

Pelican brun, Buf. viii. p. 306.-Pl. Enl. 957.

Pelican of America, Edw. t. 93--Ellis's Hudf. Bay. i. t. x.

Great Gull, Hifl. Californ. i. p. 40.

Brown Pelican, Lath. Syn. vi. p. 580. 3.-Gent. Mag. xx. to p. 2 10.ArE. Zool. ii. $\mathrm{N}^{\circ} 506$.

Habitat in America; Anfere paulo major.-4 pedes longus.

Rof rum rubro-cærulefcens : irides cinerafcentes: faccus gularis cæruleo-cinerafcens lineis rubris: caput poftice fubcriftatum, collumque albida: corpus cinereo-fufcum fupra pennis medio albidis: remiges primores nigræ: pedes plumbei.

manillen- P. fufcus, gula faccaita.

fis. Pelecanus manillenfis, Gmel. Syft. i. p 57 r.

Le Pelican brun de l'ine de Luçon, Son. Voy. p. 9r. t. 53.

Manilla Pelican, Lath. Syn. vi. p. $5^{8} 3 \cdot 4$.

Habitat in Manilla.-A rofeo folummodo differt corpore toto fufco.

5.

philippen- P. fubcriftatus aibus, corpore fupra grifeo-cinereo, gula faccata.

fis. Pelecanus philippenfis, Gmel. Syft. i. p. 57 r.

Onocrotalus philippenfis, Brif. vi. p. $527 \cdot 3 \cdot$ t. $46 .-$ Id. 8 vo. ii. p. 500. Alcatraz, Pbil. Tranf. xxiii. p. 1394.40.

Philippine Pelican, Lath. Syn. vi. p. $5^{8} 3 \cdot 5$.

Habitat in infulis Pbilippinis. $-4 \frac{\mathrm{T}}{4}$ pedes longus.

Roftrum areaque oculorum nuda, incarnata : faccus gularis pallidus : $5 \mathrm{U}_{2}$ 


\section{AVES PALMIPEDES. Pelecanus.}

coput et collun albida : occipitis cervicifque plumæ fufco alboque variæ: 6. pectus, abdomen, uropygium alba: remiges nigricantes : pedes rubri.

rufefcens. P. criftatus rufefcens, capite colloque fufcefcente-albis, cauda faturate cinerea, gula faccata.

Pelecanus rufefcens, Gmel. Syft. i. p. 57 1.

Red-backed Pelican, Lath. Syn. vi. p. 584. 6.

Haditat in Africa; Cygno major.-5 pedes longus.

Roftrum, area oculorum nuda, faccufque gularis fordide flava : crifta 4 pollices longa : caput et collum fufco-albidum: corpus pallide cinnamomeum, fubtus pallidius : fcapulares grifeo-plumbeæ : remiges nigra: pedes flavi.

7.

carolinen- P. fupra obfcurus fubtus albus, gula faccata.

fis. Pelecanus carolinenfis, Grel. Sy/t. i. p. 57 1.

Charles-town Pelican, ArE. Zool. ii. No $507 .-L a t b$. Syn. vi. p. 58 . 7.

Habit at in America; An. canadenfis magnitudine.

ß. P. fufcus, fubtus fufcefcente-albus.

A priore variat mandibula fuperiore bafi rotundata.

$\gamma$. P. dorfo inferiore nigro et obfcure albo friato.

8.

trachy- P. criftatus albus, gula faccata nigro ftriata.

rhynchos. Pelecanus erythrorhynchos, Gmel. Syyt. i. p. 57 r.

Rough billed Pelican, Lath. Syn. vi. p. 586. 8.-Pbil. Tranf. Ixii. p. 419. 54. - Faun. Amer. p. 17.

Habitat in America Septentrionali. $-4 \frac{T}{2}$ pedes longus.

Rofrum rubefcenti-flavum, fupra a medio ad apicem carina elevata, $I \frac{x}{2}$ pollicem alta, rugofa, hinc inde interrupta $:$ mandibula inferior utrinque in medio macula nigra : corpus totum album : alula remigefque primores nigre: pedes flavi.

Thagus. P. cauda rotunda, roftro ferrato, gula faccata.

Pelecanus Thagus, Gmel. Syfto i. p. 577.-Molin. Cbil. p. 212.-Id. (ed. Gall.) p. 220.

Onocrotalus roftro denticulato, Brif, vi. p. 523. A.-Id. 8 vo. ii. p. 499.

Onocrotalus 
A V ES PALMIPEDES. Pelecanus. 885

Onocrotalus mexicanus dentatus, Alcatraz, Raii Syn. p. I22.-Hernand. Mex. t. p. 672.

Saw-billed Pelican, Latb. Syn. vi. r. 579. A.

Habitat in Cbili, Mexico; folitarius; Gallopavonis magnitudine.$\mathrm{Ab}$ extremo ad extremum alarum extenfarum 9 pedes. - Nidificat in fcopulis, pullis plerumque 5 .

Roftrum pedem longum, lateribus ferratum: faccus gularis pregrandis, fubtomentofus, valde extenfilis : corpus fere ut in $f u f c o$, a quo vix differt nifi refro ferrato.

10.

Aquilus. P. cauda forficata, corpore nigro, roftro rubro, orbitis nigris.

Pelecanus Aquilus, Lin. Syft. i. p. 216. 2.-Gmel. Syft. i. p. 572-Ofb. It. p. 292 -Borowesk. Nat. iii. p. 42. 3.-Forf. Voy. i. p. 588. -Id. ii. 433 .

Fregata, Brif. vi. p. 506. 6. t. 43. f. 2. (Mas.)-Id. 8 vo. ii. p. 493 . Fregata avis, Rabihorcado, Raii Syñ. pp. 1 53. 592. 1 5. -Will. p. 305. t. 77.-Id. (Angl.) p. 395.-Petiv. Gaz. t. 54. 1.-Ulloa's Voy. ii. p. 301 .

La Fregate, Buf. viii. p. $3^{8}$ I. -Pl. Enl. 96 r. -Pernet. Voy. i. I25.Iit). Louif. ii. p. 118 .

Man of war Bird, Browen. Fam. p. 483.-Damp. Voy. i. p. 49.-Id. iii。 part 2. t. p. 99.-Sloan. Fam i. p. 30.

Frigate Bird, Alb. iii. t. 80.-Gen. Birds, p. 67. t. 16.

Frigate Pelican, Lath. Syn. vi. p. 587.9.

Habríat in Pelago, præfertim inter tropicos; longiffime recedens; alis amplifimis implexu free i 4 pedum, unde placide volat.-Longitudo 3 pedum.

Mas totus niger nitens, adultior carunculis 2 membranaceis coccineis fub gula. Femina abdomine albo: utrifque mandibula fuperioris apex multum aduncus. Orum incarnatum maculis coccineis.

I I.

minor. P. cauda forficata, corpore ferrugineo, roftro orbitifque rubris.

Pelecanus minor, Gmel. syft. i. p. 572.

Fregata minor, Brif. vi. p. 509. 7.-Id. 8 vo. ii. p. 494.

Petite Fregate, Buf. viii. p. 390.

Man of war Bird, Edrw. t. 309.

Leffer Frigate Pelican, Latb. Syn. vi. p. 590. 10.

Pracedente minor, -3 pedes long. 6 pedes lat. 
Mas roftro rubro: corpore toto nigro-nitente, pectore et abdomine cinereo-nebulofis : nares conf́picua, potius eminentes : faccus gularis membranaceus, a divaricatione mandibula inferioris ad medium collum, coloris rubri, maculis obfcuris : cavida forficata: pedes flavefcentes.

Ferina capite et corpore fupra ferrugineis: gula, jugulum, et pectus alba: rofirum et pedes ut in mare: factus gularis nullus. Aquilo nimis afinis.

12.

leucoce- P. cauda forficata, corpore fufco, capite collo petore et abdomine alphalus. bis, roftro obfcuro.

Pelecanus leucocephalus, Gmel. Syft. i. p. 572.-Amon. Acad. iv. p. 238. 7.-Oß. Voy. ii. p. 87 .

L. F regate, Buf. viii. t. 30 .

White-headed Frigate Pelican, Lath. Syn. vi. p. 591. I I.

Habitat in infula Afcenfionis, ubi homines accedentes metuere nefcit. -3 ped. long, 6 ped. lat.

Roftrum edentulum, fufcum : caput album : gula nuda : peczus et $a b$ domen alba: dorfum fufco-ferrugineum: alc ferrugineæ, remigibus nigris : cauda pennis 12 nigris.

13.

Palmer- P. cauda forficata, corpore fufco viridi nitente fubtus albo, jugulo albo ftoni.

$$
\text { nigroque vario, abdomine albo, criffo nigro. }
$$

Pelecanus Palmerfoni, Gmel. Syft. i. p. 573 .

Palmerton Frigate Pelican, Lath. Syn. vi. p. 592. 12.

Hasitat in infula Palmerfon. -3 ped. 2 poll. longus.

Roftrum nigrum, area oculorum pennis tecta : rectricum raches albæ: pedes nigricantes, ungue medio intus ferrato.

I. 4 .

Carbo. P. cauda rotundata, corpore nigro, capite fubcriftato.

Pelecanus Carbo, Zin. Syft. i. p. $216.3 .-$ Faun. Suec. No 145.-Gmel. Syft. i. p. 573.-Scop. Ann. i. No 98.-Brun. No 120. 122.-Muiler, $\mathrm{N}^{\circ}$ 146. 148.-Georgi reife, p. 169.-Frifch. t. 187.-N. $C$. Petr. iv. p. 423.-Faun.Groenl. N" 57.-Boroues. Nat. iii. p. $3^{8}$. t. 40.-Faun. Helvet.-Sepp. Vcy. t. 98.99.

Corvus aquaticus, Rai Syn. p. 122. A. 3.-Will. p. 248, t. 63.-Klein. Av. p. 144. 5:-Marf. Dan. 16. t. 36.-Befl. Muf. t. 8.

Phalacrocorax, Brif. vi. p. 5 i i. 1. t. $45 .-I d$. 8 vo. ii. p. 495.

Le Cormoran, Buf. viii. p. 310. t. 26. -Pl. Enl. 927.-Hijt. Prov. i. p. $3+\mathrm{I}$. 
AVES PALMIPEDES. Pelecanus. 887

Il Corbo aquatico, Cet. uc. Sard. t. p. 329, f. I.

Lou-foo, Ofb. Voy. ii. p. 35.-Du Hald. Cbin. t. p. 162.

Seerabe, Walb. Sch. der Nat. Berl. Gef. vii. $\mathrm{N}^{\circ} 22$. p. 430 .

Cormorant, Corvorant, Will. (Angl.) p. 329. t. 63.-Br. Zool. ii. $\mathrm{N}^{\circ}$ 291.-Id. fol. 159. t. I. 1. (Fem.) -Alb. ii, t. 81 .-Cook's laft Voy. ii. p. 297.-Lath. Syn. vi. p. 593. I3.

Habitat in Europa, America, Afia; a Sinenfibus, olim quoque ab Anglis, ad pifcium prædam adhibitus. - Inter fcopulos et faxa, æque ac in arboribus, nidificat. -3 pedes longus. - Ovum virefcens.

Roftrum nigricans : mandibula inferior cute flavefcente tecta, in facculum fub gula producta : irides virides : occiput fubcriftatum: caput et collum fupremum lineolis longitudinalibus albis : corpus nigirum pennis margine atris, fubtus nigrum: gula alba: macula ad crura exteriora alba nigro punctata : cauda pennis I4: rofrum et pedes nigri, ungue medio intus ferrato.

ß. P. cauda rotundata, corpore nigro, capite lævi.

Rofrum, gula faccata alba, ut in priore: caput et collum totum læve, nigrum, ablque ftriis albis: gula alba: macula femorum nulla.

Graculus. P. cauda rotundata, corpore nigro fubtus fufco, rectricibus duodecim, roftro edentulo.

Pelecanus Graculus, Lin. Syf. i. p. $217 \cdot 4 \cdot-$ Faun. Suec. No $146 .-$ Gmel. Syft. i. p. 574.-Brun. N $121 .-$ Muller, p. 147.-- Foun. Helvet.

Phalacrocorax minor, Brif. vi. p. 516. 2.-Id. 8vo. ii. p. 496.

Corvus aquaticus minor, Raii Syn. p. 123. A. 4.-Will. p. 249. t. 63. Cormoran, Dod. Mem. iii. p. 21 3. f. 31.-Pitf. Mem: t. p. 132 .

Petit Cormoran, ou Nigaud, Buf. viii. p. 319.

Shag, or Crane, Will. (Angl.) p. 330. t. 63.-ArEt. Zool. No 508. Lath. Syn. vi. p. $59^{8}$. 14.

HaBItat in Europa Septentrionali, Iflandia; arboribus nidificans. $2 \frac{\mathrm{T}}{2}$ ped. long. ; 3 ped. 8 poll. lat.

Caput, collum nigrum viridi-nitens : dorfum et teEtrices alarum purpureo-nigræ margine nitentes : abdomen nigricans, obfcurum, medio cinerafcens : cauda viridi-nigra: pedes nigri, digito medio intus ferrato.

$\beta . P$. roftro edentulo, corpore ex nigro-viridefcente nigroque cærulefcente 
cente varie fufco, sula lutea, cauda cuneata, Muf. Carlf. fafc iii. t. $6 \mathrm{I}$.

Habitat in finu falfo ad Prom. B. Spei.-Gula lutea a Pel. Graculo pracipue differt : cauda rectricibus duodecim.

$\gamma$. J'. cauda rotundata, corpore nigricante fubtus fufco, fupra pennis margine nigris.

Le petit Fou brun, Buf. viii. p. 374 .

Fou brun de Cayenne, $\mathrm{Pl}$. Enl. 974.

HaBitat in Cayana et infulis Caribbais. -26 pollices longus.

Rofrum pallidum apice adunco: pedes nigricantes.

16.

criftatus. P. corpore viridi-nitente fubtus obfcuro, roftro pedibufque obfcuris, ca= pite criftato.

Pelecanus criftatus, Foun. Groenl. $N^{\circ} 5^{8}-$ Brun. $N^{\circ} 1$ 23.-Ström. Söndm. 250.-Olafien. ii. t. 39.-Gmel. Syft. i. p. 575 .

Crefted Shag, Arct. Zool. p. $5^{8}$ 3. A.-Br. Zool. ii. No 292. t. 102.Id. fol. I 59.-Latb. Syn. vi. p. 600. I5.

Habitat in Europa feptentrionali.-2 ped. 3 poll. long.

Rofrum nigricans: irides virides: pennæ ad latera capitis utrinque elongata, criftam efformantes : cauda pennis I 2 obfcure viridibus: $p e$ des nigricantes. Variat capite non criftato; an varietas fexus?

17.

violaceus. P. crifta erecta, corpore toto nigro violaceo-nitente.

Pelecanus violaceus, Gmel. Syft.i. p. 575.

Violet Corvorant, Arct. Zool.ii. p. 584. B.-Lath. Syn. vi. p. 600. I6.

HaвiтAт circa Kontfchatkan infulafque vicinas.

18.

Urile. P. viridi-nitens, gutture et orbitis albis, facie nuda ex carulefcente rubra, alis caudaque obfcuris, pedibus nigris.

Pelecanus Urile, Gmel. Syft.i. p. 575 .

Urile, Sea Raven, Hift. Kant fcb. p. 117 .

Red-faced Corvorant, Arct. Zool. ii. p. 584. C.

Red-faced Shag, Latb. Syn. vi. p. 601. 17.

HABITAT in Kamtfchatke rupeftribus maritimis. $-3 \mathrm{I}-34$ poll. long.

Rofrum bafi rubefcenti-viride, apice nigro: area oculorum nuda rubra: caput et collum obicure viridi-nigricantia : collum antice dorfumque pennis 
pennis fparfis linearibus, incurvatis, albis : dorfum et ale nigricantes, nitidæ: tectricibus femorum utrinque fafciculus pennarum albarum : reco trices 12 nigricantes. Ovum gallinacei magnitudine, viride.

19.

punctatus. P. criftatus niger, cauda rotundata, orbitis nudis, alis fufco-cinereis nigro punctatis, "lateribus colli linea utrinque alba.

Pelecanus punctatus, Muf. Carlf. fafc. i. to 10.-Gmel. Syft. i. p. 574.

Pelecanus nævius, Gmel. Sy/t. i. p. 575 .

Crefted Shag, Cook's lafi. Voy. i. p. I5I.

Spotted Shag, Latb. Syn. vi. p. 602. 18.

HABITAT in nova Zealandia; inter rupes vel in arboribus nidificans; Graculi magnitudine. $-2 \mathbf{1}-24$ pollices longus.

Rof frum plumbeum : orbite nudæ, rubefcentes: caput antice et poftice criftatum: collum poftice, gula, et dorfum initium nigra: fupra oculos fafcia alba lateribus colli utrinque defcendens ad alam: dorfum medium et ale cinereo-fufce, pennis apice puncto nigro notatis: remiges impunctatx: dorfum pofterius, uropygium, abdomen, criffum, remiges et reEtrices viridi-nigra : pedes nigricantes. Variat roftro flavo vel rufefcente, et pedibus flavis. In quibufdam pennæ fupra femora ftriis albis.

20.

caruncu- P. niger fubtus albus, facie nuda carunculata rubra, orbitis elevatis ca. latus. ruleis, fafcia alarum alba.

Pelecanus carunculatus, Gmel. Syft. i. p. 576.-Forft. Voy. i. p. 4 I. Carunculated Shag, Lath. Syn. vi. p. 603. 19.

Haвiтat in nova Zealandia, et terra Statuum numerofus; præceden te paulo minor; in cefpitibus dactylidis glomeratæ nidificans.

Roftrum nigricans : irides albidæ: caput fupra tumidum : pedes incarnati aut fufcefcentes.

2 I. magella- P. niger, macula poneoculos abdomineque albis, temporibus mentonicus.

Pelecanus magellanicus, Gmel. Syft. i. p. 576.-Forf. Voy. ii。 p. 494. Magellanic Shag, Latb. Syn. vi. p. 604. 20.

Habitat in Terra del Fuego et Statuum; in cavitatibus rupium nidificans. $-3 \circ$ pollices longus.

Roftrum nigrum: coput et collum atro-nitens, tumidiufculum: pedes pallide fufci。 
890 AVES PALMIPEDES. Pelecanus,

varius. P. fufcus fubtus albus, fuperciliis pallidis, dorfo poftico uropygio femoribus remigibus caudaque nigris.

Pelecanus varius, Cmel. Syft. i. p. 576 .

Pied shag, Latb. Syn. vi. p. 605. 21-Cook's laft Voy. i. p. 151.

Habitat in nova Zealandia; in arboribus nidificans. -2 ped. 6 poli. longus. Ovum albo-cærulefcens.

Koffrum flavum, fupra obfcurum : pedes incarnati.

23.

cirrhatus. P. niger fubtus allus, vertice criftato, litura alarum alba, roftro orbitis pedibufque flavis.

Pelecanus cirrhatus, Gmel. Syft. i. p. 576.

Tufted Shag, Lath. Syn. vi. p. 606. 22.

Habitat in nova Zealandia. -2 ped. Io poll. longus.

Criffa apice acuta, e pennis totius verticis elongatis, erectis, antrorfum fpectantibus : latera capitis tota nuda : cauda rectricibus 14 , apice acutis.

24.

africanus. P. fufco-niger fubtus albo nigricanteque varius, gula alba, tectricibus alarum cæruleo-grifeis, margine et apice nigris.

Pelecanus africanus, Gmel. Sytt. i. p. 577.

African Shag, Laib. Syn. vi. p. 606. 23 .

Habitat in Africa. -20 pollices longus.

Roftrum flavicans: pedes nigri : cardda cuneiformis, rectricibus 12 , in-

25. termediis 4 , et extimis utrinque pallide fufcis, reliquis nigris.

pygmæus. P. ater, pectore virefcente, orbitis atomis albis fparfis, tectricibus alarum medio fufcis, collo pectore lateribufque punetis fparfis niveis. Pelecanus pygmzus, Pall. reije, ii. p. 712. I6. t. G. M. et F.-Decouv. Ruff. iit. p. 504.-Gmel. Syft. i. p. 574 .

Dwarf Shag, Lath. Syn. vi. p. 607.24.

Habitat in mari Cafpio ; Pelecanis vulgaribus immifta vivit hrec fpecies, tardius ex auftro advolans; vix 2uerquedula magnitudine.

Puncta colli et pectoris e pennis linearibus nigris intermixtis : caude. longiufcula, e pennis I2, cuneiformis. Femina tota fufca, fo exfolete nigra, punctis nullis.

ค. P. gula murina, roftro edentulo, pedibus nigris.

Pelecanus pygmeus, It. Pofeg. p. 25 .

Haritate 


\section{A VES PALM I PEDES. Pelecanus. $89 \pi$}

Habitat in Pojegana.-Caput et collum fuperne et ad latera caftanei coloris, punctis per collum fparfis niveis rarifimis : caput et corpus inferne tectuin plumis obfolete fufcis, caftaneo marginatis : abdomen canum fufco maculatum : tectrices alarum nigra limbo undique atro denti-

26. culato, dentibus fufcis.

baffanus. P. cauda cuneiformi, corpore albo, roftro ferrato, remigibus primoribus nigris, facie cærulea,

Pelecanus baffanus, Lin. Syft. i. p. 217.5.-Faun. Suec. No 147.-Gmel. Syft. i. p. 577.-Brun. $\mathrm{N}^{\circ}$ I 24.-Muller, $\mathrm{N}^{\circ}$ 147.-Faun. Groenl. No 59.-Borowjk. Nat. iii. p. 42.4 .

Anfer baffanus, Raii Syn. p. 122. A. 2.-Will. p. 247. t. 63.-Sibb. Scot. Ill. 20. t. g. f. 2.-Klein. Av. p. 143.2.

Sula Hoieri, Raii Syn. p. I 23. 5.-Will. p. 249

Sula baffana, Brif. vi. p. 503. 5. t. 44.-Id. 8 vo. ii. p. 492.

Fou de Baflan, Buf. viii. p. 376.-Pl. Enl. 278.

Soland Goofe, Will. (Angl.) p. 328. t. 63.-Alb. i. t. 86.

Gannet, Br. Zool. ii. No 293. t. 103. - Id. fol. 160. t. L.-Arct. Zool. ii. $\mathrm{N}^{\circ} 5$ 10.-Latb. Syn. vi. p. 608. 25 .

Haвiтат in Europe et Americe feptentrionalis pelago; Anferis magnitudine. -3 ped long.; 6 ped. lat.-Pifcibus, prafertim clupeis et ba. lecibus, victitat; nifi tempore incubationis vix appropinquans littora per 2 milliaria ; migratorius. - In infula Bafa, in medio Edinburgi aftuario fita, ingens harum avium numerus quotannis nidificat.-Unicum ovum album ponit.-Pulli adulti apud Scotos in deliciis habentur.

Corpus album : remiges primores et parvæ tectrices plurimum nigræ: roftrum, faux, faciefque nuda cærulea: linea pone oris angulos nigra, nuda : irides Havefcentes : cauda rectricibus 12 : pedes nigri, antice virefcentes, ungue medio pectinato.

$P u l l i$ et juniores varii funt ex albo et fufco aut nigricante.

$\beta$. P. fufcus albo maculatus, capite collo et pectore concoloribus, fubtus albus, area oculorum nuda nigricante.

Sula major, Brif. vi. p. 497 . 2.-Id. 8 vo. ii. p. 490.

Grand Fou, Buf. viii. p. 372 .

Great Booby, Cat. Car. i. t. 86. (caput.)-Latb. Syn. vi. p. 610. 25. A.

Habitat in Florida; præcedentis pullus.

$$
5 \times 2
$$


$\gamma$. P. fufcus maculis albis triquetris fubtus albidus fufco maculatus, roftro remigibus cauda pedibufque fufcis.

Pelecanus maculatus, Gmel. Syft. i. p. 579.

Fou tacheté, Buf. viii. p. 375.-Pl. Enl. 986.

Spotted Booby, Latb. Syn. vi. p. 6 1 4.30.

HaBITAT in Cayana; forte Baffani pullus.

27.

Pifcator. P. cauda cuneiformi, roftro ferrato, corpore albo, remigibus omnibus nigris, facie rubra.

Pelecanus Pifcator, Lin. Syft. i. p. $217.6 .-$ Aman. Aiad. iv. p. 239. (Fem.)-Gmel. Syjt. i. p. 578.-Borowfk. Nat. iii. p. 43.5 .

Sula candida, Brif. vi. p. 501 . 4. $-I d$. 8 vo. ii. p. 491 .

Le Fou blanc, Buf. viii. p. 371 .

Leffer Gannet, Lath. Syn. vi. p. 61 1. 26.

Habitat in Cbina, infula Afcenfionis, America? Anatis magnitudine. -2 ped. 7 poll. longus. - Forte eadem avis, qua, annulo æneo collo circumpofito, pifcantur Sinenfes.

Roftrum margine ferratum, et gene nudæ rubefcentes : gula nuda, nigra: pedes rubri, ungue medio ferrato. Avis tota alba, exceptis dorfo fuperiore alifque fufco-nigris.

28.

Sula. P. cauda cuneiformi, corpore albido, roftro dentato, remigibus primoribus apice nigricantibus, facie rubra.

Pelecanus Sula, Lin. Syft. i. p. $218.7 \cdot-$ Gmel. Syft.i. p. 578.-Brif.vi. p. 495 . 1.-Id. 8 vo. ii. p. 48 9.-Borowfk. Nat. iii. p. 44.6.

Anferi baffano congener fufca avis, Raii Syn. p. 191. 6.-Sloan. Fam. p. 322. t. 27 1. f. 2 . *.

Plancus Morus, Klein. Av. p. 144. 4.

Fou commun, Buf. viii. p. 368. t. 29.

Booby, Brown. Fam. p. 48 1.-Cat. Car. i. t. 87.-Lath. Syn. vi. p. 612.27.

Habitat in America aufrali, infulifque vicinis. -2 ped. 6 poll. long. Roftrum grifeum bafi fufcum : latera capitis et gula flavefcens: caput, collum, corpus fupra, ole, cauda cinereo-fufca: pectus, abdomen, femora, crifum alba : pedes flavefcentes.

Variat abdomine fufcefcente.

Pullis caput et collum alba fufco contaminata.

P. caudas 
29.

A VES PAIM I PEDES. Phaeton.

Fiber. P. cauda cuneiformi, roftro ferrato, corpore fufcefcente, remigibus omnibus nigricantibus, facie rubra.

Pelecanus Fiber, Lin. Syft. i. p. 218. 8.-Gmel. Syft. i. p. 579.

Sula fufca, Brif. vi. p. 499. 3. t. 43. f. I. -Id. 8 vo. ii. p. 49 I.

Anferi baffano congener cinereo-albus, Sloan. Fam. i. p. 31. t. 6. f. 1. Raii Syn. p. I9I. 5.

Brown Booby, Latb. Syn. vi. p. 613. 28.

Habitat in America, Africa. -2 pedes et ultra longus.

Roftrum, pedes, orbiteque nudæ, rubra : corpus cinereo-fufcum, fubtus pallidius: uropygium pallide grifeum : remiges primores obfcure cinereæ : cauda rectricibus 14 , intermediis 2 cinereis, reliquis cinereofufcis, apice grifeis.

30.

parvus. P. niger fubtus albus, facie plumofa.

Pelecanus parvus, Gmel. Syft. i. p. 579 .

Le petit Fou de Cayenne, Buf. viii. p. 374.-Pl. Enl. 973.

Leffer Booby, Lath. Syn. vi. p. 6 14. 29.

HaBitat in Cayana. -18 pollices longus.

\section{GENUS C. PHAETON.}

Roftrum cultratum, compreflum, acuminatum, fauce pone roftrum hiante.

Nares oblongæ, perviæ.

Cauda cuneiformis, rectricibus 2 intermediis longifimis. Pedes tetradactyli, palmati, digitis omnibus connexis.

I. æthereus. Ph. albus, dorfo uropygio tectricibufque alarum minoribus nigro ftriatis, rectricum fcapis bafi fafciaque fupra-oculari nigris, roftro rubro.

Phaeton æthereus, Lin. Syft. i. p. 219. 1.-Gmel. Syft. i. p. $5^{81}$ 1.-Boo rowefk. Nat, iii. p. 23. t. 34 .

Lepturus, Brif. vi. p. 480 . r. t. 42 . f. r. $-I d$. 8 vo. ii. p. 48.

Avis Tropicorum, Raii. Syn. p. 123. 6.-191. 4.-Will. p. 250. t. 76.

-Kalm. It. ii. p. 149.-OJ6. It. 291.-Tertr. Antill. ii. p. 276.

t. 246 .

Plancus 
894. AVES PALMIPEDES. Phaeton

Plancus tropicus, Klen. Av. p. 145. 7.

Rabijuncos, Ulloa's Voy. ii. p. 305.

Grand Paitle-en-queue, Buf. viii. p. 348. t. 28.-Pl. Enl. 998.-Pernet. Voy, ii. t. 75 .

Tropic Bird, Will. (Angl.) p. 331. t. 75.-Latb. Syn. vi. p. 615. r.

Habitat in Pelogo, potiffimum inter tropicos; Anatis magnitudine. -A roftri apice ad extremitatem caudæ 2 ped. ro poll. longus.-Altiffime volat; victitans pifcibus; rarius in terra nifi incubationis tempore vifus.-Nidificat in infulis folitariis maris Pacifici, ova in cuniculis pariens et incubans.

Roftrum compreffum, fanguineum, margine retrorfum ferratum: pedes obfcure flavi : trenia incurvata fupra oculos: cauda cuneata, rectricibus 14 ; intermediæ 2 fequentem $15^{\frac{3}{4}}$ pollicum longitudine excedunt.

B. Ph. albus, tænia fupra oculos fcapularibus verfus extremitatem fafcia fupra alas rectricumque fcapis in exortu nigris.

Lepturus candidus, Brif. vi. p. 48 5. 2. t. 42 . f. $2-I d$. 8 vo. ii. p. 487. Paille-en-queue de l'ine de l'Afcenfion, Buf. viii. p. 355.-Pl. Enl. 369 . Tropic Bird, Cat. Car. App. t. 14.-Brown. fam. p. 482.-Edw. t. 149. f. 2.-Latb. Syn. vi. p. 618. 1. A.

Roftrum flavefcens, bafi cinereum: color pennarum argenteo-albus: pedes flavicantes, digitis (excepta bafi) membranifque nigris.

g. Lepturus fulvus, Brif. vi. p. 48 g. 3.-Id. 8vo. ii. p. 488.-Lath. Syn. vi. p. 6rg. I. B.

Variat corpore albo-fulvefcente.

2.

melano- $\mathrm{Ph}$. albo nigroque Atriatus fubtus fronteque albus, tæenia ante poneque shynchos. oculos roftro pedibufque nigris.

Phaeton melanorhynchos, Gmel. Syft. i. p. 582.

Black-billed Tropic Bird, Latb. Syn. vi. p. 619. 2.

Habitat in infulis Tefudinum et Palmerfon Maris auftralis, $-19 \frac{\frac{1}{2}}{2}$ pollices longus.

Frons alba: remiges apice albæ: rectrices apice nigricantes: byposbondria albo nigroque ftriata.

3. rus. fuperciliari pedibufque nigris.

Phaeton 
Phaeton phoenicurus, Gmel. Syft. i. p. $5^{8} 3$.

Paille-en-queue à brins rouges, Buf. viii. p. 357 .

Paille-en-queue de l'ifle de France, $\mathrm{Pl}$. Enl. 979.

Red-tailed Tropic Bird, Latb. Syn. vi. p. 619. 3. t. 105.

Habitat in infula Mauritio communis, alibique in mari indico et auftrali, fub arboribus in foveis terre nidificans, ova 2 ochroleuca rufo maculata pariens.-Hypocbondria fufco-nigricantia : redtrices 2 intermediæ 2 I poll. longæ, fcapis bafique nigris.

\section{GENUS CI. P L O T U S.}

Roftrum rectum, acuminatum, denticulatum. Nares rima ad bafin.

Facies et mentum nuda.

Pedes breves, palmati, tetradactyli, digitis omnibus connexis.

I.

Anhinga. Pl. capite lævi, abdomine albo.

Plotus Anhinga, Lin. Syft. i. p. 2 18. 1.-Gmel. Syft. i. p. 580.-Bororofk. Nat. iii. p. 25 . t. 35 .

Anhinga, Brif. vi. p. 476 . r.-Id. 8vo. ii.p. 485.-Raii Syn. p. 124. 7. -Will. p. 250. -Id. (Angl.) p. 332. t. 72.-Klein. Av. p. 145.8. -Buf. viii. p. 448.

White-bellied Darter, Latb. Syn. vi. p. 622.x.

HaBItat in Brafilia; vix Bofchadis magnitudine. -2 ped. ro poll. longus.-Nidificat in arboribus.

Roftrum cinereum : irides aureæ: caput parvum: collum longum: caput, collum, pectus rufo-grifea : gula grifea : corpus fupra nigrum pennis fcapularibus macula alba notatis, fubtus argenteo-album: cauda elongata, rectricibus 12 nigris: pedes grifeo-flavefcentes.

2.

melano- Pl: capite lævi, abdomine nigro.

gafter. Plotus melanogafter, Gmel. Syft. i. p. 580 .

Anhinga melanogafter, Zool. Ind. p. 22. t. I 2. .

Anhinga de Cayenne, Pl. Enl. 959.

Black-bellied Anhinga, Ind. Zool. p. 13. t. I2。

Black-bellied Darter, Lath. Syn, vi. p. 624.2. 
¿96 AVES PALMIPEDES. Plotus.

Habitat in infulis Zeylona et Fava.

Refrum fupra cærulefcens fubtus rubefcens : oculi vividi : caput, collum, et peEtus fuperius pallide fufca : lateribus capitis et colli linea lata alba: dorfum, fcopulares, et tectrices alarum nigra albo lineata: abdomen, remiges, rectricefque nigra : pedes viridi-flavefcentes.

$\beta$. Pl. corpore fupra fufco fubtus nigro, fcapularibus ftriis tectricibufque alarum maculis ovatis albis.

Anhinga, Buf. viii. t. 35.-Latb. Syn. vi. p. 624. 2. A. t. 106.'

Habitat in Cayana.-Inter pectus et abdomen fafcia rufa.

$\gamma$. Pl. niger, dorfo et fcapularibus albo maculatis, tectricibus alarum albo flavicantibus, cauda apice rufa.

Anhinga noir de Cayenne, Pl. Enl. 960.-Lath. Syn. vi. p. 625. 2. B. Rofrum, pars nuda faciei, gula, et pedes flavicantes.

§. Pl. niger, capite collo et tectricibus alarum rufo fufcoque ftriatis. Anhinga roux du Senegal, Buf. viii. p. 453.-Pl. Enl. 107.-Lath. Syn. vi. p. 626. 2. C.

Habitat in Senegala.-Magnitudo procedentium.

furinamenfis.

Pl. corpore fupra fufco fubtus albo, vertice et collo pofteriore nigris, gula jugulo et fafcia oculari albis, lateribus colli albo nigroque $\mathrm{li}_{\text {- }}$ neatis.

Plotus furinamenfis, Gmel. Syft. i. p. $5^{81}$.

Le Grebe-foulque, Buf. viii. p. 248.-Pl. Enl. 893 .

Oifeau de foleil, Defcr. Surin. ii. p. 192.

Surinam Tern, Brown. Illuftr. p. 98. t, 39.

Surinam Darter, Latb. Syn. vi. p. 626. 3.

HaвiтAт in Surinamo; 2uerquedula magnitudine.-1 3 poll. longus.

-Infectis, prefertim mufcis, victitans.

Rofrum pallidum: irides rubra: vertex niger, fubcriftatus : gene caftanex: collum antice album, lateribus albo nigroque lineatum: cauda cuneiformis, restricibus apice albis : pedes fufco-flavefcentes, digitis ter quaterve nigro fafciatis. 


\section{N D EX GE NERUM.}

\begin{tabular}{|c|c|c|c|c|c|}
\hline $\mathbb{A}_{\text {ALCA }}^{\text {LAUDA }}$ & - & & $49 \mathrm{I}$ & FALCO & - \\
\hline se & - & & $\begin{array}{l}791 \\
245\end{array}$ & $\begin{array}{l}\text { FRINGILLA } \\
\text { FULICA }\end{array}$ & - \\
\hline IIS & - & & 363 & $\mathrm{G}_{A \perp B U L A}$ & \\
\hline NAS & - & & 833 & GaLLINULA & \\
\hline TENODYTE & & & 878 & Glareola & \\
\hline DEA & - & & 672 & GRA & - \\
\hline $\mathrm{cco}$ & - & & 201 & OPUS & \\
\hline EROS & - & & 141 & HIR & - \\
\hline $\mathrm{AGA}$ & - & & 147 & $\mathrm{~L}$ & - \\
\hline s & - & & I 49 & & - \\
\hline $\mathrm{CR}$ & - & & 671 & Lo & - \\
\hline $\mathrm{GU}$ & & & $5^{8} 3$ & AGRIS & \\
\hline & - & & 664 & $\mathrm{M}_{\mathrm{T}}$ & - \\
\hline $\mathrm{HI}$ & - & .. & 280 & M & - \\
\hline IUS & 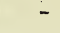 & - & 740 & Mo & \\
\hline Sul & & 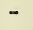 & 368 & Mo & \\
\hline $\mathrm{MBA}$ & - & - & $5^{89}$ & $\mathrm{Mu}$ & \\
\hline & - & 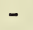 & 799 & $\mathrm{M}_{\mathrm{S}}$ & \\
\hline s & - & - & 168 & $\mathrm{Nu}$ & . \\
\hline IRA & - & - & $7^{8} 7$ & $\mathrm{Nu}$ & 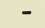 \\
\hline & - & & $15^{\circ}$ & $\mathrm{OR}_{\mathrm{R}}$ & - \\
\hline - & - & - & 622 & OTIS & \\
\hline CROTOPHAGA & & & 148 & PALAMEDEA & \\
\hline ULUS & - & - & 207 & PARADISEA & \\
\hline SORIUS & - & - & & PAR & - \\
\hline & & & 662 & Parus & \\
\hline & - & - & 789 & Pavo & 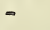 \\
\hline 急 & & & 397 & PELECANUS & \\
\hline
\end{tabular}


I N D E X G E N E R U M.

\begin{tabular}{|c|c|c|c|c|c|c|}
\hline PENELOPE & - & -619 & SCYTHROPS & - & - & 141 \\
\hline PERDIX & - & -643 & SITTA & - & - & 268 \\
\hline PhaEton & - & $\begin{array}{l}-893 \\
-\quad 8\end{array}$ & STERNA & - & - & 803 \\
\hline PHALAROPUS & - & -775 & S'TRIX & - & - & \\
\hline Phasianus & - & -625 & STRUTHIO & - & - & \\
\hline PHOENICOPT & ERUS & - 788 & STURNUS & - & - & 21 \\
\hline Рнутотома & - & -466 & Sylvia & - & - & 500 \\
\hline Picus & - & $-\quad 224$ & TANAGRA & - & - & \\
\hline PIPRA & - & 554 & TANTALUS & - & - & \\
\hline Platalea & - & -667 & TEtrao & - & - & \\
\hline Plotus & - & -895 & Tinamus & - & - & \\
\hline PODICEPS & - & -780 & Todus & $=$ & - & \\
\hline PROCELLARI & & 820 & TRINGA & - & - & \\
\hline Psittacus & - & 82 & Trochilus & - & - & \\
\hline PSOPHIA & - & 657 & Trogon & - & - & 19 \\
\hline RALLUS & - & 755 & TURDUS & - & - & 32 \\
\hline RECURVIROS & TRA & -786 & UPUPA & - & - & 27 \\
\hline RHAMPHAST & os & I 35 & URIA & - & - & 79 \\
\hline RHEA & - & 665 & VAGINALIS & - & - & 77 \\
\hline RHYNCHOPS & - & -802 & VULTUR & - & - & \\
\hline SCOLOPAX & - & -7 & YUNX & - & - & \\
\hline ScOPUS & $\infty$ & $=$ & & & & \\
\hline
\end{tabular}




\section{A T A L O G U S} NOMINUM TRIVIALI UM.

\section{I. AVES TERRESTRES.-ORDO I. ACCIPITRES.}

\section{G E N U S I. \\ Vultur.}

x. Gryphus.

2. cinereus.

3. Percnopterus.

4. leucocephalus.

5. barbarus.

6. barbatus.

7. Papa.

8. Aura.

g. Monachus.

10. fufcus.

11. niger.

12. fulvus.

13. criftatus.

14. ponticerianus.

15 . indicus.

16. ginginianus.

17. angolenfis.

18. ambuftus.

19. plancus.

20. Cheriway.

21. ferpentarius.

\section{GENUS II. \\ Falco.}

1. Harpyia.

2. albicilla.

3. melanæetus.

4. fulvus.

5. leucocephalus.

6. coronatus.
7. offifragus.

8. Chryfaetos.

g. leucogafter.

ז0. japonicus.

i1. ferox.

12. americanus.

13. finenfis.

14. Cheela.

15. a fiaticus.

16. cygneus.

17. candidus.

18. nævius.

19. maculatus.

20. hinnularius,

21. gallicus.

22. nova Hollandia.

23. auftralis.

24. Tharus.

25. glaucopis.

26. melanonotus.

27. leucoryphus.

28. Mogilnik。

29. criftatus.

3o. Haliæetus.

31. Leverianus.

32. Antillarum.

33. lagopus.

34. pennatus.

35. maritimus.

36. Forkalii.

37. Milvus。

38. ater.

39. auftriacus.

40. brafilienfic.

41. furcatus.

42. xquinoctialis.

43. Urubitinga.
44. orientalis.

45 . indicus.

46. ponticerianus.

47. Buteo.

48. variegatus.

49. jamaicenfis.

50. borealis.

51 . rufus.

52. apivorus.

53. aruginofus.

54. fclavonicus

55. marginatus.

56. rubiginofus。

57. fpadiceus.

$5^{8}$. javanicus.

59. lineatus.

6o. rufticolus,

61. obfoletus.

62. novæ Zealandia.

63. cayanenfis.

64. macrourus.

65. palumbarius

66. gentilis.

67. communis.

68. Gyrfalco.

69. inlandicus.

70 . incertus.

71. barbarus.

72. peregrinus。

73. verficolor.

74. S. Johannis.

75 . Sacer.

76. nova Terra,

77. Atellaris.

78. hyemalis.

79. rhombeus.

80. nigricollis.

8s. albi- 
81. albicollis.

82. meridionalis.

83. cirrhatus.

84. ceylanenfis.

85. melanoleucus.

86. grifeus.

87. Suflator.

88. cachinnans.

89. melanops.

9o. bidentatus.

9i. formofus.

9.2. Lanarius.

93. albicans.

94. cyaneus.

95. uliginofus.

96. calidus.

97. nitidus. .

98. Tinnunculus。

99. fparverius.

300. bohemicus.

101. Pifcator.

102. badius.

103. fufcus.

104 . dubius.

105. obfcurus.

106. columbarius:

107. Nifus.

108. fuperciliofus.

rog. vefpertinus.

I Io. vefpertinoides.

111. magniroftris.

112. vociferus.

113 . johannenfis.

114. Subbuteo.

I 5 . Lithofalco.

116. montanus.

117. aurantius.

118. plumbeus.

199. Afalon.

120. cærulefcens。

121. minutus.

122. Regulus.

123. tinus.

\section{GEN U S III.}

Strix.

- auriculatæ.

s. Bubo.

2. virginiana,
3. ceylonenfis.

4. finenfis.

5. coromanda.

6. feandiaca..

7. Ottus.

8. americana.

9. mexicana.

io. Afio.

I1. brachyotos.

12. brafiliana.

13. nævia.

14. Bakkamuna.

15. Zorca.

16. Giu.

17. deminuta.

18. Scops.

19. pulchella.

$$
\text { * * inauriculatx. }
$$

20. nyctea.

21. Wapacuthu.

22. cinerea.

23. nebulofa.

24. perfpicillata.

25. ftridula.

26. Aluco.

27. Ulula.

28. flammea.

29. fylveftris.

30. alba.

31. Noctua.

32. rufa.

33. folognienfis.

34. barbata.

35. funerea.

36. Chichieli.

37. Tolchiquatli.

38. cunicularia.

39. javanica.

40. dominicenfis.

41. cayanenfis.

42. Tengmalmi.

44. acadienfis.

45. fulva.

46. pafferina
OR D O II.

P I C F.

$\mathrm{G}_{\mathrm{EN} \text { U S IV. }}$.

Lanius.

1. forficatus.

2. malabaricus.

3. cærulefcens.

4. caftaneus.

5. lucionenfis.

6. Excubitor.

7. Nengeta.

8. ludovicianus.

9. americanus.

10. collaris.

I I. Collurio.

12. rutilus.

1 3. italicus.

14. Phœnicurus.

15. curviroftris.

16. antiguanus.

i7. criftatus.

18. canadenfis.

19. atricapillus.

20. picatus.

21. niger.

22. jocofus.

23. Emeria.

24. fenegalus.

25. Schach.

26. bicolor.

27. viridis.

28. pacificus.

29. melanocephalus.

3o. feptentrionalis。

31. pileatus.

32. brachyurus. .

33. ferrugineus.

34. tabuenfis.

35. rufus.

36. leucocephatits.

37. albus.

38. leucorhynchos.

39. varius.

40. panayenfis.

4I. ruber.

42. Pitangua. 
43. fulphuratus.

44. aurantius.

45. barbarus,

46. madagafcarienfis.

47. cayanus.

48. Nootka.

49. Boulboul.

5 o. doliatus.

5 I. nævius.

5.2. obfcurus.

53. Tyrannus.

Grons V.

Pfittacus.

* macrouri.

I. Macao.

2. Aracanga.

3. militaris.

4. Ararauna.

5. hyacinthinus.

6. Makavouanna.

7. ater.

8. obfcurus.

9. nobilis.

10. feverus.

31. Eupatria:

12. japonicus.

13. amboinenfis.

14. cyanocephalus.

15. indicus.

16. Ofbeckii.

17. hæmatodus.

18. atricapillus.

19. tabuenfis.

20. papuenfis.

$2 \mathrm{I}$. borneus.

22. coccineus.

23. elegans.

24. guebienfis.

25. variegatus.

26. Pennantii.

27. novæ Guinex.

28. ornatus.

29. Bontii.

30. Jendaya.

3. jolftitialis:

32. luteus.

33. carolinenfis.

3.4. pertinax.
35. erythropygius.

36. fmaragdinus.

37. canicularis.

38. xruginofus.

39. rufiroftris.

40. Jaguilma.

41. guianenfis.

42. marginatus.

43. olivaceus.

44. dubius.

45. chryfogafter.

46. Alexandri.

47. Sonneratii.

48. pondicerianus.

49. bimaculatus.

50. ginginianus.

5 1. virefcens.

52 . verficolor.

53. fquammofus.

54 . incarnatas.

55. murinus.

56. bifetis

57. caledonicus.

58. zealandicus.

59. novæ Hollandiæ.

6o. formofus

61. ulietanus.

62. femicollaris.

63. brafilienfis.

64. lineatus.

65. pacificus.

66. auftralis.

67. peregrinus.

68. Palmarum.

69. pipilans.

70. taitianus.

71. pufillus.

72. pygmaus.

73. agilis.

* * brachyuri.

74. coronatus.

75. Gigas.

76. Bankfii.

77. criftatus.

78. rofaceus.

79. Philippinarum.

8o. galeritus.

81 . fulphureus.

82. erythroleucus.
83. erithacus.

84. cinereus.

85. Neftor.

86. niger.

87. mafcarinus.

88. fufcus.

89. accipitrinus.

90. varius.

91. violaceus.

92. fringillacets,

93. choræus.

94. robuftus.

95. menftruus.

96. garrulus.

97. Domicella.

98. Lory.

99. puniceus.

100. ruber.

IOI. moluccenfis.

102. grandis.

103. cochinfinenfis.

104. guineenfis.

105. paraguanus.

106. cæruleocephalus.

107. finenfis.

108. macrorhynchos.

I09. nafutus.

I 10. gramineus.

111. leucocephalus.

11 2. Gerini.

113. albifrons.

114 . amazonicus:

115 . barbadenfis.

116. lucionenfis.

117. æftivus.

II 8 . luteolus.

119. ochropterus.

I 20. pulverulentus.

121. havanenfis.

122. autumnalis.

123. pileatus.

124. 'Tarabe.

125 . viridis.

126. orientalis.

127. adfcitus.

128. batavenfis.

129. feftivus.

130. erythropterus.

131. dominicenfis.

132. Paradifi.

133. Aurora,

834. cyano. 
134. cyanolyfeos. 135. fordidus.

136. melanocephalus. 137. Caica.

I38. fenegalus.

139. collarius.

140. purpureus.

141. 'Tuipara.

142. chryfopterus.

143. pullarius.

1 44. malaccenfis.

145. cervicalis.

146. afiaticus.

147. vernalis.

148. Galgulus.

149. Anaca.

150. purpuratus.

151. canus.

152. melanopterus.

153. capenfis.

154. torquatus.

155. minor.

I56. pafferinus.

157. Toui.

158. Tirica.

159. Sofove.

160. Tui.

161. erythrochloros.

162. mexicanus.

\section{Genu S VI.}

\section{Rhamphaftos.}

3. Toco.

2. dicolorus.

3. Tucanus.

4. pifcivorus.

5. erythrorhynchos.

6. picatus.

7. torquatus.

8. pavoninus.

9. viridis.

10. glaber.

11. Aracari.

12. piperivorus.

13. luteus.

14. cæruleus.

3 . dubius.

$$
6
$$

\author{
GENUS VII. \\ Momotus.
}

1. brafilienfis.

GENUS VIII.

Scythrops.

1. nova Hollandia.

GEN US IX.

\section{Buceros.}

1. Rhinoceros.

2. galeatus.

3. bicornis.

4. abyfinicus.

5. africanus.

6. malabaricus.

7. Hydrocorax.

8. panayenfis.

9. manillenfis.

10. nafutus.

11. albus.

12. plicatus.

13. ginginianus.

14. orientalis.

15. grifeus.

16. viridis.

\section{Genus $X$.}

Buphaga.

I. africana.

GEN U S XI.

Crotophaga.

s. Ani.

z. major.

3. varia.

4. ambulatoria.

Gen U XII.

Callæas.

3. ciperea.

\section{G E N U S XIII.}

Corvus.

1. Corax.

2. auftralis.

3. albicollis.

4. Corone.

5. frugilegus.

6. calvus.

7. Cornix.

8. dauuricus.

9. caledonicus.

ro. jamaicenfis.

I 1. Monedula.

12. hottentottus.

13. Balicafius.

14. novæ Guinex.

15. papuenfis.

16. pacificus.

17. tropicus.

18. glandarius.

19. criftatus.

20. Stelleri.

21. cyanus.

22. infauftus.

23. canadenfis.

24. cayanus.

25. auritus.

26. purpurafcens.

27. finenfis.

28. rufus.

29. ery throrhynchos.

30. peruvianus.

31. Havigafter.

32. Pica.

33. fenegalenfis。

34. africanus.

35. caribbæus.

36. mexicanus.

37. Zanoe.

38. argyrophthalmus.

39. Caryocatactes.

40. Pyrrhocorax.

41. Graculus.

42. Eremita.

43. brachyurus. 


\section{NOMIN UM TRIVIALIUM.}

\section{Genus XIV.}

\section{Coracias.}

\author{
1. Garrula. \\ 2. bengalenfis. \\ 3. caudata. \\ 4. fenegala. \\ 5. abyffinica. \\ 6. orientalis. \\ 7. indica. \\ 8. caffra. \\ 9. vivida. \\ Io. madagafcarienfis. \\ II. mexicana. \\ 12. Puella. \\ 13. ftriata. \\ 14. finenfis. \\ 15. vagabunda。 \\ 16. cayana. \\ 17. docilis. \\ 18. nigra. \\ 19. afra \\ 20. melanocephala. \\ 2I. ftrepera. \\ 22. varia.
}

\section{Gen U S XV.}

\section{Oriolus.}

1. perficus.

z. hemorrhous.

3. criftatus.

4. leucocephalus

5. oryzivorus.

6. ferrugineus.

7. ICterus.

8. novæ Hifpanix.

9. annulatus.

10. brafilienfis.

I1. Japacani.

12. Coftototl.

3. cinereus.

14. phœniceus.

15. americanus.

16. guianenfis.

17. ruber.

18. mexicanus.

19. flavus.

20. Baltimore,
2I. fpurius,

z2. Textor.

23. Bonana.

24. nidipendulus.

25. caftaneus.

26. Xanthorus.

27. dominicenfis.

28. Jamacaii.

29. cayanenfis.

30. chryíocephalus,

3 I. leucopterus.

32. icterocephalus.

33. melancholicus.

34. furcatus.

35. viridis.

36. capenfis.

37. virefcens.

38. cæruleus.

39. niger.

40. minor.

4x. olivaceus.

42 . aoonalafhkenfis.

43. caudacutus.

44. finenfis.

45. Galbula.

46. radiatus.

47. Picus.

\section{GENus XVI.}

\section{Gracula.}

x. religiofa.

2. calva.

3. triftis.

4. nuda.

5. foetida.

6. Barita.

7. Quifcula.

8. criftatella.

9. Saularis.

10. Atthis.

11. longiroftra.

12. Aturnina.

3. icterops.

14. fcandens.

GEN US XVII.

Paradifea,

8. apoda.
2. regia.

3. magnifica.

4. cirrhata.

5. gularis.

6. leucoptera,

7. fuperba.

8. furcata.

9. fexfetacea.

10. chalybea.

11. aurea.

12. alba.

GEN U S XVIII.

\section{Trogon.}

2. Curucuí.

2. viridis.

3. violaceus.

4. Atrigilatus.

5. rufus.

6. fafciatus.

7. maculatus.

8. afiaticus.

9. indicus.

Genus XIX.

Bucco.

I. Tamatia.

2. cayanenfis.

3. collaris.

4. maynanenfis.

5. macrorhynchos.

6. melanoleucos.

7. philippenfis.

8. niger.

9. parvus.

10. grandis.

11. viridis.

12. Lathami.

13. rubricapillus.

14. indicus.

15. zeylanicus.

I6. dubius.

17. fufcus.

18. calcaratus.

Ig. Gerini. 


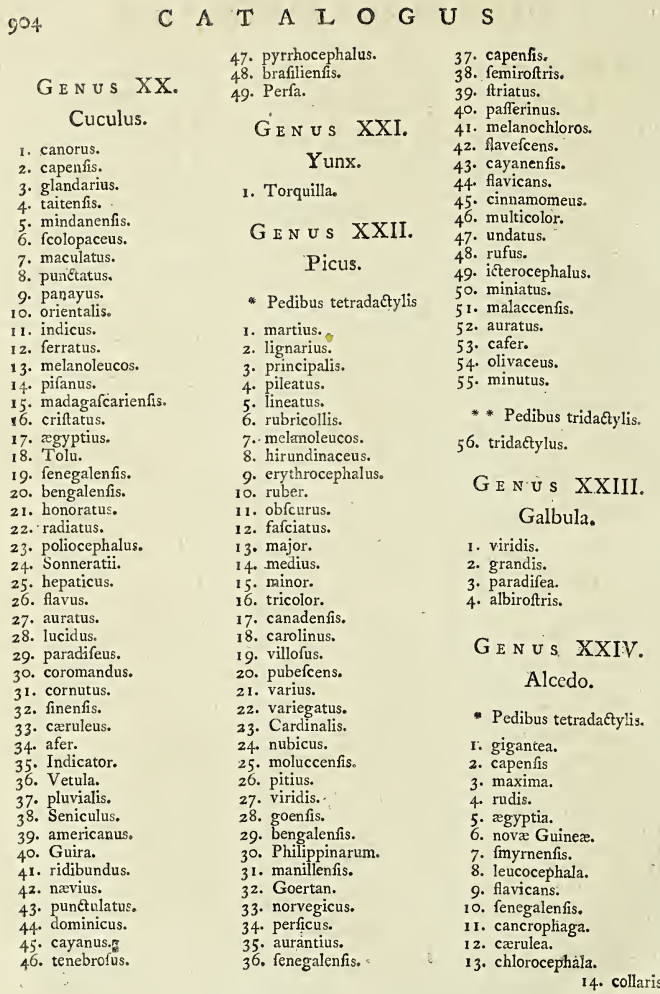




14. collaris.
35. facra
16. venerata.
17. tuta.
18. atricapilla.
19. coromanda.
20. Ifpida.
21. erithaca.
22. purpurea.
23. madagafcarienfis.
24. caruleocephala.
25. bengalenfis.
26. criftata,
27. orientalis.
28. Dea.
29. cayanenfis.
30. torquata.
31. amazona.
32. Alcyon.
33. maculata.
34. bicolor.
35. americana.
36. brafilienfis.
37. inda.
38. furinamenfis.
39. fuperciliofa.
40. leucorhyncha.
. * polat

- Pedibus tridactylis. 41. tridactyla.

\section{Genus XXV.} Sitta.

t. europea.

2. canadenfis,

3. carolinenfis. 4. jamaicenfis.

5. pufilla.

6. major.

7. navia.

8. furinamenfis.

9. caffra.

xo. longiroftra.

I1. Chloris.

\section{Gen u $\mathrm{x}$ XVI. Todus.}

1. viridis.

\author{
2. cinereus. \\ 3. fufcus. \\ 4. caruleus. \\ 5. varius, \\ 6. leucocephalus. \\ 7 . brachyurus. \\ 8. plumbeus. \\ 9. obfcurus. \\ ro. regius. \\ 11. ferrugineus. \\ 12. gularis. \\ 13. roftratus. \\ 14. nafutus. \\ 15. flavigafter.
}

\section{Gen U XXVII.}

$$
\text { Merops. }
$$

I. Apiafter.

2. viridis.

3. congener.

4. fuperciliofus.

5. philippinus.

6. cinereus.

7. flavicans.

8. coromandus.

9. brafilienfis.

ro. caftaneus.

11. chryfocephalus.

12. angolenfis.

13. erythrocephalus.

14. caruleocephalus.

15. erythropterus.

16. cayanenfis.

17. furinamenfis,

18. cincinnatus.

19. fafciculatus.

20. carunculatus.

21 . corniculatus.

22. rufus.

23. moluccenfis.

Gen us XXVIII.

$$
\text { Upupa. }
$$

ז. Epops.

2. capenfis.

3. paradifea.

4. mexicana.

5. Promerops.
6. papuenfis.

7. fuperba.

8. aurantia.

9. erythrorhynchos.

ro. indica.

\section{GEN US XXIX.}

\section{Certhia.}

เ. familiaris.

2. viridis.

3. pacifica.

4. obfcura.

5. veftiaria.

6. falcata.

7. madagafcarienfis.

8. fperata.

9. philippina.

10. fenegalenfis.

II. chalybea.

12. capenfis.

13. zeylonica.

14. olivacea.

15. currucaria.

16. Lotenia.

17. omnicolor.

18. afra.

19. polita.

20. fulva.

21. violacea.

22. afiatica.

23. pulchella.

24. famofa.

25. cinerea.

26. tabacina.

27. coccinea.

28. erythronotos.

29. Cardinalis.

3o. fanguinea.

31. virens.

32. gutturalis.

33. purpurea.

34. cyanea.

35. carulea.

36. Spiza.

37. cayana.

38. variegata。

39. brafiliana.

40. muraria.

41. fufca.

42. ignobilis. 
43. undulata.

44. carunculata.

45. furinamenis.

$4^{6 .}$ cyanogaftra.

47. aurantia.

48. Sannio.

49. N. Hollandix.

50. incana.

5 I. ciuentata.

52. borbonica.

53. flaveola.

54. peregrina.

55. armillata.

56. cinnamomea.

57. verticalis.

58. Parietum.

59. viridis.

6o. lepida.

6r. cantillans.

62. cirrhata.

63. erythrorhynchos.

64. chryfoptera.

65. longuroftra.

66. grifea.

67. melanura.

68. ænea.

69. gularis.

70. trochilea.

71. prafinoptera.

72. macaflarienfis.

73. indica.

74. amboinenfis.

GENUS XXX.

\section{Trochilus.}

- Roftro incurvato.

1. paradifeus,

2. Pella.

3. fuperciliofus.

4. Polytmus.

5. cyanurus.

6. capenfis.

7. forficatus.

8. furcatus.

9. forcipatus,

10. galeritus.

11. granatinus.

12. jugularis.
13. nitidus.

14. holofericens.

15. punctulatus.

16. gularis.

17. violaceus.

13. pectoralis.

19. leucurus.

20. Mango.

21. cincreus.

22. multicolor.

23. brafilienfis.

24. margaritaceus.

25. cyaneus.

26. dominicus.

27. Thaumantias.

28. flavifrons.

29. torquatus.

30. aurantius.

31. gularis.

32. exilis.

- Roftro reeto.

33. latipennis.

34. mellivorus.

35. Ourifia.

36. auritus.

37. rubineus.

38. Colubris.

39. fimbriatus.

40. mellifugus。

41. niger.

42. fapphirinus.

43. bicolor.

44. obfcurus.

45. hypophaus.

46. leucogafter.

47. Pegafus.

48. ruber.

49. mof chitus.

50. elatus.

51. tobagenfis.

52. guianenfis.

53. Bancrofti.

54. Carbunculus.

55. platurus.

56. criftatus.

57. pileatus.

58. ornatus.

59. collaris.

60. frontalis,
61. viridilimus,

62. amethyftinus.

63. cyanocephalus.

6. maculatus.

65. minimus.

\section{O R D O III.}

PASSERES.

GEN US XXXI.

Sturnus.

1. vulgaris.

2. capenfis.

3. ludovicianus.

4. militaris.

5. collaris.

6. carunculatus.

7. gallinaceus.

8. fericeus.

9. viridis.

10. olivaceus.

11. moritanicus.

12. Loyca.

13. Dauuricus.

14. Junceti.

15. mexicanus.

\section{GeNus XXXII.}

Turdus.

3. vifcivorus.

2. muficus.

3. guianenfis.

4. jamaicenfis.

5. minor.

6. aurocapillus,

7. Iliacus.

8. aoonalafhkæ.

9. barbaricus.

10. tripolitanus.

11. Pilaris.

12. migratorius.

13. navius.

14. Calliope.

15. muftelinus.

16. fufcus.

17. ftriatus. 
18. variegatus.

8. cayanus.

20. Pagodarum.

21. malabaricus.

22. ruficaudus.

23. Phœnicurus.

24. obfcurus.

25. ruficollis.

26. fibiricus.

27. pallidus.

28. arundinaceus.

29. plumbeus.

30. crafiroftris.

31. ulietenfis.

32. infauftus.

33. faxatilis.

34. canorus.

35. finenfis.

36. arcuatus.

37. N. Hollandia.

38. Shanhu.

39. philippenfis.

40. furatenfis.

4.1. pacificus.

42. fanduicenfis.

43. aufralis.

44. rufus.

45. polyglottus.

46. Thenca.

47. Orpheus.

4.8. dominicus.

49. brafilienfis.

5o. Merula.

5 I. leucogenus.

52. americanus.

53. curæus.

54. labradorus.

55. perficus.

56 . torquatus.

57. Cinclus.

58. leucuras.

59. rofeus.

60. cyanus.

61. folitarius.

62. manillenfis.

63. Eremita.

64. Morio.

65. erythropterus.

66. nitens.

67. æneus.

68. auratus.
69. violaceus.

70. columbinus.

7r. leucogafter.

72. dominicanus,

73. leucocephalus.

74. Cantor.

75. mauritianus.

76. nigricollis.

77. malabaricus.

78. Boubil.

79. perfpicillatus.

8o. zeylonus.

81. chryfogafter.

8z. flavus,

83 . citrinus.

84. bicolor.

85. Ourovang.

86. jugularis.

87. virefcens.

88. olivaceus.

89 . indicus.

9o. cinerafcens.

91. grifeus.

92. longiroftris.

93. fenegalenfis.

94. madagafcarienfis.

95. mindanenfis.

96. atricapillus.

97. capenfis.

98. albifrons.

99. cafer.

100. macrourus.

101. amboinenfis.

102. borbonicus.

103. ochrocephalus.

104. orientalis.

105. Saui-jala.

I06. hifpaniolenfis.

107. furinamus.

108. Palmarum,

rog. Monacha.

110. æthiopicus.

I11. abyffinicus.

II 2. pectoralis.

113. cochinfinenfis.

114. cinnamomeus.

115. rufifrons.

116. Arada.

117. Coraya.

I18. fufcipes.

19. Alapi.
120. cirrhatus.

121. Campanella.

122. Bambla.

123. auritus.

124. Colma.

I25. tinniens.

126. lineatus.

I27. formicivorus.

I28. cyanurus.

I29. grallarius.

130. africanus.

131. hudfonicus.

I32. noveboracenfis.

I33. ginginianus.

134. Dauma.

735. fpeciofus.

I36. minutus.

GENus XXXIII. Ampelis.

I. Garrulus,

2. Cotinga.

3. cayana.

4. terfa.

5. maynans.

6. Pompadora.

7. Carnifex.

8. cuprea.

9. carunculata.

IO. variegata.

II. cinerea.

12. phœnicea.

13. lutea.

14. criftata.

\section{Genus XXXIV.}

\section{Colius.}

1. capenfis.

2. fenegalenfis.

3. leuconotus,

4. Atriatus.

5. panayenfis.

6 . viridis.

7. indicus. 


G E N U XXXV.
Loxia.
3Xedibus tetradactylis.
1. curviroftra.
2. falciroftra.
3. pfittacea.
4. Coccothraufes.
5. Enucleator.
6. rubicilla.
7. capenfis.
8. aurea.
9. longicauda.
10. grofia.
11. cærulea.
12. cyanea.
13. violacea.
14. Cardinalis.
35. boetonenfis.
16. madagafcarienfis.
17. Orix.
18. mexicana.
19. brafiliana.
20. erythrocephala.
21. dominicana.
22. cucullata.
23. fibirica.
24. criftata.
25. ludoviciana.
26. maculata.
27. obfcura.
28. hudfonica.
29. canadenfis.
30. flabellifera.
31. oryzivora.
32. philippina.
33. abyfinica.
34. penfilis.
35. focia.
36. bengalenfis.
37. collaria.
38. grifea.
39. Chloris.
40. finenfis.
41. butyracea.
42. dominicenfis.
43. africana.
41. hypoxantha,

45. fulphurata.

46. flaviventris.

47. bonarienfis.

48. flavicans.

49. hordeacea.

50. mexicana.

51. Malacca.

52. molucca.

53. Atriata.

54. punctularia.

55 . undulata.

56. Pyrrhula.

57. panicivo:a.

58. feptentrionalis.

59. nigra.

6o. angolenfis.

61. torrida.

62. ferruginea.

63. melanura.

64 . fufca.

65. craffiroftris.

66. aurantia.

67. pectoralis.

68. lineola.

6. melanocephala.

70. erythromelas.

71. coronata.

72. Maia.

73. fanguiniroftris

74. virens.

75. Aftrild.

76. leucura:

77. cana.

78. caffra.

79. Totta.

80. indica.

81. malabarica.

82. melanogaftra.

83. afiatica.

84 . canora.

85. lineata.

86. perlata.

87. fafciata.

88. cantans.

89. bicolor.

9o. minuta.

91. prafina.

92. minima.

* Pedibus tridactylis.

93. tridactyla,

\section{Genus XXXVI.}

Emberiza,

1. nivalis.

2. glacialis.

3. montana.

4. hyemalis.

5. Hortulana.

6. finenfis.

7. Citrinella.

8. maelbyenfis.

9. chryfoptera.

10. Cirlus.

11. Cia.

12. Mi.iaria.

13. Schceniclus.

14. pafierina.

15. provincialis.

16. lefbia.

17. lotharingica.

18. ludovicia.

19. pittacea.

20. paradifæa.

21. ferena.

22. Vidua.

23. principalis.

24. regia.

25. longicauda.

26. panayenfis.

27. angolenfis.

28. capenfis.

29. fafciata.

30. oryzivora.

3. Quelea.

32. Textrix.

33. rubra.

34. coccinea.

35. familiaris.

36. flaveola.

37. amazona.

38. olivacea.

39. badenfis.

40. rutila.

41. ferruginea.

42. americana.

43. brafilienfis.

44. mexicana.

45. militaris.

46. melanocephala. 
47. brumalis.

48. erythropthalma.

49. lencophrys.

50. Pithyornus.

51. ruftica.

52. luêuofa.

53. aureola.

54. pufilla.

55. aretica.

56. aoonalafhkenfis.

57. atricapilla.

58. cinerea.

59. carulea.

6o. cyanea.

61. Ciris.

62. mixta.

63. quadricolor.

64 . cyanopis.

65 . viridis.

66. platenfis.

67. borbonica.

68. Calfat.

69. Tunfalli.

70. grifea.

71. furinamenfis.

72. afiatica,

73. fucata.

74. fpodocephala.

75 . chryfophrys.

\section{Genus XXXVII.}

\section{Tanagra.}

1. Jacapa.

2. brafilia.

3. rubra.

4. olivacea.

5. miffiffipenfis.

6 . variegata.

7. æeftiva.

8. magna.

9. criltata.

10. melanopis.

x. pileata.

12. melanictera.

13: atricapilla.

14. ftriata.

15. brafilienfis.

16. dominica.

1.7. Epifcopus,
18. Sayaca.

19. punctata.

20. gularis.

21. virens.

22. finenfis.

23. mexicana.

24. guianienfis.

25. cayana.

26. Gyrola.

27. carulea.

28. variabilis.

29. tricolor.

30. grifea.

31. Tatao.

32. Jacarina.

33. violacea.

34. cayanenfis,

35. atrata.

36. bonarienfis.

37. albirottris.

38. militaris.

39. albifrons.

40. flava.

41. amboinenfis.

42. filens.

43. canora.

44. capitalis.

Grenus XXXVIII.

\section{Fringilla.}

1. domeftica,

2. montana.

3. canadenfis.

4. criftata.

5. carolinenfis,

6. Petronia.

7. ftulta.

8. bononienfis.

9. leucura.

Io. brachyura.

11. dalmatica.

12. Colebs.

13. flammea.

14. ruticapilla.

15. iliaca.

16. flaviroitris

7. Montifingilla

18. lapponica.

19. nivalis.

20. Capfa,
21. arcuata.

22. elegans.

23. formofa.

24. noctis.

25. nitens.

26. melanictera.

27. melanoleuca.

28. Pecoris.

29. Jamaica.

30. cana.

31. Savannarum.

32. coccinea.

33. rofea.

34. punicea.

35 . ferruginea.

36. penfylvanica,

37. fafciata.

38. graminea.

39. cinerea.

40. Pinetorum.

41. fylvatica.

42. nortonienfis.

43. hyemalis.

44. Atriata.

45. purpurea.

46. Zena.

47. furinama.

43. longiroftris.

49. finica.

50. afiatica.

51. navia.

52. melanocephala.

53. fufca.

54. Euftachii.

55. variegata.

56. crifpa.

57. indica.

58. Carduelis.

59. Melba.

6o. afra.

61. pfittacea.

62. ery throcephala

63 . lulenfis.

64. triftis.

65. Spinus.

66. mexicana.

67. Cacatototl.

68. canaria.

69. Serinus.

7o. citrinella。

71. flaveola.

72. autumnalis, 
73. lepida.

74 . butyracea.

75. bicolor.

76. barbata.

77. Diuca.

78. ultramarina.

79. abyfinica.

80. fyriaca.

81. Linota.

82. cannabina.

83. Linaria.

84. Montium.

85. caudacuta.

86. georgiana.

87 . argentoratenfis.

88. angolenfis.

89. obicura.

90. macroura.

91. Benghalus.

92. Amandava.

93. fenegala.

94. leucotis.

95. Alario.

96. Maia.

97. granatina.

98. zeylonica.

99. fufcicollis.

100. ignita.

101. tricolor.

102. cyanomelas.

103. picta.

104. cyanocephala.

105 . torquata.

106. multicolor

107. flavicollis.

108. carthaginienfis.

109. ochracea.

110. teftacea.

11 1. imperialis.

112. auftralis.

Genus XXXIX.

Phytotoma.

x. Rara.

GENUS XL.

Mufcicapa.

ฆ. Grifola.
2. atricapilla.

3. torquata.

4. bicolor.

5. albifrons.

6. melancleuca.

7. leucomela.

8. fenegalenis.

9. criftata.

I0. borbonica.

11. collaris.

12. nigrifrons.

13. leucura.

14. ponticeriana.

15. afra.

16. cana.

17. ochracea.

18. madagafcarienfis.

19. undulata.

20. Tectec.

21. rufiventris.

22. Ruticilla.

23. flammea.

24. nigra.

25. comata.

26. hæmorrhoufa.

27. Pfidii.

28. melanictera.

29. nitens.

30. finenfis.

31. grifea.

32. flavicollis.

33. fufcefcens.

34. luzionenfis.

35. philippenfis.

36. cærulea.

37. cyanocephala.

38. manillenfis.

39. flabellifera.

40. fuperciliofa.

41. ferruginea.

42. Aedon.

43. N. Hollandix.

44. Deferti.

45. caledonica.

46. lutea.

47. ochrocephala.

48. flavifrons.

49. navia.

50. erythrogaftra,

51. fanduicenfis.

52. obfcura.
53. maculata.

54. Paradifi.

55. mutata.

56. Itriata.

57. virens.

58. viriais.

59. fibirica.

6o. crythropis.

61. olivacea.

62. martinica.

63 . fufca.

64. carolinenfis.

65. canadenfis.

66. cinnamomea.

67. fpadicea.

68. cayanenfis.

6. Tyrannus.

70. forficata.

71 . crinita.

72. ferox.

73. ludoviciana.

74. audax.

75. Petechia.

76. virgata.

77. agilis.

78. furinama.

79. fuliginofa.

8o. aurantia.

81. coronata.

82 . rufefcens.

83. cinerea.

84. pygmæa.

85. minuta.

86. barbata.

87. rubricollis.

88. Phcebe.

89. ochroleuca.

9o. nitida.

91. acadica.

92. noveboracenfia.

93. pafferina.

94. dichroa.

95. javanica.

96. alba.

97. cambaienfis.

\section{Genus XLI.}

Alauda.

8. arvenfis。

2. fulva 


\section{NOMINUM TRIVIALIUM. 9II}

\author{
2. fulva. \\ 3. arborea. \\ 4. italica. \\ 5. pratienfis. \\ 6. trivialis. \\ 7. obfcura. \\ 8. minor. \\ 9. ludoviciana. \\ I0. rubra. \\ II. mofellana. \\ I2. campeftris. \\ 13. malabarica. \\ 14. gingica. \\ 15. tatarica. \\ 16. yeltonienfis. \\ 17. Calandra. \\ I8. mongolica. \\ 19. N. Zealandix. \\ 2o. capenfis. \\ 2 s. alpeftris. \\ 22. rufa. \\ 23. cinerea. \\ 24. africana. \\ 25. criftata. \\ 26. criftatella. \\ 27. undata. \\ 28. fenegalenfis. \\ 29. teftacea. \\ 30. lufitana.
}

\section{GENUS XLII.}

\section{Motacilla.}

1. alba.

2. maderafpatenfis.

3. cinerea.

4. Boarula.

5. melanopa.

6. hudfonica,

7. indica.

8. flava.

9. citreola.

Io. capenfis,

II. afra.

12. tchutfchenfis,

13. viridis.
Grnus XLIII.

Sylvia.

I. Lúcinia.

2. madagafcarienfis.

3. hortenfis.

4. Hippolais.

5. pafierina.

6. atricapilla.

7. melanocephala.

8. mofchita.

9. Curruca.

I0. Schøenobanus,

II. aquatica.

12. arundinacea.

13. modularis.

14. Juncorum.

15. Phœnicurus,

I6. Tythys.

17. gibraltarienfis.

18. erythrogaftra.

19. Erithacus.

20. guianenfis.

2 I. atrata.

22. caffra.

23. cinerea.

24. Sylvieila,

25. Locuftella.

26. falicaria.

27. rufa,

28. Ficedula.

29. nævia.

3o. patagonica.

31. dartfordienfis.

32. africana.

33. noveboracenfis.

34. umbria.

35. flavicollis.

36. Trichas.

37. ruficauda.

38. fufcicollis.

39. crerulefcens。

40. americana.

41. penfilis.

4.2. Rubecula,

43. fuecica.

44. Sialis.

45. Dumetorum.

46. nigrirostris,
47. borealis.

48. lutefcens.

49. Rubicola.

50. Sybilla.

51. fperata.

52. caprata.

53. fulicata.

54. perfpicillata.

55. coromandelica.

56. philippenfis.

57. magna.

58. Rubetra.

59. fervida.

6o. montanella.

61. fenegalenfis.

62. maura.

$6_{3}$. fuperciliofa.

64. ferruginea.

65. cyanura.

66. aurorea.

67. friata.

68. incana.

6g. flavifrons.

70. Blackburnix.

7 I. mitrata.

72. cucullata.

73. murina.

74. Ipinicauda.

75. magellanica.

76. citrina.

77. longipes.

78. minima.

79. Oenanthe.

8o. ftapazina.

81. leucorhoa.

82. hottentotta.

83. aurantia.

84. pileata.

85. maffilienfis.

86. maculata.

87. albicapilla.

88. grifea.

89. caryophyllacea.

go. olivacea.

91. zeylonica.

92. cingalenfis.

93. finenfis.

94. madagafcarienfis,

95. borbonica.

96. mauritiana.

97. livida, 


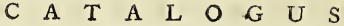

\author{
98. flavefcens. \\ 99. rufigaftra. \\ 100. undata. \\ 101. fufcata. \\ 102. fubflava. \\ 103. Petechia. \\ 104. albicollis. \\ 105. Iudoviciana. \\ 106. chloroleuca. \\ 107. auricollis. \\ 108. maculofa. \\ 109. fufcefcens. \\ I 10 . tigrina. \\ 111. Pinus. \\ 112. virens. \\ 113. icterocephala. \\ 114. dominica. \\ 115 . coronata. \\ I 16 . cincta. \\ 117. canadenfis. \\ 118. varia. \\ I 19. ruficapilla. \\ 120. penfylvanica. \\ 121. cærulea. \\ I22. Cyane. \\ 123. chryfoptera. \\ 124. chryfocephala. \\ 125. criftata. \\ 1 26. multicolor. \\ 127. æquinoctialis. \\ 128. Protonotarius. \\ I29. femitorquata. \\ 130. fulva. \\ 131. fufca. \\ 132. pinguis. \\ 133. cana. \\ 134. Calidris. \\ 135 . bonarienfis. \\ 136. Palmarum. \\ 137. bananivora. \\ 138 . vermivora. \\ 139. campeftris. \\ 140. macroura. \\ 141. longicauda. \\ 342. cyanea. \\ 143. cayana. \\ 144. cyanocephala. \\ 145. lineata. \\ I46. Velia. \\ I47. Guira. \\ 148. Troglodytes.
}

149. platenfis.

I50. ludoviciana,

I5 1 . furva.

I52. Regulus.

I53. elata.

154. Calendula.

155. Trochilus.

I5 6 . mediterranea.

157. xfiva.

158. carolinenfis.

159. futoria.

160. gularis.

161. tfchecantfchia.

162. Kamtfchatkenfis.

163. littorea.

164. longiroftris.

165. ochrura.

166. funamifica.

167. Awatcha.

168. canefcens.

169. xquinoetialis.

7. nigricollis.

171. plumbea.

172. cambaienfis.

173. guzerata.

174. afiatica.

\section{Genus XLIV. \\ Pipra.}

I. Rupicola.

2. peruviana.

3. Pareola.

4. fuperba.

5. ferena.

6. Manacus.

7. erythrocephala.

8. leucocilla.

9. leucocephala.

10. gutturalis.

11. aureola.

12. minuta.

13. ftriata.

14. nævia.

15. criftata.

16. Picicitli.

17. Rubetra.

18. torquata.

19. Miacatototl.

20. grifea.
21. albifrons.

22. atricapilla.

23. papuenfis.

24. hamorrhoa.

25. nigricollis.

26. capenfis.

27. cinerea.

28. mufica.

\section{GEN US XLV.}

Parus.

1. major.

2. Stromei.

3. cyanus.

4. peregrinus:

5. malabaricus.

6. grifeus.

7. afer.

8. ater.

9. paluftris.

10. atricapillus.

I1. hudfonicus.

12. cæruleus.

13. bicolor.

14. criftatus.

15. virginianus.

16. Cela.

17. amorofus.

8. pendulinus.

19. narbonienfis.

2o. caudatus.

21. alpinus,

22. capenfis.

23. biarmicus.

24. finenfis.

25. fibiricus.

26. macrocephalus.

27. novæ Zealandix.

28. americanus.

29. indicus.

3o. Knjaefcik.

G E N U XLVI.

Hirundo.

- Digitis tribus anticis, uno poflico.

I. ruftica.

2. tahi- 
2. tahitica.

3. urbica.

4. panayana.

5. rufa.

6. capenfis.

7. fenegalenfis.

8. fafciata.

9. ambrofiaca.

10. rip «ria.

11. rupeftris.

12. montana.

13. dauurica.

14. ery throcephala.

15. aoonalafchkenfis.

16. indica.

17. nigra.

18. dominicenfis.

19. peruviana.

20. cinerea.

21. chalybea.

22. purpurea.

23. Tapera.

24. torquata.

25. leucoptera.

26. efculenta.

27. borbonica.

28. francica.

29. americana.

30. Pelafgia.

31. acuta.

* Digitis omnibus anticis.

32. Apus.

33. Melba.

34. cayanenfis.

35. finenfis.

\section{Genus XLVII.}

\section{Caprimulgus.}

1. grandis,

2. jamaicenfis.

3. grifeus.

4. carolinenfis.

5. europæus.

6. virginianus.

7. albicollis.

8. guianenfis.

9. rufus.

10. brafilianus. 1x. femitorquatus.

12. cayanus.

13. acutus.

14. americanus.

15. torquatus.

I6. afiaticus.

17. indicus.

18. N. Hollandix.

\section{OR D O IV.}

C O LUMB E.

GE NuS XIVIII.

Columba.

* Cauda xquali.

1. Enas.

2. domeftica.

3. montana.

4. tetraoides.

5. leucocephala.

6. leucoptera.

7. martinica.

8. jamaicenfis.

9. coronata.

Io. criftata.

II. albicapilla.

12. Pompadora.

13. phœnicoptera.

14. afiatica.

15. ery throptera.

16. indica.

17. purpurata.

18. Jambos.

19. rubricapilla.

20. purpurea.

21. eimenfis.

22. vernans.

23. aromatica.

24. S. Thomæ.

25. curviroftra.

26. tannenfis.

27. pacifica.

28. mexicana.

29. nævia.

30. Hoilotl.

31. cærulea.

32. Palumbus.

33. ænea.
34. alba.

35. guinea.

36. caribaa.

37. zealandica.

38. brunnea.

39. chalcoptera.

40. madagafcarienfis.

4I. auftralis.

42. Francia.

43. maculata.

44. nicobarica.

45. fpeciofa.

46. corenfis.

47. Turtur.

48. orientalis.

49. xgyptiaca.

50. furinamenfis.

51. riforia.

52. finica.

53. ftriata.

54. cyanocephala.

55. furatenfis.

56. cambayenfis.

57. malabarica.

58 . viridis.

59. melanocephala.

6o. javanica.

61. caruleocephala.

62. fenegalenfis.

63. vinacea.

64. afra.

65. cruenta.

66. fanguinea.

67. pafferina.

68. minuta.

69. malaccenfis.

* macrouræ, cauda cuneiformi.

70. migratoria.

71. carolinenfis.

72. canadenfis.

73. marginata.

74. amboinenfis.

75. capenfis.

76. macroura.

77. bantamenfis.

78. melanoptera.

79. dominicenfis。 


\section{OR D O V. \\ GALLIN死。 \\ GEN U S XIX. \\ Pavo. \\ 1. criftatus. \\ 3. muticus. \\ 3. bicalcaratus. \\ 4. tibetanus. \\ G EN US L. \\ Meleagris.}

x. Gallopavo.

z. Satyra

GEN U S LI.

\section{Penelope.}

1. criftata.

3. Pipile.

3. cumanenfis.

4. Marail.

\section{GEN US LII.}

Numida。

z. Meleagris.

2. mitrata

3. criftata.

4. agyptiaca,

GENuS LIII.

\section{Crax.}

i. Alector.

2. globicera.

3. Pauxi.

4. galeata.

5. vociferans.

GENUS LIV.

Phafianus.

a. Gallus.
2. fuperbus.

3. Argus.

4. colchicus.

5. pictus.

6. nycthemerus,

7. criftatus.

8. africanus.

9. Motmot.

ro. mexicanus.

II. impejanus.

32. Parraqua,

13. leucomelanos،

\section{GenUS IV。} Tinamus.

1. brafilienfis,

2. cinereus.

3. variegatus.

4. Soui.

\section{GENUS LVI.}

\section{Tetrao.}

- Pedibus tetradactylis.

^. Urogallus.

2. Phafianellus,

3. Tetrix.

4. nemefianus.

5. betulinus.

6. canadenfis.

7. Umbellus.

8. Cupido.

9. Lagopus.

10. albus.

11. rupeftris.

12. lapponicus。

13. canus.

14. Bonafia.

15. fcoticus.

16. Alchata.

17. fenegalus.

18. arenarius.

19. Namaqua,

- Pedibus tridactylis。

30. Paradoxus,
GeNus LVII。

Perdix.

- Pedibus tetradactylis,

1. capenfis.

2. bicalcarata,

3. ceylonenfis.

4 fpadicea.

5. nudicollis.

6. Francolinus.

7. aragonica.

8. madagafcarienfis.

9. cinerea.

so. damafcena.

11. montana.

12. rufa.

13. rubricollis.

14. petrofa.

15. perlata.

16. a fra.

17. gingica.

18. ponticeriana.

19. nævia.

20. afiatica.

* Pedibus tetradaćtylis muticis.

21. guianenfis.

22. viridis.

23. indica.

24. virginiana,

25. marilanda.

26. ferruginea.

27. javanica.

28. Coturnix.

29. chinenfis,

30. criftata.

31. mexicana,

32. falklandica.

33. N. Hifpaniz.

34. Coyolcos.

35. Suf́citator.

36. ftriata.

37. grifea.

38. coromandelica.

39. N. Guinex.

40. manillenfis.

41. hudfonica, 


\author{
42. Kakelik. \\ 43. cafpia. \\ 44. cambaienfis. \\ * Pedibus tridactylis. \\ 45. gibraltarica. \\ 46. andalufica. \\ 47. nigricollis. \\ 48. luzonienfis.

\section{GE N U I LVIII. \\ Pfophia.}

s. crepitans.

2. undulata.

GENUS LIX.

Otis.

๘. Tarda.
2. chilenfis.

3. Tetrax.

4. Arabs.

5. afra.

6. bengalenfis.

7. aurita.

8. Houbara.

9. Rhaad.

10. indica.

xx. Gedicnemus.
OR D O VI.

STRUTHIONES.

GEN US LX.

Didus.

I. ineptus.

2. folitàrius.

3. nazarenus.
GEN U S LXI. Struthio.

r. Camelus.

GENUS LXII.

Cafuarius.

1. Emeu.

2. N. Hollandix.

\section{DIv. II. A VES A QU A T I C}

OR D O VII.

GRALL正.

GENUS LXIV.

Platalea.

4. leucorodia.

2. Ajaja.

3. pygmea.

GEN US LXV.

Palamedea.

I. cornuta.

2. criftata.

\section{GENUS LXVI.}

Mycteria.

z. americana.
2. afiatica.
Genus LXVII. Cancroma.

1. Cochlearia.

Genus LXVIII.

Scopus.

I. Umbretta.

GeNus LXIX.

\section{Ardea.}

- criftate.

x. pavonina.

2. Virgo.

* Grues, capite calvo.

3. gigantea.

4. Antigone.

5. Grus.
6. americana.

7. canadenfise

8. Argala.

... Ciconix, orbitis nudiø.

9. Ciconia.

Io. Maguari.

11. nigra.

I2. bononienfis.

.... Ardex, ungue medi. introrfum ferrato.

13. Nycticorax.

I4. jamaicenfis.

15. caledonica.

16. obfcura.

17. cayanenfis.

I8. Atellaris.

19. folonjenfis.

20. Marfigli.

2 I. danubialis.

22. undulata.

23. brafilienfiso

24. tigrina.

25. lineata 


\section{$9 \times 6$}

25. lincata.

25. flava.

27. minuta.

25. pumila.

29. exilis.

30. fenegalenfis.

31. vireicens.

32. Gardeni.

33. cyanopus.

34. N. Guinex.

35. philippenfis.

36. Squaiotta.

37. badia.

38. erythropus.

39. comata.

40. caltanea.

41. ferruginea,

42. to:quata.

43. erythrocephala.

44. Thula.

45. cyanocephala.

46. cinnamomea.

47. malaccenfis.

43. cærulea.

49. cærulefcens.

50. violacea.

51. ludoviciana.

52. ftriata.

53. carunculata.

54. cinerea.

55. rufa.

56. variegata.

56. Herodias.

57. Hudfonias.

58. rubiginofa.

59. cana.

bo. virgata.

61. rufefcens.

62. leucogafter.

63. Egretta.

64. Garzetta.

65. alba.

66. pileata.

67. nivea.

68. Galatea.

69. facra.

70. xquinoctialis.

71. atra.

72. purpurea,

73. cafpica.

\section{A T A L O G U S}

74. Botaurus.

75. purpurata.

76. fpadicea,

77. Cracra.

78. levicocephala.

79. Agami.

8o. Cocoi.

81. finenfis.

82. Johannx.

83. fufca.

84. Hoactli.

85. Hohou.

86. indica.

87. flavicollis.

88. N. Hollandix.

8. fcolopacea.

*** Roftro medio hiante.

9o. pondiceriana.

91. coromandeliana.

\section{G EN U S I XX.}

Tantalus.

1. Loculator.

2. ruber.

3. cayanenfis.

4. mexicanus.

5. melanopis.

6. albicollis.

7. grifeus.

8. fufcus.

9. albus.

10. leucocephalus.

11. Ibis.

12. xthiopicus.

13. niger.

14. Falcinellus.

35. viridis.

16. igneus.

17. calvus.

18. manillenfis.

19. minutus.

20. criftatus.

21. melanocephalus

22. Pillus.

23. Hagedafh.
GENUS LXXi.

Numenius.

8. Arquata.

3. madaga carienfis.

3. Iuzonienfis.

4. tahitienfis.

5. eucocephalus.

6. Phropis.

7. hudfonicus.

8. Guarauna.

9. borealis.

10. africanus.

I1. pygmeus.

\section{GENUS LXXII.}

\section{Scolopax.}

I. Ruficola.

2. minor.

3. paludofa.

4. major.

5. cayanenfis.

6. Gallinago.

7. gallinaria.

8. Gallinula.

9. belgica.

10. capenfis.

11. finenfis.

13. maderafpatana.

13. indica.

14. Fedoa.

15. lapponica.

16. Agocephala.

17. leucophea.

18. Limofa.

19. marmorata.

20. hudfonica.

2 I. Glottis.

22. canefcens.

23. cantabrigienfis。

24. Totanus.

25. Calidris.

26. candida.

27. femipalmata.

28. melanoleuca.

2g. flavipes. 


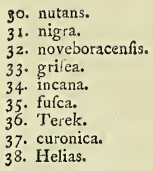

\section{GENuS LXXIII.}

\section{Tringa.}

1. Pugnax.

2. Vanellus,

3. bononienfis.

4. erythropus.

5. cayanenfis.

6. ludoviciana,

7. goenfis.

8. fenegalla.

9. Gambetta.

10. helvetica.

II. Squataiola.

12. Ochropus.

13. Glareola.

14. equettris.

15. littorea.

16. grenovicenfis。

17. leucoptera.

18. maritima.

19. undata.

20. uniformis.

2x. Calidris.

22. nævia.

23. grifea.

24. ftriata.

25. cinerea.

26. fufca.

27. lincolnienfis.

28. Hypoleucos.

29. macularia.

30. noveboracenfis.

3I. virgata.

32. borealis.

33. novæ 'Terra.

34. variegata.

35 . Cinclus.

36. ruficollis.

37. alpina.
38. pufilla,

39. iflandica.

40. autralis.

41. fafciata.

42. Keptulcha,

43. atra.

44. Canutus.

45. Interpres.

Genus LXXIV.

Charadrius.

i. Pluvialis.

2. rubidus.

3. Himantopus.

4. Calidris.

5. apricarius.

6. vociferus.

7. jamaicenfis.

8. Hiaticula.

9. alexandrinus.

10. atricapillus.

I. philippinus.

12. N. Zealandiz.

13. gregarius.

14. afiaticus.

15. tataricus.

16. mongolus.

17. Morinellus.

18. falklandicus.

19. fibiricus.

20. obfcurus.

21. fulvus.

22. leucogafter.

23. rubricollis.

24. fpinofus.

25. cayanus.

26. pileatus.

27 coronatus.

28. bilobus.

29. melanocephalus.

30. indicus.

31 . curonicus.

32. nevius.

Genus LXXV.

\section{Curforius.}

1. europxus.

2. afiaticus.

\section{Genus LXXVI.}

Hrmatopus.

1. Oftralegus.

Gen us LXXVII.

Glareola.

1. auttriaca.

2. fenegal nfis..

3. nævia.

Gen us LXXVIII.

\section{Rallus.}

1. aquaticus.

2. crepitans.

3. auitralis.

4. philippenfis.

5 . torquatus.

6. fufcus.

7. ferrugineus.

8. capenfi .

9. cærulefcens.

I0. zeylanicus.

11. pacificus.

12. tabuenfis.

13. niger.

14. fanduicenfis.

15. taitienfis.

16. obfcurus.

17. longiroftris.

18. barbaricus.

19. dubius.

20. variegatus.

21. cayanenfis.

22. jamaicenfis.

23. minutus.

24. pufillus.

Genus LXXIX.

Parra.

1. Jacana.

2. nigra.

3. brafilienfis。

4. viridis.

5. variabilis. 
6. luzonienfis.

7. finenfis.

8. africana.

9. Chavaria.

10. indica.

11. chilenfis.

GEN US LXXX.

\section{Gallinula.}

v. Crex.

2. carthagena.

3. cayanenfis.

4. ruficollis.

5. maderafpatana.

6. Porphyrio.

7. melanocephala.

8. alba.

9. martinica.

ro. flaviroltris.

II. purpurea.

12. viridis.

13. chloropus.

14. phoenicura.

15. fufca.

16. noveboracenfis.

17. carolina.

18. nævia.

19. Porzana.

20. maculata.

21. flavipes.

22. fifulans.

23. criftata.

\section{GENUS LXXXI.}

- Vaginalis.

1. Chionis.

\section{O R D O VIII.}

PINNATIPEDES.

GENUS LXXXII.

Phalaropus.

I. hyperboreus.

2. lobatus.
3. glacialis,

4. fufcus.

5. cancellatus.

Genus LXXXIII. Fulica.
1. atra.
2. aterrima.
3. criftata.
4. mexicana.
5. americana.

Genus LXXXIV. Podiceps.

I. criftatus.

2. cayanus.

3. auritus.

4. obfcurus.

5. cornutus.

6. rubricollis.

7. cafpicus.

8. thoinenfis.

9. minor.

10. diominicus.

11. hebridicus.

12. carolinenfis.

13. Iudovicianus.

OR D IX.

PALMIPEDES.

- Pedibus longioribus.

Genus LXXXV. Recurviroftra.
I. Avocetta.
2. americana.
3. alba.

Genus LXXXVI.

Corrira.

s. italica.
Genus LXXXVI?

Phonicopterus.

1. ruber.

2. chilenfis.

* Pedibus brevioribus.

Genus LXXXVIII.

Diomedea.

1. exulans.

2. fpadicea.

3. clororhynchos.

4. fuliginofa.

Genus LXXXIX.

Alca.

1. impennis.

2. cirrhata.

3. arctica.

4. labradora.

5. Torda.

6. criftatella.

7. tetracula.

8. pfittacula.

9. antiqua.

10. Alle.

xi. pygmea.

G E N U $\mathrm{XC}$.

Uria.

x. Troile.

2. Grylle.

3. lacteola.

4. marmorata.

Genus $\mathrm{XCI}$.

Colymbus.

1. glacialis.

2. Immer.

3. ftellatus.

4. arcticus.

5. feptentrionalis.

6. borealis.

7. Ari- 
7. ftriatus.

8. finenfis.

GENUS XCII.

Rhynchops.

1. nigra.

\section{GENus XCIII.}

\section{Sterna.}

x. cafpia.

2. cayana.

3. furinamenfis.

4. fuliginofa.

5. africana.

6. folida.

7. philippina,

8. fimplex.

9. nilotica.

10. Boyfii.

11. Atriata.

I2. vittata.

13. Spadicea.

14. fufcata.

15. Hirundo.

16. panaya.

17. cinerea.

18. alba.

19. minuta.

20. finenfis.

21. auftralis.

22. metopoleucos.

23. fiflipes.

24. nigra.

25. obfcurav

\section{Genus XCIV.}

\section{Larus.}

- Naribus abfque cera.

x. i尺hyætus.

2. ridibundus.

3. atricilloides.

4. atricilla.

5. minutus.

6. marinus.

7. glaucus.

8. fufcus.
9. canus.

10. eburneus.

II. tridactylus.

* Naribus cera obtectis.

12. Catarractes.

13. Keeafk.

14. crepidatus.

15. parafiticus.

Genus XCV. Procellaria.

- Naribus tubulofis.

1. gigantea.

2. brafiliana.

3. æquinoctialis.

4. grifea.

5. geiida.

6. alba.

7. antarctica.

8. capenfis.

9. glacialis.

เo. cinerea.

11. Pufinus.

12. melanopus

13. nivea.

14. defolata.

15. fuliginofa.

I6. furcata.

17. Fregata.

18. marina.

19. pelagica.

zo. urinatrix.

* Naribus difçretiso

2.1. Forteri.

22. cærulea.

23. pacifica.

24. obfcura.

\section{Genus XCVI.}

$$
\text { Merguís. }
$$

1. Merganfer.

z. Caftor.

3. imperialis.

4. Serrator.

5. cucullatus.
6. Albellus.

7. minutus.

8. furcifer.

9. fufcus.

Iо. cærulcus.

\section{GENUS XCVII.}

\section{Anas.}

x. Cygnus.

2. Olor.

3. nigricollis.

4. atrata.

5. brachyptera.

6. hybrida.

7. Cofcoroba.

8. antaretica.

9. leucoptera.

1. variegata.

11. magellanica.

12. picta.

13. crulefcens,

14. hyperborca.

15. grandis.

16. cygnoides.

17. canadenfis.

18. melanonotos,

19. gambenfis.

20. indica.

21. xgyptiaca.

2.2. cana.

23. ruficollis.

24. Cafarca.

25. montana.

26. Anfer.

27. albifrons.

28. Segetum.

29. Beringii.

3o. borealis.

31. erythropus.

32. Bernicla.

33. torrida.

34. albicans.

35. mollifima.

36. fpectabilis.

37. mofchata.

38. nilotica.

39. regia.

40. Monacha.

4i. georgica. 
520 C A T A I O G U S, \& \& :

42. perfpicillata.

43. nigra.

4.4. fuica.

45. hiftrionica.

46. fufcefcens.

47. poecilorhyncha.

48. damiatica.

49. Bof́chas.

50. curviroftra.

51. fuperciliofa.

52. autumnalis.

53. arborea.

54. Marila.

55. difcors.

56. Tadorna.

57. erythrorhyncha.

58. bihamenfis.

59. brafilienfis.

6o. clypeata.

61. mexicana.

62. rubens.

63. jamaicenfis.

64. leucocephala.

65. viduata.

66. dominicana.

67. labradora.

68. fcandiaca.

69. ftrepera.

7o. falcaria.

71. Penelope.

72. melanura.

73. capenfis.

74. americana.

75. glocitans.

76. malacorhynchos.

77. ferina.

78. rufa.

79. fulva.

8o. Jacquini.

$8 \mathrm{I}$. acuta.

82. glacialis.

83. difpar.

84. ferruginea.

85. caryophyllacea.

86. Albeola.

87. Clangula.

88. Glaucion.

89. N. Hifpanix.
90. Fuligula.

91. Nyroca.

92. N. Zealandix.

93. criltata.

94. rufina.

95. illandica.

96. obfcura.

97. fponfa.

98. galericulata:

9). Querquedula.

100. Crecca.

I0I. carolinenfis.

102. dominica.

103. fpinofa.

104. africana.

105. madagafcarienfis.

106. coromandeliana.

I07. manilienfis.

I03. formofa.

109. Hina.

110. Sparrmanni.

III. Gmelini.

I I 2. ISekufchka.

I1 3. arabica.

114. alexandrina.

II5. Gattair.

I 6. Sirfair.

GeNus XCVIII.

\section{Aptenodytes.}

1. chryfocome.

2. patachonica.

3. papua.

4. antarctica.

5. demerfa.

6. magellanica.

7. torquata.

8. Catarractes.

9. minor.

10. chiloenfis.

1 1. Molinæ.

Genus XCIX.

Pelecanus.

1. Onocrotalus.
2. rofeus.

3. fufcus.

4. manillenfis.

5. philippenfis.

6. rufefcens.

7. carolinenfis.

8. trachyrhynchos.

9. Thagus.

ro. Aquilus.

I1. minor.

12. leucocephalus.

13. Palmeritoni.

14. Carbo.

15. Graculus.

16. crifatus.

17. violaceus.

18. Urile.

19. punctatus.

20. carunculatus.

2i. magellanicus.

22. varius.

23. cirrhatus.

24. africanus.

25. pygmaus.

26. baflanus.

27. Pifcator.

28. Sula.

29. Fiber.

30. parvus.

GEN U S C.

Phac̈ton.

1. xthereus.

2. melanorhynchos.

3. phœnicurus.

\section{GEN U S CI.}

Plotus.

1. Anhinga.

2. melanogafter.

3. furinamenfis. 



(8)

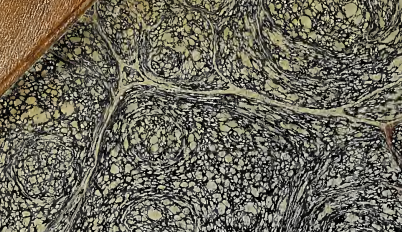

(1) 30.60

3. 60

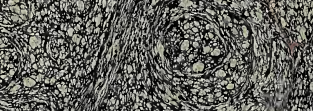

m.

Now

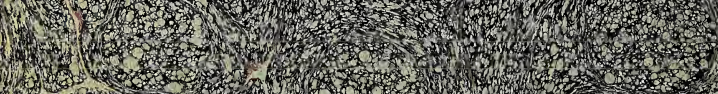

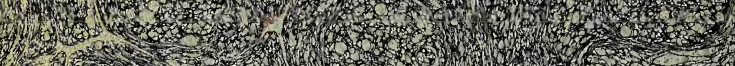

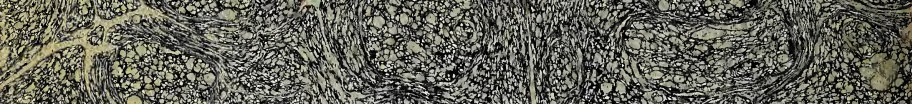
7.7.6.

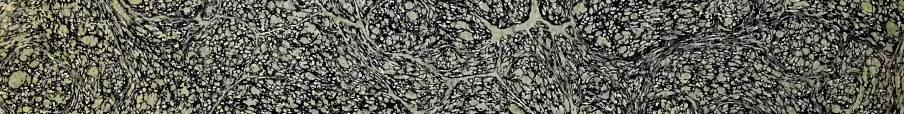
17,

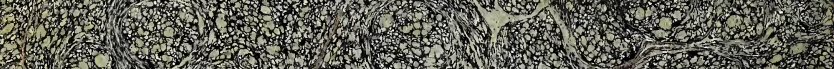
(3)

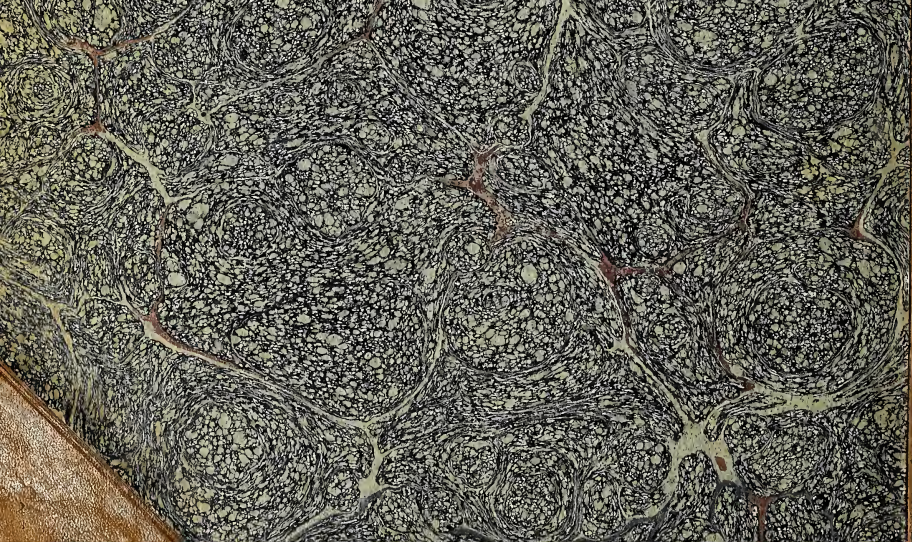

